UNIVERSIDADE DE SÃO PAULO

FACULDADE DE FILOSOFIA, LETRAS E CIÊNCIAS HUMANAS

DEPARTAMENTO DE LINGUÍSTICA

PROGRAMA DE PÓS-GRADUAÇÃO EM LINGUÍSTICA

PROPOSTA DE UM TRABALHO LEXICOGRÁFICO PARA AS NOTAS DE RODAPÉ DA OBRA ADAPTADA

I PROMESSI SPOSI DE ALESSANDRO MANZONI

Karine Marielly Rocha da Cunha

São Paulo

2010 
PROPOSTA DE UM TRABALHO LEXICOGRÁFICO PARA AS NOTAS DE RODAPÉ DA OBRA ADAPTADA

I PROMESSI SPOSI DE ALESSANDRO MANZONI

Tese de Doutorado apresentada ao Programa de Pós-Graduação em Linguística Geral e Semiótica do Departamento de Linguística da Faculdade de Filosofia, Letras e Ciências Humanas da Universidade de São Paulo como parte das exigências para a obtenção do título de doutor.

Orientadora: Profa. Dra. Maria Aparecida Barbosa

São Paulo

2010 


\section{PROPOSTA DE UM TRABALHO LEXICOGRÁFICO PARA AS NOTAS DE RODAPÉ DA OBRA ADAPTADA \\ I PROMESSI SPOSI DE ALESSANDRO MANZONI}

Tese de Doutorado apresentada ao Programa de Pós-Graduação em Linguística Geral e Semiótica do Departamento de Linguística da Faculdade de Filosofia, Letras e Ciências Humanas da Universidade de São Paulo como parte das exigências para a obtenção do título de doutor.

Banca examinadora:

$\overline{\text { Profa. Dra. Maria Aparecida Barbosa (Orientadora) }}$

$\overline{\text { Profa. Dra. Carmen Lucia Pereira Praxedes (UERJ) }}$

$\overline{\text { Profa. Dra. Claudia Fátima Moraes Martins (UFRJ) }}$

Profa. Dra. Olga Alejandra Mordente (USP)

Profa. Dra. Paola Giustina Giustina Baccin (USP)

São Paulo - 2010 
A todos os meus alunos que contribuíram para a realização desta pesquisa e àqueles que desfrutarão dos resultados alcançados. 


\title{
AGRADECIMENTOS
}

\author{
Meraviglioso, ma come non ti accorgi \\ di quanto il mondo sia meraviglioso \\ meraviglioso, perfino il tuo dolore \\ potrà apparire poi meraviglioso \\ ma guarda intorno a te che doni ti hanno fatto \\ ti hanno inventato il mare tu dici: "Non ho niente" \\ ti sembra niente il sole, la vita, l'amore. \\ Meraviglioso la luce di un mattino, l'abbraccio di un amico \\ il viso di un bambino, meraviglioso.
}

(Domenico Modugno)

As nossas vidas e as nossas histórias são como um livro cujas páginas são escritas todos os dias com ou sem notas de rodapé e que, em certos momentos, personagens que pareciam fazer parte de capítulos passados reaparecem e dão continuidade a esse milagre que é a vida. Durante esses quatro anos de doutorado muitas foram as pessoas que entraram pela primeira vez para fazer parte dessas páginas outras, presentes em capítulos anteriores, continuaram nesse e outras ainda, foram fazer parte de outros livros. Todas essas pessoas ajudaram-me a escrever essas páginas e, com certeza, constam nas notas de rodapé. Indico, a seguir, não em forma de nota de rodapé, mas como se as fossem, as pessoas a quem deixo o meu muito obrigada, independente da ordem de aparição.

A Deus, que me deu o dom da vida e a quem agradeço a cada dia por poder acordar, dormir e acordar novamente.

A minha orientadora, Maria Aparecida Barbosa, pela imensa paciência nesses últimos meses, por todo o ensinamento durante o estágio PAE (Programa de Aperfeiçoamento ao Ensino), pela constante preocupação comigo, não somente em relação à vida acadêmica, pelo grande presente que deu-me orientando-me nessa etapa. MUITO OBRIGADA!

A Vanessa (in memorian), que nos deixou tão prematuramente, pelos infinitos favores que contribuíram para o meu retorno ao Brasil em 2006. 
A Michelle Urcci e Ivan Pacheco, meus companheiros de Crusp (Conjunto Residencial da USP), pela amizade e cumplicidade que nos uniu desde o período do mestrado.

A Dayse Mara, por compartilhar os acontecimentos inerentes a quem é nascido em 3 de maio.

A Silvana Vicente Dias, presente na minha vida desde 1997, pela acolhida no Brasil em 2006 e no inverno italiano de 2008/2009.

Ao Centro de Línguas da USP, onde a pesquisa teve início, em especial a Alzira Nóbrega e Eliane Nascimento, pela disponibilidade em todos os momentos.

A Raquel Caldas, com quem tive o prazer de trabalhar no Centro de Línguas da Unicamp no primeiro semestre de 2007.

Aos professores de italiano do Ibilce (Instituto de Biociências, Letras e Ciências Exatas) da Unesp (Universidade Estadual Paulista) de São José do Rio Preto, com quem pude trabalhar no segundo semestre de 2007, em especial a Celeste Tommazello Ramos, por ter me dado as páginas que faltavam na minha minha cópia do livro I Promessi Sposi adaptado.

A Albelita Monteiro (Bel), pela presença, força e os vários telefonemas.

Aos meus pais, Maria Rocha da Cunha e Francisco Manuel da Cunha, pelo exemplo de vida, amor, humildade e, sobretudo, pela compreensão das minhas ausências nas datas especiais, principalmente Natal e Ano Novo.

A Karenine Miracelly, minha irmã e fonte de inspiração, que não poupou esforços para ver esta tese finalizada.

Aos funcionários do Departamento de Línguistica da FFLCH/USP Benhur, Erica e Robson, pela atenção, pelas cópias e pela colaboração durante a realização do Mini-Enapol de Lexicologia, Lexicografia, Terminologia, Toponímia e Tradução, organizados por mim em 2006 e 2007.

Ao CNPq, pela bolsa de estudos. 
Ao Gerson Carvalho e Ernani Fritoli, colegas da UFPR, pelo apoio em todos os momentos, as risadas, os choros e os abraços. Temos uma longa história pela frente.

A Maria Célia Martirani, que me ensinou a ser pipoca e que, como "papai do céu", presenteou-me, em uma noite fria e chuvosa de Curitiba, com um lençol térmico.

Ao Flávio Zanette e Lucia Sgobaro Zanette, pelas palavras, os abraços, as risadas, os almoços, as mensagens, as caronas, a confiança, o respeito, as missas aos domingos com o Flávio, a expectativa e, sobretudo, pela disponibilidade da casa na última semana da tese. Enfim, agradeço pela AMIZADE!

A Benilde Socreppa Schultz, que conheci em um ponto de ônibus em janeiro de 2000 na Itália; Gil Cesar Schultz e Felipe Socreppa Schultz (mammi, papi e Lipe), por terem me acolhido pela segunda vez na casa deles como uma verdadeiro membro da família, ajudando-me sempre em todas as ocasiões, sendo a minha primeira família em Curitiba. OBRIGADA!

A Paula Garcia de Freitas, pelo apoio nessa reta final e em todo este ano pelos outros acontecimentos importantes para as nossas vidas. A história está apenas iniciando.

A Fernanda Landuci Ortale, pela participação na banca de qualificação deste trabalho, pela grande ajuda no começo deste ano, em um momento muito importante da minha vida. Enfim, pela grande disponibilidade que sempre apresentou desde que nos conhecemos em 2000.

Ao Coimbra Group pela bolsa de estudos de três meses na Università degli Studi di Padova.

A Profa. Sandra Bagno da Università degli Studi di Padova que não mediu esforços para me ajudar com a pesquisa.

A Profa. Paola Baccin, pelas colocações preciosas no exame de qualificação.

A Manuela Lunati e Janice Nodari, pela prontidão em fazer os resumos para esta tese.

A Josy Carlos e Patrick Pina, pelas poucas, mas preciosas, horas de convivência no Crusp durante este ano. 
Às assistentes sociais da Coseas/USP, por possibilitarem a minha estadia no Crusp.

A Vivian Mazer pela digitalização do livro I Promessi Sposi adaptado.

A Merili Ribas pela imensa ajuda com as fichas lexicográficas.

A Silvia Pozzatti, pela preciosa consultoria lingüística, a leitura e as discussões do conteúdo das propostas de notas de rodapé.

A todos o meu muito obrigada! 
Embora ninguém possa voltar atrás e fazer um novo começo, qualquer um pode começar agora a fazer um novo fim. Chico Xavier 


\section{Resumo}

Esta pesquisa tem por objetivo principal a proposta de novas notas de rodapé para o livro I Promessi Sposi - Adattamento del testo e note di Marisa Pasqualetti, CIDEB, 2007. Inicialmente, fizemos um levantamento dos livros de leitura graduada para estrangeiros existentes no mercado editorial italiano. Verificamos que alguns dos títulos eram adaptações de obras clássicas da literatura italiana, outros eram policiais, de aventura e romance. A característica comum a esses títulos, além da linguagem controlada, é que todos eles apresentam notas de rodapé e que, na maioria das vezes, essas notas trazem um vocabulário já conhecido pelo público brasileiro. Dessa forma, colocamos as questões que pretendemos responder ao final dessa pesquisa: para quem é destinada as notas de rodapé dessas obras? A simplificação lexical é suficiente para tornar uma obra de fácil leitura? Qual é o critério usado para a escolha das palavras que vão compor as notas de rodapé dessas obras? Para a proposta das novas notas de rodapé do livro I Promessi Sposi adaptado, aplicamos a leitura da obra a sete grupos de alunos que possuíam, de certa forma, o mesmo nível de conhecimento lexical. Foi pedido a esses alunos que ao final da primeira leitura realizassem uma segunda leitura (de modo a provocar o mínimo possível de ruído na primeira leitura) preenchendo uma tabela que continha três colunas: primeira coluna - elenco das palavras que constavam nas notas de rodapé desnecessariamente; segunda coluna - palavras que não constavam nas notas de rodapé, porém, que deveriam constar (nesse caso, não seria todas as palavras desconhecidas, mas aquelas, que em uma leitura global ainda apresentavam-se incompreensíveis ou duvidosas); terceira coluna - palavras que constavam no rodapé cuja explicação era insuficiente. Analisamos as colunas de 50 fichas preenchidas pelos alunos e verificamos que, das 213 palavras e/ou expressões que faziam parte das notas de rodapé, 77 eram desnecessárias, 19 deveriam ser reformuladas e 55 deveriam ser inseridas. Ao final, o título analisado teria 191 notas destinadas ao público brasileiro, 22 a menos do que o número total utilizado pela editora.

Palavras-chave: I Promessi Sposi, Leitura Graduada, Lexicografia, Língua Italiana, Literatura Adaptada, Notas de Rodapé. 


\begin{abstract}
This research mainly aims at proposing new footnotes to the book I Promessi SposiAdattamento del testo e note di Marisa Pasqualetti, CIDEB, 2007. At first, we made a survey of the graded readers for foreigners that we have access to in the Italian publishing industry. We identified that some of the books are adaptations from classic books in the Italian literature; others were suspense, adventure or romance stories. The common feature in all these classics, besides the graded language, is that all of them present footnotes, and that most of the times the vocabulary used is already familiar to the Brazilian readers. This way, we placed the following queries that we want to elicit in our research: Whom are the footnotes addressed to? Is the lexical simplification sufficient in order to make the reading of a piece of art of easy attainability? What is the criterion used for choosing the words which will come as footnotes in these books? In order to propose the new footnotes for the adapted I Promessi Sposi, we asked 07 different groups that were basically in the same lexical level to read the story. The students were asked to do a second reading right after the first one (in such a way so as to provoke the least interference in the first reading) and were asked to fill in a table with three columns: the first column demanded a list of words that were unnecessarily explained in the footnotes; the second column asked for words that were not in the footnotes but should be (in this case, not all the words would be unknown, but also words that could result in doubts or misunderstandings in a global reading); and the third column asked for words that were in the footnotes but whose explanations were insufficient. We analyzed the columns in 50 records filled up by the students and we found that from the 213 words and expressions that were in the footnotes, 77 were unnecessary, 19 should be reformulated and 55 should be inserted. By the end, the title which was chosen should have 191 footnotes destined to the Brazilian readers, 22 less that the number used by the publishing house.
\end{abstract}

Key words: I Promessi Sposi, Graded Readers, Lexicography, The Italian Language, Adapted Literature, Footnotes. 


\section{Riassunto}

L'obiettivo principale di questa ricerca è quello di elaborare una proposta di nuove note a piè di pagina per il libro I Promessi Sposi - Adattamento del testo e note di Marisa Pasqualetti, CIDEB, 2007. Inizialmente si è proceduto ad una rassegna dei libri di lettura graduata per stranieri esistenti sul mercato editoriale italiano. È stato verificato che alcuni dei titoli erano adattamenti di opere classiche della letteratura italiana, laddove altri erano gialli, libri di avventura e romanzi. La caratteristica comune a tali titoli, oltre al linguaggio controllato, è il fatto che tutti presentino delle note a piè di pagina, e che nella maggior parte dei casi tali note si riferiscano ad un vocabolario già noto al pubblico brasiliano. Si è così giunti alla formulazione delle domande alle quali ci si propone di rispondere in conclusione della presente ricerca: a chi sono destinate le note a piè di pagina delle suddette opere? La semplificazione lessicale è sufficiente a fare di tali opere dei testi di facile lettura? Qual è il criterio che guida la scelta delle parole che entrano nella composizione delle note a piè di pagina delle stesse opere? Al fine di elaborare una proposta di nuove note a piè di pagina per il libro I Promessi Sposi nella sua versione adattata, abbiamo sottoposto alla lettura del libro 7 gruppi di alunni che possedevano approssimativamente lo stesso livello di competenza lessicale. A questi alunni è stato chiesto che, al termine della prima lettura, realizzassero una seconda lettura (in maniera tale da generare il minimo rumore possibile nella prima lettura) e compilassero una tabella a tre colonne: prima colonna - elenco delle parole che comparivano nelle note a piè di pagina ma erano superflue; seconda colonna parole che non comparivano nelle note a piè di pagina, ma che sarebbero dovute comparire (in tal caso, non si trattava di tutte le parole sconosciute, ma appena di quelle che, in una lettura globale, continuavano a presentarsi come incomprensibili o dubbiose); terza colonna - parole che comparivano nelle note a piè di pagina ma la cui spiegazione era insufficiente. Sono state quindi analizzate le colonne di 50 schede compilate dagli alunni ed è stato verificato che, delle 213 parole e/o espressioni che entravano a far parte delle note a piè di pagina, 77 erano superflue, 19 avrebbero dovuto essere riformulate e 55 avrebbero dovuto essere inserite. Come risultato, il libro analizzato avrebbe avuto 191 note destinate al pubblico brasiliano, 22 in meno rispetto al numero totale utilizzato dalla casa editrice.

Parole chiave: I Promessi Sposi, Lettura Graduata, Lessicografia, Lingua Italiana, Letteratura Adattata, Note a piè di pagina 
II - A QUESTÃO DA LÍNGUA: MANZONI E I PROMESSI SPOSI ........................ 18

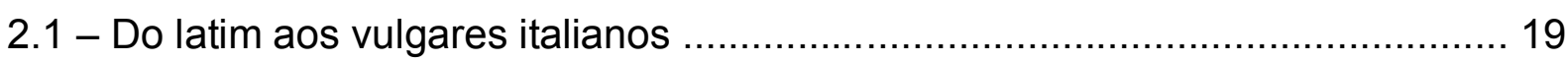

2.2 - Dos vulgares italianos à língua italiana ...................................................... 24

2.3 - Quem foi Alessandro Manzoni ........................................................ 25

2.4 - Manzoni e a "questão da língua" ................................................................ 26

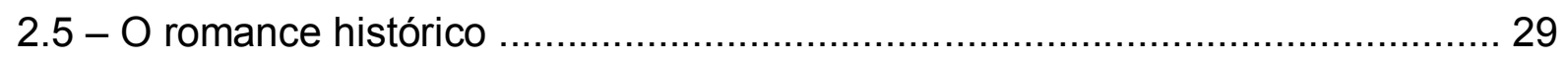

2.6 - Manzoni e I Promessi Sposi ...................................................... 30

2.6.1 - O conteúdo do romance em linhas gerais ................................................. 30

2.6.2 - O que mudou de Fermo e Lucia (1821) para I Promessi Sposi (1842)........ 33

2.6.2.1 - Do Fermo e Lucia (1821-1823) para a Ventissetana (1825-1827)............ 33

2.6.2.2 - Da Ventisettana a Quarantana ........................................................... 35

III - LITERATURA ADAPTADA: CONCEITOS E PROCEDIMENTOS.................... 39

3.1 - Mecanismos de facilitação da leitura em LE - Italiano ………....................... 41

3.1.1 - Corpora do léxico italiano .................................................................. 46

3.1.2 - Indicadores de inferência de significados em língua portuguesa na

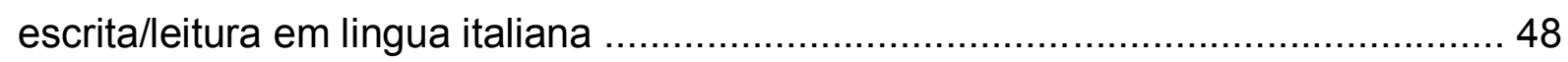

3.2 - A literatura adaptada como instrumento facilitador da leitura em LE .............. 50

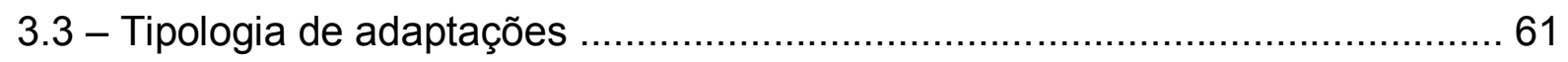

3.4 - Estrutura das notas de rodapé dos livros de literatura adaptada (facilitada) para estrangeiros em língua italiana .................................................................... 63

IV - QUESTÕES METODOLÓGICAS DA PESQUISA ......................................68

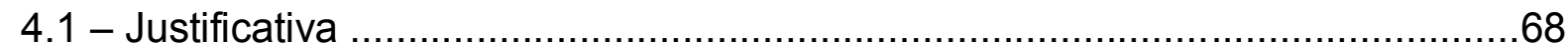

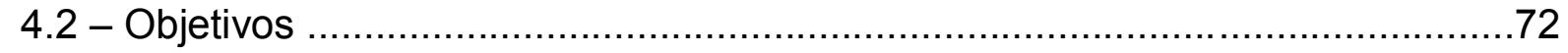

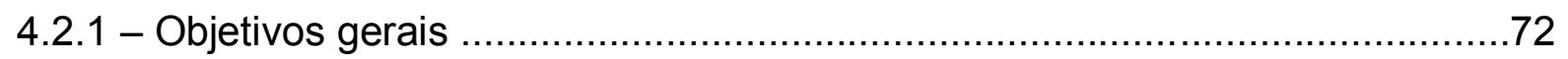

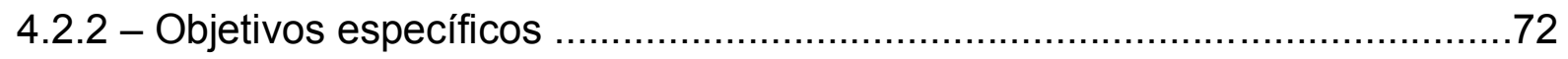

4.3 - Metodologia de Investigação e Estabelecimento do Corpus ...........................72 


\section{V - ANÁLISE DOS DADOS E PROPOSTA LEXICOGRÁFICA DAS NOVAS}

NOTAS DE RODAPÉ

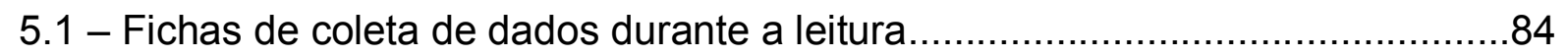

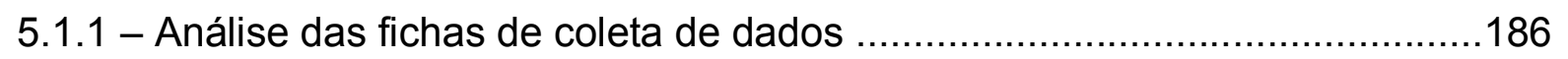

5.2 - Fichas lexicográficas das novas notas a constar no rodapé ........................198

5.3 - Fichas lexicográficas das notas reformuladas a constar no rodapé...............304

5.4 - Análise das novas notas propostas e das reformuladas ............................332

5.5 - Elenco de todas as notas a constar na obra adaptada I Promessi Sposi, de Marisa Pasqualetti, Editora Cideb, 2007..........................................................335

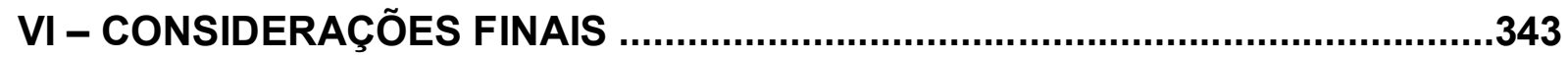

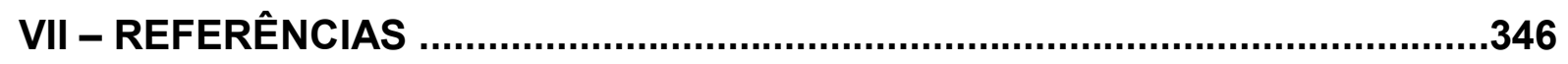




\section{I - INTRODUÇÃO}

A leitura engrandece a alma.

(Voltaire)

Geralmente, a literatura de uma língua é o reflexo dessa mesma língua em diferentes perspectivas, sejam elas sociais, culturais ou políticas. Dessa forma, quando lemos em uma determinada língua, temos a possibilidade de compreender aspectos da sociedade que essa língua representa. Esses aspectos podem referirse ao momento da edição do livro lido ou remeter a um determinado período da história.

A leitura exige a articulação de habilidades que favorecem a compreensão do texto. $\mathrm{O}$ aprendizado concreto de uma língua, seja ela materna ou estrangeira, não acontece com a memorização de regras gramaticais ou listas de palavras, mas sim quando o aprendiz torna-se capaz de reconhecer e atribuir sentido a essas regras gramaticais e às "listas de palavras" aprendidas, preocupando-se em entender, em sua globalidade, um texto lido e não somente em analisar as estruturas menores que constituem esse texto.

A obra literária I Promessi Sposi de Alessandro Manzoni traduzida em português como Os Noivos é uma das obras mais estudadas da literatura italiana, seja pelos próprios estudantes italianos, seja pelos estrangeiros que aprendem a língua italiana. A importância dessa obra não é dada somente pelo valor literário que representa, mas também pelo valor lingüístico que assumiu na história da língua italiana.

Por ser uma obra de grande relevância para os estudos de literatura e língua italiana e por existirem várias edições adaptadas e comentadas da mesma, seja para o público italiano, seja para o estrangeiro, consideramos pertinente o estudo de uma adaptação de Os Noivos para o público estrangeiro e a recepção da mesma por estudantes brasileiros de língua italiana. Para tanto, apresentamos algumas questões que nortearão a nossa pesquisa: a obra adaptada é realmente garantia de fácil leitura? A simplificação lexical é suficiente para tornar uma obra clássica 
acessível a um público formado por alunos brasileiros de língua italiana? Para que público são destinadas as notas de rodapé das obras adaptadas?

Alessandro Manzoni interessou-se pela "questão da língua italiana" em muitas de suas obras, especialmente na obra Os Noivos. Acreditava que a língua usada na sua época deveria ser nacional, isto é, única de norte a sul do país, de forma a contribuir para a unificação da Itália. Sendo assim, essa língua deveria ter como base o uso e se apresentaria próxima à realidade histórico-social daquele momento. Com esse pensamento, Manzoni escreveu Os Noivos realizando as suas intenções de criar um romance histórico-pedagógico, atribuindo o papel de protagonistas a personagens do povo e criando, para a sua época, uma língua "simples", capaz de atingir um grande público. O autor escreveu três versões do romance antes de chegar àquela definitiva de 1840-42, a qual sofreu uma grande revisão lingüística. Mesmo o autor tendo trabalhado tanto para deixar acessível a linguagem do romance, hoje em dia, tal obra apresenta ainda um vocabulário difícil para os leitores italianos e, por conseguinte, também para os leitores estrangeiros, em especial os brasileiros.

A escolha do item lexical para o nosso estudo da obra adaptada explica-se pelo fato de que, durante o período no qual Manzoni trabalhou nas três versões do romance, o que mais preocupou-o foi o léxico empregado e a compreensão do mesmo em toda a extensão do território italiano.

O nosso trabalho apresenta-se estruturado nos seguintes capítulos:

\section{A Questão da Língua: Manzoni e I Pormessi Sposi}

Nesse capítulo, de caráter descritivo e histórico, apresentaremos uma breve evolução da língua italiana até chegar à época de Manzoni. Tal evolução faz-se necessária para podermos entender a preocupação do escritor com a polêmica questione della lingua. Abordaremos o importante papel que Manzoni exerceu na história da língua italiana e as características da sua principal obra. Ressaltamos que o nosso trabalho possui um cunho lingüístico e não literário, sendo assim não trabalharemos com crítica literária, mas sim "crítica lingüística".

\section{Literatura Adaptada: Conceitos e Procedimentos}

Trataremos a leitura em língua estrangeira como produto e não como processo. Trabalharemos com o conceito de literatura adaptada e as suas implicações. Apresentaremos o levantamento feito sobre as editoras italianas que 
produzem leitura graduada para estrangeiros e falaremos dos bancos de dados que existem em relação ao léxico da língua italiana.

\section{Questões Metodológicas da Pesquisa}

Apresentaremos nesse capítulo as justificativas do trabalho, assim como os nossos objetivos ao desenvolver essa pesquisa, o corpus constituido, a metodologia que norteou as nossas investigações e as nossas expectativas quanto aos resultados finais.

\section{Proposta Lexicográfica de Novas Notas de Rodapé e Análise dos Dados}

Nesse capítulo apresentaremos as fichas de coleta de dados das unidades lexicais que constituem parte do nosso corpus, a análise das mesmas e as fichas lexicográficas das novas definições que constarão como notas de rodapé.

\section{Considerações Finais}

Chegaremos às respostas para as indagações apresentadas no início desta pesquisa.

\section{Referências Bibliográficas e Sitográficas}

Elencaremos nessa parte final as nossas fontes de pesquisa. 


\section{II - A QUESTÃO DA LÍNGUA: MANZONI E I PROMESSI SPOSI}

Bisogna studiare cos'è la lingua in generale

e non esclusivamente la bella lingua; ciascuna lingua costituisce un tutto: I'Uso è il

signore delle lingue, e unico signore, che qualsiasi altro criterio deve cedere di fronte a esso.

(A. Manzoni)

Para discorrermos sobre a questão da língua usada por Manzoni em I Promessi Sposi é fundamental traçarmos uma breve evolução da língua italiana a fim de entendermos o processo de formação da mesma e a importância que Manzoni teve para a unificação lingüística italiana.

É comum dizer que o italiano é uma língua derivada do latim, assim como o português, o francês, o espanhol, o romeno, etc. Mas qual latim? Falado em qual época? Em que região? Della Valle (2006) afirma que o italiano não deriva, isto é, não nasce do latim, mas dá continuidade a ele. O latim, por sua vez, como toda língua viva, sofreu modificações no decorrer dos séculos.

Devemos precisar que existiam dois tipos de latim, o clássico e o vulgar, isto é, aquele escrito e aquele falado pelo povo. Esse último existia em muitas variantes, pois era o resultado do contato do latim clássico com as línguas autóctones. Como o latim clássico era a representação da língua culta escrita, permaneceu praticamente idêntico ao longo de muitos anos enquanto o latim vulgar, representando a oralidade da população, sofreu notáveis modificações. As duas variantes lingüísticas - ou melhor, o latim clássico e as várias representações do vulgar, com o passar do tempo, começaram a se distanciar consideravelmente até que houve, de forma gradual, a transformação do latim vulgar nos dialetos italianos e a transformação do dialeto florentino na língua italiana.

Mais de $70 \%$ das palavras italianas são derivadas do latim, seja o falado (vulgar) seja o escrito (clássico). Muitos vocábulos mantiveram o seu significado com algumas alterações na grafia (mater - latim/madre - italiano), outros sofreram algumas transformações de significado (domina - latim, que significava dona da casa, patroa; passou a significar em italiano mulher, ou seja, donna) e outros ainda 
passaram para a língua italiana com a mesma grafia e significado original do latim (referendum).

\section{1 - Do latim aos vulgares italianos}

Entre os povos presentes antes de Cristo no território que hoje conhecemos como Itália estavam os romanos que tinham Roma como capital, a qual sofreu um período de dominação etrusca, comprovado pela herança de alguns vocábulos dessa origem, como milite (soldado), persona (pessoa) e popolo (povo). A Etrúria, atual Toscana, enfraqueceu-se e Roma ganhou o poder, tornando-se a cidade mais importante da península itálica, começando a conquistar territórios fora da mesma e dominando, em pouco tempo, toda a área do mediterrâneo.

No século II a.C., o Império Romano atingiu a sua maior dominação, indo da Península Ibérica (Espanha e Portugal) até o mar Cáspio. Os romanos, quando chegavam a um determinado local, inicialmente impunham a força militar. Depois, construíam edifícios, termas, teatros, aquedutos e, sobretudo, estradas. Todo o império tinha contato com o centro, ou seja, com Roma.

Sendo assim, Roma pôde difundir a sua língua entre as populações conquistadas. O latim difundiu-se em diferentes territórios que precedentemente falavam outras línguas, resultando, dessa forma, uma língua um pouco diferente da base imposta, que era o latim.

Quando Roma começou a perder a sua hegemonia devido às invasões dos bárbaros, novas palavras começaram a entrar na língua falada, herdadas pelo contato com os novos povos dominadores. A crise de Roma foi acompanhada pelo empobrecimento da população que compunha o Império Romano e o isolamento dos territórios conquistados. Esse isolamento proporcionou o desenvolvimento de novas línguas denominadas românicas ou neolatinas, já que não existem línguas difusas em uma área consideravelmente grande, que não sofram nenhum tipo de diferenciação.

No território italiano, tal qual o consideramos hoje, esse processo de "formação de línguas diferentes do latim" também ocorreu e essas novas línguas, sobretudo faladas, eram denominadas vulgares.mHoje é muito difícil estabelecer 
como eram os diferentes vulgares falados na Itália, pois não temos disponíveis testemunhos escritos, justamente porque não eram usados para escrever e sim na comunicação oral.

Em 960 depois de Cristo, no principado de Cápua, sul da Itália, nos arredores de Nápoles, existia um litígio pela posse de terras pertencentes ao monastério dependente de Monte Cassino. De acordo com as leis daquela época, quem comprovasse, por meio de testemunhas, que usava as terras há mais de trinta anos garantiria o direito à posse das mesmas. Foi então que se reuniram, em Cápua, as partes que reivindicavam o direito a essas terras e, o que chamamos hoje de escrivão, para poder ouvir as testemunhas. A disputa era entre a família Rodelgrimo e a abadia de Monte Cassino. Geralmente, nessas ocasiões, as testemunhas davam o seu depoimento em vulgar e o escrivão, com a finalidade de documentar, o transcrevia em latim. Porém, naquela ocasião, a transcrição foi feita em vulgar, talvez para facilitar a compreensão da leitura final do documento, uma vez que, quem estava ali reunido era o povo e não literatos conhecedores do latim. Esse documento, com a declaração das testemunhas é conhecido como a primeira manifestação escrita vulgar da língua italiana, denominado Placito di Capua, ou seja, Sentença de Cápua.

Com o intuito de ilustrar a diferença entre o latim, o vulgar meridional e o italiano de hoje, transcrevemos abaixo um trecho da declaração de uma das testemunhas, extraída de Marazzini (2004) e Migliorini (2002):

\begin{tabular}{|l|l|}
\hline Latim & $\begin{array}{l}\text { Ille autem, tenes in manu predicta abbreviatura, que memorato } \\
\text { Rodelgrimo hostenserat, et cum alia manu tetigit eam, et } \\
\text { testificando dixit: }\end{array}$ \\
\hline Vulgar & "São ko kelle terre, per kelle fini que ki contene, trenta anni le \\
& possette parte sancti Benedicti"
\end{tabular}

\begin{tabular}{|l|l|}
\hline Italiano & Egli, tenendo con la mano la predetta memoria prodotta dal sopra \\
& menzionato Rodelgrimo, e toccando con l'altra mano, rese la \\
& seguente testimonizanza: \\
& "So che quelle terre, entro quei confini che qui descrivono, trenta \\
\hline
\end{tabular}


anni le ha tenute in possesso l'amministrazione patrimoniale di San Benedetto (cioè il monastero)

As testemunhas tinham que jurar com uma mão apoiada no Evangelho e a outra no que foi transcrito o que lhe ditavam o escrivão (talvez por isso o escrivão redigiu em vulgar o documento, com a finalidade de que as testemunhas realmente entendessem o que estavam jurando) "Sei que as terras, nas fronteiras aqui descritas, eram ocupadas já há trinta anos pelo monastério beneditino", dando assim ao monastério a propriedade da terra por usucapião.

No decorrer dos séculos XI e XII, os testemunhos escritos em língua vulgar tornaram-se cada vez mais numerosos, sobretudo no centro e norte da Itália. Eram, sobretudo, textos de caráter religioso e administrativo.

No início do século XIII, especialmente na Sicília, existia um grupo de nobres e cortesãos que escreviam poesias de amor. Essas poesias eram escritas em vulgar siciliano e tinham como inspiração os poetas provençais. O vulgar usado era aquele falado na corte, ausente de palavras plebéias.

Em outras partes da Itália, começaram a usar o vulgar para escrever literatura. São Francisco de Assis, por exemplo, escreveu o "Cântico das Criaturas" em vulgar umbro com grande influência toscana. Outro exemplo é Dante Alighieri, considerado o pai da língua italiana, que escreveu a sua mais importante obra - $A$ Divina Comédia - em vulgar florentino. Além de ser um grande poeta, foi o primeiro a escrever sobre a língua vulgar, quando publicou o livro De Vulgari Eloquentia - Da eloqüência do vulgar, ou seja, da possibilidade de escrever em vulgar. Porém, mesmo sendo uma obra que tratava do uso do vulgar, foi escrita em latim, pois era considerada um tratado de filosofia da linguagem e, dessa forma, a língua exigida para tal redação era o latim.

$\mathrm{Na}$ obra De Vulgari Eloquentia, Dante identificou 14 tipos de vulgares (dialetos) existentes na sua época e começou a analisá-los para tentar encontrar o melhor, um que pudesse servir de modelo para ser usado por toda a Itália. Visualizaremos na página 22 um mapa da Itália com os vulgares classificados por Dante. Ele defendia a existência de um vulgar que pudesse representar a união lingüística e cultural italiana, que fosse áulico (que pertencesse à corte), cardinal (que servisse de referência), curial (que seguisse certas normas) e ilustre (que fosse célebre)". Propunha então, um vulgar desprovido de qualquer forma que 
caracterizasse um dialeto, ou seja, limpo de expressões que pudessem remeter a uma certa região.

Dante queria construir um vulgar de todas as cidades, mas que, ao mesmo tempo, não representasse nenhuma de forma específica. Com a Divina Comédia, escrita em vulgar florentino com influências do siciliano, não conseguiu chegar à realização do vulgar desejado. Porém, conseguiu transmitir a mensagem de que as obras literárias deveriam ser escritas em vulgar e não mais em latim. Dante foi o primeiro a refletir sobre a "questão da língua".

O vulgar florentino usado por Dante para escrever a Divina Comédia transformou-se mais tarde na base da língua literária nacional devido aos fatores elencados a seguir:

a) prestigio político, social e cultural de Florença;

b) o dialeto florentino era intermediário entre os dialetos do norte e aqueles do sul;

c) o dialeto florentino era muito parecido com o latim em confronto com os outros dialetos (vulgares), pois não tinha sido "contaminado" pelas invasões bárbaras;

Podemos dizer que esses fatores também influenciaram, quase quinhentos anos depois, a escolha de Manzoni de "risciacquare i panni in Arno". 


\section{Carta linguistica d'Italia}

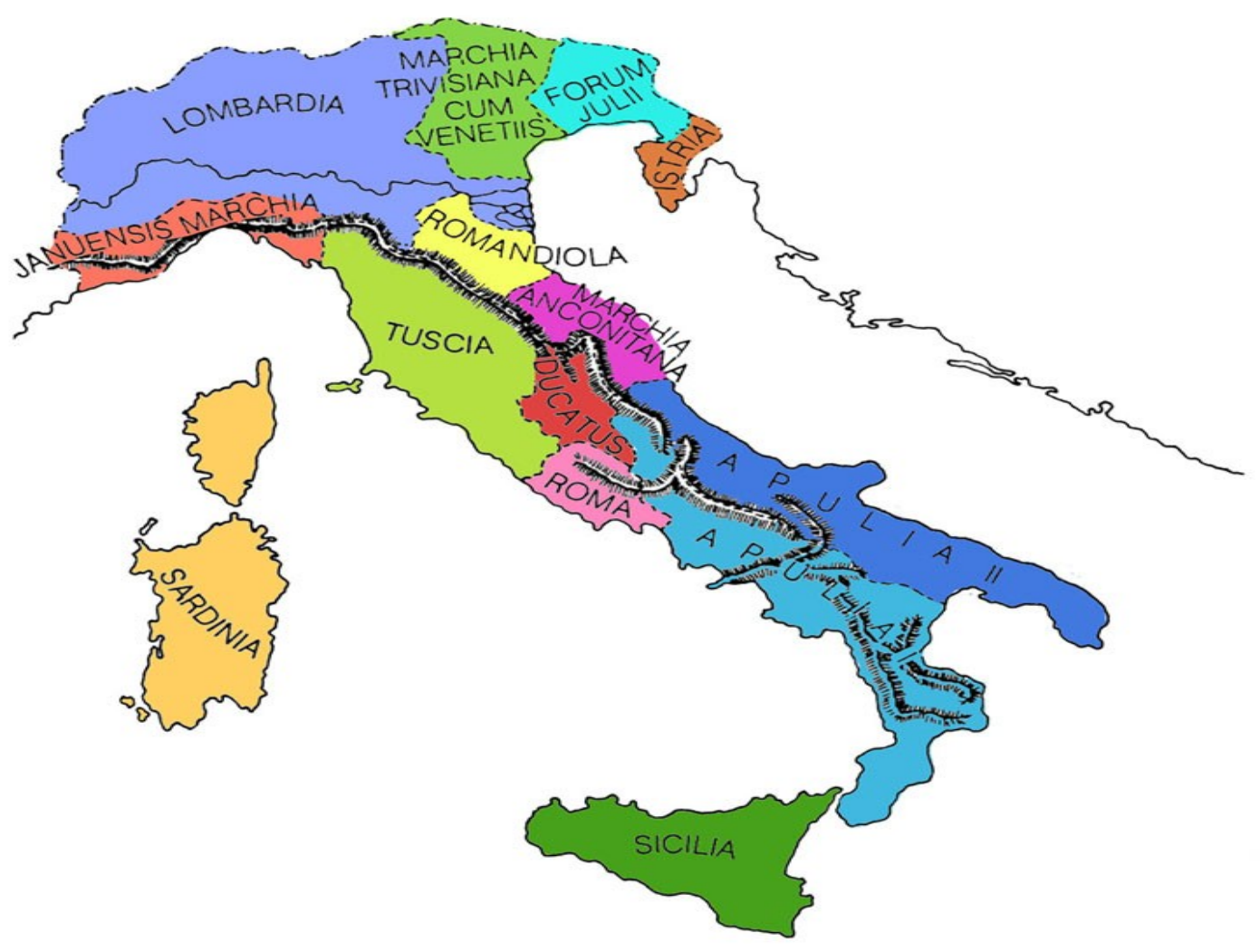

JANUENSIS MARCHIA: Dante non fornisce alcun esempio, limitandosi a constatare che "se i Genovesi a causa di un'amnesi constatare che sei Genovesi a causa di un amnesia completamente o rifarsi una nuova lingua".

LOMBARDIA: "Enter l'ora del vesper, ciòfu del mes d'ochiover" [Verso l'ora del vespro, ciò avvenne nel mese d'ottobre] MARCHIA TRIVISANA CUM VENETIIS: "Per le plaghe di Dio tu no verras" [Per le piaghe di Dio, non verrai]

FORUM JULII e ISTRIA: “Ces fas-tu?" [Che fai?]

ROMANDIOLA: "oclo meo" [occhio mio]

TUSCIA:

fiorentino: "Manichiamo, introcque che noi non facciamo altro" [Mangiamo, intanto che non facciamo altro] ene andonno li fatti de Fiorensa per Pisa" [I fatti di Firenze andarono bene per Pisa]

(Die lo comuno de Lucca" "OGiuraddio che il comune di Lucca nuota nell'abbondanza]

[Avessi rinnegata una buona volta Siena! Che è questo che [Avede?]

aretino: "Vuo' tu venire ovelle?" [Vuoi venire da qualche parte?]

MARCHIA ANCONITANA: "Chignamente state siate" [Come state...]

$$
\text { "Una fermana scopai da Cascioli, }
$$

[Incottrai una donna di Fermo presso Cascioli,

se ne andava svelta svelta, in gran fretta]

DUCATUS: "Chignamente state siate" [Come state...]

ROMA: "Messure, quinto dici?" [Signore, che dici?]

APULIA I - II: "Bòlzera che chiangesse lo quatraro"

SICILIA: "Tragemi d'este focora se t'este a bolontate" [Tràimi da questi fuochi (d'amore) se è tua volontà]

SARDINIA: "Domus nova" [Casa nuova]

"Dominus meus" [Mio signore]

Mapa com a classificação dos 14 tipos de vulgares (dialetos) elencados por Dante Alighieri com exemplos traduzidos para o ita liano ao lado direito.

Fonte: http://www.indire.it/lucabas/lkmw_file/leggereDante///dialetti.jpg 


\subsection{Dos vulgares italianos à língua italiana}

Depois da morte de Dante e dos seus contemporâneos Petrarca e Boccaccio, os literatos italianos mais cultos voltaram a escrever em latim. No entanto, não optaram por aquele medieval, mas pelo latim clássico da Roma antiga. Esse "retrocesso" é explicado pelo período vivido no século XV, ou seja, pelo Humanismo, que exaltava os ideais clássicos.

Depois do retorno ao latim clássico promovido pelo Humanismo, o problema sobre a "questão da língua" veio à tona no fim do século XV e início do século XVI com três principais correntes de pensamento:

a)Corrente Cortesã: tinha como representantes Colli, Castiglione e Trissino, sendo este último o autor de um projeto de reforma ortográfica para a língua italiana existente até então. Esses três estudiosos defendiam um ideal de língua eclético, constituído de uma base de língua toscana que aceitava outras variações italianas e de outras localidades, sobretudo provençais, desde que fossem refinadas e como descrevia Castiglione (MIGLIORINI, 2002, p. 314) "que possuíssem algum requinte na pronúncia". As obras representantes dessa corrente são: Dubbi grammaticali, Castellano (Trissino) e Cortegiano (Castiglione).

b)Corrente Florentina: defendida por Maquiavél, Giambullari e Varcchi, Os três pensadores sustentavam o uso da escrita do florentino que era falado na época. Existiu um certo conflito com outro intelectual, Tolomei, que defendia o uso da variante falada em Siena em oposição àquela florentina. A obra representativa da corrente florentina de autoria de Maquiavél é Dialogo intorno alla nostra língua.

c) Corrente Arcaizante ou Bembismo: defendia o uso da língua florentina usada no século XIV por Petrarca e Boccaccio, sendo a língua do primeiro para a poesia e do segundo para a prosa. Não defendia a língua que Dante usou para a Divina Comédia pois considerava que o autor tinha feito uso de muitas expressões grosseiras. A obra que melhor representa essa corrente é a Prose della volgar lingua de Bembo.

A corrente que recebeu maior apoio e que se desenvolveu foi a de Bembo.

Em 1582, foi fundada a Accademia della Crusca e, em 1590, os acadêmicos iniciam a elaboração de um dicionário baseado na língua toscana de Dante, Petrarca 
e Boccaccio. Mais tarde, em 1612, o dicionário foi impresso em Veneza - o Vocabolario degli Accademici della Crusca -, e passou a ser considerado, até metade do século XIX, como a maior autoridade em relação à língua italiana. Foi um dicionário de caráter histórico e normativo que estabeleceu definitivamente 0 toscano como a norma para o italiano literário, servindo também de modelo para obras lexicográficas futuras em toda a Europa.

A língua literária italiana do século XVII e XVIII ficou caracterizada como uma língua arcaica, diferente da língua oral do cotidiano que era cheia de dialetos.

Durante o lluminismo, essa postura conservadora da língua, caracterizada por ser abstrata e complicada, foi muito criticada. Os iluministas propunham a "clareza da língua francesa". O italiano começou a se abrir à influência européia, inicialmente à espanhola e portuguesa (devido às grandes navegações) e, posteriormente, à francesa e à inglesa. Essas nações contribuíram para o enriquecimento do léxico italiano. Houve uma reação purista, todavia, ela não resistiu, já que a Itália caminhava para a unificação política.

\subsection{Quem foi Alessandro Manzoni}

Manzoni nasceu em Milão em 7 de março de 1785, filho do conde Pietro e de Giulia Beccaria, filha do escritor Cesare Beccaria. Estudou em colégio de padres e, aos quinze anos, já demonstrava vocação pela poesia. Escreveu Il trionfo della libertà usando uma linguagem clássica e exaltando o liberalismo e o jacobinismo. Conhecia o francês, o dialeto milanês e o italiano (que na época era, sobretudo, escrito).

Mudou-se para Paris para ficar com a mãe depois da morte do padrasto. No ambiente francês do lluminismo, o escritor desenvolveu-se intelectualmente, fazendo amizade com pessoas importantes da época. Por algum tempo, teve a vida dividida entre a França, mais precisamente Paris, e a Itália.

Em 1808, casou-se, em cerimônia calvinista com Enrichetta Blondel. O escritor começou a repensar as suas posições filosóficas e religiosas e, dois anos depois, o casamento foi celebrado novamente, porém em cerimônia católica, visto que ele e a mulher aderiram ao catolicismo e abnegaram o calvinismo. 
Ambos voltaram para Milão, onde Manzoni começou a escrever obras com teor religioso como Inni Sacri, La Risurrezione, II nome di Maria, etc. Escreve também tragédias como II Conte di Carmagnola (1816) e reflexões sobre a língua italiana. Em 1821, começou a trabalhar na primeira redação do romance I Promessi Sposi, porém intitulado Fermo e Lucia, que concluiu em setembro de 1823.

Em 1827 publicou I Promessi Sposi em três volumes em Milão e, logo depois, foi com toda a família para Florença. Em 1842, publicou a última reescritura do $I$ Promessi Sposi com ilustrações de Francesco Gonin. Em 1860, Vittorio Emanuele II nomeou Manzoni senador do Reino da Itália e, em 1861, ano da unificação da Itália, ele presidiu a 'comissão para a unificação da língua.

Manzoni morreu aos 88 anos de complicações devido a uma queda quando saía de uma igreja em Milão. As obras do autor sempre demonstraram preocupação com a língua e tinham como temas chaves acontecimentos históricos e a providência.

\subsection{Manzoni e "a questão da língua"}

O início do século XIX é marcado pela polêmica entre os seguidores do Classicismo e os do Romantismo. Esse último foi um movimento de caráter filosófico, artístico e político nascido na Europa no fim do século XVIII, caracterizado pelo nacionalismo que consolidou os estados nacionais europeus.

$\mathrm{Na}$ Itália, Manzoni foi um dos grandes românticos e um dos primeiros a colocar o problema de como resolver a "questão da língua" do ponto de vista social e político. A expressão questione della lingua ou "questão da língua" é usada para indicar uma disputa de caráter social no âmbito literário que colocava o problema de qual língua utilizar na península italiana. Podemos dizer que essa discussão começou com Dante Alighieri no século XIV, depois passou por uma fase significante no início do século XVI com as correntes citadas anteriormente (Cortesã, Florentina e Arcaizante), tendo tido no século XIX um papel importante com Manzoni. Para alguns autores "a questão da língua" foi resolvida com Manzoni, porém sabemos que a questão prolongou-se por anos e, até hoj,e existe uma discussão sobre a língua, porém em termos diversos. 
$\mathrm{Na}$ época do fascismo, o ideal purista articulou-se assumindo uma postura que condenava o uso dos dialetos, das línguas minoritárias e de palavras estrangeiras. Mazarinni (1977, p. 190-1) escreve que a "bomba" sobre a "questão da língua" foi lançada em uma conferência proferida por Pier Paolo Pasolini no fim de 1964 e publicada em dezembro do mesmo ano na revista "Rinascita", na qual Pasolini anunciava o nascimento do novo italiano nacional, um italiano tecnológico ligado ao triângulo industrial da nova classe hegemônica do norte da Itália, a burguesia neocapitalista.

Manzoni, quando escreveu a sua principal obra (I Promessi Sposi), gostaria de criar um romance que fosse de possível compreensão do norte ao sul da Itália. Para tanto, era consciente de que deveria usar uma língua que fosse muito próxima de toda a população. Escolheu como protagonistas personagens que representavam o povo.

O escritor expôs suas idéias e preocupações sobre a língua italiana nas obras lingüísticas relacionadas abaixo:

a)Sentir messa (1835-36) : tratado no qual defende o uso vivo da língua contra as acusações dos puristas;

b)Sulla Lingua Italina (1846): carta a Giacinto Carena, linguísta italiano;

c)Saggio sul vocabolario italiano secondo l'uso di Firenze (1856): expressa as convicções de que o dialeto toscano falado deveria ser adotado como a língua dos italianos;

d)Dell'unità della lingua e dei mezzi per diffonderla (1868): relatório ao ministro da educação Broglio relacionando a língua com a nação;

e)Intorno al libro "De vulgari eloquentia" di Dante (1868): carta a Ruggiero Bonghi, escritor e jornalista, na qual Manzoni afirma que a obra de Dante não era somente um "tratado de eloqüência";

f) Intorno al vocabolario (1868): carta a Ruggiero Bonghi discutindo a validade dos dicionários;

g)Lettera al Marchese Alfonso della Valle di Casanova (1871): carta com as razões que levaram Manzoni à ultima revisão linguística da obra I Promessi Sposi.

Depois da unificação e do nascimento do Reino da Itália, ficou explícita a necessidade de uma língua para o estado, para a escola e para a administração. 
Manzoni foi solicitado pelo ministro da Educação, Broglio, e propôs meios e modos para unificar a língua, como a adoção das seguintes iniciativas:

a)professores toscanos nas escolas;

b)viagens na Toscana para os estudantes de outras regiões, de forma a proporcionar para os mesmos uma espécie de imersão linguística;

c)a compilação de um Dicionário de Uso do Florentino Vivo e sua máxima difusão.

A grande inovação manzoniana consistiu em transformar a discussão e disputa de literatos sobre a questão da língua em um problema civil que envolvia toda a nação italiana. Essa preocupação estava presente na vida do autor, desde muito cedo. Ainda bem jovem, com 21 anos, Manzoni escreveu uma carta a seu amigo Fauril, em fevereiro de 1806, retratando a sua preocupação com a língua italiana: "Per nostra sventura, lo stato dell'Italia diviso in frammenti, la pigrizia e l'ignoranza quasi generale hanno posto tanta distanza tra la lingua scritta e la parlata, che questa può dirsi quasi come lingua morta.” (MIGLIORINI, 1987, p. 548)

É importante ressaltar que, no momento da unificação nacional italiana, ou seja, em 1861, $80 \%$ da população era analfabeta e usava somente o dialeto. O processo de unificação lingüística da Itália foi lento e difícil. Podemos enumerar os acontecimentos que contribuíram para a consolidação da língua nacional no final do século XIX e início do século XX:

a)instituição da educação de base obrigatória para toda a população;

b)a obrigatoriedade do serviço militar, sendo assim, os homens deviam sair das suas cidades de origem e ir para outras que possuíam uma "língua" diferente;

c) processos migratórios;

d)o advento do rádio e da televisão.

Vale a pena lembrar que Manzoni teve opositores. Contra a proposta de fazer com que todos os italianos adotassem o florentino contemporâneo falado e de usar um dicionário como instrumento importante para a difusão dessa mesma língua, Grazadio Isaia Ascoli, um grande glotólogo italiano, foi o maior opositor de Manzoni.

Ascoli defendia que não era da forma como pensava Manzoni que se formavam as línguas nacionais. Ascoli exemplificava com a história lingüística da França, da Inglaterra, e da Alemanha. Na França, o dialeto de Paris tornou-se língua nacional devido aos séculos de centralização burocrática, intelectual e política. Na 
Alemanha, não foi um dialeto de determinada região o construitor da base da língua alemã, mas sim o alemão usado por Lutero na tradução da Bíblia, que constituiu a base da língua adotada por toda a nação, em todos os níveis sociais, graças ao progresso da alfabetização e à expansão de atividades culturais e civis que, mesmo com a falta de unidade política, estabeleceu vínculos entre todos os setores da comunidade.

A situação italiana era muito diferente. De uma parte existia uma língua literária, feita por literatos para literatos; de outra, existiam vários dialetos. $\mathrm{Na}$ época de Ascoli, ainda não tinha existido na Itália a centralização política que existiu na França e na Inglaterra, nem a intensa atividade cultural que existiu em toda a Alemanha.

Lepschy (2002) afirma que a escolha de Manzoni, a favor do florentino moderno era arbitrária. Mesmo que o italiano literário fosse baseado no florentino do século XIV, ele se desenvolveu nos séculos seguintes, recebendo influências de outras partes da Itália, que não influenciaram o dialeto de Florença, o qual, por sua vez, desenvolveu-se sem nenhuma interferência e contato com o italiano literário.

Para Ascoli, a formação de uma língua unitária, que fosse usada em toda a Itália e por todas as classes, poderia ser resultante somente de profundas mudanças sociais e culturais, tendo como única base a escrita.

\section{5 - O romance histórico}

I Promessi Sposi é considerado um romance histórico, pois mistura história e ficção, reconstruindo de forma fictícia acontecimentos e personagens históricos.

O romance histórico surgiu com o romantismo, no início do século XIX. Destacaram-se por esse gênero escritores como Walter Scott (Ivanhoe), Alexandre Dumas (Os três mosqueteiros) e Leon Tolstói (Gerra e Paz).

Manzoni tinha em mente a representação da história não dos grandes e heróicos personagens, mas, sobretudo, do povo em geral. Podemos dizer que Manzoni foi o primeiro a produzir literatura desse gênero na Itália.

Esse gênero permitiu a Manzoni escrever uma obra que fosse ao mesmo tempo verdadeira, educativa e interessante, tendo o próprio Manzoni revelado uma 
vez, em carta a um amigo, que "l'opera d'arte deve avere il vero per soggetto, l'utile per scopo e l'interessante per mezzo".

No romance de Manzoni, o difícil equilíbrio entre história e fantasia existe de maneira harmônica. Isso foi possível porque o escritor estudou minuciosamente a época na qual se desenvolveu a história que ele conta e soube criar personagens que representassem, não somente nas ações, mas também nos pensamentos, o período tratado. O autor define o romance como "Storia milanese del secolo XVII". A história desenvolve-se nas imediações da zona rural das cidades de Lecco, Monza, Milão e Bérgamo, de 7 de novembro de 1628 ao outono italiano de 1630, ou seja, por quase dois anos, tratando episódios como a guerra, a peste e a fome e o tema da Providência relacionado com o século em questão.

\section{6- Manzoni e I Promessi Sposi}

Neste momento faz-se necessário conhecer um pouco da vida de Manzoni para entendermos posteriormente algumas de suas escolhas ao escrever a obra I Promessi Sposi.

\subsection{1 - O conteúdo do romance em linhas gerais}

O romance está estruturado em 38 capítulos. Começa com uma introdução na qual Manzoni finge ter lido em um manuscrito anônimo do século XVII uma história interessante e de tê-la reescrita de forma mais simples e moderna com a finalidade de apresentá-la aos seus contemporâneos. Manzoni afirma que, tendo a história o poder de imortalizar homens e fatos importantes, ele se limitará a contar os acontecimentos referentes a personagens mais humildes com uma linguagem adaptada para que os leitores tenham acesso àquela bela história. $O$ romance passa-se no período de 1628 a 1632, na lombardia sob dominação espanhola e traz no início do primeiro capítulo uma longa e minuciosa descrição da paisagem.

Dom Abbonddio, o padre que deve celebrar o casamento de Renzo e Lucia recebe a ordem de dois capangas de Dom Rodrigo, um importante senhor da região, um fidalgo tirânico, para não realizar o casamento dos jovens noivos. O padre finge 
uma doença para poder postergar a data do casamento. Porém, Renzo descobre por meio de Pérpetua, a serva do padre, que o mesmo foi ameaçado por Dom Rodrigo. Renzo e Lucia decidem procurar ajuda. Renzo vai à procura de um advogado muito conhecido na região por conseguir resolver todos os problemas dos seus clientes. Seu nome é Azzeccagarbugli, que significa justamente isso, ou seja, azzeccare em italiano quer dizer adivinhar, acertar alguma coisa e garbuglio significa confuso, difícil. Sendo assim, o Azzeccagarbugli seria a pessoa que consegue resolver uma situação complicada.

Todavia, tal advogado não conseguiu fazer nada pois, quando descobriu que era de vontade de Dom Rodrigo que o casamento não se realizasse, teve a mesma reação de Dom Abbonddio. Lucia pediu auxílio ao Frei Cristovão, que foi falar com Dom Rodrigo, mas também não obteve nenhum êxito. Agnese, a mãe de Lucia, teve a idéia de arrumar duas testemunhas para o casamento e levá-las até a casa de Dom Abbonddio juntamente com Renzo e Lucia e tentar fazer com que Dom Abbonddio proferisse os ritos do casamento e, sem se dar conta, no momento oportuno Renzo e Lucia diriam sim com as duas testemunhas presentes, fazendo com que o casamento fosse válido. Porém, Dom Abbonddio desconfia de tudo e grita o nome do sacristão e esse, assustado, começa a tocar os sinos da igreja. Nesse mesmo momento, os capangas de Dom Rodrigo entram na casa de Lucia para raptá-la, mas não a encontram e quando escutam os sinos da igreja se assustam e vão embora. Agnese, Lucia, Renzo e os seus dois amigos fogem da casa de Dom Abbondio e vão encontrar Frei Cristovão, que sabia das intenções de Dom Rodrigo de raptar Lucia. O frei então providenciou um refúgio para Lucia e a mãe em Monza e um para Renzo em Milão.

Em Monza, Lucia foi recebida pela freira superior Gertrudes e conhece a freira de Monza, personagem amargurado que realmente existiu. Essa freira teve relações com Egidio, o qual levará Lucia para o castelo do Inominado. Em Milão, Renzo chega e encontra a cidade toda suja de farinha e alguns pães jogados nas ruas. Era um período de grande carestia e, naquele momento, ocorria uma revolta na cidade. Renzo é confundido: a polícia acredita que ele é um dos manifestantes e, por pouco, não é preso. Consegue fugir e, andando, vai de Milão até Bérgamo para procurar apoio na casa do primo Bartolo, onde começa a trabalhar em uma tecelagem.

Dom Rodrigo não desiste de raptar Lucia e, sabendo que a mesma se encontra no convento, decide pedir ajuda a uma pessoa muito importante, conhecida 
como Inominado, para poder raptar Lucia. O Inominado é um poderoso e temido criminoso que se encontra dividido entre seu feroz passado e o crescente desgosto que sente pela sua vida. Está baseado em um personagem histórico que realmente existiu. No passado, cometeu muitos crimes e agora vive o arrependimento. Quando Lucia é raptada e chega ao seu castelo, o Inominado sensibiliza-se com o olhar sofrido e piedoso de Lucia. Decide, então, que não vai entregá-la a Dom Rodrigo como havia prometido.

Lucia, desde que entra no castelo sente muito medo e temerosa do que possa Ihe acontecer faz uma promessa para Nossa Senhora: caso consiga sair sã daquelas provações, desistirá de se casar com Renzo. O Inominado, angustiado por não saber o que fazer com Lucia, decide encontrar-se com o Cardeal Frederico Borromeu, homem de grande virtude moral e espiritual que também existiu como personagem histórico. A conversa dos dois resulta na conversão do Inominado e na promessa de libertar Lucia. Livre, Lucia encontra a mãe e é hospedada por um casal milanês: Dom Ferrante e dona Praxedes.

Dom Rodrigo, enfraquecido, foge dos arredores de Milão. Dom Abbonddio arrepende-se por não ter feito o casamento de Renzo e Lucia. Renzo é procurado por toda Bérgamo, mas ninguém o encontra para avisá-lo que Lucia é livre e que podem se casar.

Nesse momento, os personagens vivem os fatos históricos da época como a guerra pela sucessão do Ducado de Mantova, a carestia e a peste. Depois de um tempo, Renzo, trocando correspondências com a mãe de Lucia, descobre que a mesma está bem e que fez a promessa que não se casaria com ele se o Inominado a libertasse. Para fugir da peste Dom Abbonddio, Perpetua e Agnese se refugiam no castelo do Inominado.

A peste cresce e, em Milão, em março de 1630, a mortalidade era alarmante. A ignorância e a superstição popular atribuíam a resposabilidade aos untores que, segundo a crença popular, espalhavam pela cidade fezes e urinas contaminadas. Os leprosários encontravam-se lotados.

Dom Rodrigo descobriu no seu corpo sinais da doença e é traído pelo amigo Griso, que o levou para o leprosário. Renzo pega a peste mas consegue se curar e vai procurar por Lucia que está também no leprosário. Lá encontra Dom Rodrigo quase morto e o perdoa, pensando que a Divina Providência deu a ele o fim merecido. Encontra Lucia curada, mas muito fraca. Frei Cristovão quebra a 
promessa que Lucia havia feito e depois de cumprir a quarentena obrigatória quando saiu do leprosário, Lucia se vê finalmente livre para casar com Renzo. Dom Abbonddio realiza o casamento somente depois de ter a certeza que Dom Rodrigo foi morto pela peste. No primeiro ano de casamento, Lucia dá à luz uma menina que recebe o nome de Maria. O romance conclui-se com a constatação de Renzo e Lucia de que a confiança em Deus é capaz de resolver todos os problemas.

\subsection{2 - O que mudou de Fermo e Lucia (1821) para I Promessi Sposi (1842)}

Solo la língua parlata in una società effettiva e continua ha carattere d'universalità, mentre la lingua scritta non è che un fortuito e vari mescuglio.

(A. Manzoni)

Manzoni começou a escrever Fermo e Lucia (nome inicial do romance que se referia ao casal de personagens principais) em 24 de abril de 1821, tendo interrompido várias vezes e terminado em 17 de setembro de 1823. A obra apresentava-se dividida em quatro volumes e trinta e sete capítulos.

Manzoni classifica a primeira escrita de Fermo e Lucia como sendo "um composto indigesto de frases um pouco lombardas, um pouco toscanas, um pouco francesas, um pouco latinas", ou seja, uma língua híbrida, fundamentada no florentino literário e recheada de palavras e expressões do dialeto milanês que deixariam a narração mais viva; cheia também de francesismos que a deixariam mais na moda e de latinismos que a deixariam mais elegante e culta (DELLA VALLE, 2006).

\subsubsection{1 - Do Fermo e Lucia (1821-1823) para a Ventissetana (1825-1827)}

Quando Manzoni terminou de escrever a primeira vez o romance, percebeu que a língua que havia usado para escrevê-lo era uma língua inexistente pois havia misturado tudo o que ele conhecia: o francês, o latim e o dialeto milanês. Decidiu então "traduzir" o romance para a língua que era considerada literária na época, a língua italiana de Florença. Para tanto usou como principal instrumento o Vocabolario Milanese-Italiano de Francesco Cherubini. Ao final da árdua tarefa, 
tendo como resultado a primeira publicação da obra, ou seja, a ventissetana, deu-se conta que aquela língua utilizada ainda não o satisfazia.

O dicionário do Cherubini, como outros dicionários dialetais daquela época, oferecia apenas elaboradas versões "cruscantes" para as palavras em dialeto. Eram às vezes propostas muito estranhas e Manzoni tentou inúmeras vezes convencer Cherubini, na sua segunda edição (1839), de usar o florentino moderno, uma língua mais viva, em oposição à linguagem adotada pela Crusca. Manzoni superestimava o efeito dos dicionários e, no relatório que fez ao ministro da Educação Broglio Dell'unità della língua e dei mezzi di diffonderla - no qual propunha (LEPSCHY, LEPSCHY, 2002) a adoção do florentino falado contemporâneo como língua nacional, ele defendia a importância que um dicionário florentino teria para a afirmação de suas teorias. O Novo Vocabolario della Lingua Italiana Secondo l'uso di Firenze foi efetivamente preparado graças ao ministro Broglio e a Giorgini e foi publicado entre 1870 e 1897.

Na edição de 1827, Manzoni procurou substituir os temos dialetais por termos estritamente toscanos. Porém, nem essa tradução do milanês para o toscano o satisfez porque, para realizá-la, ele usou uma língua morta, ou seja, a língua encontrada nos dicionários, a qual não era falada, somente escrita. Esta edição saiu em três volume, o primeiro e o segundo com a data de 1825 e o terceiro com a data de 1826. Os três volumes foram publicados juntos em junho de 1827, com uma tiragem de dois mil exemplares (edição ventisettana). Na metade de agosto do mesmo ano, o romance já se encontrava esgotado.

Além da mudança lingüística, prevalente preocupação manzoniana, essa segunda reescritura e primeira edição sofreu alterações de conteúdo e de estrutura. Alguns episódios mudaram de lugar, outros sofreram cortes e outros tiveram os detalhes aumentados, como a história do Conte Del Sagrato ( a partir da edição de 27 conhecido como o Inominado). Podemos citar as alterações elencadas a seguir:

a)análise psicológica dos sentimentos de Renzo quando passa a noite na beira do lago Adda;

b)a descrição do vinhedo de Renzo;

c) a chuva que purifica a cidade da peste;

d) o redesenhar dos personagens; 
e) mudança no nome dos personagens (Fermo Spolino para Renzo Tramaglino, Lucia Zarella para Lucia Mondella, II Conte del Sagrato para o Inominado, Vittoria por Perpetua, Geltrude por Senhora de Monza).

\subsubsection{2 - Da ventisettana à quarantana}

Em julho de 1827 Manzoni, não satisfeito com o resultado lingüístico do romance, decide de mudar-se com toda a família para Florença para iniciar a famosa "risciacquatura in Arno", ou seja, a revisão lingüística do seu romance tendo como base o dialeto culto falado em Florença.

Escreve ao amigo Grossi e usa muito bem a metáfora para "enxaguar" o romance nas águas do rio mais famoso de Floreça, o Arno, para deixar a língua da sua obra mais próxima à língua falada culta de Florença tendo como ajudantes para tal tarefa as "lavadeiras", ou seja os lingüístas Cione e Niccolini:

Ma tu sai come sono occupato: ho settantun lenzuoli (i grandi fogli a stampa del romanzo) da risciacquare, e un'acqua come Arno, e lavandaie come Cione e Niccolini, fuor di qui non le trovo in nessun luogo (CANTELLA, 1996, p. 20)

A revisão do I promessi Sposi teve como intenção, sobretudo, de aproximar a forma escrita daquela falada, eliminando as expressões que Manzoni havia usado e que não eram freqüentes no uso falado florentino, sendo essas, arcaísmos ou expressões dialetais milaneses. Substituiu várias palavras e locuções consideradas muito literárias por outras consideradas familiares como expomos no exemplo abaixo extraído de Migliorini (1987, p. 551):

accidioso por uggioso, que para a melhor compreensão dos nossos alunos seria melhor substituído pelo vocábulo tedioso ou noioso.

O número e o conteúdo dos 38 capítulos permaneceram imutáveis da obra de 1827 para aquela de 1840. As variações são essencialmente gráficas e lexicais e visam à uniformidade da língua. Essa edição saiu em 108 fascículos entre novembro de 1840 e novembro de 1842 com uma tiragem de dez mil cópias. 
Como veremos a seguir, analisando dois trechos do romance, sendo um da primeira edição de 1827 e outro da segunda de 1840, verificamos que a preocupação de Manzoni era escrever utilizando não somente uma língua mais toscana, mas também mais simples, mais comunicativa, mais linear e mais desenvolta, não se tratando somente do léxico (mesmo sendo essa a principal preocupação) ou de forma, mas também da sintaxe e da estrutura do período. É o que verificamos comparando os dois trechos a seguir (CARETTI, 1971, p. 775):

\section{Edição 1827}

Renzo rimase lì gramo e scontento, a pensar d'altro albergo.

Nella lista funebre recitatagli da don Abbondio, v'era una famiglia di contadini portata via tutta dal contagio, salvo un giovanotto, dell'età di Renzo a un dipresso e suo camerata dall'infanzia:

la casa era fuori dal villaggio, a pochissima distanza.

Quivi egli deliberò di rivolgersi a chiedere ospizio.

\section{Edição 1840}

Renzo rimase lì tristo e scontento, a pensar dove anderebbe a fermarsi.

In quella enumerazion di morti fattagli da don Abbondio, c'era una famiglia di contadini portata via tutta dal contagio, salvo un giovinotto, dell'età di Renzo a un di presso, e suo compagno fin da piccolo;

la casa era pochi passi fuori del paese.

Pensò d'andar lì.

Vitale (1992) enumera as seguintes modificações referentes às edições de 1827 e 1840:

1. substituição de construções lombardas:

\section{$\checkmark$ fatores fono-morfológicos:}

- pontando por puntando;

- sagrificata por sacrificata;

$\checkmark$ fatos lexicais:

- sulla bass'ora por sul tardi;

- birbonone por birbone; 
- baiando por gridando;

- levando la barba por alzando la barba;

$\checkmark$ locuções idiomáticas:

- torsì giù dalla speranza por perdere la speranza;

- venir giù por scendere;

fatores sintáticos:

- la è legge por è legge;

- gli è un ciuffo por è un ciuffo;

2. diminuição da forma literária:

$\checkmark$ fatores gráficos e fono-morfológicos:

- inspirato por ispirato;

- publica por pubblica;

- dubbii por dubi; varri por vari; (vogais)

- deciferare por decifrare;

- conchiudere por concludere; (consoantes)

- giungnere por giungere;

- cangiare por cambiare;

- per lo migliore por per il migliore; (artigo)

- ad ambe mani por a due mani; ambidue por tutt'e due; (numeral)

- mettervi por metterci; vi sarebbe por ci sarebbe; (adverbio)

- sieno por siano; veggio por vedo; veggono por vedono; (verbo)

$\checkmark$ fatores lexicais:

- abborritore por nemico;

- amaritudine por amarezza;

- annoverati por numerati;

- fantesca por serva;

- ogni giornata dava in maggior copia por ogni giorno eran di più;

$\checkmark$ fatores sintáticos:

- dei 13 febbraio por del 13 febbraio;

- la badessa rispose (...) dolerle assai por la badessa rispose (...) che le dispiaceva molto;

- v'ha delle eccezioni por ci sono dellle eccezioni;

- sanno benissimo come vadano queste faccende por sanno benissimo come vanno queste faccende; 
3. introdução de vocábulos florentinos:

$\checkmark$ fatores fono-morfológicos:

- bracciuolo por bracciolo; accuora por accora; si muove por si move; (vogal)

- nei por ne'; quei por que'; (apócope pós-vocalica)

- pover uomo por pover'uomo; una abilità por un'abilità; (elisão)

- ad onore por a onore; ad uno ad uno por a uno a uno; (consoante)

- artificio por artifizio; uficiali por ufiziali; (assibilação)

- mattino por mattina; un cassetto por una cassetta; (substantivo)

- diceva io por dicevo; noi ci eravamo por ci eravamo; (pronome e verbo)

- chi darebbe lor retta por che gli darebbe retta (pronome)

- vado por vo; andrò por anderò; io aveva por io avevo; (verbo)

$\checkmark$ fatores lexicais:

- tramestava polenta por dimenava polenta;

- posdomani por doman l'altro;

- I'ho tenuto nelle mie braccia por l'ho portato in collo;

4. redução dos alótropos lingüísticos:

$\checkmark$ fra il tumulto por tra il tumulto;

$\checkmark$ quistione por questione;

$\checkmark$ equalmente por ugualmente;

$\checkmark$ modo por maniera;

$\checkmark$ porre por mettere;

$\checkmark$ pigliare por prendere;

$\checkmark$ niente por nulla.

Todas essas mudanças aqui elencadas são interessantes para verificarmos também de que maneira evoluiu a língua italiana e o que ficou na língua atual. 


\section{III - LITERATURA ADAPTADA: CONCEITOS E PROCEDIMENTOS}

Le parole sono fatte, prima che per essere dette, per essere capite proprio per questo, diceva um filosofo, gli dei ci hanno dato una lingua e due

orecchie.

(Tullio de Mauro)

Tullio de Mauro, lingüista italiano, sempre demonstrou grande preocupação com a língua italiana, seja na sua evolução, seja na sua recepção pela população italiana e, mais recentemente, pelos imigrantes que residem na Itália.

Em 1983, um grupo de pais de filhos adultos com deficiência cognitiva, bibliotecários de Roma e pedagogos pediram a De Mauro para que ele projetasse instrumentos de leitura úteis a pessoas com dificuldades de leitura e compreensão que tinham apenas terminado a escola obrigatória mas que queriam manter-se informados, por meio da leitura, dos acontecimentos.

De Mauro, com sua equipe de trabalho, desde a metade dos anos setenta trabalhava com mecanismos para facilitação da compreensão da leitura em textos de divulgação. Resultado desse seu trabalho é uma coleção intitulada "Libri di Base" publicados pela Editori Riuniti, sendo a primeira experiência sistemática de divulgação científica feita com uma linguagem específica, porém clara e simples.

Em 1989, atendendo ao pedido dos pais, bibliotecários e pedagogos citdos anteriormente, De Mauro, juntamente com outros pesquisadores da Universidade de Roma "La Sapienza", lançaram o jornal "Due Parole". Esse jornal foi publicado durante oito anos e divulgado por meio impresso. Em 1997, suspenderam publicação devido ao alto custo com a impressão e à expedição do mesmo.

Alguns redatores de "Due Parole" fundaram, em 1998, "Parlar Chiaro. Associazione per la semplificazione della comunicazione di interesse pubblico" (Falar Claro. Associação pela simplificação da comunicação de interesse público). O objetivo principal da Associação era contribuir para a difusão da cultura da clareza e simplicidade lingüística na Itália. Com essa idéia, os membros da Associação contribuíram com várias instituições públicas para atingir o objetivo da simplificação 
da linguagem também na comunicação pública e institucional.

Em 2001, foi retomada a publicação de Due Parole, porém usando a forma online como meio de divulgação. O jornal manteve as suas mesmas características, ou seja, um jornal de fácil leitura com artigos escritos em uma língua muito clara, simples e precisa. Direcionado a estudantes estrangeiros que seguiam cursos iniciais de língua italiana na Itália ou no exterior e que gostariam de ter informações em língua italiana sobre a Itália; estrangeiros, na maior parte extra-comunitários, que possuíam pouca familiaridade com a língua italiana, sobretudo aquela escrita; jovens italianos freqüentadores da escola obrigatória e que geralmente liam pouco; enfim, pessoas jovens ou adultas que, depois da escola obrigatória, liam pouco porque não encontravam textos informativos adequados às suas reais capacidades lingüísticas cognitivas.

Os textos contidos em Due Parole eram escritos utilizando uma escrita controlada, ou seja, textos breves, períodos sem muita subordinação e escolha de um léxico muito comum na língua italiana. Esses critérios podem ser adotados em qualquer tipo de texto com o intuito de simplificá-lo para a maior compreensão do leitor leigo, seja ele estrangeiro ou de língua materna.

O grupo que participou da redação do jornal Due Parole era composto por lingüistas, jornalistas e alunos formados em Letras pela Universidade de Roma La Sapienza. Por meio do estudo do processo da compreensão, da legibilidade e comunicabilidade dos textos, o grupo chegou a definir alguns critérios de escrita controlada e de comunicação eficaz. Graças a anos de experimentos e aplicações de tais critérios o grupo adquiriu uma vasta experiência na simplificação da linguagem da comunicação pública e, de forma particular, na linguagem da informação e da divulgação.

Hoje em dia, com um número cada vez maior de imigrantes na Itália, é comum ver nascer estruturas para "acolher" esses imigrantes e ensiná-los a língua italiana.

Com a crescente expansão do ensino da língua italiana no exterior verifica-se também uma crescente produção de material didático para a difusão dessa língua. Assim como De Mauro se interessou, juntamente com a sua equipe, em produzir o jornal Due Parole para estrangeiros e italianos com um conhecimento básico de língua, várias editoras hoje em dia na Itália produzem livros de literatura facilitada, também conhecidos como literatura controlada. 


\section{1 - Mecanismos de facilitação da leitura em LE - Italiano}

A compreensão de um texto escrito envolve um trabalho com os processos de construção do sentido, pois "ler é uma atividade multidimensional, cujo objetivo é a construção de uma representação semântica daquilo que está escrito (DESCHÊNES, 1988)".

Alguns teóricos acreditam que o texto é apenas um encadeamento de signos verbais ou um conjunto de frases que contém um sentido estável, previamente deixado pelo autor e que será decifrado pelo leitor. Nesse processo, a compreensão passa pelo conhecimento do léxico e da gramática da língua. Porém, não podemos associar a compreensão de um texto somente ao conhecimento da gramática e do léxico da língua em questão. Existem outros fatores externos, como o conhecimento prévio do assunto tratado no texto ou do conhecimento de mundo do leitor que influencia na compreensão do texto lido.

Pietraróia, em seu livro Questões de Leitura (2001) afirma que até o início da década de 80 , as teorias sobre a leitura, seja em língua materna quanto em língua estrangeira, dividiam-se em relação a dois tipos de estratégias usadas pelos leitores:

a)estratégias ascendentes ou de baixo nível que partem das palavras e frases para chegar ao sentido global do texto;

b)estratégias descendentes ou de alto nível, que partem de um sentido geral para chegar à estrutura do texto, suas palavras, seus elementos de base.

Atualmente, pesquisas constataram que o bom leitor é aquele que usa as duas estratégias, mesmo não existindo um equilíbrio de uso entre as duas. Dois aspectos dessas pesquisas merecem ser destacados (Pietraróia, 2001, p. 24):

a) o tratamento lexical: muitos autores, como Alegria (1991) e Segui (1992), demonstraram que a apresentação de uma palavra-estímulo ativa não somente sua própria representação lexical, mas ainda a de um conjunto de palavras correspondentes a seus vizinhos ortográficos e fonéticos. Porém, além dessas ativações de representantes formais, ocorre uma ativação de vizinhos semânticos. Trata-se de um processo involuntário, rápido e de 
fraca duração, mas suficiente para influenciar a leitura dos demais termos do texto.

b) o papel do contexto no tratamento lexical: estudos de orientação cognitiva sobre a leitura provaram que, para alguns leitores, o processo de decodificação é mais rápido do que a intervenção do contexto, sendo esse usado somente para confirmar a construção do sentido feita. Outros leitores identificam as palavras de modo mais lento, permitindo que o contexto influencie de forma negativa na leitura e prejudique também os demais tratamentos, como o proposicional e o global. Quando o acesso é lento, a disponibilidade dos dados semânticos pode chegar muito tarde $e$ interromper o processo de integração proposicional, fazendo com que o leitor recorra a estratégias compensatórias, como o apoio exagerado no contexto.

As pesquisas feitas dentro da orientação cognitiva resultaram na diminuição do papel das estratégias descendentes e dos modelos mentais na compreensão escrita. Dessas novas posturas, surgiram modelos interativos de leituras, trazendo equilíbrio e coerência à compreensão escrita.

Nessa pesquisa não é o nosso objeto a descrição e a avaliação desses novos modelos de leitura. Assumimos, porém, a postura de que para uma boa compreensão do texto escrito é importante que o leitor possa usar estratégias ascendentes e descendes e assumimos que a compreensão de boa parte do léxico usado em um texto aliada a elementos extralingüísticos podem garantir o sucesso na leitura.

Mas qual é o tamanho do léxico de uma língua? Um falante nativo consegue conhecer quanto do léxico da sua língua? E um estrangeiro?

Para a língua italiana, Tullio De Mauro (1980) propôs um vocabulário de base $(\mathrm{VdB})$ com cerca de sete mil palavras que supõe serem conhecidas por qualquer pessoa que tenha completado o ensino fundamental. Este vocabulário é dividido em 3 categorias:

\begin{tabular}{|l|l|l|}
\hline Vocabulário de base & Dimensão & exemplos \\
\hline Fundamental & 2.000 palavras & $\begin{array}{l}\text { Fruta, movimento, rico, } \\
\text { escorregar, com prazer }\end{array}$ \\
\hline
\end{tabular}




\begin{tabular}{|l|l|l|}
\hline De alto uso & 2.750 palavras & $\begin{array}{l}\text { Piada, aceitar, cento, às } \\
\text { vezes }\end{array}$ \\
\hline De alta disponibilidade & 2.300 palavras & $\begin{array}{l}\text { Confiante, distancia, } \\
\text { comandar, viajante }\end{array}$ \\
\hline
\end{tabular}

*Adaptado de Camilla Bettoni, Imparare un'altra lingua, Roma-Bari,Laterza,2007, p.65.

${ }^{* *}$ O numero total das palavras em cada categoria sofre uma pequena variação quando citado por diversos autores, porém, o numero total gira sempre em torno de 7000 palavras.

A primeira categoria é definida como vocabulário fundamental e compreende cerca de duas mil palavras, sendo essas as mais freqüentes no Lessico di frequenza della lingua italiana contemporanea (LIF) elaborado por Bortolini, Tagliavini e Zampolli e publicado pela editora Garzanti em 1972.

A segunda categoria é definida como vocabulário de alto uso e a terceira categoria como vocabulário de alta disponibilidade. Uma característica interessante dessa última categoria é que mesmo sendo um vocabulário de alta disponibilidade não é quase dito e nem escrito, mas é "pensado" com alta freqüência. Veremos mais detalhes de como foi elaborado o VdB de De Mauro no próximo item, quando trataremos dos diversos léxicos de freqüência da língua italiana.

É importante ressaltar neste momento que as bases de dados dos léxicos de freqüência da língua italiana são usadas como fonte para compor as palavras utilizadas nos livros de leitura facilitada para estrangeiros e para italianos com baixo conhecimento lingüístico como é o caso do jornal, já citados por nós no começo deste capítulo, Due Parole.

Retomamos agora as três perguntas feitas anteriormente.

1 - Qual é o tamanho do léxico de uma língua?

Poderíamos dizer que o léxico de uma língua pode ser medido pelos dicionários dessa língua, mas nunca chegaremos a um número exato das unidades lexicais componentes de uma determinada língua pois, além de termos que contabilizar as unidades flexionadas (verbos conjugados, gênero e número dos substantivos, lexias complexas e compostas) teríamos que levar em conta o número de neologismos presentes na língua em questão. O léxico, diferentemente da gramática, é um sistema aberto sujeito a grandes e ocorrentes modificações se comparado à gramática. 
2 - Um falante nativo consegue conhecer quanto do léxico da sua língua?

Com certeza, um falante nativo não consegue dominar todo o inventário lexical da sua língua e o conhecimento varia de falante para falante levando em consideração vários fatores, como por exemplo a idade e a escolaridade.

3 - Quantas palavras um estrangeiro consegue conhecer em uma língua estrangeira?

Para essa pergunta também não temos uma resposta exata pois, neste caso, estão envolvidos vários fatores como a similaridade entre a língua materna e a língua estrangeira, o número de vocábulos mais freqüentes pode variar de uma língua estrangeira para outra e a tipologia lingüística (com certeza o número do léxico de freqüência de uma língua isolante é bem diferente daquele de uma língua aglutinante) é também um fator determinante. Nation e Waring (1997) sustentam que para a aprendizagem eficaz de uma segunda língua estrangeira (no caso o inglês) é necessário o conhecimento de no mínimo três mil palavras. Sabemos que esse número é considerado alto para a língua italiana tendo como base o número de palavras novas que trazem os manuais de língua italiana para estrangeiros e os livros de literatura facilitada, os quais apresentam-se divididos, na sua maior parte, em quatro ou cinco níveis, de acordo com o Quadro Comum Europeu de Referência para as Línguas Estrangeiras:
a) 500 palavras: nível $A 1$
b) 1000 palavras: nível $\mathrm{A} 1 / \mathrm{A} 2$
c) 1500 palavras: nível $\mathrm{B} 1$
d) 2000 palavras: nível B2
e) 2500 palavras: nível $\mathrm{C} 1$

Poderíamos considerar que um aluno que domine três palavras da língua italiana como sendo um nível $\mathrm{C} 1$ "potenziato". Porém, essa nossa afirmação pode ter os seus riscos, pois quais seriam essas 3000 palavras? Sabemos, por experiência de pesquisa que será demonstrada neste trabalho no capítulo 5 (Análise dos dados), que alunos expostos ao mesmo insumo (input) assimilam diferentemente o léxico, pois fazem associações diferentes e o que pode ser representativo para um, possibilitando que a utilização desse léxico seja de maneira produtiva ou passiva, não necessariamente é para o outro aluno.

Dessa forma, concordamos com a afirmação das três mil palavras para um bom conhecimento de língua, conscientes de que é difícil fazer essa 
"medida" e que as três mil unidades lexicais podem variar de aluno para aluno, mesmo tendo como base um léxico de freqüência.

Bettoni (2007) quando fala da aprendizagem do léxico em língua estrangeira nos chama atenção para a sua grande importância em detrimento à gramática dando-nos o exemplo de quando um turista vai a um país cujo idioma desconhece, a primeira coisa que faz é comprar um dicionário dessa língua e não uma gramática. Ainda, segundo a autora, nos níveis mais avançados do estudo da língua, os erros lexicais (principalmente inadequação vocabular em suas diversas esferas) em relação aos gramaticais são mais comuns, são os que os nativos notam primeiro e os que causam maiores ruídos na comunicação.

Podemos dizer que o não conhecimento de uma certa palavra no ato da leitura ou a troca do significado dessa palavra por outra pode comprometer a compreensão do texto, sendo o léxico também muito importante na leitura.

Retomando ao VdB (Vocabulario de Base) de De Mauro com as sete mil palavras, lacobini e Thorton (1994) calcularam a distribuição dessas "palavras" entre as diversas classes morfológicas e chegaram ao resultado expresso na tabela abaixo:

\begin{tabular}{|l|l|}
\hline Classe morfológica & Vocabulário de base - VdB \\
\hline Substantivo & $60,6 \%$ \\
\hline Verbo & $19,6 \%$ \\
\hline Adjetivo & $14,9 \%$ \\
\hline Advérbio & $2,0 \%$ \\
\hline Pronome & $0,8 \%$ \\
\hline Conjunção & $0,6 \%$ \\
\hline Numeral & $0,5 \%$ \\
\hline Preposição & $0,5 \%$ \\
\hline Interjeição & $0,4 \%$ \\
\hline Artigo & $0,1 \%$ \\
\hline
\end{tabular}

*Adaptado de BETTONI,2007,p.98

Percebemos que os substantivos, os verbos e os adjetivos somados 
resultam $95,1 \%$ das palavras do VdB. Essas palavras são consideradas por alguns autores como palavras conteúdo e as outras classes morfológicas como palavras funções, porém verbos como os auxiliares essere e avere são consideradas palavras funções e não conteúdo. Para Jezek (2005, p.27) as palavras "conteúdo" (ou palavra lexical ou palavra cheia) são mais fáceis de ser modificadas nas línguas em relação às palavras função (ou palavra gramatical ou palavra vazia) e as primeiras possuem uma polissemia que as segunda não podem possuir devido à classe morfológica que ocupam. Sendo assim, no processo de compreensão de um texto é normal que as "palavras conteúdos" causem maior dificuldade na compreensão que as "palavras funções".

\subsection{1 - Corpora do léxico italiano}

Como já foi citado no item anterior, descreveremos aqui de forma breve os corpora de freqüência do léxico italiano existentes.

Antes de falar dos corpora é importante citar que existe um site italiano : (www.eulogos.net) que faz o tratamento automático da língua, por exemplo se possuímos um texto e gostaríamos de verificar a legibilidade desse texto em relação às palavras que constam no mesmo, basta enviá-lo de forma eletrônica para os especialistas que esses fazem o tratamento automático dos dados e publicam os resultados.

LIF - Léxico de Freqüência da Língua Italiana Contemporânea foi elaborado em 1971 pelo Centro Nacional Universitário de Cálculo Eletrônico (CNUCE) de Pisa. Os pesquisadores que estavam à frente desse projeto eram U. Bortolini, C. Tagliavini e A. Zampolli. Trata-se do primeiro grande projeto de construção de um léxico de freqüência para a língua italiana. O léxico contém cerca de 5.000 palavras ordenadas por freqüência e segundo a ordem alfabética, retirados de um banco de dados que compunha 500.00 ocorrências de palavras retiradas de textos escritos, divididos em cinco grupos: teatro, romances, cinema, jornais e textos de diversas matérias escolares. Esses textos eram de datas entre 1947 e 1968. Representavam assim diversas formas textuais, algumas delas bem próximas à língua falada.

LIP - Léxico de Frequência do Italiano Falado, elaborado por De Mauro, Mancini, Vedovelli e Voghera e publicado em 1993, constitui a 
contraparte do LIF para o italiano falado. O corpus de onde foi extraído o LIP é constituido de cerca 500.000 palavras gráficas, transcrições de gravações feitas em Milão, Florença, Roma e Nápoles, com mais ou menos 57 horas de fala. Os discursos orais gravados estão agrupados em cinco grupos de acordo com a formalidade e a presença ou ausência do interlocutor:

1 - conversas espontâneas;

2 - conversas telefônicas;

3 - assembléia ou mesas redondas;

4 - aulas;

5 - transmissões radiofônicas;

VdB - Vocabulário de Base da Língua Italiana elaborado por De Mauro em colaboração com Emilia Passaponti e Stefan Genuini, foi publicado em 1980 e revisto em 1989. O VdB compreende palavras usadas com uma alta, média e baixa freqüência na língua italiana mas bem presente na consciência de todos os falantes. $\mathrm{O} \mathrm{VdB}$ da língua italiana utiliza as primeiras cinco mil palavras do LIF. Apresenta-se subdividido em vocabulário fundamental (FO), vocabulário de alta freqüência (AU) e vocabulário de alta disponibilidade ou familiaridade (AD). O VdB teve e tem uma autonomia lexicográfica, constituindo de maneira importante as entradas de certos dicionários escolares destinados à aprendizagem da língua italiana (dicionários pedagógicos).

Existem ainda outros corpora da língua italiana que elencamos aqui a título de curiosidade. Os que nos interessam são os descritos anteriormente, pois é com base nesses corpora que se compõe os textos de leitura facilitada para estrangeiros.

Abaixo, alguns dos os outros corpora existentes:

a) CLIPS - Corpora Linguistico per o italiano falado e escrito;

b) CORIS/CODIS Corpus do italiano escrito contemporâneo;

c) Corpus e léxico de frequência do italiano escrito;

d) Corpus do italiano televisivo;

e) O corpus LIPS que recolhe as transcrições dos textos de arquivo das provas do exame CILS - Certificazione di Italiano come Lingua Straniera dell'Università per Stranieri di Siena;

f) Corpus Penelope; 

g) LABLITA;
h) LIZ Letteratura Italiana Zanichelli;
i) Parlarltaliano;
j) TLIO Tesoro della lingua italiana delle origini;
k) VELI Vocabolario elettronico della lingua italiana;

\subsection{2 - Indicadores de inferência de significados em língua portuguesa na escrita/leitura em língua italiana}

Quando duas línguas são próximas, como no caso do português e do italiano, há uma grande probabilidade de interferência de uma na outra durante o processo inicial do aprendizado, mas também há uma grande vantagem do ponto de vista de algumas regras gramaticais que coincidem e da similaridade lexical. Essa última é necessário que seja vista com cautela porque, apesar da similaridade lexical das duas línguas, temos também a presença de falsos cognatos que, no processo de leitura, podem comprometer grande parte da compreensão.

A seguir apresentamos uma tabela que ajuda na decodificação do léxico de um texto italiano lido por um brasileiro de língua materna, sobretudo quando as palavras possuem o mesmo radical ou radicais semelhantes.

\begin{tabular}{|c|c|c|}
\hline Sufixo em italiano & Sufixo equivalente em PT & Exemplo \\
\hline -aggio & -ajem/-agem & $\begin{array}{l}\text { paggio } \\
\text { pajem } \\
\text { vantaggio } \\
\text { vantagem }\end{array}$ \\
\hline -ale & -al & $\begin{array}{l}\text { fatale } \\
\text { fatal }\end{array}$ \\
\hline -anza & -ância & $\begin{array}{l}\text { ambulanza } \\
\text { ambulância }\end{array}$ \\
\hline -ato & -ado & $\begin{array}{l}\text { chiamato } \\
\text { chamado }\end{array}$ \\
\hline
\end{tabular}




\begin{tabular}{|c|c|c|}
\hline Sufixo em italiano & Sufixo equivalente em PT & Exemplo \\
\hline -bile & -vel & $\begin{array}{l}\text { amabile } \\
\text { amável }\end{array}$ \\
\hline -eggiare & -ejar & $\begin{array}{l}\text { Veleggiare } \\
\text { velejar }\end{array}$ \\
\hline -enza & -ência & $\begin{array}{l}\text { equivalenza } \\
\text { equivalência }\end{array}$ \\
\hline -eria ${ }^{1}$ & -aria & $\begin{array}{l}\text { pizzeria } \\
\text { pizzaria }\end{array}$ \\
\hline -esse & -ês & $\begin{array}{l}\text { francese } \\
\text { francês }\end{array}$ \\
\hline -evole & -ável & $\begin{array}{l}\text { favorevole } \\
\text { favorável }\end{array}$ \\
\hline -ezza & -eza & $\begin{array}{l}\text { bellezza } \\
\text { beleza }\end{array}$ \\
\hline -gione & -gião & $\begin{array}{l}\text { religione } \\
\text { religião }\end{array}$ \\
\hline -ile & $-i l$ & $\begin{array}{l}\text { facile } \\
\text { fácil }\end{array}$ \\
\hline -ina $(0)^{2}$ & -inha(o) & $\begin{array}{l}\text { lattina } \\
\text { latinha }\end{array}$ \\
\hline -ità & -idade & $\begin{array}{l}\text { università } \\
\text { universidade }\end{array}$ \\
\hline -izzare & -izar & $\begin{array}{l}\text { caratterizzare } \\
\text { caracterizar }\end{array}$ \\
\hline- one $^{3}$ & -ão & $\begin{array}{l}\text { salone } \\
\text { salão }\end{array}$ \\
\hline -sione & -são & $\begin{array}{l}\text { visione } \\
\text { visão }\end{array}$ \\
\hline -tore & -dor & $\begin{array}{l}\text { procuratore } \\
\text { procurador }\end{array}$ \\
\hline -trice & -dora & $\begin{array}{l}\text { educatrice } \\
\text { educadora }\end{array}$ \\
\hline
\end{tabular}




\begin{tabular}{|c|c|l|}
\hline Sufixo em italiano & Sufixo equivalente em PT & Exemplo \\
\hline -uto/-ito & -ido & ricevuto \\
& & recebido \\
& & partito \\
& & partido \\
\hline -zone & -ção & Canzone \\
& & Canção \\
\hline -zione & -ção & condizione \\
& & condição \\
\hline
\end{tabular}

${ }^{1}$ sufixo produtor de nome de estabelecimentos;

${ }^{2}$ sufixo produtor de diminutivos;

${ }^{3}$ sufixo produtor de aumentativos;

Lembramos que o sucesso de uma boa leitura (compreensão satisfatória) envolve, na maioria das vezes, um conhecimento prévio do assunto e as palavras conhecidas na língua estrangeira ajudam na construção do sentido.

À luz do que diz Pietraróia (2001), a compreensão escrita deve ser vista como uma atividade de construção do sentido. Sua aprendizagem deve ser concebida como um processo lento e reflexivo, em que o leitor seja levado a trabalhar o texto em profundidade, estabelecendo relações pertinentes e produtivas entre as estruturas textuais e seus conhecimentos de mundo e sendo cada vez mais atraído e seduzido por esse imenso prazer que é a leitura em língua estrangeira.

\section{2 - A literatura adaptada como um instrumento facilitador da leitura e compreensão em italiano LE}

Até o final dos anos 90 a produção de literatura facilitada em língua estrangeira era muito comum sobretudo em língua inglesa. Hoje em dia, com o desenvolvimento de material didático para o ensino de línguas estrangeiras, principalmente em língua italiana verificamos um crescente e qualitativo 
material produzido para leitura facilitada em língua italiana. Esse material contribui para que o aprendiz de língua estrangeira tenha um contato maior com a língua em aprendizagem e que possa desenvolver gradualmente a leitura de obras adaptadas ou não nessa língua alvo.

Com uma forte presença de novas tecnologias no ensino de línguas, esses livros de literatura facilitada, na sua grande maioria são acompanhados de um CD, caracterizando-os também como um áudio-livro.

Abaixo elencamos as mais importantes editoras italianas que produzem tal material com o objetivo de ilustrar e informar como esse tipo de material cresceu, sendo um bom instrumento nas mãos de professores e alunos para o aprendizado da língua italiana e a prática de leitura nessa língua. É importante ressaltar que a maior parte desse material começou a ser publicado nessa última década.

As editoras elencadas são:

a) editora Guerra: 2 coleções;

b) editora Alma: 2 coleções (possuiu na realidade 3 coleções, porém, uma é direcionada a crianças de 6 a 11 anos e não nos interessa nessa pesquisa);

c) editora Bonacci: 1 coleção (possui na realidade 3 coleções, porém a Classici Italiani per Stranieri e Letture Italiane per Stranieri não serão abordadas na nossa pesquisa por compor um estilo diverso das obras aqui propostas para análise);

d) editora Cideb: 1 coleção;

e) editora Edilingua: 1 coleção (possui na realidade 2 coleções, porém, uma é direcionada a crianças de 6 a 11 anos e não nos interessa nessa pesquisa).

A seguir, podemos visualizar as tabelas com os títulos das publicações equivalentes de cada editora: 


\begin{tabular}{|l|l|l|l|l|}
\hline Editora & Coleção & Título & Nível \\
\hline Alma Edizioni & Letture facili per ragazzi & I bambini viola & 11 a 14 anni - livello A2 & + CD áudio \\
\hline Alma Edizioni & Letture facili per ragazzi & Il gioco più bello del mondo & 11 a 14 anni - livello B1 & + CD áudio \\
\hline Alma Edizioni & Letture facili per ragazzi & Un'avventura a Venezia & 11 a 14 anni - livello A1 & + CD áudio \\
\hline \hline
\end{tabular}

\begin{tabular}{|c|c|c|c|c|}
\hline Editora & Coleção & Título & Nível & Observação \\
\hline Alma Edizioni & Letture facili & Amore in Paradiso & A1/A2 - 1000 parole & + CD áudio \\
\hline Alma Edizioni & Letture facili & Dolce Vita & B1/B2 - 2500 parole & + CD áudio \\
\hline Alma Edizioni & Letture facili & Dolomiti & A1 - 500 parole & + CD áudio \\
\hline Alma Edizioni & Letture facili & Dov'è Yukio & A1 - 500 parole & + CD áudio \\
\hline Alma Edizioni & Letture facili & Fantasmi & A1/A2 - 1000 parole & + CD áudio \\
\hline Alma Edizioni & Letture facili & II signor Rigoni & A1 - 500 parole & + CD áudio \\
\hline Alma Edizioni & Letture facili & La commissaria & A1/A2 - 1000 parole & + CD áudio \\
\hline Alma Edizioni & Letture facili & La partita & A1/A2 - 1000 parole & + CD áudio \\
\hline Alma Edizioni & Letture facili & Linea A & B1 - 2000 parole & + CD áudio \\
\hline Alma Edizioni & Letture facili & L'ultimo Caravaggio & A2 - 1500 parole & + CD áudio \\
\hline Alma Edizioni & Letture facili & Mafia amore \& polizia & A2 - 1500 parole & + CD áudio \\
\hline Alma Edizioni & Letture facili & Maschere a Venezia & A1/A2 - 1000 parole & + CD áudio \\
\hline
\end{tabular}




\begin{tabular}{|c|c|c|c|c|}
\hline Editora & Coleção & Título & Nível & Observação \\
\hline Alma Edizioni & Letture facili & Mediterranea & B1 - 2000 parole & + CD áudio \\
\hline Alma Edizioni & Letture facili & Modele, pistole e mozzarelle & A2 - 1500 parole & + CD áudio \\
\hline Alma Edizioni & Letture facili & Nuovi casi per la commissaria & A2 - 1500 parole & + CD áudio \\
\hline Alma Edizioni & Letture facili & Opera! & B1 - 2000 parole & + CD áudio \\
\hline Alma Edizioni & Letture facili & Pasta per due & A1 - 500 parole & + CD áudio \\
\hline Alma Edizioni & Letture facili & Piccole storie d'amore & B1 - 2000 parole & + CD áudio \\
\hline Alma Edizioni & Letture facili & Radio Lina & A1 - 500 parole & + CD áudio \\
\hline Alma Edizioni & Letture facili & Un'altra vita & B1/B2 - 2500 parole & + CD áudio \\
\hline
\end{tabular}

\begin{tabular}{|l|l|l|l|l|l|}
\hline Editora & Coleção & Título & Nível \\
\hline Edilingua & Primiracconti & II manoscritto di Giotto & Observação \\
\hline Edilingua & Primiracconti & II sósia & C1/C2 \\
\hline Edilingua & Primiracconti & Lo straniero & A2/B1 & + CD áudio áudio \\
\hline Edilingua & Primiracconti & Mistero in Via dei Tulipani & A1/A2 & + CD áudio \\
\hline Edilingua & Primiracconti & Traffico in centro & A1/A2 & A2/B1 CD áudio \\
\hline Edilingua & Primiracconti & Un giorno diverso & $+C D$ áudio \\
\hline
\end{tabular}




\begin{tabular}{|l|l|l||l|l|}
\hline Editora & Coleção & Título & Nível \\
\hline Bonacci & Mosaico Italiano & Due estati a Siena & Livello 4 \\
\hline Bonacci & Mosaico Italiano & Due storie & Livello 1 \\
\hline Bonacci & Mosaico Italiano & Ferie pericolose & Livello 1 & - \\
\hline Bonacci & Mosaico Italiano & Giallo a Cortina & Livello 2 & Livello 4 \\
\hline Bonacci & Mosaico Italiano & Hacker per caso & Livello 3 \\
\hline Bonacci & Mosaico Italiano & Il mistero del quadro di Porta Portese & Livello 2 \\
\hline Bonacci & Mosaico Italiano & II mondo di Giulietta & Livello 2 \\
\hline Bonacci & Mosaico Italiano & La Straniera & Livello 3 \\
\hline Bonacci & Mosaico Italiano & Margherita e gli altri & Livello 4 \\
\hline Bonacci & Mosaico Italiano & Premio letterario & - \\
\hline Bonacci & Mosaico Italiano & Primavera a Roma & Livello 1 \\
\hline Bonacci & Mosaico Italiano & Una spiaggia rischiosa & Livello 1 \\
\hline Bonacci & Mosaico Italiano & Rapito! & Livello 1 \\
\hline
\end{tabular}




\begin{tabular}{|c|c|c|c|c|}
\hline Editora & Coleção & Título & Nível & Observação \\
\hline Cideb & Imparare legendo - Letture graduate & Amore e cinema & Livello 2/B1 - Celi 2 & + CD áudio \\
\hline Cideb & Imparare legendo - Letture graduate & Delitto in Piazza del Campo & Livello 2/B1 - Celi 2 & + CD áudio \\
\hline Cideb & Imparare legendo - Letture graduate & Giallo al Grand Hotel du Lac & Livello 1/A2 - Celi 1 & + CD áudio \\
\hline Cideb & Imparare legendo - Letture graduate & II mistero di Veronica & Livello 2/B1 - Celi 2 & + CD áudio \\
\hline Cideb & Imparare legendo - Letture graduate & II segreto del vecchio olmo & Livello 2/B1 - Celi 2 & + CD áudio \\
\hline Cideb & Imparare legendo - Letture graduate & II viaggio di Laurent & Livello 2/B1 - Celi 2 & + CD áudio \\
\hline Cideb & Imparare legendo - Letture graduate & I Promessi Sposi & Livello 2/C1 - Celi 4 & + CD áudio \\
\hline Cideb & Imparare legendo - Letture graduate & La casa sulla scogliera & Livello 2/B1 - Celi 2 & + CD áudio \\
\hline Cideb & Imparare legendo - Letture graduate & La collana longobarda & Livello 1/A2 - Celi 1 & + CD áudio \\
\hline Cideb & Imparare legendo - Letture graduate & La fuga di Bach & Livello 3/B2 - Celi 3 & + CD áudio \\
\hline Cideb & Imparare legendo - Letture graduate & Libertà & Livello 2/B1 - Celi 2 & + CD áudio \\
\hline Cideb & Imparare legendo - Letture graduate & Manichini & Livello 2/C1 - Celi 4 & + CD áudio \\
\hline Cideb & Imparare legendo - Letture graduate & Mistero all'Abbazia & Livello 3/B2 - Celi 3 & + CD áudio \\
\hline Cideb & Imparare legendo - Letture graduate & Rose rosse per il commissario & Livello 3/B2 - Celi 3 & + CD áudio \\
\hline Cideb & Imparare legendo - Letture graduate & Sandokan e le tigri di Mompracem & Livello 3/B2 - Celi 3 & + CD áudio \\
\hline Cideb & Imparare legendo - Letture graduate & $\begin{array}{l}\text { Scoprire l'Italia... con una caccia al } \\
\text { tesoro }\end{array}$ & Livello 2/B1 - Celi 2 & + CD áudio \\
\hline
\end{tabular}




\begin{tabular}{|l|l|l|l|l|}
\hline Editora & Coleção & Título & Nível \\
\hline Cideb & Imparare legendo - Letture graduate & Storie d'amore & Livello 2/B1 - Celi 2 & + CD áudio \\
\hline Cideb & Imparare legendo - Letture graduate & Tango & Livello 2/B1 - Celi 2 & + CD áudio \\
\hline Cideb & Imparare legendo - Letture graduate & Una canzone per cinque & Livello 1/A2 - Celi 1 & + CD áudio \\
\hline Cideb & Imparare legendo - Letture graduate & Veleno a colazione & Livello 2/B1 - Celi 2 & + CD áudio \\
\hline Cideb & Imparare legendo - Letture graduate & Viaggio a Venezia & Livello 3/B2 - Celi 3 & + CD áudio \\
\hline Cideb & Imparare legendo - Letture graduate & Villa dei Mughetti & Livello 2/B1 - Celi 2 & + CD áudio \\
\hline
\end{tabular}

\begin{tabular}{|l|l|l|l|l|}
\hline Editora & Coleção & Título & Nível \\
\hline Gerra & II piacere della lettura & $\begin{array}{l}\text { Altri racconti da 'Navi in Bottiglia' di } \\
\text { G. Romagnoli }\end{array}$ & Intermedio B1/B2 \\
\hline Gerra & II piacere della lettura & Due fantastici Racconti & Avanzato C1 \\
\hline Guerra & II piacere della lettura & Giampi e l'assassino a teatro & Intermedio B1/B2 \\
\hline Gerra & II piacere della lettura & Il proiettore del tempo & Avanzato C1 & - \\
\hline Gerra & II piacere della lettura & Il ritrovamento della Cupola & Intermedio B1/B2 \\
\hline Guerra & II piacere della lettura & Il valzer dei tempi & Intermedio B1/B2 & - \\
\hline
\end{tabular}




\begin{tabular}{|l|l|l|l|l|}
\hline Editora & Coleção & Título & Nível \\
\hline Gerra & II piacere della lettura & Le strane notti di Bologna & Intermedio B1/B2 \\
\hline Gerra & II piacere della lettura & L'ottimismo è il profumo della vita & Elementare A2 \\
\hline Guerra & II piacere della lettura & $\begin{array}{l}\text { Racconti da “Navi in bottiglia” di G. } \\
\text { Romagnoli }\end{array}$ & Avanzato C1 \\
\hline Gerra & II piacere della lettura & Stelle, perle e mistero & - \\
\hline Gerra & II piacere della lettura & XR45 & Elementare A2 & Elementare A2 \\
\hline Guerra & II piacere della lettura & Zia Lili è scomparsa & Intermedio B1/B2 & - \\
\hline
\end{tabular}

\begin{tabular}{|l|l|l|l|l|}
\hline Editora & Coleção & Título & Nível \\
\hline Gerra & Letture graduate per stranieri & Belfagor & Elementare A2 \\
\hline Gerra & Letture graduate per stranieri & Cavalleria rusticana & Intermedio B1/B2 \\
\hline Guerra & Letture graduate per stranieri & Dagli Appennini alle Ande & Avanzato C1 & - \\
\hline Gerra & Letture graduate per stranieri & Federigo e il suo falcone & Elementare A2 \\
\hline Gerra & Letture graduate per stranieri & $\begin{array}{l}\text { Frate Cipolla e la penna } \\
\text { dell'arcangelo Gabriele }\end{array}$ & Elementare A2 \\
& & &
\end{tabular}




\begin{tabular}{|c|c|c|c|c|}
\hline Editora & Coleção & Título & Nível & Observação \\
\hline Guerra & Letture graduate per stranieri & II lungo viaggio & Avanzato C1 & - \\
\hline Gerra & Letture graduate per stranieri & II piccolo scrivano fiorentino & Intermedio B1/B2 & - \\
\hline Gerra & Letture graduate per stranieri & II piccolo patriota padovano & Principianti A1 & - \\
\hline Guerra & Letture graduate per stranieri & Inferno: Dante incontra... & Intermedio B1/B2 & - \\
\hline Gerra & Letture graduate per stranieri & La buonissima madre & Avanzato C1 & - \\
\hline Gerra & Letture graduate per stranieri & La locandiera & Avanzato C1 & - \\
\hline Guerra & Letture graduate per stranieri & La regola francescana & Principianti A1 & - \\
\hline Gerra & Letture graduate per stranieri & $\begin{array}{l}\text { La risposta della serva Novella } \\
\text { d'Amore }\end{array}$ & Intermedio B1/B2 & - \\
\hline Gerra & Letture graduate per stranieri & La pazzia di Orlando & Avanzato C1 & - \\
\hline Guerra & Letture graduate per stranieri & L'Ignorante & Intermedio B1/B2 & - \\
\hline Gerra & Letture graduate per stranieri & $\begin{array}{l}\text { Madonna Filippa Melchisedech e il } \\
\text { Saladino }\end{array}$ & Elementare A2 & - \\
\hline Guerra & Letture graduate per stranieri & Ottobre & Principianti A1 & - \\
\hline
\end{tabular}


A página da Editora Alma (www.almaedizioni.it) descreve a coleção Italiano Facile e Italiano Facile per ragazzi da seguinte forma:

"A coleção Italiano Facile propõe uma série de histórias originais e de simples leitura. Para cada história existem testes de compreensão, exercícios e atividades didáticas. Estes testes, graduados em cinco níveis, possibilitam ao estudante que têm o italiano como língua não materna descobrir o prazer da leitura em italiano, aperfeiçoando ao mesmo tempo os próprios conhecimentos lingüísticos. Cada livro acompanha um $\mathrm{Cd}$ áudio com o texto integral do livro. Os títulos envolvem diversos gêneros (mistério, histórico, policial, aventura, romance, etc) e valendo-se de um estilo vivaz e envolvente, os textos desta coleção oferecem a possibilidade de entrar em contato com a realidade da língua viva, fora dos cânones tradicionais da aprendizagem."

"A coleção Italiano Facile per ragazzi direcionada a aprendizes que tenham de 11 a 14 anos, propõe uma série de histórias originais e motivadoras, que permitem aos pré-adolescentes que têm o italiano como língua não materna, o prazer de descobrir a leitura em língua italiana. A variedade dos gêneros no catalogo - policial, aventura, fantasia - oferece aos pré-adolescentes a possibilidade de escolher argumentos próximos aos seus interesses, possibilitando a aproximação à língua de forma prazerosa. Todas as histórias são acompanhadas de exercícios e atividades didáticas. Os livros podem ser utilizados também em sala de aula. $\mathrm{O} \mathrm{Cd}$ áudio contém a leitura dramatizada da história. O estilo brilhante e animado da recitação torna muito prazerosa a audição aos estudantes e aos autodidatas."

A página da Editora Edilingua (www.edilingua.it) descreve a coleção Primiracconti da seguinte forma:

"Primiracconti é uma coleção de histórias didatizadas para os estudantes de italiano LE/L2 e cada história vem acompanhada de breves notas, bem calibradas no texto para não pesar a leitura, para explicar as palavras mais difíceis e as expressões coloquiais ou jargões muito difundidos na Itália; originais e simpáticas ilustrações que facilitam a leitura e a torna prazerosa; atividades ara o desenvolvimento de várias competências, em particular aquelas ligadas à compreensão do texto e ao consolidação do léxico; respostas para os estudantes que queiram verificar de maneira autônoma a compreensão escrita e oral; um Cd áudio com a leitura do texto com uma voz diferente para cada personagem, para exercitar a pronúncia, a entonação e 
desenvolver algumas exercitações de escuta."

A página da Editora Cideb (www.blackcat-cideb.com) descreve a coleção Imparare Leggendo da seguinte forma:

"Imparare Leggendo é uma série de leituras graduadas, ricamente ilustradas, especificamente destinadas a estudantes estrangeiros. A coleção, articulada em quatro níveis, dá particular atenção ao grau de acessibilidade lingüística de cada texto e se presta seja ao trabalho em classe seja ao aprendizado autônomo. Possui uma série de atividades para a revisão dos pontos gramaticais e o desenvolvimento das quatro habilidades; numerosas notas para os termos mais difíceis; um suplemento depois de cada capítulo contendo interessantes informações e curiosidades sobre lugares, personagens e épocas históricas inerentes ao texto; gravação integral do texto; alguns títulos apresentam também atividades estilo CELI e sugestões para aprofundamento de pesquisas na internet."

A página da editora Guerra ( piacere della lettura e Letture graduate per stranieri da seguinte forma:

"Os textos inseridos nessa coleção II piacere della lettura oferecem a possibilidade ao estudante de aproximar-se à leitura em língua italiana. As histórias para essa coleção foram escritas de forma a passar diversão e prazer ao leitor. Os textos foram criados e elaborados de forma graduada respeitando três níveis que garante ao estudante escolher um título de acordo com o seu conhecimento lingüístico. Cada livro contém atividades criadas para verificar e consolidar a compreensão do texto e para melhorar a habilidade de leitura e enriquecer o léxico. Os livros podem ser utilizados pelo estudante de forma individual ou em grupo graças a claras referências gráficas".

A coleção Letture graduate per stranieri apresenta leituras facilitadas extraídas de obras da literatura italiana. O estudante é guiado na compreensão dos textos propostos com uma acessibilidade lingüística considerada para cada nível, seja quanto ao tipo de vocabulário escolhido quanto à estrutura gramatical utilizada. Cada história é acompanhada por notas de rodapé e ilustrações que facilitam também visualmente a leitura e a compreensão do texto; inúmeras e estimulantes atividades 
estruturais e lexicais que permitem a revisão, a consolidação e a aquisição das estruturas presentes no texto, junto com o enriquecimento do vocabulário; sinais gráficos que indicam a sílaba sobre a qual recai o acento tônico, facilitando assim a pronúncia ; uma sintética biografia do autor da obra que foi facilitada; respostas dos exercícios ao fim de cada livro permitindo também o uso autônomo do material.

A página da editora Bonacci (www.bonacci.it) descreve a coleção Mosaico Italiano da seguinte forma:

"A coleção Mosaico Italiano nasce da exigência de propor breves leituras em língua italiana, graduadas em quatro níveis de dificuldade lingüística, a estrangeiros. A histórias, escritas propositalmente para um público estrangeiro propõe uma língua facilitada e ao mesmo tempo autentica, rica de diálogos que reproduzem a fala em diversas situações comunicativas. Cada história é acompanhada por notas de rodapé que fornecem uma válida ajuda na decodificação lingüística e na compreensão dos aspectos culturais. No fim de cada texto são propostas atividades com soluções que podem ser desenvolvidas autonomamente ou feitas em classe com o auxilio do professor. A novidade de Mosaico italiano reside na escolha de não adaptar textos clássicos, mas sim de propor histórias modernas, ambientadas frequentemente nas principais cidades italianas, com protagonistas dos nossos dias."

A editora Alma (Italiano facile per bambini) e Edilingua (Prime letture in italiano Collana Raccontimmagini) apresentam coleções de leitura para crianças de 6 a 11 anos, porém decidimos não elencar esses títulos aqui pois não é o nosso objeto de estudo o material didático para essa idade.

\section{3 - Tipologia de adaptações}

Quando falamos de adaptações literárias em nosso trabalho, referimosnos a dois tipos de adaptações:

a) adaptação (facilitação) da obra para leitores da língua materna em questão; 
b) adaptação (facilitação) da obra para leitores estrangeiros.

Geralmente, a adaptação (facilitação) é efetuada tendo como produto uma obra resumida que "perde", na maioria das vezes, um pouco do estilo do autor mas não o conteúdo da história narrada, apresentando então uma relação de forma versus conteúdo em relação aos títulos originais. Observamos a ocorrência de adaptações, sobretudo para as obras clássicas da literatura universal, sendo essa ocorrência comum em todas as línguas.

Os grandes clássicos são sempre traduzidos e adaptados para a literatura infantil, como é o caso da Bíblia para crianças, Ilíada, Odisséia, Eneida, Dom Quichote, A Divina Comédia, etc. Essas adaptações, muitas vezes, são também apresentadas na forma de histórias em quadrinhos, o que comprova a mudança de estilo da apresentação da obra original em questão, mas não a mudança do núcleo da obra, ou seja, do conteúdo da história contada.

O processo de adapatação não ocorre somente com clássicos de outras línguas que são traduzidos e adaptados para a nossa, mas também com clássicos da nossa língua que são "recontados" de uma forma facilitada. Esse processo é consideravelmente visível na literatura destinada ao vestibular, quando esses títulos são recontados através de filmes, desenhos animados, histórias em quadrinhos e edições comentadas ou resumidas, apresentando, quase sempre, essas duas últimas modalidades um quantidade significativa de notas de rodapé, seja para explicar o significado de certas palavras e/ou expresões, seja para dar indicações temporais ou de outra natureza inerentes à história narrada.

A editora Escala apresenta duas coleções de literatura adaptada (facilitada): Literatura Brasileira em Quadrinhos; na qual propõe os clássicos da Literatura Brasileira; e a coleção Recontar, na qual propõe os clássicos da Literatura Universal.

A editoria italiana apresenta as mesmas características e dispõe de uma terceira classe de obra adaptada, que seria aquela adaptada para o público estrangeiro, como citamos no item anterior (3.2 - A literatura adaptada como um instrumento facilitador da leitura e compreensão em italiano LE).

Essa terceira classe é a que norteia o nosso trabalho e, por isso, no item a seguir apresentaremos as características da estrutura das notas de rodapé 
(elemento comum a todas as obras dessa classe) presentes nessas obras.

3.4 - Estrutura das notas de rodapé dos livros de literatura adaptada (facilitada) para estrangeiros em língua italiana.

Analisando as 7 coleções de literatura adaptada (facilitada) para estrangeiros produzidas na Itália por cinco editoras pudemos constatar que todas elas utilizam notas de rodapé nas suas edições e essas notas visam à explicação do significado de palavras ou expressões por meio de:

a) desenhos (seja nas obras de nível mais elementar, seja naquelas de nível mais avançado);

b) definições caracterizadas por equivalência de palavras (uma ou mais palavras como sinônimo da palavra que consta no rodapé);

c) definições por extensão (explicação do significado da palavra por meio de uma frase);

d) definições por antônimos;

e) definições com exemplos (de forma a tornar mais clara a definição);

A seguir, ilustramos com as notas extraídas de algumas obras: 


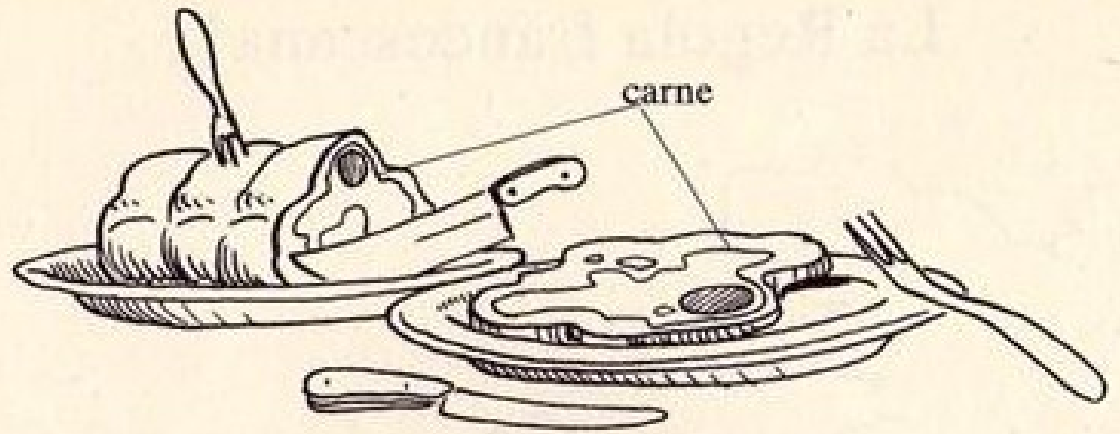

no quaresima: infatti non mangiano carne nei loro conventi. Ma quando sono in viaggio, possono mangiare tutto ciò che la gente gli dà poiché devono vivere di elemosina. Un giorno due di questi frati, durante un loro viaggio, arrivinano in una ostería dove incontrano un mercante.

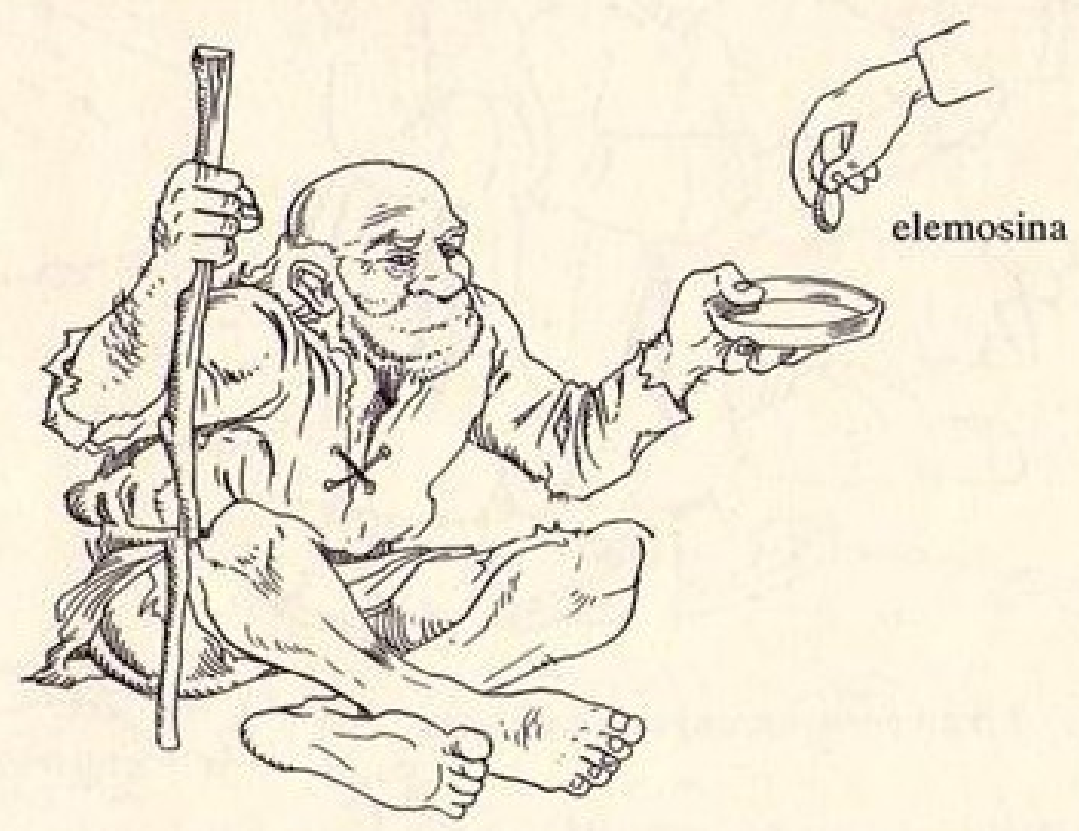

fare quaresima non mangiare carne. La Quaresima, nella religione cattolica, è un periodo di 40 giorni che viene prima della Pasqua, che è una festa molto importante convento luogo dove vivono i frati osteria luogo dove è possibile mangiare e bere mercante persona che vende e compra nei mercati

Fonte: COVINO BISACCIA, M.A. FRANCOMACARO, M.R. La Regola Francescana, Letture Graduate per Stranieri. Livello principianti, Edizioni Guerra, 1997. 


\section{II segreto del vecchio olmo}

Le campane della chiesa suonano la mezzanotte. Nascondono, per un attimo, un rumore debole, ma costante. Proviene dalle assi del ponticello che collega il sentiero al vecchio mulino. Qualcuno le sta segando.

Intanto, un uomo con un impermeabile scuro sta arrivando lungo il sentiero attraverso il bosco. Il vento scuote i rami e piove forte. È arrivato al ponte. Ha davanti la forma scura del mulino in rovina.

"Dove sei?" grida. Gli scivola il cappuccio. ${ }^{2}$ Una falce di luna, ${ }^{3}$ fra le nuvole, ne illumina il viso.

"Qui, al mulino. Attraversa il ponte!" risponde una voce roca. ${ }^{4}$ "Ho i soldi, vieni a prenderli."

"Vedi, non è stato difficile. Dopotutto, hai anche i diamanti di Andrea. Vendendoli, avrai ancora del denaro, ti rifarai della perdita" dice il farmacista, mentre avanza, passo dopo passo, verso il destino.

"Ti sbagli. Non li ho. Non li ho trovati."

"Dove possono essere?"

"Alla locanda. Forse nella sua stanza, in qualche valigia..."

II farmacista è ormai convinto di poter trovare i diamanti, ma non vede che qualcosa gli è scivolato dall'impermeabile e, soprattutto, non si accorge che le assi del ponticello stanno per spezzarsi. Dopo pochi istanti, precipita nel vuoto con un urlo.

1. ponticello : ponte piccolo e corto.

2. cappuccio :

3. falce di luna :

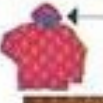

4. roca : rauca, fioca, debole.

46

Fonte:FOLCO,D. II Segreto del Vecchio Olmo. Imparare Leggendo. Livello 2, B1, Cideb, 2006. 
De Maffeis gli sta davanti e scuote la testa. Sembra dispiaciuto. lo guardo lui e guardo Filippo.

Filippo non è un ladro, 10 so bene. Invece De Maffeis è una volpe, anzi un lupo, un lupo cattivo.

Ho capito tutto.

"Voglio venire con voi in questura" " dico ai poliziotti. "lo sono sicura... Filippo è innocente. Non ho alcun dubbio su quanto è successo:"

L'ho detto a Filippo, I'ho detto ai poliziotti: De Maffeis ha voluto vendicarsi del fatto che io e Filippo stiamo insieme e non solo... che abbiamo usato il suo studio per fare un film, ... il nostro film.

"È venuto in studio ieri sera e ci ha visto. Si è arrabbiato e ha pensato a come vendicarsi."

"Ma vi aveva dato il permesso di girare il film, no?" chiede la donna poliziotto.

"Non a noi, a uno degli attori, al signor Affina" rispondo io.

"Lei afferma quindi che è un furto simulatoz da De Maffeis perché è innamorato di lei ed è geloso della sua relazione con Filippo?"

"Si, ne sono sicura."

1. questura : sede della polizta.

2. Simulato : non vero.

93

Fonte: MEDAGLIA, C. Amore e Cinema, Imparare Leggendo. Livello 2, B1, Cideb,2007. 


\section{CAP IV}

- Scrivi tu le canzoni? - domanda Valentina a Roberto.

- Sì, ti piacciono?

- Molto. Sono fantastiche!

"Questa Valentina non è male" - pensa Roberto.

- Allora, dov'è questa festa?

Valentina spiega tutto. Alla fine...

- Cosa? Fantasmi? Non mi piace questa idea...

- Che cosa sono i fantasmi? - chiede Dick.

- Sono gli spiriti dei morti.

Interviene Giovanni:

- Sono tutte sciocchezze. Nella casa non ci sono fantasmi. E' solo un po' vecchia...

- Io ho paura - dice Rita.

- Tu hai sempre paura...

- Ragazzi, non cominciate con le vostre discussioni - dice Valentina - E' tardi.

- Va bene, torniamo a casa... Ciao, ragazzi.

- Ciao, ci vediamo sabato.

Rita, Giovanni e Valentina escono dal garage.

interviene (inf. intervenire) : comincia a parlare. Es.: nella discussione interviene Michele e dice...

sciocchezze: cose stupide, senza importanza. Es.: non mi piace quella persona, dice solo sciocchezze.

\section{Note}

Fonte: DE GIULI, A. NADDEO, C. M. Fantasmi, Letture Facili, Livello 2, B1, Alma Edizioni,2004 


\section{IV - QUESTÕES METODOLÓGICAS DA PESQUISA}

\section{1 - Justificativa}

Alessandro Manzoni, o autor de Os Noivos, acreditava que a arte e a literatura deveriam ser populares, historicamente verdadeiras e nacionais, devendo mostrar obrigação civil e, consequentemente, mostrar uma linguagem que falasse ao coração e à consciência do povo. Manzoni interessou-se pelo "problema da língua" em muitas de suas obras, até o fim de sua vida. À linguagem rígida e fria dos clássicos opunha uma língua "verdadeira" e falada, a língua usada pela classe culta florentina. Manzoni defendia que a língua também deveria ser nacional e contribuir para a unificação da Itália, por isso, teria que ser baseada no uso e apresentar-se próxima à realidade histórico-social do momento. Assim, escreveu / Promessi Sposi, realizando plenamente as suas intenções de criar um romance histórico-pedagógico, dando o papel de protagonista a personagens do povo e criando uma língua "simples" capaz de atingir um grande público. O autor escreveu três versões do romance antes de chegar àquela definitiva de 1840-42, na qual fez uma grande revisão linguística. Mesmo o autor tendo trabalhado tanto para deixar acessível a linguagem do romance, hoje em dia, tal obra apresenta ainda um vocabulário difícil para os leitores italianos. Conseqüentemente, existem várias adaptações, resumos e edições comentadas da obra original, pois tal romance é leitura obrigatória nas escolas italianas.

Já que a dificuldade linguística é apresentada por nativos da língua alvo, não poderia ser diferente também com estudantes brasileiros que, por necessidade ou mesmo curiosidade, queiram conhecer uma obra tão significativa para a história de uma língua como é I Promessi Sposi para a língua italiana.

Pesquisando o mercado italiano, encontramos várias adaptações, resumos e edições comentadas, mas muito pouco dessas obras é para uso específico do público estrangeiro ou precisamente o público brasileiro. Dessa forma, o presente trabalho é justificado pela necessidade da existência de uma adaptação de Os noivos para o público leitor brasileiro, sendo essa adaptação formulada sobretudo do 
ponto de vista lexical com fins a aproximar o leitor da leitura acabando com as barreiras de incompreensão no que se refere ao léxico do texto em questão.

A escolha do item lexical para o estudo da obra explica-se devido ao fato de que era o léxico empregado e a sua compreensão do norte ao sul da Itália que mais preocupava Mazoni quando ele Manzoni trabalhava nas três versões do romance.

A idéia deste trabalho criou forma quando começamos a dar aula no Centro de Línguas da FFLCH/USP no segundo semestre de 2006, ministrando as disciplinas Língua Italiana Instrumental I e II. O objetivo das disciplinas era oferecer subsídios para a leitura de textos das mais diversas naturezas, já que o público que cursava tais disciplinas pertencia às mais diversas áreas, porém com uma prevalência de alunos que seguiam o curso de graduação em letras nas suas várias habilitações. Trabalhávamos com os alunos do Italiano Instrumental I com a leitura de pequenos textos no início do curso, passando posteriormente à leitura de livros de leitura graduada. Esses livros consistem em narrar breves histórias com um número controlado de palavras novas na língua estrangeira alvo, isto é, apresentamse classificados por níveis como: "Nível 1 - 500 palavras", "Nível 2 - 1000" palavras, e assim sucessivamente. Na maioria das vezes, a classificação dessas obras levam em consideração o Quadro Europeu Comum de Referência para as Línguas QECR. A possibilidade de ler um livro, por mais simples que seja, em um curso como esse proporciona ao aluno o estímulo para continuar estudando a língua e colocar-se desafios como o de ler sempre um novo livro, mesmo sendo adaptado, porém com um número maior de palavras novas.

Certo dia, trabalhando com a disciplina Italiano Instrumental no centro de línguas da USP, uma aluna nos perguntou se na literatura italiana existia algum livro expressivo, tal qual Dom Casmurro é para a literatura brasilieira. A nossa resposta foi positiva e enumeramos uma série de títulos da literatura italiana porém nos concentramos na história e na motivação da escrita do título / Promessi Sposi, de Manzoni. A aluna então nos perguntou se seguisse a disciplina Italiano Instrumental I e II conseguiria, ao fim do curso ler tal título. Não respondemos a sua pergunta mas não a ignoramos. Lembramo-nos que possuíamos uma fotocópia do I Promessi Sposi adaptado. Logo em seguida, tivemos a oportunidade de ir para a Itália, onde fizemos um levantamento de várias edições de I Promessi Sposi como obra não original e sim adaptada. Este levantamento constou de livros adaptados, 
comentados e simples resumos. Analisando um montante de 18 livros resolvemos dar uma atenção especial para:

a) II Romanzo di Renzo e Lucia, adattamento per la scuola de I Promessi Sposi di Alessandro Manzoni. Vittorio Panico. Vestigium Scuola, 1999;

b) I Promessi Sposi di Piero Chiara, Arnaldo Mondadori, 1996;

c) Riassunto de I Promessi Sposi. Riassunti - Commenti - Personaggi - Temi Svolti. Editrice II Girasole;

d) I Promessi Sposi - Adattamento del testo e note di Marisa Pasqualetti, CIDEB, 2007;

d) I Promessi Sposi - Edizione Ridotta a cura di Lorenzo Rolla. Casa Editrice Edisco;

e) I Promessi Sposi, riassunto, personaggi, date, luoghi del romanzo di Alessandro Manzoni a cura di A. M. Bignami. Edizioni Esagono, 2000;

f) I Promessi Sposi di Alessandro Manzoni, il riassunto. Vittorio Panico, Memory Book, 2006;

g) I Promessi Sposi a Fumetti. Riduzione di Claudio Nizzi, San Paolo, 2001;

Dos livros listados acima, percebemos que o mais indicado para ser trabalhado com o grupo da disciplina Instrumental II seria I Promessi Sposi Adattamentodel testo e note di Marisa Pasqualetti, CIDEB, 2007 devido aos seguintes motivos:

a)apresentar uma estrutura não tão resumida e nem tão ampla em relação à história original;

b)apresentar notas de rodapé das unidades lexicais consideradas de difícil compreensão;

c) apresentar exercícios de compreensão depois de cada capítulo;

d)apresentar as ilustrações da obra original;

e)apresentar elementos extras de contextualização dos acontecimentos históricos ao fim de cada capítulo;

f) conter um cd audio dos capítulos, configurando-se assim, um audio-livro;

g)fazer parte de uma coleção de literatura adaptada para estrangeiros e estar classificado como nível C1 em relação ao Quadro Europeu Comum de Referências para o ensino de línguas estrangeiras. 
A última justificativa do elenco anterior é uma das principais, já que o nível indicado para a leitura do livro é médio-alto, o que significa que o aluno deverá ter um nível alto de língua.

Neste momento, gostaríamos de ressaltar que não somos a favor da leitura do livro I Promessi Sposi adaptado por alunos dos cursos de letras/Italiano pois acreditamos que esses alunos devam fazer a leitura da obra original, dada a importância de tal título para a literatura italiana e por conseguinte a formação literária desses discentes. Porém, para leitores não especialistas em língua italiana e que não tenham atingido um nível de língua italiana suficiente para a leitura de $I$ Promessi Sposi em original recomendamos os títulos adaptados mesmo concientes de que esses, em relação à forma, perderam muito, se não tudo, do original. Todavia, conservam o conteúdo do obra, mesmo que desprovido da richesa de detalhes.

Trabalhando com as leituras graduadas das editoras Cideb (Collana Imparare Leggendo), Bonacci (Collana Mosaico Italiano), Alma (Letture Facili) e Guerra (II Piacere della Lettura e Letture Graduate per Stranieri) percebemos que todos os títulos produzidos por essas elas trazem sempre notas de rodapé com a explicação das unidades lexicais consideradas de difícil codificação pelos leitores.

Porém, essas notas de rodapé nem sempre são úteis para os leitores brasileiros pois na maioria das vezes trazem a explicação de vocábulos que são verdadeiros cognatos ou mesmo algumas definições não tão elucidativas.

Analisando I Promessi Sposi - Adattamento del testo e note di Marisa Pasqualetti, CIDEB, 2007 utilizado em classe como livro de leitura, verificamos que as inúmeras notas existentes eram de verdadeiros cognatos em relação à língua italiana e o português brasileiro, como por exemplo a ocorrência das palavras: calvo, prepotente, barba, pena, etc; ou de palavras muito parecidas em italiano e português, como: scopo, martellare, saldare, implorare; para as quais as notas seriam dispensáveis. Em oposição ao descrito até o momento, encontramos algumas palavras cujas notas seriam importantes constar no rodapé. Contudo, não constam. São alguns exemplos: fitte, cupa, inoltra. Há palavras que apresentam a nota e, no entanto, essa nota não é tão esclarecedora, como por exemplo as unidades lexicais rabbrividire e pendio.

Dessa forma, percebemos que era necessário realizarmos um estudo lexicográfico no que se referia às notas de rodapé dessas obras de leitura 
graduada, de modo a fazer com que essas obras proporcionem realmente uma "leitura facilitada". Escolhemos, pelos motivos já arrolados, por trabalhar com a obra adaptada I Promessi Sposi.

\section{2 - Objetivos}

\subsection{1 - Objetivo Geral}

O objetivo geral da pesquisa é fazer um estudo lexicográfico da obra adaptada I Promessi Sposi de Alessandro Manzoni, propondo um glossário com fins pedagógicos.

\subsection{2 - Objetivos Específicos}

Partindo da pergunta (hipótese) do nosso trabalho - a simplificação lexical é suficiente para tornar uma obra clássica acessível a um público formado por estudantes de língua italiana? - temos como objetivos específicos responder as questões que seguem:

a)quais são os títulos existentes atualmente no mercado italiano de literatura adaptada para estrangeiros?

b)qual é o critério de escolha das palavras que constam nas notas de rodapé dos livros de literatura adaptada?

c) a quem é destinada as notas de rodapé dos livros de literatura adaptada?

d) usando os sufixos existentes no italiano e os seus equivalentes em português, quais são as possibilidades de inferência de significado para um grande número de palavras?

\section{3 - Metodologia de investigação e estabelecimento do corpus}

Aplicamos a leitura do I Promessi Sposi - Adattamento del testo e note di Marisa Pasqualetti, CIDEB, 1999 e 2007 a 11 grupos de alunos que tinham teoricamente, de acordo com o número de horas de língua estudada e da ênfase na 
habilidade de leitura e decodificação lexical, um conhecimento (sempre em relação ao léxico) de nível B1/B2 correspondente ao Quadro Comum Europeu de Referência para o Ensino de Línguas. Esses grupos apresentavam as seguintes especificações:

a)grupo 1 - alunos do curso Italiano Instrumental // do Centro de Linguas da USP do primeiro semestre de 2007 (13 alunos);

b)grupo 2 - alunos do curso Italiano Instrumental // do Centro de Linguas da USP do segundo semestre de 2007 (11 alunos);

c) grupo 3 - alunos do curso Italiano 2 do Centro de Línguas da Unicamp do primeiro semestre de 2007 (19 alunos);

d)grupo 4 - alunos do curso de Letras/Tradução da Unesp de São José do Rio Preto que cursavam ao mesmo tempo duas disciplinas referentes à língua italiana: Prática de tradução em Língua Italiana II e Língua Italiana III no segundo semestre de 2007 (14 alunos);

e)grupo 5 - alunos do curso Italiano Instrumental II da UFPR/Curitiba no primeiro semestre de 2008 (12 alunos);

f) grupo 6 - alunos do curso Italiano 4 do Centro de Línguas da UFPR/Curitiba no segundo semestre de 2008 (14 alunos);

g)grupo 7 - alunos do curso de Letras/Italiano da disciplina Italiano Básico II da UFPR/Curitiba no segundo semestre de 2008 (10 alunos);

h)grupo 8 - alunos do curso Italiano Instrumental II da UFPR/Curitiba no segundo semestre de 2008 (10 alunos);

i) grupo 9 - alunos do curso Italiano Instrumental II da UFPR/Curitiba no primeiro semestre de 2009 (11 alunos);

j) grupo 10 - alunos do curso Italiano Instrumental // da UFPR/Curitiba no segundo semestre de 2009 (9 alunos);

k)grupo 11 - alunos do curso de Letras/Italiano da disciplina Italiano Básico II da UFPR/Curitiba no segundo semestre de 2009 (11 alunos).

A tarefa dos alunos era realizar uma primeira leitura global do livro, de forma integral, evitando ao máximo a existência de "ruído" nesse primeiro processo. Posteriormente, em uma segunda leitura, cada aluno deveria preencher uma ficha denominada "ficha de coleta das unidades lexicais". Essa ficha é composta pelos seguintes campos (a seguir modelo da ficha vazia e preenchida):

a) número da ficha em negrito na parte superior, do lado esquerdo; 
b) título da ficha alinhado do lado esquerdo com o nome da obra em questão, editora e ano de publicação (para este trabalho, como usamos duas edições da obra adaptada em questão, encontraremos a variante 1999 e 2007);

c) localização em negrito alinhada à esquerda identificada por cinco campos separados por uma barra (/), os quais indicam respectivamente: instituição onde foi coletada a ficha, ano de coleta, semestre, sigla identificadora do aluno que preencheu a ficha e curso ao qual pertencia o aluno;

d) primeira coluna, destinada a elencar as palavras que constam nas notas de rodapé do livro, mas que são desnecessárias, pois o aluno já conhecia o significado;

e) segunda coluna, destinada a elencar as palavras de difícil compreensão que constam somente no texto, mas poderiam constar nas notas de rodapé. É importante ressaltar que os alunos foram instruídos a elencar as palavras que realmente ofereciam dificuldade para a compreensão e cujo significado não poderia ser depreendido com uma leitura global. Sendo assim, nessa coluna não consta todas as palavras desconhecidas, mas aquelas de significado difícil de ser inferido e que o não conhecimento de tal significado poderia comprometer a compreensão global do texto;

f) terceira coluna destinada a elencar as palavras que constam já nas notas de rodapé, mas que apresentam uma explicação não muito clara ou insuficiente para a elucidação do significado da palavra em questão.

\section{Modelo vazio da "Ficha de coleta de dados das unidades lexicais"}

\begin{tabular}{l} 
Número:09 \\
Ficha de coleta de dados das unidades lexicais - I Promessi Sposi - Cideb - 1999 \\
Localização: UFPR/2008/2/FS/Instrumental II \\
\hline \begin{tabular}{l|lc|l|}
\hline \multicolumn{1}{|c|}{ que constam } & Palavras que são & Palavras que constam no rodapé \\
desnecessariamente no rodapé & necessárias, mas não \\
constam no rodapé explicação é insuficiente
\end{tabular} \\
\hline
\end{tabular}




\section{Modelo preenchido da "Ficha de coleta de dados das unidades lexicais"}

\section{Número:02}

Ficha de coleta das unidades lexicais e/ou expressões durante a leitura - I Promessi Sposi - Cideb - 2007

Localização: UFPR/2009/2/AB/Instrumental II

\begin{tabular}{|c|c|c|}
\hline $\begin{array}{l}\text { Palavras que constam no } \\
\text { rodapé } \\
\text { desnecessariamente }\end{array}$ & $\begin{array}{l}\text { Palavras que são necessárias, mas } \\
\text { não constam no rodapé }\end{array}$ & $\begin{array}{l}\text { Palavras que constam no rodapé } \\
\text { cuja explicação é insuficiente }\end{array}$ \\
\hline Acconsentire & Adosso & Adda \\
\hline Affiorare & Aggiunge & Alito \\
\hline Afflitto & Ammirandola & Boccone \\
\hline Avvocato & Angosciata & Breviario \\
\hline Baracca & Aprite & Calamaio \\
\hline Barba & Bicchiere & Carestia \\
\hline Bubbone & Boschi & Cupo \\
\hline Cadavere & Bravi & Filanda \\
\hline Calvo & Capponi & Forca \\
\hline Carozza & Carestia & Inchino \\
\hline Chirurgo & Carichi & Livido \\
\hline Collera & Chiarita & Minacciare \\
\hline Compassione & Chiude & Palo \\
\hline Contagiare & Colpa & Panca \\
\hline Deo gratias & Corsa & Pendio \\
\hline Dote & Corso & Posate \\
\hline Fare voto & Cortile & Rabbrividire \\
\hline Feroci & Cugino & Racolto \\
\hline Governatore & Davvero & Radunarsi \\
\hline Implorare & Deluso & Rannicchiata \\
\hline In ozio & Eppure & Rapire \\
\hline Incamminarsi & Fazzoletto & Rintocco \\
\hline Infermo & Fidanzata & Riversasi \\
\hline Infiammare & Fiduciosa & Sagrestano \\
\hline Invano & Figliolo & Sarto \\
\hline Irritare & Finché & Sorgenti \\
\hline La pace sia con voi! & Folla & Svanire \\
\hline Maledizione & Gemiti & Treccia \\
\hline Martellare & Grida & Volto \\
\hline Miglio & Guarire & Zimbello \\
\hline Monastero & Infatti & \\
\hline Monotono & Ondeggiare & \\
\hline Monsignore illustrissimo & Macchie & \\
\hline Ospizio & Nascosto & \\
\hline Parlatorio & Nozze & \\
\hline
\end{tabular}




\begin{tabular}{|l|l|l|}
\hline Pena & Osteria & \\
Perseguitare & Patto & \\
Peste & Pianti & \\
Pozzo & Popolani & Potrei \\
Prepotente & Povero & \\
Presentimento & Preghiere & \\
Revocare & Prete & \\
Ribattere & Purtroppo & \\
Rugosa & Rabbia & \\
Saldare & Raggiunge & \\
Scorta & Rimasti & \\
Tabernacolo & Salgono & \\
Testimone & Sfuggito & \\
Tiranno & Sottrasi & \\
Tumulto & Spiegatemi & \\
Umiltà & Tedesco & \\
& Turbato & \\
& Ubriaco & \\
& Voluta & \\
& Vorrebbe & \\
\hline
\end{tabular}

Vale ressaltar que para elaborar e analisar os dados das três tabelas levamos em consideração a descrição e classificação feita por Marello (2004, p. 222) no que diz respeito aos tipos de vocabulários de um aprendiz de línguas:

a) vocabulário de base: lista de palavras de alta frequência, alto uso e alta disponibilidade estabelecida por De Mauro e seus colaboradores (1993). Compreende mais ou menos 6.700 na versão da pesquisa de 1980 e 7.050 naquela de 1991;

b) vocabulário potencial: conjunto de todas as palavras, em particular as palavras compostas ou derivadas, podendo o aprendiz não ter tido nunca contato com essas palavras, mas que é capaz de entendê-las sem explicações tendo como base as regras da morfologia derivacional, o conhecimento lingüístico (até mesmo relativo a outras línguas), o conhecimento de mundo, ou hipóteses fundamentadas no contexto no qual essas palavras são encontradas. Este vocabulário potencial constitui uma parte não ativa do vocabulário receptivo, o qual é impossível determinar a extensão, pois cada aprendiz está sujeito a um número de input/insumo; 
c) vocabulário produtivo, di comunicazione, ativo: o conjunto de todas as unidades lexicais das quais o falante serve-se para produzir textos escritos ou comunicar-se oralmente;

d)vocabulário receptivo, de compreensão, passivo: conjunto de todas as unidades lexicais das quais o falante serve-se para entender textos escritos o orais.

Dos 11 grupos com os quais trabalhamos, pudemos compilar um corpus inicial de 134 fichas de coleta de dados das unidades lexicais. Analisando posteriormente essas fichas, tivemos que proceder a uma seleção do que poderia compor nosso corpus final. Do total de 134 fichas, ficamos apenas com 50 fichas. $O$ descarte das outras deve-se aos seguintes fatores:

a)percebemos que algumas fichas não foram preenchidas seguindo as instruções, o que, em alguns casos, resultava em fichas com a segunda coluna imensa e praticamente dados mínimos na primeira coluna;

b)alguns alunos reproduziram as fichas dos colegas, o que resultava em um certo número de fichas iguais;

c) as fichas produzidas pelos alunos da Unesp foram inutilizadas pois como esses alunos possuíam uma prática tradutória grande em sala de aula verificou-se que tal grupo possuía um conhecimento vocabular muito maior do que os outros grupos analisados;

d)as fichas produzidas pelos alunos da Unicamp também foram inutilizadas pois, apesar desses alunos estarem teoricamente em um mesmo nível dos outros grupos, por se tratar de um grupo de língua e não um grupo de italiano instrumental, a parte vocabular ainda não estava tão desenvolvida pois trabalhava-se as quatro habilidades ao mesmo tempo, o que faz com que a compreensão escrita levasse um pouco mais de tempo para atingir o nível por nós desejado na pesquisa;

e)outras fichas por nós inutilizadas foram aquelas produzidas pelos alunos da USP nos dois semestres do ano de 2007. Mesmo sendo dois grupos que seguimos desde o começo e oferecemos o mesmo input de língua italiana verificamos que os alunos estavam muito mais preocupados em preencher a ficha de coleta de dados do que realmente ler e compreender o livro, causando assim um grande ruído na leitura. 
Atribuímos também a eliminação e conseguente redução do nosso corpus ao período inicial no qual estávamos testando e aperfeiçoando a nossa metodologia de pesquisa. Dessa forma, podemos dizer que trabalhamos somente com as fichas produzidas pelos grupos 5, 6, 7, 8, 9, 10 e 11 produzidas nos dois semestres de 2008 e 2009, sendo todas elas coletadas na UFPR. Desses sete grupos podemos ainda especificar:

a) quatro eram de Italiano Instrumental 2 . Ao final do trabalhado realizado os grupos estavam com 120 horas de língua italiana. Eram grupos compostos por alunos de diversos cursos de graduação e pós-graduação da UFPR, de idade compreendida entre 19 e 50 anos. Esses grupos tinham como foco principal a leitura em língua italiana. Dos 4 grupos, trabalhamos com 3 no Italiano Instrumental 1, dessa forma, todos eles receberam o mesmo input de língua italiana por parte do professor, constituindo assim 4 grupos teoricamente homogêneos;

b) dois eram do Italiano Básico 2. Ao final do trabalho realizado os grupos estavam com 240 horas de língua italiana. Eram grupos compostos por alunos da graduação em letras de idade entre 18 e 40 anos. Nesses grupos eram exploradas as quatro habilidades no processo de aprendizagem da língua italiana. Trabalhamos com os dois grupos também com a disciplina Italiano Básico 1 que antecedia a Italiano Básico 2, dessa forma, todos eles receberam o mesmo input de língua italiana, sendo então dois grupos homogêneos entre si;

c) um era do Italiano 4. Ao final do trabalho realizado o grupo estava com 240 horas de língua italiana. Era um grupo do Centro de Línguas da UFPR, composto por alunos de diversos cursos de graduação e profissionais já formados. A idade variava entre 20 e 47 ano.

De acordo com a descrição dos grupos por nós escolhidos para compor o corpus da pesquisa podemos perceber que existe uma certa homogeneidade entre eles e a prevalência de um público que estuda a língua italiana com objetivos específicos de compreensão de leitura (4 grupos). Percebemos que para um grupo que estuda a língua italiana visando ao desenvolvimento das quatro habilidades é necessário que tenha, no mínimo, o dobro da carga horária de um grupo que estuda a língua com a finalidade específica da compreensão da leitura para que se chegue aos mesmos resultados. 
Depois da seleção das 50 fichas que compõe o nosso corpus, a etapa seguinte foi selecionar, analisando os dados fornecidos pelos alunos nas fichas, quais palavras (e/ou expressões) deveriam sair das notas de rodapé (coluna 1), quais deveriam entrar (coluna 2) e quais deveriam ser redefinidas (coluna 3 ). $\mathrm{Na}$ realidade tínhamos 51 fichas e resolvemos diminuir esse número para $50 \mathrm{com}$ a finalidade de facilitar a análise estatística das mesmas já que uma das fichas não apresentava tanta relevância para o grupo como um todo.

Posteriormente à seleção das palavras (e/ou expressões) das colunas 2 e 3 , baseando-se no critério de maior freqüência nas fichas de coleta, computamos 55 ocorrênciaas a ser definidas (coluna 2) e 19 a ser reformuladas. Para tal etapa propusemos as fichas que seguem (dois modelos) com os seguintes campos:

a) Título da ficha em negrito com o número indicador, alinhado à direita da página;

b) Unidade lexical ou expressão;

c) Contexto no qual ocorre a unidade lexical ou expressão seguido pelo número da página do livro onde está registrada a ocorrência;

d) Definição existente (esse campo está presente somente para as ocorrências da coluna 3);

e) Definição presente no dicionário De Mauro Paravia;

f) Definição presente no dicionário Dire;

g) Definição presente no dicionário II Sabatini-Coletti on-line;

h) Definição presente no dicionário II Devoto-Oli 2008

i) Definição presente no dicionário Lo Zingarelli 2004;

j) Definição presente no dicionário Parola Chiave;

k) Definição proposta; 
Ficha lexicográfica para as novas palavras que constarão nas notas de rodapé 6

\begin{tabular}{|c|c|}
\hline Unidade lexical & Altrove \\
\hline Contexto & $\begin{array}{l}\text { Sapendo che desiderano mettere su casa altrove, il marchese si offre } \\
\text { di comprare le loro casucce. (120) }\end{array}$ \\
\hline Definiçao De Mauro Paravia & $\begin{array}{l}\text { al·tró·ve } \\
\text { avv. FO } \\
\text { in altro luogo: andare, stare, trovarsi altrove | essere altrove col } \\
\text { pensiero, essere distratto, assente, pensare ad altro }\end{array}$ \\
\hline Definição Dire & $\begin{array}{l}\text { avv. In altro luogo: Cercatelo altrove. } \\
\text { [lat. Alter = altro], contr. Proprio }\end{array}$ \\
\hline Definição II Sabatini-Coletti & $\begin{array}{l}\text { [al-tró-ve] avv. } \\
\qquad \begin{array}{l}\text { • In un altro luogo: trovarsi a. \| fig. avere la testa a., essere } \\
\text { distratto } \\
\text { • sec. XIV }\end{array}\end{array}$ \\
\hline Definição II Devoto-Oli 2008 & $\begin{array}{l}\text { Altrove } \\
\text { <al-tró-ve> avv. } \\
\text { In altro luogo, da un'altra parte, presso altra gente: quel giorno mi } \\
\text { trovavo a.; aver la testa a., pensare ad altro• Come s.m. (invar.), } \\
\text { luogo che simboleggia l'assenza dell'empirico, del quotidiano, del } \\
\text { banale e che richiama un desiderio o una speranza di fuga: il sogno di } \\
\text { un altrove di giustizia } \\
\text { Lat. aliter ubi | metà sec. XIII }\end{array}$ \\
\hline Definição Lo Zingarelli 2004 & $\begin{array}{l}\text { [lat. aliter ubi; 1279] } \\
\text { avv. } \\
\text { * In altro luogo (con verbi sia di stato sia di moto): in quei giorni mi } \\
\text { trovavo altrove; sono diretto altrove; mi rivolgerò altrove I Essere } \\
\text { altrove col pensiero, avere la testa altrove, (fig.) essere distratto, } \\
\text { assente, lontano col pensiero. }\end{array}$ \\
\hline Definição Parola Chiave & avv. In altro luogo, da un'altra parte *em outro lugar \\
\hline Definição Proposta & Da un'altra parte, in un altro luogo. \\
\hline
\end{tabular}


Ficha lexicográfica para definição reformulada 6

\begin{tabular}{|c|c|}
\hline Unidade lexical & Rabbrividire \\
\hline Contexto & $\begin{array}{l}\text { A poco a poco il loro paese si allontana: si vedono le case, il } \\
\text { palazzotto di Don Rodrigo, e Lucia rabbrividisce.(34) }\end{array}$ \\
\hline Definição existente & - rabbrividire: sentire brividi (di freddo, paura, orrore). (34) \\
\hline Definiçao De Mauro Paravia & $\begin{array}{l}\text { rab·bri-vi·dìre } \\
\text { v.intr. e tr. Co } \\
\text { 1. v.intr. (essere, rar. avere) sentire brividi di freddo o di paura: } \\
\text { rabbrividi e si chiuse il cappotto } \\
\text { 2. v.intr. (essere, rar. avere) fig., provare sgomento, paura o } \\
\text { raccapriccio: rabbrividi al pensiero di quello che sarebbe potuto } \\
\text { succedere } \\
\text { 3. v.intr. (essere, rar. avere) BU avere un brivido di piacere, provare } \\
\text { una sensazione di gradevole sorpresa } \\
\text { 4. v.intr. (essere, rar. avere) LE oscillare sotto le intemperie: } \\
\text { rabbrividian le rose | sotto la pioggia (Carducci) } \\
\text { 5. v.tr. BU provocare una sensazione di sgomento, di paura: il } \\
\text { pensiero della morte la rabbrividiva }\end{array}$ \\
\hline Definição Dire & $\begin{array}{l}\text { v.intr. Tremare per il freddo o per la paura: Ho dimenticato la giacca } \\
\text { ed ora rabbrividisco dal freddo. }\end{array}$ \\
\hline Definição II Sabatini-Coletti & $\begin{array}{l}\text { rabbrividire [rab-bri-vi-dì-re] v.intr. (aus. essere, non com. avere; } \\
\text { rabbrividisco, rabbrividisci ecc.) [sogg-v] } \\
1 \text { Avere i brividi per il freddo } \\
2 \text { fig. Provare un senso di paura, di ribrezzo o di orrore; } \\
\text { anche in costr. causativa: un racconto da far } r \text {. } \text { sec. XVIII }\end{array}$ \\
\hline Definição II Devoto-Oli 2008 & $\begin{array}{l}\text { Rabbrividire } \\
\text { <rab-bri-vi-dì-re> v.intr. (rabbrividisco, rabbrividisci, ecc.; aus. essere, } \\
\text { meno com. avere) } \\
\text { 1. Avere, sentire i brividi: questo gelo mi fa r.; r. per il freddo, per la } \\
\text { febbre. } \\
\text { 2. fig. Provare una sensazione di spavento, orrore o raccapriccio; } \\
\text { inorridire, raccapricciare (anche con la prep. di): al solo ripensarci } \\
\text { rabbrividisco; quella vista mi fece } r \text {.; r. di paura, di terrore. } \\
\text { Der. di brivido, col pref. } r a(d)-\mid \text { sec. XVIII. }\end{array}$ \\
\hline Definição Lo Zingarelli 2004 & $\begin{array}{l}\text { Rabbrividire } \\
\text { [comp. di r(i)- e abbrividire; av. 1742] } \\
\text { v. intr. (io rabbrividisco, tu rabbrividisci; aus. essere, raro avere) } \\
1 \text { Avere, sentire i brividi: rabbrividire al gelo invernale. } \\
2 \text { (fig.) Provare paura, orrore e sim.: rabbrividire allo spettacolo } \\
\text { doloroso. SIN. Inorridire, fremere. }\end{array}$ \\
\hline Definição Parola Chiave & $\begin{array}{l}\text { v.intr.[ rabbrividisco, rabbrividisci; aus. essere] Avere um brivido, } \\
\text { sentire i brividi: a quella vista rabbrividi; rabbrividire di freddo, di paura } \\
\text { *arrepiar-se }\end{array}$ \\
\hline Definição Proposta & Sentire freddo per la paura. \\
\hline
\end{tabular}


A escolha dos dicionários foi graças à importância que os mesmos representam para a língua italiana. O dicionário Dire foi escolhido por ser um representante da tipologia "dicionários pedagógicos". Já que as propostas das nossas notas têm um caracter pedagógico, é de fundamental importância que exista um dicionário com essas características para compor um dos itens da ficha lexicográfica.

A escolha do dicionário Parola Chiave foi atribuída ao fato de que esse dicionário foi elaborado para um público brasileiro, sendo a obra de alta relevância para o nosso corpus, já que as novas notas que propomos para a obra adaptada I Promessi Sposi tem como base um público leitor brasileiro. 


\section{V - ANÁLISE DOS DADOS E PROPOSTA LEXICOGRÁFICA DAS NOVAS NOTAS DE RODAPÉ}

Apresentamos nesse momento as 50 fichas referentes à coleta de dados durante a leitura do livro I Promessi Sposi - Adattamento del testo e note di Marisa Pasqualetti, CIDEB, 1999 e 2007.

Essas fichas de coleta compõem o corpus do nosso trabalho e analisando-as chegamos à conclusão de quais palavras e/ou expressões deveriam constar nas notas de rodapé, quais deveriam ser eliminadas e quais deveriam aparecer com uma explicação mais elucidativa. 
5.1 - Fichas de coleta de dados durante a leitura 


\section{Número:01}

Ficha de coleta das unidades lexicais e/ou expressões durante a leitura - I Promessi Sposi - Cideb - 2007

Localização: UFPR/2009/2/DC/Instrumental II

\begin{tabular}{|c|c|c|}
\hline $\begin{array}{l}\text { Palavras que constam no } \\
\text { rodapé desnecessariamente }\end{array}$ & $\begin{array}{l}\text { Palavras que são necessárias, } \\
\text { mas não constam no rodapé }\end{array}$ & $\begin{array}{l}\text { Palavras que constam no rodapé } \\
\text { cuja explicação é insuficiente }\end{array}$ \\
\hline A buon mercato & Accade & Alito \\
\hline Afflitto & Accolta & Bubbone \\
\hline Anziano & Addirittura & Calamaio \\
\hline Baracca & Adosso & Carestia \\
\hline Cadavere & Arcivescovo & Chiasso \\
\hline Calvo & Ária & Educanda \\
\hline Carozza, & Augarata & Erede \\
\hline Colpa & Balbetta & Galli \\
\hline Compassione & Balbettare & Gocce \\
\hline Contagiare & Bravi & Grandinare \\
\hline Convento & Capolavoro & Inchino \\
\hline Di quando in quando & Colloquio & Lotta di successione \\
\hline Distrarre & Curato & Niente meno che \\
\hline Divincolarsi & Dibattuto & Ospizio \\
\hline Dote & Dirupi & Paggio \\
\hline Esuberante & Eppure & Palo \\
\hline Governatore & Fazzoletto & Pendio \\
\hline Impegno & Filatoio & Posate \\
\hline In ozio & Griso & Predica \\
\hline Incamminarsi & Guarisco & Rabbrividire \\
\hline Indizio & Guarita & Raccolto \\
\hline Infermo & Impaurito & Rade \\
\hline Ingannare & Innominato & Rannicchiata \\
\hline Ingannare II tempo & Lazzaretto & Rintocco \\
\hline Invano & Lume & Rivelare \\
\hline Lepre & Monatti & Riversarsi \\
\hline Monastero & Mosso & Sorgenti \\
\hline Monotono & Ognuno & Sorgere \\
\hline Paglia & Orto & Stropiccio \\
\hline Paura & Oste & Stufato \\
\hline Persecuzione & Parroci & Svenire \\
\hline Perseguitare & Popolani & Vigna \\
\hline Peste & Presso & Vita \\
\hline polso & Provvede & Volto \\
\hline Pozzo & Quaggiù & Zimbelli \\
\hline Precipizio & Radunati & \\
\hline Rimorso & Riesce & \\
\hline Rugosa & Riva & \\
\hline
\end{tabular}




\begin{tabular}{|l|l|l|}
\hline Senza scrupoli & Scherzi & \\
Sotterrare & Scoppia & \\
Tirano & Seppe & \\
Ungere & Sottrarsi & \\
& Sportello & \\
& Sudiciume & \\
& Suore & \\
& Svilupparono & \\
& Turbato & \\
& Voluta & \\
\hline
\end{tabular}




\section{Número:02}

Ficha de coleta das unidades lexicais e/ou expressões durante a leitura - I Promessi Sposi - Cideb - 2007

Localização: UFPR/2009/2/AB/Instrumental II

\begin{tabular}{|c|c|c|}
\hline $\begin{array}{l}\text { Palavras que constam no } \\
\text { rodapé desnecessariamente }\end{array}$ & $\begin{array}{l}\text { Palavras que são necessárias, } \\
\text { mas não constam no rodapé }\end{array}$ & $\begin{array}{l}\text { Palavras que constam no rodapé } \\
\text { cuja explicação é insuficiente }\end{array}$ \\
\hline Acconsentire & Adosso & Adda \\
\hline Affiorare & Aggiunge & Alito \\
\hline Afflitto & Ammirandola & Boccone \\
\hline Avvocato & Angosciata & Breviario \\
\hline Baracca & Aprite & Calamaio \\
\hline Barba & Bicchiere & Carestia \\
\hline Bubbone & Boschi & Cupo \\
\hline Cadavere & Bravi & Filanda \\
\hline Calvo & Capponi & Forca \\
\hline Carozza & Carestia & Inchino \\
\hline Chirurgo & Carichi & Livido \\
\hline Collera & Chiarita & Minacciare \\
\hline Compassione & Chiude & Palo \\
\hline Contagiare & Colpa & Panca \\
\hline Deo gratias & Corsa & Pendio \\
\hline Dote & Corso & Posate \\
\hline Fare voto & Cortile & Rabbrividire \\
\hline Feroci & Cugino & Racolto \\
\hline Governatore & Davvero & Radunarsi \\
\hline Implorare & Deluso & Rannicchiata \\
\hline In ozio & Eppure & Rapire \\
\hline Incamminarsi & Fazzoletto & Rintocco \\
\hline Infermo & Fidanzata & Riversasi \\
\hline Infiammare & Fiduciosa & Sagrestano \\
\hline Invano & Figliolo & Sarto \\
\hline Irritare & Finché & Sorgenti \\
\hline La pace sia con voi! & Folla & Svanire \\
\hline Maledizione & Gemiti & Treccia \\
\hline Martellare & Grida & Volto \\
\hline Miglio & Guarire & Zimbello \\
\hline Monastero & Infatti & \\
\hline Monotono & Ondeggiare & \\
\hline Monsignore illustrissimo & Macchie & \\
\hline Ospizio & Nascosto & \\
\hline Parlatorio & Nozze & \\
\hline Pena & Osteria & \\
\hline Perseguitare & Patto & \\
\hline Peste & Pianti & \\
\hline
\end{tabular}




\begin{tabular}{|l|l|l|}
\hline Polso & Popolani & \\
Pozzo & Potrei & \\
Prepotente & Povero & \\
Resentimento & Preghiere & \\
Ribattere & Prete & \\
Rugosa & Purtroppo & Rabbia \\
Saldare & Raggiunge & \\
Scorta & Rimasti & \\
Tabernacolo & Salgono & \\
Testimone & Sfuggito & \\
Tiranno & Sottrasi & \\
Tumulto & Spiegatemi & \\
Umiltà & Tedesco & \\
& Turbato & \\
& Ubriaco & \\
& Voluta & \\
& Vorrebbe & \\
\hline
\end{tabular}




\section{Número:03}

Ficha de coleta das unidades lexicais e/ou expressões durante a leitura - I Promessi Sposi - Cideb - 1999

Localização: UFPR/2008/2/MR/Básico II

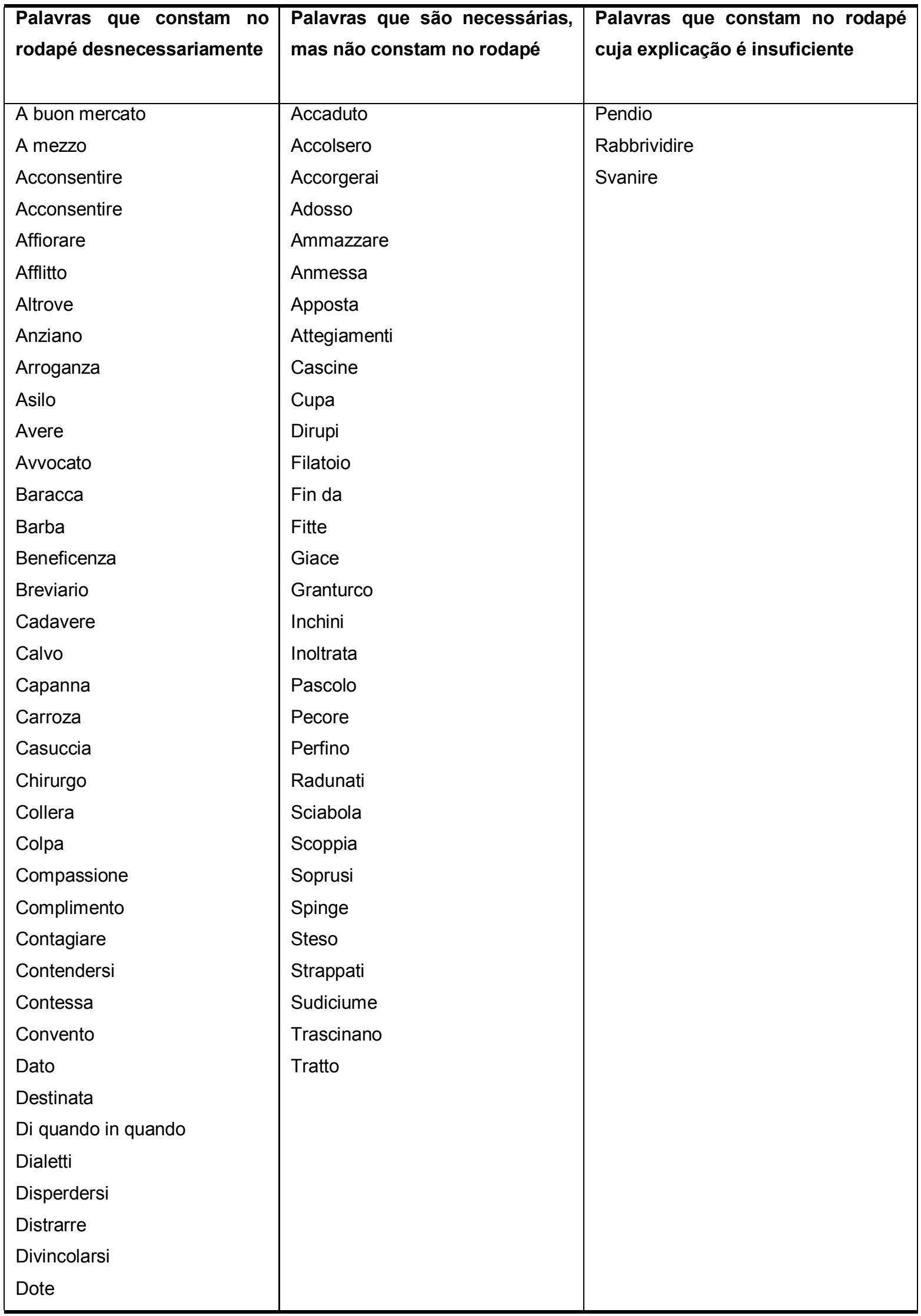




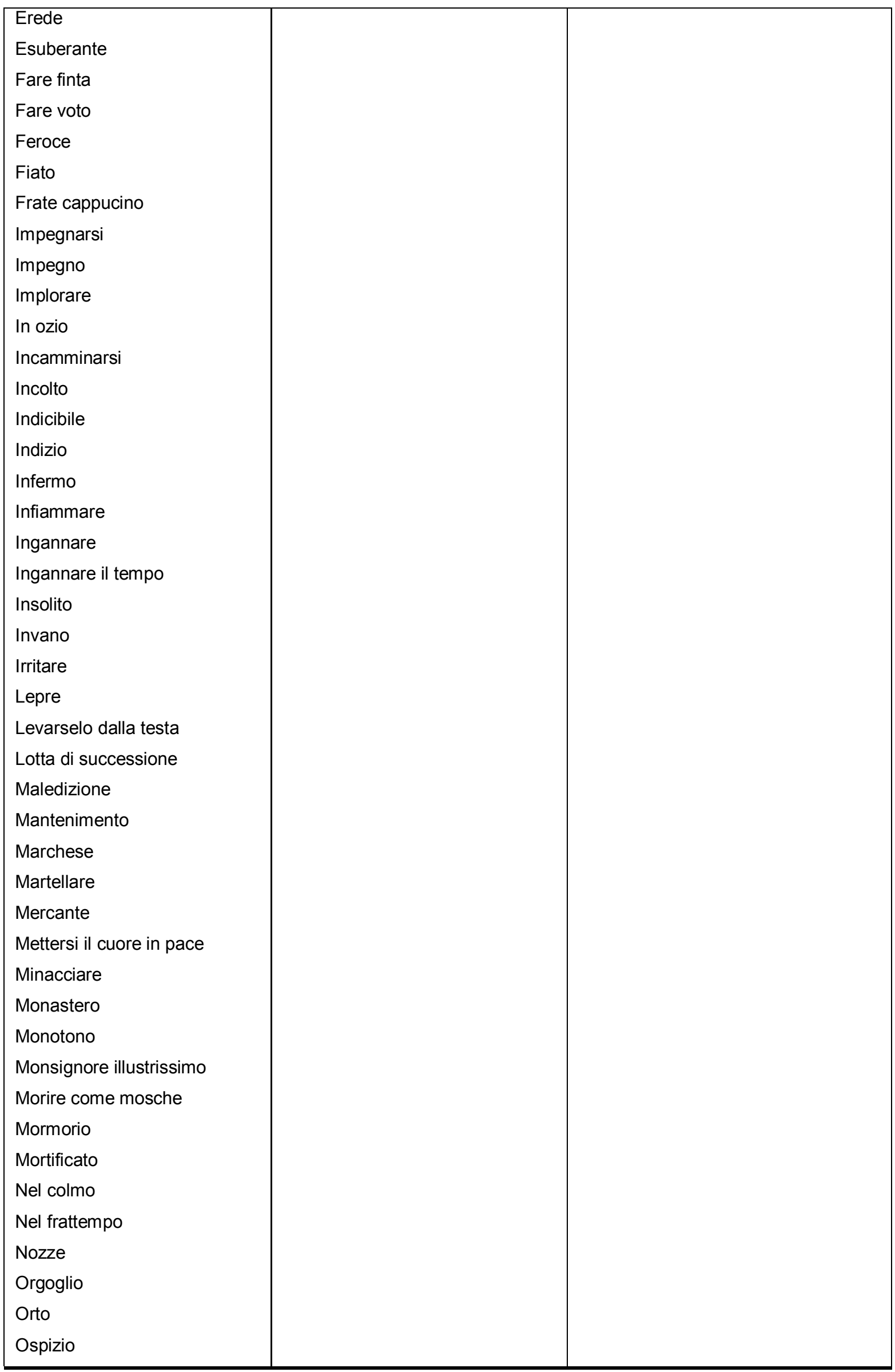




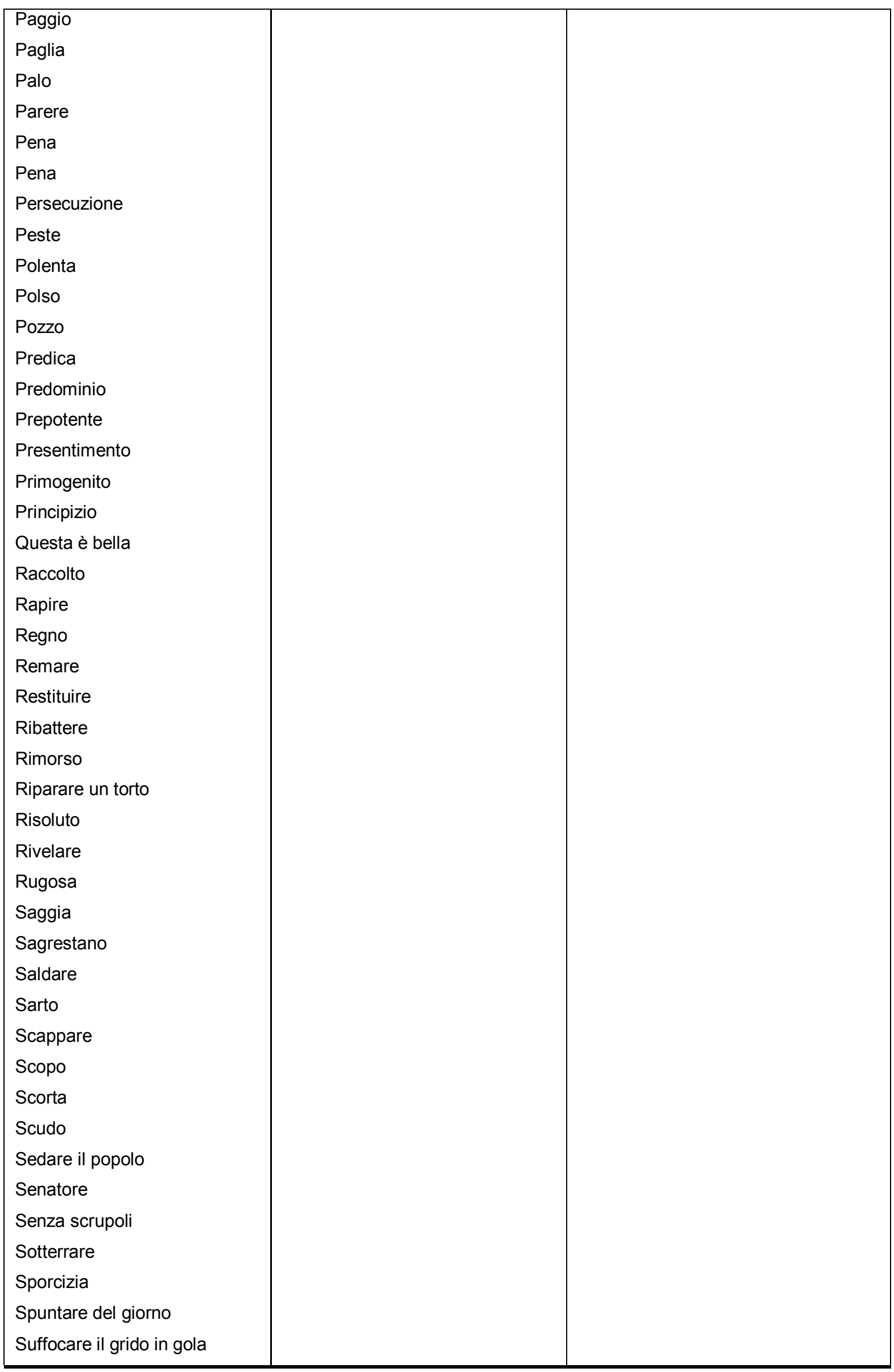




\begin{tabular}{|l|l|l|}
\hline Svenire & & \\
Sventurata & & \\
Terrore & & \\
Testimone & & \\
Tintinnio & & \\
Tiranno & & \\
Titoli nobiliari & & \\
Treccia & & \\
Turbato & & \\
Umiltà & & \\
Ungere & & \\
Urlare & & \\
Vedova & & \\
Venire alla luce & & \\
Vergogna & & \\
Vigna & & \\
Vita & & \\
\hline
\end{tabular}




\section{Número:04}

Ficha de coleta das unidades lexicais e/ou expressões durante a leitura - I Promessi Sposi - Cideb - 2007

Localização: UFPR/2009/2/PA/Basico II

\begin{tabular}{|c|c|c|}
\hline $\begin{array}{l}\text { Palavras que constam no } \\
\text { rodapé desnecessariamente }\end{array}$ & $\begin{array}{l}\text { Palavras que são necessárias, } \\
\text { mas não constam no rodapé }\end{array}$ & $\begin{array}{l}\text { Palavras que constam no rodapé } \\
\text { cuja explicação é insuficiente }\end{array}$ \\
\hline A buon mercato & Altrove & Alito \\
\hline Avvocato & Adosso & Calamaio \\
\hline Barba & Affannoso & Cappone \\
\hline Bussare & Afferra & Panca \\
\hline Cadavere & Altrove & Pendio \\
\hline Calvo & Anzi & Posate \\
\hline Carrozza & Apposta & Rannicchiata \\
\hline Contagiare & Buio & Scommettere \\
\hline Dialetti & Campagna & Spregiudicato \\
\hline Feroce & Campanaro & Treccia \\
\hline Frate cappuccino & Capita & Vigne spoglie \\
\hline Governatore & Capita & \\
\hline Impari & Capo & \\
\hline Impegno & Carichi & \\
\hline Implorare & Cascine & \\
\hline Incamminarsi & Casetta & \\
\hline Indizio & Corsa & \\
\hline Invano & Deluso & \\
\hline Irritare & Ebbene & \\
\hline La pace sia con voi & Fatti & \\
\hline Lepre & Fazzoletto & \\
\hline Martelare & Figlioli & \\
\hline Miglia & Filatoio & \\
\hline Monastero & Fitte & \\
\hline Monotono & Gettano & \\
\hline Peste c & Giace & \\
\hline Precipizio & Gocce & \\
\hline Presentimento & Guai & \\
\hline Prete & Guance & \\
\hline Ribattere & Guarire & \\
\hline Risoluto & Guarisco & \\
\hline Rugosa & Guarita & \\
\hline Saggia & Inginocchiò & \\
\hline Sagrestano & Lancio & \\
\hline Senatore & Liscio & \\
\hline Svanire & Mento & \\
\hline Testimone & Monaca & \\
\hline Tiranno & Mosso & \\
\hline Tumulto & Nascosto & \\
\hline
\end{tabular}




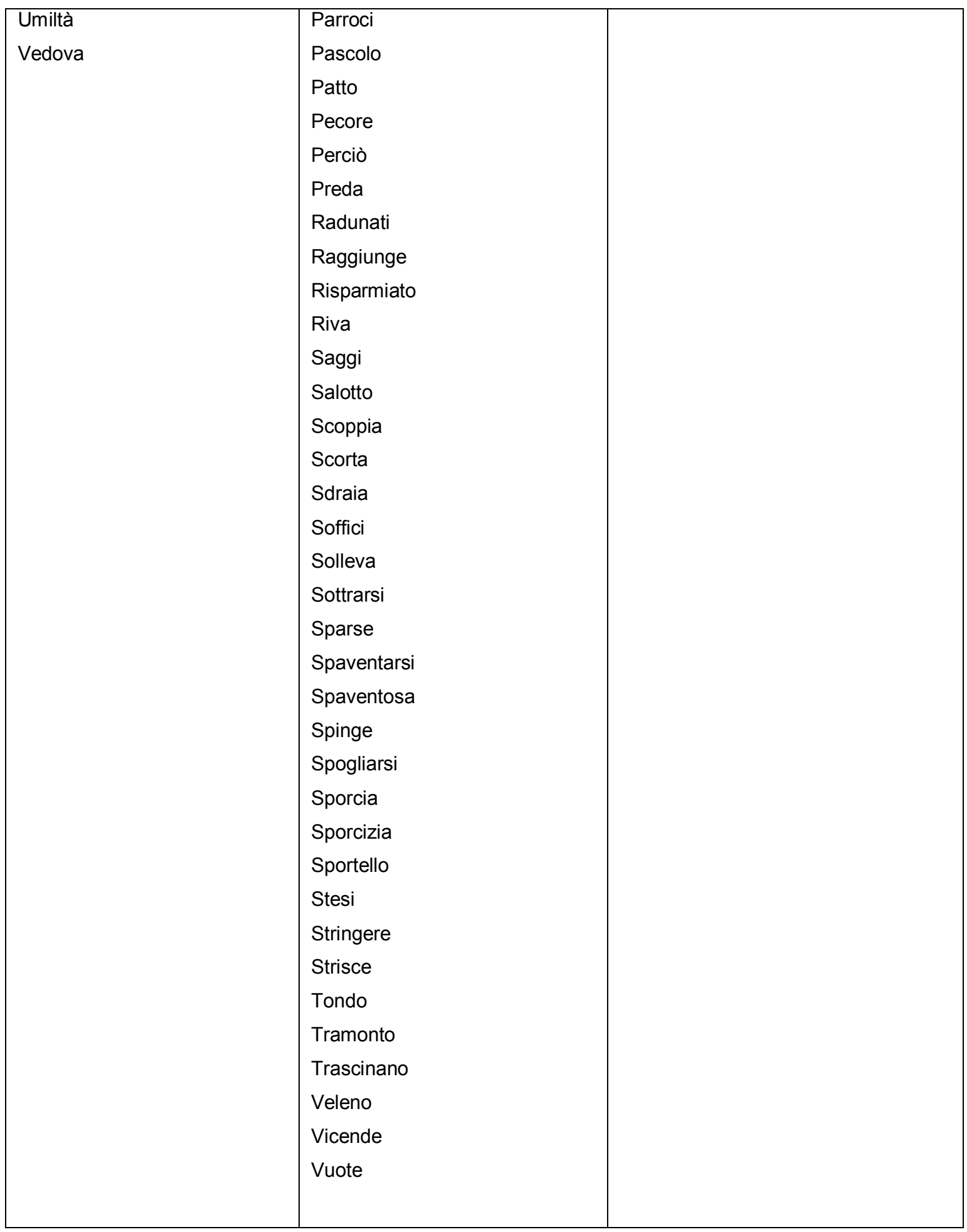




\section{Número:05}

Ficha de coleta das unidades lexicais e/ou expressões durante a leitura - I Promessi Sposi - Cideb - 2007

Localização: UFPR/2009/2/LG/Basico II

\begin{tabular}{|c|c|c|}
\hline $\begin{array}{l}\text { Palavras que constam no } \\
\text { rodapé desnecessariamente }\end{array}$ & $\begin{array}{l}\text { Palavras que são necessárias, } \\
\text { mas não constam no rodapé }\end{array}$ & $\begin{array}{l}\text { Palavras que constam no rodapé } \\
\text { cuja explicação é insuficiente }\end{array}$ \\
\hline Barbe & Accade & Alito \\
\hline Beneficenza & Adosso & Bubbone \\
\hline Cadavere & Affaccia & Pendio \\
\hline Calvo & Anzi & Rannicchiata \\
\hline Carestia & Balbettare & Sorgenti \\
\hline Collera & Bugiarda & \\
\hline Compassione & Buio & \\
\hline Complimento & Campanaro & \\
\hline Destinata & Carnagione & \\
\hline Di quando in quando & Casse & \\
\hline Dialetti & Cime & \\
\hline Dote & Colpa & \\
\hline Esuberante & Colpito & \\
\hline Fare voto & Costretto & \\
\hline Feroce & Cupa & \\
\hline Frate Cappuccino & Deluso & \\
\hline Governatore & Diffidente & \\
\hline Grandinare & Ebbero & \\
\hline liluminismo & Edilizio & \\
\hline Impegno & Fronzoli & \\
\hline Implorare & Giace & \\
\hline Infermo & Granturco & \\
\hline Ingannare & Guance & \\
\hline Ingannare il tempo & Incorniciato & \\
\hline Irritare & Mandria & \\
\hline La pace sai com voi & Maniche & \\
\hline Lepre & Matti & \\
\hline Maledizione & Mento & \\
\hline Monotono & Minacce & \\
\hline Monsignore illustrissimo & Paragonati & \\
\hline Pena & Quindi & \\
\hline Peste & Raggiunge & \\
\hline Precipizio & Raggiunto & \\
\hline Predica & Redditizia & \\
\hline Predominio & Scherma & \\
\hline Prepotente & Sciabola & \\
\hline Primogenito & Scomposta & \\
\hline Restituire & Soffici & \\
\hline
\end{tabular}




\begin{tabular}{|l|l|l|}
\hline Rimorso & Soppia & \\
Rissorgimento & Soprusi & \\
Romanticismo & Sostenevano & \\
Rugosa & Sottomessa & \\
Saldare & Spinse & \\
Senatore & Spogliarsi & \\
Tiranno & Spostiamoci & \\
Tumulto & Stormo & \\
Umiltá & Subirne & \\
Vedova & Superba & \\
Vergogna & Svolsero & \\
& Tondo & \\
& Tramontato & \\
& Vicende & \\
& & \\
\hline
\end{tabular}




\section{Número:06}

Ficha de coleta das unidades lexicais e/ou expressões durante a leitura - I Promessi Sposi - Cideb - 2007

Localização: UFPR/2009/2/MV/Básico II

\begin{tabular}{|c|c|c|}
\hline $\begin{array}{l}\text { Palavras que constam no } \\
\text { rodapé desnecessariamente }\end{array}$ & $\begin{array}{l}\text { Palavras que são necessárias, } \\
\text { mas não constam no rodapé }\end{array}$ & $\begin{array}{l}\text { Palavras que constam no rodapé } \\
\text { cuja explicação é insuficiente }\end{array}$ \\
\hline Afflitto & Accade & Alito \\
\hline Barba & Addosso & Azzeccagarbugli \\
\hline Bussare & Ammazzare & Calamaio \\
\hline Cadavere & Appoggiato & Raccolto \\
\hline Cólera & Attesa & Rannichiata \\
\hline Di quando in quando & Branchi di pecore & \\
\hline Dialetti & Butta & \\
\hline Distrarre & Cancelli & \\
\hline Dote & Cortile & \\
\hline Fare voto & Curato & \\
\hline Feroce & Entrambi & \\
\hline Il tempo in ozio & Fianco & \\
\hline Imbróglio & Filatoio & \\
\hline Implorare & Folla & \\
\hline Incamminare & Guadagnare & \\
\hline Infermo & Guai & \\
\hline Ingannare & Guance & \\
\hline Irritare & Intanto & \\
\hline La pace sai com voi & Mento & \\
\hline Maledizione & Monatti & \\
\hline Monastero & Ormai & \\
\hline Monótono & Pascolo & \\
\hline Niente meno che & Pendii & \\
\hline Ospizio & Perciò & \\
\hline Peste & Piuttosto & \\
\hline Precipizio & Presso & \\
\hline Prepotente & Rami & \\
\hline Prete & Reca & \\
\hline Rapire & Ridotta & \\
\hline Ribattere & Rifiuta & \\
\hline Rugosa & Risparmiati & \\
\hline Scudo & Ritrovo & \\
\hline Senatore & Scoppia & \\
\hline Signarotto & Soffice & \\
\hline Tiranno & Sostenerlo & \\
\hline Tumulto & Spogliarsi & \\
\hline Umiltà & Spostiamoci & \\
\hline Ungere & Strappati & \\
\hline Vedova & Strisce & \\
\hline
\end{tabular}




\section{Número:07}

Ficha de coleta das unidades lexicais e/ou expressões durante a leitura - I Promessi Sposi - Cideb - 2007

Localização: UFPR/2009/2/PM/Básico II

\begin{tabular}{|c|c|c|}
\hline $\begin{array}{l}\text { Palavras que constam no } \\
\text { rodapé desnecessariamente }\end{array}$ & $\begin{array}{l}\text { Palavras que são necessárias, } \\
\text { mas não constam no rodapé }\end{array}$ & $\begin{array}{l}\text { Palavras que constam no rodapé } \\
\text { cuja explicação é insuficiente }\end{array}$ \\
\hline A buon mercato & Accade & Alito \\
\hline Acconsente & Ascesa & Biacca \\
\hline Affiorano & Attilata & Capponi \\
\hline Afflitti & Beiro & Collera \\
\hline Apalancati & Berretti & Contendevano \\
\hline Asilo & Brano & Fatto la spia \\
\hline Averi & Butta & Galli \\
\hline Baracche & Deluso & Pendii \\
\hline Breviario & Di corsa & Raccolto \\
\hline Cadaveri & Difridente & Raggrinza \\
\hline Calvo & Fianchi & Trina \\
\hline Carrozza & Fiocchi & \\
\hline Compassione & Fioretto & \\
\hline Complimenti & Fiorire & \\
\hline Contagrati & Folla & \\
\hline Destinata & Giubba & \\
\hline Disperdersi & Inchini & \\
\hline Dote & Incorniciato & \\
\hline Esuberante & Lazzaretto & \\
\hline Frate cappuccini & Manivuote & \\
\hline Illustrissimo & Matti & \\
\hline Imbroglio & Mento & \\
\hline Impari & Minacce & \\
\hline Implora & Nascosto & \\
\hline Incammina & osteria & \\
\hline Indizio & Pascolo & \\
\hline Ingannò & Piuttosto & \\
\hline Invano & Polsi & \\
\hline Irritarlo & Ridotta & \\
\hline La pace sia con voi & Rigidi & \\
\hline Lepre & Ritrovo & \\
\hline Maledizione & Saggi & \\
\hline Martellare & Scarso & \\
\hline Mercante & Sciabola & \\
\hline Miglia & Scomposta & \\
\hline Monastero & Sfuggè & \\
\hline Monotoni & Si reca & \\
\hline Mormorio & Soffici & \\
\hline Ospizi & Sottomessa & \\
\hline
\end{tabular}




\begin{tabular}{|l|l|l|}
\hline Ozio & Sottrarsi & \\
Parlatorio & Spense & Strisce \\
Pazzi & Vicende & \\
Precipezi & & \\
Primogenito & & \\
Rapire & & \\
Remorso & & \\
Restituire & & \\
Ribatte & & \\
Rugosa & & \\
Saldare & & \\
Scrupoli & & \\
Sorge & & \\
Stupito & & \\
Successione & & \\
Testemoni & & \\
Tumulto & & \\
Umiltà & & \\
Vergogna & & \\
Voto & & \\
\hline
\end{tabular}




\section{Número:08}

Ficha de coleta das unidades lexicais e/ou expressões durante a leitura - I Promessi Sposi - Cideb - 2007

Localização: UFPR/2009/2/AS/Instrumental II

\begin{tabular}{|c|c|c|}
\hline $\begin{array}{l}\text { Palavras que constam no } \\
\text { rodapé desnecessariamente }\end{array}$ & $\begin{array}{l}\text { Palavras que são necessárias, } \\
\text { mas não constam no rodapé }\end{array}$ & $\begin{array}{l}\text { Palavras que constam no rodapé } \\
\text { cuja explicação é insuficiente }\end{array}$ \\
\hline Alito & Accadute & Acconsentire \\
\hline Avere & Accaduto & Affiorare \\
\hline Barba & Accolsero & Afflitto \\
\hline Chiasso & Accolta & Anziano \\
\hline Collera & Accolti & Arroganza \\
\hline Contendersi & Accorge & Beneficenza \\
\hline Feroci & Addirittura & Cadavere \\
\hline Grandinare & Afferra & Calvo \\
\hline Impari & Alza & Carrozza \\
\hline Implora & Alzatevi & Compassione \\
\hline In lungo e in largo & Ammala & Contagiare \\
\hline Inchino & Ammalati & Convento \\
\hline Incolto & Ammessa & Destinata \\
\hline Irritarlo & Appaiono & Dote \\
\hline Lanzichenecchi & Appare & Esuberante \\
\hline Maledizione & Appogiato & Filanda \\
\hline Panca & Arcivescovo & Frate cappucino \\
\hline Pena & Aria & Governatore \\
\hline Pendio & Arrabbiato & Impegnarsi \\
\hline Posate & Attesa & Incamminarsi \\
\hline Prepotente & Avvicina & Indizio \\
\hline Rabbrividire & Balbettare & Infermo \\
\hline Raccolto & Basso & Ingannare \\
\hline Rannicchiata & Bevanda & Marchese \\
\hline Restituire & Bianche & Martellare \\
\hline Ribatte & Bicchiere & Mercante \\
\hline Riscuotere dei soldi & Botteghe & Monótono \\
\hline Scenata & Bravi & Monsignore \\
\hline Signorotto & Burro & Mormorio \\
\hline Sorgenti & Cattivo & Mortificato \\
\hline Stufato & Cenno & Orgoglio \\
\hline Testimoni & Col & Paglia \\
\hline Tintinnio & Condurrò & Peste \\
\hline Treccia & Cortile & Polenta \\
\hline Umiltà & Cortile & Predomínio \\
\hline Vita & Cugino & Primogênito \\
\hline \multirow[t]{2}{*}{ Zimbello } & Cupa & Remare \\
\hline & Curato & Rimorso \\
\hline
\end{tabular}




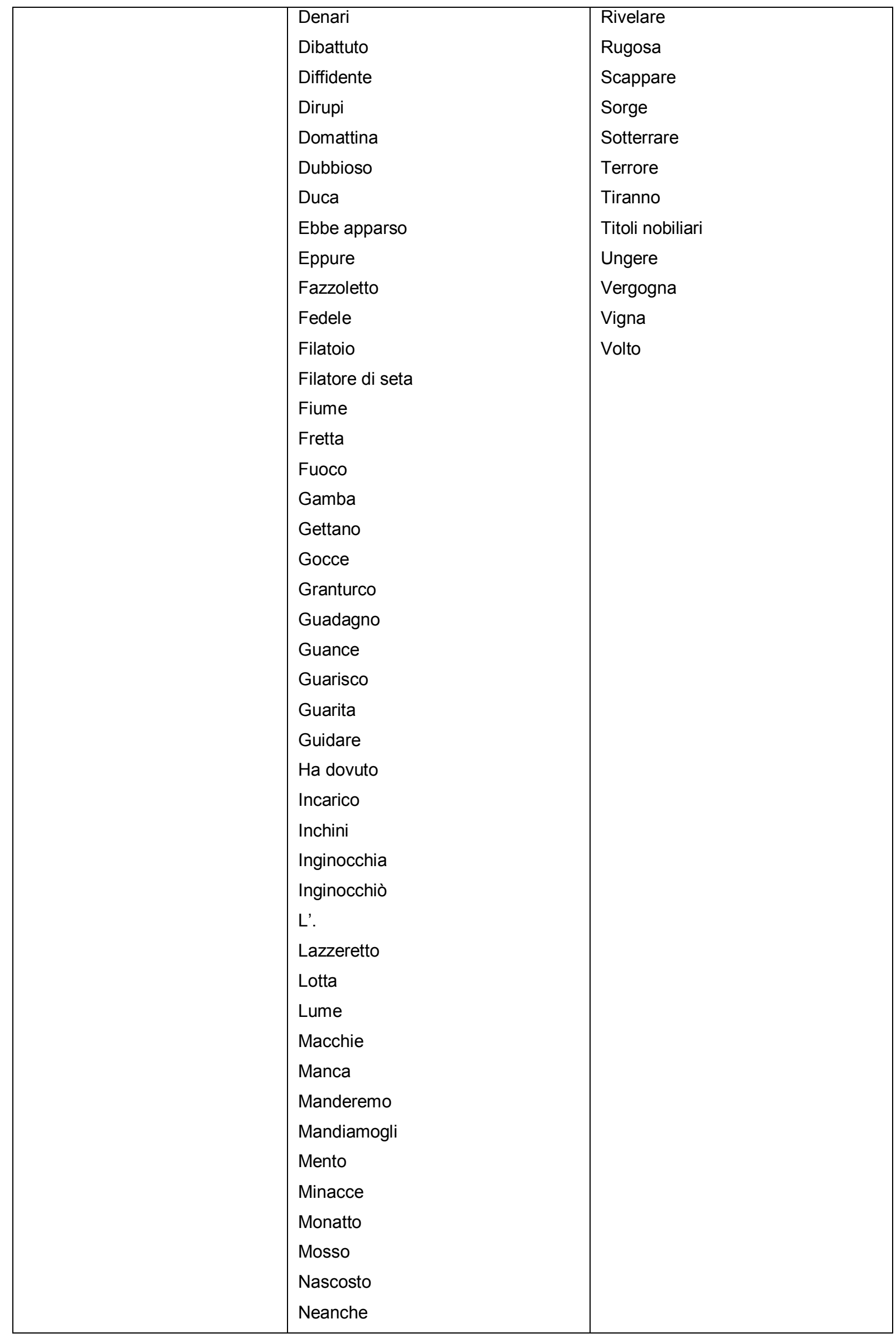




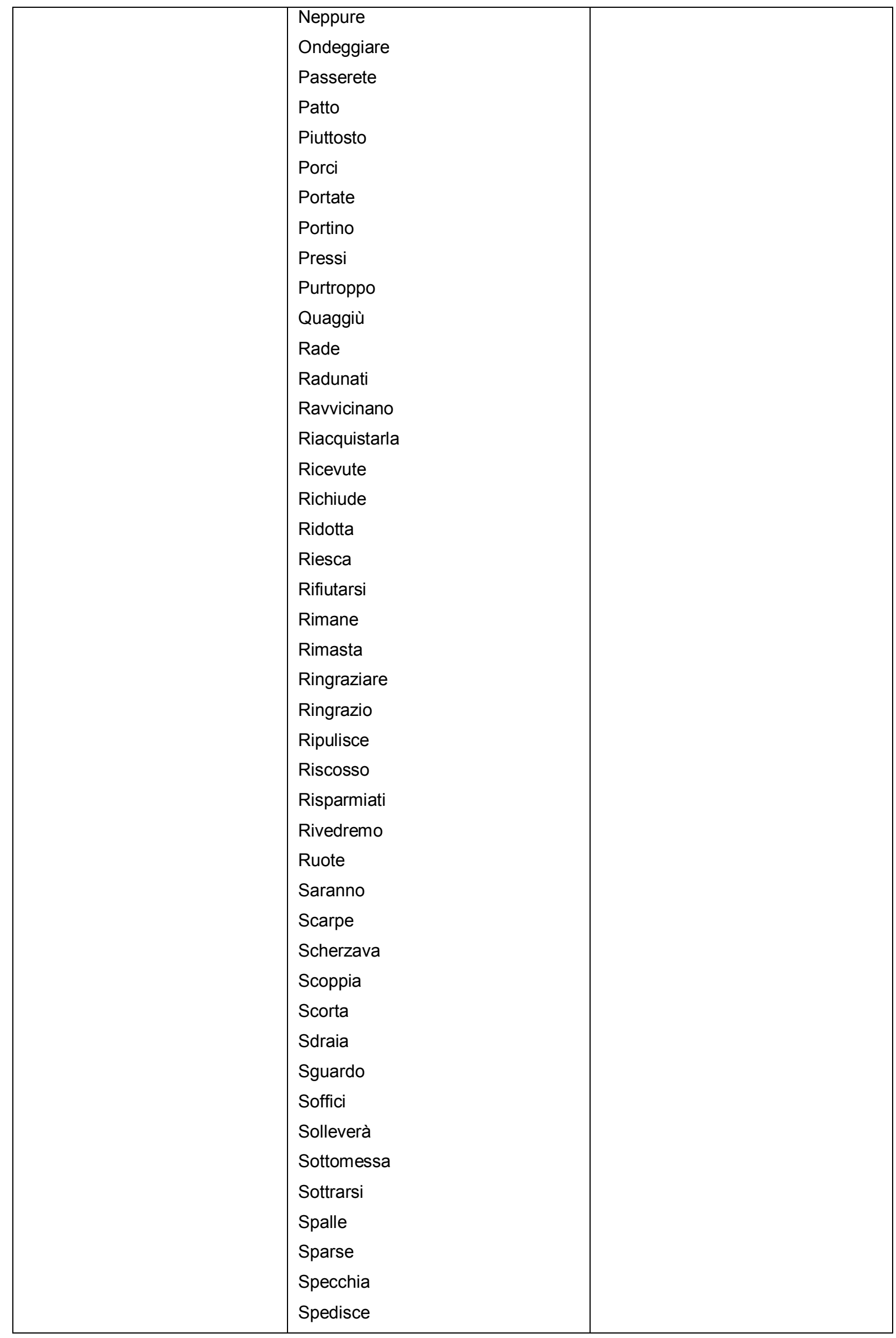




\begin{tabular}{|l|l|l|}
\hline & Spinge & \\
Spinse & Spogliarsi & \\
Sportello & Spostiamoci & \\
Spuntare & Stanchezza & \\
Starsene & \\
Stesi & \\
Strisce & \\
Striscia & \\
Sudiciume & \\
Sveglia & \\
Svolgevano & \\
Tondo & \\
& Tovaglia & \\
Tramontato & \\
& Trascinano & \\
Tremila & \\
Ubriaco & \\
Urla & \\
Veleno & \\
Vendetta & \\
Voluto & \\
& \\
\hline
\end{tabular}




\section{Número:09}

Ficha de coleta das unidades lexicais e/ou expressões durante a leitura - I Promessi Sposi - Cideb - 1999 Localização: UFPR/2008/2/FS/Instrumental II

\begin{tabular}{|c|c|c|}
\hline $\begin{array}{l}\text { Palavras que constam no } \\
\text { rodapé desnecessariamente }\end{array}$ & $\begin{array}{l}\text { Palavras que são necessárias, } \\
\text { mas não constam no rodapé }\end{array}$ & $\begin{array}{l}\text { Palavras que constam no rodapé } \\
\text { cuja explicação é insuficiente }\end{array}$ \\
\hline 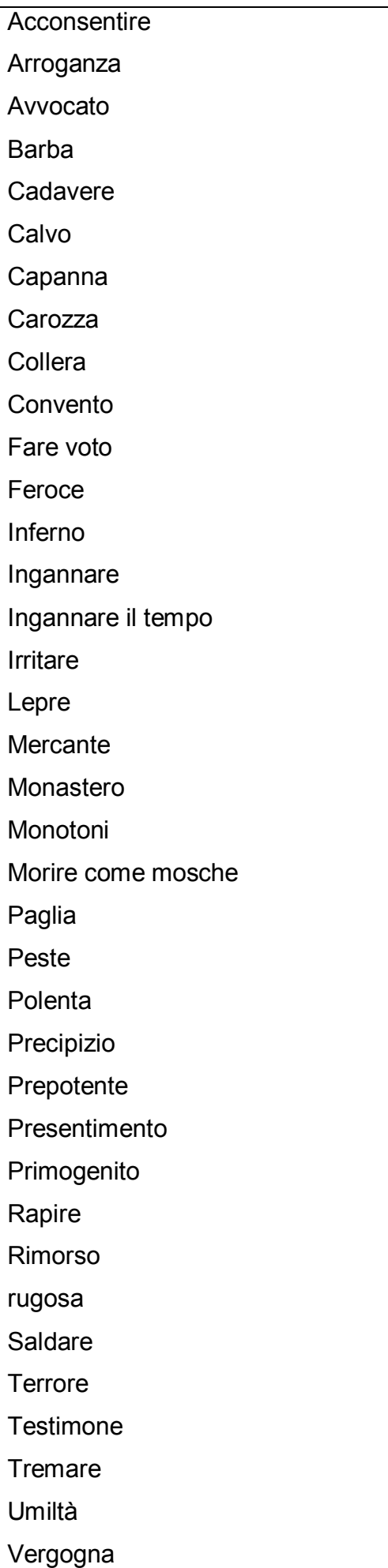 & $\begin{array}{l}\text { Accaduto } \\
\text { Agnello } \\
\text { Alzateni } \\
\text { Arrabiato } \\
\text { Cappone } \\
\text { Deluso } \\
\text { Dirupi } \\
\text { Guance } \\
\text { Inginhoccia } \\
\text { Lasciare } \\
\text { Lontana } \\
\text { Mento } \\
\text { Mortificato } \\
\text { Rami } \\
\text { Sbagliato } \\
\text { Subirne i suprosi } \\
\text { Sudiciume } \\
\text { Suora } \\
\text { Trattengono } \\
\text { Ubriaco } \\
\text { Vicende } \\
\text { Vicino }\end{array}$ & $\begin{array}{l}\text { Divisa } \\
\text { In lungo i largo } \\
\text { Levarselo dalla testa } \\
\text { Niente meno che } \\
\text { Palo } \\
\text { Panca } \\
\text { Pendio } \\
\text { Rannicchiata } \\
\text { Sorgentio } \\
\text { Stropiccio } \\
\text { Svanire } \\
\text { Volto } \\
\text { Zimbello }\end{array}$ \\
\hline
\end{tabular}




\section{Número:10}

Ficha de coleta das unidades lexicais e/ou expressões durante a leitura - I Promessi Sposi - Cideb - 2007

Localização: UFPR/2009/1/BP/Instrumental II

\begin{tabular}{|c|c|c|}
\hline $\begin{array}{l}\text { Palavras que constam no } \\
\text { rodapé desnecessariamente }\end{array}$ & $\begin{array}{l}\text { Palavras que são necessárias, } \\
\text { mas não constam no rodapé }\end{array}$ & $\begin{array}{l}\text { Palavras que constam no rodapé } \\
\text { cuja explicação é insuficiente }\end{array}$ \\
\hline Avvocato & Abbia & Affaccendata \\
\hline Beneficenza & Abbigliamento & Alito \\
\hline Beneficenza & Adosso & Grandinare \\
\hline Cadaveri & Affaccia & Infiamma \\
\hline Calvo & Afferra & Pali \\
\hline Calvo & Agnello & Panca \\
\hline Carrozza & Aiuterà & Posate \\
\hline Contagiati & Alzatevi & Predica \\
\hline Dialetti & Ammassati & Sorgenti \\
\hline Disperdersi & Anatra & Spregiudicati \\
\hline Governatore & Andrò & Svanisce \\
\hline Illuministe & Aria & Zimbello \\
\hline Implora & Attillata & \\
\hline Incolto & Attimo & \\
\hline Indizio & Avvia & \\
\hline Infermi & Bambole & \\
\hline Irritarlo & Bicchiere & \\
\hline La pace sia con voi & Bisogna & \\
\hline Maledizione & Bocche & \\
\hline Martellare & Botteghe & \\
\hline Monotoni & Branco & \\
\hline Mosche & Broso & \\
\hline Nobiliari & Buio & \\
\hline Nobiliari & Capolavoro & \\
\hline Ospizi & Cappone & \\
\hline Ozio & Cattura & \\
\hline Peste & Cavolo & \\
\hline Polsi & Chiude & \\
\hline Predominio & Chiuse & \\
\hline Predominio & Colpito & \\
\hline Presentimento & Convinto & \\
\hline Restituire & Corsa & \\
\hline Romancticismo & Cugino & \\
\hline Scampata & Curato & \\
\hline Senatore & Darci & \\
\hline Spia & Davvero & \\
\hline Spuntare del giorno & Dintorni & \\
\hline Testimoni & Domanda & \\
\hline
\end{tabular}




\begin{tabular}{|c|c|}
\hline $\begin{array}{l}\text { Tiranno } \\
\text { Tumulto } \\
\text { Umiltà }\end{array}$ & $\begin{array}{l}\text { Domattina } \\
\text { Dunque } \\
\text { Entrambi } \\
\text { Erbacce } \\
\text { Erede } \\
\text { Fermano } \\
\text { Fiduciosa } \\
\text { Filatore } \\
\text { Fiocchi } \\
\text { Folla } \\
\text { Foraggi } \\
\text { Fuoco } \\
\text { Gialla } \\
\text { Ginocchio } \\
\text { Giubba } \\
\text { Gocce grosse } \\
\text { Granturco } \\
\text { Gregge } \\
\text { Guadagnare } \\
\text { Guaggiù } \\
\text { Guance } \\
\text { Guarita } \\
\text { Imparare } \\
\text { Impaurito } \\
\text { Lardo } \\
\text { Legata } \\
\text { Livello } \\
\text { Lontani } \\
\text { Lungo } \\
\text { Macchie } \\
\text { Panca } \\
\text { Maiale } \\
\text { Manchera } \\
\text { Mandria } \\
\text { Manovre } \\
\text { Mantello } \\
\text { Manzo } \\
\text { Minacciato } \\
\text { Monatti } \\
\text { Muoiono } \\
\text { Poiosa } \\
\text { Panea } \\
\text { Pato }\end{array}$ \\
\hline
\end{tabular}




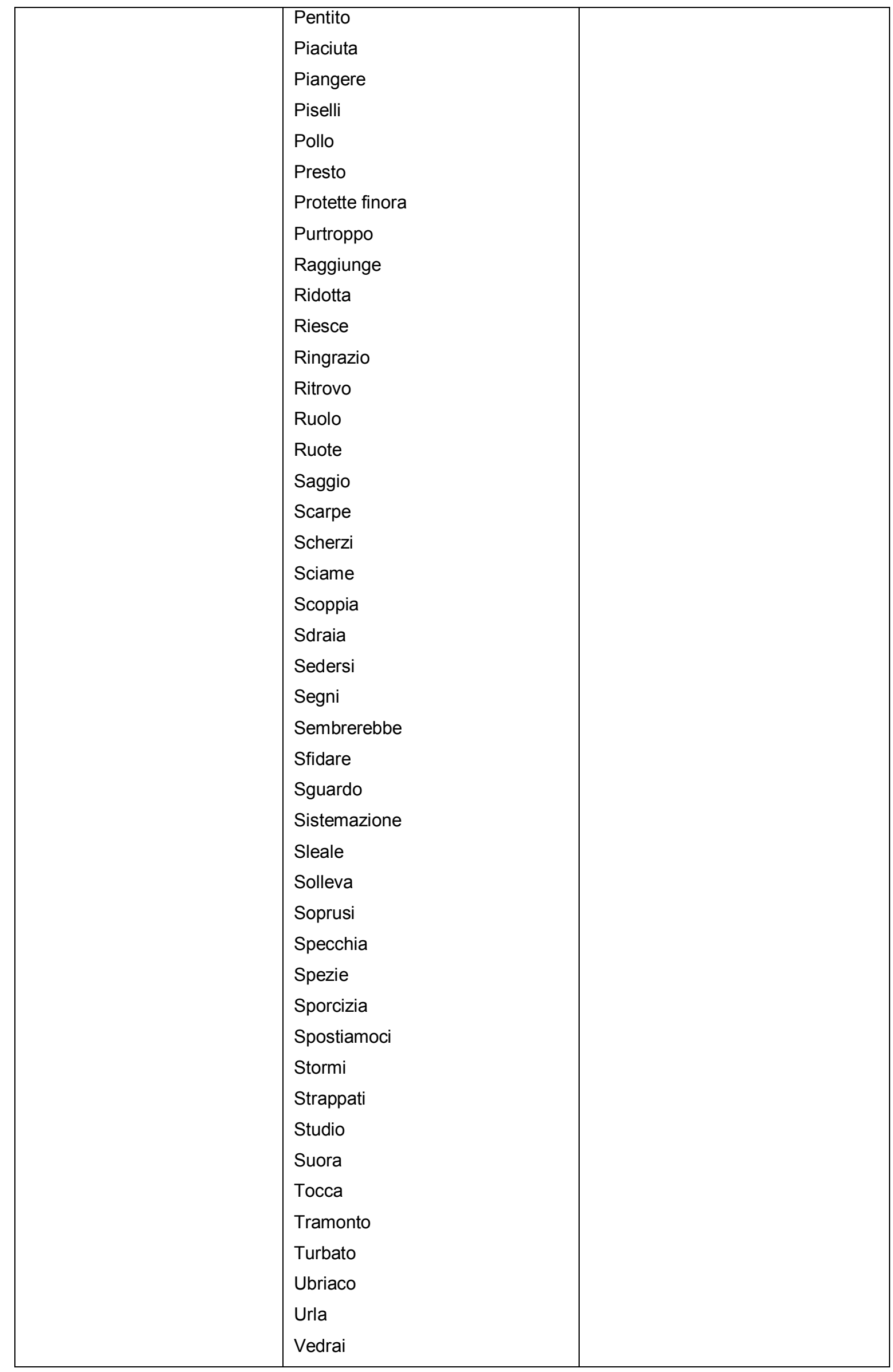




\begin{tabular}{|l|l|l|}
\hline & Vernaccia & \\
Vicende & \\
& Vince & \\
Vorrei & \\
\hline
\end{tabular}


Número:11

Ficha de coleta das unidades lexicais e/ou expressões durante a leitura - I Promessi Sposi - Cideb - 1999

Localização: UFPR/2008/1/ACO/Instrumental II

\begin{tabular}{|c|c|c|}
\hline $\begin{array}{l}\text { Palavras que constam no } \\
\text { rodapé desnecessariamente }\end{array}$ & $\begin{array}{l}\text { Palavras que são necessárias, } \\
\text { mas não constam no rodapé }\end{array}$ & $\begin{array}{l}\text { Palavras que constam no rodapé } \\
\text { cuja explicação é insuficiente }\end{array}$ \\
\hline $\begin{array}{l}\text { Governatore } \\
\text { Martellare } \\
\text { Prepotente } \\
\text { Presentimento } \\
\text { Regno } \\
\text { Remare } \\
\text { Senatore }\end{array}$ & $\begin{array}{l}\text { Ammazzare } \\
\text { Avrò - avrà } \\
\text { Filatoio } \\
\text { Fiume } \\
\text { Folla } \\
\text { Guadagno } \\
\text { Impauriti } \\
\text { Implosa } \\
\text { Incarico } \\
\text { Lazzaretto } \\
\text { Minace } \\
\text { Monaca } \\
\text { Nobiluomo } \\
\text { Passcolo } \\
\text { Ridotta } \\
\text { Ritrovo } \\
\text { Sportello } \\
\text { Tramontato } \\
\text { Vendetta }\end{array}$ & $\begin{array}{l}\text { Addirittura } \\
\text { Alito } \\
\text { Azzeccagarbugli } \\
\text { Barba } \\
\text { Capponi } \\
\text { Fiasco } \\
\text { Frattempo } \\
\text { Minacciare } \\
\text { Niente meno che } \\
\text { Rannicchiata } \\
\text { Rapire } \\
\text { Signorotto } \\
\text { Sogenti } \\
\text { Sorgere } \\
\text { Stufato } \\
\text { Svanire } \\
\text { Treccia } \\
\text { Volto }\end{array}$ \\
\hline
\end{tabular}


Número:12

Ficha de coleta das unidades lexicais e/ou expressões durante a leitura - I Promessi Sposi - Cideb - 1999

Localização: UFPR/2008/1/FM/Instrumental II

\begin{tabular}{|c|c|c|}
\hline $\begin{array}{l}\text { Palavras que constam no } \\
\text { rodapé desnecessariamente }\end{array}$ & $\begin{array}{l}\text { Palavras que são necessárias, } \\
\text { mas não constam no rodapé }\end{array}$ & $\begin{array}{l}\text { Palavras que constam no rodapé } \\
\text { cuja explicação é insuficiente }\end{array}$ \\
\hline $\begin{array}{l}\text { Calvo } \\
\text { Convento } \\
\text { Illuminismo } \\
\text { Inferni } \\
\text { Irritare } \\
\text { Maledizione } \\
\text { Remare } \\
\text { Romanticismo } \\
\text { Rugosa } \\
\text { Spuntare del giorno } \\
\text { Testimoni } \\
\text { Umiltà }\end{array}$ & $\begin{array}{l}\text { Botega } \\
\text { Cibo } \\
\text { Impauriti } \\
\text { Raggiungere } \\
\text { Seta }\end{array}$ & $\begin{array}{l}\text { Alito } \\
\text { Capponi } \\
\text { Carestia } \\
\text { Filanda } \\
\text { Posate } \\
\text { Svanire } \\
\text { Treccia } \\
\text { Volto }\end{array}$ \\
\hline
\end{tabular}


Número:13

Ficha de coleta das unidades lexicais e/ou expressões durante a leitura - I Promessi Sposi - Cideb - 1999

Localização: UFPR/2008/1/GP/Instrumental II

\begin{tabular}{|c|c|c|}
\hline $\begin{array}{l}\text { Palavras que constam no } \\
\text { rodapé desnecessariamente }\end{array}$ & $\begin{array}{l}\text { Palavras que são necessárias, } \\
\text { mas não constam no rodapé }\end{array}$ & $\begin{array}{l}\text { Palavras que constam no rodapé } \\
\text { cuja explicação é insuficiente }\end{array}$ \\
\hline $\begin{array}{l}\text { Acconsentire } \\
\text { Barba } \\
\text { Capanna } \\
\text { Colera } \\
\text { Feroce } \\
\text { Impegno } \\
\text { Presentimento } \\
\text { Prete } \\
\text { Scappare } \\
\text { Umiltà }\end{array}$ & $\begin{array}{l}\text { Addirittura } \\
\text { Attesa } \\
\text { Capuccini } \\
\text { Casetta } \\
\text { Contadino } \\
\text { Coraggio } \\
\text { Curato } \\
\text { Erbacce } \\
\text { Fatti } \\
\text { Fidanzati } \\
\text { Filatoio } \\
\text { Finora } \\
\text { Guarire } \\
\text { Monaca } \\
\text { Patto } \\
\text { Popolani } \\
\text { Pressi } \\
\text { Radinati } \\
\text { Raggiungere } \\
\text { Salgono } \\
\text { Scherzi } \\
\text { Specchia } \\
\text { Spinge } \\
\text { Strappati } \\
\text { Sudiciume } \\
\text { Tramaglino } \\
\text { Pand }\end{array}$ & $\begin{array}{l}\text { Alito } \\
\text { Levarsello dalla testa } \\
\text { Pali } \\
\text { Pendio } \\
\text { Scommettere } \\
\text { Sorgere }\end{array}$ \\
\hline
\end{tabular}




\section{Número:14}

Ficha de coleta das unidades lexicais e/ou expressões durante a leitura - I Promessi Sposi - Cideb - 1999

Localização: UFPR/2008/1/AG/Instrumental II

\begin{tabular}{|c|c|c|}
\hline $\begin{array}{l}\text { Palavras que constam no } \\
\text { rodapé desnecessariamente }\end{array}$ & $\begin{array}{l}\text { Palavras que são necessárias, } \\
\text { mas não constam no rodapé }\end{array}$ & $\begin{array}{l}\text { Palavras que constam no rodapé } \\
\text { cuja explicação é insuficiente }\end{array}$ \\
\hline Acconsentire & Accaduto & Carestia \\
\hline Acconsentire & Accolta & Grandinare \\
\hline Afflitto & Altrove & Niente meno che \\
\hline Anziano & Annoiato & Raccolto \\
\hline Avvocato & Apposta & Rannicchiata \\
\hline Breviario & Bacione in viso & Sfiorita \\
\hline Cadavere & Bei & Sorgere \\
\hline Calvo & Butta la tovaglia addoso & Treccia \\
\hline Carrozza & Cattura & \\
\hline Collera & Coinvolto & \\
\hline Contagiare & Cugino & \\
\hline Contessa & Entrambi & \\
\hline Convento & Fatti & \\
\hline Distrarre & Fidanzata & \\
\hline Divincolarsi & Filatoio & \\
\hline Dote & Folla & \\
\hline Governatore & Guadagno & \\
\hline Imbroglio & Guai & \\
\hline Implorare & Guarita & \\
\hline In ozio & Imparare & \\
\hline Incamminarsi & Incarico & \\
\hline Indizio & Mancherà & \\
\hline Lepre & Nascosto & \\
\hline Maledizione & Paese & \\
\hline Marchese & Popolani & \\
\hline Martellare & Pressi & \\
\hline Monastero & Prete & \\
\hline Monotono & Quaggiù & \\
\hline Parlatorio & Radunare & \\
\hline Pena & Rapire & \\
\hline Peste & Riferisce & \\
\hline Polenta & Risparmiato & \\
\hline Precipizio & Spinge & \\
\hline Prepotente & Veleno & \\
\hline Presentimento & & \\
\hline Remare & & \\
\hline Restituire & & \\
\hline Ribattere & & \\
\hline
\end{tabular}




\begin{tabular}{|l|l|l|}
\hline Risoluto & & \\
Rivelare & & \\
Rugosa & & \\
Saldare & & \\
Sbalordita & & \\
Scappare & & \\
Scorta & & \\
Scudo & & \\
Senatore & & \\
Spuntare del giorno & & \\
Testimone & & \\
Umiltà & & \\
Ungere & & \\
Venire alla luce & & \\
Volto & & \\
& & \\
\hline
\end{tabular}




\section{Número:15}

Ficha de coleta das unidades lexicais e/ou expressões durante a leitura - I Promessi Sposi - Cideb - 2007

Localização: UFPR/2009/1/RO/Literatura Celin

\begin{tabular}{|c|c|c|}
\hline $\begin{array}{l}\text { Palavras que constam no } \\
\text { rodapé desnecessariamente }\end{array}$ & $\begin{array}{l}\text { Palavras que são necessárias, } \\
\text { mas não constam no rodapé }\end{array}$ & $\begin{array}{l}\text { Palavras que constam no rodapé } \\
\text { cuja explicação é insuficiente }\end{array}$ \\
\hline Barba & Abelli & Cadetto \\
\hline Carrozza & Acconsente & Galli \\
\hline Feroce & Affaciava & Indicibile \\
\hline Governatore & Afferra & Riversarsi \\
\hline Illuminismo & Amarezza & Senatore \\
\hline Impegno & Ammassati & Signorotto \\
\hline Implorare & Appaiono & Soprusi \\
\hline Incamminarsi & Apparso & Sposina \\
\hline Ingannò & Attesa & Stropiccio \\
\hline Maledizione & Branco & Tappa \\
\hline Monastero & Bravi & Titoli nobiliari \\
\hline Mormorio & Campagna & Trina \\
\hline Pena & Cancelli & Vernaccia \\
\hline Predica & Corsa & \\
\hline Prepotente & Filatoio & \\
\hline Presentimento & Fitte & \\
\hline Prete & Folte & \\
\hline Restituire & Guance & \\
\hline Ribattere & Inoltrata & \\
\hline Romanticismo & Lancio & \\
\hline Saldare & Monatto & \\
\hline Scopo & Nascosto & \\
\hline Testimone & Ombre vaganti & \\
\hline Tumulto & Oste & \\
\hline Umiltà & Posto & \\
\hline Vedova & Preda & \\
\hline & Pressi & \\
\hline & Recare & \\
\hline & Ridare & \\
\hline & Rimproverà & \\
\hline & Rivolgere & \\
\hline & Scendere & \\
\hline & Scoppia & \\
\hline & Smette & \\
\hline & Sollevare & \\
\hline & Soprannome & \\
\hline & Sostegno & \\
\hline & Spinge & \\
\hline
\end{tabular}




\begin{tabular}{|l|l|l|}
\hline Spinse & \\
Sporcizia & Strappati & \\
Cascine & Avviare & \\
Capanna & \\
Panca & \\
Altrove & \\
\hline
\end{tabular}


Número:16

Ficha de coleta das unidades lexicais e/ou expressões durante a leitura - I Promessi Sposi - Cideb - 1999

Localização: UFPR/2008/2/ML/Italiano 4 Celin

\begin{tabular}{|c|c|c|}
\hline $\begin{array}{l}\text { Palavras que constam no } \\
\text { rodapé desnecessariamente }\end{array}$ & $\begin{array}{l}\text { Palavras que são necessárias, } \\
\text { mas não constam no rodapé }\end{array}$ & $\begin{array}{l}\text { Palavras que constam no rodapé } \\
\text { cuja explicação é insuficiente }\end{array}$ \\
\hline 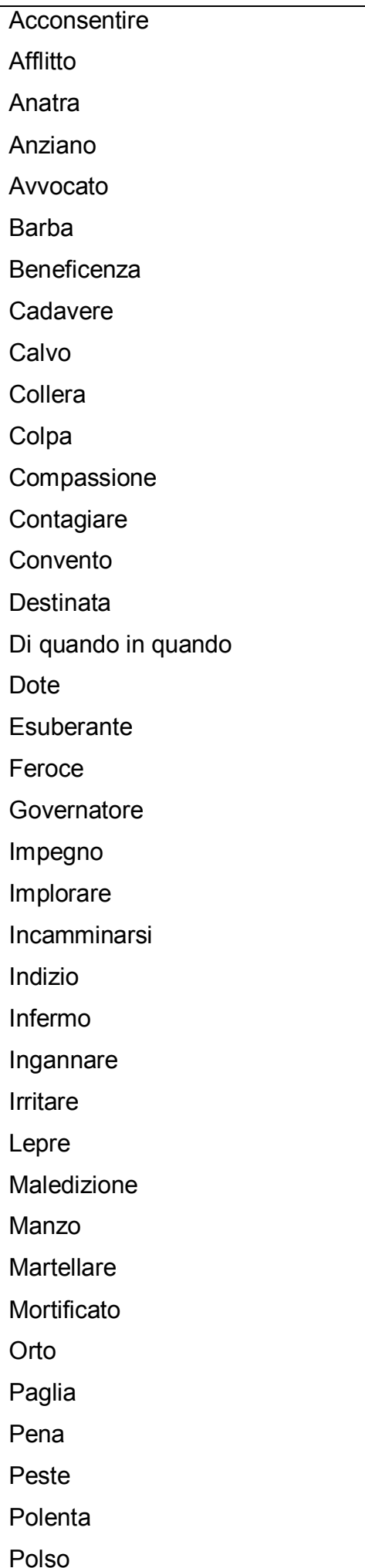 & $\begin{array}{l}\text { Addolcirli } \\
\text { Addosso } \\
\text { Altrove } \\
\text { Cortile } \\
\text { Dibattuto } \\
\text { Dirupi } \\
\text { Guance } \\
\text { Mestiere } \\
\text { Patire } \\
\text { Rispose } \\
\text { Scoppia } \\
\text { Soprusi } \\
\text { Sottrarsi } \\
\text { Spostarsi } \\
\text { Tramonto } \\
\text { Treccia }\end{array}$ & $\begin{array}{l}\text { Dialetto } \\
\text { Inchino } \\
\text { La pace sia con voi } \\
\text { Scenata } \\
\text { Senatore }\end{array}$ \\
\hline
\end{tabular}




\begin{tabular}{|l|l|l|}
\hline Pozzo & & \\
Precipizio & & \\
Predominio & & \\
Prepotente & & \\
Rapire & & \\
Rapire & & \\
Regno & & \\
Remare & & \\
Restituire & & \\
Rimorso & & \\
Risoluto & & \\
Rivelare & & \\
Rugosa & & \\
Saldare & & \\
Scappare & & \\
Sotterrare & & \\
Terrore & & \\
Testimone & & \\
Tiranno & & \\
Umiltà & & \\
Ungere & & \\
Urlare & & \\
Vedova & & \\
Vergogna & & \\
Vigna & & \\
\hline
\end{tabular}




\section{Número:17}

Ficha de coleta das unidades lexicais e/ou expressões durante a leitura - I Promessi Sposi - Cideb - 1999

Localização: UFPR/2008/2/FC/Italiano 4 Celin

\begin{tabular}{|c|c|c|}
\hline $\begin{array}{l}\text { Palavras que constam no } \\
\text { rodapé desnecessariamente }\end{array}$ & $\begin{array}{l}\text { Palavras que são necessárias, } \\
\text { mas não constam no rodapé }\end{array}$ & $\begin{array}{l}\text { Palavras que constam no rodapé } \\
\text { cuja explicação é insuficiente }\end{array}$ \\
\hline Acconsente & addolcirli & Alito \\
\hline Avvocato & Aggiunge & Carestia \\
\hline Barba & Ammazzare & Raccolto \\
\hline Contagiati & Attesa & Sorge \\
\hline Convento & Cortile & Volto \\
\hline Disperdersi & Denari & \\
\hline Facesse & Dirupi & \\
\hline Feroci & Facesse & \\
\hline Fialtoio & Filatoio & \\
\hline Implora & Folla & \\
\hline Paglia & Giace & \\
\hline Pena & Guai & \\
\hline Prepotente & Guance & \\
\hline Presentimento & Liscio & \\
\hline Remare & Mantello & \\
\hline Restituire & Mento & \\
\hline Ribatte & Minacci & \\
\hline Rugosa & Mortificato & \\
\hline Scorta & Nascosto & \\
\hline Testimoni & Pascolo & \\
\hline Umiltà & Pieno & \\
\hline & Piuttosto & \\
\hline & Scomposta & \\
\hline & Scoppia & \\
\hline & Smette & \\
\hline & Strisce & \\
\hline & Sudiciume & \\
\hline
\end{tabular}




\section{Número:18}

Ficha de coleta das unidades lexicais e/ou expressões durante a leitura - I Promessi Sposi - Cideb - 1999

Localização: UFPR/2008/1/WB/Instrumental II

\begin{tabular}{|c|c|c|}
\hline $\begin{array}{l}\text { Palavras que constam no } \\
\text { rodapé desnecessariamente }\end{array}$ & $\begin{array}{l}\text { Palavras que são necessárias, } \\
\text { mas não constam no rodapé }\end{array}$ & $\begin{array}{l}\text { Palavras que constam no rodapé } \\
\text { cuja explicação é insuficiente }\end{array}$ \\
\hline A buon mercato & Accolta & Azzeccagarbugli \\
\hline Acconsentire & Affera & Grandinare \\
\hline Anziano & Campagna & Pendii \\
\hline Avvocato & Campanaro & Raccolto \\
\hline Barba & Capo & Rannicchiata \\
\hline Bussare & Colpa & Restituire \\
\hline Calvo & Corsa & Sorgere \\
\hline Carrozza & Cugino & Sporcizia \\
\hline Compassione & Dirupi & \\
\hline Contagiare & Fidanzati & \\
\hline Disperdersi & Filatoio & \\
\hline Distrarre & Gemiti & \\
\hline Feroce & Guaggiù & \\
\hline Governatore & Guarita & \\
\hline In ozio & Inchini & \\
\hline Incamminarsi & Insegnare & \\
\hline Inferno & Intanto & \\
\hline Infiammare & Lazzaretto & \\
\hline Ingannare il tempo & Minacce & \\
\hline Irritare & Minacciosa & \\
\hline Marchese & Monaca & \\
\hline Martellare & Opere & \\
\hline Miglio & ormai & \\
\hline Monastero & Osteria & \\
\hline monotono & Piaciuta & \\
\hline Morire come mosche & Pianti & \\
\hline Nel frattempo & Pietosa & \\
\hline Nozze & Scomposta & \\
\hline Ospizio & Scoppia & \\
\hline Parere & Spargerà & \\
\hline Pena & Sparse & \\
\hline Perseguitare & Sportello & \\
\hline Peste & Stringere & \\
\hline Polenta & Tabernacolo & \\
\hline Precipizio & Urla & \\
\hline Prepotente & & \\
\hline Presentimento & & \\
\hline Rapire & & \\
\hline
\end{tabular}




\begin{tabular}{|l|l|l|}
\hline Ribattere & & \\
Rincarare & & \\
Risoluto & & \\
Rivela & & \\
Rugosa & & \\
Saggia & & \\
Scappare & & \\
Sedare il popolo & & \\
Spargersi & & \\
Stufato & & \\
Turbato & & \\
Umiltà & & \\
Venire alla luce & & \\
Vigna & & \\
\hline
\end{tabular}




\section{Número:19}

Ficha de coleta das unidades lexicais e/ou expressões durante a leitura - I Promessi Sposi - Cideb - 1999

Localização: UFPR/2008/1/EF/Instrumental II

\begin{tabular}{|c|c|c|}
\hline $\begin{array}{l}\text { Palavras que constam no } \\
\text { rodapé desnecessariamente }\end{array}$ & $\begin{array}{l}\text { Palavras que são necessárias, } \\
\text { mas não constam no rodapé }\end{array}$ & $\begin{array}{l}\text { Palavras que constam no rodapé } \\
\text { cuja explicação é insuficiente }\end{array}$ \\
\hline $\begin{array}{l}\text { Barba } \\
\text { Carrozza } \\
\text { Collera } \\
\text { Dialetti } \\
\text { Feroci } \\
\text { Governatore } \\
\text { Implorare } \\
\text { Incamminarsi } \\
\text { Irritare } \\
\text { Martellare } \\
\text { Monotono } \\
\text { Prepotente } \\
\text { Preseguire } \\
\text { Presentimento } \\
\text { Remare } \\
\text { Scappare } \\
\text { Senatore } \\
\text { Testimone } \\
\text { Umiltà } \\
\text { Vedova }\end{array}$ & $\begin{array}{l}\text { Cadavere } \\
\text { Calvo } \\
\text { Capolavoro } \\
\text { Compassione } \\
\text { Distrarre } \\
\text { Dote } \\
\text { Fare voto } \\
\text { Inferno } \\
\text { Nobiluomo } \\
\text { Peste } \\
\text { Precipizio } \\
\text { Rivelare } \\
\text { Rugosa }\end{array}$ & $\begin{array}{l}\text { Alito } \\
\text { Calamaio } \\
\text { Carestia } \\
\text { Forca } \\
\text { Inchino } \\
\text { Raccolto } \\
\text { Rannicchiata } \\
\text { Sorgere } \\
\text { Stufato }\end{array}$ \\
\hline
\end{tabular}


Número:20

Ficha de coleta das unidades lexicais e/ou expressões durante a leitura - I Promessi Sposi - Cideb - 1999

Localização: UFPR/2008/1/FU/Instrumental II

\begin{tabular}{|c|c|c|}
\hline $\begin{array}{l}\text { Palavras que constam no } \\
\text { rodapé desnecessariamente }\end{array}$ & $\begin{array}{l}\text { Palavras que são necessárias, } \\
\text { mas não constam no rodapé }\end{array}$ & $\begin{array}{l}\text { Palavras que constam no rodapé } \\
\text { cuja explicação é insuficiente }\end{array}$ \\
\hline $\begin{array}{l}\text { Afflitto } \\
\text { Avvocato } \\
\text { Cadavere } \\
\text { Calvo } \\
\text { Carrozza } \\
\text { Contagiare } \\
\text { Dote } \\
\text { Governatore } \\
\text { Implorare } \\
\text { Inferno } \\
\text { Irritare } \\
\text { Peste } \\
\text { Polenta } \\
\text { Prepotente } \\
\text { Presentimento } \\
\text { Remare } \\
\text { Rugosa } \\
\text { Testimone } \\
\text { Umiltà }\end{array}$ & $\begin{array}{l}\text { Campane } \\
\text { Fidanzati } \\
\text { Filatoio } \\
\text { Palazzotto }\end{array}$ & $\begin{array}{l}\text { Alito } \\
\text { Erede } \\
\text { Grandinare } \\
\text { Minacciare } \\
\text { Pendio } \\
\text { Posate } \\
\text { Raccolto } \\
\text { Rannicchiata } \\
\text { Rivelare } \\
\text { Sorgenti } \\
\text { Sorgere } \\
\text { Svanire } \\
\text { Treccia } \\
\text { Volto }\end{array}$ \\
\hline
\end{tabular}




\section{Número:21}

Ficha de coleta das unidades lexicais e/ou expressões durante a leitura - I Promessi Sposi - Cideb - 1999 Localização: UFPR/2008/1/RB/Instrumental II

\begin{tabular}{|c|c|c|}
\hline $\begin{array}{l}\text { Palavras que constam no } \\
\text { rodapé desnecessariamente }\end{array}$ & $\begin{array}{l}\text { Palavras que são necessárias, } \\
\text { mas não constam no rodapé }\end{array}$ & $\begin{array}{l}\text { Palavras que constam no rodapé } \\
\text { cuja explicação é insuficiente }\end{array}$ \\
\hline 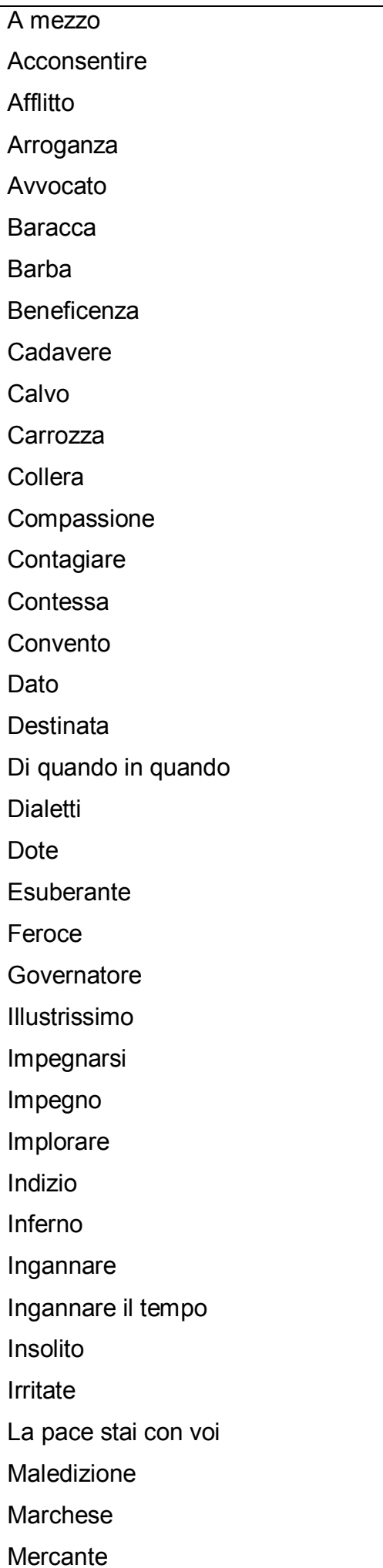 & $\begin{array}{l}\text { Cibi } \\
\text { Monaca } \\
\text { Risorgimento } \\
\text { Sdraia } \\
\text { Sopracciglia }\end{array}$ & $\begin{array}{l}\text { Alito } \\
\text { Boccone } \\
\text { Calamaio } \\
\text { Contendersi } \\
\text { Niente meno che } \\
\text { Parlatorio } \\
\text { Pendio } \\
\text { Rannicchiata } \\
\text { Rapire } \\
\text { Rintocco } \\
\text { Sipario } \\
\text { Sorgere } \\
\text { Treccia } \\
\text { Volto }\end{array}$ \\
\hline
\end{tabular}




\begin{tabular}{|l|l|l|}
\hline Monastero & & \\
Monotono & & \\
Monsignore & & \\
Orgoglio & & \\
Ospizio & & \\
Paglia & & \\
Pena & & \\
Pena & & \\
Polenta & & \\
Precipizio & & \\
Prepotente & & \\
Presentimento & & \\
Regimogenito & & \\
Remare & & \\
Restituire & \\
Rimorso & \\
Rugosa & \\
Saldare & \\
Scappare & \\
Senatore & \\
Senza scrupoli & \\
Sotterrare & \\
Tabernacolo & \\
Terrore & \\
Testimone & \\
Tiranno & \\
Titoli nobiliari & \\
Venire alla luce & \\
Vergogna & \\
Vigna & \\
\hline
\end{tabular}




\section{Número:22}

Ficha de coleta das unidades lexicais e/ou expressões durante a leitura - I Promessi Sposi - Cideb - 1999 Localização: UFPR/2008/1/NC/Instrumental II

\begin{tabular}{|l|l|l|}
\hline $\begin{array}{l}\text { Palavras que constam no } \\
\text { rodapé desnecessariamente }\end{array}$ & $\begin{array}{l}\text { Palavras que são necessárias, } \\
\text { mas não constam no rodapé }\end{array}$ & $\begin{array}{l}\text { Palavras que constam no rodapé } \\
\text { cuja explicação é insuficiente }\end{array}$ \\
\hline Barba & Bravi & Alito \\
Calvo & Fermano & Estufato \\
Carrozza & Improvvisamente & Niente meno che \\
Feroce & Incarico & Rannicchiata \\
Monotono & Lazzaretto & Treccia \\
Pena & Spostiamoci & Vita \\
Pozzo & & \\
Precipizio & & \\
Prepotente & & \\
Remari & & \\
Rugosa & & \\
Scappare & & \\
Spuntare del giorno & & \\
Tiranno & & \\
& & \\
\end{tabular}




\section{Número:23}

Ficha de coleta das unidades lexicais e/ou expressões durante a leitura - I Promessi Sposi - Cideb - 1999

Localização: UFPR/2008/1/NC1/Instrumental II

\begin{tabular}{|c|c|c|}
\hline $\begin{array}{l}\text { Palavras que constam no } \\
\text { rodapé desnecessariamente }\end{array}$ & $\begin{array}{l}\text { Palavras que são necessárias, } \\
\text { mas não constam no rodapé }\end{array}$ & $\begin{array}{l}\text { Palavras que constam no rodapé } \\
\text { cuja explicação é insuficiente }\end{array}$ \\
\hline Anziano & Accade & Afflitto \\
\hline Barba & Altrimenti & Alito \\
\hline Beneficenza & Attesa & Azzeccagarbugli \\
\hline Cadavere & Cappuccini & Bombala \\
\hline Calvo & Carichi & Bubbone \\
\hline Carrozza & Colpito & Cappone \\
\hline Compassione & Corsa & Di quando in quando \\
\hline Complimento & Cugino & Impari \\
\hline Esuberante & Dietro & In lungo e in largo \\
\hline Feroci & Fermano & Inchino \\
\hline Governatore & Guance & Niente meno che \\
\hline Implorare & Impaurito & Palo \\
\hline Ingannare & Leggero & Pendio \\
\hline Maledizione & Mancherà & Posate \\
\hline Monotono & Monaca & Rabbrividire \\
\hline Orgoglio & Nascosto & Raggrinzarsi \\
\hline Peste & Ormai & Rannicchiata \\
\hline Precipizio & Osteria & Recarsi \\
\hline Prepotente & Piuttosto & Restituire \\
\hline Rapire & Presto & Rintocco \\
\hline Remare & Qualche & Riscuotere dei soldi \\
\hline Restituire & Raggiungere & Riversarsi \\
\hline Rimorso & Riesce & Scottarsi \\
\hline Rugosa & Ritrovo & Siccità \\
\hline Sagrestano & Salotto & Sorgenti \\
\hline Saldare & Soffici & Sorgere \\
\hline Sotterrare & Sotto & Spargersi \\
\hline Sventurata & Spaventarsi & Stufato \\
\hline Terrore & Spinge & Svanire \\
\hline Testimone & Strisce & Tintinnio \\
\hline Tiranno & Sveglia & Treccia \\
\hline Titoli nobiliari & Tondo & Volto \\
\hline Umiltà & Tovaglia & \\
\hline Vergogna & Verso & \\
\hline Vigna & & \\
\hline
\end{tabular}




\section{Número:24}

Ficha de coleta das unidades lexicais e/ou expressões durante a leitura - I Promessi Sposi - Cideb - 1999

Localização: UFPR/2008/2/DM/Italiano 4 Celin

\begin{tabular}{|c|c|c|}
\hline $\begin{array}{l}\text { Palavras que constam no } \\
\text { rodapé desnecessariamente }\end{array}$ & $\begin{array}{l}\text { Palavras que são necessárias, } \\
\text { mas não constam no rodapé }\end{array}$ & $\begin{array}{l}\text { Palavras que constam no rodapé } \\
\text { cuja explicação é insuficiente }\end{array}$ \\
\hline Afflitto & Accolsero & Rabbrividisce \\
\hline Anziano & Accolta & Raccolto \\
\hline Arroganza & Afferra & Volto \\
\hline Avvocato & Altrove & Zitti zitti \\
\hline Barba & Amarezza & \\
\hline Beneficenza & Ammala & \\
\hline Cadaveri & Aria & \\
\hline Calvo & Aria & \\
\hline Chirurgo & Bei & \\
\hline Collera & Ben & \\
\hline Compassione & Branchi & \\
\hline Contagiati & C'entra & \\
\hline Contessa & Casse & \\
\hline Dialetti & Colonna & \\
\hline Dote & Colpire & \\
\hline Feroce & Contadino & \\
\hline Governatore & Corsa & \\
\hline Impegnarsi & Curato & \\
\hline Implora & Curato & \\
\hline Incammina & Dette & \\
\hline Indizio & Dirupi & \\
\hline Infermi & Dunque & \\
\hline Infiammare & Duomo & \\
\hline Inganna il tempo & Farle coraggio & \\
\hline Irritarlo & Finché & \\
\hline Mantenimento & Fiorente & \\
\hline Marchese & Folla & \\
\hline Martellare & Giace & \\
\hline Mercante & Gocce rade & \\
\hline Monotono & Guai & \\
\hline Mormorio & Guance & \\
\hline Paglia & Guarisco & \\
\hline Pena & Guarita & \\
\hline Perseguitava & Inoltrata & \\
\hline Peste & Insegna & \\
\hline Polenta & Lancio & \\
\hline Precipizio & Legano & \\
\hline Predominio & Licenziati & \\
\hline
\end{tabular}




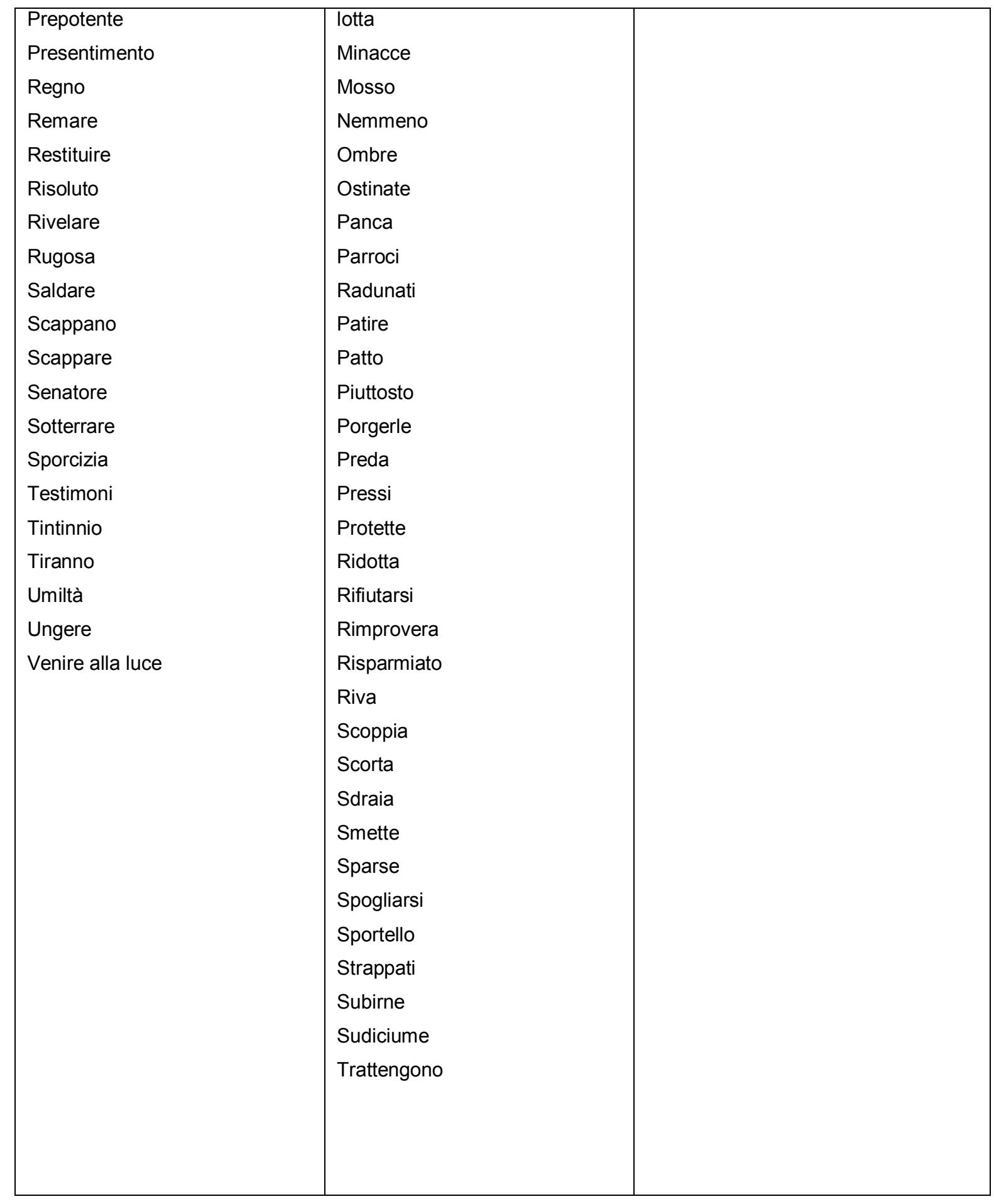




\section{Número:25}

Ficha de coleta das unidades lexicais e/ou expressões durante a leitura - I Promessi Sposi - Cideb - 1999

Localização: UFPR/2008/2/DJ/Italiano 4 Celin

\begin{tabular}{|c|c|c|}
\hline $\begin{array}{l}\text { Palavras que constam no } \\
\text { rodapé desnecessariamente }\end{array}$ & $\begin{array}{l}\text { Palavras que são necessárias, } \\
\text { mas não constam no rodapé }\end{array}$ & $\begin{array}{l}\text { Palavras que constam no rodapé } \\
\text { cuja explicação é insuficiente }\end{array}$ \\
\hline 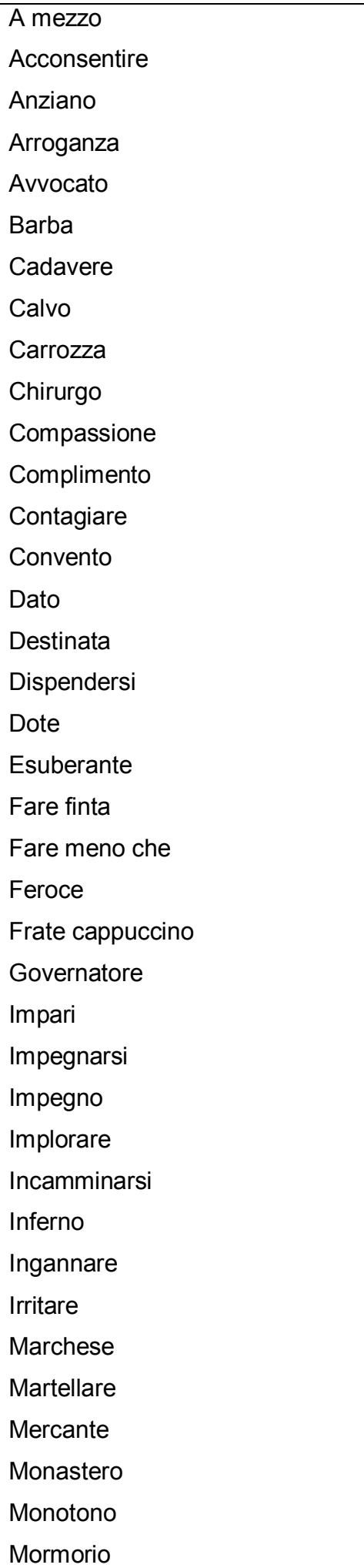 & $\begin{array}{l}\text { Bolliti } \\
\text { Cavolo } \\
\text { Chiostro } \\
\text { Circonvallazione } \\
\text { Dietologo } \\
\text { Figliolo } \\
\text { Giudizio } \\
\text { Gocce rade } \\
\text { Guai } \\
\text { Guarita } \\
\text { Inginocchia } \\
\text { Piselli } \\
\text { Prugne } \\
\text { Pugio } \\
\text { Ricoverari } \\
\text { Soddisfatto } \\
\text { Turbato }\end{array}$ & $\begin{array}{l}\text { Breviario } \\
\text { Calamaio } \\
\text { Chiasso } \\
\text { Erede } \\
\text { Grandinare } \\
\text { Imbroglio } \\
\text { Posate } \\
\text { Rabbrividire } \\
\text { Rannicchiata } \\
\text { Rapire } \\
\text { Rintocco } \\
\text { Sfiorita } \\
\text { Sorgenti } \\
\text { Sorgere } \\
\text { Stropiccio } \\
\text { Stufato } \\
\text { Svanire } \\
\text { Volto } \\
\text { Zimbello }\end{array}$ \\
\hline
\end{tabular}




\begin{tabular}{|l|l|l|}
\hline Nel frattempo & & \\
Nozze & & \\
Orgoglio & & \\
Paglia & & \\
Pena & & \\
Pena & & \\
Perseguitare & & \\
Peste & & \\
Precipizio & & \\
Prepotente & & \\
Presentimento & & \\
Primogenito & & \\
Remare & & \\
Restituire & & \\
Ribattere & & \\
Rimorso & \\
Risoluto & \\
Rivelare & \\
Rugosa & \\
Saldare & \\
Scappare & \\
Senza scrupoli & \\
Sotterrare & \\
Spuntare del giorno & \\
Sventurata & \\
Terrore & \\
Testimone & \\
Tiranno & \\
Umiltà & \\
Venire alla luce & \\
Vergogna & \\
\hline
\end{tabular}


Número:26

Ficha de coleta das unidades lexicais e/ou expressões durante a leitura - I Promessi Sposi - Cideb - 1999

Localização: UFPR/2008/2/MP/Italiano 4 celin

\begin{tabular}{|c|c|c|}
\hline $\begin{array}{l}\text { Palavras que constam no } \\
\text { rodapé desnecessariamente }\end{array}$ & $\begin{array}{l}\text { Palavras que são necessárias, } \\
\text { mas não constam no rodapé }\end{array}$ & $\begin{array}{l}\text { Palavras que constam no rodapé } \\
\text { cuja explicação é insuficiente }\end{array}$ \\
\hline $\begin{array}{l}\text { Arroganza } \\
\text { Barba } \\
\text { Cadavere } \\
\text { Calvo } \\
\text { Carrozza } \\
\text { Contessa } \\
\text { Convento } \\
\text { Dialetti } \\
\text { Feroce } \\
\text { Governatore } \\
\text { Irritare } \\
\text { Monastero } \\
\text { Monotono } \\
\text { Orgoglio } \\
\text { Pena } \\
\text { Peste } \\
\text { Polenta } \\
\text { Prepotente } \\
\text { Presentimento } \\
\text { Regno } \\
\text { Senatore } \\
\text { Umiltà }\end{array}$ & $\begin{array}{l}\text { Fiducioso } \\
\text { Mandano a monte } \\
\text { Minacce } \\
\text { Recarsi } \\
\text { Rimandare }\end{array}$ & $\begin{array}{l}\text { Addirittura } \\
\text { Alito } \\
\text { Niente meno che } \\
\text { Perfino } \\
\text { Posate } \\
\text { Raccolto } \\
\text { Rannicchiata } \\
\text { Restituire } \\
\text { Rintocco } \\
\text { Spargersi } \\
\text { Svanire } \\
\text { Volto }\end{array}$ \\
\hline
\end{tabular}




\section{Número:27}

Ficha de coleta das unidades lexicais e/ou expressões durante a leitura - I Promessi Sposi - Cideb - 1999

Localização: UFPR/2008/2/GD/Basico II

\begin{tabular}{|c|c|c|}
\hline $\begin{array}{l}\text { Palavras que constam no rodapé } \\
\text { desnecessariamente }\end{array}$ & $\begin{array}{l}\text { Palavras que são necessárias, mas } \\
\text { não constam no rodapé }\end{array}$ & $\begin{array}{l}\text { Palavras que constam no rodapé } \\
\text { cuja explicação é insuficiente }\end{array}$ \\
\hline A buon mercato & Accorre & Cappone \\
\hline Acconsentire & Addosso & Il paese della cuccagna \\
\hline Acconsentire & Altrimenti & Pendio \\
\hline Afflitto & Altrove & Posate \\
\hline Anziano & Appoggiato & Protetta \\
\hline Avvocato & Aria & Raccolto \\
\hline Barba & Cenno & Sarto \\
\hline Cadavere & Colpisce & Sorge \\
\hline Calvo & Contadino & Spia \\
\hline Capanna & Cui & Vita \\
\hline Carestia & Curato & Volto \\
\hline Carrozza & Deluso & \\
\hline Chirurgo & Domattina & \\
\hline Collera & Entrambi & \\
\hline Compassione & Erede & \\
\hline Contagiare & Filatoio & \\
\hline Convento & Finché & \\
\hline Dato & Folla & \\
\hline Dote & Frattempo & \\
\hline Fare voto & Guarisco & \\
\hline Feroce & Guarita & \\
\hline Impegnarsi & Impaurito & \\
\hline Implorare & Inchino & \\
\hline Incamminarsi & Infatti & \\
\hline Inferno & Lancio & \\
\hline Irritare & Mento & \\
\hline Lepre & Mosso & \\
\hline Marchese & Osteria & \\
\hline Martellare & Riesca & \\
\hline Monastero & Scorta & \\
\hline Monotono & Spinge & \\
\hline Nozze & Tradimento & \\
\hline Orto & Tramonto & \\
\hline Paglia & Turbato & \\
\hline Pena & & \\
\hline Pena & & \\
\hline Peste & & \\
\hline Precipizio & & \\
\hline
\end{tabular}




\begin{tabular}{|l|l|l|}
\hline Presentimento & & \\
Remare & & \\
Restituire & & \\
Rivelare & & \\
Rugosa & & \\
Saldare & & \\
Scappare & & \\
Sotterrare & & \\
Spuntare del giorno & & \\
Tabernacolo & & \\
Testimone & & \\
Tiranno & & \\
Umiltà & & \\
Urlare & & \\
Vigna & & \\
\hline
\end{tabular}




\section{Número:28}

Ficha de coleta das unidades lexicais e/ou expressões durante a leitura - I Promessi Sposi - Cideb - 1999 Localização: UFPR/2008/2/ISD/Basico II

\begin{tabular}{|c|c|c|}
\hline $\begin{array}{l}\text { Palavras que constam no rodapé } \\
\text { desnecessariamente }\end{array}$ & $\begin{array}{l}\text { Palavras que são necessárias, mas } \\
\text { não constam no rodapé }\end{array}$ & $\begin{array}{l}\text { Palavras que constam no rodapé } \\
\text { cuja explicação é insuficiente }\end{array}$ \\
\hline 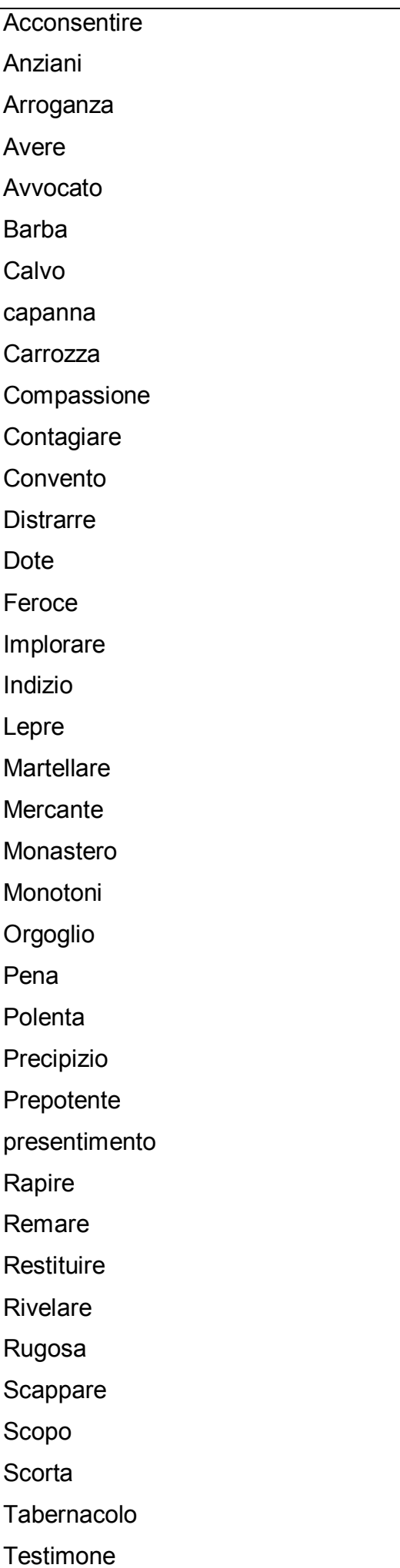 & $\begin{array}{l}\text { Accorgere } \\
\text { Accori } \\
\text { Altrove } \\
\text { Colpito } \\
\text { Dirupi } \\
\text { Entrambi } \\
\text { Filatore di seta } \\
\text { Finché } \\
\text { Folla } \\
\text { Gioia } \\
\text { Gocce } \\
\text { Guarire } \\
\text { Guarita } \\
\text { Matti } \\
\text { Mosso } \\
\text { Osteria } \\
\text { Patto } \\
\text { Quaggiù } \\
\text { Rade } \\
\text { Spingere } \\
\text { Strappati } \\
\text { Tramontato }\end{array}$ & $\begin{array}{l}\text { Rannicchiata } \\
\text { Sorge } \\
\text { Svanire } \\
\text { Volto }\end{array}$ \\
\hline
\end{tabular}


Tiranno 


\section{Número:29}

Ficha de coleta das unidades lexicais e/ou expressões durante a leitura - I Promessi Sposi - Cideb - 1999

Localização: UFPR/2008/2/NC2/Basico II

\begin{tabular}{|c|c|c|}
\hline $\begin{array}{l}\text { Palavras que constam no } \\
\text { rodapé desnecessariamente }\end{array}$ & $\begin{array}{l}\text { Palavras que são necessárias, } \\
\text { mas não constam no rodapé }\end{array}$ & $\begin{array}{l}\text { Palavras que constam no rodapé } \\
\text { cuja explicação é insuficiente }\end{array}$ \\
\hline 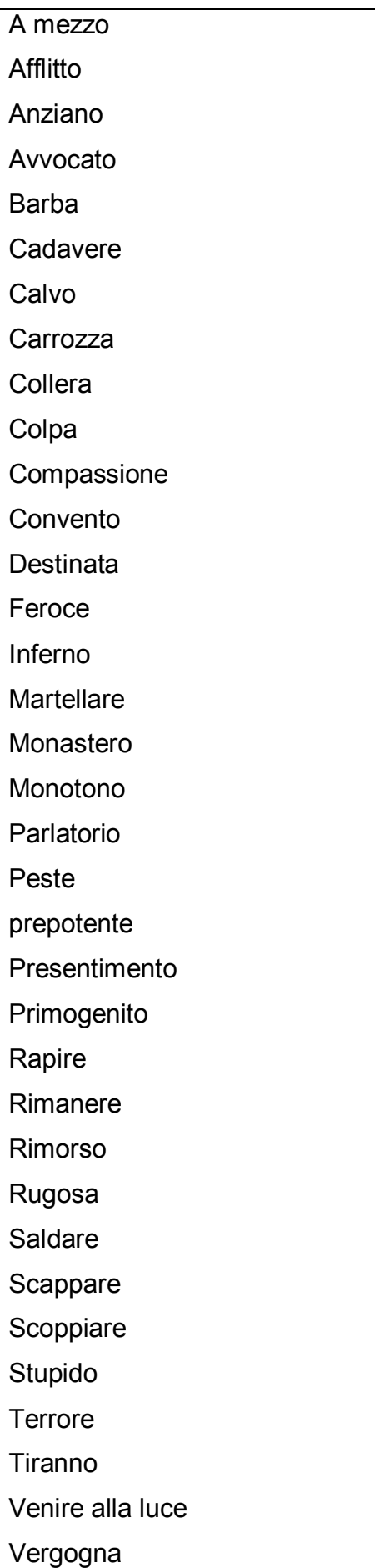 & $\begin{array}{l}\text { Accaduto } \\
\text { Addosso } \\
\text { Appaiono } \\
\text { Campanaro } \\
\text { Corsa } \\
\text { Gocce } \\
\text { Gradita } \\
\text { Guai } \\
\text { Guance } \\
\text { Mento } \\
\text { Mestiere } \\
\text { Minacce } \\
\text { Nemmeno } \\
\text { Popolani } \\
\text { Pregio } \\
\text { Quaggiù } \\
\text { Quindi } \\
\text { Sdraia } \\
\text { Specchia }\end{array}$ & $\begin{array}{l}\text { Azzeccagarbugli } \\
\text { Birbone } \\
\text { Calamaio } \\
\text { Filande } \\
\text { Grandinare } \\
\text { Madre badessa } \\
\text { Palo } \\
\text { Panca } \\
\text { Posate } \\
\text { Rabbrividire } \\
\text { Raccolto } \\
\text { Rannicchiata } \\
\text { Riscuotere } \\
\text { Sagrestano } \\
\text { Sarto } \\
\text { Scommettere } \\
\text { Sipario } \\
\text { Sorgente } \\
\text { Sorgere } \\
\text { Tintinnio }\end{array}$ \\
\hline
\end{tabular}




\section{Número:30}

Ficha de coleta das unidades lexicais e/ou expressões durante a leitura - I Promessi Sposi - Cideb - 1999

Localização: UFPR/2008/2/AS/Italiano 4 celin

\begin{tabular}{|c|c|c|}
\hline $\begin{array}{l}\text { Palavras que constam no } \\
\text { rodapé desnecessariamente }\end{array}$ & $\begin{array}{l}\text { Palavras que são necessárias, } \\
\text { mas não constam no rodapé }\end{array}$ & $\begin{array}{l}\text { Palavras que constam no rodapé } \\
\text { cuja explicação é insuficiente }\end{array}$ \\
\hline A buon mercato & Accorsero & Accolto \\
\hline Anziano & Colpito & Acconsentire \\
\hline Arroganza & Congratulazione & Bubbone \\
\hline Asilo & Costretto & Chiasso \\
\hline Avvocato & Diffidente & Collera \\
\hline Bambola & Dirupi & Erede \\
\hline Barba & Fatemi & Filanda \\
\hline Cadavere & Gradita & Frate cappuccino \\
\hline Calvo & Guarisco & Grandinare \\
\hline Carrozza & Impaurito & Livido \\
\hline Complimento & Infatti & Maledizione \\
\hline Contagiare & Lazzaretto & Minacciare \\
\hline Destinata & Mendicante & Orgoglio \\
\hline Dialetti & Minacce & Paggio \\
\hline Esuberante & Monatti & Palo \\
\hline Feroce & Nascosto & Raggrinzarsi \\
\hline Governatore & Nobiluomo & Rannicchiata \\
\hline Impegno & Preghiera & Rapire \\
\hline Implorare & Rimproverava & Regno \\
\hline Ingannare & Salgono & Restituire \\
\hline Monotono & Scomposta & Scenata \\
\hline Nozze & Scoppia & Scommettere \\
\hline Ospizio & Scrupoli & Scudo \\
\hline Pena & Sdraia & Sfiorita \\
\hline Pena & Spinge & Spargersi \\
\hline Polenta & Stabilirono & Tintinnio \\
\hline Polso & Svilupparono & Volto \\
\hline Precipizio & Ubriaco & \\
\hline Predominio & Urla & \\
\hline Prepotente & & \\
\hline Presentimento & & \\
\hline Remare & & \\
\hline Rivelare & & \\
\hline Rugosa & & \\
\hline Scappare & & \\
\hline Senatore & & \\
\hline Soffocare il grido in gola & & \\
\hline Terrore & & \\
\hline
\end{tabular}


Testimone

Umiltà

Vergogna 


\section{Número:31}

Ficha de coleta das unidades lexicais e/ou expressões durante a leitura - I Promessi Sposi - Cideb - 1999

Localização: UFPR/2008/2/GP/Italiano 4 Celin

\begin{tabular}{|c|c|c|}
\hline $\begin{array}{l}\text { Palavras que constam no } \\
\text { rodapé desnecessariamente }\end{array}$ & $\begin{array}{l}\text { Palavras que são necessárias, } \\
\text { mas não constam no rodapé }\end{array}$ & $\begin{array}{l}\text { Palavras que constam no rodapé } \\
\text { cuja explicação é insuficiente }\end{array}$ \\
\hline Acconsente & Afferra & Alito \\
\hline Afflitti & Altrove & Raccolto \\
\hline Anziani & Aria & Rannicchiata \\
\hline Arroganza & Bravi & Svanisce \\
\hline Averi & Buio & \\
\hline $\mathrm{Ba}$ & Carichi & \\
\hline Beneficenza & Colpito & \\
\hline Bussare & Corsa & \\
\hline Cadaveri & Cortile & \\
\hline Capanna & Deluso & \\
\hline Chirurgo & Dibattuto & \\
\hline Compassione & Dirupi & \\
\hline Contagiati & Entrambi & \\
\hline Contessa & Filatoio & \\
\hline Convento & Fitte & \\
\hline Dati & Gettano & \\
\hline Dialetti & Giace & \\
\hline Distraendola & Guai & \\
\hline Dote & Guance & \\
\hline Esuberante & Incarico & \\
\hline Feroce & Lazzaretto & \\
\hline Governatore & Liscio & \\
\hline Implora & Mento & \\
\hline Incammina & Minacce & \\
\hline Indicibile & Nascosto & \\
\hline Infermi & Patto & \\
\hline Ingannò & Piuttosto & \\
\hline Invano & Quaggiù & \\
\hline Irritarlo & Radunati & \\
\hline La pace sia con voi & Rifiutarsi & \\
\hline Lepre & Risparmiato & \\
\hline Marchese & Sdraia & \\
\hline Mercante & Sottrarsi & \\
\hline Miglia & Spinge & \\
\hline Monastero & Ubriaco & \\
\hline Monotoni & & \\
\hline Mortificato & & \\
\hline Nozze & & \\
\hline
\end{tabular}




\begin{tabular}{|l|l|l|}
\hline Orto & & \\
Paglia & & \\
Perseguitava & & \\
Polsi & & \\
Precipizi & & \\
Prepotente & & \\
Presentimento & & \\
Prete & & \\
Regno & & \\
Remare & & \\
Restituire & & \\
Rimorso & & \\
Rivela & & \\
Saldare & & \\
Scappano & & \\
Scappare & & \\
Senza scrupoli & & \\
Sorge & & \\
Testimoni & & \\
Tiranno & & \\
Turbato & \\
Umiltà & \\
Vedova & & \\
Vergogna & & \\
Volto & & \\
\hline
\end{tabular}




\section{Número:32}

Ficha de coleta das unidades lexicais e/ou expressões durante a leitura - I Promessi Sposi - Cideb - 2007

Localização: UFPR/2009/2/ACP/Instrumental II

\begin{tabular}{|c|c|c|}
\hline $\begin{array}{l}\text { Palavras que constam no } \\
\text { rodapé desnecessariamente }\end{array}$ & $\begin{array}{l}\text { Palavras que são necessárias, } \\
\text { mas não constam no rodapé }\end{array}$ & $\begin{array}{l}\text { Palavras que constam no rodapé } \\
\text { cuja explicação é insuficiente }\end{array}$ \\
\hline Acconsentire & Accade & Alito \\
\hline Cadavere & Addirittura & Barba \\
\hline Calvo & Afferra & Brache \\
\hline Carestia & Altrimenti & Calamaio \\
\hline Carrozeza & Ammazzare & Disperdersi \\
\hline Compassione & Ammessa & Fare laspia \\
\hline Contagiare & Anatra & Forca \\
\hline Destinata & Arriciati & Grandinare \\
\hline Dialetti & Ativaloni & Ingannare il tempo \\
\hline Dote & Attegiamenti & Mettere giudizio \\
\hline Esuberante & Attesa & Monsignore Illustrissimo \\
\hline Governatore & Attibata & Niente meno che \\
\hline Iluminismo & Brutto & Palo \\
\hline Implorare & Campagna & Rabbrividire \\
\hline Incolto & Capolavoro & Raccolto \\
\hline Infermo & Cascine & Rannichiata \\
\hline Ingannare & Contadini-setaioli & Restituire \\
\hline Irritare & Cortile & Riscuotere dei soldi \\
\hline Lepre & Cugino & Riversarsi \\
\hline Maledizione & Di Corsa & Scenata \\
\hline Martelare & Ebbene & Sorgere \\
\hline Monastero & Ebbero & Stropiccio \\
\hline Monótono & Edilizio & Stufato \\
\hline Perseguitare & Eppure & Svanire \\
\hline Peste & Fazzoleto & Trina \\
\hline Precipizio & Fianchi & Volto \\
\hline Predomínio & Fiduciosa & \\
\hline Prepotente & Fiocchi & \\
\hline Presentimento & Fronzoli & \\
\hline Rimorso & Giace & \\
\hline Romanticismo & Giubba & \\
\hline Rugosa & Gorgiera & \\
\hline Saldare & Guadagnare & \\
\hline Senatore & Guantoni & \\
\hline Testimone & Guarisco & \\
\hline Tiranno & Guarita & \\
\hline Titoli Nobiliarsi & Lazzareto & \\
\hline Tumulto & Liscio & \\
\hline
\end{tabular}




\begin{tabular}{|c|c|}
\hline $\begin{array}{l}\text { Umiltá } \\
\text { Vergogna }\end{array}$ & $\begin{array}{l}\text { Maiale } \\
\text { Manzo } \\
\text { Merletto } \\
\text { Minacce } \\
\text { Mosso } \\
\text { Nascondendosi } \\
\text { Nemmeno } \\
\text { Pascolo } \\
\text { Pollo } \\
\text { Presso } \\
\text { Riacquistarla } \\
\text { Ridotta } \\
\text { Riso } \\
\text { Risparmiati } \\
\text { Riva } \\
\text { Ruolo } \\
\text { Salgono } \\
\text { Scarso } \\
\text { Sdraia } \\
\text { Sottomessa } \\
\text { Spinge } \\
\text { Spotiamoci } \\
\text { Svolsero } \\
\text { Tramontano } \\
\text { Trascinano } \\
\text { Vicende }\end{array}$ \\
\hline
\end{tabular}




\section{Número:33}

Ficha de coleta das unidades lexicais e/ou expressões durante a leitura - I Promessi Sposi - Cideb - 1999

Localização: UFPR/2008/2/GP/Italiano 4 Celin

\begin{tabular}{|c|c|c|}
\hline $\begin{array}{l}\text { Palavras que constam no } \\
\text { rodapé desnecessariamente }\end{array}$ & $\begin{array}{l}\text { Palavras que são necessárias, } \\
\text { mas não constam no rodapé }\end{array}$ & $\begin{array}{l}\text { Palavras que constam no rodapé } \\
\text { cuja explicação é insuficiente }\end{array}$ \\
\hline A mezzo & Ammazzare & Bambola \\
\hline Acconsentire & Attratto & Calamaio \\
\hline Affiorare & Cascine & Contendersi \\
\hline Afflito & Cattura & Pendio \\
\hline Anziano & Colpito & Rabbrividire \\
\hline Arroganza & Contadina & Racolto \\
\hline Asilo & Diabatutto & Riscuotere dei soldi \\
\hline Avere & Filatoio & Sorgere \\
\hline Avvocato & Folla & Svanire \\
\hline Barba & Gettano & \\
\hline Barraca & Giace liscio & \\
\hline Breviario & Guadagno & \\
\hline Carestia & Inoltrata & \\
\hline Carrozza & Lecco & \\
\hline Chirurgo & Minace & \\
\hline Colera & Monatti & \\
\hline Colpa & Muro & \\
\hline Compassione & ondeggiare & \\
\hline Contagiare & Osterie & \\
\hline Convento & Portatemi da Ferrer & \\
\hline Destinata & Pressi & \\
\hline Di quando in quando & Radunati & \\
\hline Dialetti & Ridota & \\
\hline Dispendersi & Salotto & \\
\hline Esuberante & Scorta & \\
\hline Fare finta & Sottrarsi & \\
\hline Fare la spia & Spinge & \\
\hline Fare voto & Spogliarsi & \\
\hline Feroce & Spostiamoci & \\
\hline Fiato & Svilupparono & \\
\hline Frate Capuccino & Trascinano & \\
\hline Governatore & Vendetta & \\
\hline Impari & & \\
\hline Impegnarsi & & \\
\hline Implorare & & \\
\hline Incamminarsi & & \\
\hline Indicio & & \\
\hline Infermo & & \\
\hline
\end{tabular}




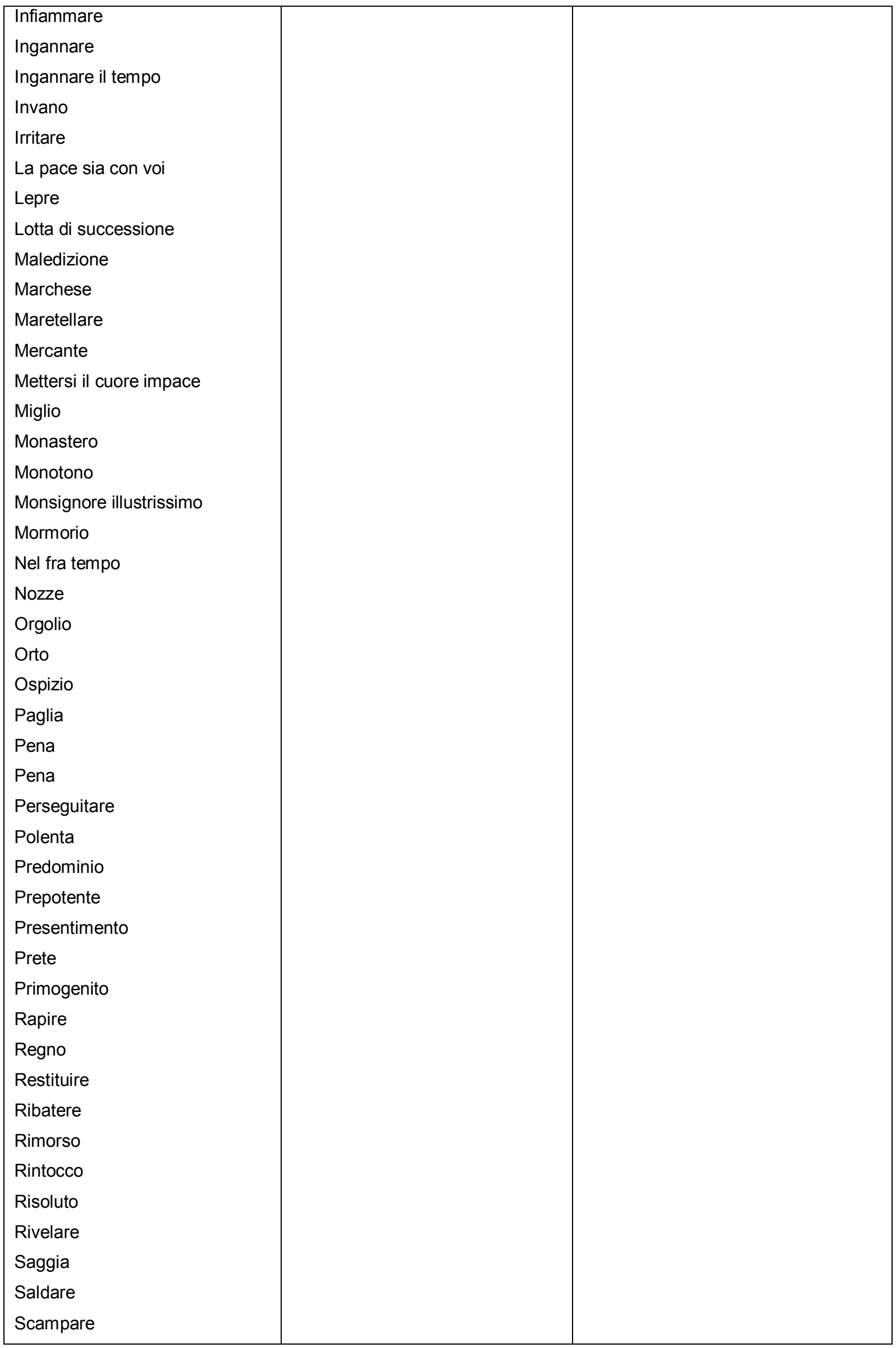




\begin{tabular}{|l|l|l|}
\hline Scappare & & \\
Scorta & & \\
Senatore & & \\
Senza scrupoli & & \\
Soffocare il gridoingola & & \\
Soterrare & & \\
Sporcizia & & \\
Spuntare del giorno & & \\
Terrore & & \\
Testimone & & \\
Tirano & & \\
Titoli nobiliari & & \\
Turbato & & \\
Umiltà & & \\
Ungere & & \\
Urlare & & \\
Vedova & & \\
Venire alla luce & & \\
Vergogna & & \\
Vigna & & \\
Volto & & \\
Zitti zitti & \\
\hline
\end{tabular}




\section{Número:34}

Ficha de coleta das unidades lexicais e/ou expressões durante a leitura - I Promessi Sposi - Cideb - 1999

Localização: UFPR/2008/2/BPL/Instrumental II

\begin{tabular}{|c|c|c|}
\hline $\begin{array}{l}\text { Palavras que constam no rodapé } \\
\text { desnecessariamente }\end{array}$ & $\begin{array}{l}\text { Palavras que são necessárias, } \\
\text { mas não constam no rodapé }\end{array}$ & $\begin{array}{l}\text { Palavras que constam no rodapé } \\
\text { cuja explicação é insuficiente }\end{array}$ \\
\hline Avvocato & Abbia & Affacendata \\
\hline Beneficenza & Abbigliamento & Alito \\
\hline Cadaveri & Adosso & Grandinare \\
\hline Calvo & Affacaccia & Infiamma \\
\hline Carrozza & Afferra & Pali \\
\hline Contagiati & Agnello & Panca \\
\hline Dialetti & Aiuterà & Posate \\
\hline Disperdersi & Alzatevi & Predica \\
\hline Governatore & Ammassati & Sorgenti \\
\hline Illuministe & Anatra & Spregiudicati \\
\hline Implora & Andrò & Svanisce \\
\hline Incolto & Aria & Zimbello \\
\hline Indizio & Attillata & \\
\hline Infermi & Attimo & \\
\hline Irritarlo & Avvia & \\
\hline La pace sia con voi & Bambole & \\
\hline Maledizione & Bicchiere & \\
\hline Martellare & Bisogna & \\
\hline Monotoni & Bocche & \\
\hline Mosche & Botteghe & \\
\hline Nobiliari & Branco & \\
\hline Ospizi & Broso & \\
\hline Ozio & Buio & \\
\hline Peste & Capolavoro & \\
\hline Polsi & Cappone & \\
\hline Precipizi & Cattura & \\
\hline Predominio & Cavolo & \\
\hline Presentimento & Chiude & \\
\hline Restituire & Chiuse & \\
\hline Romanticismo & Colpito & \\
\hline Scampata & Convinto erede & \\
\hline Senatore & Corsa & \\
\hline Spia & Cugino & \\
\hline Spuntare del giorno & Curato & \\
\hline Testimoni & Darci & \\
\hline Tiranno & Davvero & \\
\hline Tumulto & Dintorni & \\
\hline Umiltà & Domanda & \\
\hline
\end{tabular}




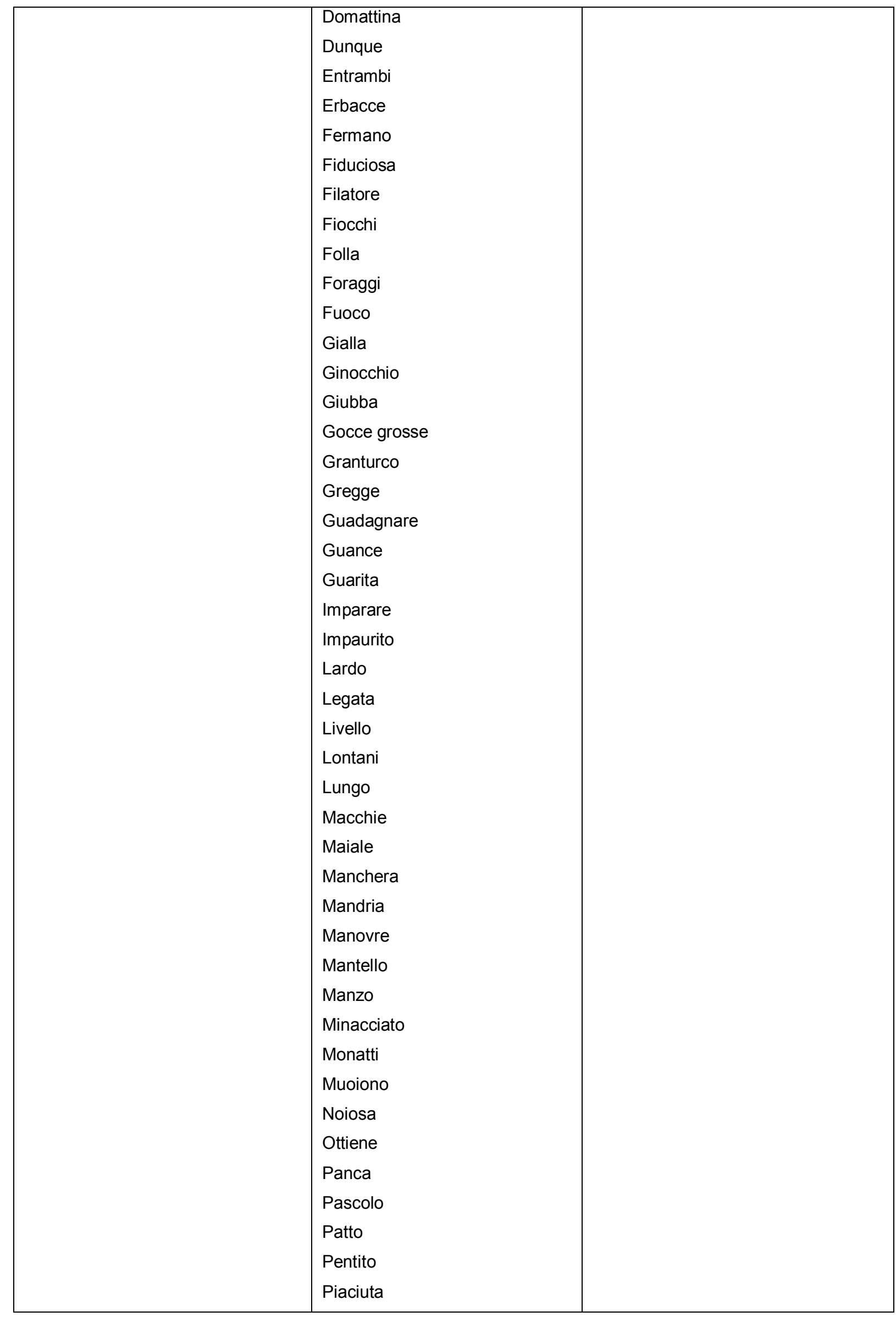




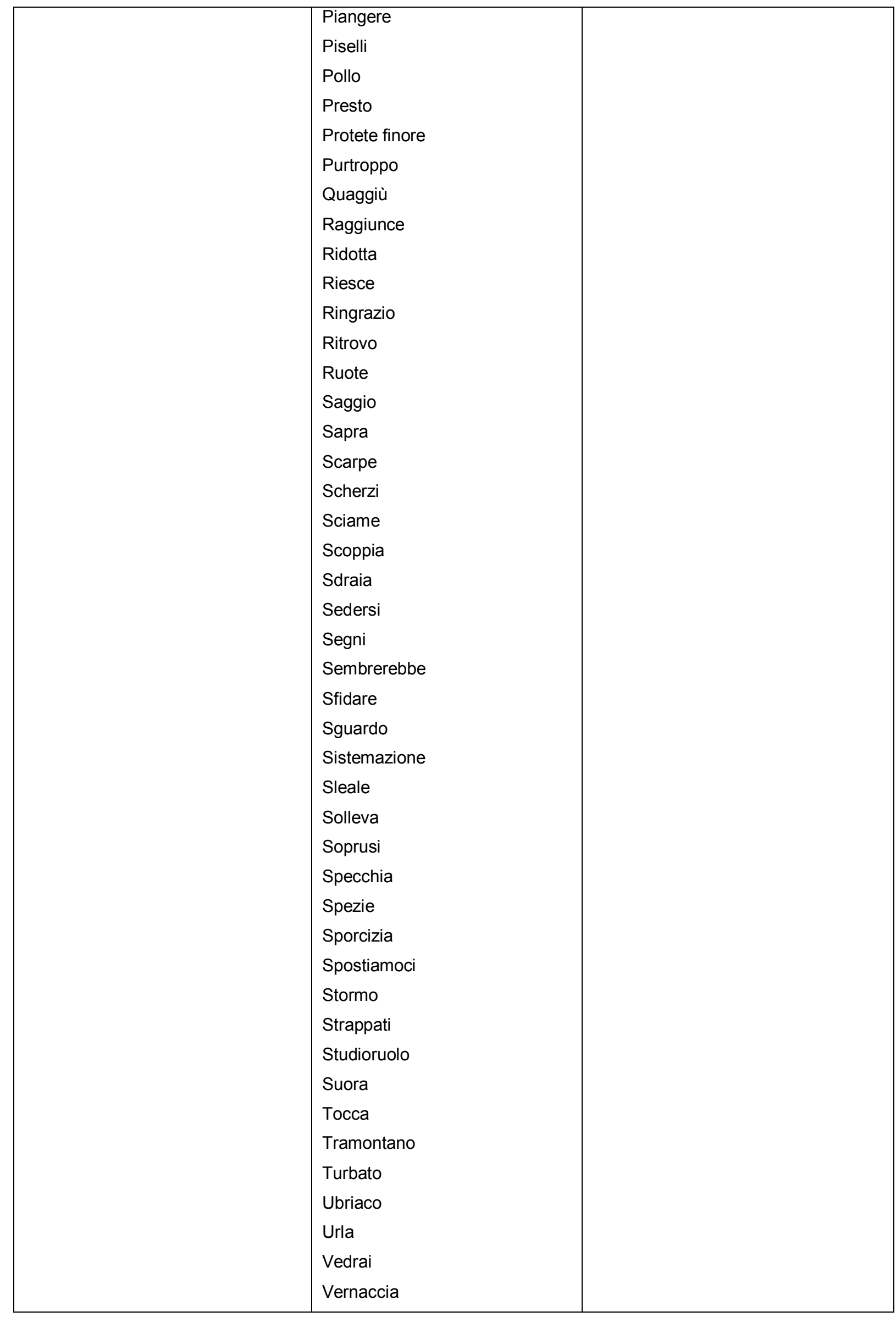




\begin{tabular}{|l|l|l|}
\hline & Vicende & \\
& Vince & \\
Vorrei & \\
\hline
\end{tabular}




\section{Número:35}

Ficha de coleta das unidades lexicais e/ou expressões durante a leitura - I Promessi Sposi - Cideb - 2007

Localização: UFPR/2009/1/RP/Instrumental II

\begin{tabular}{|c|c|c|}
\hline $\begin{array}{l}\text { Palavras que constam no rodapé } \\
\text { desnecessariamente }\end{array}$ & $\begin{array}{l}\text { Palavras que são necessárias, } \\
\text { mas não constam no rodapé }\end{array}$ & $\begin{array}{l}\text { Palavras que constam no rodapé } \\
\text { cuja explicação é insuficiente }\end{array}$ \\
\hline Afflitti & Abassa & Alito \\
\hline Asilo & Abbrelli & Branche \\
\hline Barba & Accade & Calamaio \\
\hline Beneficenza & Afferra & Destinatta \\
\hline Cadavere & Alza & Disperdersi \\
\hline Calvo & Annoiato & Forca \\
\hline Carrozza & Anzi & Inchino \\
\hline Chirurgo & Aria & Lepre \\
\hline Compassione & Ascoltato & Pali \\
\hline Contagiare & Atteggiamento & Posate \\
\hline Distraendola & Attillata & Raccolto \\
\hline Dote & Balbettare & Raggrinzarsi \\
\hline Esuberante & Banche & Rincarare \\
\hline Frate cappuccino & Basso & Rintocco \\
\hline Illuminismo & Bastoni & Riscuotere dei soldi \\
\hline Implorare & Beretti & . \\
\hline Indizio & Bicchiere & Scenata \\
\hline Infermo & Bocche & Sorgenti \\
\hline Ingannò & Buio & Stare alla larga \\
\hline Irritare & Butta la tovaglia addosso & Svanisce \\
\hline La pace sia con voi & Capo & Treccia \\
\hline Maledizione & Carico & Trina \\
\hline Marchese & Cattura & Volto \\
\hline Monastero & Cenno & \\
\hline Monotoni & Cime & \\
\hline Mormorio & Corsa & \\
\hline Pena & Costretto & \\
\hline Perseguitare & Cupa & \\
\hline Precipizio & Curato & \\
\hline Predominio & Darci & \\
\hline Presentimento & Diffidente & \\
\hline Primogenito & Diventa & \\
\hline Ribattere & Edilizio & \\
\hline Risoluto & Fazzoletto & \\
\hline Romanticismo & Finché & \\
\hline Rugosa & Fiocchi & \\
\hline Saldare & Fissano & \\
\hline Senza scrupoli & Folla & \\
\hline
\end{tabular}




\begin{tabular}{|c|c|}
\hline $\begin{array}{l}\text { Sorgere } \\
\text { Testimone } \\
\text { Tiranno } \\
\text { Tumulto } \\
\text { Umiltà } \\
\text { Vergogna }\end{array}$ & $\begin{array}{l}\text { Foraggi } \\
\text { Forniti } \\
\text { Ginocchio } \\
\text { Gioielli } \\
\text { Gocce } \\
\text { Guance } \\
\text { Lancio } \\
\text { Liscia } \\
\text { Lontana } \\
\text { Mancherà } \\
\text { Manovre } \\
\text { Matti } \\
\text { Minacce } \\
\text { Mosso } \\
\text { Nascosto } \\
\text { Neanche } \\
\text { Neppure } \\
\text { Oserà } \\
\text { Ostinate } \\
\text { Parroci } \\
\text { Pentito } \\
\text { Piaciuta } \\
\text { Piumato } \\
\text { Piuttosto } \\
\text { Polsi } \\
\text { Potrebbe } \\
\text { Presso } \\
\text { Purtroppo } \\
\text { Quaggiù } \\
\text { Ravvicinano } \\
\text { Ridotta } \\
\text { Rimasti } \\
\text { Ringraziare } \\
\text { Riposo } \\
\text { Rossa } \\
\text { Saggi } \\
\text { Saprà } \\
\text { Saranno } \\
\text { Sbagliato } \\
\text { Scorta } \\
\text { Sdraia } \\
\text { Sottomessa } \\
\text { Spaventosa } \\
\text { Spinge }\end{array}$ \\
\hline
\end{tabular}




\begin{tabular}{|l|l|l|}
\hline & Strappati & \\
Suora & Sviluppati & \\
& Tale & \\
Troverete & \\
& Turbato & \\
& Ucciso & \\
& Vicende & \\
\hline
\end{tabular}




\section{Número:36}

Ficha de coleta das unidades lexicais e/ou expressões durante a leitura - I Promessi Sposi - Cideb - 1999

Localização: UFPR/2008/2/WR/Instrumental II

\begin{tabular}{|c|c|c|}
\hline $\begin{array}{l}\text { Palavras que constam no } \\
\text { rodapé desnecessariamente }\end{array}$ & $\begin{array}{l}\text { Palavras que são necessárias, } \\
\text { mas não constam no rodapé }\end{array}$ & $\begin{array}{l}\text { Palavras que constam no rodapé } \\
\text { cuja explicação é insuficiente }\end{array}$ \\
\hline Afflitto & Accaduto & Alito \\
\hline Avvocato & Addoso & Branco \\
\hline Calvo & Aggiunge & Calamaio \\
\hline Compassione & Alzatevi & Grandinare \\
\hline Contagiare & Apogliate & Inchino \\
\hline Distrarre & Augurata & Inchino \\
\hline Dote & Cibo & Niente meno che \\
\hline Feroce & Dirupi & Posate \\
\hline Governatore & Diventato & Rabrividire \\
\hline Imbroglio & Eppure & Rintocco \\
\hline Impegnarsi & Fazzoletto & Sarto \\
\hline Implorare & Filatoio & Scommettere \\
\hline Incamminarsi & Gocce & Sorgenti \\
\hline Indizio & Guai & Sorgere \\
\hline Infermo & Guarire & Svanire \\
\hline Ingannare il tempo & Lasci & Tintinnio \\
\hline Irritare & Manacce & Treccia \\
\hline Maledizione & Nascosto & Volto \\
\hline Martellare & Occhiali & \\
\hline Monastero & Parroci & \\
\hline Monotono & Quaggiù & \\
\hline Orto & Radunati & \\
\hline Ospizio & Sbalorditta & \\
\hline Ozio & Spargerà & \\
\hline Pena & Sportello & \\
\hline Polenta & Stringere & \\
\hline Precipizio & Sudiciume & \\
\hline Prepotente & Sveglia & \\
\hline Presentimento & Trattengono & \\
\hline Rapire & Turbato & \\
\hline Remare & & \\
\hline Restituire & & \\
\hline Risoluto & & \\
\hline Rivelare & & \\
\hline Rugosa & & \\
\hline Saldare & & \\
\hline Scappare & & \\
\hline Sotterrare & & \\
\hline
\end{tabular}


Testimone

Tiranno

Umiltà 


\section{Número:37}

Ficha de coleta das unidades lexicais e/ou expressões durante a leitura - I Promessi Sposi - Cideb - 2007

Localização: UFPR/2008/2/NV/Italiano 4 Celin

\begin{tabular}{|c|c|c|}
\hline $\begin{array}{l}\text { Palavras que constam no } \\
\text { rodapé desnecessariamente }\end{array}$ & $\begin{array}{l}\text { Palavras que são necessárias, } \\
\text { mas não constam no rodapé }\end{array}$ & $\begin{array}{l}\text { Palavras que constam no rodapé } \\
\text { cuja explicação é insuficiente }\end{array}$ \\
\hline 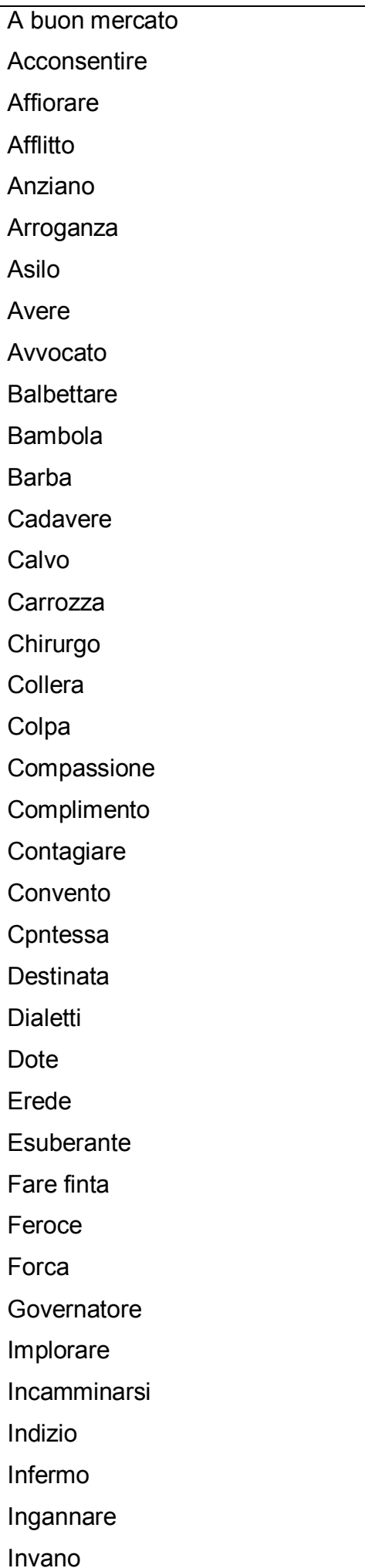 & $\begin{array}{l}\text { Aria } \\
\text { Cancelli } \\
\text { filatoio } \\
\text { Giace } \\
\text { Guadagno } \\
\text { Pascolo } \\
\text { Quaggiù } \\
\text { Scomposta } \\
\text { Scoppia } \\
\text { Sottrarsi } \\
\text { Spinge } \\
\text { Sportello } \\
\text { Spostiamoci }\end{array}$ & $\begin{array}{l}\text { Azzeccagarbugli } \\
\text { Calamaio } \\
\text { Lanzichenecchi } \\
\text { Niente meno che } \\
\text { Rabbrividire } \\
\text { Rannicchiata } \\
\text { Spargersi } \\
\text { Svanire }\end{array}$ \\
\hline
\end{tabular}




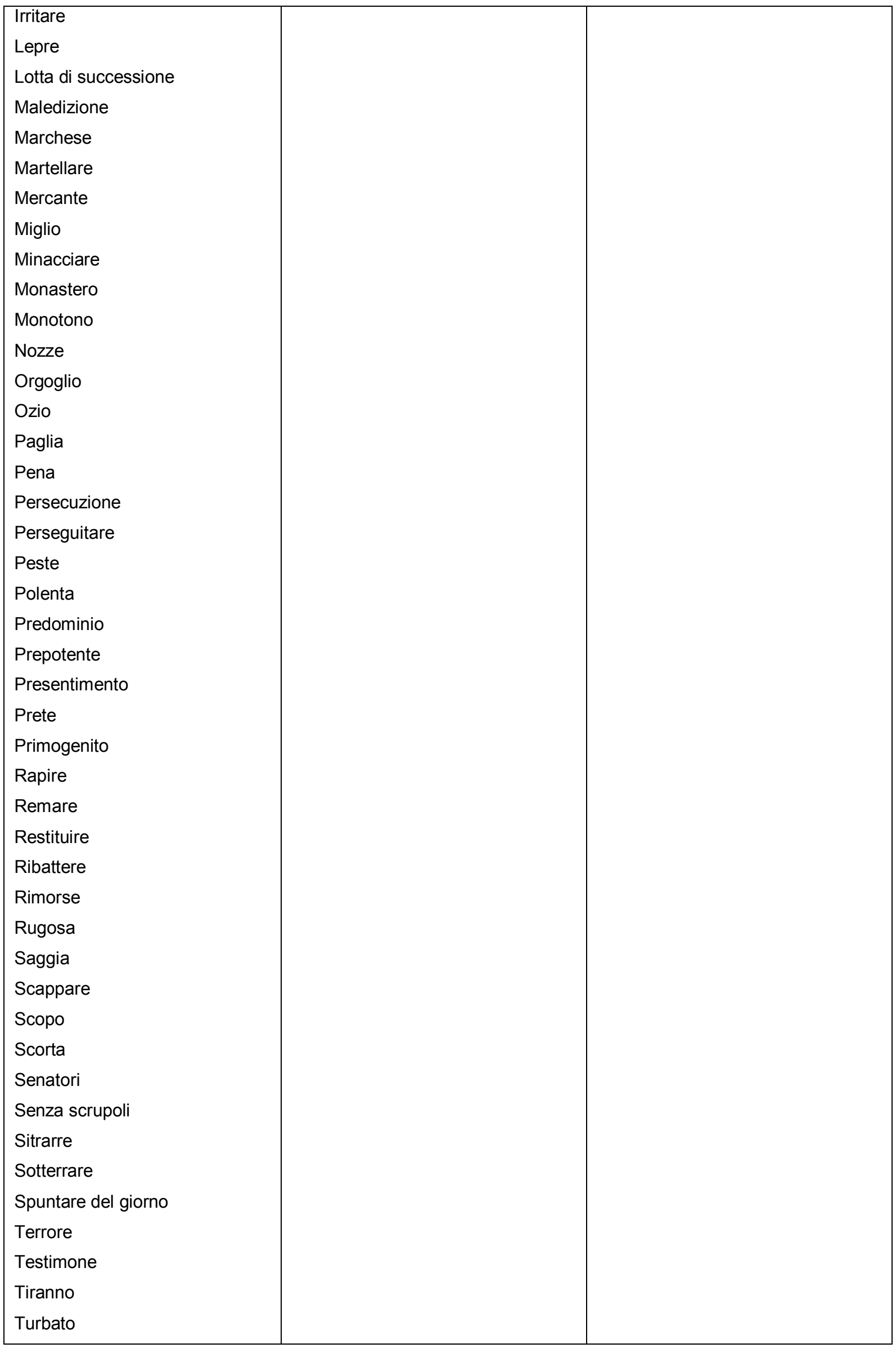




\begin{tabular}{|l|l|l|}
\hline Umiltà & & \\
Urlare & & \\
Vedova & & \\
Vergogna & & \\
Vigna & & \\
\hline
\end{tabular}




\section{Número:38}

Ficha de coleta das unidades lexicais e/ou expressões durante a leitura - I Promessi Sposi - Cideb - 2007

Localização: UFPR/2009/1/NC3/Instrumental II

\begin{tabular}{|c|c|c|}
\hline $\begin{array}{l}\text { Palavras que constam no } \\
\text { rodapé desnecessariamente }\end{array}$ & $\begin{array}{l}\text { Palavras que são necessárias, } \\
\text { mas não constam no rodapé }\end{array}$ & $\begin{array}{l}\text { Palavras que constam no rodapé } \\
\text { cuja explicação é insuficiente }\end{array}$ \\
\hline Afflitti & Adosso & Disperdersi \\
\hline Avvocato & Amarezza & Eredi \\
\hline Barba & Andarsene & Fare la spia \\
\hline Cadaveri & Apposta & Filanda \\
\hline Collera & Beretti & Galli \\
\hline Contagiati & Bollita & Governatore \\
\hline Destinata & Casetta & Ospizio \\
\hline Feroci & Chi piu chi meno & Rabbrividire \\
\hline Implora & Colletti & Riversarsi \\
\hline Invano & Colloquio & Scommettere \\
\hline Irritarlo & Colui & Sipario \\
\hline La pace dia con voi & Combattuto & Sorge \\
\hline Maledizione & Corsa & Spregiudicato \\
\hline Monotoni & Costretto & \\
\hline Perseguitava & Di prima mattina & \\
\hline Polsi & Fatemi spazio & \\
\hline Precipizi & Fave & \\
\hline Prepotente & Gorgiera & \\
\hline Prete & Il vicario di provvisione & \\
\hline Primogenito & Lardo & \\
\hline Prsentimento & Lazzaretto & \\
\hline Restituire & Merletto & \\
\hline Rimorso & Pietanza & \\
\hline Rimorso & Piselli & \\
\hline Risoluto & Pregio & \\
\hline Senza scrupoli & Provvede & \\
\hline Testimoni & Raccoglie intorno a lui & \\
\hline Umiltà & Redditizia & \\
\hline Vergogna & Ribatte & \\
\hline & Richiesta & \\
\hline & Sfuggi & \\
\hline & Si fa largo & \\
\hline & Soffice & \\
\hline & Sopracciglia & \\
\hline & Sottrarsi & \\
\hline & Sparsimi & \\
\hline & Spostiamoci & \\
\hline & Tondo & \\
\hline & Vicende & \\
\hline
\end{tabular}




\section{Número:39}

Ficha de coleta das unidades lexicais e/ou expressões durante a leitura - I Promessi Sposi - Cideb - 1999

Localização: UFPR/2008/2/VB/Italiano 4 Celin

\begin{tabular}{|c|c|c|}
\hline $\begin{array}{l}\text { Palavras que constam no } \\
\text { rodapé desnecessariamente }\end{array}$ & $\begin{array}{l}\text { Palavras que são necessárias, } \\
\text { mas não constam no rodapé }\end{array}$ & $\begin{array}{l}\text { Palavras que constam no rodapé } \\
\text { cuja explicação é insuficiente }\end{array}$ \\
\hline $\begin{array}{l}\text { Arroganza } \\
\text { Avere } \\
\text { Calvo } \\
\text { Contagiati } \\
\text { Destinata } \\
\text { Dote } \\
\text { Esuberante } \\
\text { Governatore } \\
\text { Implora } \\
\text { Incammina } \\
\text { Indizio } \\
\text { Maledizione } \\
\text { Mercanti } \\
\text { Monotoni } \\
\text { Mormorio } \\
\text { Orgoglio } \\
\text { Ozio } \\
\text { Precipizi } \\
\text { Predominio } \\
\text { Prepotente } \\
\text { Presentimento } \\
\text { Primogenito } \\
\text { Rugosa } \\
\text { Scampata } \\
\text { Scrupoli } \\
\text { Testimoni } \\
\text { Tiranno } \\
\text { Voto }\end{array}$ & $\begin{array}{l}\text { Accoglie } \\
\text { Affera } \\
\text { Aggiunge } \\
\text { Apinge } \\
\text { Colpire } \\
\text { Dichiarare } \\
\text { Fazzoletto } \\
\text { Filatoio } \\
\text { Fra sè } \\
\text { Guai } \\
\text { Inaspettata } \\
\text { Inginocchia } \\
\text { Monatto } \\
\text { Perciò } \\
\text { Scoppia } \\
\text { Spaventarsi } \\
\text { Spaventosa } \\
\text { Striscia } \\
\text { Vendetta }\end{array}$ & $\begin{array}{l}\text { Azzeccagarbugli } \\
\text { Bubboni } \\
\text { Calamaio } \\
\text { Fatto la spia } \\
\text { Grandinare } \\
\text { Impegno } \\
\text { Infiamma } \\
\text { Minacciare } \\
\text { Niente meno che } \\
\text { Panca } \\
\text { Raccolto } \\
\text { Rannicchiata } \\
\text { Restituire } \\
\text { Sagrestano } \\
\text { Sorge }\end{array}$ \\
\hline
\end{tabular}




\section{Número:40}

Ficha de coleta das unidades lexicais e/ou expressões durante a leitura - I Promessi Sposi - Cideb - 2007

Localização: UFPR/2009/1/NC4/Instrumental II

\begin{tabular}{|c|c|c|}
\hline $\begin{array}{l}\text { Palavras que constam no } \\
\text { rodapé desnecessariamente }\end{array}$ & $\begin{array}{l}\text { Palavras que são necessárias, } \\
\text { mas não constam no rodapé }\end{array}$ & $\begin{array}{l}\text { Palavras que constam no rodapé } \\
\text { cuja explicação é insuficiente }\end{array}$ \\
\hline $\begin{array}{l}\text { Barba } \\
\text { Sorge } \\
\text { Soffio }\end{array}$ & 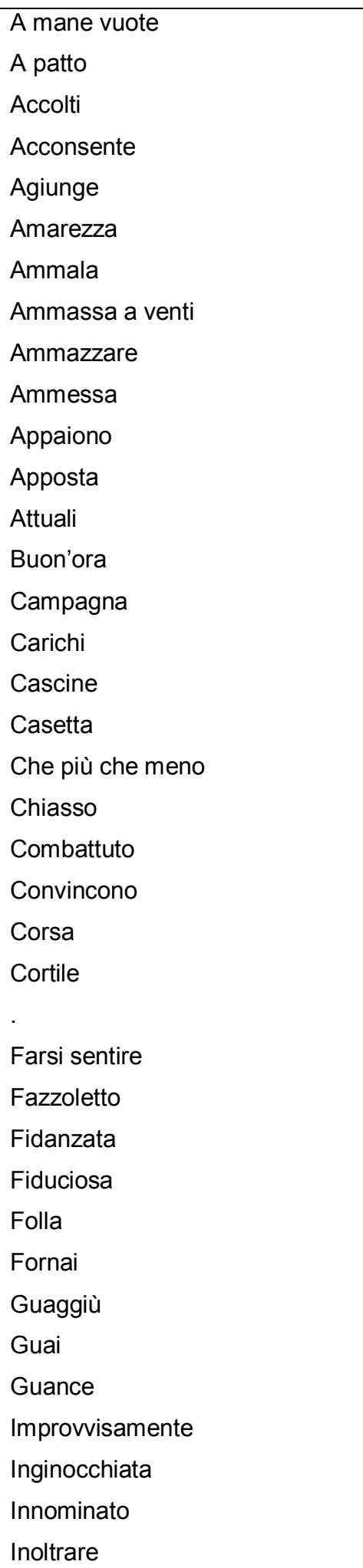 & $\begin{array}{l}\text { Come un branco } \\
\text { Complimento } \\
\text { Raccolti } \\
\text { Rannicchiata } \\
\text { Sfogarsi } \\
\text { Solleverà } \\
\text { Rimprovera } \\
\text { Ungere } \\
\text { Spregiudicati } \\
\text { Svanire }\end{array}$ \\
\hline
\end{tabular}




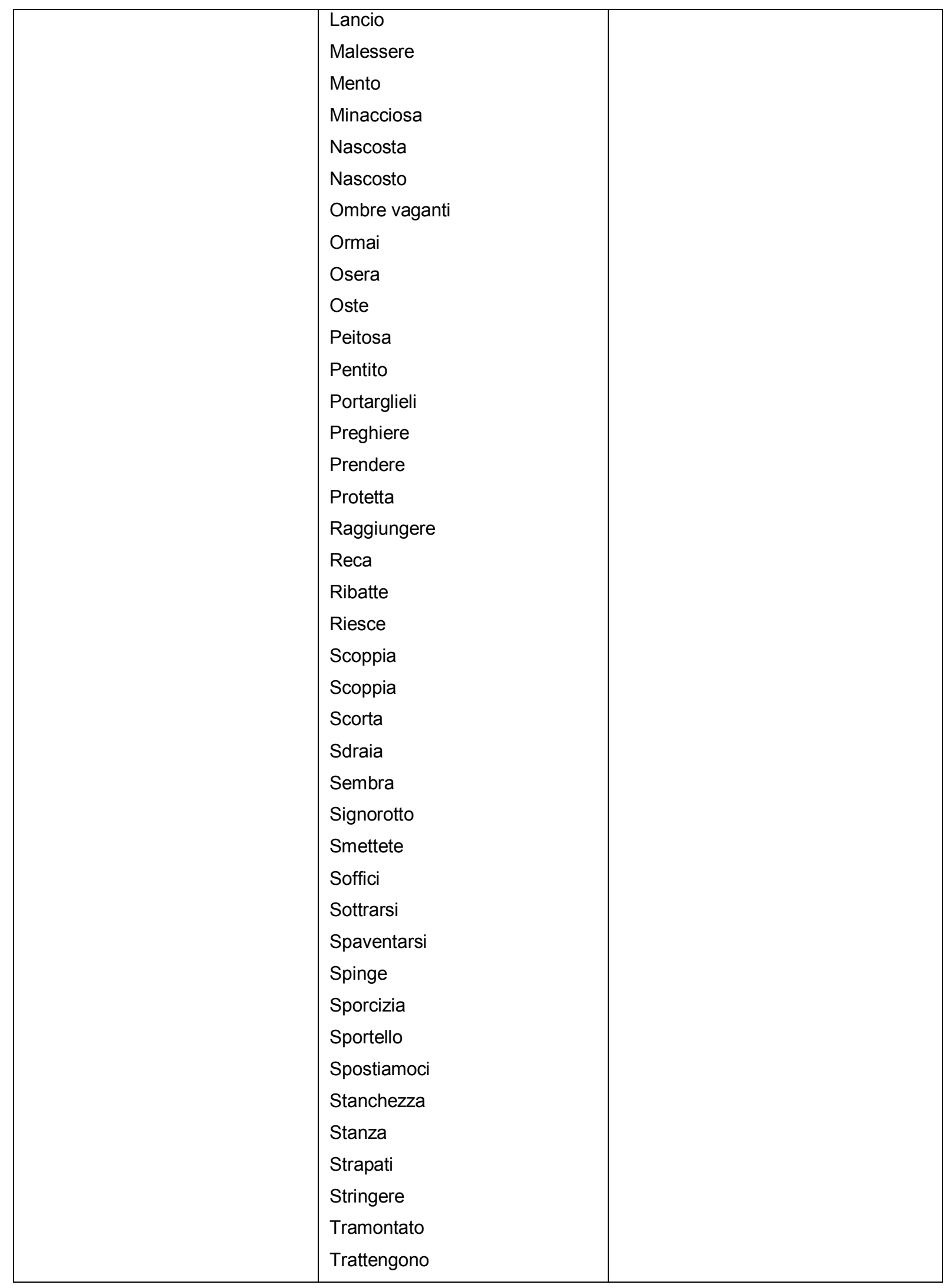




\section{Número:41}

Ficha de coleta das unidades lexicais e/ou expressões durante a leitura - I Promessi Sposi - Cideb - 2007

Localização: UFPR/2009/2/CA/Básico II

\begin{tabular}{|c|c|c|}
\hline $\begin{array}{l}\text { Palavras que constam no } \\
\text { rodapé desnecessariamente }\end{array}$ & $\begin{array}{l}\text { Palavras que são necessárias, } \\
\text { mas não constam no rodapé }\end{array}$ & $\begin{array}{l}\text { Palavras que constam no rodapé } \\
\text { cuja explicação é insuficiente }\end{array}$ \\
\hline Afflitto & Addolcirli & Bubbone \\
\hline Barba & Adosso & Calamaio \\
\hline Cadavere & Affolamento & Rannicchiate \\
\hline Calvo & Agnello & Stropiccio \\
\hline Carrozza & Altrove & Svanisce \\
\hline Compassione & Ammarezza & Trina \\
\hline Contagiare & Anatra & \\
\hline Dialetti & Avvenire & \\
\hline Governatore & Avvincente & \\
\hline Indizio & Cavolo & \\
\hline Infermo & Costretto & \\
\hline Lepre & Diffidente & \\
\hline Monotoni & Dunque & \\
\hline Precipizi & Fucile & \\
\hline Rimorso & Inoltrata & \\
\hline Rugosa & Lardo & \\
\hline Senatore & Mantello & \\
\hline Umiltà & Manzo & \\
\hline Vergogna & Mite & \\
\hline & Neppure & \\
\hline & Notai & \\
\hline & Pascolo & \\
\hline & Pecore & \\
\hline & Presso & \\
\hline & Rassegnazione & \\
\hline & Ricoveravi & \\
\hline & Riva & \\
\hline & Ruolo & \\
\hline & Sciabola & \\
\hline & Scopiare & \\
\hline & Sobirne & \\
\hline & Soffici & \\
\hline & Soprannome & \\
\hline & Soprusi & \\
\hline & Spinge & \\
\hline & Strisce & \\
\hline & Tondo & \\
\hline & Vendicarsi & \\
\hline
\end{tabular}




\section{Número:42}

Ficha de coleta das unidades lexicais e/ou expressões durante a leitura - I Promessi Sposi - Cideb - 1999

Localização: UFPR/2008/2/APMS/Instruemntal II

\begin{tabular}{|c|c|c|}
\hline $\begin{array}{l}\text { Palavras que constam no } \\
\text { rodapé desnecessariamente }\end{array}$ & $\begin{array}{l}\text { Palavras que são necessárias, } \\
\text { mas não constam no rodapé }\end{array}$ & $\begin{array}{l}\text { Palavras que constam no rodapé } \\
\text { cuja explicação é insuficiente }\end{array}$ \\
\hline Afflitto & Accade & Alito \\
\hline Asilo & Aggiunge & Azzeccare \\
\hline Avvocato & Altrove & Brache \\
\hline Baracca & Atteggiamento & Branco \\
\hline Barba & Berretti & Filanda \\
\hline Cadavere & Bugiarda & Lotta di successione \\
\hline Calvo & Butta & Palo \\
\hline Carrozza & Cascine & Posate \\
\hline Collera & Colpa & Raccolto \\
\hline Compassione & Colpiste & Radunarsi \\
\hline Contagiare & Cupa & Raggrinzarsi \\
\hline Dialetti & Denaro & Riscuotere dei soldi \\
\hline Dote & Difidente & Riversarsi \\
\hline Esuberante & Fiochi & Sorgenti \\
\hline Fare voto & Gorgiera & Sorgere \\
\hline Feroce & Guance & Stufato \\
\hline Governatore & Incarico & Treccia \\
\hline Illuminismo & Lazzaretto & Trina \\
\hline Implorare & Mento & Volto \\
\hline Incamminarsi & Monatto & \\
\hline Indizio & Piuttosto & \\
\hline Infermo & Riacquistarla & \\
\hline Ingannare & Rimasti & \\
\hline Irritare & Riscosso & \\
\hline Martellare & Scherma & \\
\hline Mercante & Scorta & \\
\hline Monastero & Sottomessa & \\
\hline Monotono & Spostiamoci & \\
\hline Mormorio & Stabilirono & \\
\hline ozio & Strappati & \\
\hline Pena & Sviluppati in pianura & \\
\hline Perseguitare & Svolsero & \\
\hline Peste & Tenerio & \\
\hline Precipizio & Tovaglia & \\
\hline Predominio & Urla & \\
\hline Prepotente & Vedrete & \\
\hline Presentimento & Vicende & \\
\hline Primogenito & Vorrebbe & \\
\hline
\end{tabular}


Restituire

Ribattere

Rimorso

Romanticismo

Rugosa

Senatore

Senza scrupoli

Testimone

Tiranno

Tumulto

Umiltà

Vergogna 


\section{Número:43}

Ficha de coleta das unidades lexicais e/ou expressões durante a leitura - I Promessi Sposi - Cideb - 1999

Localização: UFPR/2008/2/TDC/Básico II

\begin{tabular}{|c|c|c|}
\hline $\begin{array}{l}\text { Palavras que constam no } \\
\text { rodapé desnecessariamente }\end{array}$ & $\begin{array}{l}\text { Palavras que são necessárias, } \\
\text { mas não constam no rodapé }\end{array}$ & $\begin{array}{l}\text { Palavras que constam no rodapé } \\
\text { cuja explicação é insuficiente }\end{array}$ \\
\hline A buon mercato & Addirittura & Sorgenti \\
\hline Acconsentire & Addosso & Rannicchiata \\
\hline Acconsentire & Altrove & Svanire \\
\hline Affiorare & Aria & Levarselo dalla testa \\
\hline Afflitto & Attesa & \\
\hline Anziano & Bei & \\
\hline Avvocato & Cascine & \\
\hline Baracca & Cattura & \\
\hline Barba & Dirupi & \\
\hline Cadavere & Ebbene & \\
\hline Calvo & Entrambi & \\
\hline Capanna & Fazzoletto & \\
\hline Carrozza & Figlioni & \\
\hline Compassione & Fitte & \\
\hline Contagiare & Fretta & \\
\hline Convento & Giace & \\
\hline Dato & Guadagno & \\
\hline Distrarre & Guaggiù & \\
\hline Dote & Guai & \\
\hline Fare voto & Guance & \\
\hline Feroce & Inoltrata & \\
\hline Governatore & Mento & \\
\hline Impegnarsi & Mestieri & \\
\hline Impegno & Ombre & \\
\hline Implorare & Ostinate & \\
\hline Incamminarsi & Pecore & \\
\hline Incolto & Piuttosto & \\
\hline Indizio & Preda & \\
\hline Infermo & Preghiere & \\
\hline Infiammare & Pressi & \\
\hline Ingannare il tempo & Rabbrividisce & \\
\hline Irritare & Rade & \\
\hline Lepre & Radunati & \\
\hline Lotta di successione & Risparmiati & \\
\hline Maledizione & Riva & \\
\hline Marchese & Rivolgersi & \\
\hline Martellare & Scherzi & \\
\hline Miglio & Scoppia & \\
\hline
\end{tabular}




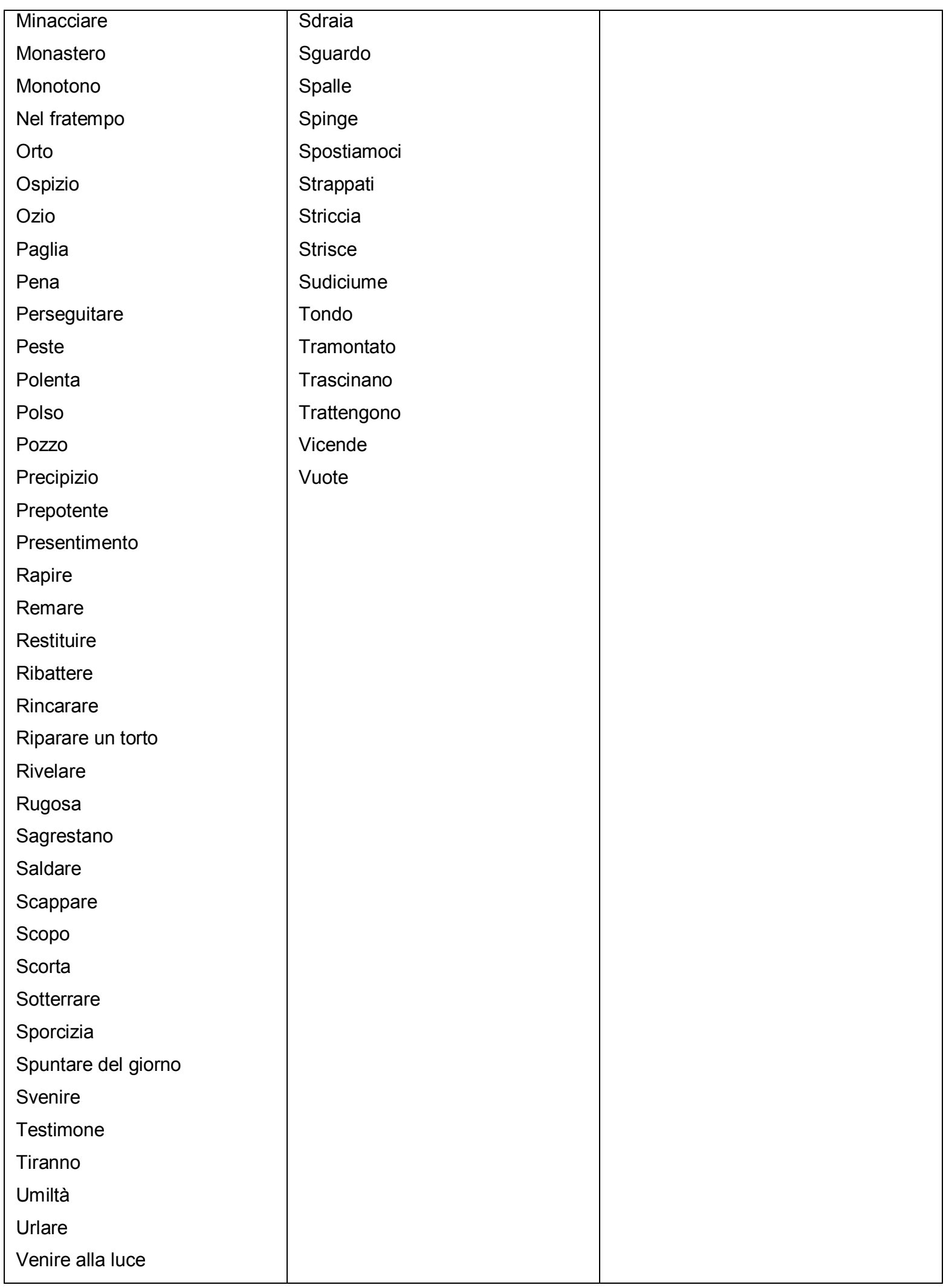




\section{Número:44}

Ficha de coleta das unidades lexicais e/ou expressões durante a leitura - I Promessi Sposi - Cideb - 2007

Localização: UFPR/2009/1/JPP/Instrumental II

\begin{tabular}{|c|c|c|}
\hline $\begin{array}{l}\text { Palavras que constam no } \\
\text { rodapé desnecessariamente }\end{array}$ & $\begin{array}{l}\text { Palavras que são necessárias, } \\
\text { mas não constam no rodapé }\end{array}$ & $\begin{array}{l}\text { Palavras que constam no rodapé } \\
\text { cuja explicação é insuficiente }\end{array}$ \\
\hline A buon mercato & Affaccendata & Azzeccagarbugli \\
\hline Adda & Alito & Boccone \\
\hline Affiorare & Allevamento & Brache \\
\hline Afflitto & Barba & Branco \\
\hline Asilo & Benestante & Calamaio \\
\hline Balbetta & Biacca & Cappone \\
\hline Baracca & Breviario & Educanda \\
\hline Barela & Bubbone & Fare a spia \\
\hline Beneficenza & Cadetto & Feltro \\
\hline Bussare & Casuccia & Grandinare \\
\hline Cadavere & Chiasso & Imari \\
\hline Calvo & Contendersi & Ingarbugliato \\
\hline Carrozza & Cupo & Lineamento \\
\hline Chirurgo & Curato & Palo \\
\hline Collera & Deo gratias & Pendio \\
\hline Compassione & Dietologo & Posate \\
\hline Destinata & Disperdersi & Raccolto \\
\hline Dialetti & Erede & Raggrinzarsi \\
\hline Distrarre & Fiasco & Rannicchiata \\
\hline Dote & Fiato & Rintocco \\
\hline Esuberante & Filanda & Riscuotere \\
\hline Feroci & Forragi & Riversarsi \\
\hline Forno & Grembiule & Sarto \\
\hline Galli & Inchino & Tintinnio \\
\hline Governatore & Indispettita & Trascinare \\
\hline Illuminismo & Insolito & Treccia \\
\hline Impegno & Lanzichenecchi & Trina \\
\hline Incolto & Lepre & \\
\hline Indicibile & Livido & \\
\hline Indizio & Miglio & \\
\hline Infermo & Nozze & \\
\hline Infiammare & Paggio & \\
\hline Ingannare & Panca & \\
\hline Maledizione & Podestà & \\
\hline Martellare & Polso & \\
\hline Mercante & Predica & \\
\hline Monastero & Rabbrividire & \\
\hline Monotono & Rincarare & \\
\hline
\end{tabular}




\begin{tabular}{|l|l|l|}
\hline Mormorio & Riparare torto & \\
Ospizio & Rugosa & \\
Ozio & Saggia & Saio \\
Pena & Sbarlodita & \\
Peste & Scampare & \\
Pozzo & Scommettere & \\
Precipizio & Scopo & \\
Rapire & Scorta & \\
Restituire & Scostarsi & \\
Ribattere & Scuotere & \\
Rimorso & Sfarzoso & \\
Risoluto & Sfogarsi & \\
Risorgimento & Sfondare & \\
Romanticismo & Siccità & \\
Senatore & Sipario & \\
Sopruso & Spalancato & \\
Sorgente & Spargersi & \\
Spregiudicato & Stupito & \\
Stropiccio & Sventurata & \\
Stufato & Tabernacolo & \\
Svenire & Vernaccia & Vina spoglia \\
Tumulto & Vita & \\
Ungere & Volto & \\
Vergogna & Zimbello & \\
Volitivo & & \\
\end{tabular}




\section{Número:45}

Ficha de coleta das unidades lexicais e/ou expressões durante a leitura - I Promessi Sposi - Cideb - 1999

Localização: UFPR/2008/1/BG/Instrumental II

\begin{tabular}{|c|c|c|}
\hline $\begin{array}{l}\text { Palavras que constam no } \\
\text { rodapé desnecessariamente }\end{array}$ & $\begin{array}{l}\text { Palavras que são necessárias, } \\
\text { mas não constam no rodapé }\end{array}$ & $\begin{array}{l}\text { Palavras que constam no rodapé } \\
\text { cuja explicação é insuficiente }\end{array}$ \\
\hline Acconsente & Adatta & Adda \\
\hline Afflitti & Ammaia & Alito \\
\hline Asilo & Ammalati & Capone \\
\hline Avvocato & Anzi & Chiasso \\
\hline Barba & Anziani & Contendevano \\
\hline Beneficenza & Apparso & Pali \\
\hline Cadaveri & Assenti & Posate \\
\hline Calvo & Atteggiamento & Prete \\
\hline Carrozza & Bacioni & Rannicchiata \\
\hline Compassione & Bati & Stufato \\
\hline Contagiati & Berretti & Trina \\
\hline Destinata & Bicchiere & Volto \\
\hline Di quando in quando & Bugiarda & \\
\hline Dialetti & Capanna & \\
\hline Dispendersi & Carico & \\
\hline Distraendola & Carnagione & \\
\hline Dote & Cavolo & \\
\hline Esuberante & Chiesa & \\
\hline Fare la spia & Chiesa & \\
\hline Feroce & Chiudere & \\
\hline Frate cappuccino & Ciascuno & \\
\hline Governatore & Cibo & \\
\hline Illuministe & Contenuti & \\
\hline Implora & Corsa & \\
\hline Incamminarsi & Cortile & \\
\hline Indizio & Costretto & \\
\hline Infermi & Cotto & \\
\hline Inganna il tempo & Cugino & \\
\hline Ingannò & Desiderio & \\
\hline Irritarlo & Dietro & \\
\hline La pace sia con voi & Domattina & \\
\hline Maledizione & Ebbe & \\
\hline Martellare & Erbacce & \\
\hline Mercante & Fave piselli & \\
\hline Miglia & Fazzoletto & \\
\hline Monastero & Fermano & \\
\hline Monotono & Fichi & \\
\hline Niente meno che & Fiduciosa & \\
\hline
\end{tabular}




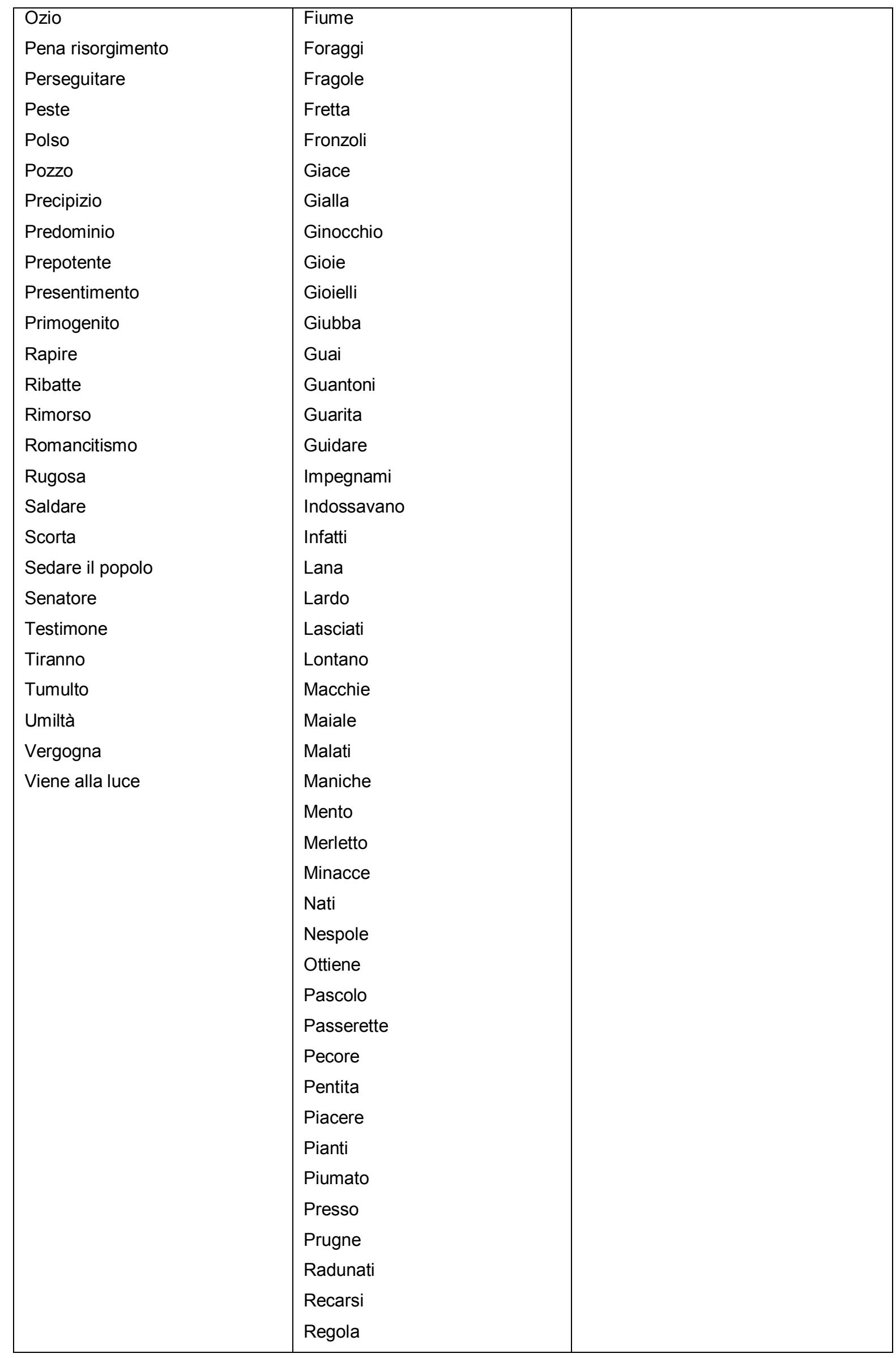




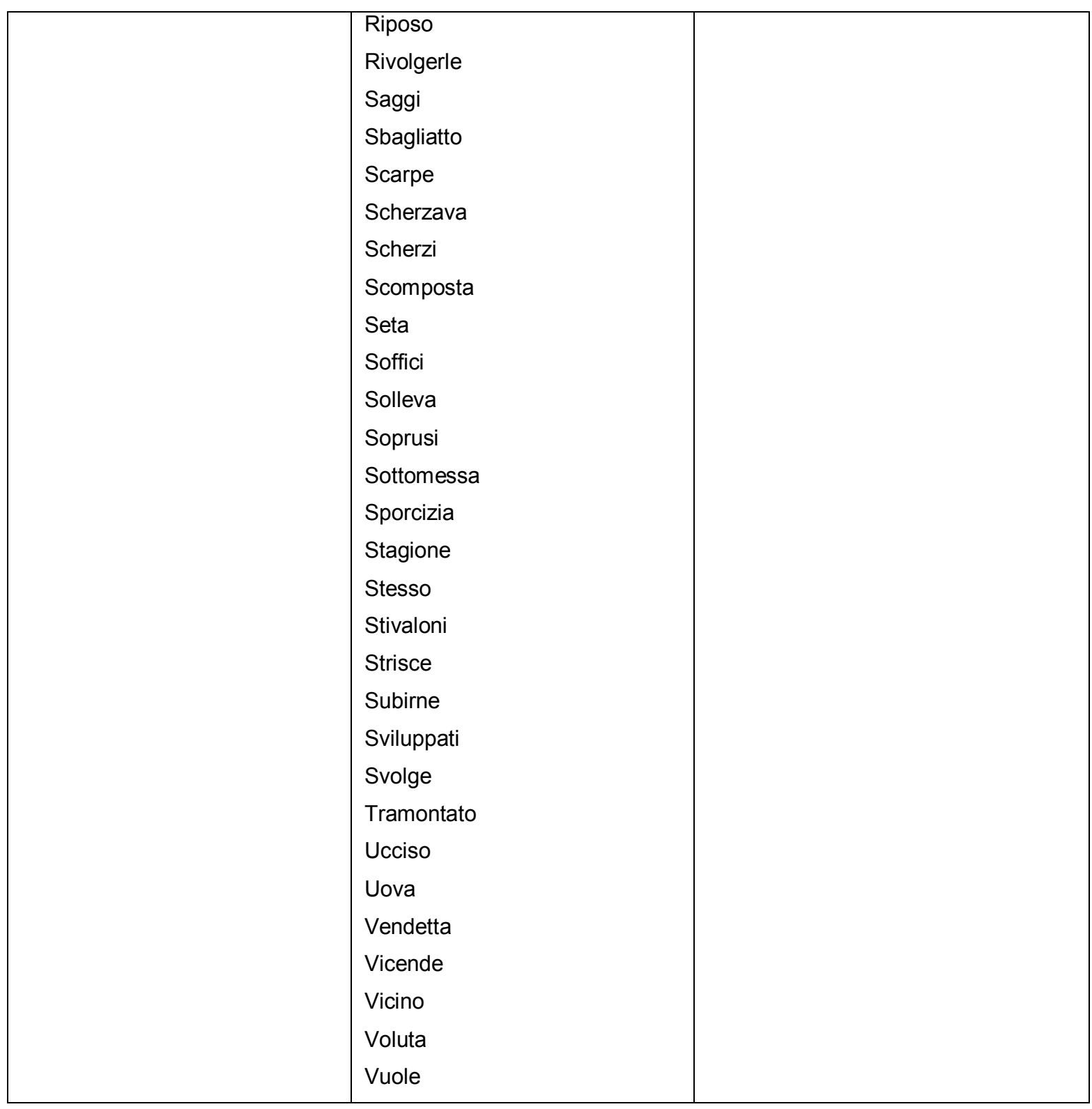




\section{Número:46}

Ficha de coleta das unidades lexicais e/ou expressões durante a leitura - I Promessi Sposi - Cideb - 1999

Localização: UFPR/2008/2/IL/Italiano 4 Celin

\begin{tabular}{|c|c|c|}
\hline $\begin{array}{l}\text { Palavras que constam no } \\
\text { rodapé desnecessariamente }\end{array}$ & $\begin{array}{l}\text { Palavras que são necessárias, } \\
\text { mas não constam no rodapé }\end{array}$ & $\begin{array}{l}\text { Palavras que constam no rodapé } \\
\text { cuja explicação é insuficiente }\end{array}$ \\
\hline Avvocato & Accolta & Alito \\
\hline Barba & Affanoso & Calamaio \\
\hline Cadavere & Affera & Livido \\
\hline Contagiare & Spogliate & Panca \\
\hline Convento & Attesa & Posate \\
\hline Fare voto & Augurata & Rannichiata \\
\hline Governatore & Buio & Restituire \\
\hline Implora & Colpito & Sarto \\
\hline Indizio & Deluso & Svanire \\
\hline Infermo & Dibattuto & Volto \\
\hline Inganò & Entrambi & Zitti zitti \\
\hline Lepre & Erede & \\
\hline Maledizione & Fazzolletto & \\
\hline Monastero & Filatoio & \\
\hline Monotoni & Gettano & \\
\hline Papire & Gioia & \\
\hline Peste & Gocce & \\
\hline Polenta & Guadagno & \\
\hline Precipizi & Guai & \\
\hline Prepotente & Guance & \\
\hline Presentimento & Guarisco & \\
\hline Prete & Levatello & \\
\hline Remare & Minacce & \\
\hline Sotterrare & Nascosto & \\
\hline Testimoni & Oserà & \\
\hline Umiltà & Perfino & \\
\hline & Pressi & \\
\hline & Quaggiù & \\
\hline & Rubassi & \\
\hline & Scoppia & \\
\hline & Sdraia & \\
\hline & Sottrarsi & \\
\hline & Sportello & \\
\hline & Spostiamoci & \\
\hline & Striscia & \\
\hline & Sudiciume & \\
\hline & Tramontato & \\
\hline & Trattengono & \\
\hline & Ubriaco & \\
\hline
\end{tabular}




\section{Número:47}

Ficha de coleta das unidades lexicais e/ou expressões durante a leitura - I Promessi Sposi - Cideb - 2007

Localização: UFPR/2009/1/GC/Instrumental II

\begin{tabular}{|c|c|c|}
\hline $\begin{array}{l}\text { Palavras que constam no } \\
\text { rodapé desnecessariamente }\end{array}$ & $\begin{array}{l}\text { Palavras que são necessárias, } \\
\text { mas não constam no rodapé }\end{array}$ & $\begin{array}{l}\text { Palavras que constam no rodapé } \\
\text { cuja explicação é insuficiente }\end{array}$ \\
\hline A mezzo & Accadute & Alito \\
\hline Afflitto & Accoglienza & Biacca \\
\hline Baracca & Adatta & Boccone \\
\hline Barba & Addosso & Brache \\
\hline Cadavere & Affermazione & Breviario \\
\hline Collera & Ammazzare & Chiasso \\
\hline Contagiare & Ampio & Cupo \\
\hline Dialetti & Annoiato & Erede \\
\hline Dote & Apaventarsi & Feltro \\
\hline Feroce & Arricciati & Filanda \\
\hline Illuminismo & Attesa & Grandinare \\
\hline Indizio & Avrebbero & In lungo e in largo \\
\hline Infermo & Avuto & Inchino \\
\hline Livido & Bambole & Levarselo dalla testa \\
\hline Ozio & Berretti & Lineamento \\
\hline Pena & Bocche & Minacciare \\
\hline Peste & Branchi & Niente meno che \\
\hline Prepotente & Butta & Palo \\
\hline Presentimento & Cadere & Parlatorio \\
\hline Revocare & Capolavoro & Pendio \\
\hline Risoluto & Chiedono & Posate \\
\hline Romanticismo & Chiuse & Rabbrividire \\
\hline Senatore & Chiuso & Raccolto \\
\hline Ungere & Cioè & Ragrinzarsi \\
\hline Vedova & Coinvolto & Rannicchiata \\
\hline \multirow[t]{13}{*}{ Venire alla luce } & Colletti & Rapire \\
\hline & Collo & Rintocco \\
\hline & Colpito & Riscuotere dei soldi \\
\hline & Cortile & Signorotto \\
\hline & Cugino & Siporio \\
\hline & Cugino & Sorgenti \\
\hline & Cuochi & Spregiudicato \\
\hline & Curato & Stare alla larga \\
\hline & Davanti & Stroppicio \\
\hline & Diventò & Stufato \\
\hline & Domani & Svanire \\
\hline & Dunque & Treccia \\
\hline & Entrambi & Trina \\
\hline
\end{tabular}




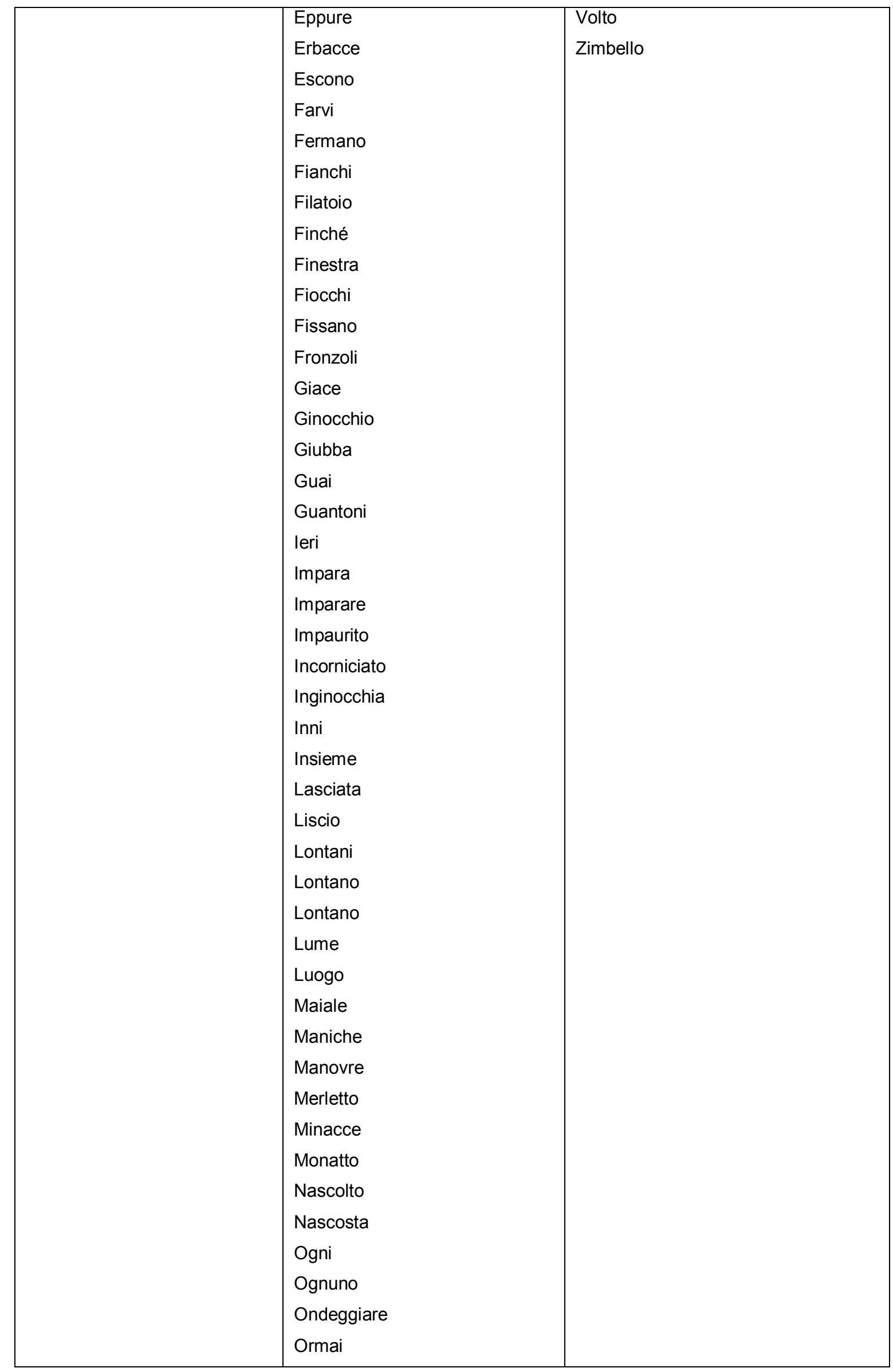




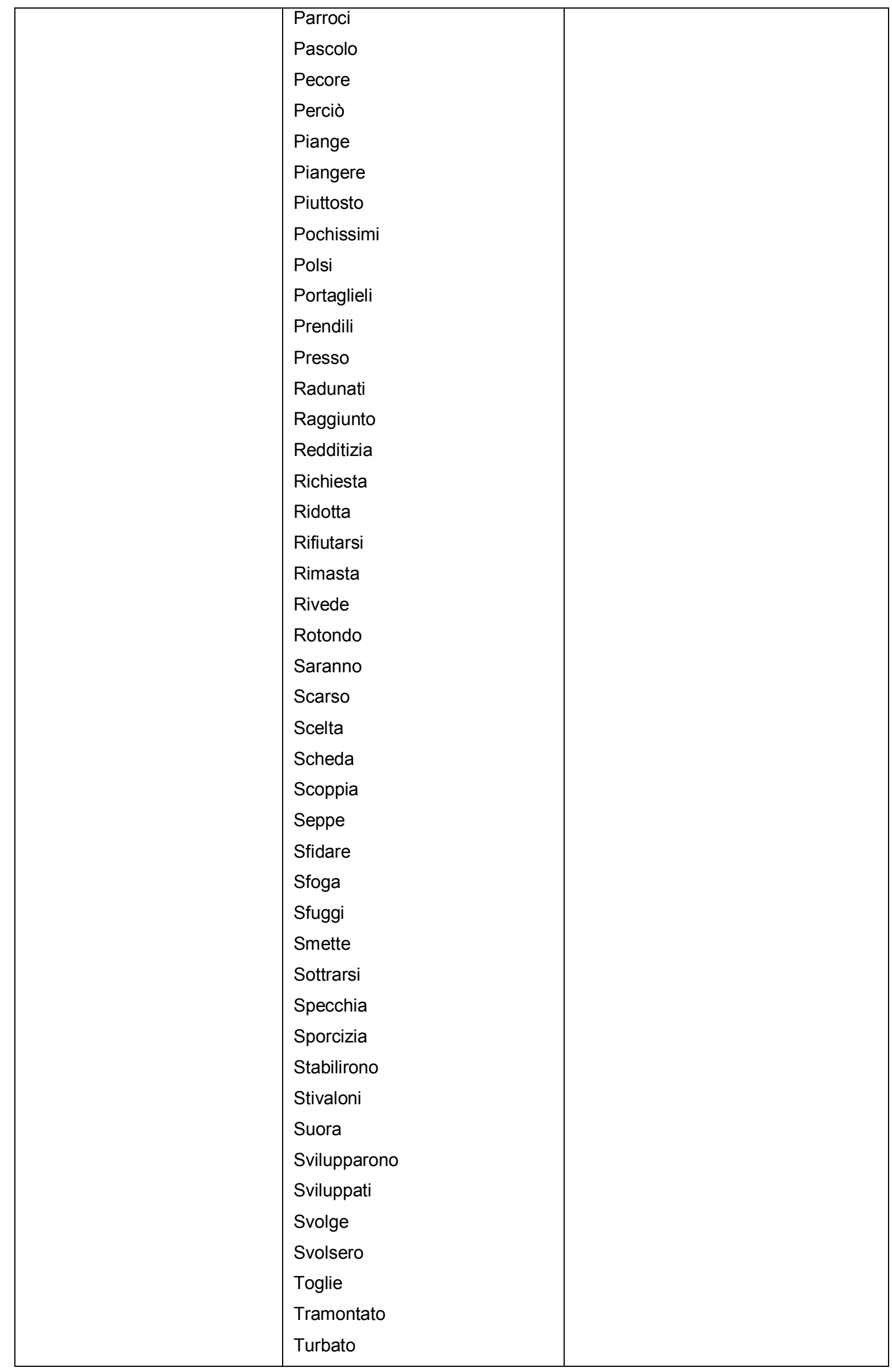




\begin{tabular}{|l|l|l|}
\hline & Ubriaco & \\
& Ucciso & \\
Urla & \\
Urla & \\
Urla & \\
& Venuto & \\
& Vicende & \\
\hline
\end{tabular}




\section{Número:48}

Ficha de coleta das unidades lexicais e/ou expressões durante a leitura - I Promessi Sposi - Cideb - 2007

Localização: UFPR/2009/1/MS/Instrumental II

\begin{tabular}{|c|c|c|}
\hline $\begin{array}{l}\text { Palavras que constam no } \\
\text { rodapé desnecessariamente }\end{array}$ & $\begin{array}{l}\text { Palavras que são necessárias, } \\
\text { mas não constam no rodapé }\end{array}$ & $\begin{array}{l}\text { Palavras que constam no rodapé } \\
\text { cuja explicação é insuficiente }\end{array}$ \\
\hline Afflitto & Aiuterà & Boccone \\
\hline Asilo & Alza & Branche \\
\hline Baracca & Avvinandosi & Bussare \\
\hline Barba & Bisogna & Bussare \\
\hline Cadavere & Chiedere & Calamaio \\
\hline Calvo & Colpito & Collera \\
\hline Carrozza & Cominciarono & Destinata \\
\hline Compliemnto & Cortile & Feltro \\
\hline Esuberante & Decaduta & Filanda \\
\hline Feroce & Ferito & Imbroglio \\
\hline Governatore & Fidanzato & Inchino \\
\hline Illuminismo & $\mathrm{Fu}$ & Levarselo dalla testa \\
\hline Incamminarsi & Gemiti & Minacciare \\
\hline Infermo & Guadagnare & Rannicchiata \\
\hline Inganare & Impauriti & Rapire \\
\hline Irritare & Impoverita & Rintocco \\
\hline Lepre & Incorniciato & Riversardi \\
\hline Mercante & Malessere & Saggia \\
\hline Monastero & Mettono & Scenata \\
\hline Monotomo & Minacce & Sipario \\
\hline Ospizio & Minacciato & Sorgere \\
\hline Pena & Mortificato & Spalancato \\
\hline Perseguitare & Nobiluomo & Svanire \\
\hline Peste & Nonostante & Treccia \\
\hline Polso & Offrire & Trina \\
\hline Precipizio & Orgoglio & Vita \\
\hline Prepotente & Ospitare & Volto \\
\hline Presentimento & Parroco & Zimbello \\
\hline Primogenito & Perduto & \\
\hline Rimorso & Popolo & \\
\hline Risorgimento & Porgere & \\
\hline Romanticismo & Portavano & \\
\hline Senatore & Potremo & \\
\hline Tabernacolo & Protetta & \\
\hline \multirow[t]{4}{*}{ Tirano } & Racconta & \\
\hline & Raggiunto & \\
\hline & Riacquistarla & \\
\hline & Riceveva & \\
\hline
\end{tabular}




\begin{tabular}{|l|l|l|}
\hline & Riesce & \\
Rivolgono & Scherma & \\
Schermitore & Sdraia & \\
Semplice & Sguardo & \\
Soddisfatto & Sostenevano & \\
Spinge & Svilupparono & \\
& Tramontato & \\
Ucciso & Vacanze & \\
& & \\
\hline
\end{tabular}




\section{Número:49}

Ficha de coleta das unidades lexicais e/ou expressões durante a leitura - I Promessi Sposi - Cideb - 1999

Localização: UFPR/2008/2/LLQ/Instrumental II

\begin{tabular}{|c|c|c|}
\hline $\begin{array}{l}\text { Palavras que constam no } \\
\text { rodapé desnecessariamente }\end{array}$ & $\begin{array}{l}\text { Palavras que são necessárias, } \\
\text { mas não constam no rodapé }\end{array}$ & $\begin{array}{l}\text { Palavras que constam no rodapé } \\
\text { cuja explicação é insuficiente }\end{array}$ \\
\hline Acconsentire & Accaduto & Levarselo dalla testa \\
\hline Afflitto & Afferra & Minacciare \\
\hline Arroganza & Altrimenti & Niente meno che \\
\hline Asilo & Alza & Panca \\
\hline Avvocato & Arrabbiato & Pendio \\
\hline Balbettare & Campagna & Posate \\
\hline Baracca & Campanaro & Rannicchiata \\
\hline Barba & Campane & Sagrestano \\
\hline Bussare & Cattivo & Sorgenti \\
\hline Cadavere & Costretto & Volto \\
\hline Calvo & Diffidente & \\
\hline Capanna & Eppure & \\
\hline Carrozza & Fiduciosa & \\
\hline Collera & Filatore & \\
\hline irritare & Fiume & \\
\hline Colpa & Guadagno & \\
\hline Compassione & Inoltrata & \\
\hline Contagiare & Insegna & \\
\hline Convento & Lontani & \\
\hline Dato & Minacce & \\
\hline Deo gratias & Minacciosa & \\
\hline Destinata & Monaca & \\
\hline Di quando in quando & Nati & \\
\hline Disperdersi & Oltre & \\
\hline Distrarre & Osteria & \\
\hline Dote & Pascolo & \\
\hline Educanda & Pecore & \\
\hline . & Radunati & \\
\hline Erede & Riacquistarla & \\
\hline Esuberante & Richiesta & \\
\hline Fare voto & Riesca & \\
\hline Feroce & Rispose & \\
\hline Governatore & Riva & \\
\hline Impari & Salgono & \\
\hline Impegno & Scherzava & \\
\hline Implorare & Scoppia & \\
\hline In ozio & Sdraia & \\
\hline Incamminarsi & Sembra & \\
\hline
\end{tabular}




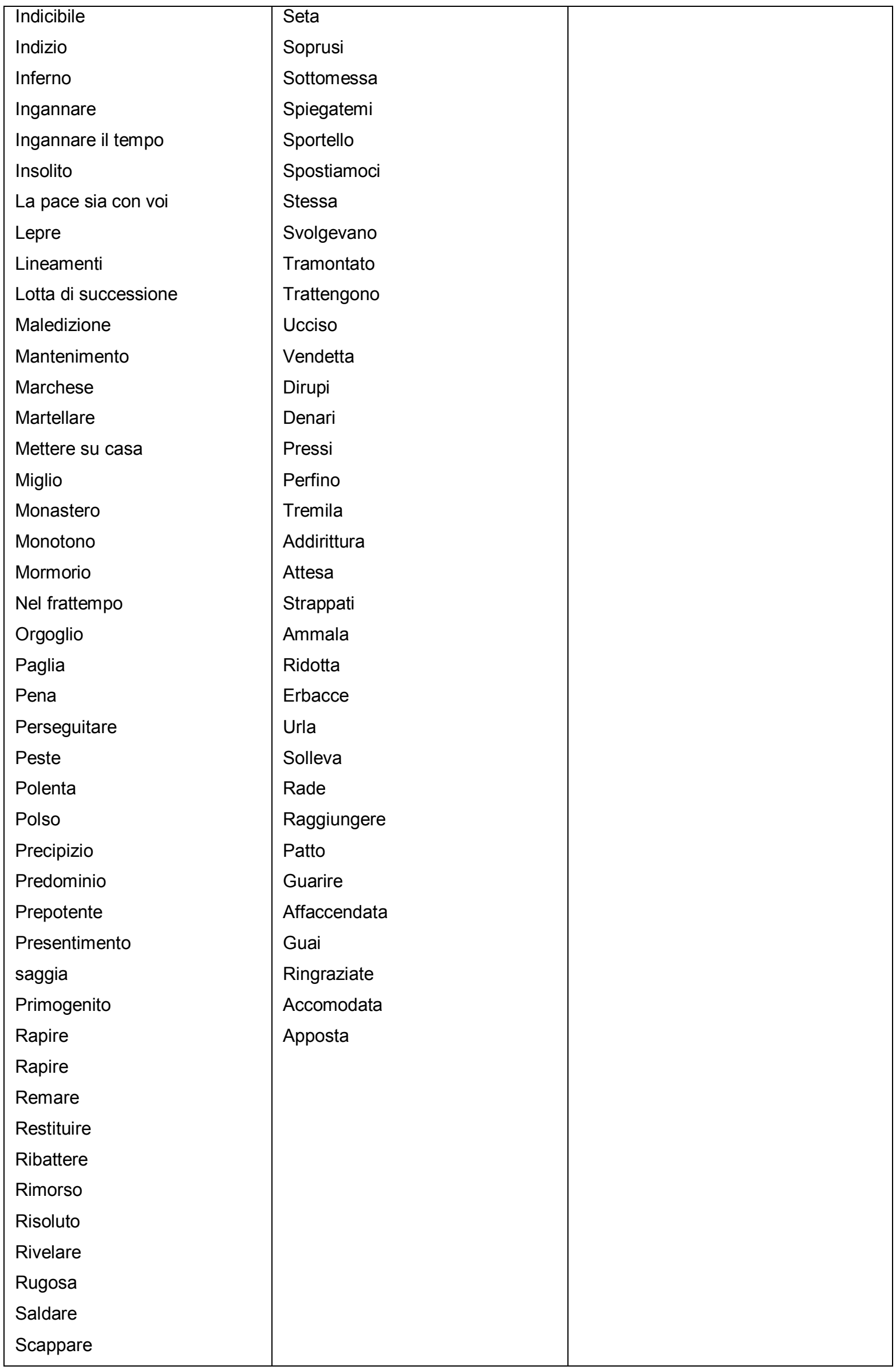




\begin{tabular}{|l|l|l|}
\hline Scorta & & \\
Senza scrupoli & & \\
Spargersi & & \\
Sporcizia & & \\
Spostare & & \\
Spuntare del giorno & & \\
Tabernacolo & & \\
Terrore & & \\
Testimone & & \\
Tiranno & & \\
Titoli nobiliari & & \\
Umiltà & & \\
Venire alla luce & & \\
Vergogna & & \\
\hline
\end{tabular}


Número: 50

Ficha de coleta das unidades lexicais e/ou expressões durante a leitura - I Promessi Sposi - Cideb - 1999

Localização: UFPR/2008/2/GM/Basico II

\begin{tabular}{|c|c|c|}
\hline $\begin{array}{l}\text { Palavras que constam no } \\
\text { rodapé desnecessariamente }\end{array}$ & $\begin{array}{l}\text { Palavras que são necessárias, } \\
\text { mas não constam no rodapé }\end{array}$ & $\begin{array}{l}\text { Palavras que constam no rodapé } \\
\text { cuja explicação é insuficiente }\end{array}$ \\
\hline A buon mercato & Accogliere con gioia & Alito \\
\hline A mezzo & Addosso & Sagrestano \\
\hline Acconsente & Afferra & \\
\hline Afflitto & Altrimenti & \\
\hline Anziano & Amarezza & \\
\hline Argoglio & Ammassati & \\
\hline Arroganza & Anatra & \\
\hline Asilo & Anzi & \\
\hline Averi & Appena & \\
\hline Avvocato & Apposta & \\
\hline Balbettare & Aria & \\
\hline Bambola & Attesa & \\
\hline Baracca & Avvenire & \\
\hline Barba & Carestia & \\
\hline Beneficenza & Cascine & \\
\hline Cadavere & Chinando & \\
\hline Calvo & Colloquio & \\
\hline Carrozza & Colpito & \\
\hline Collera & Contadino & \\
\hline Colpa & Cortile & \\
\hline Compassione & Carnagione & \\
\hline Complimento & Dirupi & \\
\hline Contagiare & Entrambi & \\
\hline Contessa & Eppure & \\
\hline Convento & Fazzoletto & \\
\hline Dato & Fece & \\
\hline Destinata & Figlioli & \\
\hline Di quando in quando & Filatoio & \\
\hline Dialetti & Filatore & \\
\hline Distrarre & Finché & \\
\hline Dote & Fiorenti & \\
\hline Esuberante & Fioretto & \\
\hline Fare finta & Fitte & \\
\hline Fare la spia & Fretta & \\
\hline Fare voto & Gettano & \\
\hline Feroce & Gocce & \\
\hline Forno & Gradita & \\
\hline Frate cappuccino & Granturco & \\
\hline
\end{tabular}




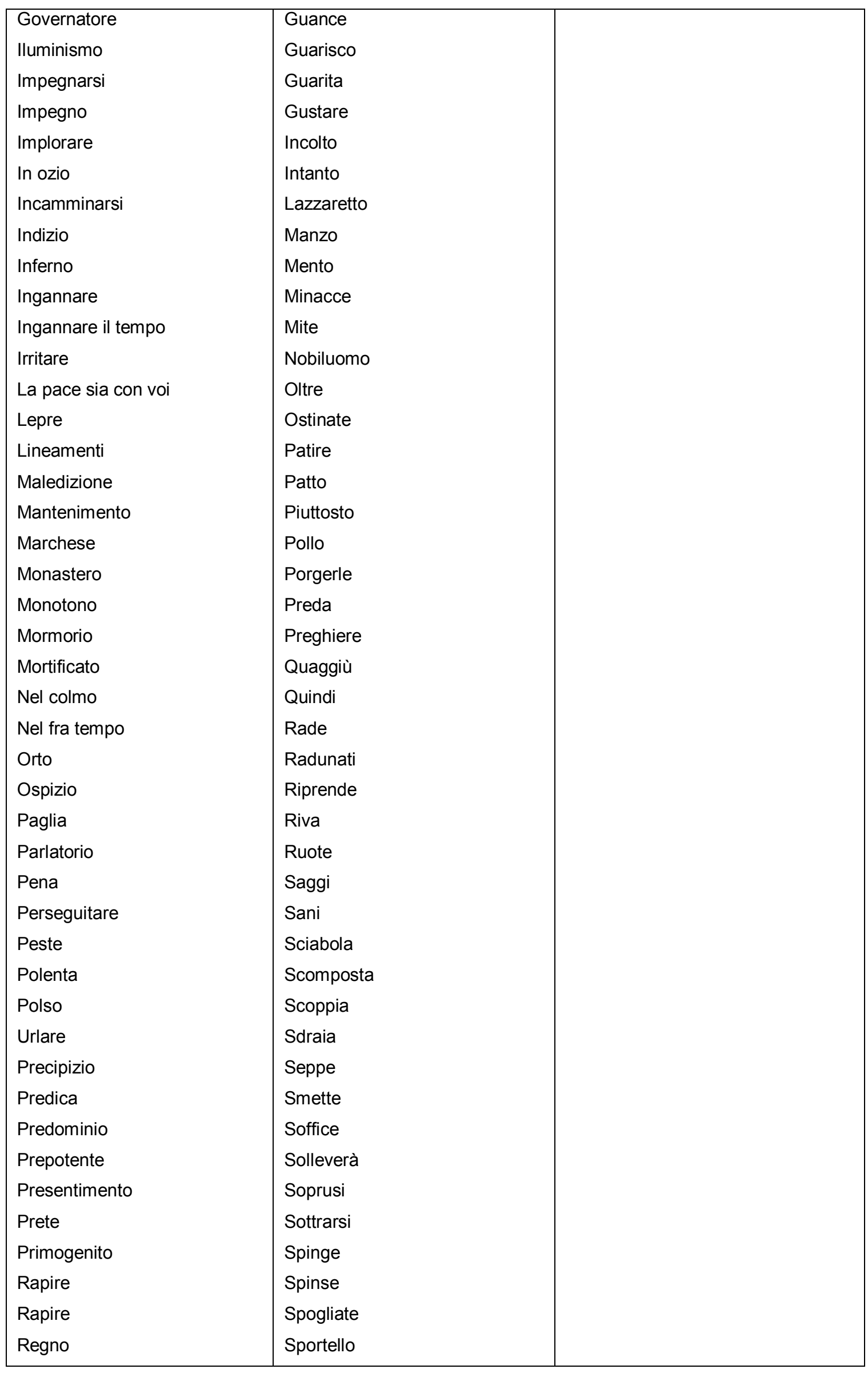




\begin{tabular}{|l|l|l|}
\hline Remare & Spostiamoci & \\
Restituire & Strappati & \\
Ribattere & Stringere & \\
Rimorso & Strisce & \\
Rivelare & Subirne & \\
Romanticismo & Sudiciume & \\
Rugosa & Suora & \\
Saggia & Talmente & \\
Scorta & Tramontato & \\
Senatore & Trattengono & \\
Senza scrupoli & Vendetta & \\
Soffocare il grido in gola & \\
Sorgere & \\
Sotterrare & \\
Spazientito & \\
Sporcizia & \\
Sventurata & \\
Terrore & \\
Tintinnio & \\
Tiranno & \\
Turbato & \\
Umiltà & \\
Ungere & \\
Venire alla luce & \\
Vergogna & \\
Vigna & \\
Volto & \\
Zitti zitti & & \\
& & \\
& \\
& \\
\end{tabular}




\subsection{1 - Análise das fichas de coleta de dados}

Para a coleta de dados utilizamos duas edições do I Promessi Sposi da editora Cideb, uma de 1999 e outra de 2007. No início da nossa pesquisa tínhamos somente a edição de 1999. Com o nosso estágio de doutoramento na Università degli Studi di Padova, pudemos ter acesso à edição de 2007 e assim também usá-la com os nossos alunos.

Com o intuito de uniformizar os dados da pesquisa e fazer o tratamento dos dados da maneira mais homogênea possível, fizemos um levantamento das diferenças apresentadas na edição de 1999 e naquela de 2007. A seguir apresentamos o levantamento do ponto de vista das notas de rodapé presentes em ambas as edições:

Palavras presentes nas notas de rodapé da obra adaptada I Promessi Sposi

\begin{tabular}{|l|l|l|l|}
\hline Edição de 1999 & \multicolumn{2}{l|}{ Edição de 2007 } \\
\hline 01 & Illuminismo & 01 & Illuminismo \\
\hline 02 & Romanticismo & 02 & Romanticismo \\
\hline 03 & Vedova & 03 & Vedova \\
\hline 04 & Contessa & & \\
\hline 05 & Regno & & \\
\hline 06 & Dialetti & 04 & Dialetti \\
\hline 07 & Senatore & 05 & Senatore \\
\hline 09 & Prete & 06 & Prete \\
\hline 10 & Barba & 07 & Barba \\
\hline 11 & Feroce & 09 & Feroce \\
\hline 12 & Prepotente & 10 & Prepotente \\
\hline 13 & Signoroto & 11 & Signoroto \\
\hline 14 & Bussare & 12 & Bussare \\
\hline 15 & Balbettare & 13 & Balbettare \\
\hline 16 & Filanda & 14 & Filanda \\
\hline 17 & Turbato & 16 & Saggia \\
\hline 18 & Presentimento & & \\
\hline 19 & Saggia & & \\
\hline & & 15 & Presentimento \\
\hline
\end{tabular}




\begin{tabular}{|c|c|c|c|}
\hline 20 & Azzeccagarbugli & 17 & Azzeccagarbugli \\
\hline 21 & Avvocato & 18 & Avvocato \\
\hline 22 & Cappone & 19 & Cappone \\
\hline 23 & Nozze & 20 & Nozze \\
\hline 24 & Pena & 21 & Pena \\
\hline 25 & Minacciare & 22 & Minacciare \\
\hline 26 & Collera & 23 & Collera \\
\hline 27 & Galli & 24 & Galli \\
\hline \multirow[t]{6}{*}{28} & Risorgimento & 25 & Risorgimento \\
\hline & & 26 & Sfarzoso \\
\hline & & 27 & Brache \\
\hline & & 28 & Feltro \\
\hline & & 29 & Trina \\
\hline & & 30 & Biacca \\
\hline 29 & Volto & 31 & Volto \\
\hline \multirow[t]{2}{*}{30} & Volitivo & 32 & Volitivo \\
\hline & & 33 & Adda \\
\hline 31 & Sorgere & 34 & Sorgere \\
\hline 32 & Irritare & 35 & Irritare \\
\hline 33 & Umiltà & 36 & Umiltà \\
\hline 34 & Predica & 37 & Predica \\
\hline 35 & Ribattere & 38 & Ribattere \\
\hline 36 & Spazientito & & \\
\hline 37 & Implorare & 39 & Implorare \\
\hline 38 & Maledizione & 40 & Maledizione \\
\hline 39 & Testimone & 41 & Testimone \\
\hline 40 & Imbroglio & 42 & Imbroglio \\
\hline 41 & Restituire & 43 & Restituire \\
\hline 42 & La pace sai com voi & 44 & La pace sai com voi \\
\hline 43 & Acconsentire & & \\
\hline 44 & Scommettere & 45 & Scommettere \\
\hline 45 & Rapire & 46 & Rapire \\
\hline
\end{tabular}




\begin{tabular}{|l|l|l|l|}
\hline 46 & Recarsi & & \\
\hline 47 & Zitti zitti & & \\
\hline 48 & Riscuotere dei soldi & 47 & Riscuotere dei soldi \\
\hline 49 & Saldare & 48 & Saldare \\
\hline 50 & Scopo & 49 & Scopo \\
\hline 51 & Deo gratias & 50 & Deo gratias \\
\hline 52 & Martellare & 51 & Martellare \\
\hline 53 & Scostarsi & 52 & Scostarsi \\
\hline 54 & Sipario & 53 & Sipario \\
\hline 55 & Stupito & 54 & Stupito \\
\hline 56 & Scappare & & \\
\hline 57 & Rintocco & 55 & Rintocco \\
\hline 58 & Forca & 56 & Forca \\
\hline 59 & Fare la spia & 57 & Fare la spia \\
\hline 60 & Alito & 58 & Alito \\
\hline 61 & Remare & 71 & Mormorio \\
\hline 62 & Rabbrividire & & \\
\hline 63 & Sorgenti & 59 & Rabbrividire \\
\hline 64 & Pendio & 60 & Sorgenti \\
\hline 65 & Mercante & 61 & Pendio \\
\hline 66 & Sopruso & 62 & Mercante \\
\hline 67 & Impari & 63 & Sopruso \\
\hline 68 & Frate cappuccino & 64 & Impari \\
\hline 69 & Asilo & 65 & Frate cappuccino \\
\hline 70 & Indicibile & & Asilo \\
\hline 71 & Avere & & Avere \\
\hline 72 & Saio & & \\
\hline 73 & Folla & Saio \\
\hline 74 & Arroganza & Testa rasa & \\
\hline 75 & Mormorio & Orgoglio & \\
\hline 76 & & \\
\hline & & & \\
\hline 76 & & & \\
\hline
\end{tabular}




\begin{tabular}{|c|c|c|c|}
\hline 78 & Incamminarsi & 72 & Incamminarsi \\
\hline 79 & Impegno & 73 & Impegno \\
\hline 80 & Monastero & 74 & Monastero \\
\hline 81 & Parlatorio & 75 & Parlatorio \\
\hline \multirow[t]{2}{*}{82} & Inchino & 76 & Inchino \\
\hline & & 77 & Cupo \\
\hline 83 & Sfiorita & & \\
\hline 84 & Perseguitare & 78 & Perseguitare \\
\hline 85 & Branco & 79 & Branco \\
\hline 86 & Invano & 80 & Invano \\
\hline 87 & Lepre & 81 & Lepre \\
\hline 88 & Mortificato & & \\
\hline 89 & Tabernacolo & 82 & Tabernacolo \\
\hline 90 & Convento & & \\
\hline 91 & Carestia & 83 & Carestia \\
\hline 92 & II paese della cucagna & 84 & Il paese della cucagna \\
\hline 93 & Lineamenti & 85 & Lineamenti \\
\hline 94 & Raggrinzarsi & 86 & Raggrinzarsi \\
\hline 95 & Primogênito & 87 & Primogênito \\
\hline 96 & Cadetto & 88 & Cadetto \\
\hline 97 & Bambola & & \\
\hline 98 & Destinata & 89 & Destinata \\
\hline 99 & Esuberante & 90 & Esuberante \\
\hline 100 & Paggio & 91 & Paggio \\
\hline 101 & Scenata & 92 & Scenata \\
\hline 102 & Colpa & & \\
\hline 103 & Vergogna & 93 & Vergogna \\
\hline 104 & Rimorso & 94 & Rimorso \\
\hline 105 & Terrore & & \\
\hline 106 & Indispettita & 95 & Indispettita \\
\hline 107 & Complimento & 96 & Complimento \\
\hline 108 & Madre Badessa & \begin{tabular}{|l|}
97 \\
\end{tabular} & Madre Badessa \\
\hline
\end{tabular}




\begin{tabular}{|c|c|c|c|}
\hline 109 & Ingannare & 98 & Ingannare \\
\hline 110 & Educanda & 99 & Educanda \\
\hline 111 & Senza scrupoli & 100 & Senza scrupoli \\
\hline 112 & Sventurata & 101 & Sventurata \\
\hline 113 & Persecuzione & & \\
\hline 114 & Insolito & \begin{tabular}{|l|}
102 \\
\end{tabular} & Insolito \\
\hline 115 & Fare finta & 103 & Fare finta \\
\hline 116 & Raccolto & 104 & Raccolto \\
\hline 117 & Governatore & 105 & Governatore \\
\hline 118 & Forno & 106 & Forno \\
\hline 119 & Rincarare & 107 & Rincarare \\
\hline 120 & Riversarsi & 108 & Riversarsi \\
\hline 121 & Radunarsi & 109 & Radunarsi \\
\hline 122 & Sfondare & 110 & Sfondare \\
\hline 123 & Questa è bella & 111 & Questa è bella \\
\hline 124 & Pozzo & 112 & Pozzo \\
\hline 125 & Spargersi & 113 & Spargersi \\
\hline 126 & Carrozza & 114 & Carrozza \\
\hline 127 & A buon mercato & 115 & A buon mercato \\
\hline 128 & Sedare II popolo & 116 & Sedare II popolo \\
\hline 129 & Disperdersi & 117 & Disperdersi \\
\hline 130 & Parere & & \\
\hline 131 & Boccone & 118 & Boccone \\
\hline 132 & Fiasco & 119 & Fiasco \\
\hline 133 & Stufato & 120 & Stufato \\
\hline 134 & Calamaio & 121 & Calamaio \\
\hline 135 & Zimbello & 122 & Zimbello \\
\hline 136 & Trascinare & 123 & Trascinare \\
\hline 137 & Dato & \begin{tabular}{|l|}
124 \\
\end{tabular} & Dato \\
\hline 138 & Spuntare del giorno & 125 & Spuntare del giorno \\
\hline 139 & Polso & 126 & Polso \\
\hline 140 & Urlare & & \\
\hline
\end{tabular}




\begin{tabular}{|c|c|c|c|}
\hline 141 & Scappare & & \\
\hline 142 & Miglio & 127 & Miglio \\
\hline 143 & Incolto & 128 & Incolto \\
\hline 144 & Capanna & & \\
\hline 145 & Paglia & & \\
\hline 146 & Affiorare & 129 & Affiorare \\
\hline 147 & Treccia & 130 & Treccia \\
\hline 148 & Podestà & 131 & Podestà \\
\hline 149 & Infiammare & 132 & Infiammare \\
\hline 150 & Nel fratempo & & \\
\hline \multirow[t]{2}{*}{151} & Monótono & 133 & Monótono \\
\hline & & 134 & Tumulto \\
\hline 152 & Tiranno & 135 & Tiranno \\
\hline 153 & Scorta & 136 & Scorta \\
\hline 154 & Contendersi & 137 & Contendersi \\
\hline 155 & Predomino & 138 & Predomino \\
\hline 156 & Beneficenza & 139 & Beneficenza \\
\hline 157 & Titoli nobiliari & 140 & \begin{tabular}{|l} 
Titoli nobiliari \\
\end{tabular} \\
\hline 158 & Elemosina & 141 & Elemosina \\
\hline 159 & Mantenimento & & \\
\hline 160 & Precipizio & 142 & Precipizio \\
\hline 161 & Calvo & 143 & Calvo \\
\hline 162 & Rugosa & 144 & Rugosa \\
\hline 163 & Rapire & & \\
\hline 164 & Vita & 145 & Vita \\
\hline 165 & Divincolarsi & & \\
\hline 166 & Soffocare II grido in gola & 146 & Soffocare II grido in gola \\
\hline 167 & Svenire & 147 & Svenire \\
\hline 168 & Impegnarsi & & \\
\hline 169 & Rivelare & & \\
\hline 170 & Compassione & 148 & Compassione \\
\hline 171 & Rannicchiata & 149 & Rannicchiata \\
\hline
\end{tabular}




\begin{tabular}{|c|c|c|c|}
\hline 172 & Sfogarsi & 150 & Sfogarsi \\
\hline 173 & Pena & & \\
\hline 174 & Fare voto & 151 & Fare voto \\
\hline 175 & Monsignore illustrissimo & 152 & Monsignore illustrissimo \\
\hline 176 & Niente meno che & 153 & Niente meno che \\
\hline 177 & Riparare um torto & 154 & Riparare um torto \\
\hline 178 & Afflitto & 155 & Afflitto \\
\hline 179 & Rovinare & 156 & Rovinare \\
\hline 180 & Chiasso & 157 & Chiasso \\
\hline 181 & Sarto & 158 & Sarto \\
\hline 182 & Distrarre & 159 & Distrarre \\
\hline 183 & Anziano & & \\
\hline 184 & Benestante & 160 & Benestante \\
\hline 185 & Scudo & 161 & Scudo \\
\hline 186 & Dote & 162 & Dote \\
\hline 187 & Sbalordita & 163 & Sbalordita \\
\hline 188 & Morire come mosche & 164 & Morire come mosche \\
\hline 189 & Ospizio & 165 & Ospizio \\
\hline 190 & Siccità & 166 & Siccità \\
\hline 191 & Lotta di successione & 167 & Lotta di successione \\
\hline 192 & Erede & 168 & Erede \\
\hline 193 & Peste & 169 & Peste \\
\hline 194 & Sotterrare & & \\
\hline 195 & Posate & 170 & Posate \\
\hline 196 & Breviário & 171 & Breviario \\
\hline 197 & Vigna & 172 & Vigna spoglia \\
\hline 198 & Palo & 173 & Palo \\
\hline 199 & Sporcizia & & \\
\hline 200 & Cadavere & 174 & Cadavere \\
\hline 201 & Contangiare & 175 & Contangiare \\
\hline 202 & Ungere & 176 & Ungere \\
\hline 203 & Panca & 177 & Panca \\
\hline
\end{tabular}




\begin{tabular}{|c|c|c|c|}
\hline 204 & Lívido & 178 & Lívido \\
\hline 205 & Bubbone & 179 & Bubbone \\
\hline 206 & Spregiudicato & 180 & Spregiudicato \\
\hline 207 & Nel colmo & & \\
\hline 208 & Vernaccia & 181 & Vernaccia \\
\hline 209 & Chirurgo & 182 & Chirurgo \\
\hline 210 & Stropiccio & 183 & Stropiccio \\
\hline 211 & Barella & 184 & Barella \\
\hline 212 & Bergamasco & 185 & Bergamasco \\
\hline \multirow[t]{2}{*}{213} & Scampare & 186 & Scampare \\
\hline & & 187 & Mettere giudizio \\
\hline 214 & Lanzichenecchi & 188 & Lanzichenecchi \\
\hline 215 & Polenta & & \\
\hline 216 & Tintinnio & 189 & Tintinnio \\
\hline 217 & Baracca & 190 & Baracca \\
\hline 218 & Svanire & 191 & Svanire \\
\hline 219 & Indizio & 192 & Indizio \\
\hline 220 & In lungo e in largo & 193 & In lungo e in largo \\
\hline 221 & Infermo & 194 & Infermo \\
\hline 222 & Spalancato & 195 & Spalancato \\
\hline 223 & Di quando in quando & 196 & Di quando in quando \\
\hline 224 & Fiatto & 197 & Fiatto \\
\hline 225 & Mettersi II cuore in pace & 198 & Mettersi II cuore in pace \\
\hline 226 & Levarselo dalla testa & 199 & Levarselo dalla testa \\
\hline 227 & Grandinare & 200 & Grandinare \\
\hline 228 & Orto & & \\
\hline 229 & Mettere su casa & 201 & Mettere su casa \\
\hline 230 & Ingannare II tempo & 202 & Ingannare II tempo \\
\hline 231 & In ozio & 203 & In ozio \\
\hline 232 & Stare alla larga & 204 & Stare alla larga \\
\hline 233 & Scuotere & 205 & Scuotere \\
\hline 234 & Risoluto & 206 & Risoluto \\
\hline
\end{tabular}




\begin{tabular}{|l|l|r|l|}
\hline 235 & Marchese & 207 & Marchese \\
\hline 236 & Sagrestano & 208 & Sagrestano \\
\hline 237 & Casuccia & 209 & Casuccia \\
\hline & & 210 & Revocare \\
\hline 238 & A mezzo & 211 & A mezzo \\
\hline 239 & Venire alla luce & 212 & Venire alla luce \\
\hline & & 213 & Affacendata \\
\hline
\end{tabular}

Percebemos que a primeira edição contém mais notas do que a segunda, isso não significa que a primeira está mais completa. Para fazer a nossa proposta de notas, levamos em consideração a última edição, a de 2007. Percebemos que algumas notas propostas na edição de 1999 não foram repropostas na de 2007 e os nossos alunos não as elencaram, pois se tratavam de palavras de fácil decodificação ou já conhecidas: contessa, regno, scappare, arroganza, orgoglio, mortificato, convento, colpa, terrore, persecuzione, parere, capanna, paglia, mantenimento, rapire, impegnarsi, rivelare, pena, anziano, sotterrare, polenta e orto.

Outras palavras e expressões foram substituídas por sinônimos, como foi o caso de turbato por preoccupato; spazientito por irritato; urlare por gridare; divincolarsi por agitarsi; nel colmo por nel período di massima difusione. Porém, as palavras turbato (página30) e urlare (68) apresentam outras ocorrrencias onde não foram substituídas o que causou a necessidade da definição das mesmas devido a grande ocorrência na ficha de coletas de dados preenchida durante a leitura.

Algumas foram mantidas no texto, porém tiradas do rodapé como recarsi, bambola e nel fratempo, o que não provocou nenhum problema na compreensão da leitura.

Percebemos também a supressão de certas palavras devido às modificações ocorridas na nova edição de 2007, como foi o caso de zitti zitti e sfiorita:

"Poi, nel silenzio della notte, zitti zitti nel buio tra gli orti e i campi i due promessi
sposi si dirigono verso la casa di Don Abbondio" (edição 1999)
"Poi, nel silenzio della notte, i due promessi sposi si dirigono verso la casa di Don
Abbondio" (edição 2007) 
Poteva avere venticinque anni, ancora bella, ma di una bellezza sfiorita e scomposta. (edição 1999)

Può avere venticinque anni, è ancora bella, ma ha uno squardo cupo e inquieto. (edição 2007)

Verificamos também que as unidades lexicais folla e sporcizia foram retiradas do rodapé entretanto nas fichas de coleta de dados os alunos apontaram as definições dessas unidades como necessárias.

Interessante também registar que verificamos na edição de 1999 o uso do pronome Lei como tratamento formal, e na edição de 2007, Marisa Pasqualetti adotou a segunda pessoa do plural como tratamento formal:

"Improvvisamente due giovani com la barba lunga e gli occhi feroci lo fermano e gli chiedono: Lei ha intenzione di celebrare il matrimonio di Renzo Tramaglino e Lucia Mondella domani, vero?"

"Improvvisamente due giovani com la barba lunga e gli occhi feroci lo fermano e gli chiedono: Avete intenzione di celebrare il matrimonio di Renzo Tramaglino e Lucia Mondella domani, vero?"

Na edição de 1999, o personagem Cristoforo é denominado Padre Cristofaro enquanto na de 2007, vem chamado de Fra Cristofaro.

Os alunos que leram a edição de 1999 e compilaram as fichas de coleta de dados indicaram as unidades lexicais dirupo e sudiciume para constar nas notas de rodapé, porém não incluímos tais unidades pois a edição de 2007 apresenta outros sinônimos. Dessa forma incluímos somente sporcizia.

Dopo un viaggio in mezzo ai monti e ai dirupi, si arriva in paese. (1999)

Dopo un viaggio in mezzo ai monti e ai precipizi, si arriva in paese. (2007)

Entra in una delle due stanze al piano terra: il sudiciume copre tutto il pavimento. (1999) Entra in una delle due stanze al piano terra: la sporcizia copre tutto il pavimento. (2007) 
Tratando os dados das 50 fichas de coleta de dados, através de uma análise estatística de frequência em relação à ocorrência da palavras nas fichas, onde a frequência mínima 15 era já considerda palavra e/ou expressão eleita para compor as notas, chegamos a nossa proposta para as novas notas de rodapé.

Elegemos 55 novas notas para constar no rodapé e 19 notas para ser reelaboradas. Excluímos as 77 notas que constam na tabela abaixo.

\begin{tabular}{|c|c|c|}
\hline \multicolumn{3}{|c|}{ Palavras e experssões excluídas das notas de rodapé } \\
\hline Illuminismo & Romanticismo & Vedova \\
\hline Dialetti & Senatore & Prete \\
\hline Barba & Feroce & Prepotente \\
\hline Presentimento & Saggia & Avvocato \\
\hline Pena & Collera & Galli \\
\hline Adda & Irritare & Umiltà \\
\hline Predica & Ribattere & Implorare \\
\hline Maledizione & Testimone & Restituire \\
\hline La pace sia con voi & Rapire & Saldare \\
\hline Martellare & Mercante & Frate cappuccino \\
\hline Asilo & Mormorio & Incamminarsi \\
\hline Impegno & Monastero & Perseguitare \\
\hline Invano & Lepre & Primogenito \\
\hline Destinata & Esuberante & Vergogna \\
\hline Rimorso & Complimento & Ingannare \\
\hline Senza scrupoli & Governatore & Pozzo \\
\hline Carrozza & Dato & Polso \\
\hline Monotono & Tumulto & Tiranno \\
\hline Predominio & Beneficenza & Titoli nobiliari \\
\hline Precipizio & Calvo & Rugosa \\
\hline Compassione & fare voto & Monsignore illustrissimo \\
\hline Afflitto & Distrarre & Dote \\
\hline Peste & Breviario & Cadavere \\
\hline Contagiare & Baracca & Indizio \\
\hline Infermo & Ingannare il tempo & In ozio \\
\hline Marchese & Venire alla luce & \\
\hline
\end{tabular}


Os próximos itens $(5.2$ e 5.3$)$ destinam-se às fichas lexicográficas para compor as definições das novas notas que constarão no rodapé e também aquelas reformuladas. 


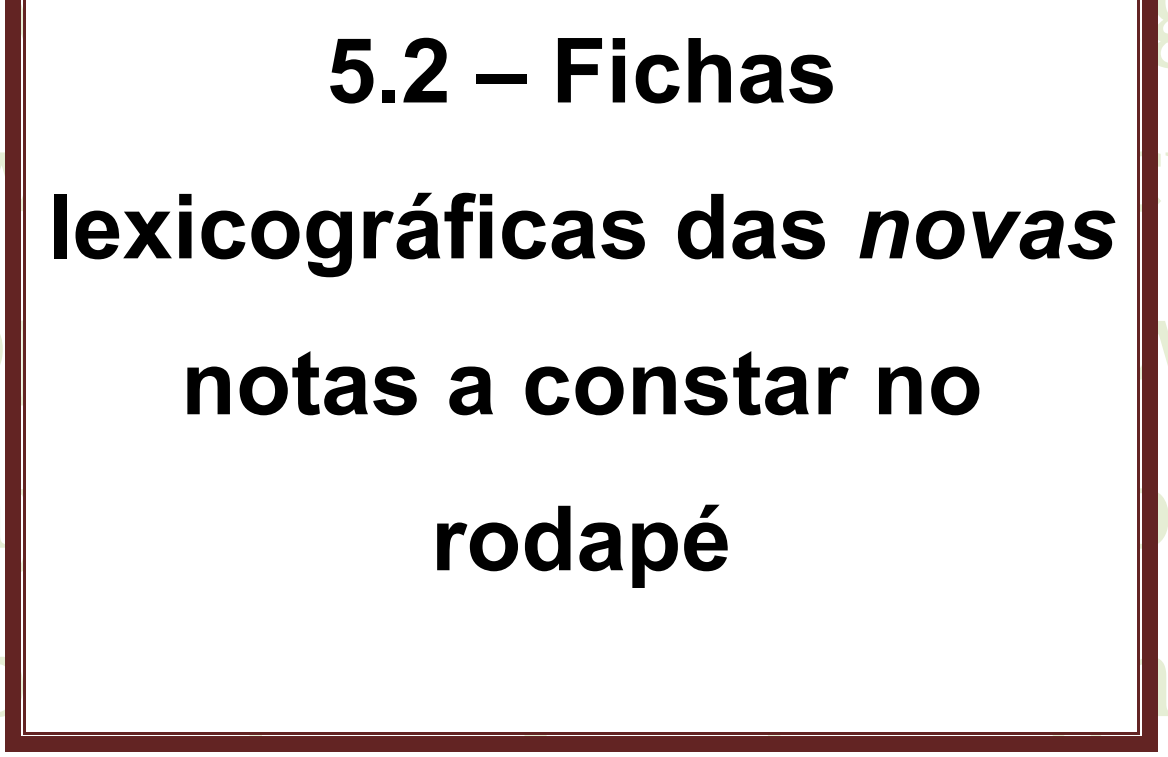


Ficha lexicográfica para as novas palavras que constarão nas notas de rodapé 1

\begin{tabular}{|c|c|}
\hline Unidade lexical & Accadere (accade/accaduto) \\
\hline Contexto & $\begin{array}{l}\text { In famiglia, come accade in quest'epoca presso i nobili, Alessandro } \\
\text { parla francese o il dialetto milanese e impara l'italiano a scuola sui } \\
\text { testi dei grandi scrittori del passato: l'italiano che conosciamo oggi } \\
\text { infatti, a quei tempi è ancora una lingua scritta che pochissime } \\
\text { parlano. (4) }\end{array}$ \\
\hline Definiçao De Mauro Paravia & $\begin{array}{l}\text { ac·ca·dé·re } \\
\text { v.intr. (essere) } \\
\text { 1. FO succedere, spec. per caso o all'improvviso: che cosa ti è } \\
\text { accaduto?; queste cose accadono spesso; impers.: accade a tutti di } \\
\text { dimenticare qcs.; accade che sia ricco, si dà il caso | TS filos. } \\
\text { divenire, con rif. alla storia umana (e in opposizione a essere) } \\
\text { 2. LE sopraggiungere, capitare, venire a proposito: fin che accadesse } \\
\text { alcuna nave buona (Ariosto) } \\
\text { 3. OB convenire, essere opportuno }\end{array}$ \\
\hline Definição Dire & $\begin{array}{l}\text { v.intr. Succedere, capitare: Oggi in classe è accaduta uma cosa molto } \\
\text { buffa. } \\
\text { Derivato da cadere, sin. avvenire } \\
\text { II verbo è usato di solito alla terza persona singolare e plurale } \\
\text { (es. Accadono strane cose in questi giorni.) e spesso nella forma } \\
\text { impersonale accade / è accaduto che (es. Spesso accade che } \\
\text { dimentichi le chiavi.) }\end{array}$ \\
\hline Definição II Sabatini-Coletti & $\begin{array}{l}\text { accadere [ac-ca-dé-re] v.intr. (aus. essere; irr.: coniug. come cadere) } \\
\text { [sogg-v-prep.arg] • Succedere, capitare casualmente a qlcu., più } \\
\text { spesso con il soggetto posposto e con specificazione di tempo e } \\
\text { luogo: ieri a Mario è accaduta una cosa buffa; in usi generalizzati, } \\
\text { anche con l'arg. sottinteso: sono accadute cose terribili. Con frase } \\
\text { soggettiva al posto del sogg. il v., in } 3^{a} \text { sing., assume valore impers.: } \\
\text { ci accadde di incontrarlo sul treno } \text { sec. XIII }\end{array}$ \\
\hline Definição II Devoto-Oli 2008 & $\begin{array}{l}\text { Accadere } \\
\text { <ac-ca-dé-re> v.intr. (coniugato come cadere; aus. essere) } \\
\text { Avvenire, succedere, capitare (per lo più di fatti casuali o improvvisi): } \\
\text { non accadrà più; accaddero strani fatti; con le prep. a, in: questo } \\
\text { accade solo a chi non sta attento; sono cose che accadono anche } \\
\text { nelle migliori famiglie; con che e l'ind.: accadde che cominciarono a } \\
\text { gridare; con la prep. a e con la prep. di e l'inf.: può a. a chiunque di } \\
\text { commettere uno sbaglio. }\end{array}$ \\
\hline Definição Lo Zingarelli 2004 & $\begin{array}{l}\text { FLESSIONE } \\
\text { aaccadere [lat. parl. *accadere, da *cadere 'cadere'; av. 1292] } \\
\text { v. intr. (coniug. come cadere; aus. essere; anche impers.) } \\
1 \text { Succedere, per lo più per caso: questo accade ai buoni; accadono } \\
\text { cose strane; mi accadde di rivederlo a teatro; può accadere che fuori } \\
\text { sia un cielo di stelle (PAVESE). SIN. Avvenire, capitare. } \\
2 \text { †Essere opportuno, convenire: Soccorrer qui, non lacrimare accade } \\
\text { (ARIOSTO). }\end{array}$ \\
\hline Definição Parola Chiave & $\begin{array}{l}\text { v.intr. [coniugato come cadere; aus. essere] Avvenire, succedere, } \\
\text { capitare: è accaduta una disgrazia; temo che gli sia accaduto } \\
\text { qualcosa; ti accade spesso incontrarlo? *acontecer }\end{array}$ \\
\hline Definição Proposta & Succede \\
\hline
\end{tabular}


Ficha lexicográfica para as novas palavras que constarão nas notas de rodapé 2

\begin{tabular}{|c|c|}
\hline Unidade lexical & Accogliere (accoglie/accolsero/accolta) \\
\hline Contexto & $\begin{array}{l}\text { Lodovico, ferito, fu portato nel convento da alcuni passanti che } \\
\text { avevano assistito alla scena e i frati lo accolsero. "E un brav'uomo } \\
\text { che ha ucciso un criminale," sostenevano tutti "lo ha fatto per } \\
\text { difendersil"(39) } \\
\text { È lì che Lucia viene accolta.(89) }\end{array}$ \\
\hline Definiçao De Mauro Paravia & $\begin{array}{l}\text { ac·cò·glie·re } \\
\text { v.tr. (io accòlgo) Fo } \\
\text { 1a. ospitare: ci ha accolti in casa sua | di qcs., contenere, raccogliere: } \\
\text { l'albergo accoglie numerosi pensionanti, la sala accoglie mille } \\
\text { persone } \\
\text { 1b. ricevere all'arrivo qcn. o qcs.: accogliere un amico; accogliere una } \\
\text { notizia, apprenderla; spec. seguito da un avv. di modo: accogliere a } \\
\text { braccia aperte, accogliere freddamente una notizia | ammettere, } \\
\text { includere: accogliere nel proprio gruppo } \\
\text { 2. accettare, approvare: accogliere una proposta, una richiesta, una } \\
\text { preghiera } \\
\text { 3. LE capire, intendere: per quanto ho da lor detti accolto, | m'han } \\
\text { promessa e venduta a un mercadante (Ariosto) } \\
\text { 4. OB ammainare: accogliere le vele }\end{array}$ \\
\hline Definição Dire & $\begin{array}{l}\text { v.tr. 1- Ricevere qualcuno, ospitare presso di sè: La mamma ha } \\
\text { accolto con molto piacere i miei amici. 2- Accetare, approvare: La } \\
\text { direzione ha accolto la tua domanda. 3- Contenere: Il nuovo } \\
\text { polisportivo può accogliere cinquantamila spettatori. } \\
\\
\text { II- ind.pres. io accolgo, tu accogli, egli accoglie, noi accogliamo, voi } \\
\text { accogliete, essi accolgono; pass. rem. io accolsi, tu accogliesti, egli } \\
\text { accolse, noi accogliemmo, voi accoglieste, essi accolsero; fut. semp. } \\
\text { io accoglierò, tu accoglierai...; cong.pres. che io accolga...; cond.pres. } \\
\text { io accoglierei, tu accoglieresti...; part.pass. accolto. } \\
\text { [lat. colligere = raccogliere], contr. } 12 \text { respingere, rifiutare }\end{array}$ \\
\hline Definição II Sabatini-Coletti & $\begin{array}{l}\text { accogliere [ac-cò-glie-re] v.tr. (irr.: coniug. come cogliere) [sogg-v- } \\
\text { arg] } \\
\text { 1 Ricevere qlcu.; anche con compl. predicativo riferito } \\
\text { all'arg.: ci ha accolti come amici; estens. ospitare qlcu. o } \\
\text { disporre per qlcu. un ambiente; freq. al passivo: fui accolta } \\
\text { con gioia; in senso fig., detto di sensazioni, manifestazioni } \\
\text { che raggiungono o colpiscono qlcu.: un sole caldo ci accolse } \\
\mathbf{2} \text { Accettare, approvare qlco.: a. una proposta; soddisfare, } \\
\text { esaudire qlco.: a. una richiesta; far proprio, adottare qlco.: a. } \\
\text { un'idea } \\
\text { 3 Contenere in sé SIN ospitare: il teatro può a. molti } \\
\text { spettatori } \\
\text { • sec. XIII }\end{array}$ \\
\hline Definição II Devoto-Oli 2008 & $\begin{array}{l}\text { accogliere } \\
\text { <ac-cò-glie-re> (poet. accorre) v.tr. (coniugato come cogliere) } \\
\text { 1. Ricevere presso di sé, ammettere nel proprio gruppo, ospitare: a. } \\
\text { qualcuno in casa, fra i propri amici; lo accolse come un fratello; fu } \\
\text { accolto con gioia.2. Accettare ciò che viene proposto o offerto, } \\
\text { approvare: a. una preghiera, una proposta, una richiesta, un } \\
\text { consiglio.3. Ricevere dentro di sé, contenere: è uno stadio capace di } \\
\text { a. settantamila spettatori.4. lett. Mettere insieme, raccogliere, } \\
\text { riunire.5. rifl. (lett.). Raccogliersi, radunarsi, riunirsi• Farsi accanto, }\end{array}$ \\
\hline
\end{tabular}




\begin{tabular}{|c|c|}
\hline & $\begin{array}{l}\text { stringersi a qualcuno (con la prep. a): Lo buon maestro a me tutto } \\
\text { s'accolse (Dante). } \\
\text { Dal lat. volg. *accolliğ̈re, der. di colliğ̌re 'raccogliere', col pref. ad- I } \\
\text { fine sec. XII }\end{array}$ \\
\hline Definição Lo Zingarelli 2004 & $\begin{array}{l}\text { accogliere o taccorre } \\
\text { [comp. del lat. ad e colligere, da legere 'raccogliere'; 1250] } \\
\text { A v. tr. (coniug. come cogliere) } \\
1 \text { Ricevere qlcu. o qlco. con varia disposizione d'animo: accogliere } \\
\text { con piacere un amico, un dono; accogliere con rincrescimento una } \\
\text { brutta notizia. } \\
2 \text { Approvare, accettare: accogliere una proposta, una istanza. } \\
\text { CONTR. Rifiutare. } \\
3 \text { Contenere, ospitare: il nuovo stadio può accogliere centomila } \\
\text { spettatori; l'ospedale accoglie più di seicento infermi. } \\
4 \text { (lett.) Raccogliere, radunare: preziosi / vasi accogliean le lagrime } \\
\text { votive (FOSCOLO). } \\
\text { B accogliersi v. rifl. } \\
\text { * (lett.) Convenire, riunirsi, raccogliersi: Li uomini poi che 'ntorno } \\
\text { erano sparti / s'accolsero a quel loco (DANTE Inf. XX, 88-89). }\end{array}$ \\
\hline Definição Parola Chiave & $\begin{array}{l}\text { v.tr. [coniugato come cogliere] } 1 \text { Ricevere: mi accolse gentilmente, } \\
\text { con freddezza; ha accolto con piacere la notizia *receber <> } \\
\text { Ospitare: un asilo che accoglie gli orfani *acolher <> Ammettere a far } \\
\text { parte: lo hanno accolto nel loro gruppo *aceitar } 2 \text { Accettare, esaudire, } \\
\text { approvare: accogliere una domanda, una richiesta, una proposta } \\
\text { *atender } 3 \text { Contenere: una sala che può accogliere molta gente } \\
\text { *acomodar }\end{array}$ \\
\hline Definição Proposta & Ricevere (riceverono, ricevuta) \\
\hline
\end{tabular}


Ficha lexicográfica para as novas palavras que constarão nas notas de rodapé 3

\begin{tabular}{|c|c|}
\hline Unidade lexical & Addirittura \\
\hline Contexto & $\begin{array}{l}\text { Addirittura re Luigi XIII, con il cardinale Richelieu, si è mosso con un } \\
\text { esercito verso questa città dell'Italia nordorientale per sostenerlo. (98) }\end{array}$ \\
\hline Definiçao De Mauro Paravia & $\begin{array}{l}\text { ad·di·rit·tù·ra } \\
\text { avv. FO } \\
\text { 1a. senz'altro: tutto ciò è addirittura inconcepibile } \\
\text { 1b. perfino: conoscere addirittura un ministro | nientemeno: sborsare } \\
\text { addirittura cento milioni; con uso escl.: «ho mangiato sei paste» } \\
\text { "addirittura!» } \\
\text { 2. OB direttamente, senza esitare }\end{array}$ \\
\hline Definição Dire & avv. Perfino, sicuramente: $\dot{E}$ addirittura più mite di quanto credessi. \\
\hline Definição II Sabatini-Coletti & $\begin{array}{l}\text { addirittura [ad-di-rit-tù-ra] avv. } \\
1 \text { (Precede o segue l'elemento cui si riferisce; tale } \\
\text { elemento può essere una singola parola o l'informazione } \\
\text { nuova della frase) Perfino, proprio: è una cifra a. ridicola } \\
\text { (ridicola, a.); questa estate abbiamo patito a. il freddo } \\
\text { (abbiamo a. patito; a. abbiamo patito); in uso assol., in tono } \\
\text { escl., col sign. di "nientedimeno!", come espressione di } \\
\text { meraviglia e perplessità di fronte a un'affermazione altrui: "E } \\
\text { venuto apposta dal Canada" "Addirittura!" } \\
2 \text { Direttamente, decisamente, senza porre altro in mezzo: } \\
\text { vediamoci a. all'aeroporto } \\
\text { • sec. XV }\end{array}$ \\
\hline Definição II Devoto-Oli 2008 & $\begin{array}{l}\text { Addirittura } \\
\text { <ad-di-rit-tù-ra> (arc. a dirittura) avv. } \\
\text { Senz'altro, direttamente (per lo più con l'idea di eliminare qualsiasi } \\
\text { motivo di compromesso, di riserva, di indugio).2. Nientemeno, } \\
\text { persino: conosce a. il ministro. } \\
\text { Dalla loc. a dirittura | prima del } 1431\end{array}$ \\
\hline Definição Lo Zingarelli 2004 & $\begin{array}{l}\text { [comp. di a- (2) e dirittura; av. 1431] } \\
\text { avv. } \\
1 \text { Perfino, senz'altro: è addirittura mostruoso quello che dici; voi } \\
\text { calpestate addirittura ogni principio; sembra che il tempo si sia } \\
\text { addirittura fermato | (enfat.) Nientedimeno: ti sei messo addirittura due } \\
\text { maglioni! } \\
2 \text { Direttamente: è meglio che ci troviamo addirittura alla stazione | } \\
\text { (lett.) Senza indugio: lui doveva tornare alla parrocchia addirittura, per } \\
\text { affari urgenti (MANZONI). }\end{array}$ \\
\hline Definição Parola Chiave & $\begin{array}{l}\text { avv. } 1 \text { Assolutamente: di questo addirittura non se ne parla } \\
\text { *absolutamente Perfino: stava addirittura per cadere *justamente } 2 \\
\text { Direttamente: vediamoci addirittura a casa *sem falta }\end{array}$ \\
\hline Definição Proposta & Anche \\
\hline
\end{tabular}


Ficha lexicográfica para as novas palavras que constarão nas notas de rodapé 4

\begin{tabular}{|c|c|}
\hline Unidade lexical & Addosso \\
\hline Contexto & $\begin{array}{l}\text { "Questo è mio!" Don Abbondio infatti le butta la tovaglia addosso e } \\
\text { comincia a gridare: "Perpetua! Perpetua! Tradimento! Aiuto!" (33) }\end{array}$ \\
\hline Definiçao De Mauro Paravia & $\begin{array}{l}\text { ad·dòs-so } \\
\text { avv., inter. Fo } \\
\text { 1. avv., sulla persona, sul corpo: mettere, portare, tenere qcs. } \\
\text { addosso; avere addosso, indossare; fig., levarsi qcn., qcs. d'addosso, } \\
\text { liberarsene | nei propri indumenti: farsi la pipi addosso | in sé: avere i } \\
\text { brividi addosso } \\
\text { 2. avv., minacciosamente o pericolosamente vicino: avere gli } \\
\text { inseguitori addosso } \\
\text { 3. inter., come incitamento ad assalire qcn.: addosso al ladro; anche } \\
\text { ass.: addosso! }\end{array}$ \\
\hline Definição Dire & $\begin{array}{l}\text { avv. 1- Sopra, sul corpo: Infilati addosso un maglione. 2- A stretto } \\
\text { contatto: Non starmi addosso con questo caldo. 3- Nell'animo: La } \\
\text { nebbia mi mette addosso tanta malinconia. } \\
\text { MODI DI DIRE } \\
\text { Dare addosso ad una persona. (Scagliarsi contro qualcuno.) } \\
\text { Mettere le meni addosso ad uno. (Malmenarlo.) }\end{array}$ \\
\hline Definição II Sabatini-Coletti & $\begin{array}{l}\text { addosso [ad-dòs-so] avv., escl. } \\
\text { • avv. } \\
1 \text { Sulle spalle, sulla persona: mettersi, portare qlco. a.; si } \\
\text { presentò con a. un mantello oppure con un mantello a. I| } \\
\text { farsela a., fare nei vestiti i propri bisogni fisiologici fig. } \\
\text { provare una gran paura } \\
2 \text { Dentro, nel corpo o nell'animo: avere a. l'influenza • loc. } \\
\text { prep. addosso a (anche con assorbimento della a nelle } \\
\text { forme pronominali atone: p.e. ci è piombato addosso) } 1 \text {. } \\
\text { Sopra: mi è caduto a. un calcinaccio | mettere le mani a. a } \\
\text { qlcu., aggredirlo fisicamente; anche fare verso di lui approcci } \\
\text { sessuali indesiderati || figg. dare a. a qlcu., perseguitarlo con } \\
\text { accuse e critiche | stare a. a qlcu., assillarlo | mettere gli } \\
\text { occhi a. a qlcu., a qlco., desiderarlo | tagliare i panni a. a } \\
\text { qlcu., dirne male | parlarsi a., parlare solo per il piacere di } \\
\text { starsi a sentire } 2 \text {. Contro: mi sono venuti a. con una moto | } \\
\text { tirarsi a. una valanga di insulti, di improperi ecc., provocare il } \\
\text { biasimo su di sé } 3 \text {. Molto vicino, a contatto o quasi: mi stai } \\
\text { troppo a. } \\
\text { • escl. Esprime incitamento ad andare contro qlcu.: dagli, } \\
\text { addosso! • sec. XIII }\end{array}$ \\
\hline Definiço II Devoto-Oli 2008 & $\begin{array}{l}\text { addosso } \\
\text { <ad-dòs-so> (arc. a dosso) avv. } \\
\text { 1. Sulle spalle, sulla persona: veniva con un gran carico di legna a. } \\
\text { star bene a., dell'abito che vada a pennello Unito ad a forma la loc. } \\
\text { prep. addosso a: gettare la colpa a. a qualcuno• locc. (fig.). Avere } \\
\text { molti anni a., essere vecchio; tagliare i panni a. a qualcuno, sparlarne } \\
\text { alle spalle; vivere a. a qualcuno, sfruttarlo; farsela a., di chi si fa } \\
\text { prendere dalla paura, dal panico o dallo scoraggiamento (propr., di } \\
\text { bambini o malati che fanno i loro bisogni nei panni di cui sono } \\
\text { vestiti).2. Contro, sopra: andare, venire a., investire; dare a., assalire } \\
\text { (fig., dar torto); metter le mani a. a qualcuno, picchiarlo o, con altro } \\
\text { senso, catturarlo• locc. (fig.). Stare a. a qualcuno, dominarlo, } \\
\text { opprimerlo, ma anche stimolarlo, sollecitarlo; levarsi qualcuno d'a., }\end{array}$ \\
\hline
\end{tabular}




\begin{tabular}{|c|c|}
\hline & $\begin{array}{l}\text { liberarsene; tirarsi a. un guaio, procacciarselo; gli è piovuta a. quella } \\
\text { disgrazia, lo ha colpito inaspettatamente. 3. Dentro di sé, in corpo: } \\
\text { aver l'argento vivo a., detto per lo più di bambini che non riescono a } \\
\text { stare un minuto fermi; avere il diavolo a., essere posseduto dal } \\
\text { demonio (fig., essere di pessimo umore); avere il malanno, la } \\
\text { maledizione a., essere sfortunatissimo• Con altro senso, 'a carico', } \\
\text { sentito come una sorta di condanna: con una moglie e due figlie di } \\
\text { quella specie a.l• Parlarsi, piangersi a., con una insistenza immotivata } \\
\text { e quindi interpretata sfavorevolmente.4. estens. Molto vicino, } \\
\text { accosto: la canonica è a. alla chiesa. }\end{array}$ \\
\hline Definição Lo Zingarelli 2004 & 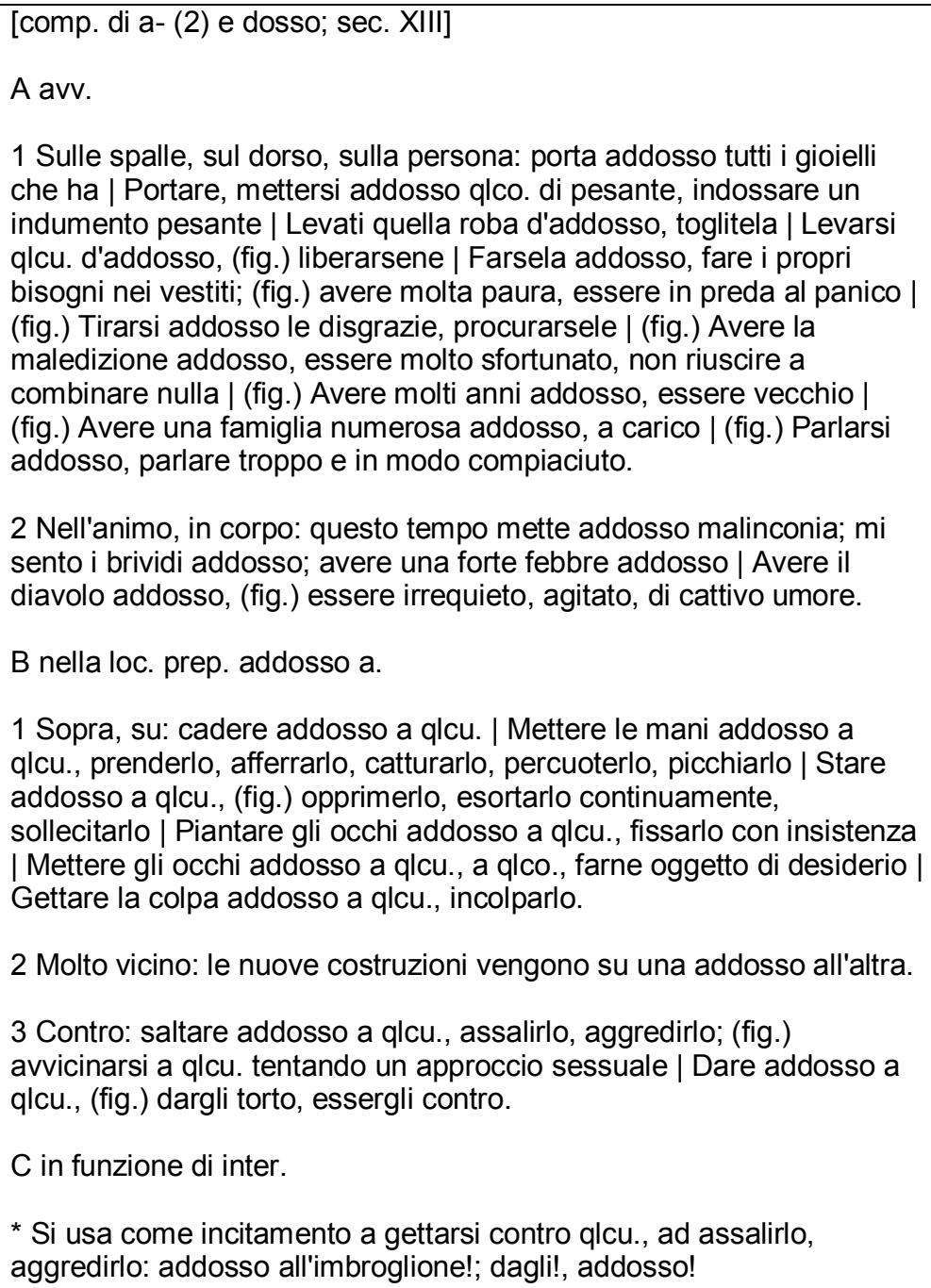 \\
\hline Definição Parola Chiave & $\begin{array}{l}\text { avv. } 1 \text { Sulle spalle, sulla persona (anche): avere addosso dei soldi; } \\
\text { sentire addosso il peso degli anni *consigo; nos ombros | Avere } \\
\text { addosso un vestito *usar uma roupa } 2 \text { Nell'animo, in corpo: avere } \\
\text { addosso la malinconia i brividi *na alma, no corpo | Avere il diavolo } \\
\text { addosso = essere impaziente irrequieto *ter o diabo no corpo } \\
\text { <>prep. (Seguito da a) } 1 \text { Su, sopra: cascare addosso a qualcuno } \\
\text { *sobre, em cima de | Stare addosso a qualcuno = fargli continue } \\
\text { richieste; controllarlo; opprimerlo *Ficar em cima de } \\
\text { alguém;persegui-lo } 2 \text { Molto vicino, accanto: un paese con le case } \\
\text { l'una addosso all'altra *encostado } 3 \text { Contro: scagliarsi addosso a } \\
\text { qualcuno *contra <>inter. Grido di incitamento a gettarsi contro } \\
\text { qualcuno *pega! }\end{array}$ \\
\hline Definição Proposta & Sopra una persona o cosa. \\
\hline
\end{tabular}


Ficha lexicográfica para as novas palavras que constarão nas notas de rodapé 5

\begin{tabular}{|c|c|}
\hline Unidade lexical & Afferra \\
\hline Contexto & $\begin{array}{l}\text { Ma Don Rodrigo afferra quella mano minacciosa e dice al frate: } \\
\text { "Uscite subito di qui!"(28) }\end{array}$ \\
\hline Definiçao De Mauro Paravia & $\begin{array}{l}\text { af·fer-rà-re } \\
\text { v.tr., v.intr. (io affèrro) AU } \\
\text { 1a. v.tr., prendere velocemente e con forza: afferrare qcs. al volo; } \\
\text { afferrare qcn. per il bavero, per i capelli } \\
\text { 1b. v.tr., fig., cogliere: afferrare l'occasione } \\
\text { 2. v.tr., fig., capire, intuire: afferrare il senso di un discorso; anche } \\
\text { ass.: hai afferrato? I sentire: il rumore impediva di afferrare le sue } \\
\text { parole } \\
\text { 3. v.tr. OB colpire con la spada } \\
\text { 4. v.tr. e intr. (avere) OB TS mar. ancorare, attraccare }\end{array}$ \\
\hline Definição Dire & $\begin{array}{l}\text { v.tr. 1- Prendere e tenere stretto: Quel bimbo non vuole entrare in } \\
\text { classe ed affera il vestito della mamma. 2- Comprendere: Hai } \\
\text { afferrato il concetto? / v.rifl. (afferrarsi) Aggrapparsi con forza: La } \\
\text { scimmia si afferra ai rami degli alberi. } \\
\text { derivato da ferro, v.tr.:sin. } 2 \text { capire, contr. } 1 \text { lasciare }\end{array}$ \\
\hline Definição II Sabatini-Coletti & $\begin{array}{l}\text { afferrare [af-fer-rà-re] v. (affèrro ecc.) } \\
\text { • v.tr. [sogg-v-arg] } \\
1 \text { Prendere qlco. con decisione SIN ghermire; con arg. } \\
\text { Indicante persona è freq. la specificazione della parte del } \\
\text { corpo o del vestito che si stringe: a. il ladro per la gola II fig. } \\
\text { a. un'occasione al volo, cogliere il momento opportuno } \\
2 \text { fig. Capire a pieno qlco. SIN comprendere: a. un concetto; } \\
\text { in contesto noto l'arg. può essere sottinteso: hai afferrato? } \\
\text { • afferrarsi } \\
\text { • v.rifl. [sogg-v-prep.arg] Attaccarsi con forza a qlco., anche } \\
\text { in senso fig. SIN aggrapparsi: a. a un'illusione } \\
\text { • sec. XIII }\end{array}$ \\
\hline Definição II Devoto-Oli 2008 & $\begin{array}{l}\text { Afferrare } \\
\text { <af-fer-rà-re> v.tr. (affèrro, ecc.) } \\
\text { Prendere e tenere stretto con forza: a. le redini; a. un } \\
\text { coltello, una pistola; a. qualcuno per il collo, per il bavero; } \\
\text { anche con la prep. a: gli afferrò il braccio fig. A. } \\
\text { l'occasione, cogliere il momento opportuno.2. fig. Arrivare a } \\
\text { comprendere, capire, intendere: hai afferrato il senso delle } \\
\text { sue parole?; con che e l'ind.: hai afferrato che te ne devi } \\
\text { andare?; anche assol.: non ho afferrato.3. rifl. Attaccarsi, } \\
\text { aggrapparsi, appigliarsi (con la prep. a): afferrarsi a un ramo, } \\
\text { alla ringhiera; fig.: a. al più piccolo pretesto, a un'illusione.4. } \\
\text { rifl. recipr. Tenersi con forza a vicenda: i due lottatori si } \\
\text { afferrarono. } \\
\text { Dal lat. tardo adferrare 'impugnare il ferro, l'arma' | sec. XIII }\end{array}$ \\
\hline
\end{tabular}




\begin{tabular}{|c|c|}
\hline Definição Lo Zingarelli 2004 & $\begin{array}{l}\text { afferrare } \\
\text { [lat. parl. *afferrare, da ferrum 'ferro, spada' (?); sec. XIII] } \\
\text { A v. tr. (io affèrro) } \\
1 \text { Prendere e tenere stretto con forza: afferrare una spada; afferrare } \\
\text { qlcu. per un lembo della giacca, per una manica, per i capelli. } \\
2 \text { (fig.) Saper profittare di una circostanza favorevole: afferrare } \\
\text { l'occasione, l'opportunità, il momento. SIN. Cogliere. } \\
3 \text { (fig.) Comprendere bene il significato di qlco.: afferrare un'idea, una } \\
\text { parola, un concetto, un pensiero, una spiegazione; non riusci ad } \\
\text { afferrare quello che dicevano. SIN. Capire. } \\
4 \text { (lett.) †Colpire col ferro: Sotto l'elmo il buon Ruggier l'afferra } \\
\text { (ARIOSTO). } \\
\text { B afferrarsi v. rifl. } \\
\text { * Attaccarsi con forza: afferrarsi alle sporgenze di una roccia, a un } \\
\text { cespuglio | Appigliarsi (anche fig.): afferrarsi a un'illusione, a una } \\
\text { scusa. }\end{array}$ \\
\hline Definição Parola Chiave & $\begin{array}{l}\text { v.tr. 1Prendere e tenere com forza: lo afferrò per un braccio *agarrar } \\
2 \text { Capire, comprendere: non ho afferrato il senso del suo discorso } \\
\text { *apreender <> afferrarsi v.pr. Attaccarsi con forza S aggrapparsi, } \\
\text { appigliarsi: si afferrò a un sostegno *agarrar-se }\end{array}$ \\
\hline Definição Proposta & Prendere con forza. \\
\hline
\end{tabular}


Ficha lexicográfica para as novas palavras que constarão nas notas de rodapé 6

\begin{tabular}{|c|c|}
\hline Unidade lexical & Altrove \\
\hline Contexto & $\begin{array}{l}\text { Sapendo che desiderano mettere su casa altrove, il marchese si offre } \\
\text { di comprare le loro casucce. (120) }\end{array}$ \\
\hline Definiçao De Mauro Paravia & $\begin{array}{l}\text { al-tró·ve } \\
\text { avv. FO } \\
\text { in altro luogo: andare, stare, trovarsi altrove | essere altrove col } \\
\text { pensiero, essere distratto, assente, pensare ad altro }\end{array}$ \\
\hline Definição Dire & $\begin{array}{l}\text { avv. In altro luogo: Cercatelo altrove. } \\
\text { [lat. Alter = altro], contr. Proprio }\end{array}$ \\
\hline Definição II Sabatini-Coletti & $\begin{array}{l}\text { [al-tró-ve] avv. } \\
\qquad \begin{array}{l}\text { • In un altro luogo: trovarsi a. \| fig. avere la testa a., essere } \\
\text { distratto } \\
\text { • sec. XIV }\end{array}\end{array}$ \\
\hline Definição II Devoto-Oli 2008 & $\begin{array}{l}\text { Altrove } \\
<\text { al-tró-ve> avv. } \\
\text { In altro luogo, da un'altra parte, presso altra gente: quel giorno mi } \\
\text { trovavo a.; aver la testa a., pensare ad altro• Come s.m. (invar.), } \\
\text { luogo che simboleggia l'assenza dell'empirico, del quotidiano, del } \\
\text { banale e che richiama un desiderio o una speranza di fuga: il sogno di } \\
\text { un altrove di giustizia } \\
\text { Lat. alíter ubi | metà sec. XIII }\end{array}$ \\
\hline Definição Lo Zingarelli 2004 & $\begin{array}{l}\text { [lat. aliter ubi; 1279] } \\
\text { avv. } \\
\text { * In altro luogo (con verbi sia di stato sia di moto): in quei giorni mi } \\
\text { trovavo altrove; sono diretto altrove; mi rivolgerò altrove | Essere } \\
\text { altrove col pensiero, avere la testa altrove, (fig.) essere distratto, } \\
\text { assente, lontano col pensiero. }\end{array}$ \\
\hline Definição Parola Chiave & avv. In altro luogo, da un'altra parte *em outro lugar \\
\hline Definição Proposta & Da un'altra parte, in un altro luogo. \\
\hline
\end{tabular}


Ficha lexicográfica para as novas palavras que constarão nas notas de rodapé 7

\begin{tabular}{|c|c|}
\hline Unidade lexical & Ammazzare/Ammazzati \\
\hline Contexto & $\begin{array}{l}\text { Vedi questi quattro capponi che dovevo ammazzare per il pranzo di } \\
\text { nozze? (12) }\end{array}$ \\
\hline Definiçao De Mauro Paravia & $\begin{array}{l}\text { am·maz·zà-re } \\
\text { v.tr. FO } \\
\text { 1a. uccidere, spec. con violenza: ammazzare qcn. a bastonate | di } \\
\text { animali da allevamento: macellare, abbattere: ammazzare un vitello | } \\
\text { far morire, causare la morte: la fame ha ammazzato molte persone } \\
\text { 1b. fig., ferire gravemente qcn. colpendolo ripetutamente: ammazzare } \\
\text { qcn. di botte } \\
\text { 2. OB uccidere a colpi di mazza } \\
\text { 3. CO fig., stancare molto, sfinire: ammazzare qcn. di fatica, questo } \\
\text { caldo mi ammazza; anche ass.: un lavoro che ammazza | deprimere, } \\
\text { mortificare: ammazzare lo spirito } \\
\text { 4. TS giochi in alcuni giochi di carte: superare la carta dell'avversario } \\
\text { con una di maggior valore }\end{array}$ \\
\hline Definição Dire & $\begin{array}{l}\text { v.tr. Uccidere qualcuno in maniera particolarmente cruenta: I } \\
\text { rapinatori hanno ammazzato il cassiere della banca. 2- Affaticare } \\
\text { gravemente: quel lavoro lo ammazza. / v.rifl. (ammazzarsi) } \\
\text { Suicidarsi. } \\
\text { derivato da mazza, v.tr.: sin. } 1 \text { assassinare, } 2 \text { sfiancare } \\
\text { MODI DI DIRE } \\
\text { Ammazzare il tempo. (Far passare il tempo.) } \\
\text { Ammazzare l'anno. (Festeggiarne la fine.) } \\
\text { PROVERBI } \\
\text { Ne ammazza più la gola che la spada. (La gola è più dannosa delle } \\
\text { armi.) }\end{array}$ \\
\hline Definição II Sabatini-Coletti & $\begin{array}{l}\text { [am-maz-zà-re] v. } \\
\text { • v.tr. [sogg-v-arg] } \\
\mathbf{1} \text { Uccidere un essere vivente in maniera cruenta SIN } \\
\text { assassinare: a. un ladro; macellare animali domestici SIN } \\
\text { abbattere: a. il maiale || fig. a. il tempo, farlo passare in } \\
\text { fretta tenendosi occupati } \\
\mathbf{2} \text { fig. Stremare qlcu.: il lavoro lo ammazza; snaturare, } \\
\text { distruggere qlco.: la televisione ammazza il dialogo } \\
\text { • ammazzarsi } \\
\text { • v.rifl. [sogg-v] } \\
\mathbf{1} \text { Uccidere se stessi volontariamente SIN suicidarsi } \\
\mathbf{2} \text { Morire accidentalmente in modo violento: a. con la moto \|| } \\
\text { fig. a. di fatica, di lavoro, lavorare molto } \\
\mathbf{3} \text { Detto di più persone, causare reciprocamente la morte } \\
\text { l'una dell'altra • sec. XIII }\end{array}$ \\
\hline
\end{tabular}




\begin{tabular}{|c|c|}
\hline Definição II Devoto-Oli 2008 & $\begin{array}{l}\text { ammazzare } \\
\text { <am-maz-zà-re> v.tr. } \\
\text { 1. Uccidere con mezzi violenti, accoppare, assassinare: fu } \\
\text { ammazzato a sangue freddo Ammazza! ammazza!, incitamento a } \\
\text { dare addosso a qualcuno, equivalente a dalli! dalli! Ammazzalo! (euf. } \\
\text { ammàppelo!), interiezione romanesca di accentuato stupore fig. A. il } \\
\text { tempo, la noia, impegnarsi in qualcosa per non stare senza far nulla, } \\
\text { per non annoiarsi Non ammazzerebbe una mosca, di chi non fa del } \\
\text { male a nessuno Va' a mori' ammazzato!, ingiuria romanesca } \\
\text { equivalente a va' al diavolo.2. Macellare animali da allevamento, } \\
\text { abbattere: a. un vitello; anche assol.: fino a giovedi il macellaio non } \\
\text { ammazza.3. estens. Far morire, provocare la morte: ne ammazza più } \\
\text { la gola che la spada (prov.).4. fig. Ridurre una persona in gravi } \\
\text { condizioni colpendola ripetutamente (anche con la prep. di): a. } \\
\text { qualcuno di botte, di pugni.5. fig. Stancare molto, estenuare, } \\
\text { sfiancare, sfinire, stremare, stroncare: questo caldo mi ammazza; } \\
\text { anche assol.: una salita che ammazza• Deprimere, mortificare: } \\
\text { brutture che ammazzano lo spirito• Deteriorare, distruggere: la } \\
\text { violenza negli stadi ammazza il calcio.6. Nel gioco delle carte, } \\
\text { superare la carta dell'avversario con una carta di maggior valore: a. il } \\
\text { tre di briscola con l'asso.7. rifl. Togliersi la vita, uccidersi, suicidarsi: } \\
\text { s'è ammazzato con un colpo di pistola alla tempia• Perdere la vita in } \\
\text { modo accidentale e violento, essere causa della propria morte per } \\
\text { sregolatezza o imprudenza (anche con le prep. con, in): ha } \\
\text { sorpassato in curva, e per poco non si ammazzava; a. con la moto, in } \\
\text { un incidente d'auto.8. rifl. (fig.). Affaticarsi eccessivamente, } \\
\text { sfacchinare fino a perdere la salute (con le prep. di, da, con, per): } \\
\text { ammazzarsi di fatica, di lavoro; a. dallo (o con lo, per lo) studio; con } \\
\text { la prep. per e l'inf.: a. per tirare avanti la famiglia. } \\
\text { Der. di mazza, col pref. a(d)-, passato dal valore di 'agire con la } \\
\text { mazza' a quello più intenso e insieme più particolare di 'uccidere' I } \\
\text { seconda metà sec. XIII }\end{array}$ \\
\hline Definição Lo Zingarelli 2004 & $\begin{array}{l}\text { Ammazzare } \\
\text { [comp. di a- (2) e mazza; sec. XIII] } \\
\text { A v. tr. } \\
1 \text { Uccidere in modo violento: I'hanno ammazzato come un cane | } \\
\text { Abbattere: per Pasqua si ammazza l'agnello | (est.) Causare la morte: } \\
\text { la malattia l'ha ammazzato in pochi mesi. } \\
2 \text { (fig.) Affaticare gravemente: questo lavoro ci ammazza | Logorare, } \\
\text { deprimere: l'inazione mi ammazza | Ammazzare il tempo, occuparlo in } \\
\text { qualche modo per vincere la noia, ingannare un'attesa e sim. } \\
3 \text { In alcuni giochi di carte, superare la carta giocata dall'avversario } \\
\text { con una di valore più alto. } \\
4 \text { †Percuotere e uccidere con la mazza. } \\
\text { B ammazzarsi v. rifl. } \\
1 \text { Darsi la morte: ammazzarsi col veleno; per il dispiacere si è } \\
\text { ammazzato | (est.) Causare la propria morte: ammazzarsi con una } \\
\text { vita sregolata. } \\
2 \text { (fig.) Affaticarsi gravemente: ammazzarsi di lavoro; ammazzarsi col } \\
\text { troppo studio. } \\
\text { C ammazzarsi v. intr. pron. } \\
\text { * Trovare involontariamente la morte: si è ammazzato in un incidente } \\
\text { automobilistico. }\end{array}$ \\
\hline
\end{tabular}




\begin{tabular}{|l|l|}
\hline Definição Parola Chiave & $\begin{array}{l}\text { v.tr. 1 Uccidere com mezzi violenti: lo ammazzò con una coltellata }<> \\
\text { Far morire: l'ha ammazzato una polmonite } 2 \text { Spossare, stremare: un } \\
\text { caldo che ammazza *matar <> ammazzarsi v.pr. 1 Suicidarsi *matar- } \\
\text { se 2 Perdere la vita: s'è ammazzato in un incidente *morrer } 3 \\
\text { Affaticarsi eccessivamente: ammazzarsi di lavoro *matar-se }\end{array}$ \\
\hline Definição Proposta & Far morire, uccidere. \\
\hline
\end{tabular}


Ficha lexicográfica para as novas palavras que constarão nas notas de rodapé 8

\begin{tabular}{|c|c|}
\hline Unidade lexical & Aria \\
\hline Contexto & Da qualche giorno c'è grande aria di festa, perché Lucia si sposa.(11) \\
\hline Definiçao De Mauro Paravia & 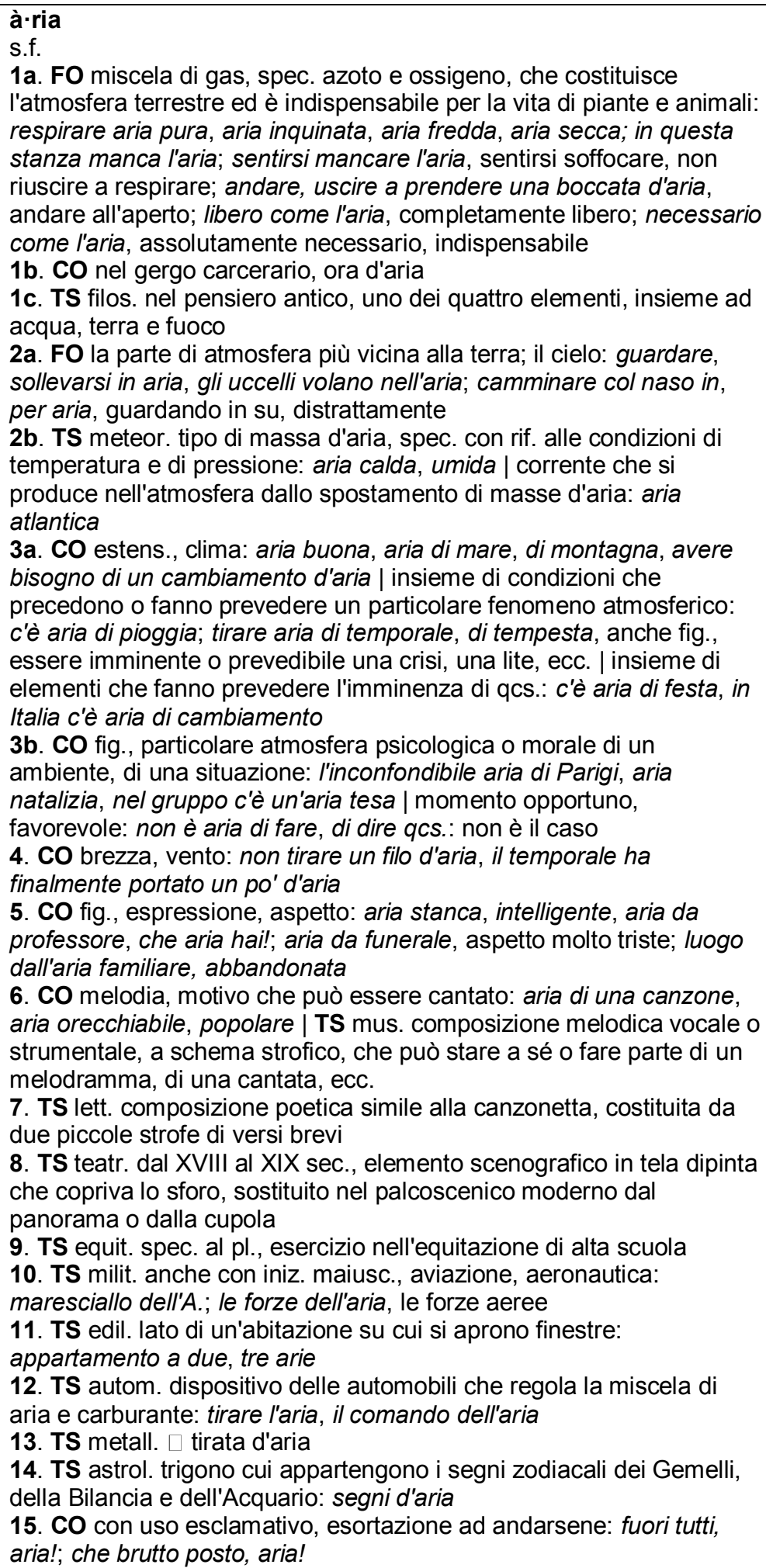 \\
\hline
\end{tabular}




\begin{tabular}{|c|c|}
\hline Definição Dire & $\begin{array}{l}\text { n.f. 1- Miscela di gas (prevalentemente azoto e ossigeno) che } \\
\text { avvolge la terra per trecento chilometri di altezza ed è indispensabile } \\
\text { alla vita degli organismi: In città l'aria è piena di smog. 2- Clima: } \\
\text { Adoro l'aria di montagna. 3- In musica, melodia cantabile per voci o } \\
\text { strumenti. } \\
\text { [gr. aér = aria] } \\
\text { MODI DI DIRE } \\
\text { Darsi delle arie. (Fare il superbo.) } \\
\text { Avere un'aria dolce, antipatica... (Avere un aspetto dolce, } \\
\text { antipatico...) Cambiare aria. (Cambiare località.) } \\
\text { Discorsi in aria. (Senza logica.) } \\
\text { PROVERBI } \\
\text { Aria alla finestra, colpodi balestra. (Gli spifferi fanno male alla salute.) }\end{array}$ \\
\hline Definição II Sabatini-Coletti & $\begin{array}{l}\text { [à-ria] s.f. } \\
1 \text { Atmosfera che avvolge la Terra, costituita da una miscela } \\
\text { gassosa in cui prevalgono azoto e ossigeno: a. fresca; } \\
\text { estens. lo spazio che si leva sulla Terra nel cielo: stare in a. } \\
\text { || colpo d'a., lieve infreddatura causata da una corrente d'aria } \\
\text { |andare a gambe all'a., cadere fig. fallire || figg. prendere } \\
\text { una boccata d'a., uscire all'aperto | dare a. alla stanza, aprire } \\
\text { le finestre | prendere a., infreddarsi, raffreddarsi | campare } \\
\text { d'a., mangiare molto poco | a. fritta, ragionamento ovvio, } \\
\text { banale, inutile | castelli in a., fantasticherie | c'è qlco. nell'a., } \\
\text { avere la sensazione di qlco. di imminente | andare all'a., non } \\
\text { realizzarsi | campato per a., privo di riscontro, infondato } \\
\mathbf{2} \text { Aria mossa, vento: un filo d'a. || fig. tira a. cattiva, brutta, si } \\
\text { preparano, sono in vista avvenimenti negativi } \\
\text { 3 estens. Clima: a. di mare || fig. cambiare a., andarsene } \\
\text { } \\
\text { - sig. Clima psicologico, atmosfera morale: a. serena } \\
\text { - dim. arietta | pegg. ariaccia } \\
\mathbf{5} \text { fig. Aspetto, sembianza, atteggiamento, apparenza: avere } \\
\text { un'a. triste || figg. darsi delle a., vantarsi | avere l'a. di, } \\
\text { sembrare: ha l'a. di un gran signore } \\
\text { smettere qlco.: basta, aria! } \\
\mathbf{6} \text { mus. Brano strofico di tipo melodico, vocale o strumentale } \\
\mathbf{7} \text { Componimento poetico in versi brevi per musica, partic. di } \\
\text { moda nel sec. XVIII } \\
\end{array}$ \\
\hline Definição II Devoto-Oli 2008 & $\begin{array}{l}\text { à-ria> s.f. } \\
\text { Miscuglio gassoso di azoto ( } 78 \% \text { in volume) e di ossigeno } \\
\text { ( } 21 \% \text { in volume), con piccole quantità di altri gas, che }\end{array}$ \\
\hline
\end{tabular}




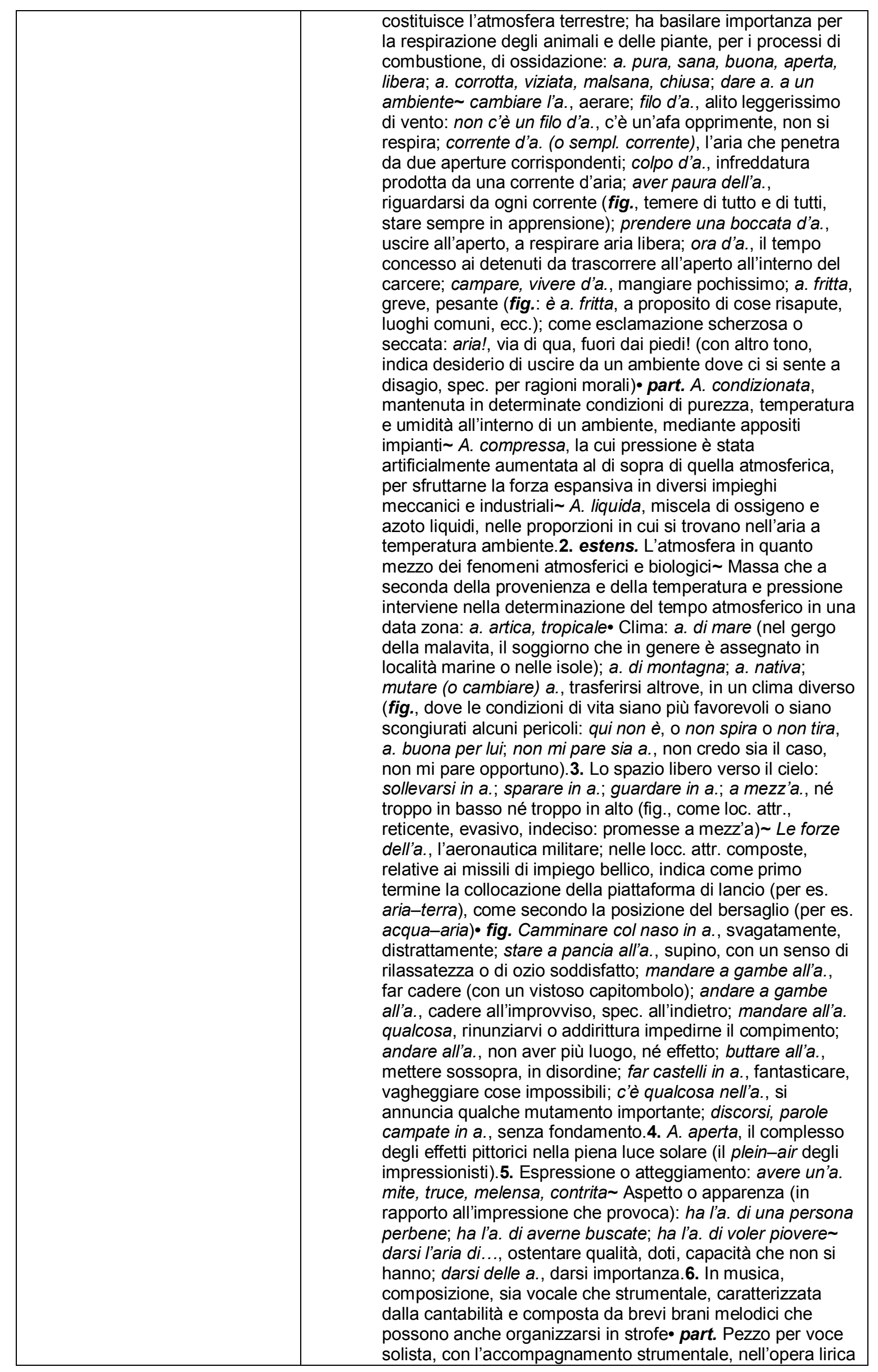




\begin{tabular}{|c|c|}
\hline & $\begin{array}{l}\text { deputato all'espressione degli affetti (contrapposto al } \\
\text { recitativo, in cui si svolge l'elemento narrativo).7. Ognuno } \\
\text { degli elementi di scenario in tela, che nel palcoscenico } \\
\text { tradizionale sono sospesi alla graticciata e servono a coprirla } \\
\text { agli occhi degli spettatori.8. Nell'equitazione di alta scuola, } \\
\text { ognuna delle figure o passi che il cavaliere fa eseguire al } \\
\text { cavallo; a. basse, quelle che non comportano lo stacco } \\
\text { simultaneo degli arti del cavallo dal terreno; a. alte, quelle in } \\
\text { cui il cavallo si distacca dal suolo.9. In astrologia: elemento } \\
\text { a., nella suddivisione dei segni secondo l'elemento } \\
\text { dominante di ciascuno, trigono di cui fanno parte i segni dei } \\
\text { Gemelli, della Bilancia e dell'Acquario (segni d'a.).10. Nel } \\
\text { linguaggio corrente, sin. di starter: tirare l'a.dim. ariétta (v.). } \\
\text { pegg. Ariàccia } \\
\text { Lat. a ra (accusativo di ä̌r), divenuto per metatesi *area, } \\
\text { aria | inizio sec. XIV }\end{array}$ \\
\hline Definição Lo Zingarelli 2004 & 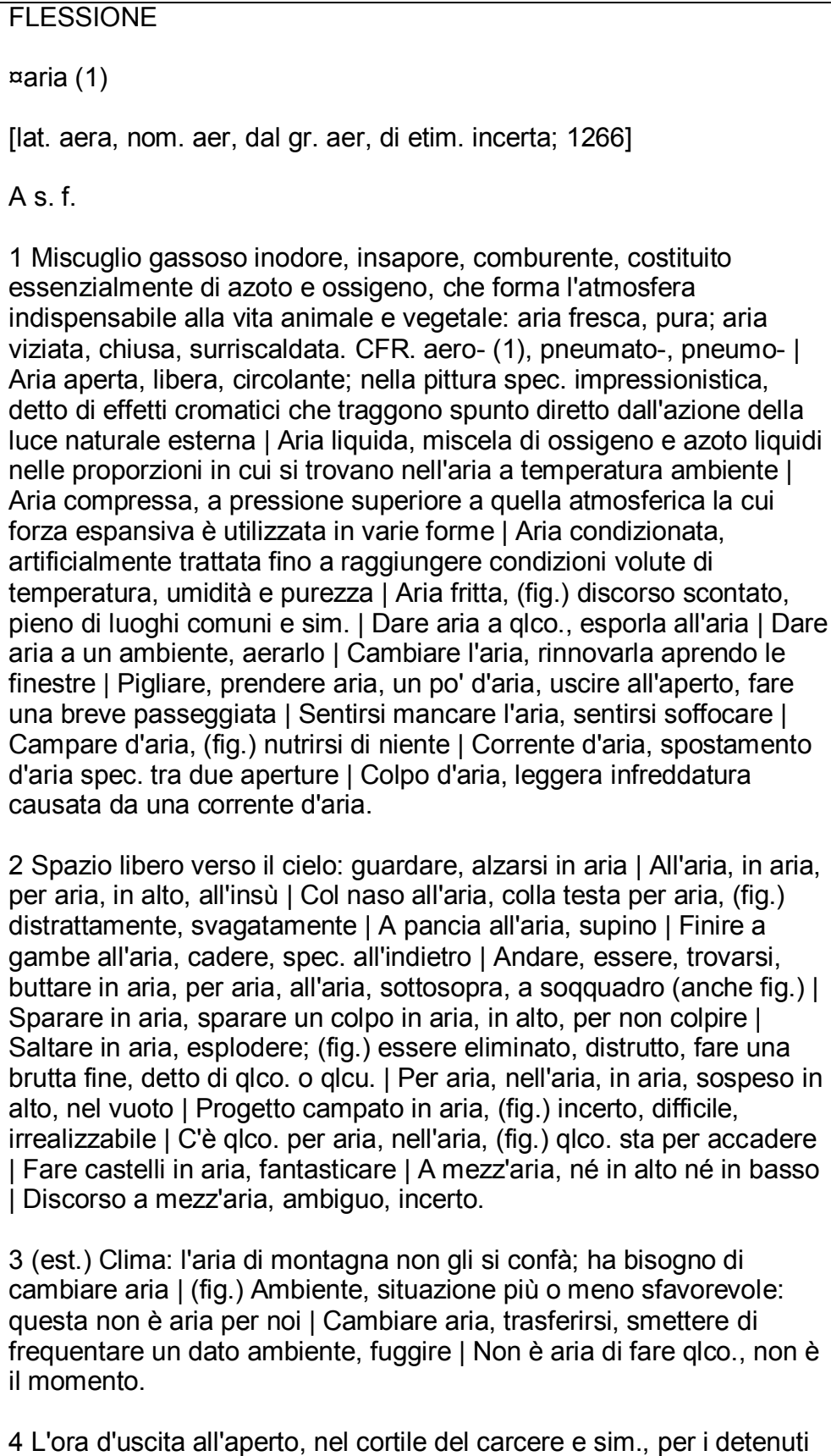 \\
\hline
\end{tabular}




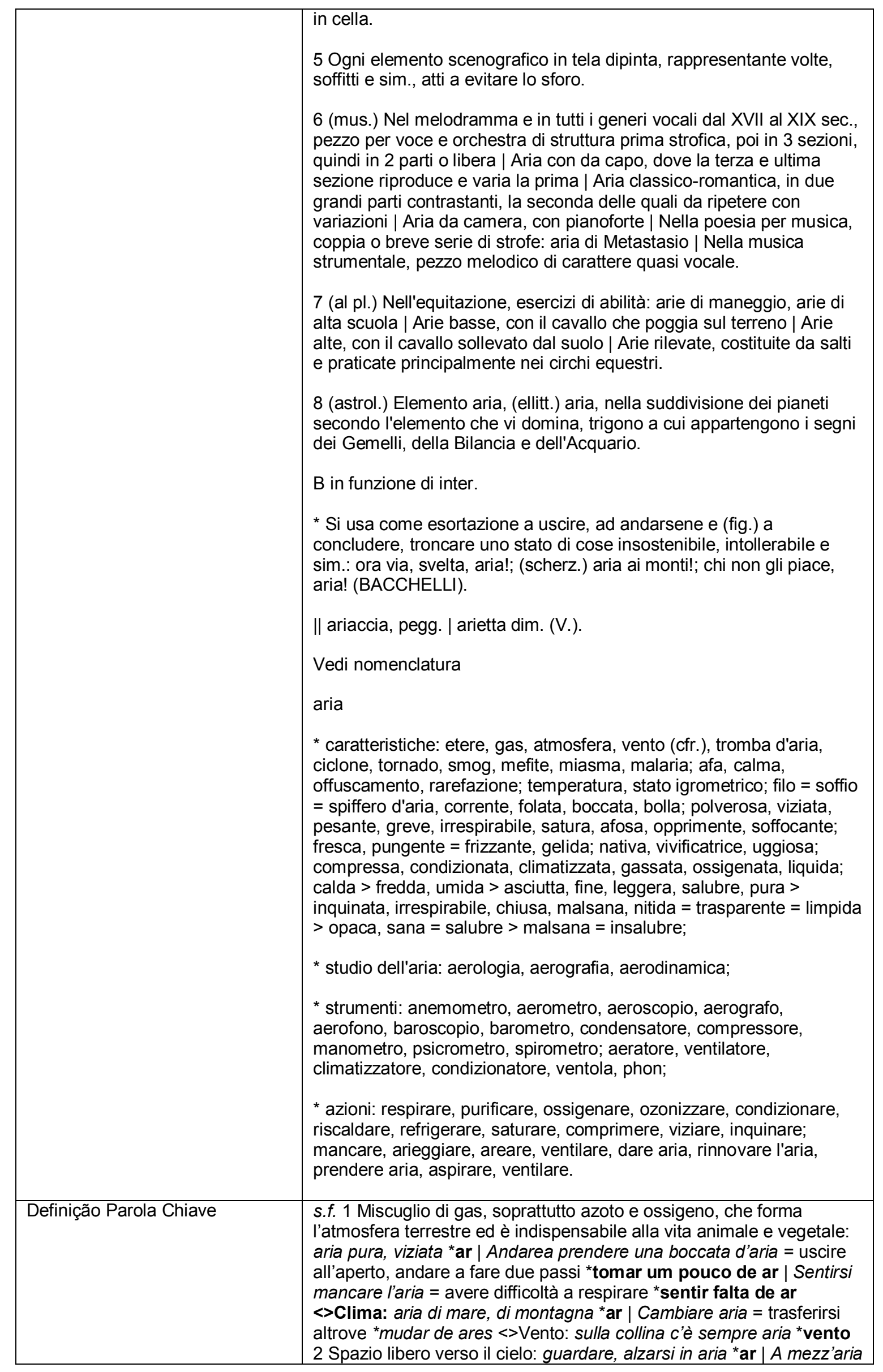




\begin{tabular}{|l|l|}
\hline & $\begin{array}{l}\text { = a media altezza dal suolo *a pouca altura Mandare all'aria = far } \\
\text { fallire *mandar pelos ares | Saltare in aria = esplodere *ir pelos ares } \\
\text { 3 Aspetto, espressione, atteggiamento: avere un'aria intelligente, } \\
\text { scontenta, di disapprovazione *ar | Darsi delle arie = darsi troppa } \\
\text { importanza, essere presuntuoso *dar-se ares 4 Melodia, brano } \\
\text { musicale: un'aria molto orecchiabile *ária }\end{array}$ \\
\hline Definição Proposta & Clima, atmosfera. \\
\hline
\end{tabular}


Ficha lexicográfica para as novas palavras que constarão nas notas de rodapé 9

\begin{tabular}{|c|c|}
\hline Unidade lexical & In Attesa \\
\hline Contexto & $\begin{array}{l}\text { Lucia, che non ha mai visto un monastero, rimana incantata ad } \\
\text { osservare, in attesa di fare il suo inchino alla signora. (45) }\end{array}$ \\
\hline Definiçao De Mauro Paravia & $\begin{array}{l}\text { at·té·sa } \\
\text { s.f. FO } \\
\text { 1. l'attendere; il tempo trascorso nell'attendere: l'attesa del treno, di un } \\
\text { amico; una lunga attesa } \\
\text { 2. spec. al pl., ciò, spec. positivo, che ci si attende da qualcuno o } \\
\text { dall'evolversi di una situazione: deludere, soddisfare le attese } \\
\text { 3. TS telef. } \square \text { attesa in blocco }\end{array}$ \\
\hline Definição Dire & $\begin{array}{l}\text { n.f. 1- Tempo trascorso ad aspettare: l'attesa in stazione è stata } \\
\text { lunga. 2- Speranza: Contro ogni attesa ho superato il concorso. } \\
\text { Derivato da attendere, sin. } 2 \text { aspettativa }\end{array}$ \\
\hline Definição II Sabatini-Coletti & $\begin{array}{l}\text { attesa [at-té-sa] s.f. } \\
\begin{array}{l}1 \text { Lasso di tempo che intercorre tra il preannuncio di un } \\
\text { evento e il suo verificarsi: a. di una notizia; stato d'animo di } \\
\text { chi aspetta: a. penosa \| sala d'a., sala d'aspetto } \\
2 \text { (spec. pl.) Ciò che ci si attende SIN speranze, } \\
\text { aspettative: le vostre a. sono andate deluse • sec. XIII }\end{array}\end{array}$ \\
\hline Definição II Devoto-Oli 2008 & $\begin{array}{l}\text { Attesa } \\
\text { <at-té-sa> s.f. } \\
\text { II tempo trascorso nell'aspettare: sala d'a.; siamo in a. di } \\
\text { notizie; mettere, lasciare in a. (al telefono), sospendere } \\
\text { temporaneamente la comunicazione senza interrompere il } \\
\text { collegamento loc. Essere in (dolce) attesa, aspettare un } \\
\text { bambino, essere incinta• Anche, lo stato d'animo di chi } \\
\text { attende il realizzarsi di qualcosa conforme alle proprie } \\
\text { speranze: c'era grande a. per la prima del concerto; deludere } \\
\text { l'a.2. Lavoro di semplice a., la prestazione (di portiere, } \\
\text { fattorino, ecc.) che per la sua stessa natura impone intervalli } \\
\text { di inattività. }\end{array}$ \\
\hline Definição Lo Zingarelli 2004 & $\begin{array}{l}\text { FLESSIONE } \\
\text { aattesa [da atteso; sec. XIII] s. f. } \\
1 \text { L'attendere: sala d'attesa; I'attesa del treno, di un amico | Lista } \\
\text { d'attesa, V. lista nel sign. } 2 \text { | Periodo di tempo che trascorre } \\
\text { nell'attendere: quell'attesa non finiva mai; I'attesa durò a lungo | Stato } \\
\text { d'animo di chi attende: I'attesa fu penosa; si consumava nell'attesa | } \\
\text { In attesa, nell'attesa, aspettando | (eufem., colloq.) Essere in attesa, } \\
\text { in dolce attesa, essere in gravidanza, aspettare un bambino. } \\
2 \text { (spec. al pl.) Aspettativa: corrispondere, venir meno alle attese; } \\
\text { tradire le attese. }\end{array}$ \\
\hline Definição Parola Chiave & $\begin{array}{l}\text { s.f. } 1 \text { II fatto di attendere: l'attesa di un ospite; sono in attesa di notizie } \\
\text { <> II tempo durante cui si attende: l'atessa fu lunga <>espera } 2 \\
\text { (spec. al pl.) Aspettativa: lo spettacolo ha deluso le mie attese } \\
\text { *expectativa }\end{array}$ \\
\hline Definição Proposta & Aspettando. \\
\hline
\end{tabular}


Ficha lexicográfica para as novas palavras que constarão nas notas de rodapé 10

\begin{tabular}{|c|c|}
\hline Unidade lexical & Cascine \\
\hline Contexto & $\begin{array}{l}\text { Quando vuole riposarsi, si ferma in alcune cascine in mezzo ai } \\
\text { campi, perché ormai di osterie non ne vuole più sapere. (105) }\end{array}$ \\
\hline Definiçao De Mauro Paravia & $\begin{array}{l}\text { ca·scìna } \\
\text { s.f. } \\
\text { 1. AU complesso di fabbricati adibiti a stalla, abitazione, fienile e } \\
\text { magazzini, talvolta disposti intorno a un cortile centrale | casa } \\
\text { colonica, casolare } \\
\text { 2a. RE emil., fienile posto sopra la stalla } \\
\text { 2b. RE emil., luogo in cui si conservano e si fanno stagionare i } \\
\text { formaggi, spec. il grana prodotto nell'anno } \\
\text { 3a. RE tosc., stalla; edificio annesso alla stalla per la produzione di } \\
\text { latte, formaggi e burro } \\
\text { 3b. RE tosc., cascino } \\
\text { 3c. RE tosc., mensola di legno di faggio su cui si mettono ad } \\
\text { asciugare e stagionare le forme di formaggio | legno di cascina }\end{array}$ \\
\hline Definição Dire & $\begin{array}{l}\text { n.f. Gruppo di case contadine raccolte attorno ad un cortile: Lo zio } \\
\text { possiede una cascina in compagna. } \\
\text { sin. Casale }\end{array}$ \\
\hline Definição II Sabatini-Coletti & $\begin{array}{l}\text { cascina [ca-scì-na] s.f. } \\
\text { • Costruzione agricola con stalla, fienile e altri locali affacciati } \\
\text { su un cortile } \\
\text { • sec. XVII }\end{array}$ \\
\hline Definição II Devoto-Oli 2008 & $\begin{array}{l}\text { Cascina } \\
\text { <ca-scì-na> s.f. } \\
\text { Tipo di insediamento agricolo caratteristico dell'Italia sett., } \\
\text { costituito da fabbricati raccolti intorno a un grande cortile, } \\
\text { comprendenti stalle e locali per la lavorazione del latte. } 2 \text {. } \\
\text { tosc. Cerchio di faggio dove si preme il latte rappreso per } \\
\text { fare il cacio; cascino• Assicella di legno di faggio usata per } \\
\text { fare scatole (detta anche legno di c.). } \\
\text { Der. dim. di un lat. volg. *capsia, class. capsa 'cassa' | sec. XVII }\end{array}$ \\
\hline Definição Lo Zingarelli 2004 & $\begin{array}{l}\text { [vc. di area sett., prob. dal lat. parl. *capsia(m), per il classico } \\
\text { capsa(m) 'cassa, recipiente' (?); av. 1604] } \\
\text { s. f. } \\
\text { * Casa colonica o parte di essa destinata al ricovero degli animali di } \\
\text { allevamento, al deposito di mangime e attrezzi, con locali in cui si } \\
\text { producono burro e formaggio | (sett.) Azienda agricola a prevalente } \\
\text { indirizzo zootecnico per la produzione del latte | (sett.) Fattoria, } \\
\text { casolare. } \\
\text { || cascinetta, dim. | cascinotto, dim. m. }\end{array}$ \\
\hline Definição Parola Chiave & $\begin{array}{l}\text { s.f. Costruzione di campagna comprendente sia stanze d'abitazione } \\
\text { sia locali d'uso agricolo (fienile, stalla, caseificio, ecc.) *fazenda; casa } \\
\text { de campo }\end{array}$ \\
\hline Definição Proposta & Case di agricoltori. \\
\hline
\end{tabular}


Ficha lexicográfica para as novas palavras que constarão nas notas de rodapé 11

\begin{tabular}{|c|c|}
\hline Unidade lexical & Colpito \\
\hline Contexto & $\begin{array}{l}\text { In questa fase della vita viene colpito da un grave lutto: la notte di } \\
\text { Natale del } 1833 \text { muore Enrichetta. (5) }\end{array}$ \\
\hline Definiçao De Mauro Paravia & $\begin{array}{l}\text { col·pì-to } \\
\text { p.pass., agg. } \\
\text { 1. p.pass. } \square \text { colpire } \\
\text { 2. agg. CO raggiunto da un colpo: colpito con un bastone, colpito da } \\
\text { una sassata; anche s.m. } \\
\text { 3. agg. CO estens., colto da un malanno fisico; anche s.m.: i colpiti da } \\
\text { influenza sono tanti } \\
\text { 4. agg. CO estens., colto, preso da uno stato d'animo, da } \\
\text { un'impressione: colpito da meraviglia, da stupore | impressionato: } \\
\text { sono colpito dalla tua generosità | fig., offeso, danneggiato: colpito } \\
\text { negli affetti più cari | TS dir. raggiunto da un provvedimento legale: } \\
\text { colpito da un'ingiunzione, da un mandato di cattura }\end{array}$ \\
\hline Definição Dire & $\begin{array}{l}\text { v.tr. 1- Battere, percuotere, ferire: Mi colpi con un pugno. 2- Provocare } \\
\text { emozione in qualcuno: La notizia mi ha colpito molto. 3- Danneggiare, } \\
\text { nuocere: Molte alluvioni hanno colpito la mia regione. 4- Punire: II } \\
\text { governo colpi i truffatori con dure sanzioni. } \\
\text { derivato da colpo, sin. } 2 \text { impressionare, commuovere }\end{array}$ \\
\hline Definição II Sabatini-Coletti & $\begin{array}{l}\text { colpire [col-pì-re] v. (colpisco, colpisci ecc.) } \\
\text { • v.tr. [sogg-v-arg] } \\
1 \text { Percuotere qlcu.: c. un avversario; battere qlco.: c. la palla; } \\
\text { anche, centrare qlcu. o qlco. con un proiettile: c. il nemico \|l } \\
\text { c. ancora, nel I. giornalistico, agire nuovamente } \| \text { fig. c. qlcu. } \\
\text { nel vivo, urtare la sua suscettibilità } \\
2 \text { fig. Fare una forte impressione su qlcu.: la notizia mi ha } \\
\text { colpito } \\
\mathbf{3} \text { fig. Danneggiare qlcu. o qlco.: un tributo che colpisce } i \\
\text { meno abbienti } \\
\text { • colpirsi } \\
\text { • v.rifl. [sogg-v] Di due o più persone, percuotersi } \\
\text { reciprocamente } \\
\text { • [sogg-v-arg] Colpire inavvertitamente una parte del proprio } \\
\text { corpo, con la specificazione del modo o del mezzo: c. il dito } \\
\text { con il martello • sec. XIII }\end{array}$ \\
\hline Definição II Devoto-Oli 2008 & $\begin{array}{l}\text { colpito >> } \\
\text { colpire } \\
\text { <col-pì-re> v.tr. (colpisco, colpisci, ecc.) } \\
\text { 1. Percuotere una o più volte, battere (anche con le prep. con, a, in, } \\
\text { su): c. un avversario; c. con un pugno, con un bastone; c. alla spalla, } \\
\text { alla mascella; c. in fronte, in pieno viso; c. sulla testa; anche assol.: } \\
\text { c. dove capita; anche tr. pron.: si colpi il petto più volte fig. C. al } \\
\text { cuore, riferito a persona, ferirla o impressionarla profondamente; } \\
\text { riferito a cosa, metterla in crisi nelle basi, nelle fondamenta: hanno } \\
\text { colpito al cuore la nostra azienda fig. C. nel segno, ottenere il } \\
\text { risultato voluto o indovinare, azzeccare. } 2 \text {. Centrare, cogliere con un } \\
\text { tiro, un lancio, uno sparo, ecc. (anche con la prep. con): il calciatore }\end{array}$ \\
\hline
\end{tabular}




\begin{tabular}{|c|c|}
\hline & 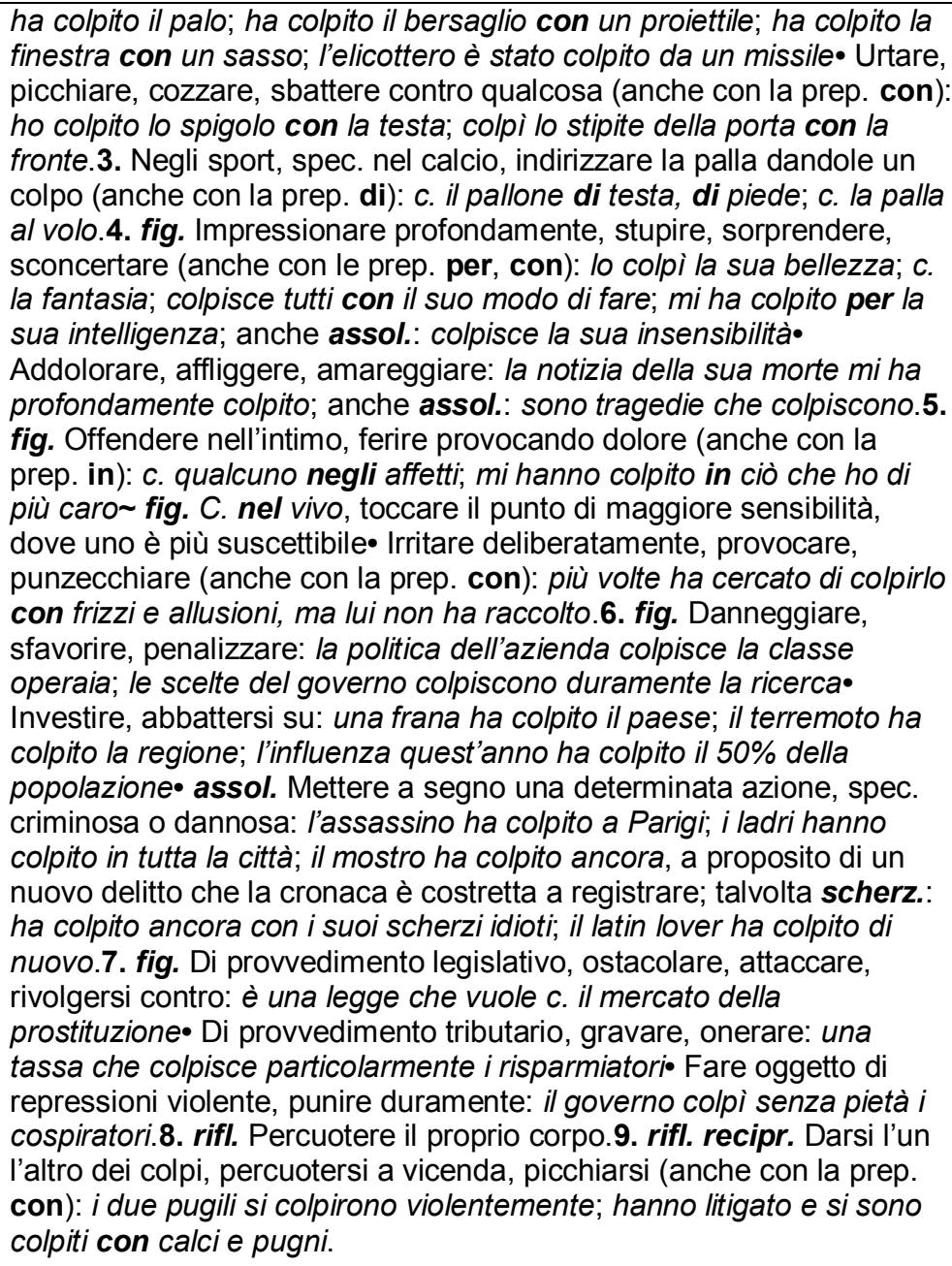 \\
\hline Definição Lo Zingarelli 2004 & $\begin{array}{l}\text { FLESSIONE } \\
\text { acolpire [da colpo; sec. XIII] } \\
\text { v. tr. (io colpisco, tu colpìsci) } \\
1 \text { Assestare uno o più colpi, con le mani o con un oggetto: lo schiaffo } \\
\text { lo colpì in pieno viso; colpire qlcu. con un pugno, con una sassata; lo } \\
\text { colpì alla testa con un bastone | Colpire il bersaglio, centrarlo | } \\
\text { Danneggiare o ferire con il colpo di un'arma da lancio o da fuoco: la } \\
\text { nave fu colpita dalla bomba; la freccia mi colpì alla gamba; ho sparato } \\
\text { in aria per non colpire nessuno | Colpire nel segno, (fig.) essere nel } \\
\text { giusto, individuare esattamente qlco. | (fig.) Colpire qlcu. nel vivo, } \\
\text { toccarlo nella suscettibilità, rivelarne il punto debole. } \\
2 \text { (fig.) Provocare una profonda impressione: quella scena mi ha } \\
\text { molto colpito. } \\
3 \text { (est.) Danneggiare con azioni violente, illegali e sim.: un'ondata di } \\
\text { rapine ha colpito tutta la zona | (est.) Punire, sottomettere a } \\
\text { provvedimenti disciplinari, aggravi finanziari e sim.: il provvedimento } \\
\text { colpirà i trafficanti | (est.) Attaccare, criticare aspramente: vuol colpire } \\
\text { la scienza ne' suoi ciarlatani (DE SANCTIS). }\end{array}$ \\
\hline Definição Parola Chiave & $\begin{array}{l}\text { v.tr. [colpisco, colpisci] 1- Raggiungerecon um copo, com dei copi: } \\
\text { colpire qualcuno con un pugno, con un bastone, con un sasso; la } \\
\text { nave fu colpita da due cannonate *atingir Denneggiare: l'epidemia ha } \\
\text { colpito i più deboli *afetar <>Punire: colpire con multe le auto in sosta } \\
\text { vietata * punir } 3 \text { Impressionare fortemente: la notizia mi ha molto }\end{array}$ \\
\hline
\end{tabular}


Ficha lexicográfica para as novas palavras que constarão nas notas de rodapé 12

\begin{tabular}{|c|c|}
\hline Unidade lexical & Cortile \\
\hline Contexto & Appena arrivati, entrano nel primo cortile e da lì nel parlatorio.(44) \\
\hline Definiçao De Mauro Paravia & $\begin{array}{l}\text { cor·tìlle } \\
\text { s.m. AU } \\
\text { 1. area scoperta situata nella parte opposta alla facciata di un edificio, } \\
\text { o interna a esso, o compresa tra più edifici, che ha spec. la funzione } \\
\text { di dare luce e aria agli ambienti che non si affacciano sulla strada: } \\
\text { cortile della scuola, finestra che dà sul cortile, ingresso dal cortile; } \\
\text { cortile interno, interamente delimitato da edifici; cortile esterno, } \\
\text { collegato a un edificio tramite recinzioni o fabbricati secondari } \\
\text { 2. aia: animali da cortile }\end{array}$ \\
\hline Definição Dire & $\begin{array}{l}\text { n.m. 1- Spazio scoperto all'interno di uno o più edifici: Alcuni } \\
\text { condomini non vogliono che si giochi nel cortile 2- Corte della casa di } \\
\text { compagna: Nel cortile della fattoria ci sono polli e conigli. } \\
\text { derivato da corte pl. cortili sin. } 2 \text { aia }\end{array}$ \\
\hline Definição II Sabatini-Coletti & $\begin{array}{l}\text { [cor-tì-le] s.m. } \\
\begin{array}{l}1 \text { Area libera, scoperta, interna a un edificio o compresa tra } \\
\text { più edifici contigui } \\
2 \text { Nella casa colonica, aia, corte } \| \text { animali da c., polli, oche, } \\
\text { conigli ecc. } \\
\text { • dim. cortiletto } \\
\text { • sec. XIV }\end{array}\end{array}$ \\
\hline Definição II Devoto-Oli 2008 & $\begin{array}{l}\text { Cortile } \\
\text { <cor-tì-le> s.m. } \\
\text { Area scoperta compresa tra i corpi di fabbrica di un palazzo } \\
\text { o di un edificio pubblico o privato, destinata a dare aria e } \\
\text { luce agli ambienti interni, al passaggio delle persone o ad } \\
\text { altre funzioni: il c. di Palazzo Vecchio; il c. della scuola.2. } \\
\text { Nelle case coloniche, sin. di corte e di aia; animali da c., } \\
\text { polli, conigli, anatre, ecc.dim. cortilétto. dim. e pegg. } \\
\text { cortilùccio. accr. cortilóne. pegg. Cortilàccio } \\
\text { Der. di corte I prima metà sec. XIV }\end{array}$ \\
\hline Definição Lo Zingarelli 2004 & $\begin{array}{l}\text { [da corte; 1312] } \\
\text { s. m. } \\
1 \text { Area libera scoperta, interna a uno o più edifici, per illuminare e } \\
\text { ventilare gli ambienti interni. } \\
2 \text { Corte della casa colonica | Animali da cortile, pollame e sim. | (fig., } \\
\text { spreg.) Rissa, litigio e sim. da cortile, volgare, chiassoso. } \\
\text { || cortilaccio, pegg. | cortiletto, dim. | cortilone, accr. }\end{array}$ \\
\hline Definição Parola Chiave & $\begin{array}{l}\text { s.m. Area scoperta all'interno di un edificio o delimitata da più edifici } \\
<>\text { Area attigua a una casa colonica } \mathbf{S} \text { corte *quintal; pátio }\end{array}$ \\
\hline Definição Proposta & $\begin{array}{l}\text { Área interna e scoperta di un edifício destinata a dare luce e } \\
\text { ventilazione. }\end{array}$ \\
\hline
\end{tabular}


Ficha lexicográfica para as novas palavras que constarão nas notas de rodapé 13

\begin{tabular}{|c|c|}
\hline Unidade lexical & Cugino \\
\hline Contexto & $\begin{array}{l}\text { Un servo lo introduce nel salotto davanti al padrone che sta } \\
\text { pranzando con i suoi amici, fra cui il cugino, il Conte Attilio. (27) }\end{array}$ \\
\hline Definiçao De Mauro Paravia & $\begin{array}{l}\text { 'cu·gì no } \\
\text { s.m. } \\
\text { 1a. AU persona che ha un legame di parentela reciproco con qcn. per } \\
\text { essere figlio di uno zio o di una zia: Paolo e Fabio sono cugini; cugino } \\
\text { materno, per parte di madre; è andato con suo cugino, è andato con il } \\
\text { cugino; può precedere un n.p.: mio cugino Mario } \\
\text { 1b. TS dir. parente in linea collaterale: cugino di quarto grado; cugino } \\
\text { di secondo, di terzo grado, biscugino } \\
\text { 2. CO fig., chi discende da un ramo comune: i nostri cugini d'Oltralpe, } \\
\text { i francesi } \\
\text { 3. TS stor. appellativo che i carbonari si davano tra loro } \\
\text { 4. TS stor. titolo che i re di Francia davano a parenti, grandi feudatari, } \\
\text { dignitari della corona e cardinali }\end{array}$ \\
\hline Definição Dire & $\begin{array}{l}\text { n.m. Figlio di uno zio o di una zia: Mio cogino è il mio migliore amico. } \\
\text { [lat. consobrinus = cugino], f. cugina, m.pl. cugini, f.pl. cugine }\end{array}$ \\
\hline Definição II Sabatini-Coletti & $\begin{array}{l}\text { [cu-gì-no] s.m. (f. -na) } \\
\text { • Figlio di un fratello o di una sorella del proprio padre o della } \\
\text { propria madre \| c. di secondo grado, figli di cugini } \\
\text { • dim. cuginetto } \\
\text { • sec. XII }\end{array}$ \\
\hline Definição II Devoto-Oli 2008 & $\begin{array}{l}\text { cugino } \\
<\text { cu-gì-no> s.m. (f. -a) } \\
\text { Figlio di uno zio o di una zia; c. di secondo grado, parentela tra figli di } \\
\text { cugini• Affiliato a una società segreta (per es. la Carboneria) Mafioso } \\
\text { della stessa cosca o famiglia• Epiteto attribuito a membri di comunità } \\
\text { o etnie di lontane origini comuni.dim. cuginétto. accr. fam. cuginóne. } \\
\text { pegg. fam. cuginàccio, scherz. cuginàstro, fam. cuginàzzo } \\
\text { Dal fr. antico cosin, dal lat. consobrinus 'cugino' | prima del } 1313\end{array}$ \\
\hline Definição Lo Zingarelli 2004 & $\begin{array}{l}\text { [ant. fr. cosin, dal lat. consobrinu(m) 'cugino'. V. consobrino; sec. XIII] } \\
\text { s. m. (f. -a) } \\
1 \text { (dir.) Parente in linea collaterale: cugino di quarto grado; cugino di } \\
\text { sesto grado. } \\
2 \text { Correntemente, figlio di uno zio o di una zia: primo cugino | Cugino } \\
\text { di secondo, di terzo grado, biscugino | Cugino nipote, figlio del cugino. } \\
3 \text { Titolo dato dai re di Francia ai parenti, ai grandi feudatari, ai dignitari } \\
\text { della corona e ai cardinali. } \\
\text { || cuginetto, dim. }\end{array}$ \\
\hline Definição Parola Chiave & s.m. Figlio di uno zio o di una zia *primo \\
\hline Definição Proposta & Parente, figlio di una zia. \\
\hline
\end{tabular}


Ficha lexical 14

\begin{tabular}{|c|c|}
\hline Unidade lexical & Curato \\
\hline Contexto & $\begin{array}{l}\text { "Sono venuto, signor curato, per sapere quando dobbiamo trovarci in } \\
\text { chiesa." (9) }\end{array}$ \\
\hline Definiçao De Mauro Paravia & $\begin{array}{l}\text { 1'cu·rà-to } \\
\text { s.m. } \\
\text { 1. Co sacerdote che esercita la cura delle anime dei fedeli in una } \\
\text { parrocchia } \\
\text { 2. TS dir.can. sacerdote assegnato a un parroco come coadiutore }\end{array}$ \\
\hline Definição Dire & $\begin{array}{l}\text { n.m. vedi PARROCO } \\
\text { n.m. Sacerdote che sta a capo di una parrocchia: /l parroco in } \\
\text { persona verrà a benedire le case. } \\
\text { [gr. parékhein = offrire], pl. parroci }\end{array}$ \\
\hline Definição II Sabatini-Coletti & $\begin{array}{l}\text { [cu-rà-to] s.m. } \\
\text { • Parroco; anche, sacerdote che ha la cura delle anime in un } \\
\text { territorio non ancora costituito in parrocchia } \\
\text { • sec. XV }\end{array}$ \\
\hline Definição II Devoto-Oli 2008 & $\begin{array}{l}\text { Curato } \\
\text { <cu-rà-to> s.m. } \\
\text { Sin. di parroco; propr., il sacerdote assegnato a un parroco come } \\
\text { coadiutore, cappellano. } \\
\text { Dal lat. mediev. curatus, der. di cura 'cura (d'anime)' | sec. XVII }\end{array}$ \\
\hline Definição Lo Zingarelli 2004 & $\begin{array}{l}\text { curato (1) } \\
\text { part. pass. di curare; anche agg. } \\
\text { * Nei sign. del v. } \\
\text { curato (2) } \\
\text { [detto così perché ha cura delle anime; 1619] } \\
\text { s. m. } \\
1 \text { Sacerdote che esercita la cura delle anime. SIN. Pievano, prevosto, } \\
\text { parroco | In alcune regioni italiane, sacerdote che aiuta il parroco. } \\
2 \text { In diritto canonico, sacerdote che coadiuva il parroco, o sacerdote } \\
\text { con poteri quasi parrocchiali. } \\
3 \text { (agr.) Varietà coltivata di pero a maturazione tardiva dal frutto } \\
\text { piuttosto grosso. }\end{array}$ \\
\hline Definição Parola Chiave & $\begin{array}{l}\text { agg. Accurato, preciso: un lavoro molto curato *cuidadoso <> } \\
\text { Ordinato, pulito: una persona curata *asseado } \\
\text {-Não consta como substantivo. }\end{array}$ \\
\hline Definição Proposta & Parroco. \\
\hline
\end{tabular}


Ficha lexicográfica para as novas palavras que constarão nas notas de rodapé 15

\begin{tabular}{|c|c|}
\hline Unidade lexical & Di corsa \\
\hline Contexto & $\begin{array}{l}\text { Renzo arriva di corsa e vede Lucia, mentre esce di casa nel suo } \\
\text { vestito da sposa: le amiche la circondano, ammirandola, e lei sorride } \\
\text { felice. (11) }\end{array}$ \\
\hline Definiçao De Mauro Paravia & $\begin{array}{l}\text { loc.avv. CO } \\
\text { 1. correndo: arrivare di corsa } \\
\text { 2. in gran fretta; fare le cose di corsa, farle in fretta e senza } \\
\text { accuratezza }\end{array}$ \\
\hline Definição Dire & $\begin{array}{l}\text { Corsa } \\
\text { n.f. 1- Andatura veloce: Sono arrivato in tempo perché ho fatto una } \\
\text { corsa. 2- Gara di velocità: Mi piace partecipare alle gare di corsa. 3- } \\
\text { Ciascun tragitto di un mezzo pubblico: L'ultima corsa dell'autobus è } \\
\text { alle venti. 4- Sforzo affannoso compiuto per raggiugere un obiettivo: } \\
\text { Nella società }\end{array}$ \\
\hline Definição II Sabatini-Coletti & $\begin{array}{l}\text { [cór-sa] s.f. } \\
1 \text { Andatura, movimento veloce: a passo di c.; andare di c.; } \\
\text { spazio percorso con tale andatura: una c. di un chilometro \| } \\
\text { figg. di c., in fretta | fare una c. in un luogo, andare e tornare } \\
\text { senza soffermarsi per via: fare una c. alla posta } \\
2 \text { sport. Gara di velocità tra uomini, animali o veicoli: } c \text {. } \\
\text { ciclistica, ippica; in partic., sport del correre: allenarsi per la } \\
\text { c. } \| \text { andare, giocare alle c., alle corse ippiche \|l fig. essere in } \\
\text { c. per qlco., essere in competizione con altri per ottenere } \\
\text { qlco. } \\
\mathbf{3} \text { estens. Moto di un veicolo: è vietato scendere dal treno in } \\
\text { c.; viaggio di un mezzo pubblico: biglietto di c. semplice } \\
\mathbf{4} \text { mecc. Distanza percorsa da un elemento che compie un } \\
\text { moto alterno; il movimento stesso: } \text { c. del pistone } \\
\mathbf{5} \text { fig. Perseguimento di un obiettivo a cui si cerca di giungere } \\
\text { a ogni costo, superando gli altri: } c \text {. al successo; c. agli } \\
\text { armamenti } \\
\mathbf{6} \text { fig. Crescita rapida e smodata SIN salita: c. dei prezzi } \\
\text { • dim. corsetta, corsettina } \\
\text { • sec. XIV }\end{array}$ \\
\hline Definição II Devoto-Oli 2008 & $\begin{array}{l}\text { corsa } \\
\text { <cór-sa> s.f. } \\
\text { 1. Modo di locomozione veloce per il quale si solleva un piede prima } \\
\text { di aver posato l'altro: rallentare la c.; era affaticato per la c.• Tratto di } \\
\text { strada percorso correndo: una c. di due chilometri.2. Rapida gita, } \\
\text { breve viaggio o spostamento: devo fare una c. a Roma; faccio una c. } \\
\text { in banca e torno subito.3. Lo sport del correre, gara di velocità: c. } \\
\text { campestre; c. ad ostacoli; c. automobilistica, ciclistica; c. a } \\
\text { cronometro, vedi cronometro; cavallo da c.• al pl. (assol.). Andare alle } \\
\text { c., all'ippodromo, in quanto la riunione comprende più gare.4. Viaggio } \\
\text { periodico di veicoli in servizio pubblico: l'ultima c. è alle } 24 \text {; il loro } \\
\text { movimento: è proibito scendere dal tram in c.• Spazio percorso al } \\
\text { suolo o presso il suolo da un aereo per acquisire o smaltire velocità: } \\
\text { c. di atterraggio, c. di decollo• Guerra di c., pirateria tollerata o } \\
\text { autorizzata dallo stato (spec. nei secc. XV-XIX).5. Misura dello }\end{array}$ \\
\hline
\end{tabular}




\begin{tabular}{|c|c|}
\hline & $\begin{array}{l}\text { spostamento di un organo con movimento limitato e rettilineo, part. } \\
\text { nel caso di movimento alternativo: la c. dello stantuffo.6. fig. } \\
\text { Affannosa e avida ricerca: c. al guadagno; c. agli armamenti, il rapido } \\
\text { intensificarsi della produzione bellica da parte delle nazioni, spec. in } \\
\text { previsione di un conflitto Essere in c. per qualcosa, competere con } \\
\text { altri per ottenere uno stesso risultato o raggiungere uno stesso } \\
\text { scopo.dim. non com. corserèlla, corsétta (v.), corsettina } \\
\text { Femm. sost. di corso }{ }^{1} \text {, p. pass. di correre | prima del } 1313\end{array}$ \\
\hline Definição Lo Zingarelli 2004 & $\begin{array}{l}\text { [da corso (2); av. 1313] } \\
\text { s. f. } \\
1 \text { II correre | Andatura veloce di uomini, animali o veicoli: andare di } \\
\text { corsa; ho fatto una corsa in macchina, in bicicletta; corsa di velocità, } \\
\text { di resistenza | A passo di corsa, con passi rapidi | A tutta corsa, di } \\
\text { gran corsa, molto velocemente | Di corsa, (fig.) prontamente, in fretta | } \\
\text { Pigliare la corsa, mettersi a correre | Fare una corsa in qualche luogo, } \\
\text { farvi una visita rapida e sim. | Essere in corsa per qlco., (fig.) } \\
\text { competere, gareggiare con altri aspirando a uno stesso scopo. } \\
2 \text { Sport del correre, gara di velocità tra uomini, animali o veicoli: corsa } \\
\text { su strada, su pista, campestre; corse piane, a ostacoli; corsa nel } \\
\text { sacco; corsa al trotto, al galoppo; corse di cani, di cavalli; corse } \\
\text { ciclistiche, automobilistiche; corsa in linea, a tappe, a cronometro, } \\
\text { dietro motori. } \\
3 \text { (al pl., per anton.) Corse di cavalli: andare alle corse. } \\
4 \text { (fig.) Tentativo frenetico di superare altri nell'acquisire qlco. e gener. } \\
\text { nel conseguire un fine: corsa all'oro; corsa agli armamenti. } \\
5 \text { Ciascuno dei viaggi di un mezzo di trasporto pubblico spec. fra due } \\
\text { stazioni terminali: quant'è il prezzo della corsa? } \\
6 \text { (est.) Tragitto percorso da un mezzo di locomozione pubblico o } \\
\text { privato | (aer.) Spazio percorso al suolo o presso il suolo da un aereo } \\
\text { per acquisire o smaltire la velocità necessaria alla sostentazione } \\
\text { dinamica: corsa di atterraggio, di decollo. } \\
7 \text { (fis.) Percorso ripetuto e uguale delle oscillazioni del pendolo, dello } \\
\text { stantuffo, del bilanciere e di qualsiasi elemento a moto alterno. } \\
\text { commercio dei nemici e a impedire quello dei neutrali: guerra di corsa; } \\
\text { nave, legno da corsa. } \\
\text { II corsaccia, pegg. | corserella, dim. | corsetta, dim. (V.) | corsettina, } \\
\text { dim. | corsina, dim. }\end{array}$ \\
\hline Definição Parola Chiave & $\begin{array}{l}\text { Corsa s.f. II correre; movimento, spostamento veloce di una persona, } \\
\text { di un animale, di un veicolo: andare di corsa; fare una corsa a piedi, in } \\
\text { macchina, a cavallo; salire sul treno in corsa *corrida | Fare una } \\
\text { corsa in un luogo = andarvi e ritornare subito indietro *dar um pulo a } \\
\text { algum lugar | Fare una cosa di corsa = in fretta *fazer algo } \\
\text { correndo <> Gara di velocità: corse podistiche, ciclistiche, } \\
\text { automobilistiche; andare alle corse (dei cavalli) } 2 \text { Viaggio, tragitto di } \\
\text { un mezzo di trasporto pubblico: l'ultima corsa dell'autobus parte tra } \\
\text { poco; pagare al tassista il prezzo della corsa } 3 \text { Aspirazione affannosa } \\
\text { a qualcosa in competizione con gli altri: corsa al successo, al } \\
\text { guadagno *corrida }\end{array}$ \\
\hline Definição Proposta & Correndo. \\
\hline
\end{tabular}


Ficha lexicográfica para as novas palavras que constarão nas notas de rodapé 16

\begin{tabular}{|c|c|}
\hline Unidade lexical & Entrambi \\
\hline Contexto & $\begin{array}{l}\text { "Ma quando vengono i guai, o per colpa o senza colpa, ci vuole La } \\
\text { fiducia in Dio per addolcirli" concludono entrambi. (122) }\end{array}$ \\
\hline Definiçao De Mauro Paravia & $\begin{array}{l}\text { en·tràm·bi } \\
\text { pron.num.pl., agg.num.pl. FO } \\
\text { 1. pron.num.pl., l'uno e l'altro, tutti e due: vogliono rivederti entrambi, } \\
\text { entrambe hanno lasciato un messaggio } \\
\text { 2. agg.num.pl., davanti a sostantivo preceduto da articolo, tutti e due: } \\
\text { in entrambi i casi bisogna intervenire, si possono fare entrambe le } \\
\text { cose }\end{array}$ \\
\hline Definição Dire & $\begin{array}{l}\text { pron. e agg.num.pl. Tutti e due, l'uno e l'altro: Li ho invitati entrambi } \\
\text { alla festa ma verrà solo uno dei due perchè l'altro è ammalat. } \\
\text { [lat. inter ambos = fra tutti e due] }\end{array}$ \\
\hline Definição II Sabatini-Coletti & $\begin{array}{l}\text { [en-tràm-bi] agg., pron. num. m. pl. (f. entrambe) } \\
\text { • agg. Tutti e due, sempre premesso al s. accompagnato } \\
\text { dall'art. determ.: sentire e. le versioni } \\
\text { • pron. Nel sign. dell'agg.: sono venuti e. } \\
\text { • sec. XIII }\end{array}$ \\
\hline Definição II Devoto-Oli 2008 & $\begin{array}{l}\text { entrambi } \\
\text { <en-tràm-bi> (arc. entrambo) pron. m.pl. (f. -e) } \\
\text { Tutti e due: già lassi erano entrambi (Tasso); anche con valore di } \\
\text { agg. (seguito però sempre dall'art.): e. gli occhi, e. le pagine. } \\
\text { Lat. inter ambos | sec. XIII }\end{array}$ \\
\hline Definição Lo Zingarelli 2004 & $\begin{array}{l}\text { entrambi o tentrambo, tintrambo, †trambi } \\
\text { [dal lat. inter ambos 'con l'uno e l'altro'; sec. XIII] } \\
\text { A agg. num. (f. entràmbe) } \\
\text { * Tutti e due, l'uno e l'altro (seguito dall'art. det.): entrambi i } \\
\text { comandanti morirono; entrambe le figlie sono bionde. SIN. Ambedue. } \\
\text { B anche pron.: colei Sofronia, Olindo egli s'appella, / d'una cittade } \\
\text { entrambi e d'una fede (TASSO); sa che da trambi è sommamente } \\
\text { amato (ARIOSTO). }\end{array}$ \\
\hline Definição Parola Chiave & $\begin{array}{l}\text { agg. e pronome m.pl. [f. entrambe] Tutti e due S ambedue: entrambi } i \\
\text { genitori sono morti; ho parlato con entrambi }{ }^{\text {ambos }}\end{array}$ \\
\hline Definição Proposta & Tutti e due. \\
\hline
\end{tabular}


Ficha lexicográfica para as novas palavras que constarão nas notas de rodapé 17

\begin{tabular}{|c|c|}
\hline Unidade lexical & Fazzoletto \\
\hline Contexto & $\begin{array}{l}\text {... mentre si volta per indicare La direzione, l'atro la prende per la vita } \\
\text { e la fa salire con forza in carrozza: lei urla e si agita, ma un altro } \\
\text { 'bravo' le mette un fazzoletto sulla bocca e le soffoca il grido in gola. } \\
\text { (84) }\end{array}$ \\
\hline Definiçao De Mauro Paravia & $\begin{array}{l}\text { faz·zo·lét·to } \\
\text { s.m. AU } \\
\text { 1. quadrato di tessuto leggero variamente colorato e rifinito, usato per } \\
\text { soffiarsi il naso, asciugarsi il sudore e sim.: mettere il fazzoletto nella } \\
\text { borsa, prendere il fazzoletto | fare, farsi un nodo al fazzoletto, legarne } \\
\text { un'estremità per ricordarsi di qcs. | sventolare il fazzoletto, per } \\
\text { salutare } \\
\text { 2. capo d'abbigliamento costituito da un quadrato di stoffa, spec. di } \\
\text { seta, che si porta intorno al collo, nel taschino o sul capo a seconda } \\
\text { delle dimensioni } \\
\text { 3. fig., piccolo appezzamento di terra: coltivare il proprio fazzoletto di } \\
\text { terra } \\
\text { 4. CO il gioco infantile della bandiera } \\
\text { 5. TS tess. piccolo taglio di tessuto con stampe di prova }\end{array}$ \\
\hline Definição Dire & $\begin{array}{l}\text { n.m. 1- Quadrato di stoffa per soffiare il naso: In tasca ho sempre il } \\
\text { fazzoletto. 2- Area piccolissima: II nonno possiede in campagna un } \\
\text { fazzoletto di terra. } \\
\text { alterato dim. di fazzolo = scialle }\end{array}$ \\
\hline Definição II Sabatini-Coletti & 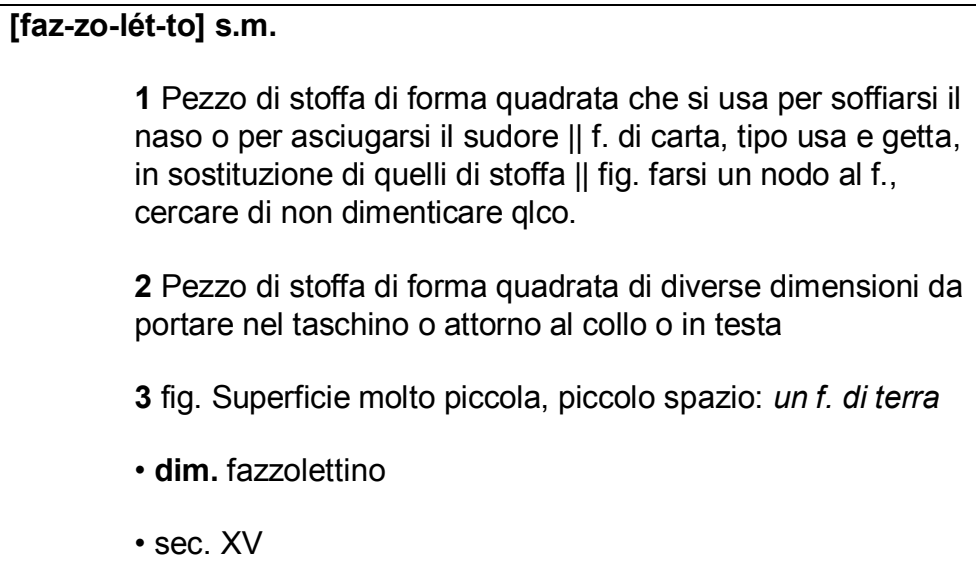 \\
\hline Definição II Devoto-Oli 2008 & $\begin{array}{l}\text { Fazzoletto } \\
\text { <faz-zo-lét-to> s.m. } \\
\text { 1. Quadrato di tela, lino o seta, che si usa per far fronte alle più } \\
\text { minute esigenze di comodità e d'igiene: } f \text {. da naso; } f \text {. da uomo, da } \\
\text { donna; tenere il } f \text {. in tasca, nella borsetta; farsi (o fare) un nodo al f., } \\
\text { per ricordarsi di qualcosa fig. Spazio circoscritto e molto limitato: un } \\
\text { f. di terra• Di maggiori dimensioni e di lana, cotone o seta, può far } \\
\text { parte dell'abbigliamento sia maschile che femminile.2. Nelle marine } \\
\text { militari, la cravatta di seta nera che, legata anteriormente con un } \\
\text { cordone bianco, è portata a completamento dell'uniforme.dim. } \\
\text { fazzolettino. dim. e pegg. fazzolettùccio. accr. fazzolettóne. pegg. } \\
\text { fazzolettàccio } \\
\text { Der. dim. di fazzolo | } 1483\end{array}$ \\
\hline Definição Lo Zingarelli 2004 & [dim. di fazzolo; av. 1471] \\
\hline
\end{tabular}




\begin{tabular}{|l|l|}
\hline & $\begin{array}{l}\text { S. m. } \\
\text { * Quadrato spec. di lino o di cotone, per soffiarsi il naso, asciugare il } \\
\text { sudore e sim.: fazzoletto da donna, da uomo | Fare un nodo al } \\
\text { fazzoletto, annodarne una cocca, per ricordare qlco. | Grande } \\
\text { quadrato, di seta o altri tessuti, per coprire la testa e sim.: portare il } \\
\text { fazzoletto annodato sotto il mento. CFR. foulard | (fig.) Fazzoletto di } \\
\text { terra, campo molto piccolo. } \\
\text { I| fazzolettino, dim. | fazzolettone, accr. | fazzolettuccio, dim. }\end{array}$ \\
\hline Definição Parola Chiave & $\begin{array}{l}\text { s.m. Pezzo di tela o di carta di forma quadrata, per soffiarsi il naso, } \\
\text { asciugarsi il sudore, ecc. <> Quadrato di stoffa portato intorno al collo, } \\
\text { nel taschino o, dalle donne, usato per coprire la testa *lenço }\end{array}$ \\
\hline Definição Proposta & $\begin{array}{l}\text { Pezzo di tessuto, generalmente di cotone, usato per pulire il } \\
\text { naso o da mettere al collo o sul capo. }\end{array}$ \\
\hline
\end{tabular}


Ficha lexicográfica para as novas palavras que constarão nas notas de rodapé 18

\begin{tabular}{|c|c|}
\hline Unidade lexical & Filatoio \\
\hline Contexto & $\begin{array}{l}\text { Renzo, che ha lavorato in un filatoio del bergamasco sotto il falso } \\
\text { nome di Antonio Rivolta, dopo aver preso la peste ed esserne guarito } \\
\text { curandosi da solo, decide di tornare a casa. (103) }\end{array}$ \\
\hline Definiçao De Mauro Paravia & $\begin{array}{l}\text { fi·la·tó·io } \\
\text { s.m. CO TS tess. } \\
\text { 1. macchina per la filatura } \\
\text { 2a. reparto della filanda in cui si esegue la torsione e l'avvolgimento } \\
\text { del filo sulle spole } \\
\text { 2b. estens., la filanda stessa }\end{array}$ \\
\hline Definição Dire & Não consta. \\
\hline Definição II Sabatini-Coletti & $\begin{array}{l}\text { fi-la-tó-io] s.m. (pl. -toi) } \\
1 \text { Macchina utilizzata per ridurre le fibre tessili in fili } \\
2 \text { Reparto di una fabbrica dove si filano le fibre tessili } \\
\text { • sec. XIV }\end{array}$ \\
\hline Definição II Devoto-Oli 2008 & $\begin{array}{l}\text { filatoio } \\
\text { <fi-la-tó-io> s.m. (pl. -ói) } \\
\text { 1. La macchina che effettua le ultime e definitive operazioni di filatura } \\
\text { delle fibre tessili (stiro, torsione, avvolgimento); } f \text {. ad anello, vedi } \\
\text { RING.2. II reparto della filanda in cui si compie l'ultima torsione del filo } \\
\text { e la sua raccolta in bobine. } \\
\text { Der. di filare }{ }^{2} \text { | inizio sec. XIV }\end{array}$ \\
\hline Definição Lo Zingarelli 2004 & $\begin{array}{l}\text { [da filato; 1312] } \\
\text { s. m. } \\
1 \text { Macchina per la filatura. } \\
2 \text { (raro) Arcolaio I †Girare il filatoio, (fig.) girare la fantasia o aver } \\
\text { paura. } \\
3 \text { Parte della filanda in cui si completa la filatura e si procede } \\
\text { all'avvolgimento del filo su bobine. } \\
4 \text { (tess.) Filatoio ad anelli, ring. }\end{array}$ \\
\hline Definição Parola Chiave & Não consta. \\
\hline Definição Proposta & Dove si lavorano i filati (cotone o seta) per fare dei tessuti. \\
\hline
\end{tabular}


Ficha lexicográfica para as novas palavras que constarão nas notas de rodapé 19

\begin{tabular}{|c|c|}
\hline Unidade lexical & Folla \\
\hline Contexto & $\begin{array}{l}\text { Alla fine la folla sfonda la porta e tutti si gettano sulle casse del pane: } \\
\text { è la rivolta.(63) } \\
\text {... e a salvarlo dall'ira della folla. (65) }\end{array}$ \\
\hline Definiçao De Mauro Paravia & $\begin{array}{l}\text { fól-la, fòl-la } \\
\text { s.f. FO } \\
\text { 1. grande quantità di persone riunite in un luogo: strade piene di folla, } \\
\text { una folla di bagnanti sulla spiaggia, mescolarsi alla folla, farsi strada } \\
\text { tra la folla | spreg., volgo, popolino: demagogia buona per le folle, } \\
\text { ottenere l'apprezzamento della folla } \\
\text { 2. estens., iperb., gruppo numeroso di persone: essere circondato da } \\
\text { una folla di amici, di ammiratori, di adulatori } \\
\text { 3. fig., concitata moltitudine di pensieri, sentimenti e sim.: essere } \\
\text { assalito da una folla di ricordi } \\
\text { 4. OB ammasso di cose che esercita una pressione in un luogo; tale } \\
\text { pressione } \\
\text { 5. TS scient. insieme di elementi di varia natura: folla di particelle } \\
\text { 6. TS tess. acqua da concia in cui vengono fatte bollire le falde } \\
\text { imbastite per ottenere il feltro da cappelli. }\end{array}$ \\
\hline Definição Dire & $\begin{array}{l}\text { n.f. 1- Moltitudine di persone concentrate in un luogo: Una folla } \\
\text { immensa si accalca nella piazza. 2- Insieme, massa confusa: A volte } \\
\text { sono assalito da una folla di ricordi. }\end{array}$ \\
\hline Definição II Sabatini-Coletti & $\begin{array}{l}\text { folla [fòl-la o fól-la] s.f. } \\
1 \text { Grande numero di persone riunite insieme; anche, numero } \\
\text { eccessivo SIN calca, ressa; estens. gruppo numeroso SIN } \\
\text { schiera, stuolo: avere una } f . \text { di ammiratori; anche con } \\
\text { valore spreg. SIN massa: mi tengo lontano dalla } f \text {. \|l bagno } \\
\text { di f., riferito a un personaggio importante, contatto con la } \\
\text { gente } \\
2 \text { fig. Massa confusa di pensieri, di emozioni: una } f . \text { di } \\
\text { sensazioni in testa } \\
\text { - sec. XIV }\end{array}$ \\
\hline Definição II Devoto-Oli 2008 & $\begin{array}{l}\text { Folla } \\
<\text { fòl-la> s.f. } \\
\text { Moltitudine anonima di persone: far f., accalcarsi; anche spreg., } \\
\text { massa, volgo: non bisogna credere agli applausi della } f \cdot \bullet \text { fig. Cumulo } \\
\text { eccessivo od opprimente: una f. di preoccupazioni; fu assalito in un } \\
\text { punto da una folla di rimembranze dolorose, e di dolorosi } \\
\text { presentimenti (Manzoni) }\end{array}$ \\
\hline Definição Lo Zingarelli 2004 & $\begin{array}{l}\text { FLESSIONE } \\
\text { afolla o folla } \\
\text { [da follare, come calca da calcare: in orig. il sign. di folla era solo } \\
\text { quello di 'pressione'; sec. XIV] } \\
\text { s. f. } \\
1 \text { Quantità di gente riunita insieme: una folla festante si assiepava } \\
\text { lungo la strada; una folla immensa e festosa traboccava di contrada in } \\
\text { contrada (NIEVO) | (fig.) Bagno di folla, il trattenersi a lungo tra una } \\
\text { folla entusiasta durante una manifestazione pubblica, detto spec. di }\end{array}$ \\
\hline
\end{tabular}




\begin{tabular}{|l|l|}
\hline & $\begin{array}{l}\text { personaggio famoso. } \\
2 \text { (est., anche spreg.) Gente, massa: aveva tentato d'uscire dal suo } \\
\text { guscio e comunicare con la folla (SVEVO); non mi interessano gli } \\
\text { applausi della folla. } \\
3 \text { (fig.) Gran numero di cose: una folla di pensieri disordinati. SIN. } \\
\text { Moltitudine. }\end{array}$ \\
\hline Definição Parola Chiave & $\begin{array}{l}\text { s.f. Grande quantità di persone riunite assieme: una piazza piena di } \\
\text { folla; si fece largo tra la folla *multidão }\end{array}$ \\
\hline Definição Proposta & Molte persone insieme. \\
\hline
\end{tabular}


Ficha lexicográfica para as novas palavras que constarão nas notas de rodapé 20

\begin{tabular}{|c|c|}
\hline Unidade lexical & Giace \\
\hline Contexto & $\begin{array}{l}\text { Sulla Riva, una barca aspetta Renzo, Lucia e Agnese: non tira un } \\
\text { alito di vento, il lago giace liscio e piano e sembrerebbe immobile, se } \\
\text { non fosse per l'ondeggiare leggero della luna che vi si specchia. (34) }\end{array}$ \\
\hline Definiçao De Mauro Paravia & $\begin{array}{l}\text { gia.cé·re } \\
\text { v.intr. (essere, rar. avere) Fo } \\
\text { 1a. stare sdraiato, disteso, anche perché costretto a letto da malattia } \\
\text { e sim.: giacere per terra, sul letto, giacere infermo } \\
\text { 1b. rimanere a terra privo di vita: cadde al suolo e giacque esanime } \\
\text { 1c. essere morto, sepolto: giacere nella tomba; qui giace, nelle } \\
\text { iscrizioni funerarie } \\
\text { 2. OB fare l'amore, avere un rapporto sessuale con qcn. } \\
\text { 3. CO trovarsi, essere situato in basso o in un paesaggio } \\
\text { pianeggiante: il lago giace nel mezzo della vallata, la città giace nel } \\
\text { piano } \\
\text { 4. CO fig., permanere in una situazione materiale o morale disagiata, } \\
\text { indesiderabile: giacere nella miseria più nera, giacere in carcere; } \\
\text { giacere nella disperazione } \\
\text { 5. CO di qcs., essere dimenticato, trascurato: il parco e la villa } \\
\text { giacciono nell'abbandono | restare inutilizzato: ha una fortuna che } \\
\text { giace in banca | restare non sbrigato, inevaso: la mia pratica giace } \\
\text { negli archivi } \\
\text { 6. TS mat. di una linea o un punto, essere situato: la retta giace sul } \\
\text { piano } \\
\text { 7. LE essere abbattuto, incapace di reazione: giacqui: insensato, } \\
\text { attonito, I non dimandai conforto (Leopardi) }\end{array}$ \\
\hline Definição Dire & $\begin{array}{l}\text { v.intr. 1- Stare disteso: II ragazzo, dopo aver giocato, giaceva sul } \\
\text { prato per riposarsi un po'. 2- Essere collocato, trovarsi: La vallata } \\
\text { giace tra due montagne. 3- Nel linguaggio burocratico, essere } \\
\text { sospeso, rimanere innativo: Molte pratiche importanti giacciono } \\
\text { ancora in ufficio. } \\
\text { II- ind.pres. Io giaccio, tu giaci, egli giace, noi giaciamo voi giacete, } \\
\text { essi giacciono; pass.rem. io giacqui, tu giacesti, egli giacque, noi } \\
\text { giaccemmo, voi giaceste, essi giacquero; cong.pres. che io giaccia, } \\
\text { che tu giaccia, che egli giaccia, che noi giacciamo, che voi giacciate, } \\
\text { che essi giacciano; part.pass. giaciuto. } \\
\text { [lat. iacere = giacere] }\end{array}$ \\
\hline Definição II Sabatini-Coletti & $\begin{array}{l}\text { [gia-cé-re] v.intr. (aus. essere o avere; irr.: ind.pres. giàccio, giaci, } \\
\text { giace, giacciamo o giaciamo, giacéte, giàcciono, pass.rem. giàcqui, } \\
\text { giacésti ecc.; congiunt.pres. giàccia, giacciamo, giacciate, giàcciano; } \\
\text { part.pass. giaciuto) } \\
\text { • [sogg-v-prep.arg] } \\
\mathbf{1} \text { Essere adagiato su un piano orizzontale: l'ammalato } \\
\text { giaceva nel letto; essere sepolto in un luogo: g. nel cimitero } \\
\text { del paese; in geometria, essere situato: la retta giace sul } \\
\text { piano } \\
\text { 2 fig. Riferito a carte, denaro, indagini, essere abbandonati in } \\
\text { un certo posto: le pratiche dell'affare giacciono negli uffici } \\
\mathbf{3} \text { Detto di luoghi, essere collocato in una certa posizione: il } \\
\text { paese giace ai piedi della montagna } \\
\mathbf{4} \text { fig. Trovarsi in una certa situazione, spec. disagiata: } g \text {. }\end{array}$ \\
\hline
\end{tabular}




\begin{tabular}{|c|c|}
\hline & $\begin{array}{l}\text { nella miseria più nera } \\
\text { • sec. XIII }\end{array}$ \\
\hline Definição II Devoto-Oli 2008 & 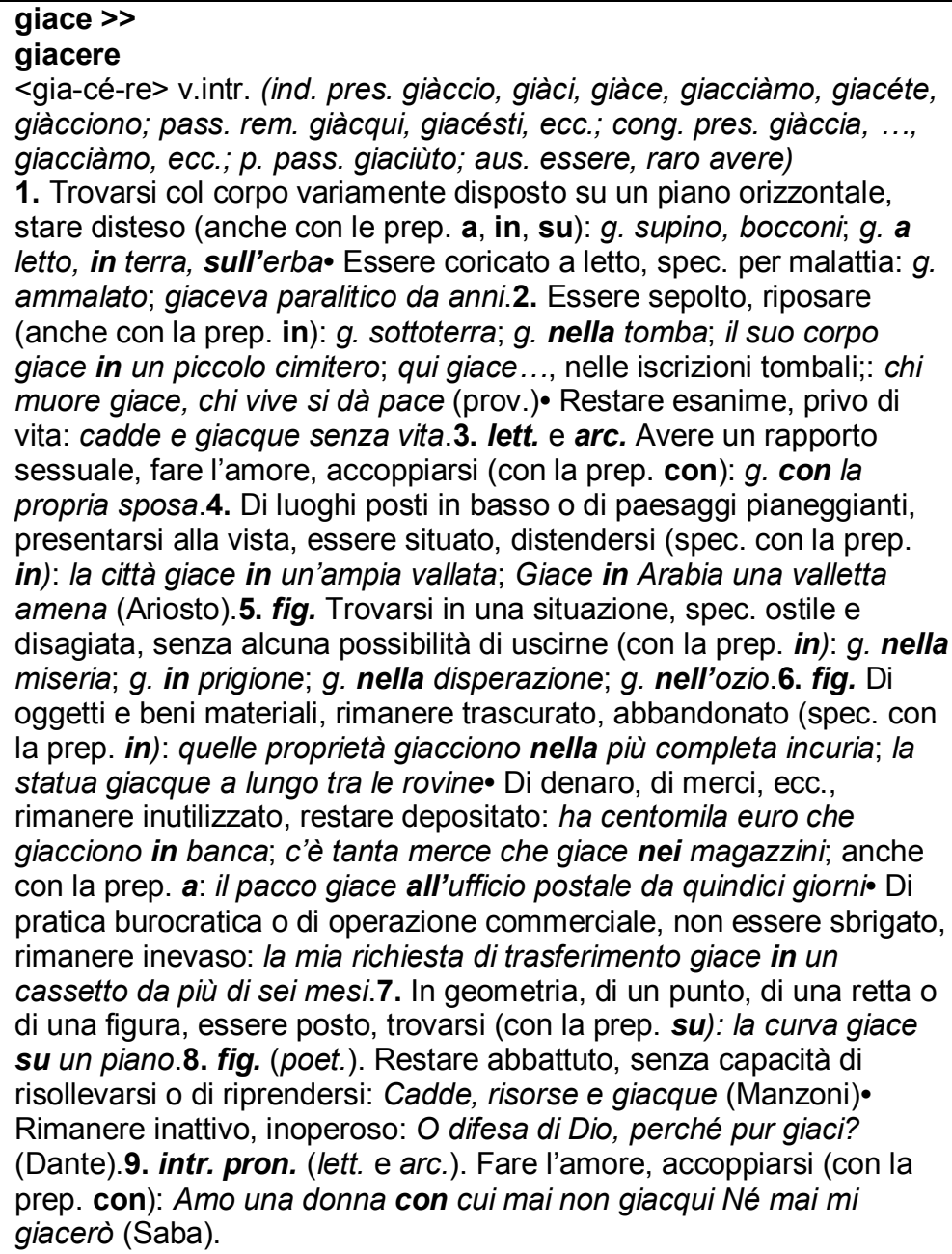 \\
\hline Definição Lo Zingarelli 2004 & $\begin{array}{l}\text { FLESSIONE } \\
\text { agiacere o (tosc.) diacere, tiacere } \\
\text { [lat. iacere 'essere steso, abbattuto' (opposto a stare), da iacere } \\
\text { 'buttare (giù)', di orig. indeur.; 1266] } \\
\text { A v. intr. (pres. io giàccio, tu giàci, egli giàce, noi giacciàmo, (evit.) } \\
\text { giaciàmo, voi giacète, essi giàcciono; pass. rem. io giàcqui, †giacètti, } \\
\text { tu giacèsti; congv. pres. io giàccia, ecc., noi giacciàmo, (evit.) } \\
\text { giaciàmo, voi giacciàte, (evit.) giaciàte, essi giàcciano; part. pass. } \\
\text { giaciùto; aus. essere, raro avere) } \\
1 \text { Stare disteso: giacere a letto, a terra, sul fianco, supino, bocconi; } \\
\text { mettersi a giacere; giacere ammalato | Qui giace, qui è sepolto, nelle } \\
\text { iscrizioni funerarie | †Morire senza giacere, all'improvviso. } \\
2 \text { (spec. lett.) Essere situato, posto: il paese giace in una valle | } \\
\text { †Come giace nel testo, come è scritto nel testo. } \\
3 \text { (mat.) Appartenere a: la retta giace su, in un piano. } \\
4 \text { Stare inerte, inattivo: il capitale giace inutilizzato; giacere nell'ozio, } \\
\text { nel vizio; mi pare da credere sia l'uomo nato, certo non per marcire } \\
\text { giacendo, ma per stare faccendo (ALBERTI) | La domanda, la pratica }\end{array}$ \\
\hline
\end{tabular}




\begin{tabular}{|l|l|}
\hline & $\begin{array}{l}\text { giace negli uffici, non ha corso. } \\
5 \text { (fig., lett.) Rimanere abbattuto senza capacità di riprendersi: con } \\
\text { vece assidua / cadde risorse e giacque (MANZONI) | Essere } \\
\text { depresso, avvilito. } \\
6 \text { †Essere meno ripido, pianeggiante. } \\
7 \text { †Dormire. } \\
\text { B v. intr. (aus. essere, raro avere) e giacersi v. intr. pron. } \\
\text { * (lett.) Avere rapporti sessuali con qlcu.: amo una donna con cui mai } \\
\text { non giacqui, / né mai mi giacerò (SABA). } \\
\text { C giacersi v. intr. pron. } \\
\text { * †Stare disteso (con valore intens.): uno ne ferio, sì che in sull'erba } \\
\text { morendo si giacque (BOCCACCIO) | Dormire. }\end{array}$ \\
\hline Definição Parola Chiave & $\begin{array}{l}\text { v.intr. [pres. Giaccio, giaci, giace, giacciamo, giacete, giacciono; } \\
\text { pass.rem. giaciuto; aus. essere o avere] } 1 \text { Stare disteso, sdraiato: } \\
\text { giacere a letto, a terra, su un fianco *jazer | Qui giace = qui è sepolto } \\
\text { (nelle iscrizioni funebri) *aqui jaz <> Stare, trovarsi in una condizione } \\
\text { negativa: il giardino giaceva nel più completo abbandono } 3 \text { Essere } \\
\text { situato: il villaggio giace in fondo alla vallata } 3 \text { Essere fermo, } \\
\text { accantonato in un certo posto (detto spec. di merci e di pratiche } \\
\text { burocratiche) *jazer }\end{array}$ \\
\hline Definição Proposta & \begin{tabular}{l} 
Si presenta. \\
\hline
\end{tabular} \\
\hline
\end{tabular}




\begin{tabular}{|c|c|}
\hline Unade lexical & Guadagnare \\
\hline Contexto & $\begin{array}{l}\text {...ma i fornai non sono disposti a lavorare senza guadagnare e si } \\
\text { rivolgono direttamente al Governatore, Don Gonzalo Fernandez de } \\
\text { Cordova, che rincara di nuovo il pane. (62) }\end{array}$ \\
\hline Definiçao De Mauro Paravia & $\begin{array}{l}\text { gua.da·gnà-re } \\
\text { v.tr., v.intr. FO } \\
\text { 1a. v.tr., ottenere come utile, come profitto o ricevere come } \\
\text { compenso: guadagnare denaro, guadagnare trenta milioni all'anno, } \\
\text { guadagnare il } 7 \% \text {, quanto guadagni al mese? | anche ass.: in questo } \\
\text { lavoro si guadagna, non si guadagna; guadagnare bene, avere delle } \\
\text { buone entrate } \\
\text { 1b. v.tr., estens., spec. ass., ottenere come vantaggio, come } \\
\text { beneficio: c'è da guadagnare ad ascoltarlo } \\
\text { 1c. v.tr., fig., ottenere come riconoscimento delle proprie qualità, } \\
\text { meritare: guadagnare le lodi, la stima altrui } \\
\text { 2. v.tr., raggiungere, spec. con sforzo e difficoltà: guadagnare la vetta, } \\
\text { guadagnare il traguardo } \\
\text { 3. v.tr. RE sett., vincere a un gioco: guadagnare cento milioni al } \\
\text { totocalcio } \\
\text { 4. v.intr. (avere) co divenire più piacevole, spec. dal punto di vista } \\
\text { estetico: Anna guadagna con i capelli corti, la stanza guadagna in } \\
\text { luminosità con una tappezzeria chiara }\end{array}$ \\
\hline Definição Dire & $\begin{array}{l}\text { Guadagnare } \\
\text { v.tr. ricavare un compenso, un profitto da un lavoro, da uno scambio: } \\
\text { In questi ultimi mesi ha guadagnato molto. }\end{array}$ \\
\hline Definição II Sabatini-Coletti & $\begin{array}{l}\text { guadagnare [gua-da-gnà-re] v. (1ª pl. guadagniamo) } \\
\text { - v.tr. [sogg-v-arg] } \\
1 \text { Ricevere remunerazione del proprio lavoro: g. un sacco di } \\
\text { soldi; ricavare un profitto da un'attività, ottenendo più di quanto } \\
\text { speso: g. il trenta per cento } \\
2 \text { fig. Ottenere qlco. come riconoscimento del proprio impegno, } \\
\text { delle proprie qualità: g. la fiducia di qlcu. || avere tutto da g., non } \\
\text { rischiare nulla | g. terreno, avanzare, avvantaggiarsi | g. la meta, } \\
\text { la vetta, raggiungere un traguardo } \\
3 \text { Vincere una somma al gioco: g. centomila euro } \\
\text { - v.intr. (aus. avere) [sogg-v] } \\
1 \text { Ricevere uno stipendio; freq. con la specificazione del modo: } \\
\text { g. bene } \\
2 \text { guadagnarci, fare una migliore figura: con la cornice il quadro } \\
\text { ci guadagna } \\
\text { - guadagnarsi } \\
\text { - v.rifl. [sogg-v-arg] Con valore intensivo, ottenere qlco. quale } \\
\text { profitto dei propri sforzi e del proprio impegno || g. da vivere, } \\
\text { ottenere il denaro necessario per vivere } \\
\text { - sec. XII }\end{array}$ \\
\hline
\end{tabular}




\begin{tabular}{|c|c|}
\hline Definição II Devoto-Oli 2008 & 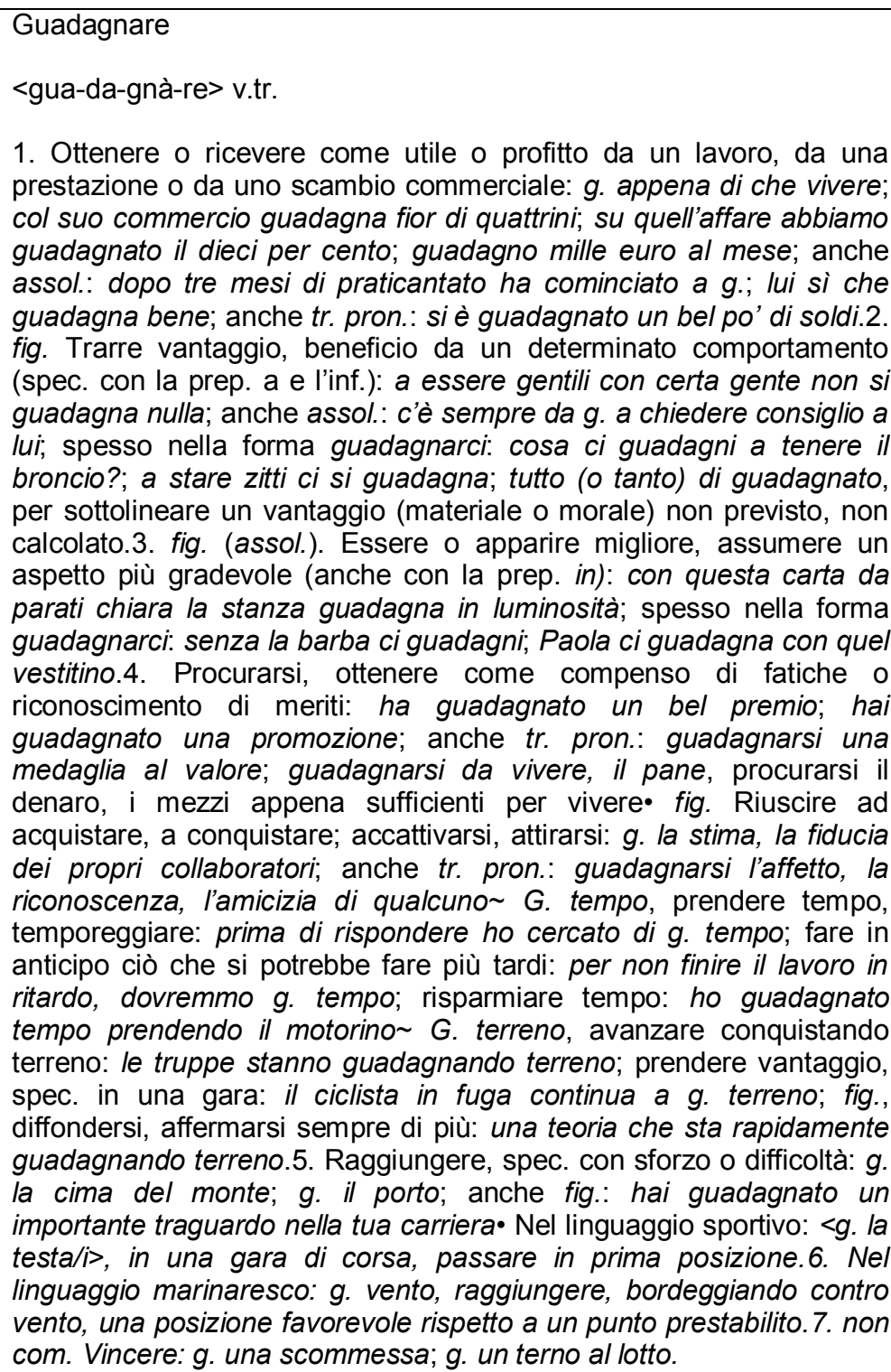 \\
\hline Definição Lo Zingarelli 2004 & $\begin{array}{l}\text { FLESSIONE } \\
\text { aguadagnare } \\
\text { [francone *waidhanjan 'portare al pascolo ('waidha)', traendone } \\
\text { profitto; 1266] } \\
\text { A v. tr. (coniug. come segnare) } \\
1 \text { Trarre da un lavoro o da un'attività un compenso o un profitto: } \\
\text { guadagnare uno stipendio scarso, buono, notevole; guadagnare una } \\
\text { percentuale su ogni vendita | (est.) Procurarsi utilità, vantaggi (anche } \\
\text { fig.): c'è tutto da guadagnare e nulla da perdere. } \\
2 \text { Riuscire a ottenere, a conquistare (anche fig.): guadagnare una } \\
\text { promozione, il favore del popolo, l'amicizia di qlcu.; cose acerbissime } \\
\text { e piene di malinconie, che... sarebbe meglio perdere che... } \\
\text { guadagnare (ALBERTI) | Guadagnare qlcu. alla propria causa, farselo } \\
\text { amico e alleato | Guadagnare terreno, occuparlo (detto di un } \\
\text { esercito); (est.) aumentare il proprio vantaggio sugli inseguitori; (fig.) } \\
\text { affermarsi sempre di più: è un'idea che guadagna terreno | } \\
\text { Guadagnare tempo, ottenere una dilazione | Nel linguaggio sportivo, } \\
\text { conquistare un certo vantaggio sugli avversari: guadagnare due punti, } \\
\text { tre minuti | Guadagnare la testa, in una gara di corsa, passare in }\end{array}$ \\
\hline
\end{tabular}




\begin{tabular}{|c|c|}
\hline & $\begin{array}{l}\text { prima posizione. } \\
3 \text { (fig.) Raggiungere, spec. con difficoltà: guadagnare il mare aperto, il } \\
\text { porto, la soglia di casa | Guadagnare il vento, al vento, navigare di } \\
\text { bolina fino a raggiungere un punto sopravvento rispetto a quello di } \\
\text { partenza I Guadagnare il sopravvento, portarsi sopravvento rispetto a } \\
\text { un'altra imbarcazione. } \\
4 \text { (est.) Meritare: guadagnare un premio. SIN. Conquistare, ottenere. } \\
5 \text { Vincere: guadagnare un premio, una scommessa; guadagnare una } \\
\text { bella somma al gioco. } \\
\text { B v. intr. (aus. avere) } \\
\text { * Fare migliore figura, apparire meglio: guadagnare molto con la } \\
\text { barba; un quadro che guadagnerebbe in una luce migliore | } \\
\text { Guadagnarci, trarre un vantaggio economico da qlco.; (est.) giovarsi: } \\
\text { se lo vendi subito, ci guadagni; con quel vestito elegante, ci } \\
\text { guadagna; ogni religione ci guadagna assai a tenersi lontana dalla } \\
\text { politica (NIEVO). } \\
\text { C guadagnarsi v. tr. pron. } \\
\text { * Procurarsi, meritarsi, ottenere: s'è guadagnato una ricompensa; lui } \\
\text { che se le era ben guadagnate, quelle medaglie (PIRANDELLO) | } \\
\text { Guadagnarsi il pane col sudore della fronte, ottenere di che vivere } \\
\text { con molta fatica | Guadagnarsi la vita, il pane, industriarsi per } \\
\text { campare | Guadagnarsi (o guadagnare) l'animo di qlcu., ottenerne la } \\
\text { completa fiducia. }\end{array}$ \\
\hline Definição Parola Chiave & $\begin{array}{l}\text { Guadagnare } \\
\text { v.tr. ricavare come compenso da un lavoro o come profitto da } \\
\text { un'attività economica: guadagna un buon stipendio; ganhar, ganhar } \\
\text { o pão. }\end{array}$ \\
\hline Definição Proposta & Ricevere il salario \\
\hline
\end{tabular}


Ficha lexicográfica para as novas palavras que constarão nas notas de rodapé 22

\begin{tabular}{|c|c|}
\hline Unidade lexical & Guaio (guai) \\
\hline Contexto & $\begin{array}{l}\text { "Io non sono andata a cercare } i \text { guai, sono loro che sono venuti a } \\
\text { cercare me." }(104,122)\end{array}$ \\
\hline Definiçao De Mauro Paravia & $\begin{array}{l}\text { guà·io } \\
\text { S.m. Fo } \\
\text { 1a. situazione spiacevole o difficile, per lo più imprevista: essere, finire, } \\
\text { cacciarsi, mettersi nei guai, in un brutto guaio, in un mare di guai; cercare guai: } \\
\text { comportarsi in modo da attirarsi qcs. di spiacevole o dannoso; passare un } \\
\text { guaio, dei guai: attraversare una situazione difficile, problematica } \\
\text { 1b. grave incidente, sventura: sapessi che guaio mi è capitato! } \\
\text { 1c. con valore attenuato, inconveniente, fastidio: è bel un guaio questo } \\
\text { sciopero dei treni } \\
\text { 2. danno causato da un'azione sventata: fare, combinare un guaio } \\
\text { 3. causa di preoccupazione; problema: ognuno ha i propri guai; quell'uomo è } \\
\text { un vero guaio per la moglie } \\
\text { 4. OB LE spec. al pl., lamento acuto: quivi sospiri, pianti e alti guai | risonavan } \\
\text { per l'aere sanza stelle (Dante) }\end{array}$ \\
\hline Definição Dire & $\begin{array}{l}\text { n.m. disastro: Bel guaio hai combinato! Situazione pericolosa: quel } \\
\text { ragazzo ogni giorno si caccia in un guaio. Problema: Questo ritardo } \\
\text { del treno è un bel guaio! }\end{array}$ \\
\hline Definição II Sabatini-Coletti & 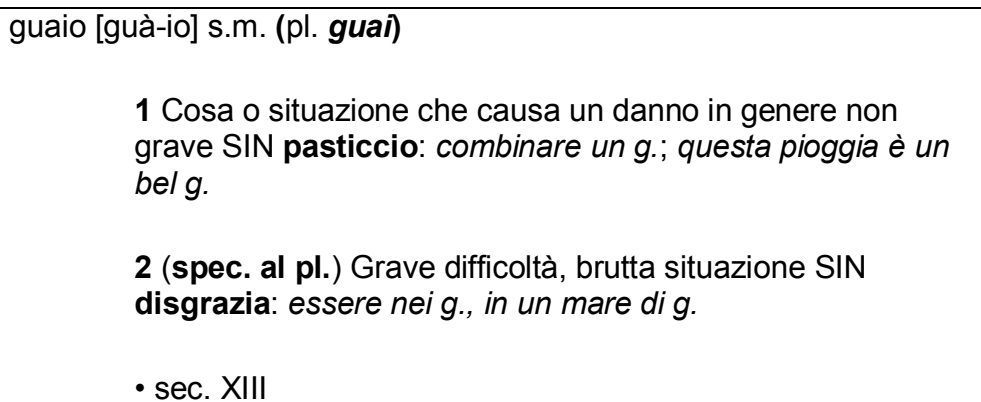 \\
\hline Definição II Devoto-Oli 2008 & $\begin{array}{l}\text { guà-io> s.m. (pl. -ài) } \\
\text { 1. Incidente spiacevole, dalle conseguenze più o meno serie: mi è } \\
\text { capitato un g.• Motivo di ostacolo o impedimento: il progetto è bello, il } \\
\text { g. è che mancano i soldi• Situazione difficile o dolorosa, disgrazia: mi } \\
\text { trovo in un gran g.2. arc. Voce acuta di lamento.dim. fam. guaiétto. } \\
\text { pegg. fam. guaiàccio } \\
\text { Tratto dalla interiezione guai intesa come plurale | sec. XIII }\end{array}$ \\
\hline Definição Lo Zingarelli 2004 & $\begin{array}{l}\text { FLESSIONE } \\
\text { aguaio } \\
\text { [sostantivazione del presunto pl. guai (V.); av. 1292] } \\
\text { s. m. } \\
1 \text { Malanno, disgrazia: passare un guaio; trovarsi in un brutto guaio | } \\
\text { Andare in cerca di guai, (fig.) procurarseli da sé | V. anche guai. } \\
2 \text { Impiccio, fastidio: Che guaio, ho perso la chiave! } \\
3 \text { (spec. al pl.) †Lamenti alti e acuti: Quivi sospiri, pianti e alti guai / } \\
\text { risonavan per l'aere sanza stelle (DANTE Inf. III, 22-23). }\end{array}$ \\
\hline Definição Parola Chiave & $\begin{array}{l}\text { s.m. grave difficoltà; disgrazia, malanno: essere in um guaio, nei } \\
\text { guai; gli è capitato un bel guaio! Danno: combini un sacco di guai. }\end{array}$ \\
\hline
\end{tabular}




\begin{tabular}{|l|l|}
\hline & $\begin{array}{l}\text { Incoveniente, seccatura: il guaio è che ho dimenticato le chiave. } \\
\text { Problema }\end{array}$ \\
\hline Definição Proposta & Problemi, situazioni difficili. \\
\hline
\end{tabular}


Ficha lexicográfica para as novas palavras que constarão nas notas de rodapé 23

\begin{tabular}{|c|c|}
\hline Unidade lexical & Guarire/guarisco/guarita \\
\hline Contexto & "L'ho trovata! Viva! Guarita!"(117) \\
\hline Definiçao De Mauro Paravia & $\begin{array}{l}\text { gua.rì.re } \\
\text { v.tr. e intr. Fo } \\
\text { 1a. v.tr., rimettere in salute, far tornare sano: quel medico lo ha } \\
\text { guarito da una malattia considerata incurabile, la dieta e il riposo lo } \\
\text { guariranno meglio di qualsiasi medicina } \\
\text { 1b. v.tr., far passare una malattia: lo sciroppo mi ha guarito il mal di } \\
\text { gola } \\
\text { 2a. v.tr., fig., liberare da un male morale: questa lezione lo ha guarito } \\
\text { da tutte le sue fisime } \\
\text { 2b. v.tr., fig., far passare una sofferenza, un'abitudine, un vizio o sim.: } \\
\text { il tempo guarisce molti mali } \\
\text { 3a. v.intr. (essere) tornare a essere sano, riacquistare la salute: penso } \\
\text { che guarirai presto, è guarito dal morbillo } \\
\text { 3b. v.intr. (essere) di una malattia, aver fine, scomparire: la polmonite } \\
\text { guarisce con estrema lentezza } \\
\text { 3c. v.intr. (essere) di una ferita, rimarginarsi: la sbucciatura del mio } \\
\text { ginocchio è ormai completamente guarita } \\
\text { 4. v.intr. (essere) fig., liberarsi da un male morale: guarire dall'invidia, } \\
\text { da una brutta abitudine, dal vizio del gioco }\end{array}$ \\
\hline Definição Dire & $\begin{array}{l}\text { v.tr.1 Ridare la salute a qualcuno: Questa terapia mi ha guarito in } \\
\text { breve tempo. } 2 \text { Liberare da qualcosa di negativo: Chi può guarirti } \\
\text { dalla pigrizia? } 3 \text { Curare, far scomparire una malattia: Queste gocce } \\
\text { guariscono la tosse. / v.intr. 1- Ritornare in salute: Ancora non sono } \\
\text { completamente guarito dall'influenza. } 2 \text { Detto di malattia, scomparire: } \\
\text { II morbillo guarisce in otto giorni } 3 \text { Liberarsi da un vizio: Finalmente il } \\
\text { babbo è guarito dal vizio del fumo. } \\
\text { III- ind.press. io guarisco, tu guarisci, egli guarisce, noi guariamo, voi } \\
\text { guarite, essi guariscono; cong.pres. che io guarisca, che tu guarisca, } \\
\text { che egli guarisca, che noi guariamo, che voi guariate, che essi } \\
\text { guariscano. } \\
\text { [germ. Warjan = difendere, mettere a riparo], v.tr.: sin. } 1 \text { sanare, } \\
\text { contr. } 1 \text { contagiare }\end{array}$ \\
\hline Definição II Sabatini-Coletti & $\begin{array}{l}\text { guarire [gua-rì-re] v. (guarisco, guarisci ecc.) } \\
\text { • v.tr. [sogg-v-arg] Detto di un medicinale, una cura o un } \\
\text { medico, rimettere in salute una persona malata: g. un } \\
\text { lebbroso; far scomparire una malattia: g. il morbillo } \\
\text { • [sogg-v-arg-prep.arg] fig. Liberare qlcu. da qlco. di } \\
\text { negativo: ha guarito molta gente dal vizio del fumo } \\
\text { • v.intr. (aus. essere) [sogg-v] } \\
1 \text { Di persona, recuperare uno stato di salute: mio figlio è } \\
\text { guarito } \\
2 \text { Detto di malattia, regredire fino a non esserci più } \\
\text { • sec. XIII }\end{array}$ \\
\hline
\end{tabular}




\begin{tabular}{|c|c|}
\hline Definição II Devoto-Oli 2008 & $\begin{array}{l}\text { guarire } \\
\text { <gua-rì-re> (arc. guerire) v.tr. e intr. (guarisco, guarisci, ecc.; come } \\
\text { intr., aus. essere) } \\
\text { 1. tr. Ricondurre a uno stato normale di efficienza fisica, rimettere in } \\
\text { salute, ristabilire (anche con la prep. da): g. un paziente; il riposo lo } \\
\text { guarirà; lo psichiatra non è riuscito a guarirlo dalla depressione.2. tr. } \\
\text { Riferito a malattia, provocarne la regressione fino a completa } \\
\text { guarigione dell'ammalato, curare (anche con la prep. a): i medici le } \\
\text { hanno finalmente guarito l'infezione alla gamba; la terapia mi ha } \\
\text { permesso di g. il tumore.3. tr. (fig.). Liberare da un vizio, da un difetto, } \\
\text { da un male morale (anche con la prep. da): le letture mi hanno guarito } \\
\text { dall'ignoranza; anche assol:: il lavoro guarisce dalla pigrizia• } \\
\text { Eliminare, cancellare (un vizio, un difetto, una situazione di } \\
\text { sofferenza, ecc.): g. la noia, la malinconia.4. intr. Recuperare la } \\
\text { salute, ristabilirsi, rimettersi (anche con la prep. da): ancora non sono } \\
\text { perfettamente guarito; g. dall'influenza• Di organo o parte del corpo, } \\
\text { riacquistare la piena funzionalità, tornare sano (anche con la prep. a): } \\
\text { ancora non corro, ma il ginocchio mi è guarito.5. intr. Di malattia, } \\
\text { regredire, scomparire, risolversi: l'otite è guarita in pochi giorni• Di } \\
\text { ferita, rimarginarsi, cicatrizzarsi: la ferita è finalmente guarita.6. intr. } \\
\text { (fig.). Liberarsi da un vizio, da un difetto, ecc. (con la prep. da): g. dal } \\
\text { vizio del gioco; devo g. da questa abitudine di bere. } \\
\text { Dal longob. *warjan 'mettere riparo, difendere' I prima del 1294 }\end{array}$ \\
\hline Definição Lo Zingarelli 2004 & $\begin{array}{l}\text { [germ. *warjan 'mettere riparo, tenere lontano' e anche 'difendere'; } \\
1262 \text { ca.] } \\
\text { A v. tr. (io guarìsco, tu guarìsci) } \\
1 \text { Risanare, riportare in salute: guarire qlcu. dalla scarlattina | } \\
\text { †Guarire un'acqua, purificarla dall'inquinamento | Far passare una } \\
\text { malattia: una terapia per guarire la polmonite. } \\
2 \text { (fig.) Rendere qlcu. libero da un vizio e sim.: guarire qlcu. dalla } \\
\text { pigrizia, dalla caparbietà. } \\
\text { B v. intr. (aus. essere) } \\
1 \text { Rimettersi in salute: è guarito per le cure. } \\
2 \text { (fig.) Liberarsi da un vizio e sim.: è guarito dal vizio del gioco, del } \\
\text { fumo. } \\
3 \text { Esaurirsi, passare: l'infiammazione guarirà in un mese. } \\
\text { || PRov. II tempo guarisce i mali. }\end{array}$ \\
\hline Definição Parola Chiave & $\begin{array}{l}\text { v.tr. \{guarisco, guarisci] Rimetere in buona salute una persona: la } \\
\text { cura lo ha guarito in pocchi giorni <> Far passare una malattia: } \\
\text { l'influenza si guarisce anche col riposo *curar <> v.intr. \{aus. essere] } \\
\text { Recuperare la salute, tornare in condizioni normali: è guarito in poco } \\
\text { tempo; il braccio rotto non ‘ancora guarito <> Passare, scomparire } \\
\text { (detto di malattia): l'infezione guarirà in pochi giorni <> Liberarsi di un } \\
\text { male morale, di un vizio: è guarito dalla gelosia, dal vizio del gioco } \\
\text { *sarar }\end{array}$ \\
\hline Definição Proposta & Di nuovo sano dopo una malattia. \\
\hline
\end{tabular}


Ficha lexicográfica para as novas palavras que constarão nas notas de rodapé 24

\begin{tabular}{|c|c|}
\hline Unidade lexical & Impaurito \\
\hline Contexto & $\begin{array}{l}\text { Perciò, tutto impaurito, ritorna a casa dalla sua serva Perpetua e si } \\
\text { chiude in camera, dicendole di non aprire a nessuno. (9) }\end{array}$ \\
\hline Definiçao De Mauro Paravia & $\begin{array}{l}\text { im·pa·u·rìto } \\
\text { p.pass., agg. } \\
\text { 1. p.pass. } \square \text { impaurire, impaurirsi } \\
\text { 2. agg. CO spaventato, pieno di paura: rannicchiarsi impaurito in un } \\
\text { angolo, espressione impaurita }\end{array}$ \\
\hline Definição Dire & $\begin{array}{l}\text { v.tr. Spaventare: II rombodel tuono impaurisce il mio cane. } \\
\text { III- ind.press. io impaurisco, tu impaurisci, egli impaurisce, noi } \\
\text { impauriamo, voi impaurite, essi impauriscono; cong.pres. che io } \\
\text { impaurisca, che tu impaurisca, che egli impaurisca, che noi } \\
\text { impauriamo, che voi impaurite, che essi impauriscano. / v.intr.pron. } \\
\text { (impaurirsi) Provare spavento: Di notte ad ogni minimo rumore mi } \\
\text { impaurisco. } \\
\text { derivato da paura, v.tr.: contr. rincuorare, v.intr.pron.: contr. } \\
\text { tranquillizzarsi }\end{array}$ \\
\hline Definição II Sabatini-Coletti & $\begin{array}{l}\text { impaurire [im-pau-rì-re] v. (impaurisco, impaurisci ecc.) } \\
\text { • v.tr. [sogg-v-arg] Riempire qlcu. di paura, spaventarlo SIN } \\
\text { allarmare: questo film mi impaurisce } \\
\text { • v.intr. (aus. essere) [sogg-v] Essere colto da paura SIN } \\
\text { spaventarsi: i. per il buio } \\
\text { • impaurirsi } \\
\text { • v.rifl. [sogg-v] Prendere paura } \\
\text { • sec. XIV }\end{array}$ \\
\hline Definição II Devoto-Oli 2008 & $\begin{array}{l}\text { impaurito >> } \\
\text { impaurire } \\
\text { <im-pau-rì-re> (arc. o lett. impaurare) v.tr. e intr. (impaurisco, } \\
\text { impaurisci, ecc.) } \\
\text { 1. tr. Incutere spavento, sgomento, apprensione; spaventare, } \\
\text { intimorire: } i . \text { qualcuno con le minacce; il buio lo impaurisce; ormai } \\
\text { adulto negli anni, la morte non m'impaura (Bufalino). } 2 \text {. intr. (aus. } \\
\text { essere) e intr. pron. (più com.). Cedere a uno stato improvviso di } \\
\text { ansia o di sgomento, prendere paura, spaventarsi (anche con la prep. } \\
\text { per): impaurirsi per i tuoni, per il temporale; il bambino s'impaurisce } \\
\text { per un nonnulla. } \\
\text { Der. di paura, col pref. in- }{ }^{2} \text { I prima metà sec. XIV }\end{array}$ \\
\hline Definição Lo Zingarelli 2004 & $\begin{array}{l}\text { FLESSIONE } \\
\text { aimpaurire [comp. di in- (1) e paura; } 1262 \text { ca.] } \\
\text { A v. tr. (io impaurìsco, tu impaurisci) } \\
\text { * Riempire di paura: impaurire qlcu. con grida, minacce; il buio lo } \\
\text { impaurisce. SIN. Allarmare, spaventare. } \\
\text { B v. intr. (aus. essere) e impaurirsi v. intr. pron. } \\
\text { * Spaventarsi. }\end{array}$ \\
\hline
\end{tabular}



*amedontrar «> impaurirsi v.pr. Spaventarsi *amedontrar-se

Con molta paura. 
Ficha lexicográfica para as novas palavras que constarão nas notas de rodapé 25

\begin{tabular}{|c|c|}
\hline Unidade lexical & Lazzaretto \\
\hline Contexto & $\begin{array}{l}\text { "Non c'è più, è al lazzaretto" risponde la donna e richiude subito la } \\
\text { finestra.(107) }\end{array}$ \\
\hline Definiçao De Mauro Paravia & $\begin{array}{l}\text { laz.za'rét·to } \\
\text { s.m. } \\
\text { 1. Co in passato, ospedale o luogo di ricovero per i lebbrosi; estens., } \\
\text { ospedale o luogo di ricovero per persone affette da malattie incurabili } \\
\text { o contagiose: lazzaretto per gli appestati } \\
\text { 2. BU luogo di quarantena per persone o merci che provengono da } \\
\text { luoghi infetti }\end{array}$ \\
\hline Definição Dire & $\begin{array}{l}\text { n.m. In passato, ospedale per malattie contagiose: Le persone } \\
\text { colpite dalla peste furono portate al lazzaretto. }\end{array}$ \\
\hline Definição II Sabatini-Coletti & $\begin{array}{l}\text { lazzaretto [laz-za-rét-to] s.m. } \\
\qquad \begin{array}{l}\text { Ospedale dove un tempo si ricoveravano in isolamento } \\
\text { persone colpite da malattie infettive o contagiose } \\
\text { • sec. XVI }\end{array}\end{array}$ \\
\hline Definição II Devoto-Oli 2008 & $\begin{array}{l}\text { lazzeretto } \\
\text { <lač-Te-rét-to> (o lazzaretto) s.m. } \\
\text { In passato, ospedale per l'isolamento degli ammalati incurabili o affetti } \\
\text { da malattie contagiose. } \\
\text { Der. di Nazaret, tratto da S. Maria di Nazareth, isola del porto } \\
\text { veneziano destinata ad accogliere un ospedale di isolamento, incr. } \\
\text { con lazzaro }{ }^{1} \text { | sec. XVI }\end{array}$ \\
\hline Definição Lo Zingarelli 2004 & $\begin{array}{l}\text { [dal n. dell'isola venez. (S. Maria di) Nazarèth (per il monastero così } \\
\text { intitolato, ivi esistente), prima località apprestata per la quarantena, } \\
\text { con sovrapposizione del n. del patrono degli appestati, S. Lazzaro; } \\
\text { av. 1512] } \\
\text { s. m. } \\
\text { * Ospedale per lebbrosi | Ospedale per malattie infettive ed } \\
\text { epidemiche: lazzaretto per gli appestati, per i colerosi | Zona di } \\
\text { quarantena per merci o persone provenienti da luoghi infetti. }\end{array}$ \\
\hline Definição Parola Chiave & Não consta. \\
\hline Definição Proposta & $\begin{array}{l}\text { Luogo dove andavano le persone con malattie incurabili e } \\
\text { contagiose. }\end{array}$ \\
\hline
\end{tabular}


Ficha lexicográfica para as novas palavras que constarão nas notas de rodapé 26

\begin{tabular}{|c|c|}
\hline Unidade lexical & Minacce \\
\hline Contexto & E sa anche che le loro minacce sono sempre pericolose. (8) \\
\hline Definiçao De Mauro Paravia & $\begin{array}{l}\text { mi-nàc·cia } \\
\text { s.f. } \\
\text { 1a. AU discorso o frase che ha lo scopo di annunciare a qualcuno un } \\
\text { danno, un male, un castigo, spec. allo scopo di intimorire o } \\
\text { costringere a fare o non fare qcs.: minaccia di vendetta, di morte; } \\
\text { costringere con minacce } \\
\text { 1b. TS dir.pen. reato commesso da chi provoca in altri il timore di un } \\
\text { danno ingiusto } \\
\text { 2a. AU fig., spec. al pl., indizio che preannuncia l'approssimarsi di } \\
\text { un'eventualità sfavorevole e indesiderata: minaccia di bufera, minacce } \\
\text { di guerra } \\
\text { 2b. AU fig., pericolo incombente: vive sotto la minaccia del } \\
\text { licenziamento } \\
\text { 2c. AU segno precursore di una malattia: minaccia di infarto } \\
\text { 3. TS etol. l'insieme dei comportamenti tenuti da un animale per } \\
\text { allontanare altri animali della stessa specie o potenziali predatori }\end{array}$ \\
\hline Definição Dire & $\begin{array}{l}\text { n.f. 1- Azione o parola con cui si spaventa qualcuno per convincerlo a } \\
\text { fare o non fare qualcosa: L'uomo consegnò al ladro il portafoglio sotto } \\
\text { la minaccia di un'arma. 2- Pericolo che incombe: Nella fabbrica c'è la } \\
\text { minaccia di uno sciopero. } \\
\text { [lat. minax = minaccioso], pl. minacce, sin. } 1 \text { intimidazione, } 2 \text { rischio }\end{array}$ \\
\hline Definição II Sabatini-Coletti & $\begin{array}{l}\text { minaccia [mi-nàc-cia] s.f. (pl. -ce) } \\
1 \text { Parola o atto finalizzati a spaventare, con la prospettiva di } \\
\text { un danno, un male, un castigo ecc., e quindi a dissuadere o } \\
\text { a costringere a fare qlco. SIN intimidazione: } m \text {. di morte } \\
\mathbf{2} \text { dir. Reato commesso da chi provoca in altri il timore di un } \\
\text { danno ingiusto } \\
\mathbf{3} \text { Pericolo incombente SIN rischio: la } m \text {. di una frana; il } \\
\text { male minacciato: la } m \text {. della galera } \\
\text { • agg.rel. non derivati dal lemma: }(1,2) \text { minatorio, } \\
\text { intimidatorio } \\
\text { • sec. XIII }\end{array}$ \\
\hline Definição II Devoto-Oli 2008 & $\begin{array}{l}\text { minacce >> } \\
\text { minaccia } \\
\text { <mi-nàc-cia> s.f. (pl. -ce) } \\
\text { 1. Tentativo di imporre la propria volontà incutendo il timore di un } \\
\text { imminente danno o pericolo (nei casi più gravi può costituire reato): } \\
\text { m. di morte, di scandalo• estens. Capacità di destare una profonda } \\
\text { apprensione: un silenzio pieno di minacce; anche, imminenza di un } \\
\text { male o di un pericolo: c'è m. di tempesta.2. In etologia, l'insieme dei } \\
\text { comportamenti esibiti da un individuo per allontanare individui della } \\
\text { stessa specie o potenziali predatori: } m \text {. difensiva, m. aggressiva } \\
\text { Lat. minaciae -arum (reso sing.), der. di minax -acis 'minaccioso', dal } \\
\text { tema di minari 'minacciare' | sec. XIII }\end{array}$ \\
\hline Definição Lo Zingarelli 2004 & FLESSIONE \\
\hline
\end{tabular}




\begin{tabular}{|l|l|}
\hline & $\begin{array}{l}\text { aminaccia } \\
\text { [lat. minaciae, nom. pl., da minax, genit. minacis 'minaccioso'. V. } \\
\text { minace; 1262 ca.] } \\
\text { s. f. (pl. -ce) } \\
1 \text { Atto compiuto per incutere timore o discorso fatto per spaventare: } \\
\text { minaccia a mano armata; profferire minacce di morte, di accusa, di } \\
\text { guerra. SIN. Intimidazione. } \\
2 \text { (fig.) Pericolo di un male futuro: silenzio pieno di minacce; c'è } \\
\text { minaccia di inondazione. }\end{array}$ \\
\hline Definição Parola Chiave & $\begin{array}{l}\text { s.f. [PL. -ce] 1 Atto, parola, discorso che ha lo scopo di incutere } \\
\text { timore S intimidazione: ha ricevuto una minaccia di morte; lo hanno } \\
\text { costretto con le minacce } 2 \text { Pericolo incombente: c'è minaccia di } \\
\text { pioggia; aumenta la minaccia di un'epidemia *ameaça }\end{array}$ \\
\hline Definição Proposta & \begin{tabular}{l} 
Promessa di future offese. \\
\hline
\end{tabular} \\
\hline
\end{tabular}


Ficha lexicográfica para as novas palavras que constarão nas notas de rodapé 27

\begin{tabular}{|c|c|}
\hline Unidade lexical & Monatto (monatti) \\
\hline Contexto & $\begin{array}{l}\text { Il terrore della morte invade Don Rodrigo e, soprattutto, la paura di } \\
\text { essere preso dai monatti e portato al lazzaretto. (102) }\end{array}$ \\
\hline Definiçao De Mauro Paravia & $\begin{array}{l}\text { mo·nàt·to } \\
\text { s.m. TS stor. } \\
\text { nei secc. XVI e XVII, chi, durante le epidemie di peste, era addetto al } \\
\text { trasporto dei malati, alla sepoltura dei cadaveri e alla distruzione di } \\
\text { oggetti contagiosi }\end{array}$ \\
\hline Definição Dire & $\begin{array}{l}\text { n.m. Chi, nel passato, durante le pestilenze, trasportava i malati e } \\
\text { seppelliva i morti. }\end{array}$ \\
\hline Definição II Sabatini-Coletti & $\begin{array}{l}\text { monatto [mo-nàt-to] s.m. } \\
\text { • Inserviente pubblico addetto a trasportare i malati e a } \\
\text { seppellire i morti durante le pestilenze di Cinque e Seicento } \\
\text { • sec. XVI }\end{array}$ \\
\hline Definição II Devoto-Oli 2008 & $\begin{array}{l}\text { Monatto } \\
<\text { mo-nàt-to> s.m. } \\
\text { Servente pubblico addetto un tempo al trasporto dei malati e dei } \\
\text { cadaveri in caso di epidemia. } \\
\text { Dal lombardo monatt, di etimo incerto | sec. XVI }\end{array}$ \\
\hline Definição Lo Zingarelli 2004 & $\begin{array}{l}\text { [vc. milan. di etim. incerta; av. 1584] } \\
\text { s. m. } \\
\text { * Addetto al trasporto dei malati e dei morti, ai tempi delle epidemie di } \\
\text { peste. }\end{array}$ \\
\hline Definição Parola Chiave & Não consta. \\
\hline Definição Proposta & Chi nell'epoca della peste trasportava i malati e i morti. \\
\hline
\end{tabular}


Ficha lexicográfica para as novas palavras que constarão nas notas de rodapé 28

\begin{tabular}{|c|c|}
\hline Unidade lexical & Di nascosto \\
\hline Contexto & $\begin{array}{l}\text { E Agnese: "Ecco: ci ho pensato io. Verrò con voi e mi metterò a } \\
\text { parlare con Perpetua, mentre voi entrerete di nascosto. So io qual è } \\
\text { un argomento che le interessa..." (30) }\end{array}$ \\
\hline Definiçao De Mauro Paravia & $\begin{array}{l}\text { loc.avv. CO } \\
\text { in modo da non farsi vedere da nessuno: incontrarsi, entrare di } \\
\text { nascosto; l'ha fatto di nascosto da me }\end{array}$ \\
\hline Definição Dire & $\begin{array}{l}\text { agg. 1- Che sta in un luogo dove non può essere visto: II mio diario } \\
\text { segreto era nascosto in fondo al cassetto. 2- Che non si manifesta } \\
\text { chiaramente: II mio amico a causa della sua timidezza spesso tiene } \\
\text { nascosti i suoi pensieri. } \\
\text { part.pass. di nascondere, sin. } 1 \text { celato, } 2 \text { segreto, contr. } 2 \text { evidente, } \\
\text { palese }\end{array}$ \\
\hline Definição II Sabatini-Coletti & $\begin{array}{l}\text { nascosto [na-scó-sto] agg. } \\
1 \text { Sottratto alla vista, non visibile: trovare un oggetto } n . ; \\
\text { estens. appartato, isolato: un villaggio } n \text {. tra i monti } \\
2 \text { fig. Tutt'altro che palese, poco sospettabile all'apparenza, } \\
\text { anche in senso iron. SIN segreto, intimo: avere doti, virtù } n \text {. } \\
\| \text { di } \mathbf{n} \text {., in segreto, senza farsi vedere, senza farlo sapere: } \\
\text { incontrarsi di } n \text {.; fare qlco. di } n \text {. da qlcu. } \\
\text { • avv. nascostamente, di } n . \text { in segreto } \cdot \text { sec. XIII }\end{array}$ \\
\hline Definição II Devoto-Oli 2008 & $\begin{array}{l}\text { Nascosto } \\
\text { <na-scó-sto> agg. } \\
\text { Sottratto alla vista, non visibile: un tesoro n.; tenere qualcosa } n \text {. } \\
\text { Lontano, appartato, isolato, remoto: un paesino } n \text {. tra i monti.2. fig. } \\
\text { Intimo, interiore: il travaglio d'un pensiero nascosto (Manzoni); Non } \\
\text { evidente, non palese, segreto, imprevedibile, spesso con una } \\
\text { sfumatura ironica: narrami le virtù } n \text {. di quel ragazzo loc. avv. Di } \\
\text { nascosto, senza che altri si accorga o venga a sapere, furtivamente: } \\
\text { incontrarsi di } n . ; \text { entrare di } n \text {. in un luogo; con le prep. da, di, a: si } \\
\text { vedono di } n \text {. dai (o, meno com., dei, ai) genitori.3. In botanica, sin. di } \\
\text { dormiente.4. In araldica, attributo dei supporti quando hanno la testa } \\
\text { racchiusa in un elmo. } \\
\text { P. pass. di nascondere | sec. XIII }\end{array}$ \\
\hline Definição Lo Zingarelli 2004 & $\begin{array}{l}\text { FLESSIONE } \\
\text { anascosto part. pass. di nascondere; anche agg. } \\
1 \text { Sottratto alla vista, occultato: un plico nascosto | (est.) Isolato, } \\
\text { appartato: uno chalet nascosto nel verde. } \\
2 \text { (fig.) Che non si rivela, che non è evidente: virtù nascoste; verità } \\
\text { nascosta. CFR. cripto- | Di nascosto, senza farlo sapere, capire, } \\
\text { vedere e sim. ad altri: agire, incontrarsi di nascosto; leggeva il libro di } \\
\text { nascosto dall'insegnante. } \\
\text { || nascostamente, avv. Di nascosto; segretamente. }\end{array}$ \\
\hline Definição Parola Chiave & $\begin{array}{l}\text { agg. } 1 \text { Situato in modo da non esssere visibile: uma casetta nascosta } \\
\text { nel bosco *escondida } 2 \text { Non evidente: quel ragazzo ha doti nascoste } \\
\text { <> Celato, segreto: mi ha tenuto nascosta la verità *oculto | Di } \\
\text { nascosto = segretamente, senza farlo sapere o capire ad altri: si }\end{array}$ \\
\hline
\end{tabular}


Ficha lexicográfica para as novas palavras que constarão nas notas de rodapé 29

\begin{tabular}{|c|c|}
\hline Unidade lexical & Osteria \\
\hline Contexto & $\begin{array}{l}\text { E sera. Renzo con i suoi testimoni, Tonio e Gervaso, si reca } \\
\text { all'osteria del paese per offrire loro la cena. (31) }\end{array}$ \\
\hline Definiçao De Mauro Paravia & $\begin{array}{l}\text { O·ste-rì·a } \\
\text { s.f. CO } \\
\text { 1. locale pubblico, spec. di livello modesto, in cui si servono vini, } \\
\text { liquori e altre bevande e che talvolta offre servizio di trattoria: } \\
\text { abbiamo cenato in un'osteria fuori città } \\
\text { 2. colloq., con valore interiettivo, per esprimere meraviglia, stupore o } \\
\text { rabbia, disappunto: osteria che caldo! } \\
\text { 3. OB locanda, albergo }\end{array}$ \\
\hline Definição Dire & $\begin{array}{l}\text { n.f. Locale pubblico di modeste condizioni dove è possibile mangiare } \\
\text { e bere in modo genuino: Nel mio paese c'è una graziosa osteria. } \\
\text { derivato da oste, sin. taverna, locanda }\end{array}$ \\
\hline Definição II Sabatini-Coletti & $\begin{array}{l}\text { osteria [o-ste-rì-a] s.f. } \\
\qquad \begin{array}{l}\text { • Locale pubblico dove si servono vino, altre bevande e } \\
\text { spesso pasti alla buona: ritrovarsi all'o. } \\
\text { • sec. XIV }\end{array}\end{array}$ \\
\hline Definição II Devoto-Oli 2008 & $\begin{array}{l}\text { osteria } \\
<0-\text { ste-rì-a> s.f. } \\
\text { Locale pubblico, di tono dimesso, con mescita di vini o anche con } \\
\text { servizio di trattoria• In passato, locanda dove si poteva mangiare e } \\
\text { trovare alloggio• fig. Simbolo di polemica sguaiata o anche violenta: } \\
\text { un dibattito da osteria pop. O.!, esclamazione eufem. (per ostia!) di } \\
\text { ammirazione, sorpresa, disappunto.dim. osteriétta, osteriòla. dim. e } \\
\text { pegg. osteriùccia. pegg. osteriàccia. }\end{array}$ \\
\hline Definição Lo Zingarelli 2004 & $\begin{array}{l}\text { FLESSIONE } \\
\text { osteria } \\
\text { [da oste (1); av. 1363] } \\
\text { s. f. } \\
1 \text { Locale pubblico dove si servono vino e altre bevande, talvolta con } \\
\text { servizio di trattoria: bere un bicchiere di vino all'osteria | Bettola, } \\
\text { taverna: passa le sue serate all'osteria | Osteria!, (pop.) esclamazione } \\
\text { di meraviglia, ammirazione, disappunto ecc. } \\
2 \text { †Albergo, locanda. } \\
\text { || osteriaccia, pegg. | osterietta, dim. | osteriuccia, pegg. }\end{array}$ \\
\hline Definição Parola Chiave & $\begin{array}{l}\text { s.f. Locale pubblico dove si servono vino e altre bevande, e talvolta } \\
\text { anche cibi *taverna }\end{array}$ \\
\hline Definição Proposta & Ristorante semplice. \\
\hline
\end{tabular}


Ficha lexicográfica para as novas palavras que constarão nas notas de rodapé $\mathbf{3 0}$

\begin{tabular}{|c|c|}
\hline Unidade lexical & Pascolo \\
\hline Contexto & $\begin{array}{l}\text { "Addio, monti sorgenti dalle acque ed elevati al cielo, e ville bianche } \\
\text { sparse sui pendii, come branchi di pecore al pascolo, addio!"(34) }\end{array}$ \\
\hline Definiçao De Mauro Paravia & $\begin{array}{l}\text { pà·sco-lo } \\
\text { s.m. AU } \\
\text { 1. terreno di vegetazione erbacea, spec. spontanea, che non viene } \\
\text { falciata ma pascolata direttamente dal bestiame: pascolo montano, } \\
\text { valli piene di pascoli e alpeggi | l'erba in quanto foraggio per il } \\
\text { bestiame: pascolo abbondante } \\
\text { 2. il pascolare: portare le greggi al pascolo } \\
\text { 3. fig., alimento, nutrimento spirituale o culturale: i classici sono un } \\
\text { buon pascolo per la mente }\end{array}$ \\
\hline Definição Dire & $\begin{array}{l}\text { n.m. 1- Terreno dove gli animale possono brucare erba: Vicino alla } \\
\text { baita di mio nonno c'è un pascolo. 2- Assunzione del cibo da parte } \\
\text { degli animale che brucano l'erba: Sui terreni coltivati c'è il divieto di } \\
\text { pascolo. [lat. pascuun = pascolo] }\end{array}$ \\
\hline Definição II Sabatini-Coletti & $\begin{array}{l}\text { pascolo [pà-sco-Io] s.m. } \\
1 \text { Luogo, terreno perlopiù incolto in cui il bestiame bruca } \\
\text { l'erba spontanea: } p \text {. alpino, montano; erba, foraggio di } \\
\text { questo terreno: lasciare un campo a p. } \\
2 \text { estens. Assunzione del cibo da parte degli animali erbivori: } \\
\text { il p. delle mucche } \text { - sec. XIV }\end{array}$ \\
\hline Definição II Devoto-Oli 2008 & 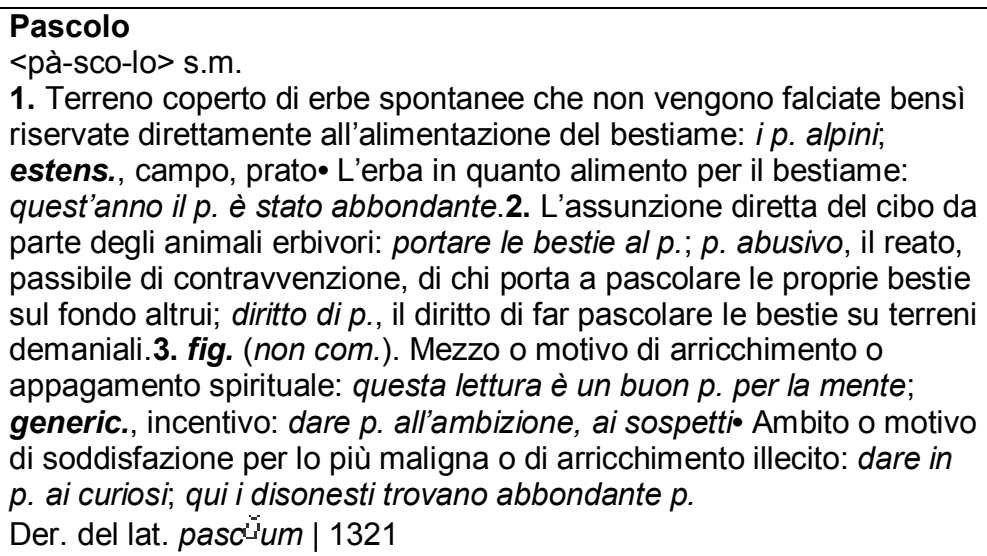 \\
\hline Definição Lo Zingarelli 2004 & $\begin{array}{l}\text { [lat. pascuu(m), da pascere 'pascere'; sec. XIV] } \\
\text { s. m. } \\
1 \text { Distesa erbosa su cui pasturano gli animali: pascolo montano, } \\
\text { alpino; i verdi pascoli | (est.) Erba di pastura: pascolo grasso. } \\
2 \text { Attività del pascolare: mandare, condurre i buoi al pascolo; servitù } \\
\text { di pascolo. } \\
3 \text { (fig.) Alimento o nutrimento spirituale: trovare gradito pascolo nella } \\
\text { lettura | (raro, fig.) Dare in pascolo, porgere materia di maldicenza. }\end{array}$ \\
\hline Definição Parola Chiave & $\begin{array}{l}\text { s.m. Terreno coperto di erbe adatte all'alimentazione del bestiame: } i \\
\text { pascoli alpini <> II pascolare: portare le bestie al pascolo *pasto }\end{array}$ \\
\hline Definição Proposta & Terreno con erba destinata al pasto degli erbivori. \\
\hline
\end{tabular}


Ficha lexicográfica para as novas palavras que constarão nas notas de rodapé 31

\begin{tabular}{|c|c|}
\hline Unidade lexical & A patto di \\
\hline Contexto & $\begin{array}{l}\text { "Ah" dice fra sé Don Abbondio, tornato a casa "se la peste facesse } \\
\text { sempre andare le cose cosi, ce ne vorrebbe una per ogni } \\
\text { generazione. A patto di guarire, naturalmente!" (121) }\end{array}$ \\
\hline Definiçao De Mauro Paravia & $\begin{array}{l}\text { A patto (che) } \\
\text { loc.cong. CO } \\
\text { seguito da verbo al congt., introduce una proposizione concessiva } \\
\text { esplicita, soltanto se: ti concederò di uscire a patto che tu studi }\end{array}$ \\
\hline Definição Dire & $\begin{array}{l}\text { n.m. 1- Accordo fra due o più parti: Nessuno dei due scioglierà il } \\
\text { patto. 2- Condizione: Verrò a patto che tu mi racconti cosa ti è } \\
\text { successo. } \\
\text { [lat. pactum = patto], sin. } 1 \text { intesa } \\
\text { PROVERBI } \\
\text { Patti chiari e amicizia lunga. (Se gli accordi tra le parti sono precisi } \\
\text { non sorgeranno contrasti.) }\end{array}$ \\
\hline Definição II Sabatini-Coletti & $\begin{array}{l}\text { patto [pàt-to] s.m. } \\
1 \text { Accordo fra due o più individui o parti; anche, particolare } \\
\text { convenzione contenuta in un contratto: sottoscrivere, } \\
\text { osservare, violare il p.; intesa internazionale bilaterale o } \\
\text { plurilaterale di importanza politica: } p \text {. di non aggressione || } \\
\text { venire, scendere a patti, raggiungere un compromesso | } \\
\text { stare ai p., mantenere un accordo, una promessa | p. } \\
\text { sociale, accordo tra sindacati, imprenditori e governo | patti } \\
\text { in deroga, nella disciplina degli affitti, contratto che può } \\
\text { derogare alla legge dell'equo canone | p. di sangue, in } \\
\text { antichi riti tribali o in organizzazioni segrete, alleanza o } \\
\text { iniziazione suggellata mescolando alcune gocce di sangue } \\
\text { dei contraenti | nel prov. p. chiari, amicizia lunga, per avere } \\
\text { buoni rapporti è necessario parlare chiaramente e rispettare } \\
\text { gli accordi } \\
2 \text { estens. Condizione: stabilire un p.; a nessun p. • loc. } \\
\text { cong. a p. che, di, a condizione che, di, purché: accetto, a p. } \\
\text { di partire subito } \\
\text { • sec. XIII }\end{array}$ \\
\hline Definição II Devoto-Oli 2008 & $\begin{array}{l}\text { Patto } \\
\text { <pàt-to> s.m. } \\
\text { 1. Convenzione o accordo fra due o più persone o parti, avente vario } \\
\text { oggetto o contenuto: fare, concludere, stringere un p.; } p \text {. d'armistizio; } \\
\text { p. coniugale, nuziale, la promessa e il vincolo stesso del matrimonio; } \\
\text { p. colonico, il contratto collettivo che disciplina i contratti di mezzadria } \\
\text { e colonia; fig.: fare un p. col diavolo, a proposito di persona disposta } \\
\text { a tutto pur di ottenere ciò che vuole, o, anche, che riesce a } \\
\text { conservare la propria giovinezza a dispetto degli anni• } P \text {. sociale, nel } \\
\text { linguaggio politico e sindacale, accordo per interrompere i contrasti } \\
\text { sulle trattative contrattuali e sulle rivendicazioni salariali, anche sulla } \\
\text { base di reciproche concessioni economiche e normative tra lo Stato, i } \\
\text { datori di lavoro e i lavoratori; anche, secondo i filosofi del XVII e del } \\
\text { XVIII secolo, accordo volontario tra individui, che costituisce il } \\
\text { fondamento della società } P \text {. territoriale, accordo tra sindacati, } \\
\text { imprenditori ed enti locali per promuovere lo sviluppo economico di un } \\
\text { determinato territorio• } P \text {. generazionale, l'impegno, da parte delle } \\
\text { nuove generazioni, di prestare assistenza alla popolazione anziana }\end{array}$ \\
\hline
\end{tabular}




\begin{tabular}{|c|c|}
\hline & $\begin{array}{l}\text { mediante lavori socialmente utili• Nel linguaggio biblico, l'alleanza di } \\
\text { Dio col popolo eletto cui si contrappone col cristianesimo la garanzia } \\
\text { della vita eterna in cambio della fede: donde le espressioni antico e } \\
\text { nuovo p., rispettivamente a proposito delle due concezioni religiose } \\
\text { ebraica e cristiana e anche dei libri dell'Antico e del Nuovo } \\
\text { Testamento• Nel diritto privato, contratto in quanto accordo di volontà } \\
\text { che crea un vincolo giuridico; più spesso, singola convenzione } \\
\text { accessoria di un contratto P. in deroga, contratto di locazione di } \\
\text { immobili con il quale le parti (eventualmente con l'assistenza di } \\
\text { associazioni di categoria di inquilini e proprietari) possono convenire il } \\
\text { pagamento di un canone di locazione superiore a quello consentito (il } \\
\text { cosiddetto equo canone) P. civile di solidarietà, (sigla pacs), } \\
\text { riconoscimento giuridico delle unioni di fatto, sul modello della legge } \\
\text { approvata in Francia nel 1999• Nel diritto internazionale, accordo di } \\
\text { speciale importanza politica: } p \text {. di alleanza, di non aggressione• } P \text {. di } \\
\text { stabilità e di crescita, protocollo del trattato di Maastricht che impone } \\
\text { ai paesi dell'Unione europea che aderiscono all'Unione monetaria di } \\
\text { mantenere il rapporto tra deficit e PIL al di sotto del } 3 \% \text {. } 2 \text {. Ciascuno } \\
\text { dei punti fissati da un accordo o da una convenzione: stare ai p.; } \\
\text { mancare, venire meno ai p.; venire o scendere a patti, a proposito di } \\
\text { un atteggiamento o di un comportamento improvvisamente } \\
\text { condiscendente (talvolta con un senso di avvilimento o di } \\
\text { compromesso)• Condizione: } p \text {. vantaggioso, gravoso; a qualsiasi p., a } \\
\text { qualsiasi costo; a nessun p., in nessun modo, per nessun motivo; a p. } \\
\text { che..., a p. di..., purché } \\
\text { Lat. pactum, der. di pacisci 'patteggiare', che ha la stessa radice di } \\
\text { pax pacis 'pace' | sec. XIII }\end{array}$ \\
\hline Definição Lo Zingarelli 2004 & $\begin{array}{l}\text { FLESSIONE apatto } \\
\text { [lat. pactu(m), dalla stessa famiglia di pax, genit. pacis 'pace'; } 1262 \\
\text { ca.] } \\
\text { s. m. } \\
\text { 1 Accordo o convenzione stabilita tra due o più parti: fare patti giusti, } \\
\text { iniqui, vantaggiosi; stabilire un patto di guerra; rispettare il patto | } \\
\text { Stare ai patti, rispettare ogni elemento di un accordo | Non stare ai } \\
\text { patti, non accettarli o non rispettarli | †Tenere il patto, osservarlo: } \\
\text { pensa poi di non tenere il patto, / perché non ha timor né riverenzia / } \\
\text { di Dio e di santi (ARIOSTO) | Sciogliere il patto, annullarlo, spec. di } \\
\text { comune accordo | Rompere il patto, non tenervi fede | Venire, } \\
\text { scendere a patti, trattare, transigere (anche fig.) | Fare i patti col } \\
\text { diavolo, (fig.) accordarsi con chiunque, pur di ottenere ciò che si vuole } \\
\text { | Patto in deroga, V. deroga | (est.) Promessa: patto nuziale, } \\
\text { d'amicizia, d'onore | Patto territoriale, accordo tra sindacati, } \\
\text { imprenditori ed enti locali per la promozione dello sviluppo economico } \\
\text { in un comprensorio omogeneo. CFR. Contratto d'area. } \\
2 \text { Condizione: a questi patti non accetto; comprare a buon patto | A } \\
\text { nessun patto, a nessuna condizione | A patto che, col patto di, a } \\
\text { condizione che, di | (raro) Modo: a ogni patto. } \\
3 \text { (filos.) Accordo volontario tra individui che, secondo i filosofi del XVII } \\
\text { e del XVIII sec., era all'origine della società. } \\
\text { || PROV. Patti chiari amici cari. } \\
\end{array}$ \\
\hline Definição Parola Chiave & $\begin{array}{l}\text { s.m. } 1 \text { Accordo stabilito tra due o più parti: stringere con qualcuno } \\
\text { patto d'alleanza; rispettare, rompere un patto * pacto | Stare ai patti = } \\
\text { rispettarli *respeitar acordos | Scendere, venire a patti = accettare } \\
\text { un accordo, raggiungere un compromesso *chegar a um acordo } 2 \\
\text { Condizione: gli perdono a patto che mi chieda scusa *condição }\end{array}$ \\
\hline Definição Proposta & A condizione di. \\
\hline
\end{tabular}


Ficha lexicográfica para as novas palavras que constarão nas notas de rodapé 32

\begin{tabular}{|c|c|}
\hline Unidade lexical & Piuttosto che \\
\hline Contexto & $\begin{array}{l}\text { "Quello che ha detto il frate è la pura verità," aggiunge Lucia "vorrei } \\
\text { morire, piuttosto che cadere nelle mani di quel signore!" (46) }\end{array}$ \\
\hline Definiçao De Mauro Paravia & $\begin{array}{l}\text { piut·tò·sto } \\
\text { loc.cong. Co } \\
\text { invece di, anziché: piuttosto che perdere tempo, comincia a studiare | } \\
\text { pur di non: piuttosto che uscire con lui sto a casa }\end{array}$ \\
\hline Definição Dire & $\begin{array}{l}\text { avv. 1- Più volentieri, di preferenza, invece: Non ho voglia di uscire, } \\
\text { piuttosto guarderei un bel film. 4- Molto, abbastanza: Oggi mi sento } \\
\text { piuttosto stanco. / loc.cong. (piuttosto che) Anziché: Preferisco } \\
\text { giocare piuttosto che studiare. }\end{array}$ \\
\hline Definição II Sabatini-Coletti & $\begin{array}{l}\text { piuttosto [piut-tò-sto] avv. } \\
1 \text { Abbastanza, alquanto; tempera il sign. dell'elemento cui si } \\
\text { riferisce, esprimendo cautela nel giudizio: è un tipo p. strano; } \\
\text { è p. tardi } \\
2 \text { Combinato con che, ha il valore di "anziché" e istituisce } \\
\text { una comparazione di preferenza: conviene prendere l'aereo } \\
\text { p. che il treno; in situazione nota, con ellissi del termine di } \\
\text { confronto equivale a "preferibilmente": per prima colazione } \\
\text { mangio p. pane e marmellata } \\
\text { 3 Significa "magari", "perfino" quando il termine di paragone } \\
\text { è rappresentato da una coordinata avversativa: } p \text {. chiederò } \\
\text { l'elemosina, ma non mi sottometterò mai a lui } \\
\text { - In funzione di cong. testuale, col sign. di "invece", } \\
\text { conferisce valore avversativo, segnalando un'alternativa } \\
\text { preferibile: non stare lì senza far niente: p., vieni qui ad } \\
\text { aiutarmi (oppure vieni qui ad aiutarmi, p.); preceduta da o, } \\
\text { equivale a "o meglio", "anzi": scrivigli un biglietto, o p. vai a } \\
\text { trovarlo; si usa anche tra due elementi allinterno della stessa } \\
\text { frase: ti aspetto stasera, o p. domani sera; talora segnala un } \\
\text { cambiamento di tema nel discorso: parliamo sempre di } \\
\text { lavoro. P., perché non facciamo qualche progetto per } \\
\text { l'estate? } \\
\text { • sec. XIII } \\
\text { • Da ultimo, piuttosto che ricorre come loc. cong. disgiuntiva, } \\
\text { col sign. di "o", "oppure": p.e. si sente dire "leggo romanzi, p. } \\
\text { che racconti", nel senso di "leggo romanzi oppure racconti" } \\
\text { (indifferentemente gli uni o gli altri). Si tratta però di un uso } \\
\text { ambiguo e improprio: una frase come la precedente infatti si } \\
\text { presta a essere interpretata in tutt'altro modo: "leggo } \\
\text { romanzi, anziché racconti" (cioè preferisco i romanzi ai } \\
\text { racconti) }\end{array}$ \\
\hline Definição II Devoto-Oli 2008 & $\begin{array}{l}\text { piuttosto } \\
<\text { piut-tò-sto> avv. } \\
\text { 1. Forma durativa e approssimata di più, che è invece momentaneo e } \\
\text { puntuale: p. d'estate che d'inverno rispetto a più d'estate che } \\
\text { d'inverno In senso modale, indica non opzione ma solo propensione: } \\
\text { portato p. all'indulgenza che all'astratta giustizia.2. Alquanto: }\end{array}$ \\
\hline
\end{tabular}




\begin{tabular}{|c|c|}
\hline & $\begin{array}{l}\text { traversata p. burrascosa; è p. tardi; mi sembri piuttosto stanca.3. } \\
\text { Associato a di o a che, introduce una proposizione comparativa: } p \text {. di } \\
\text { incontrarlo, cambio strada; preferisco che mi critichi p. che mi ignori. } \\
\text { Comp. di più e dell'avv. tosto e cioè 'più presto' | sec. XIII }\end{array}$ \\
\hline Definição Lo Zingarelli 2004 & $\begin{array}{l}\text { [comp. di più e tosto 'presto'; av. 1294] } \\
\text { A avv. } \\
1 \text { Più facilmente, più spesso: qui piove piuttosto in primavera che in } \\
\text { autunno; fa piuttosto caldo che freddo | A preferenza, più volentieri: } \\
\text { prenderei piuttosto una bevanda calda | O piuttosto, o meglio: ti } \\
\text { scriverò per informarti, o piuttosto verrò io direttamente; facciamo } \\
\text { così, o piuttosto in quest'altro modo. } \\
2 \text { Alquanto: oggi mi sento piuttosto stanco; ha dei gusti piuttosto } \\
\text { discutibili; è un uomo piuttosto irascibile | Abbastanza: piuttosto bene; } \\
\text { piuttosto male. } \\
3 \text { †Più presto. } \\
\text { B nelle loc. cong. piuttosto di, piuttosto che } \\
1 \text { Anziché (introduce una prop. compar. con il v. al congv. o all'inf.): } \\
\text { preferisco che muoia piuttosto che tradisca; fa mille cose piuttosto che } \\
\text { studiare; piuttosto di cedere voglio andare in rovina! | Con ellissi del } \\
\text { v.: piuttosto la morte; piuttosto la miseria! } \\
2 \text { (colloq., impropr.) Oppure, ovvero (con valore disgiuntivo): alla sera } \\
\text { mangio soltanto del formaggio piuttosto che un uovo o della verdura. }\end{array}$ \\
\hline Definição Parola Chiave & $\begin{array}{l}\text { avv. } 1 \text { Alquanto, notevolmente: è piuttosto tardi, devo andare; gioca } \\
\text { piuttosto bene *um tanto; bastante } 2 \text { Più spesso, più facilmente: qui } \\
\text { fa piuttosto freddo che caldo *mais <> Preferibilmente, più volentieri: } \\
\text { non ho fame, vorrei piuttosto da bere *de preferência | O piuttosto = } \\
\text { o ancor meglio: vediamoci al parco, o piuttosto venite da me *ou } \\
\text { melhor } 3 \text { Piuttosto che, piuttosto di = anziché, pur di non: è meglio } \\
\text { farlo oggi piuttosto che domani; piuttosto di cedere si farebbe } \\
\text { ammazzare *do que; em vez de }\end{array}$ \\
\hline Definição Proposta & Invece di. \\
\hline
\end{tabular}


Ficha lexicográfica para as novas palavras que constarão nas notas de rodapé 33

\begin{tabular}{|c|c|}
\hline Unidade lexical & Presso (nei pressi di) \\
\hline Contexto & $\begin{array}{l}\text { Renzo è stato nascosto dal cugino Bortolo nei pressi di Bergamo, } \\
\text { mentre Lucia è rimasta in casa di Donna Prassede. (97) }\end{array}$ \\
\hline Definiçao De Mauro Paravia & $\begin{array}{l}\text { 'près-so } \\
\text { avv., prep., s.m., agg. Fo } \\
\text { 1. avv., spec. preceduto da un altro avv. di luogo, vicino: si trovava lì } \\
\text { presso, abitano qui presso, li presso scaricano le merci } \\
\text { 2. prep., vicino a, in prossimità di: l'interrutore è presso la porta, } \\
\text { fermarsi presso il marciapiede, sedersi presso qcn., un villaggio } \\
\text { presso il fiume; sempre seguito dalla preposizione di davanti a } \\
\text { pronome personale: presso di me, di lui } \\
\text { 3. prep., spec. nel linguaggio burocratico, indica un luogo } \\
\text { determinato: il documento è depositato presso la pretura, il bando si } \\
\text { troverà presso la segreteria | estens., in casa di, presso l'abitazione } \\
\text { di: era ospite presso un'amica; come indicazione di recapito postale: } \\
\text { Carlo Rossi presso signor Bianchi | alle dipendenze di: è stato tre anni } \\
\text { presso quell'azienda, lavora presso l'ospedale | nell'ambiente di: ha } \\
\text { un'ottima reputazione presso l'accademia, gode di piena fiducia } \\
\text { presso le banche; nell'opinione, nella considerazione di: uno scrittore } \\
\text { molto apprezzato presso i critici | negli scritti, nelle opere, nel pensiero } \\
\text { di un autore: la teoria della relatività presso Einstein | nella cultura, } \\
\text { nella civiltà, nei costumi di un popolo, di un gruppo sociale e sim.: le } \\
\text { danze tribali presso gli africani } \\
\text { 4. prep. LE con valore temporale spec. seguito dalla prep. a, vicino a, } \\
\text { intorno a: se presso al matin ver si sogna (Dante) | BU essere, } \\
\text { trovarsi sul presso a fare qcs.: stare per fare qcs. } \\
\text { 5. s.m. Co al pl., i luoghi intorno a un punto determinato: la farmacia } \\
\text { si trovava nei pressi; in quei pressi, da quelle parti, lì vicino } \\
\text { 6. agg. OB vicino, prossimo nello spazio; la via più pressa: più breve } \\
\text { e veloce }\end{array}$ \\
\hline Definição Dire & $\begin{array}{l}\text { avv. Accanto, vicino: Là presso costruiranno un supermercato. / prep. } \\
\text { 1- Nelle vicinanze di, accanto a: La mia casa è situata presso la } \\
\text { stazione. 2- Alle dipendenze di: Lavoro presso una fabbrica di } \\
\text { calzature. / n.m. Al plurale, paraggi, dintorni: La mamma ha } \\
\text { parcheggiato l'auto nei pressi del teatro. } \\
\text { avv.: contr. Iontano, n.m.: sin. Vicinanze }\end{array}$ \\
\hline Definição II Sabatini-Coletti & $\begin{array}{l}\text { presso [près-so] prep., avv., s. } \\
\text { • prep. } \\
\mathbf{1} \text { Vicino a, in prossimità di: } p \text {. la chiesa; } p \text {. Firenze } \\
\mathbf{2} \text { In casa di, alle dipendenze di, nella sede di, nelle mani di, } \\
\text { in: abita p. la madre; l'azienda p. cui lavoro; rifugiarsi p. } \\
\text { un'ambasciata; in vendita p. i migliori negozi; davanti a pron. } \\
\text { pers. è seguito da di: il documento è p. di me; negli indirizzi } \\
\text { indica la ditta, le persone che costituiscono il recapito: Lia } \\
\text { Baldi, p. Rossi, via Garibaldi } 3 \\
\mathbf{3} \text { estens. Indica attribuzione di un'opinione, un'usanza a } \\
\text { persone o collettività: non riscuote fiducia nemmeno p. i suoi } \\
\text { seguaci; una moda che furoreggia p. i giovani } \\
\text { • avv. (sempre preceduto da un avv. locativo) non com. } \\
\text { Nelle vicinanze, accanto: mi trovavo li p. quando ci fu } \\
\text { l'attentato }\end{array}$ \\
\hline
\end{tabular}




\begin{tabular}{|c|c|}
\hline & $\begin{array}{l}\text { - s.m. (al pl.) Solo nella loc. prep. nei pressi di, vicino, nei } \\
\text { dintorni: essere nei p. della città } \\
\text { - sec. XIII }\end{array}$ \\
\hline Definição II Devoto-Oli 2008 & $\begin{array}{l}\text { Presso } \\
\text { <près-so> avv., prep. e s.m. } \\
\text { 1. avv. Vicino; assol., (arc.): Trapassate oltre sanza farvi presso } \\
\text { (Dante); oggi, solo rinforzato con qui (qui presso) o nelle locuzioni da } \\
\text { presso, di presso; a un di presso, circa.2. Come prep., indica } \\
\text { vicinanza o prossimità nello spazio in complementi di stato in luogo } \\
\text { o di moto a luogo: si combatté p. il fiume; giunti che fummo p. } \\
\text { Firenze; fig., consente di associare alla nozione di 'prossimità' varie } \\
\text { sfumature di 'pertinenza': ambasciatore p. la Repubblica italiana; } \\
\text { intervenne p. il competente ministero; parole che si ritrovano p. } \\
\text { numerosi autori di quel secolo; ha lavorato per molti anni p. questa } \\
\text { ditta; la loc. presso a può avere valore spaziale (un giardino p. alla } \\
\text { casa), temporale ( } p \text {. a morire), modale (p. a poco); la loc. presso di, } \\
\text { non com. nel sign. spaziale (proprio e fig.), è frequente col pronome } \\
\text { personale tonico, generalmente alludendo alla casa o al paese nativo: } \\
\text { lo accolse presso di sé; presso di noi questo uso è sconosciuto• arc. } \\
\text { Come agg. (anche invar.), col sign. di 'vicino': mena il mio ospite alla } \\
\text { più pressa stufa che ci sia (Firenzuola).3. s.m. (al pl.). Vicinanze: vive } \\
\text { nei p. di Torino; l'ho incontrato nei p. del Duomo. }\end{array}$ \\
\hline Definição Lo Zingarelli 2004 & $\begin{array}{l}\text { FLESSIONE } \\
\text { apresso } \\
\text { [lat. presse 'strettamente', da pressus, part. pass. di premere } \\
\text { 'premere'; } 1262 \text { ca.] } \\
\text { A avv. } \\
\text { * (raro) Nelle vicinanze (spec. preceduto da altri avv.): abitava qui } \\
\text { presso; non trovava il martello, e lo aveva lì presso | Da presso, da } \\
\text { vicino: ormai gli inseguitori incalzano da presso | A un di presso, } \\
\text { pressappoco: saranno a un di presso tre metri | V. anche dappresso, } \\
\text { dipresso, pressappoco, pressoché. SIN. Vicino. } \\
\text { B prep. } \\
\text { 1 Vicino a, accanto a (con v. di stato e di moto): arriva fin presso il } \\
\text { fiume; ha una villa presso Napoli; siediti presso la finestra; stare } \\
\text { presso il caminetto | Anche nelle loc. presso a, (lett.) presso di: si } \\
\text { fermò presso a un ruscello; presso della torricella nascoso s'era } \\
\text { (BOCCACCIO) | (est.) In casa di: abita ancora presso i genitori; } \\
\text { vivono presso i nonni; i bambini sono presso una zia | Nella loc. } \\
\text { presso di (davanti a un pron. pers. atono): lo accolse presso di sé; } \\
\text { presso di loro ti troverai bene | (lett.) Nelle loc. presso a, presso di, } \\
\text { (fig.) a paragone di, in confronto a | †Presso a, presso di, circa. } \\
2 \text { (est., fig.) Indica un rapporto o una relazione, spec. di dipendenza, } \\
\text { con una persona o un ambiente: ha lavorato presso di noi per molti } \\
\text { anni; è impiegato presso una ditta commerciale; farà pratica presso } \\
\text { questo ufficio; è stato già ambasciatore presso la Santa Sede; fu } \\
\text { segretario presso un principe romano | Nell'opinione di (indica } \\
\text { relazioni sociali): ha molto prestigio presso la corte; ha trovato favore } \\
\text { presso un ricco mecenate; gode fama, presso il popolo, di uomo } \\
\text { democratico | Nelle opere di, nel pensiero di, nel linguaggio di, e sim.: } \\
\text { troviamo qualche riferimento a questo fatto presso alcuni antichi } \\
\text { scrittori; presso i toscani sono comuni alcune locuzioni altrove } \\
\text { sconosciute | Nell'ambiente, nella cerchia di: questa moda si è diffusa } \\
\text { velocemente presso i giovani; ho assunto informazioni presso la } \\
\text { parrocchia | Nella civiltà di: presso alcune tribù primitive è d'uso il }\end{array}$ \\
\hline
\end{tabular}




\begin{tabular}{|c|c|}
\hline & $\begin{array}{l}\text { sacrificio cruento; presso i Greci veniva praticato l'ostracismo. } \\
3 \text { (lett.) Intorno, vicino a (con valore temp.): mi svegliai presso il } \\
\text { mattino | Anche nella loc. presso a: essere presso alla meta, alla } \\
\text { morte | Sul punto di: essere presso a morire. } \\
4 \text { †Dopo. } \\
\text { C agg. } \\
\text { * (lett.) †Vicino. } \\
\text { D s. m. } \\
1 \text { (al pl.) Luoghi vicini, dintorni: la mia villa nei pressi di Roma; si } \\
\text { aggirava nei pressi di casa mia | †Prossimità, vicinanza (con valore } \\
\text { temporale): sul presso del mattino. } \\
2 \text { (fig.) †Gravezza, affezione: noi... cenammo, ridendoci di quei gran } \\
\text { pressi che fa la fortuna (CELLINI). }\end{array}$ \\
\hline Definição Parola Chiave & $\begin{array}{l}\text { prep. } 1 \text { Vicino a, accanto a: un paesino presso Aosta; venne a sederci } \\
\text { presso di me *perto de <> in casa di, insieme con: si rifugio presso } \\
\text { un amico; abitare presso una zia *em casa de; junto } 2 \text { In: lavora } \\
\text { presso una casa editrice; ho chiesto informazioni presso la scuola } \\
{ }^{*} \text { em <> Tra (gli appartenenti a un determinato gruppo): ha molto } \\
\text { succeso presso i giovani *entre <> s.m.pl.I pressi = le vicinanze, i } \\
\text { dintorni: abita nei pressi della stazione, di Roma *os arredores }\end{array}$ \\
\hline Definição Proposta & Vicino a, nelle vicinanze di. \\
\hline
\end{tabular}


Ficha lexicográfica para as novas palavras que constarão nas notas de rodapé 34

\begin{tabular}{|c|c|}
\hline Unidade lexical & Quaggiù \\
\hline Contexto & $\begin{array}{l}\text { "Anch'io, ma il Signore mi ha voluto lasciare ancora quaggiù. Ah, } \\
\text { Renzo, perché sei qui?" (110) }\end{array}$ \\
\hline Definiçao De Mauro Paravia & $\begin{array}{l}\text { quag.giù } \\
\text { avv. Co } \\
\text { qui in basso: vieni quaggiù a vedere; preceduto da prep.: da, di } \\
\text { quaggiù non sento cosa dici; con valore pleonastico, precede un } \\
\text { avverbio o un complemento di luogo: quaggiù in basso, quaggiù in } \\
\text { cantina | estens., qui a sud: una perturbazione che dall'Inghilterra sta } \\
\text { arrivando quaggiù in Italia | estens., nel mondo, nella vita terrena, in } \\
\text { contrapposizione a lassù, con riferimento al cielo, alla vita } \\
\text { ultraterrena: purtroppo non è più quaggiù tra noi }\end{array}$ \\
\hline Definição Dire & $\begin{array}{l}\text { agg. Qui in basso, in questo luogo: Scendi a vedere cosa ho trovato } \\
\text { quaggiù in cantina! contr. quassù }\end{array}$ \\
\hline Definição II Sabatini-Coletti & $\begin{array}{l}\text { quaggiù [quag-giù] avv. } \\
1 \text { Qui sotto, in questo luogo situato più in basso di un altro } \\
\text { (p.e. di quello in cui è l'interlocutore): q. ci sono delle } \\
\text { infiltrazioni d'acqua \| di q., da q., di qui in basso: di q. il } \\
\text { panorama non si vede } \\
\mathbf{2} \text { fig. Su questa terra, contrapposta al cielo: chi ha tribolato } \\
\text { q. avrà il suo compenso in paradiso \| i beni di q., i beni } \\
\text { terreni • sec. XIV }\end{array}$ \\
\hline Definição II Devoto-Oli 2008 & $\begin{array}{l}\text { quaggiù } \\
\text { <quag-giù> (arc. quaggiuso) avv. } \\
\text { 'Qua in basso', 'in questo luogo' (meno elevato rispetto a chi ascolta): } \\
\text { avverbio di luogo di valore approssimato come qua, ma precisato nel } \\
\text { senso del basso, o in quello di luogo di pianura o posto a Sud: vieni } \\
\text { q.; da q. non riesco a sentirti; q. le estati sono lunghe e torride; } \\
\text { spesso per indicare la Terra, il mondo in cui si vive, contrapposto a } \\
\text { lassù, nel sign. di 'in cielo', 'nell'altra vita': i beni, le cose di q.; Cosi } \\
\text { qua giù si gode E la strada del ciel si trova aperta (Petrarca). } \\
\text { Comp. di qua e giù I prima del } 1321\end{array}$ \\
\hline Definição Lo Zingarelli 2004 & $\begin{array}{l}\text { quaggiù o †quaggiuso, (lett.) †qua giù, †qua giuso } \\
\text { [comp. di qua (1) e giù; av. 1300] avv. } \\
1 \text { In questo luogo, posto in basso rispetto alla persona cui ci si rivolge } \\
\text { (con v. di stato e di moto): sono quaggiù in cortile; vieni quaggiù ad } \\
\text { aiutarmi; quaggiù, in cantina fa molto fresco | (est.) Con riferimento a } \\
\text { un luogo di pianura o posto al sud: quaggiù la vita è molto diversa; } \\
\text { quaggiù gli inverni sono miti | (fig.) Qua sulla Terra, in questo mondo: } \\
\text { noi quaggiù siamo di passaggio; le cose, quaggiù, sono misere; così } \\
\text { qua giù si gode / e la strada del ciel si trova aperta (PETRARCA). } \\
\text { CONTR. Lassù. } \\
2 \text { Nelle loc. avv. da, di quaggiù, stando qua in basso: da quaggiù non } \\
\text { si vede niente; dalla Terra: stelle... tanto picciole che distinguere di } \\
\text { qua giù non le potemo (DANTE). }\end{array}$ \\
\hline Definição Parola Chiave & $\begin{array}{l}\text { agg. Qui in basso: venite quaggiù *aqui embaixo }<>\text { Qui al sud: } \\
\text { quaggiù facciamo i bagni in primavera *aqui no sul }\end{array}$ \\
\hline Definição Proposta & Sulla terra. \\
\hline
\end{tabular}


Ficha lexicográfica para as novas palavras que constarão nas notas de rodapé 35

\begin{tabular}{|c|c|}
\hline Unidade lexical & Radunato (radunati) \\
\hline Contexto & $\begin{array}{l}\text { A questo punto il Cardinale chiede se tra i parroci radunati ci sia per } \\
\text { caso anche quello del paese di Lucia. (87) }\end{array}$ \\
\hline Definiçao De Mauro Paravia & $\begin{array}{l}\text { ra·du·nà'to } \\
\text { p.pass., agg., s.m. } \\
\text { 1. p.pass., agg. } \square \text { radunare, radunarsi } \\
\text { 2. s.m. LE chi viene radunato o si unisce a un assembramento, a un } \\
\text { raduno: una gran parte de' radunati ... s'eran rivoltati a lui (Manzoni) }\end{array}$ \\
\hline Definição Dire & $\begin{array}{l}\text { radunare: v.tr. 1- Riunire: L'allenatore ha radunato i ragazzi negli } \\
\text { spogliatoi. 2- Ammucchiare, unire insieme: Raduna i giornali vecchi in } \\
\text { soffitta. / v.intr.pron. (radunarsi) Ritrovarsi nello stesso luogo, riunirsi: } \\
\text { Molti tifosi si sono radunati allo stadio per la finale del campionato. } \\
\text { derivato da adunare, v.tr.: sin. } 2 \text { raccogliere, raggruppare, } \\
\text { v.intr.pron.: sin. confluire, contr. disperdersi }\end{array}$ \\
\hline Definição II Sabatini-Coletti & $\begin{array}{l}\text { radunare [ra-du-nà-re] v. } \\
\text { • v.tr. [sogg-v-arg] Riunire, raccogliere in un luogo più } \\
\text { persone o cose o animali: r. le proprie cose; anche con } \\
\text { specificazione locativa: r. gli studenti in cortile } \\
\text { • radunarsi } \\
\text { • v.rifl. [sogg-v] Raccogliersi in un luogo: i lavoratori si sono } \\
\text { radunati in assemblea } \\
\text { • sec. XIII }\end{array}$ \\
\hline Definição II Devoto-Oli 2008 & $\begin{array}{l}\text { <ra-du-nà-re> (arc. ragunare e raunare) v.tr. } \\
\text { Riunire insieme, raccogliere in uno stesso luogo: } r \text {. le proprie } \\
\text { cose; il pastore raduna il gregge } \text { Riunire in adunata, } \\
\text { chiamare a raccolta: } r \text {. le truppe.2. estens. Mettere assieme } \\
\text { in grande quantità, ammassare, accumulare: } r \text {. libri, vestiti; è } \\
\text { riuscito a r. enormi ricchezze.3. estens. Riunire per formare } \\
\text { un gruppo o una raccolta rispondenti a criteri precisi, } \\
\text { raggruppare: il ministro ha deciso di r. una serie di esperti; } \\
\text { per la mostra hanno radunato opere prodotte in vari paesi } \\
\text { europei.4. estens. Raccogliere energie fisiche o morali in } \\
\text { vista di uno scopo o di una prova: } r \text {. le proprie forze per } \\
\text { un'impresa; raduna le tue energie e preparati al viaggio; i } \\
\text { soldati dovettero r. tutto il proprio coraggio.5. In marina: } r \text {. le } \\
\text { rotte, nella navigazione stimata, sommare i diversi tratti di } \\
\text { rotta nelle loro differenze di latitudine e di longitudine.6. intr. } \\
\text { pron. Di persone, raccogliersi in uno stesso luogo, riunirsi } \\
\text { (spec. con la prep. in): gli scioperanti si radunarono in } \\
\text { piazza; le truppe si radunarono nel fortino.7. intr. pron. } \\
\text { (lett.). Di cose, raccogliersi insieme, confluire, concentrarsi: } \\
\text { tutto quello che ciascun uomo va perdendo... tutto sale e si } \\
\text { raguna costà (Leopardi).8. intr. pron. (arc.). Unirsi in una } \\
\text { lega, allearsi (con la prep. con): Avvegna che con popol si } \\
\text { rauni Oggi colui... (Dante). } \\
\\
\text { Der. di adunare, col pref. } r \text { - | sec. XIII. }\end{array}$ \\
\hline Definição Lo Zingarelli 2004 & radunare o tragunare, traunare \\
\hline
\end{tabular}




\begin{tabular}{|l|l|}
\hline [comp. di r(i)- e adunare; 1262 ca.] \\
A v. tr. \\
1 Riunire, adunare in uno stesso luogo: radunare il popolo sulla \\
piazza | Mettere insieme raccogliendo qua e là: radunare un esercito \\
di sbandati | (fig., lett.) Raccogliere: Raduno tutto il mio coraggio \\
(MORAVIA). \\
2 (est.) Ammassare, accumulare: radunare tesori. \\
3 (mar.) Radunare le rotte, eseguire il calcolo grafico e analitico per \\
determinare, partendo da un punto osservato, le coordinate del punto \\
stimato dopo aver percorso rotte diverse. \\
B radunarsi v. intr. pron. \\
* Raccogliersi, riunirsi, assembrarsi. \\
\hline Definição Parola Chiave \\
$\begin{array}{l}\text { v.tr. Riunire, mettere insieme: il comizio radunò una gran folla; } \\
\text { raduna le tue cose prima di partire. *reunir; juntar <> radunarsi v.pr. } \\
\text { Riunirsi in uno stesso luogo: } i \text { dimostranti si radunarono nella piazza } \\
\text { *reunir-se }\end{array}$ \\
\hline Definição Proposta \\
\begin{tabular}{l} 
Riuniti. \\
\hline
\end{tabular}
\end{tabular}


Ficha lexicográfica para as novas palavras que constarão nas notas de rodapé 36

\begin{tabular}{|c|c|}
\hline Unidade lexical & Raggiungere (raggiunge) \\
\hline Contexto & $\begin{array}{l}\text { Da Pescarenico, un paese sulla riva del fiume Adda, dove si trova il } \\
\text { suo convento, raggiunge la cassetta di Agnese, che l'ha mandato a } \\
\text { chiamare. (26) }\end{array}$ \\
\hline Definiçao De Mauro Paravia & $\begin{array}{l}\text { rag·giùn·ge·re } \\
\text { v.tr. FO } \\
\text { 1a. arrivare ad allinearsi con una persona o con un gruppo che } \\
\text { precede nel movimento: lo raggiunsi velocemente, raggiungere un } \\
\text { ladro in fuga | arrivare a riunirsi con qcn. che si trova già in un altro } \\
\text { luogo: ti raggiungo più tardi a casa tua } \\
\text { 1b. fig., arrivare al livello di qcn. nel lavoro, nella carriera o sim.: il } \\
\text { nuovo scolaro ha raggiunto il livello dei compagni } \\
\text { 2a. di qcn., arrivare in un determinato punto: raggiungere una cima; } \\
\text { accedere a un determinato luogo: raggiungere un rifugio in quota, si } \\
\text { può raggiungere San Fruttuoso a piedi o col battello } \\
\text { 2b. di qcs., toccare un determinato livello: la temperatura ha raggiunto } \\
\text { i trenta gradi, l'inquinamento atmosferico ha raggiunto il livello di } \\
\text { guardia } \\
\text { 3. fig., conseguire, conquistare: raggiungere una meta, una } \\
\text { promozione; raggiungere le vette del successo; ottenere, trovare: } \\
\text { raggiungere la calma, la tranquillità } \\
\text { 4. di qcs., riuscire a colpire: la pallottola lo raggiunse in pieno petto } \\
\text { 5. LE congiungere, ricongiungere: raggiugne e l'una e l'altra cocca } \\
\text { (Poliziano) }\end{array}$ \\
\hline Definição Dire & $\begin{array}{l}\text { v.tr. 1- Arrivare in un luogo: Da casa mia raggiungo la scuola in } \\
\text { cinque minuti. 2- Arrivare al punto in cui si trova qualcun altro: } \\
\text { L'agente ha raggiunto il ladro. 3- Ottenere, conseguire: Quel cantante } \\
\text { ha finalmente raggiunto il successo. } \\
\text { II - ind.pass.rem. io raggiunsi, tu raggiungesti, egli raggiunse, noi } \\
\text { raggiungemmo, voi raggiungeste, essi raggiunsero; part.pass. } \\
\text { raggiunto. } \\
\text { derivato da giungere, sin. } 2 \text { prendere, } 3 \text { conquistareguadagnare }\end{array}$ \\
\hline Definição II Sabatini-Coletti & $\begin{array}{l}\text { raggiungere [rag-giùn-ge-re] v.tr. (irr.: coniug. come giungere) } \\
\text { • [sogg-v-arg] } \\
\mathbf{1} \text { Toccare un certo luogo, arrivarvi: il fuoco ha raggiunto le } \\
\text { abitazioni } \\
\mathbf{2} \text { Toccare un certo valore: la temperatura ha raggiunto } i \text { venti } \\
\text { sotto zero } \\
\mathbf{3} \text { Giungere a riunirsi con persone o veicoli che precedono: } r \text {. } \\
\text { una motocicletta; estens. contattare qlcu.: } r \text {. l'amico } \\
\text { telefonicamente } \\
\mathbf{4} \text { Riferito a messaggi o notizie, arrivare a qlcu.; freq. al } \\
\text { passivo: è stato raggiunto da un avviso di garanzia } \\
\mathbf{5} \text { fig. Ottenere, conseguire qlco.: } r \text {. il successo } \\
\text { • [sogg-v-arg-prep.arg] Centrare, colpire qlcu. in un punto } \\
\text { preciso; più freq. al passivo: è stato raggiunto da un proiettile } \\
\text { alla gamba }\end{array}$ \\
\hline
\end{tabular}




\begin{tabular}{|c|c|}
\hline & - sec. XIV \\
\hline Definição II Devoto-Oli 2008 & $\begin{array}{l}\text { raggiungere } \\
\text { <rag-giùn-ge-re> (arc. raggiugnere) v.tr. (coniugato come giungere) } \\
\text { 1. Arrivare ad affiancarsi o allinearsi con persone o veicoli che } \\
\text { precedono annullando la distanza da loro; riprendere: r. un corridore; } \\
\text { r. un'automobile; il ciclista in fuga è stato raggiunto dal gruppo; gli } \\
\text { agenti della stradale hanno raggiunto l'auto• Arrivare a riunirsi con } \\
\text { qualcuno che si trovava già in un luogo: ora non posso venire ma vi } \\
\text { raggiungo più tardi; r. gli amici in discoteca; raggiungimi alla } \\
\text { stazione.2. Di notizia, avviso, ecc., arrivare a qualcuno: è stato } \\
\text { raggiunto da un avviso di garanzia; era all'estero dove lo ha raggiunto } \\
\text { la notizia dell'incidente.3. fig. Arrivare allo stesso livello di qualcuno o } \\
\text { qualcosa in un determinato ambito: cercava di r. il primo della classe; } \\
\text { la squadra è stata raggiunta in vetta alla classifica.4. Giungere, } \\
\text { pervenire in un determinato luogo: } r \text {. la cima del monte; } r \text {. il Polo } \\
\text { Nord.5. Giungere a un determinato livello, toccare: la temperatura ha } \\
\text { raggiunto i } 40^{\circ} \text { C.6. fig. Conseguire un risultato, una meta, un } \\
\text { obiettivo; conquistare: } r \text {. una posizione sociale elevata; ha raggiunto } \\
\text { una vittoria molto prestigiosa• Ottenere un determinato stato interiore: } \\
\text { r. la felicità; r. la pace dei sensi; dopo anni di sofferenza finalmente ha } \\
\text { raggiunto la tranquillità.7. Di cosa, arrivare a colpire, centrare: è stato } \\
\text { raggiunto da una pallottola; lo sparo lo raggiunse in pieno petto; un } \\
\text { sasso lo ha raggiunto sulla testa.8. arc. Congiungere, unire.9. intr. } \\
\text { pron. (lett.). Ricongiungersi, riunirsi (con la prep. con): l' mi raggiunsi } \\
\text { con la scorta mia (Dante). }\end{array}$ \\
\hline Definição Lo Zingarelli 2004 & $\begin{array}{l}\text { raggiungere o traggiugnere } \\
\text { [comp. di r(i)- e aggiungere; 1313] } \\
\text { A v. tr. (coniug. come giungere) } \\
1 \text { Arrivare a riunirsi con qlcu. nella corsa, il cammino e sim.: } \\
\text { raggiungere qlcu. a metà strada; raggiungere il fuggitivo. } \\
2 \text { (est.) Arrivare a cogliere, colpire, toccare qlco.: raggiungere il } \\
\text { bersaglio | (est.) Toccare un luogo: raggiungere la vetta. } \\
3 \text { (fig.) Conseguire, ottenere, conquistare: raggiungere la meta, il } \\
\text { proprio intento, la promozione. } \\
4 \text { †Unire, congiungere, ricongiungere: raggiugne e l'una e l'altra cocca } \\
\text { (POLIZIANO). } \\
\text { B raggiungersi v. rifl. } \\
\text { * †Unirsi, ricongiungersi. }\end{array}$ \\
\hline Definição Parola Chiave & $\begin{array}{l}\text { v.tr. [coniugato come giungere] } 1 \text { Arrivare ad affiancarsi a chi ci } \\
\text { precede, colmando la distanza che ci separa da lui (anche): correva } \\
\text { forte ma sono riuscito a raggiungerlo; la nostra squadra ha } \\
\text { raggiuntola prima in classifica *alcançar <> Cogliere, colpire (anche): } \\
\text { fu raggiunto da una pallottola in pieno petto; la notizia lo raggiunse } \\
\text { mentre usciva *atingir; alcançar } 2 \text { Arrivare in un luogo: raggiungere } \\
\text { la vetta <> Arrivare a un dato livello, limite, misura: la temperatura ha } \\
\text { raggiunto i } 35 \text { gradi all'ombra; un'auto che raggiunge i } 200 \mathrm{~km} \text { all'ora } \\
\text { <> Conseguire, ottenere, conquistare: raggiungere lo scopo; ha } \\
\text { raggiunto una discreta posizione economica *atingir }\end{array}$ \\
\hline Definição Proposta & Arrivare ad un luogo. \\
\hline
\end{tabular}


Ficha lexicográfica para as novas palavras que constarão nas notas de rodapé 37

\begin{tabular}{|c|c|}
\hline Unidade lexical & Ridurre (ridotta) \\
\hline Contexto & $\begin{array}{l}\text { Proseguendo per la sua strada, Renzo passa davanti alla sua vigna e } \\
\text { vede in che stato è ridotta. (104) }\end{array}$ \\
\hline Definiçao De Mauro Paravia & 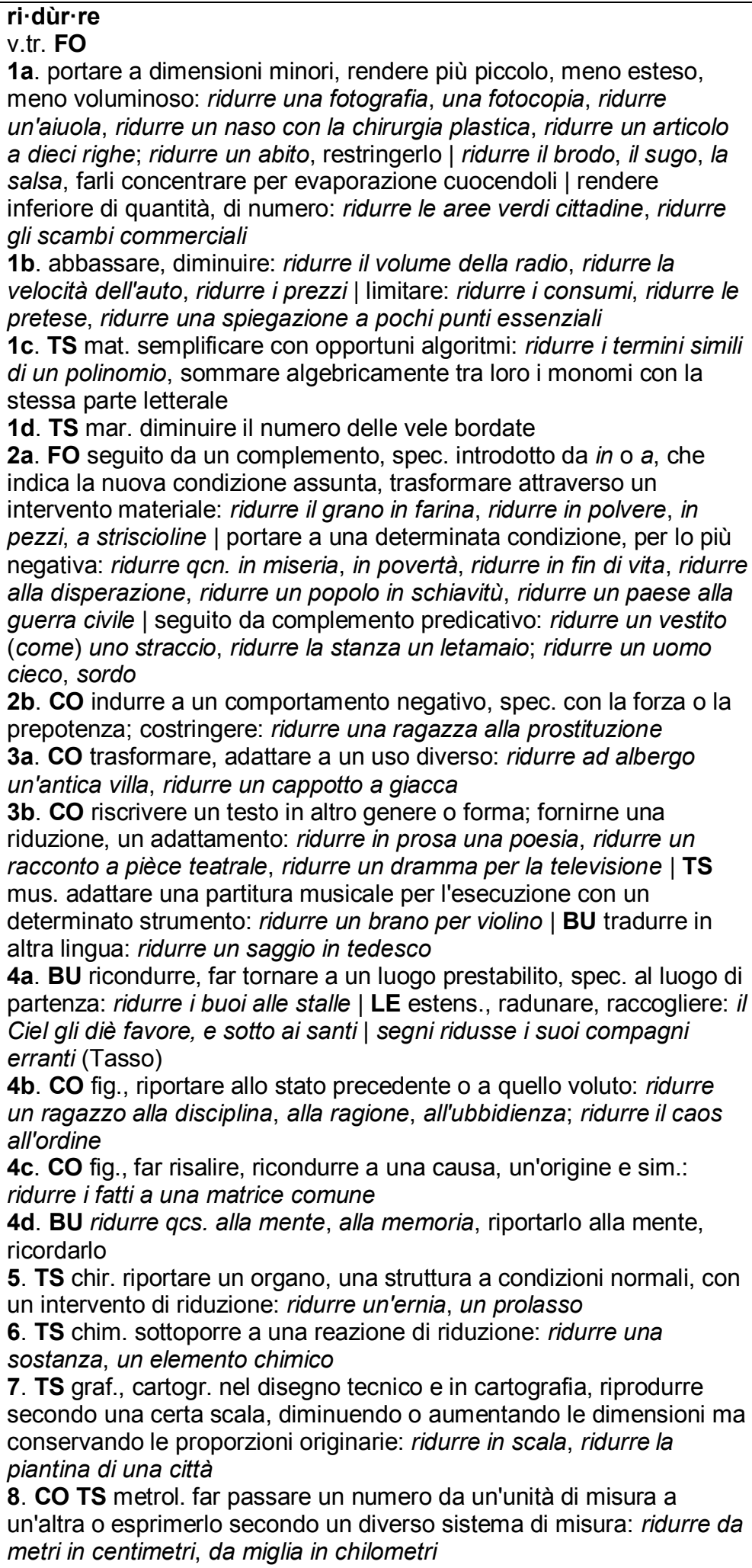 \\
\hline
\end{tabular}




\begin{tabular}{|c|c|}
\hline Definição Dire & $\begin{array}{l}\text { v.tr Portare qualcuno o qualcosa a una condizione diversa, } \\
\text { generalmente peggiore: Guarda come hai ridotto il tuo quaderno! }\end{array}$ \\
\hline Definição II Sabatini-Coletti & 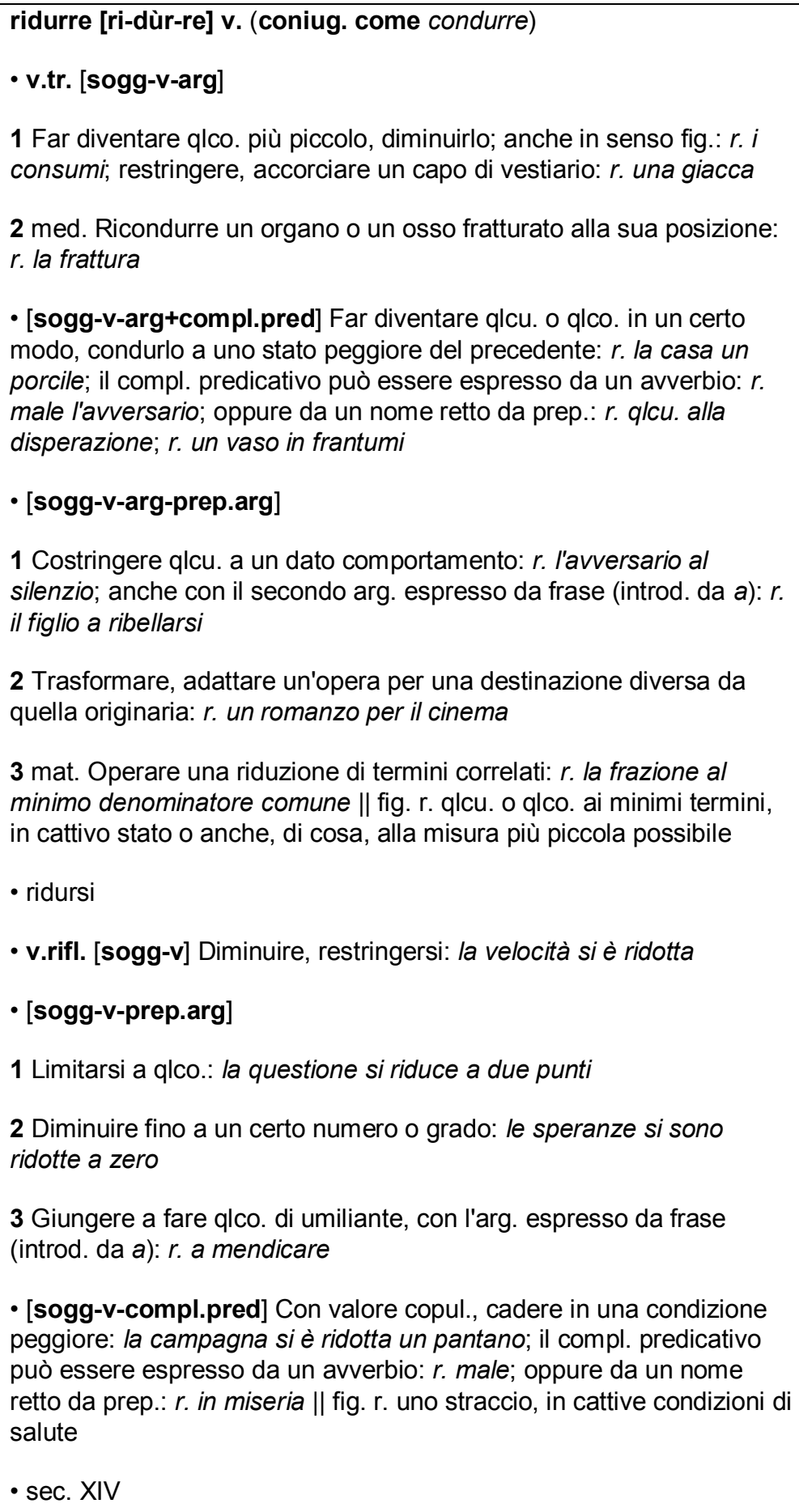 \\
\hline Definição II Devoto-Oli 2008 & $\begin{array}{l}\text { ridurre } \\
\text { <ri-dùr-re> (arc. redurre, riducere, reducere) v.tr. (coniugato come } \\
\text { addurre) } \\
\text { 1. Rendere inferiore di numero, diminuire (anche con la prep. a): } r \text {. il } \\
\text { numero dei disoccupati; } r \text {. le corse notturne degli autobus; il direttore } \\
\text { ha deciso di } r \text {. gli alunni a venti per classe } \text { Portare a dimensioni } \\
\text { minori, rimpicciolire, rimpiccolire: } r \text {. una fotografia; } r \text {. il formato di un } \\
\text { testo; } r \text {. l'area del parcheggio; l'autore vuole } r \text {. il primo capitolo a soli } \\
\text { due paragrafie In marina: } r \text {. la velatura, diminuire il numero delle vele } \\
\text { bordate.2. In chirurgia, ricollocare un viscere o un osso nella loro } \\
\text { posizione normale con un intervento di riduzione: } r \text {. un'ernia, una }\end{array}$ \\
\hline
\end{tabular}




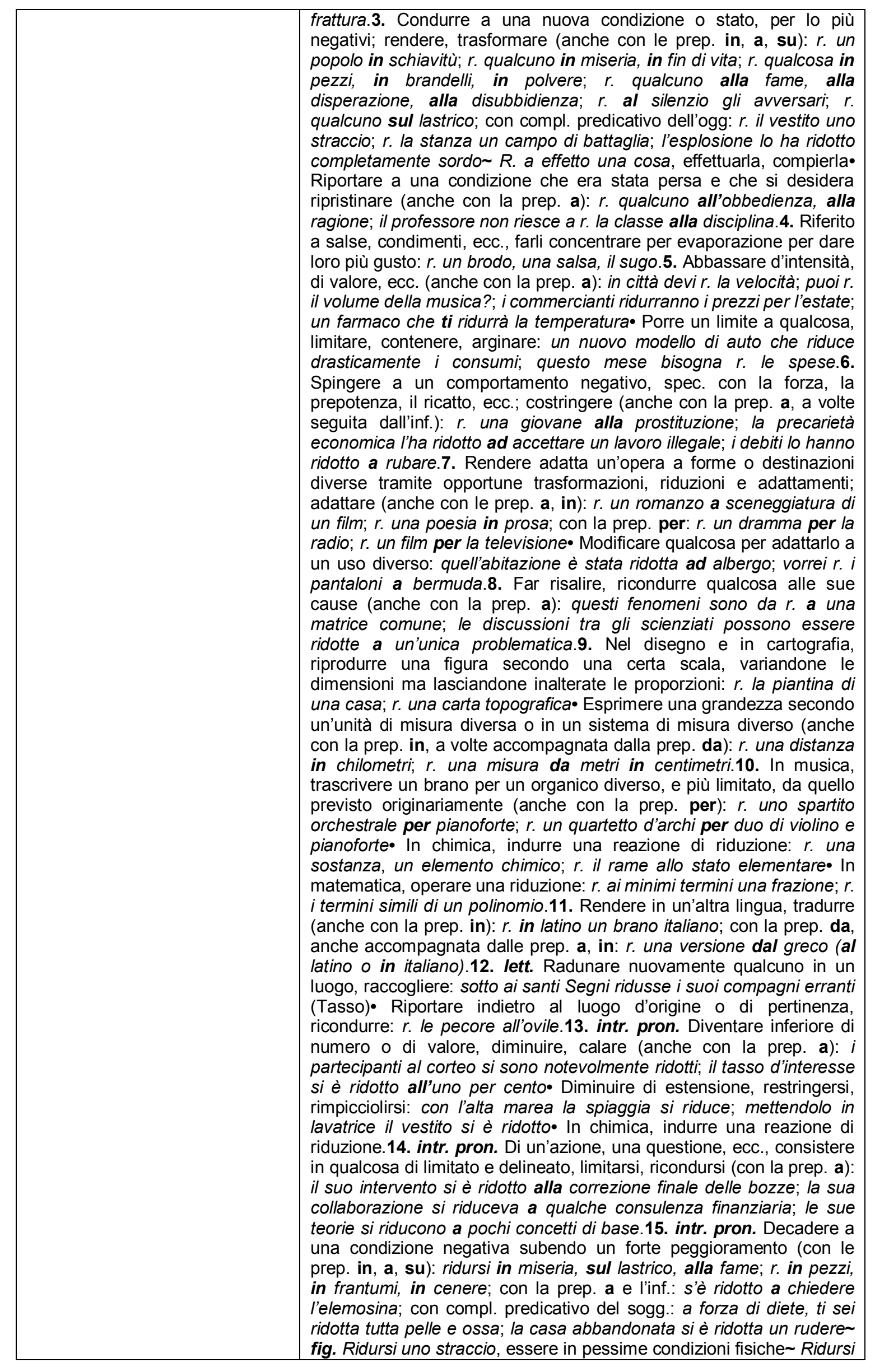




\begin{tabular}{|c|c|}
\hline & $\begin{array}{l}\text { all'ultimo (momento), aspettare fino alla fine di fare qualcosa, } \\
\text { trovandosi a doverlo fare in tutta fretta: per scrivere quest'articolo mi } \\
\text { sono ridotto all'ultimo momento.16. intr. pron. (non com.). Ritirarsi in } \\
\text { un luogo, rifugiarsi (con le prep. in, su): si ridusse in un casolare di } \\
\text { campagna; si ridusse su un'isola deserta Ridursi a vita privata, } \\
\text { ritirarsi dalla scena pubblica. } \\
\text { Lat. reduč̈re 'ricondurre', der. di duč̈re 'condurre', col pref. re- }\end{array}$ \\
\hline Definição Lo Zingarelli 2004 & 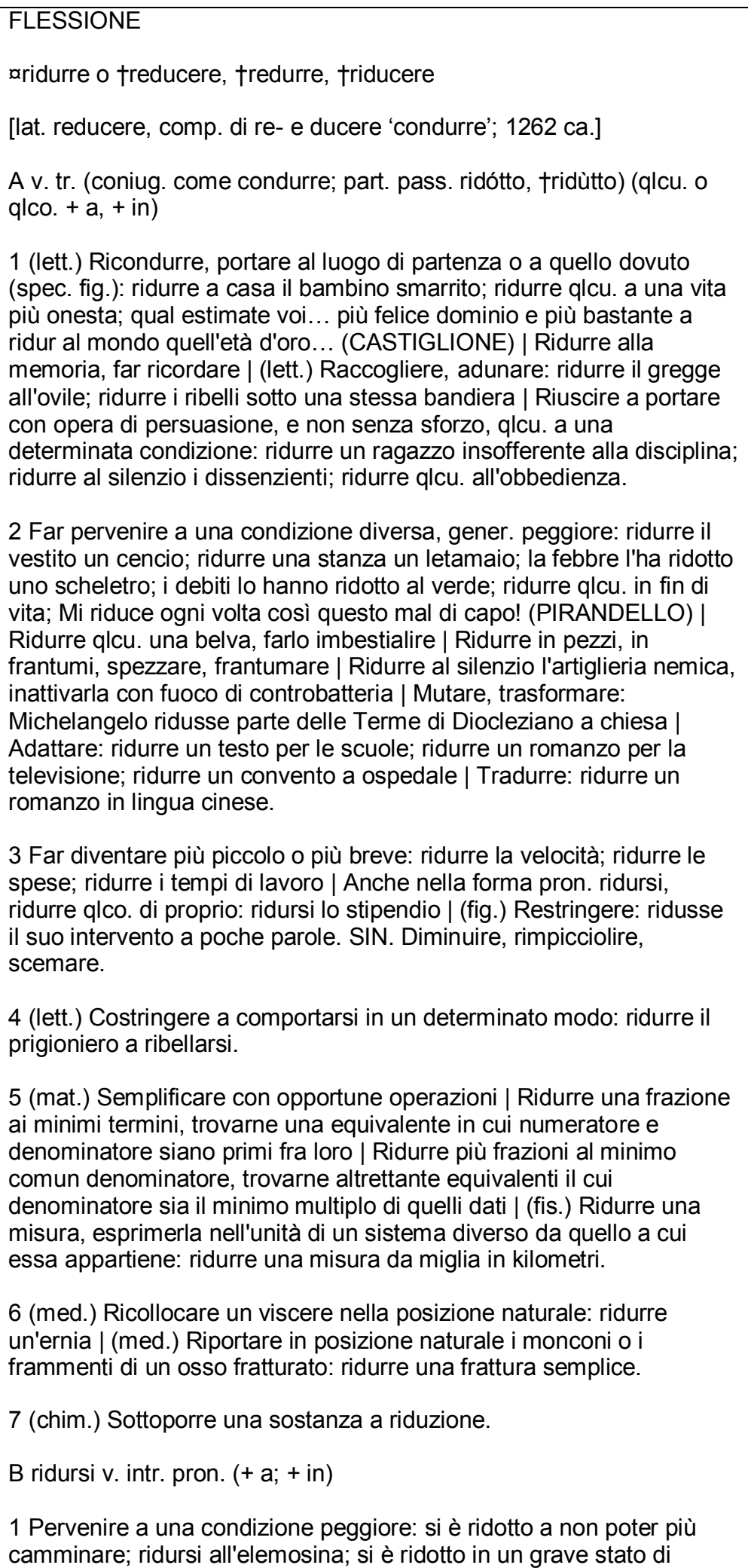 \\
\hline
\end{tabular}




\begin{tabular}{|l|l|}
\hline & $\begin{array}{l}\text { prostrazione | Ridursi all'ultimo, fare le cose all'ultimo momento. } \\
\text { 2 Diminuire, calare, detto di cose: ridursi alla metà; il suo lavoro si è } \\
\text { ridotto a ben poco | Essere riconducibile, consistere: Tutto il sapere si } \\
\text { riduceva a un poco di grammatica (MURATORI). } \\
3 \text { (lett.) Rifugiarsi, ritirarsi: ridursi in un'isola, in una stanzetta, a vita } \\
\text { privata | (raro) Portarsi (anche fig.): ridursi in Ungheria; si ridusse in } \\
\text { salvo | †Ricoverarsi. } \\
\text { II PROV. Bacco, tabacco e Venere riducon l'uomo in cenere. }\end{array}$ \\
\hline Definição Parola Chiave & $\begin{array}{l}\text { v. tr. Far finire qulacuno o qualcosa in condizioni peggiori: ridurre } \\
\text { qualcuno in fin di vita, in miseria, alla disperazione; ha ridotto il vaso } \\
\text { in pezzi. Reduzir }\end{array}$ \\
\hline Definição Proposta & \begin{tabular}{l} 
Come si è degradata \\
\hline
\end{tabular} \\
\hline
\end{tabular}


Ficha lexicográfica para as novas palavras que constarão nas notas de rodapé 38

\begin{tabular}{|c|c|}
\hline Unidade lexical & Scoppiare (scoppia) \\
\hline Contexto & $\begin{array}{l}\text { A queste parole Don Rodrigo scoppia a ridere e aggiunge: "Ebbene, } \\
\text { consigliatele di venire a mettersi sotto la mia protezione: non le } \\
\text { mancherà più nulla e nessuno oserà farle del male!" (28) }\end{array}$ \\
\hline Definiçao De Mauro Paravia & 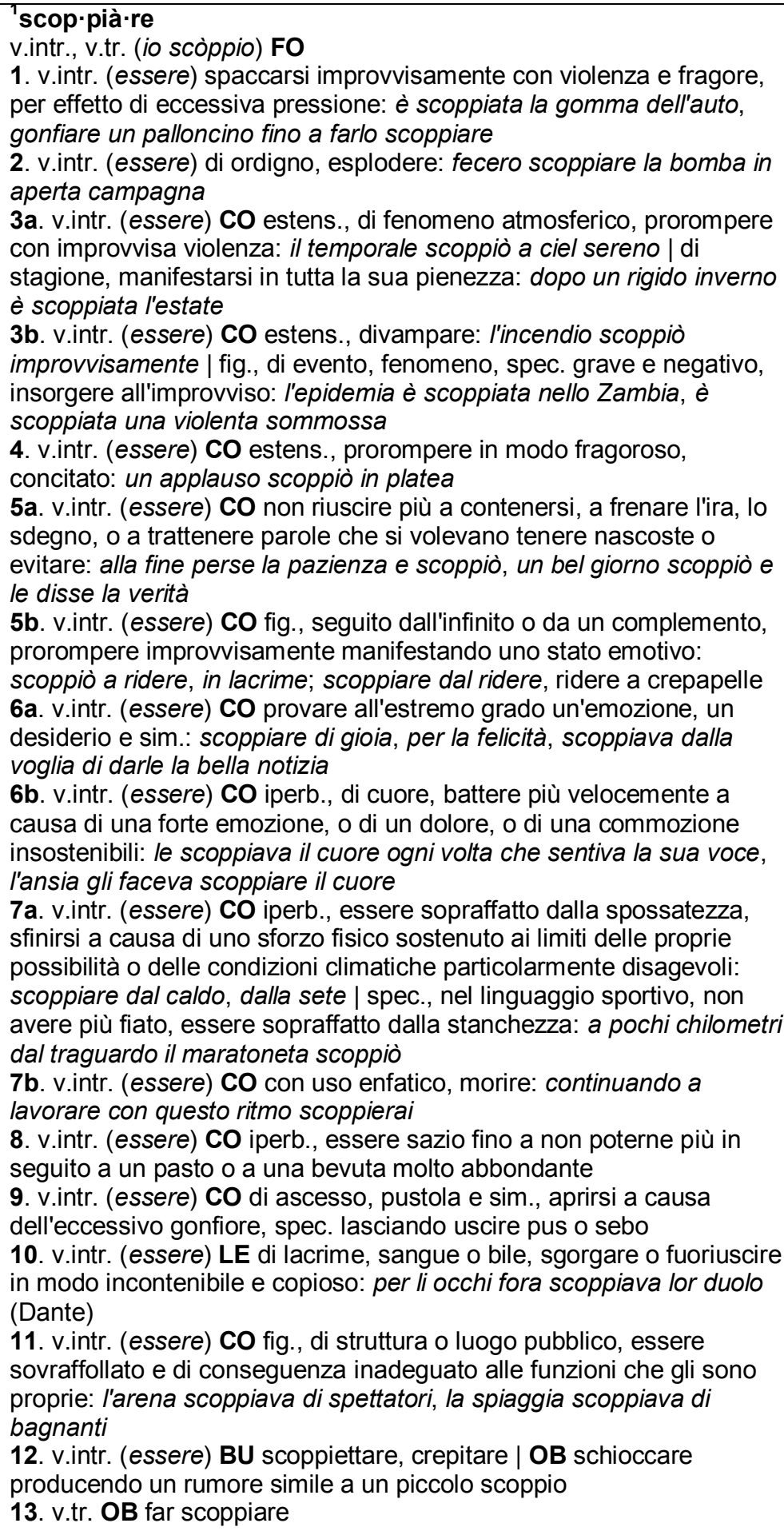 \\
\hline Definição Dire & $\begin{array}{l}\text { v.intr. 1- Rompersi all'improvviso e rumorosamente per eccessiva } \\
\text { pressione, detto di recipienti e corpi cavichiusi: Il bambino piange } \\
\text { perché il suo palloncino è scoppiato. 2- Manifestarsi con violenza: } \\
\text { verso il pomeriggio scoppiò un tremendo temporale. 3- Prorompere: }\end{array}$ \\
\hline
\end{tabular}




\begin{tabular}{|c|c|}
\hline & $\begin{array}{l}\text { Dopo il mio scherzo tutti scoppiarono a ridere. } \\
\text { Derivato da scoppio, sin. } 12 \text { esplodere, } 2 \text { scatenarsi }\end{array}$ \\
\hline Definição II Sabatini-Coletti & $\begin{array}{l}\text { scoppiare [scop-pià-re] v.intr. (aus. essere; scòppio ecc.) } \\
\text { • [sogg-v] } \\
\text { 1 Spaccarsi improvvisamente in più pezzi per una tensione } \\
\text { interna non più contenuta SIN esplodere: è scoppiata una } \\
\text { bomba || figg. mangiare fino a s., fino a non poterne più | s. } \\
\text { dal caldo, non resistere a un'eccessiva temperatura | s. a } \\
\text { piangere, in una risata, prorompere } \\
\mathbf{2} \text { fig. Manifestarsi all'improvviso e con violenza: è scoppiata } \\
\text { una guerra } \\
\mathbf{3} \text { fig. Cedere, avendo esaurito tutte le forze fisiche o } \\
\text { psichiche SIN crollare: sto per s.; non riuscire più a frenarsi: } \\
\text { se non gli dico tutto, scoppio } \\
\text { • [sogg-v-prep.arg] fig. Essere stracolmo di persone o di } \\
\text { oggetti: il salone scoppia di gente; l'autostrada scoppia per il } \\
\text { traffico || s. di salute, essere visibilmente in perfetta forma } \\
\text { fisica } \\
\text { • sec. XIV }\end{array}$ \\
\hline Definição II Devoto-Oli 2008 & 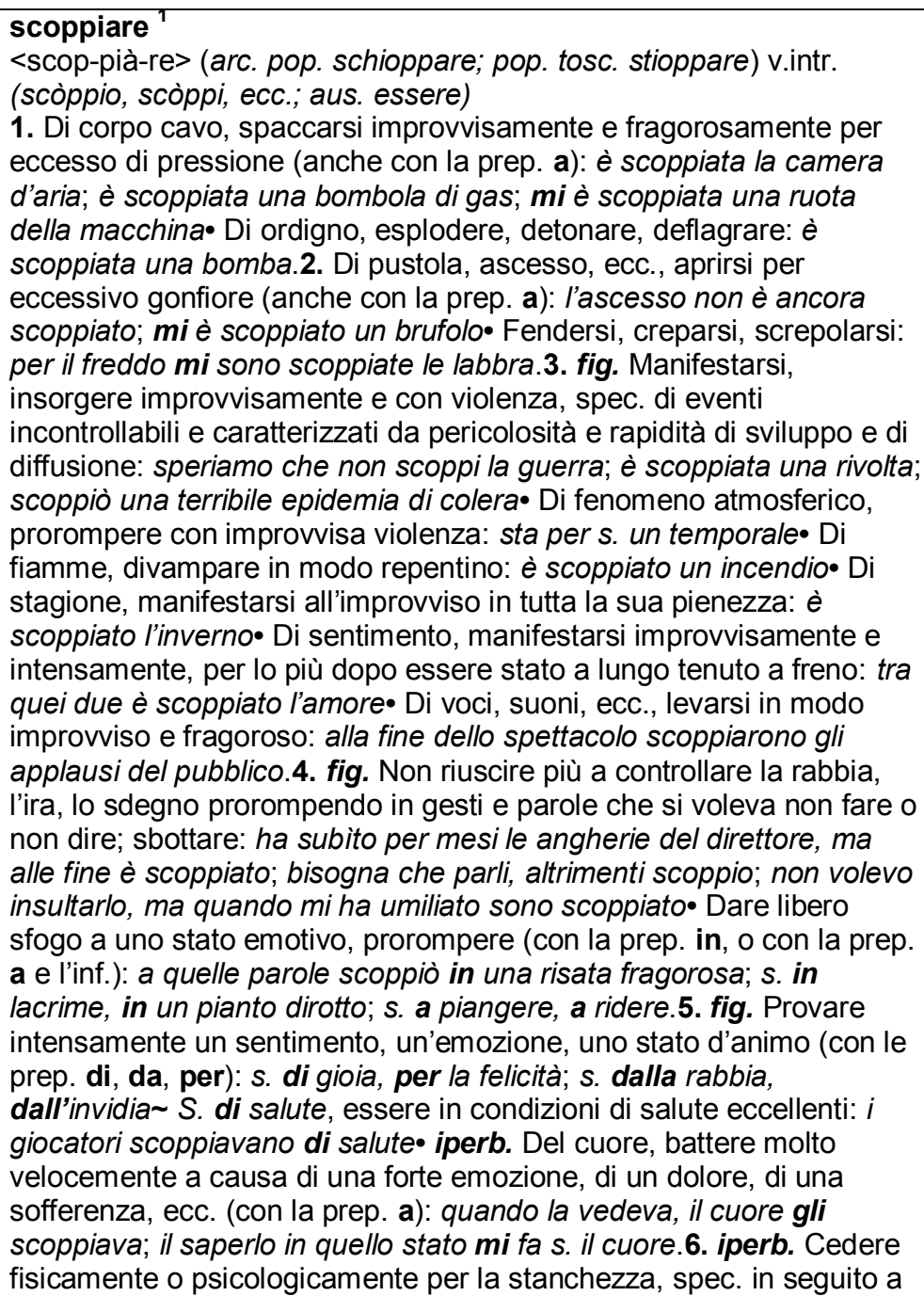 \\
\hline
\end{tabular}




\begin{tabular}{|c|c|}
\hline & $\begin{array}{l}\text { uno sforzo prolungato ed eccessivo: ho retto due settimane a quei } \\
\text { ritmi di lavoro, ma poi sono scoppiato• Non farcela più a sostenere } \\
\text { una situazione di disagio fisico o di bisogno fisiologico; schiattare, } \\
\text { morire, crepare (spec. con la prep. da): qui dentro fa un freddo } \\
\text { terribile: sto scoppiando; s. dal caldo; s. dalla fame, dalla sete S. } \\
\text { dalle risa, dal ridere, ridere a crepapelle• Nel linguaggio sportivo, non } \\
\text { avere più fiato, cedere per un improvviso esaurimento delle energie: il } \\
\text { ciclista è scoppiato sulle prime salite; a pochi chilometri dal traguardo } \\
\text { il maratoneta è scoppiato.7. fig. Essere sazio in seguito a un pasto o } \\
\text { a una bevuta sostanziosi: non ce la faccio a mangiare il dolce: sto } \\
\text { scoppiando; “Un altro bicchiere di vino?" "No, grazie: scoppio"; } \\
\text { mangiare fino a s., mangiare smodatamente.8. fig. Di città, strade, } \\
\text { istituzioni, ecc., restare quasi paralizzate nel loro funzionamento per } \\
\text { congestione o sovraffollamento (spec. con la prep. per): nelle ore di } \\
\text { punta la città scoppia per il traffico; un'università che scoppia per i } \\
\text { troppi studenti॰ generic. Essere eccessivamente affollato (spec. con } \\
\text { la prep. di): la sala scoppia di gente; il teatro scoppiava di } \\
\text { spettatori.9. non com. Schioccare, scoppiettare.10. arc. (fig.). Del } \\
\text { pianto, scaturire, prorompere: Per li occhi fora scoppiava lor duolo } \\
\text { (Dante). }\end{array}$ \\
\hline Definição Lo Zingarelli 2004 & 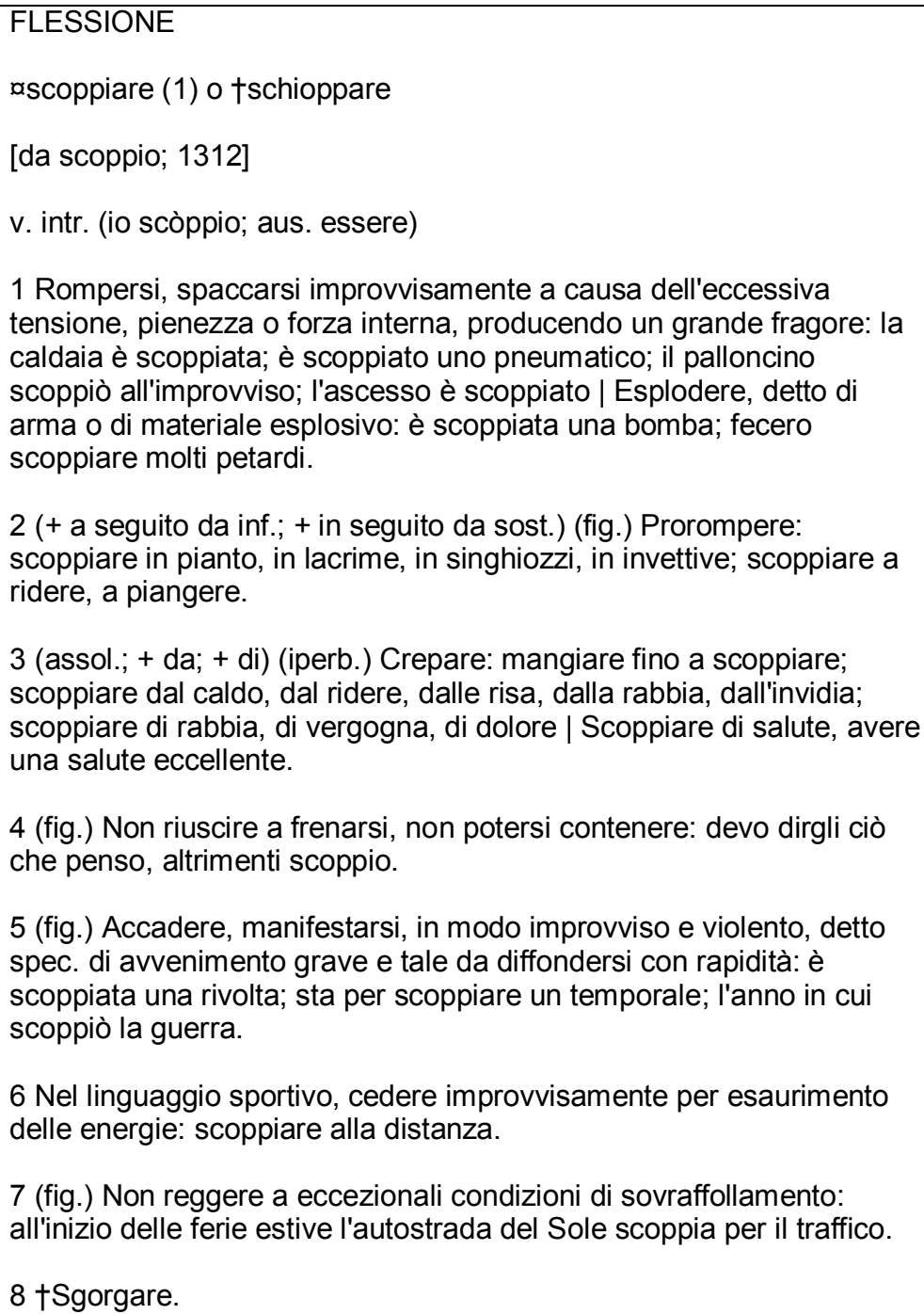 \\
\hline Definição Parola Chiave & $\begin{array}{l}\text { v.intr. [aus. essere] } 1 \text { Rompersi all'improviso, con violenza e per lo più } \\
\text { con fragore, per effetto di eccessiva pressione interna: è scoppiato un } \\
\text { pneumatico; le tubature sono scoppiate per il gelo <> estourar } \mathbf{2}\end{array}$ \\
\hline
\end{tabular}




\begin{tabular}{|l|l|}
\hline & $\begin{array}{l}\text { Prompere: scoppiare in lacrime, a ridere *prorromper; desatar }<> \\
\text { Non poterne più, non poter più resistere: scoppiare dalle risa, dalla } \\
\text { rabbia; devo parlare, altrimenti sccoppio *explodir | Scoppiare dal } \\
\text { caldo = non sopportarlo *morrer de calor <> essere pieno, } \\
\text { stracolmo: il teatro scoppiava di gente *transbordar } 3 \text { Manifestarsi, } \\
\text { insorgere all'improvviso e con violenza: è scoppiata la guerra, } \\
\text { un'epidemia; sta per scoppiare un temporale *estourar; desabar } 4 \\
\text { Cedere improvvisamente per la stanchezza: il ciclista è scoppiato a } \\
\text { metà salita *ficar estafado; cair de exaustão }\end{array}$ \\
\hline Definição Proposta & Esplodere, esplode. \\
\hline
\end{tabular}


Ficha lexicográfica para as novas palavras que constarão nas notas de rodapé 39

\begin{tabular}{|c|c|}
\hline Unidade lexical & Sdraiarsi \\
\hline Contexto & $\begin{array}{l}\text { Vede uma capanna, entra dentro e si sdraia sulla paglia: ha proprio } \\
\text { bisogno di una bella dormita! (69) }\end{array}$ \\
\hline Definiçao De Mauro Paravia & $\begin{array}{l}\text { șdra-iàr-si } \\
\text { v.pronom.intr. Co } \\
\text { mettersi distesi, coricarsi: sdraiarsi sul letto, su un prato; sdraiarsi a } \\
\text { prendere il sole; sdraiarsi prono, supino | distendersi per riposare: } \\
\text { sdraiarsi mezz'oretta dopo pranzo }\end{array}$ \\
\hline Definição Dire & $\begin{array}{l}\text { v.rifl. Distendersi, adagiarsi: In spiaggia mi sdraio volentieri sulla } \\
\text { sabbia per abbronzarmi. } \\
\text { sin. stendersi }\end{array}$ \\
\hline Definição II Sabatini-Coletti & $\begin{array}{l}\text { sdraiare [sdra-ià-re] v. (sdràio ecc.) } \\
\text { • v.tr. [sogg-v-arg-prep.arg] Mettere disteso qlcu. in un } \\
\text { luogo SIN coricare: s. un ferito sulla barella } \\
\text { • sdraiarsi } \\
\text { • v.rifl. [sogg-v] Distendersi sul letto per riposare } \\
\text { • [sogg-v-prep.arg] Mettersi disteso a giacere in un luogo } \\
\text { SIN stendersi: s. sull'erba • sec. XVII }\end{array}$ \\
\hline Definição II Devoto-Oli 2008 & $\begin{array}{l}\text { Sdraiare } \\
\text { <sdra-ià-re> v.tr. (sdràio, sdrài, ecc.) } \\
\text { 1. Mettere in posizione supina o distesa, coricare, distendere, } \\
\text { stendere (anche con la prep. su): sdraiarono il ferito sul letto.2. } \\
\text { estens. (non com.). Buttare a terra, abbattere: l'ha sdraiato con un } \\
\text { pugno; il vento ha sdraiato il grano.3. rifl. Mettersi disteso, coricarsi, } \\
\text { distendersi, stendersi (anche con la prep. su): si è sdraiato supino; ci } \\
\text { siamo sdraiati a prendere il sole; s. per terra; s. sul letto, sul divano; } \\
\text { s. sull'erba, su un prato• Con uso assol., stendersi sul letto per } \\
\text { riposare: ho molto sonno: vado a sdraiarmi. } \\
\text { Lat. *(e)xderadiare (der. di radĭ us 'raggio', con i due pref. ex- e de-) } \\
\text { 'stendere le braccia e le gambe a raggio' I sec. XVII }\end{array}$ \\
\hline Definição Lo Zingarelli 2004 & $\begin{array}{l}\text { FLESSIONE asdraiare } \\
\text { [lat. parl. *exderadiare, da radius 'raggio', con doppio pref. ex-de: } \\
\text { 'disporre le membra a raggio'; 1618] } \\
\text { A v. tr. (io sdràio) } \\
\text { * Mettere a giacere: sdraiare un bambino sul letto. } \\
\text { B sdraiarsi v. rifl. } \\
1 \text { Mettersi a giacere, stendersi: sdraiarsi sull'erba. } \\
2 \text { (fig.) Esprimere un consenso incondizionato, appiattirsi: sdraiarsi } \\
\text { sulle proposte del governo. }\end{array}$ \\
\hline Definição Parola Chiave & $\begin{array}{l}\text { v.tr. Mettere in giacere S stendere, coricare: sdraiarono il malato sul } \\
\text { letto *deitar <> sdraiarsi v.pr Mettersi a giacere } \mathbf{S} \text { stendersi: straiarsi } \\
\text { sull'erba *deitar-se }\end{array}$ \\
\hline Definição Proposta & Stendersi su una superficie per riposare. \\
\hline
\end{tabular}


Ficha lexicográfica para as novas palavras que constarão nas notas de rodapé $\mathbf{4 0}$

\begin{tabular}{|c|c|}
\hline Unidade lexical & Soffice (soffici) \\
\hline Contexto & $\begin{array}{l}\text { Andando avanti, Renzo nota per terra qualcosa di strano: sono strisce } \\
\text { bianche e soffici, sembra neve... ma è farina! (47) }\end{array}$ \\
\hline Definiçao De Mauro Paravia & $\begin{array}{l}\text { sòf·fi·ce, sóf·fi·ce } \\
\text { agg. Co } \\
\text { 1a. che cede morbidamente alla pressione: un soffice manto di neve, } \\
\text { lana, cuscino soffice | confortevole, comodo: letto, divano soffice } \\
\text { 1b. estens., che ha apparenza o consistenza spumosa: un soffice } \\
\text { strato di panna, soffici nubi } \\
\text { 2a. fig., di luce, soffusa, sfumata | di suono, attutito, smorzato } \\
\text { 2b. fig., accomodante, condiscendente: comportamento, approccio } \\
\text { soffice } \\
\text { 3. TS agr. di terreno, amminutato e reso permeabile all'aria e } \\
\text { all'acqua, particolarmente adatto alla coltivazione } \\
\text { 4. TS ecol. } \square \text { dolce }\end{array}$ \\
\hline Definição Dire & $\begin{array}{l}\text { agg. Morbido: Ho comprato un maglione di lana soffice. } \\
\text { m.f.pl. soffici }\end{array}$ \\
\hline Definição II Sabatini-Coletti & $\begin{array}{l}\text { soffice [sòf-fi-ce] agg. } \\
1 \text { Che cede dolcemente alla minima pressione SIN morbido, } \\
\text { molle: cuscino s. } \\
\mathbf{2} \text { fig. Non violento, non traumatico: l'impatto con il nuovo } \\
\text { ambiente è stato s.; non rigido: atteggiamento s. • sec. XIV }\end{array}$ \\
\hline Definição II Devoto-Oli 2008 & $\begin{array}{l}\text { Soffice } \\
\text { <sòf-fi-ce> agg. } \\
\text { 1. Che cede dolcemente alla pressione; di gradevole o confortevole } \\
\text { morbidezza: materasso s.; pane s., ben lievitato.2. fig. Per influenza } \\
\text { dell'ingl. soft, blando, pacato, attutito, mitigato: atmosfera s.; } \\
\text { atterraggio s. } \\
\text { Etimo incerto | sec. XIV }\end{array}$ \\
\hline Definição Lo Zingarelli 2004 & $\begin{array}{l}\text { FLESSIONE asoffice [lat. supplice(m) 'supplichevole', con } \\
\text { sovrapposizione di *suffiectere, comp. di flectere 'piegare' (?); av. } \\
\text { 1320] } \\
\text { agg. } \\
1 \text { Che si piega e cede con facilità alla pressione: lana morbida e } \\
\text { soffice; guanciale, materasso soffice | (fig.) Soft. SIN. Morbido. } \\
\text { CONTR. Duro. } \\
2 \text { (ecol.) Dolce. } \\
3 \text { (aer.) Volo soffice, quello effettuato mediante aeromobili, derivati dal } \\
\text { deltaplano, che utilizzano, per la propulsione, l'energia muscolare } \\
\text { umana o l'energia solare. } \\
\text { || sofficemente, avv. In modo soffice. }\end{array}$ \\
\hline Definição Parola Chiave & $\begin{array}{l}\text { agg. Che cede facilmente alla pressione S morbido: lana soffice; un } \\
\text { cuscino, un letto soffice *macio }\end{array}$ \\
\hline Definição Proposta & Il contrario di duro. \\
\hline
\end{tabular}


Ficha lexicográfica para as novas palavras que constarão nas notas de rodapé $\mathbf{4 1}$

\begin{tabular}{|c|c|}
\hline Unidade lexical & Sopruso (soprusi) \\
\hline Contexto & $\begin{array}{l}\text { Per circa } 150 \text { anni (dal } 1550 \text { al 1700) la popolazione locale fu } \\
\text { costretta a pagare per il mantenimento dell'esercito spagnolo e a } \\
\text { subirne i soprusi. (75) }\end{array}$ \\
\hline Definiçao De Mauro Paravia & $\begin{array}{l}\text { so·prù-șo } \\
\text { s.m. AU } \\
\text { atto o comportamento che, in contrasto con la volontà, i diritti o gli } \\
\text { interessi altrui, fa prevalere i propri, ricorrendo alla prepotenza e } \\
\text { all'abuso, soverchieria: patire, subire, commettere soprusi, sentire un } \\
\text { ordine come un sopruso }\end{array}$ \\
\hline Definição Dire & $\begin{array}{l}\text { n.m. Azione prepotente fatta ai danni di qualcuno: Non tollera } i \\
\text { soprusi dei ragazzi più grandi. } \\
\text { Derivato da uso, sin. Angheria }\end{array}$ \\
\hline Definição II Sabatini-Coletti & $\begin{array}{l}\text { sopruso [so-prù-so] s.m. } \\
\qquad \begin{array}{l}\text { Prepotenza, sopraffazione: subire, commettere un s. } \\
\text { • sec. XVI }\end{array}\end{array}$ \\
\hline Definição II Devoto-Oli 2008 & $\begin{array}{l}\text { Sopruso } \\
<\text { so-prù-\$̦o> s.m. } \\
\text { Impiego arbitrario della propria autorità o di una posizione di } \\
\text { superiorità o di forza per imporre la propria volontà a danno e offesa } \\
\text { dei diritti altrui. } \\
\text { Der. di } u s^{2} \text {, col pref. sopra- | sec. XVI }\end{array}$ \\
\hline Definição Lo Zingarelli 2004 & $\begin{array}{l}\text { FLESSIONE } \\
\text { sopruso } \\
\text { [comp. di sopr- e uso; av. 1540] } \\
\text { s. m. } \\
\text { * Prepotenza, soperchieria, sopraffazione: fare un sopruso a qlcu.; } \\
\text { fare, commettere, un sopruso; ricevere, subire, un sopruso; è stato un } \\
\text { sopruso dei superiori. }\end{array}$ \\
\hline Definição Parola Chiave & $\begin{array}{l}\text { s.m. Atto di prepotenza compiuto abusando del proprio potere o della } \\
\text { propria forza S sopraffazione, angheria: subire un sopruso } \\
\text { *arbitrariedade }\end{array}$ \\
\hline Definição Proposta & $\begin{array}{l}\text { Atto di prepotenza, maltrattamento, impiego arbitrario } \\
\text { dell'autorità. }\end{array}$ \\
\hline
\end{tabular}


Ficha lexicográfica para as novas palavras que constarão nas notas de rodapé 42

\begin{tabular}{|c|c|}
\hline Unidade lexical & Sottrarsi \\
\hline Contexto & $\begin{array}{l}\text { "Deve sapere, madre," comincia a raccontare il frate "che questa } \\
\text { giovane ha dovuto lasciare il suo paese per sottrarsi a gravi pericoli: } \\
\text { un nobile prepotente la perseguitava...." (46) }\end{array}$ \\
\hline Definiçao De Mauro Paravia & $\begin{array}{l}\text { sot·tràr-si } \\
\text { v.pronom.intr. Co } \\
\text { 1a. salvaguardarsi da pericoli, da danni fisici o morali, da situazioni } \\
\text { spiacevoli, ecc. } \\
\text { 1b. liberarsi da costrizioni, dalla sottomissione a un'autorità; } \\
\text { affrancarsi da un potere politico opprimente: sottrarsi alla } \\
\text { dominazione straniera } \\
\text { 2. estens., esimersi da un impegno, da un'incombenza, da un ordine; } \\
\text { venire meno, mancare: sottrarsi alle proprie responsabilità } \\
\text { 3. sfuggire agli sguardi: si sottrasse alla sua vista | ritrarsi da una } \\
\text { persona, spec. sciogliendosi dal suo abbraccio }\end{array}$ \\
\hline Definição Dire & $\begin{array}{l}\text { v.rifl. Sfuggire, evitare: Non ha potuto sottrarsi all'invito degli amici. } \\
\text { [lat. subtrahere = sottrarre], v.tr.: contr. } 1 \text { aggiungere, sommare, } \\
\text { addizionare }\end{array}$ \\
\hline Definição II Sabatini-Coletti & Não consta. \\
\hline Definição II Devoto-Oli 2008 & Não consta. \\
\hline Definição Lo Zingarelli 2004 & $\begin{array}{l}\text { FLESSIONE } \\
\text { sottrarre o †sottraggere, †suttrarre } \\
\text { [lat. subtrahere 'trarre (trahere) di sotto, via (sub)'; av. 1249] } \\
\text { A v. tr. (coniug. come trarre) } \\
1 \text { (qlco. o qlcu. + a, lett. + da) Levare via, togliere: sottrarre qlco. alla } \\
\text { vista altrui; sottrarre qlcu. agli sguardi dei curiosi | Liberare, salvare: } \\
\text { sottrarre qlcu. a un pericolo; e mi sottrasse a li mondani inganni } \\
\text { (SANNAZARO); per sottrarmi da un sì fiero pericolo (GOLDONI). } \\
2 \text { Rapire, rubare, togliere con l'inganno: sottrarre un documento a } \\
\text { qlcu.; mi ha sottratto del denaro. } \\
3 \text { (+ da) (mat.) Eseguire una sottrazione: sottrarre una parte } \\
\text { dall'intero. CONTR. Addizionare. } \\
4 \text { †Allettare, sedurre. } \\
\text { B sottrarsi v. rifl. (+ a; lett. + da) } \\
\text { * Sfuggire, liberarsi, evitare: sottrarsi a un pericolo, alla vigilanza di } \\
\text { qlcu.; per sottrarmi da quei bricconi che mi circondano (GOLDONI). }\end{array}$ \\
\hline Definição Parola Chiave & $\begin{array}{l}\text { v.tr. [coniugato come trarre] } 1 \text { Portar via qualcosa ad altri con l'astuzia } \\
\text { o con l'inganno } \mathbf{S} \text { rubare: il ladro gli sottrasse il portafoglio } 2 \text { Levare, } \\
\text { portar via o salvare, liberare da qualcosa: coprirono il cadavere per } \\
\text { sottrarlo alla vista dei curiosi; sottrarre qualcuno alla morte } 3 \text { Eseguire } \\
\text { una sottrazione *subitrai }\end{array}$ \\
\hline Definição Proposta & Scappare, fuggire. \\
\hline
\end{tabular}


Ficha lexicográfica para as novas palavras que constarão nas notas de rodapé $\mathbf{4 3}$

\begin{tabular}{|c|c|}
\hline Unidade lexical & Spingere (spinge) \\
\hline Contexto & $\begin{array}{l}\text { A sentire il nome di Don Rodrigo, il dottor Azzeccagarbugli smette di } \\
\text { parlare, si alza, spinge Renzo con le mani verso la porta, chiama la } \\
\text { serva e gli fa restituire i capponi dicendo: "Via, via, non voglio niente, } \\
\text { non voglio niente!" (12) }\end{array}$ \\
\hline Definiçao De Mauro Paravia & $\begin{array}{l}\text { spìn-ge-re } \\
\text { v.tr. e intr. Fo } \\
\text { 1a. v.tr., sottoporre qcs. a una pressione momentanea o prolungata } \\
\text { per spostarla in una determinata direzione, spec. in avanti: spingere } \\
\text { un mobile contro il muro I premere un organo di comando di un } \\
\text { meccanismo, in modo da azionare il meccanismo stesso: spingere un } \\
\text { tasto, un pulsante | far funzionare una macchina sfruttandone il più } \\
\text { possibile la potenza: spingere l'auto ad alta velocità } \\
\text { 1b. v.tr., sottoporre una persona a una pressione momentanea o } \\
\text { prolungata per aiutarla o costringerla a procedere o a spostarsi in una } \\
\text { determinata direzione, per farla vacillare o cadere, ecc.: spingere una } \\
\text { persona a terra; anche ass.: non spingere } \\
\text { 1c. v.tr., del vento, di un corso d'acqua, delle onde marine, ecc., } \\
\text { trascinare in una determinata direzione o contro un ostacolo: il vento } \\
\text { ha spinto la nave contro gli scogli } \\
\text { 2. v.tr., distendere o ritrarre con energia una parte del corpo: spingere } \\
\text { la pancia in dentro } \\
\text { 3. v.tr., dirigere lo sguardo in una direzione, farlo arrivare fino a un } \\
\text { dato punto: spingere gli occhi oltre l'orizzonte } \\
\text { 4. v.tr., fig., sollecitare, muovere, indurre a determinate azioni o } \\
\text { comportamenti: il bisogno lo ha spinto a rubare } \\
\text { 5. v.tr., fig., far procedere un'attività, un affare, una questione, ecc.: } \\
\text { spingere un progetto; spingere le vendite, incrementarle con } \\
\text { opportune azioni promozionali } \\
\text { 6. v.tr., fig., portare oltre un certo limite: non spingere oltre le tue } \\
\text { pretese } \\
\text { 7. v.intr. (avere) esercitare una pressione, far pressione contro qcs.: } \\
\text { l'enorme massa d'acqua spinge contro la diga } \\
\text { 8. v.intr. (avere) fig., darsi da fare, adoperarsi per ottenere qcs.: sta } \\
\text { spingendo per far assumere suo figlio }\end{array}$ \\
\hline Definição Dire & $\begin{array}{l}\text { v.tr. 1- Premere su una cosa o su una persona per farla muovere: Per } \\
\text { entrare in quel negozio basta spingere la porta girevole. 2- Premere } \\
\text { una cosa per farla penetrare in dentro: Ispingi il bottone se vuoi } \\
\text { chiamare l'ascensore. 3- Indurre, incitare: Le lodi dell'insegnante mi } \\
\text { spingono a studire di più. 4- Portare fino ad uno certo punto: Ha } \\
\text { spinto la propria audacia oltre il limite. } \\
\text { Il- ind.pres. io spingo, tu spingi, egli spinge, noi spingiamo, voi } \\
\text { spingete, essi spingono; pass.rem. io spinsi, tu spingesti, egli spinse, } \\
\text { noi spingemmo, voi spingeste, essi spinsero; part.pass. spinto. } \\
\text { I v.intr.pron. (spingersi) 1- Inoltrarsi: La comitiva si spinse fin nel } \\
\text { cuore del bosco. } 2 \text { - Andare oltre il limite consentito: Si spinse fino ad } \\
\text { insultare i compagni. } \\
\text { v.tr.: sin. } 2 \text { pigiare, v.intr.pron.: sin. } 1 \text { avanzare, addentrarsi }\end{array}$ \\
\hline Definição II Sabatini-Coletti & $\begin{array}{l}\text { spingere [spìn-ge-re] v. (irr.: ind.pres. spingo, spingi ecc., pass.rem. } \\
\text { spinsi, spingesti ecc.; part.pass. spinto) } \\
\text { • v.tr. [sogg-v-arg] } \\
1 \text { Premere un oggetto per abbassarlo SIN pigiare, }\end{array}$ \\
\hline
\end{tabular}




\begin{tabular}{|c|c|}
\hline & $\begin{array}{l}\text { schiacciare: s. il pedale del freno } \\
2 \text { Esercitare una pressione su qlcu. o su qlco. per spostarlo } \\
\text { SIN sospingere: s. la moto fino all'officina; s. il compagno } \\
\text { fuori dalla porta; in contesto noto o in usi generalizzati l'arg. } \\
\text { può essere sottinteso: smettila di s.! } \\
\text { • [sogg-v-arg-prep.arg] } \\
\text { 1 fig. Portare, far giungere qlco. fino a un certo limite: s. la } \\
\text { propria arroganza fino all'inverosimile } \| \text { s. lo sguardo } \\
\text { lontano, estenderlo, protenderlo } \\
\text { 2 fig. Indurre, incitare qlcu. a fare qlco. SIN istigare, } \\
\text { spronare: s. l'amante al delitto; spesso con il secondo arg. } \\
\text { espresso da frase (introd. da a): s. il figlio a continuare gli } \\
\text { studi } \\
\text { - v.intr. (aus. avere) [sogg-v-prep.arg] Fare pressione } \\
\text { contro qlco.: l'acqua spinge contro la diga; s. } \\
\text { sull'acceleratore } \\
\text { • spingersi } \\
\text { • v.rifl. [sogg-v] Detto di due o più persone, darsi } \\
\text { reciprocamente spinte } \\
\text { s. in alto mare, fino alla cima del monte; in senso fig., andare } \\
\text { oltre i limiti di ciò che è opportuno, lecito: la sua } \\
\text { maleducazione si è spinta a tanto? • sec. XIV }\end{array}$ \\
\hline Definição II Devoto-Oli 2008 & $\begin{array}{l}\text { Spingere } \\
\text { <spin-ge-re> (arc. o region. spignere) v.tr. e intr. (ind. pres. spingo, } \\
\text { spingi, ecc.; pass. rem. spinsi, spingésti, ecc.; p. pass. spinto; come } \\
\text { intr., aus. avere) } \\
\text { 1. tr. Premere in modo continuo oppure con un colpo secco e violento } \\
\text { su un oggetto mobile per determinarne lo spostamento o la } \\
\text { penetrazione dentro un altro oggetto; sospingere: s. il carretto; s. } \\
\text { un'automobile in panne; s. il divano contro la parete; gli spinse il } \\
\text { pugnale nel petto; se la chiave non gira, spingila forte dentro la toppa• } \\
\text { Di agenti atmosferici, trascinare in una determinata direzione: la } \\
\text { tempesta spinse la nave contro gli scogli; il vento ha spinto l'aquilone } \\
\text { in alto.2. tr. Fare pressione sul dispositivo di comando di un } \\
\text { meccanismo, affinché quest'ultimo si metta in funzione; pigiare, } \\
\text { schiacciare: s. l'acceleratore; s. un tasto del computer, s. l'interruttore } \\
\text { della luce; per azionare il motore devi s. quel pulsante.3. tr. Muovere } \\
\text { con energia una parte del corpo in una data direzione: s. le braccia in } \\
\text { avanti; s. il petto in fuori; s. la pancia in dentro.4. tr. Esercitare una } \\
\text { pressione contro una o più persone, spec. per farle muovere in una } \\
\text { data direzione o per farle cadere: gli ultras hanno spinto i tifosi contro } \\
\text { le transenne; la ressa mi ha spinto verso l'uscita; sull'autobus un } \\
\text { signore mi ha spinto involontariamente a terra; anche assol.: ragazzi, } \\
\text { smettetela di s.!5. tr. Riferito allo sguardo, protenderlo in una } \\
\text { direzione, farlo arrivare fino a un certo punto: s. lo sguardo lontano; s. } \\
\text { la vista, gli occhi oltre l'orizzonte.6. tr. (fig.). Condurre, portare avanti } \\
\text { fino a un certo limite di convenienza, decenza o opportunità: ha spinto } \\
\text { la propria audacia fino a farle delle proposte disoneste; ha spinto } \\
\text { troppo oltre la sua ipocrisia.7. tr. (fig.). Stimolare a un'azione, } \\
\text { spronare, sollecitare (anche con la prep. a, a volte seguita dall'inf.): se } \\
\text { non ci fosse la moglie a spingerlo, non uscirebbe mai di casa; l'amore } \\
\text { per l'avventura la spinge a continui viaggi; il parroco ha spinto i fedeli } \\
\text { a dedicarsi al volontariato• Portare a determinati comportamenti, } \\
\text { atteggiamenti o stati d'animo, spec. negativi; istigare, indurre: quella } \\
\text { grave perdita lo spinse alla disperazione; il fallimento l'ha spinto al }\end{array}$ \\
\hline
\end{tabular}




\begin{tabular}{|c|c|}
\hline & $\begin{array}{l}\text { suicidio; la miseria l'ha spinta a rubare.8. tr. (fig.). Aiutare per mezzo } \\
\text { di un appoggio, di un sostegno, di una raccomandazione; favorire: le } \\
\text { sue amicizie politiche lo hanno spinto molto nella carriera• Dare } \\
\text { impulso a una data attività o iniziativa, incentivare, promuovere: il } \\
\text { direttore ha spinto molto questo progetto.9. intr. Esercitare una } \\
\text { pressione, fare pressione (spec. con le prep. contro, su): l'acqua del } \\
\text { fiume spingeva contro i terrapieni; la terra caduta con la frana } \\
\text { spingeva sui muri delle case• Premere su un dispositivo di comando } \\
\text { di un meccanismo per metterlo in funzione: il pilota spingeva a fondo } \\
\text { sull'acceleratore; s. sui pedali.10. intr. (fig.). Darsi da fare con } \\
\text { insistenza per ottenere qualcosa, adoperarsi, brigare (anche con la } \\
\text { prep. per, a volte seguita dall'inf.): la commissione spingeva affinché il } \\
\text { direttore presentasse le dimissioni; il padre spinge per l'assunzione } \\
\text { del figlio (o per far assumere il figlio).11. rifl. recipr. Darsi delle } \\
\text { spinte, spintonarsi: i due calciatori si sono spinti sotto gli occhi } \\
\text { dell'arbitro.12. intr. pron. Giungere, arrivare in un luogo; inoltrarsi, } \\
\text { sospingersi: non vi consiglio di spingervi oltre la linea di sicurezza; la } \\
\text { spedizione si spinse fino al Polo Sud; si è spinto a piedi fino al } \\
\text { rifugio.13. intr. pron. (fig.). Arrivare fino a un certo limite di } \\
\text { opportunità, convenienza o decenza; osare, ardire: non credevo che } \\
\text { si sarebbe spinto a tanto; la sua faccia tosta si è spinta fino a } \\
\text { chiedermi dei soldi; la sua audacia si è spinta troppo oltre. } \\
\text { Lat. volg. *expingĕre, der. di pang̈̌re 'ficcare', col pref. ex- 'da' | inizio } \\
\text { sec. XIII }\end{array}$ \\
\hline Definição Lo Zingarelli 2004 & 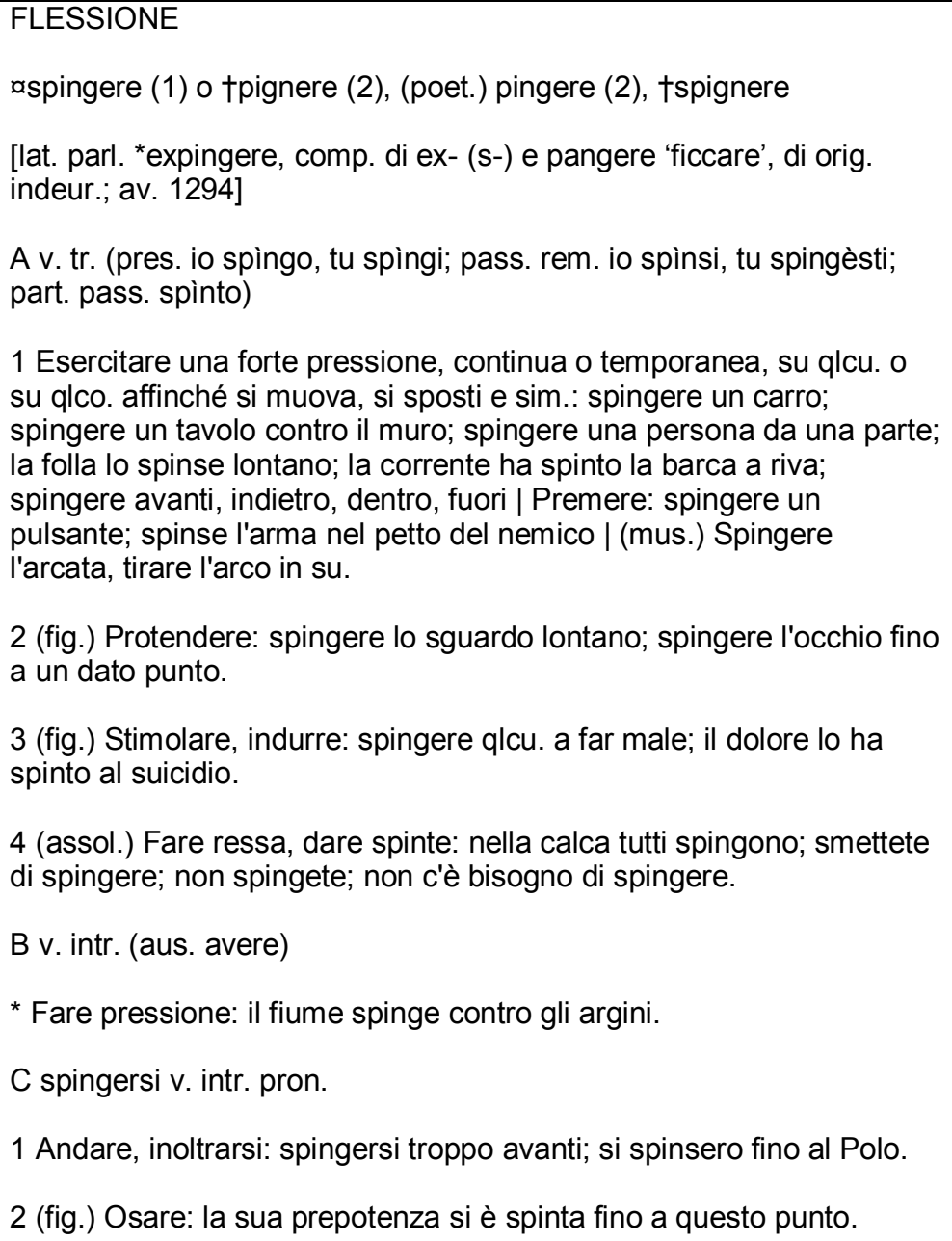 \\
\hline Definição Parola Chiave & $\begin{array}{l}\text { v.tr. [pres. spingo, spingi; pass.rem. spinsi, spingesti; part.pass. } \\
\text { spinto] 1- Esercitare su qualcosa o qualcuno una pressione, una forza } \\
\text { capace di muoverlo o spostarlo: spingiamo il tavolo contro la parete; }\end{array}$ \\
\hline
\end{tabular}




\begin{tabular}{|c|c|}
\hline & $\begin{array}{l}\text { la corrente spinse al largo la barca; mi ha spinto facendomi cadere } \\
\text { *empurrar <> Premere: spingi il pulsante per aprire *apertar } 2 \\
\text { Indirizzare, protendere: spingere lontano lo sguardo; spinsi il petto in } \\
\text { fuori! *dirigir; avançar } 3 \text { Indurre: la disperazione l'ha spinto al } \\
\text { suicidio <> Incitare, stimolare: spingere il figlio a continuare gli studi } \\
\text { *induzir <> v.intr. [aus. avere] Dare spinte, fare ressa: smettila di } \\
\text { spingere!; la folla spingeva da ogni lato *empurrar <> spingersi v.pr. } \\
\text { Inoltrarsi, arrivare fino a un determinado punto (anche): la spedizione } \\
\text { si spinse fino al Polo; non pensavo che la sua avidità si spingesse } \\
\text { fino a questo punto *avançar; chegar }\end{array}$ \\
\hline Definição Proposta & Fare pressione su una cosa o persona per spostarla. \\
\hline
\end{tabular}


Ficha lexicográfica para as novas palavras que constarão nas notas de rodapé 44

\begin{tabular}{|c|c|}
\hline Unidade lexical & Sportello \\
\hline Contexto & $\begin{array}{l}\text { Mentre cammina per strada con gli occhi bassi, vede una carrozza } \\
\text { ferma, con due viaggiatori davanti allo sportello aperto. (83) }\end{array}$ \\
\hline Definiçao De Mauro Paravia & $\begin{array}{l}\text { spor·tèl·lo } \\
\text { s.m. AU } \\
\text { 1. elemento di chiusura o apertura che gira su cerniere o scorre su } \\
\text { guide: lo sportello di un armadio, del frigo, della lavatrice, lo sportello } \\
\text { di una gabbia | porta di accesso di un veicolo: lo sportello dell'auto, di } \\
\text { una carrozza ferroviaria } \\
\text { 2a. in banche, uffici pubblici, ecc., apertura in una parete divisoria di } \\
\text { vetro o settore di un bancone in cui un impiegato può parlare } \\
\text { direttamente con il pubblico offrendo determinati servizi: sportello } \\
\text { bancario, postale; fare la coda allo sportello | estens., il servizio } \\
\text { offerto al pubblico: lo sportello effettua orario continuato } \\
\text { 2b. agenzia o filiale di un istituto di credito: la BNA ha aperto un } \\
\text { nuovo sportello in centro } \\
\text { 3. TS arte ciascuno degli elementi laterali di un trittico, che si } \\
\text { richiudono sulla tavola centrale per mezzo di cerniere }\end{array}$ \\
\hline Definição Dire & $\begin{array}{l}\text { n.m. Imposta girevole che serve a chiudere: Quando hai finito di } \\
\text { vestirti chiudi lo sportello del guardaroba 2- Portiera degli autoveicoli: } \\
\text { Metti la sicura allo sportello dell'auto. 3- Negli uffici che svolgono un } \\
\text { servizo pubblico, ciascuno dei vani attraverso i quali il personale } \\
\text { comunica con il pubblico: Conosco bene l'impiegato che sta allo } \\
\text { sportello numero tre. } \\
\text { derivato da portello, sin. } 1 \text { anta }\end{array}$ \\
\hline Definição II Sabatini-Coletti & $\begin{array}{l}\text { sportello [spor-tèl-lo] s.m. } \\
1 \text { Serramento di chiusura di piccoli vani: s. di una gabbia; } \\
\text { porta d'accesso di veicoli e vetture ferroviarie SIN portiera } \\
2 \text { Piccola porta inserita in un portone } \\
\mathbf{3} \text { Apertura di vetro o altro materiale, che separa gli impiegati } \\
\text { di un ufficio dal pubblico, attraverso cui avvengono scambi di } \\
\text { documenti, denaro o altro tra le due parti: fare la coda } \\
\text { davanti a uno s.; il servizio che viene svolto in tale modo: } \\
\text { oggi sono di s. II s. automatico, all'esterno delle sedi degli } \\
\text { istituti bancari, impianto computerizzato sempre aperto ai } \\
\text { clienti, che effettua operazioni quali il prelievo e il deposito di } \\
\text { denaro mediante l'inserimento di una tessera magnetica } \\
\text { fornita dei dati personali | impiegato di s., addetto ai servizi al } \\
\text { pubblico } \\
\mathbf{4} \text { estens. Filiale o agenzia di banca } \\
\mathbf{5} \text { Ufficio di informazione al pubblico: l'assessore ha creato } \\
\text { uno s. per i giovani } \\
\text { - sec. XVII } \\
\text { ripiegano delle due tavole laterali di un trittico che si } \\
\text { dim. sportellino | accr. sportellone }\end{array}$ \\
\hline
\end{tabular}




\begin{tabular}{|c|c|}
\hline Definição II Devoto-Oli 2008 & $\begin{array}{l}\text { sportello } \\
\text { <spor-tèl-lo> s.m. } \\
\text { 1. Elemento girevole su cerniere, destinato ad assicurare la chiusura } \\
\text { di un vano: lo s. della credenza, di un armadio; gli s. di un vagone } \\
\text { ferroviario; negli infissi, sin. di imposta; nelle autovetture, sin. di } \\
\text { portiera• Ciascuna delle tavole laterali di un trittico, che si chiudono } \\
\text { sul pannello centrale.2. Negli uffici destinati a servizi pubblici, } \\
\text { ciascuno dei vani o degli spazi attraverso i quali il personale } \\
\text { comunica col pubblico: far la coda davanti allo s.; chiudere gli s., a } \\
\text { proposito di banche, sospendere i pagamenti S. unico, ufficio, } \\
\text { generalmente della pubblica amministrazione, che accorpa servizi } \\
\text { svolti precedentemente da uffici diversi, permettendo in tal modo di } \\
\text { snellire le procedure burocratiche e facilitando l'accesso dell'utente } \\
\text { alle informazioni• Nell'organizzazione bancaria. s. bancario, ogni } \\
\text { ufficio installato da una banca in una determinata località; s. } \\
\text { automatico, impianto installato all'esterno di istituti bancari e } \\
\text { attraverso il quale il correntista può servirsi del servizio di } \\
\text { bancomat.dim. sportellétto, sportellino. accr. sportellóne }\end{array}$ \\
\hline & Da portello, con s-intensivo | inizio sec. XIV \\
\hline Definição Lo Zingarelli 2004 & $\begin{array}{l}\text { FLESSIONE } \\
\text { asportello } \\
\text { [da portello, con s-; sec. XIII] } \\
\text { s. m. } \\
1 \text { Imposta girevole su cerniere verticali | Imposta, scuretto di infisso | } \\
\text { †Porticina inclusa nel portone di un edificio. } \\
2 \text { Porta di carrozza ferroviaria, automobile, aereo e veicoli in genere. } \\
3 \text { Apertura attraverso la quale, nelle banche e in alcuni uffici, gli } \\
\text { impiegati possono comunicare col pubblico: fare la coda davanti allo } \\
\text { sportello | Chiudere gli sportelli, nelle banche, sospendere operazioni } \\
\text { e pagamenti | Sportello automatico, impianto, collocato all'esterno di } \\
\text { una banca, che consente a un correntista di effettuare operazioni } \\
\text { bancarie, previa introduzione di una tessera magnetica e } \\
\text { composizione di un numero di codice personale. } \\
4 \text { (est., per anton.) Ufficio di una banca a diretto contatto con il } \\
\text { pubblico | Correntemente, filiale o agenzia di una banca: la Banca di } \\
\text { Roma ha aperto dieci nuovi sportelli | Ufficio che fornisce consulenze, } \\
\text { informazioni e sim. su un determinato argomento | Sportello unico, } \\
\text { ufficio, spec. della pubblica amministrazione, che permette di snellire } \\
\text { le procedure burocratiche, accorpando servizi prima svolti da uffici } \\
\text { diversi e semplificando l'accesso dell'utente alle informazioni. } \\
5 \text { Ognuna delle tavole laterali di un trittico che, per mezzo di cerniere, } \\
\text { si rovesciano a coprire il dipinto. } \\
\text { || sportellino, dim. | sportellone, accr. }\end{array}$ \\
\hline Definição Parola Chiave & $\begin{array}{l}\text { s.m. } 1 \text { Anta girevole su cerniere che serve ad aprire e a chiudere un } \\
\text { vano: lo sportello della credenza, del forno, di una gabbia <> Porta di } \\
\text { automezzi, carrozze ferroviarie e altri veicoli * porta } 2 \text { In alcuni uffici, } \\
\text { apertura in una parete attraverso la quale gli impiegati comunicano } \\
\text { col pubblico: fare la fila davanti allo sportello di una banca *guichê }\end{array}$ \\
\hline Definição Proposta & Porta di un veicolo. \\
\hline
\end{tabular}


Ficha lexicográfica para as novas palavras que constarão nas notas de rodapé 45

\begin{tabular}{|c|c|}
\hline Unidade lexical & Spostarsi (spostiamoci) \\
\hline Contexto & $\begin{array}{l}\text { Ma spostiamoci sul lago di Como: quello stesso giorno arriva una } \\
\text { lettera al Podestà di Lecco con l'ordine di portare in prigione Lorenzo } \\
\text { Tramaglino, filatore di seta, sfuggito alle forze dell'ordine a Milano. } \\
\text { (70) }\end{array}$ \\
\hline Definiçao De Mauro Paravia & $\begin{array}{l}\text { spo-stà-re } \\
\text { v.tr. (io spòsto) Fo } \\
\text { 1. rimuovere qcs. dal posto in cui si trova mettendolo altrove: spostare } \\
\text { un mobile, un tavolo, un divano | far muovere una persona dal posto } \\
\text { in cui si trova: spostare qcn. per liberarsi il passaggio, mi ha spostato } \\
\text { con uno spintone } \\
\text { 2. trasferire da un luogo a un altro: spostare la sede di un ufficio, la } \\
\text { fermata è stata spostata più avanti | trasferire qcn. a una diversa } \\
\text { residenza o sede di lavoro: è stato spostato in un nuovo ufficio, in una } \\
\text { nuova città } \\
\text { 3. collocare più avanti o più indietro nel tempo: spostare la data del } \\
\text { meeting, spostare di una settimana l'inizio della scuola } \\
\text { 4. fig., fam., produrre modificazioni e mutamenti in una condizione, in } \\
\text { una situazione, ecc.: la sua telefonata sposta tutti i miei programmi } \\
\text { 5. fig., volgere, indirizzare a un ambito diverso: spostare il discorso su } \\
\text { un nuovo argomento, i recenti eventi hanno spostato l'attenzione } \\
\text { dell'opinione pubblica sui problemi della sanità } \\
\text { 6. TS chim. influenzare l'equilibrio di un sistema in un senso o in un } \\
\text { altro, agendo sui parametri dai quali dipende la composizione del } \\
\text { sistema in condizioni di equilibrio } \\
\text { spo.stàr.si } \\
\text { v.pronom.intr. (io mi spòsto) co } \\
\text { 1. di qcn., cambiare il posto, la posizione occupata: spostati, che mi } \\
\text { levi la luce | muoversi da un luogo a un altro: spostarsi in auto da } \\
\text { Torino a Milano, mio padre si sposta sovente per affari | trasferirsi: } \\
\text { spostarsi in nuovi uffici, in un alloggio più ampio, spostarsi in un altro } \\
\text { paese } \\
\text { 2. fig., recedere da un'opinione, un atteggiamento o sim.: non } \\
\text { spostarsi di un passo, di una virgola, di un capello, di un millimetro, } \\
\text { essere irremovibile, restare fisso sulle proprie idee } \\
\text { 3. di qcs., cambiare di posto, di posizione: il sole si sposta nel cielo, il } \\
\text { maltempo si sta spostando verso sud | subire uno spostamento: la } \\
\text { lancetta si sposta per impulso meccanico } \\
\text { 4. fig., deviare, concentrandosi o indirizzandosi su altro: il discorso si } \\
\text { spostò su altro argomento }\end{array}$ \\
\hline Definição Dire & $\begin{array}{l}\text { v.tr. Rimuovere da un luogo: E meglio spostare quel mobile da li } \\
\text { perché è troppo ingombrante. 2- Rinviare nel tempo: II medico ha } \\
\text { spostato l'orario delle visite. / v.rifl. (spostarsi) Detto di persona, } \\
\text { muoversi da un posto ad un altro, o cambiare posizione: Spostati, } \\
\text { altrimenti non posso passare. / v.intr.pron. (spostarsi) Cambiare } \\
\text { sede, subire uno spostamento: Le nuvole si spostano velocemente a } \\
\text { causa del vento. } \\
\text { derivato da posto, v.tr.: sin. } 2 \text { differire, v.rifl.: contr. fermarsi }\end{array}$ \\
\hline Definição II Sabatini-Coletti & $\begin{array}{l}\text { spostare [spo-stà-re] v. (spòsto ecc.) } \\
\text { • v.tr. [sogg-v-arg-prep.arg-prep.arg] Mutare di posto qlcu. } \\
\text { o qlco.; trasferirlo da una sede in un'altra: s. un funzionario } \\
\text { da un ufficio a un altro, i mobili da una stanza in un'altra; } \\
\text { spesso con uno o entrambi gli arg. indiretti sottintesi: s. la } \\
\text { libreria dallo studio, la poltrona in salotto; s. una sedia }\end{array}$ \\
\hline
\end{tabular}




\begin{tabular}{|c|c|}
\hline & $\begin{array}{l}\text { - [sogg-v-arg] } \\
1 \text { Di persona o animale, mutare posizione a una parte del } \\
\text { proprio corpo: sposta il piede!; freq. con specificazione della } \\
\text { direzione: sposta le braccia più in alto } \\
2 \text { Rinviare un impegno, freq. con specificazione temporale } \\
\text { SIN rimandare: s. l'orario della conferenza; anche con } \\
\text { specificazione della data: s. la riunione a sabato } \\
\text { - spostarsi } \\
\text { - v.rifl. [sogg-v-prep.arg-prep.arg] Cambiare di posto, } \\
\text { passando da un luogo a un altro: s. da una città a un'altra; } \\
\text { spesso con uno o entrambi gli arg. indiretti sottintesi: le } \\
\text { pecore si spostano dai pascoli di montagna; s. per lavoro \|I } \\
\text { fig. non s. di un millimetro, essere irremovibile } \\
\text { - [sogg-v] Di persona o animale, mutare posizione: spostati, } \\
\text { non riesco a vedere bene } \\
\text { - sec. XVI }\end{array}$ \\
\hline Definição II Devoto-Oli 2008 & 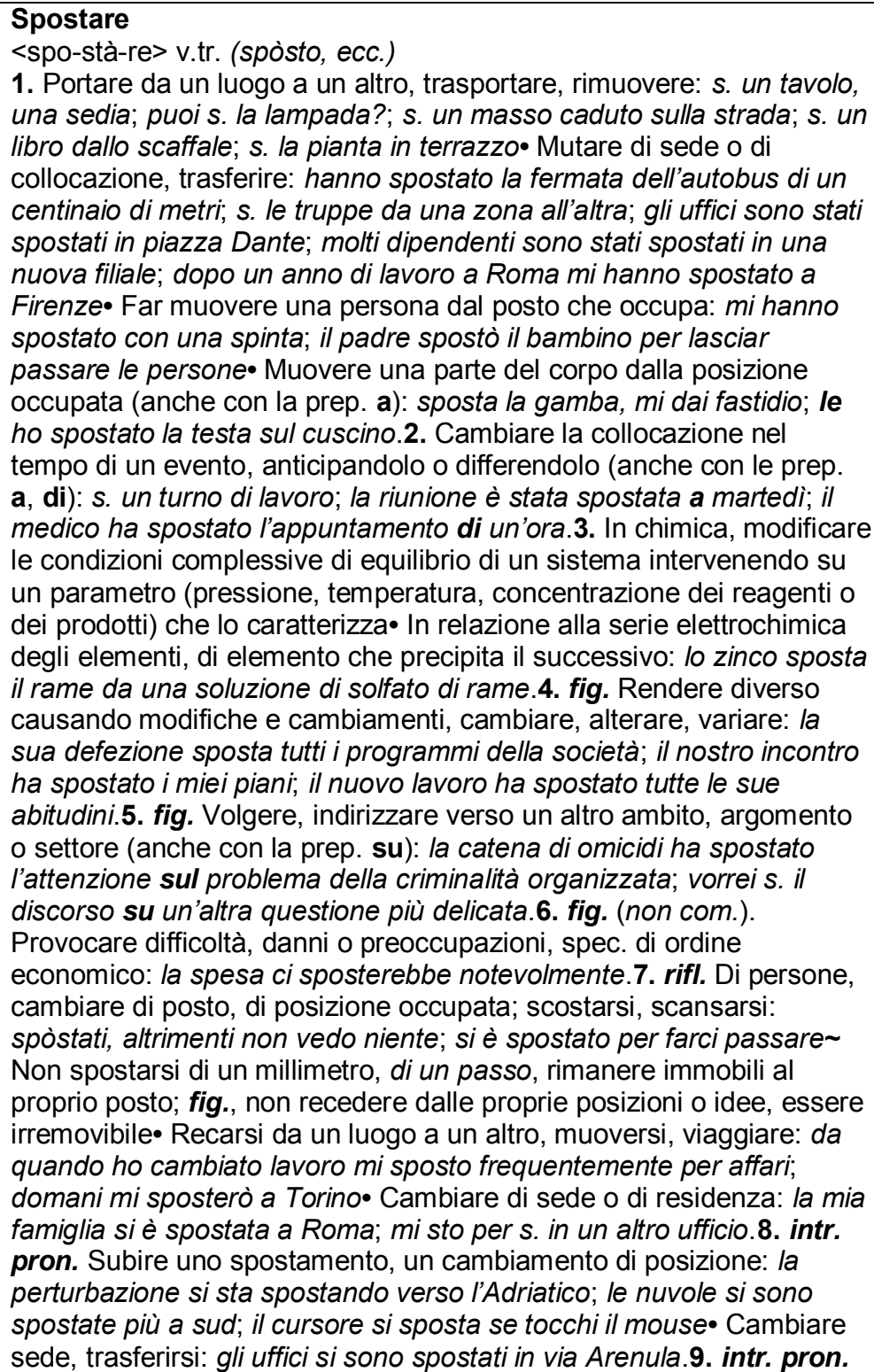 \\
\hline
\end{tabular}




\begin{tabular}{|c|c|}
\hline & $\begin{array}{l}\text { (fig.). Essere rivolto, indirizzato verso un altro argomento, ambito o } \\
\text { settore (con la prep. su): l'interesse generale si è spostato sulla crisi } \\
\text { di governo. } \\
\text { Der. di posto, con s- sottrattivo | } 1584\end{array}$ \\
\hline Definição Lo Zingarelli 2004 & $\begin{array}{l}\text { FLESSIONE } \\
\text { aspostare } \\
\text { [da posto, con s-; 1584] } \\
\text { A v. tr. (io spòsto) } \\
1 \text { Trasferire altrove qlcu. o qlco. dal posto, la posizione, la condizione } \\
\text { in cui si trovava o che gli era abituale: spostare una sedia, un } \\
\text { armadio; spostare un impiegato da un ufficio a un altro | Cambiare nel } \\
\text { tempo: hanno spostato l'orario della conferenza. } \\
2 \text { (fig., disus.) Recare danno, dissestare: questo imprevisto mi sposta. } \\
3 \text { (mus.) Trasportare in altro tono. } \\
4 \text { (mar.; disus.) Dislocare. } \\
\text { B spostarsi v. rifl. } \\
\text { * Muoversi dal posto, dalla posizione, che si occupa o che è abituale, } \\
\text { detto di persona: spostati ché devo passare; da Roma mi sposterò a } \\
\text { Napoli; si è spostato in un altro ufficio | Non spostarsi di un passo, } \\
\text { (fig.) restare fermo sulle posizioni prese. } \\
\text { C spostarsi v. intr. pron. } \\
\text { * Muoversi dal luogo o dalla posizione abituale, detto di cosa: la } \\
\text { lancetta si è spostata; l'accento si sposta sull'ultima sillaba | (fig.) } \\
\text { Passare, trasferirsi: il dibattito si è spostato su un altro tema. }\end{array}$ \\
\hline Definição Parola Chiave & $\begin{array}{l}\text { v.tr. } 1 \text { Rimovere qualcosa o qualcuno da dove si trova; trasferire da } \\
\text { un posto a un altro: non riesco a spostare questo armadio; lo hanno } \\
\text { spostato in un altro ufficio *remover <> Cambiare posizione a } \\
\text { qualcosa: sposta un po' la testa *mudar de posição } 2 \text { Cambiare di } \\
\text { orario, di data S rimandare (o anche anticipare): spostare l'ora della } \\
\text { partenza; la partita è stata spostata l'ora della partenza; la partita è } \\
\text { stata spostata a domani *mudar; adiar <> spostarsi v.pr. Muoversi } \\
\text { dal ponto in cui si è: spostati che non vedo niente! *afastar-se <> } \\
\text { Cambiare di posto, di posizione: la lancetta si è spostata *deslocar- } \\
\text { se <> Trasferirsi da un luogo a un altro: nel suo lavoro deve spostarsi } \\
\text { di continuo *viajar }\end{array}$ \\
\hline Definição Proposta & Cambiare luogo (cambiamo luogo). \\
\hline
\end{tabular}


Ficha lexicográfica para as novas palavras que constarão nas notas de rodapé 46

\begin{tabular}{|c|c|}
\hline Unidade lexical & Striscia/strisce \\
\hline Contexto & $\begin{array}{l}\text { Andando avanti, Renzo nota per terra qualcosa di strano: sono } \\
\text { strisce bianche e soffici, sembra neve... ma è farina! (47) }\end{array}$ \\
\hline Definiçao De Mauro Paravia & $\begin{array}{l}\text { strì scia } \\
\text { s.f. AU } \\
\text { 1. pezzo di materiale di spessore sottile e di forma lunga e stretta: } \\
\text { una striscia di carta, di plastica, di stoffa; striscia di cuoio, quella usata } \\
\text { per affilare i rasoi } \\
\text { 2a. estens., linea, riga, traccia lunga e sottile: tracciare una striscia; } \\
\text { strisce verticali, orizzontali } \\
\text { 2b. tratto, porzione di una superficie che ricorda tale forma: una } \\
\text { striscia di terra, una striscia di mare, quella striscia di campo è } \\
\text { coltivata a patate, dalla finestra si scorge una striscia di cielo } \\
\text { 3. al pl., passaggio pedonale } \\
\text { 4. CO serie di vignette allineate che costituiscono un racconto a } \\
\text { fumetti; strip } \\
\text { 5. TS geom. parte di piano compresa tra due rette parallele } \\
\text { 6. TS aer. parte della pista di un aeroporto in cui avvengono i decolli e } \\
\text { gli atterraggi } \\
\text { 7. TS mar. } \square \text { ferzo }\end{array}$ \\
\hline Definição Dire & 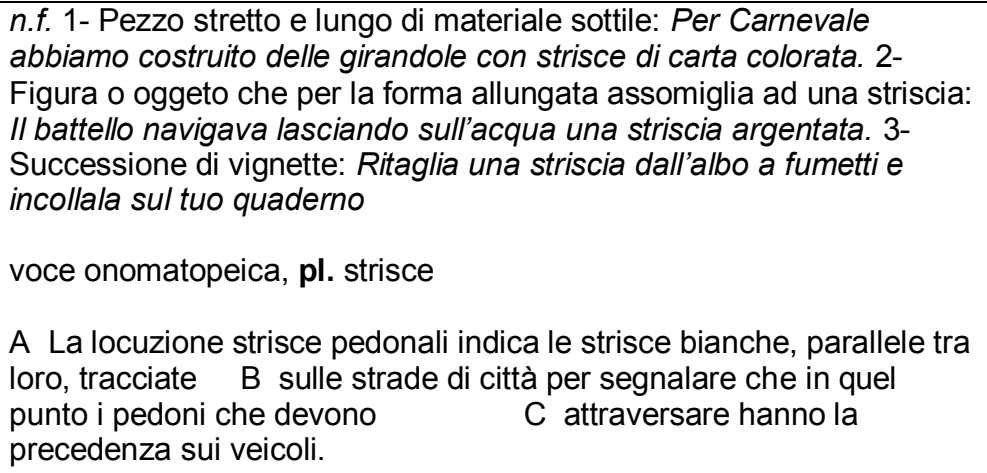 \\
\hline Definição II Sabatini-Coletti & $\begin{array}{l}\text { striscia [strì-scia] s.f. (pl. -sce) } \\
1 \text { Elemento di materiale vario di forma allungata e stretta: s. } \\
\text { di carta, di cuoio } \\
2 \text { estens. Tutto ciò che, per il suo andamento lungo e stretto, } \\
\text { ha la forma di una striscia: } s \text {. di terreno \| s. pedonali (anche } \\
\text { assol. strisce), righe bianche, parallele, tracciate su strade } \\
\text { urbane per segnalare un attraversamento pedonale | a stelle } \\
\text { e strisce, americano, statunitense } \\
3 \text { Storiella a fumetti in cui le vignette sono su di una sola } \\
\text { linea; estens. fumetto } \\
\text { • dim. strisciolina } \\
\text { - sec. XIV }\end{array}$ \\
\hline Definição II Devoto-Oli 2008 & $\begin{array}{l}\text { striscia } \\
\text { <stri-scia> s.f. ( } p l . \text {-sce) } \\
\text { 1. Porzione riconducibile a una figura notevolmente allungata, } \\
\text { idealmente o realmente delimitata da due bordi paralleli: una s. di } \\
\text { pelle; una s. di carta moschicida; una s. di territorio• Nell'attrezzatura } \\
\text { navale, ciascuno dei vari teli che, cuciti insieme, formano la vela.2. } \\
\text { estens. In geometria, la regione di piano compresa fra due rette } \\
\text { parallele Elemento allungato o lineare di una certa ampiezza: una }\end{array}$ \\
\hline
\end{tabular}




\begin{tabular}{|c|c|}
\hline & $\begin{array}{l}\text { maglia a strisce; s. pedonali, passaggio pedonale segnalato da strisce } \\
\text { bianche dipinte sulla carreggiata stradale; anche, traccia lunga e } \\
\text { stretta: lasciare una s. luminosa; al pl., pasta da minestra in forma di } \\
\text { nastri• Negli aeroporti, zona rettangolare adibita al decollo e } \\
\text { all'atterraggio di aerei.3. La serie di disegni disposti orizzontalmente } \\
\text { su una linea, che costituiscono le varie sequenze di un fumetto; } \\
\text { estens., fumetto• Programma televisivo, generalmente di breve } \\
\text { durata, trasmesso quotidianamente o con cadenza regolare: s. } \\
\text { sceneggiata, s. di economia.dim. striscétta, striscettina, } \\
\text { strisci(u)òla, strisciolìna. accr. striscióna, striscióne } 1 \mathrm{~m} . \text { (v.) }\end{array}$ \\
\hline Definição Lo Zingarelli 2004 & $\begin{array}{l}\text { FLESSIONE } \\
\text { astriscia } \\
\text { [vc. di orig. onomat.; trad. dell'ingl. comic strips, propr. 'strisce } \\
\text { comiche o d'avventura, fumetti' nel sign. 3; 1319] } \\
\text { s. f. (pl. -sce, lett. -scie) } \\
1 \text { Pezzo stretto e lungo di materiale vario: una striscia di carta, di } \\
\text { stoffa, di tela. } \\
2 \text { Ciò che ha aspetto, forma stretta e allungata, simile a una riga: } \\
\text { decoro a strisce orizzontali, verticali | Stelle e strisce, V. stella | } \\
\text { Traccia lunga e sottile: una striscia biancastra. } \\
3 \text { Breve storia o episodio a fumetti formata da una serie di vignette } \\
\text { affiancate su una sola linea: le strisce di Charlie Brown. SIN. Strip (2). } \\
4 \text { (aer.) Zona rettangolare in un aeroporto, preparata per il decollo e } \\
\text { l'atterraggio di aerei. } \\
5 \text { Porzione di territorio esteso nel senso della lunghezza: una lunga } \\
\text { striscia di costa. } \\
6 \text { In geometria, regione di piano compresa tra due rette parallele. } \\
7 \text { (al pl.) Passaggio pedonale delimitato da zebratura: attraversare } \\
\text { sulle strisce. SIN. Zebre. } \\
\text { || striscetta, dim. | striscettina, dim. | strisciolina, dim. | strisciona, accr. } \\
\text { | striscione, accr. m. (V.) | strisciuola, dim. }\end{array}$ \\
\hline Definição Parola Chiave & $\begin{array}{l}\text { s.f. } 1 \text { Pezzo lungo e stretto di materiale vario: una striscia di carta, di } \\
\text { tela, di gomma; tagliare qualcosa a strisce *tira } 2 \text { Segno, traccia o } \\
\text { portazione di spazio lunga e stretta: una maglietta a strisce bianche e } \\
\text { rosse; l'aereo lasciava dietro di sé una striscia biancastra; una stricia } \\
\text { di cielo azzuro; una striscia di terra coltivata *faixa I Strisce (pedonali) } \\
\text { = passaggio pedonale delimitado da una serie di strisce bianche } \\
\text { parallele *faixa de pedestres }\end{array}$ \\
\hline Definição Proposta & Residuo lungo e stretto lasciato da una sostanza. \\
\hline
\end{tabular}


Ficha lexicográfica para as novas palavras que constarão nas notas de rodapé 47

\begin{tabular}{|c|c|}
\hline Unidade lexical & Sporcizia \\
\hline Contexto & $\begin{array}{l}\text { Entra in una delle sue stanze al piano terra: la sporcizia copre tutto il } \\
\text { pavimento. (104) }\end{array}$ \\
\hline Definiçao De Mauro Paravia & $\begin{array}{l}\text { spor-cì-zia } \\
\text { s.f. AD } \\
\text { 1a. l'essere sporco, caratteristica di chi o di ciò che è sporco: la } \\
\text { sporcizia di una persona, di una stanza } \\
\text { 1b. sozzume, luridume di persone o cose: togliersi la sporcizia di } \\
\text { dosso, vivere nella sporcizia } \\
\text { 2. BU fig., atto turpe, parola oscena; porcheria: fare, dire delle } \\
\text { sporcizie }\end{array}$ \\
\hline Definição Dire & $\begin{array}{l}\text { n.f. 1- Sudiciume: Nella tua camera c'è troppa sporcizia. 2- Azione } \\
\text { volgare, oscena: Cerca di non fare sporcizie. } \\
\text { derivato da sporco, sin. } 1 \text { sozzura, } 2 \text { indecenza }\end{array}$ \\
\hline Definição II Sabatini-Coletti & $\begin{array}{l}\text { sporcizia [spor-cì-zia] s.f. } \\
1 \text { Caratteristica e stato di chi o di ciò che è sporco } \\
2 \text { Cosa, roba sporca SIN sudiciume } \\
3 \text { fig. Corruzione morale, depravazione: s. d'animo; atto } \\
\text { turpe; parola oscena, scurrile } \\
\text { • sec. XV }\end{array}$ \\
\hline Definição II Devoto-Oli 2008 & $\begin{array}{l}\text { sporcizia } \\
\text { <spor-cì-zia> (non com. sporchizia) s.f. } \\
\text { 1. Vistosa negligenza nei confronti dell'igiene, della pulizia e della } \\
\text { decenza, motivo di disgusto o di repulsione.2. concr. Materiale di } \\
\text { rifiuto, in quanto costituisce ingombro sgradevole e indecente: levare } \\
\text { la s.; iperb., a proposito di un aspetto intollerabilmente disordinato e } \\
\text { trascurato (questa stanza è una s.) o anche di un sapore disgustoso o } \\
\text { addirittura ributtante (questa minestra è una s.)• fig. Manifestazione o } \\
\text { espressione di ributtante oscenità o turpitudine. }\end{array}$ \\
\hline Definição Lo Zingarelli 2004 & $\begin{array}{l}\text { FLESSIONE } \\
\text { asporcizia o (raro) sporchizia } \\
\text { [dal lat. spurcitia(m), da spurcus 'sporco'; av. 1349] } \\
\text { s. f. } \\
1 \text { Caratteristica, condizione di chi (o di ciò che) è sporco. CONTR. } \\
\text { Pulizia. } \\
2 \text { Cosa sporca: togliere la sporcizia; vivere nella sporcizia. } \\
3 \text { (fig.) Comportamento disonesto, corrotto | Cosa, azione, parola, } \\
\text { volgare, oscena: dire, fare, sporcizie; libro pieno di sporcizie. }\end{array}$ \\
\hline Definição Parola Chiave & $\begin{array}{l}\text { s.f. Sudiciume: una casa di uma sporcizia incredibile *sujeira }<> \\
\text { Roba sporca: butta via quella sporcizia * porcaria }\end{array}$ \\
\hline Definição Proposta & Accumulo di polvere e altre sostanze sgradevoli. \\
\hline
\end{tabular}


Ficha lexicográfica para as novas palavras que constarão nas notas de rodapé 48

\begin{tabular}{|c|c|}
\hline Unidade lexical & Tramontare \\
\hline Contexto & II sole è tramontato e molti tornano a casa. (65) \\
\hline Definiçao De Mauro Paravia & $\begin{array}{l}\text { tra-mon·tà-re } \\
\text { v.intr. (io tramónto; essere) AU } \\
\text { 1. di un astro e spec. del sole e della luna: scomparire sotto la linea } \\
\text { dell'orizzonte } \\
\text { 2. fig., declinare, avere fine, terminare: una moda che non tramonta, } \\
\text { la sua fama sta tramontando }\end{array}$ \\
\hline Definição Dire & $\begin{array}{l}\text { v.intr. 1- Scomparire a poco a poco al di là dell'orizonte, detto di corpi } \\
\text { celesti: /l sole sta tramontando. 2- Terminare, venir meno: /l successo } \\
\text { di quell'attore è tramontato troppo presto. } \\
\text { derivato da monte, sin. } 1 \text { calare } 2 \text { svanire, contr. } 1 \text { sorgere, levarsi }\end{array}$ \\
\hline Definição II Sabatini-Coletti & $\begin{array}{l}\text { tramontare [tra-mon-tà-re] v.intr. (aus. essere; tramónto ecc.) } \\
\text { [sogg-v] } \\
\text { • Detto di corpi celesti, scomparire oltre l'orizzonte SIN } \\
\text { calare: il sole è tramontato; in senso fig., venir meno, avere } \\
\text { fine SIN svanire: tramonta la speranza } \\
\text { •In funzione di s.m., tramonto, spec. nella loc.: al tramontar } \\
\text { del sole • sec. XIV }\end{array}$ \\
\hline Definição II Devoto-Oli 2008 & $\begin{array}{l}\text { Tramontare } \\
\text { <tra-mon-tà-re> v.intr. (tramónto, ecc.; aus. essere) } \\
\text { 1. Di un astro (spec. del sole o della luna), scomparire sotto } \\
\text { l'orizzonte di un dato luogo per effetto della rotazione terrestre; calare: } \\
\text { il sole tramonta alle otto; la luna sta tramontando.2. fig. Avere fine, } \\
\text { venire meno, per lo più con un senso di dolore e di nostalgia; } \\
\text { dileguarsi, finire, scomparire, svanire, terminare: la giovinezza è già } \\
\text { tramontata; le sue speranze stanno tramontando. } \\
\text { Der. di monte, col pref. tra-; propr. "andare al di là dei monti" | sec. } \\
\text { XIV }\end{array}$ \\
\hline Definição Lo Zingarelli 2004 & $\begin{array}{l}\text { FLESSIONE } \\
\text { atramontare } \\
\text { [comp. di tra- e del denominale di monte, nel senso, quindi, di } \\
\text { '(calare) al di là dei monti'; sec. XII] } \\
\text { A v. intr. (io tramónto; aus. essere) } \\
1 \text { Sparire sotto la linea dell'orizzonte, detto del Sole e di altri corpi } \\
\text { celesti. CONTR. Sorgere. } \\
2 \text { (fig.) Declinare, spegnersi: sono entusiasmi che tramonteranno } \\
\text { presto | La sua stella sta tramontando, (fig.) non è più in auge o di } \\
\text { moda, detto di persone o cose | Finire: è una vita che sta tramontando } \\
\text { | (fig.) Cessare, venir meno: sono tramontate le speranze di ritrovare i } \\
\text { superstiti. } \\
\text { B in funzione di s. m. solo sing. } \\
\text { * Tramonto: ci vedremo al tramontare del sole. }\end{array}$ \\
\hline Definição Parola Chiave & $\begin{array}{l}\text { v.intr. [aus. essere] 1- Detto di corpi celesti, scomparire sotto la linea } \\
\text { dell'orizzonte: /l Sole, la Luna sta tramontando *pôr-se } 2 \text { Venir meno, } \\
\text { finire, svanire: è tramontata anche l'ultima speranza di salvezza }\end{array}$ \\
\hline
\end{tabular}




\begin{tabular}{|l|l|}
\hline & *acabar \\
\hline Definição Proposta & Si dice di quando il sole va via, al termine della giornata. \\
\hline
\end{tabular}


Ficha lexicográfica para as novas palavras que constarão nas notas de rodapé 49

\begin{tabular}{|c|c|}
\hline Unidade lexical & Turbato \\
\hline Contexto & $\begin{array}{l}\text { Intanto Don Rodrigo, ancora turbato per le parole del frate, } \\
\text { scomettere con il cugino Attilio che sarà capace di rapire Lucia e } \\
\text { ordina al Griso, capo dei bravi', di prendere tutti gli uomini che gli } \\
\text { servono, in modo che la cosa riesca. (30) }\end{array}$ \\
\hline Definiçao De Mauro Paravia & $\begin{array}{l}\text { tur-bà-to } \\
\text { p.pass., agg. } \\
\text { 1. p.pass. } \square \text { turbare, turbarsi } \\
\text { 2. agg. CO in preda a turbamento, agitato, inquieto: essere, mostrarsi } \\
\text { turbato | che rivela turbamento: sguardo, volto turbato } \\
\text { 3. agg. CO del tempo, guastato, rannuvolato } \\
\text { 4. agg. OB LE del mare, agitato, burrascoso: par senza governo in } \\
\text { mar turbato, I rotte vele ed antenne, eccelsa nave (Tasso) } \\
\text { 5. agg. OB LE adirato, corrucciato: per la qual cosa l'Angiulier } \\
\text { turbatissimo disse al Fortarrigo una grandissima villania (Boccaccio) } \\
\text { 6. agg. TS fon. di vocale in cui si combinano i caratteri propri di vocali } \\
\text { cardinali diverse (ad es. la ü, che richiede la posizione della lingua } \\
\text { propria della i e la posizione delle labbra propria della } u \text { ) }\end{array}$ \\
\hline Definição Dire & $\begin{array}{l}\text { v.tr. 1- Mettere in agitazione: La notizia ci ha turbato. 2- Alterare o } \\
\text { sconvolgere una situazione o il regolare svolgimento di qualcosa: Un } \\
\text { incubo mi ha turbato il sonno. } \\
\text { sin. } 1 \text { agitare, } 2 \text { disturbare }\end{array}$ \\
\hline Definição II Sabatini-Coletti & $\begin{array}{l}\text { turbato [tur-bà-to] agg. } \\
\text { • Interiormente agitato, confuso: rimanere } t \text {. a una brutta } \\
\text { notizia; che rivela un turbamento interiore: volto } t \text {. } \\
\text { • sec. XIV }\end{array}$ \\
\hline Definição II Devoto-Oli 2008 & $\begin{array}{l}\text { turbato } \\
\text { <tur-bà-to> agg. } \\
\text { 1. Sottratto, con effetti più o meno notevoli, a uno stato di normalità o } \\
\text { quiete: ristabilire l'ordine } t \text {. non com. o lett. Riferito a elemento } \\
\text { naturale, agitato, burrascoso, tempestoso: acque t.; par senza } \\
\text { governo in mar turbato, Rotte vele ed antenne, eccelsa nave (Tasso); } \\
\text { tempo, cielo t., rannuvolato, coperto. } \\
\text { 2. fig. In preda a un'interiore agitazione, a uno stato di forte } \\
\text { inquietudine o smarrimento; preoccupato, inquieto, sconvolto, scosso: } \\
\text { essere, apparire, mostrarsi t.; essere t. in volto• Che rivela } \\
\text { inquietudine, turbamento: avere il volto t.; occhi t.; voce } t \text {. } \\
\text { 3. fig. (arc.). Adirato, corrucciato. } \\
\text { 4. In fonologia, di vocale che presenta una combinazione di caratteri } \\
\text { propri di vocali diverse (per es. ü, che richiede la posizione della } \\
\text { lingua propria di } i \text { e la posizione delle labbra propria di } u \text { ).dim. lett. } \\
\text { Turbatétto } \\
\text { P. pass. di turbare | sec. XIV }\end{array}$ \\
\hline Definição Lo Zingarelli 2004 & $\begin{array}{l}\text { FLESSIONE } \\
\text { turbato }\end{array}$ \\
\hline
\end{tabular}




\begin{tabular}{|l|l|}
\hline & $\begin{array}{l}\text { part. pass. di turbare; anche agg. } \\
1 \text { (lett.) Agitato, sconvolto: acque turbate | (lett.) Perturbato. } \\
2 \text { Che è in uno stato di turbamento: apparire turbato | Che rivela } \\
\text { turbamento: avere il volto turbato. } \\
3 \text { †lncollerito, adirato. } \\
\text { || turbatetto, dim. } \\
\text { I| turbatamente, avv. (raro) Con turbamento. }\end{array}$ \\
\hline Definição Parola Chiave & $\begin{array}{l}\text { agg. In preda a turbamento; che rivela un turbamento interiore S } \\
\text { agitado, sconvolto, inquieto: a quella notizia rimase turbato; volto, } \\
\text { sguardo turbato *perturbado }\end{array}$ \\
\hline Definição Proposta & Preocupato, agitato, inquieto. \\
\hline
\end{tabular}


Ficha lexicográfica para as novas palavras que constarão nas notas de rodapé 50

\begin{tabular}{|c|c|}
\hline Unidade lexical & Ubriaco \\
\hline Contexto & $\begin{array}{l}\text { I clienti si divertono ad ascoltare e Renzo, ormai ubriaco, è diventato } \\
\text { lo zimbello del gruppo. (67) }\end{array}$ \\
\hline Definiçao De Mauro Paravia & $\begin{array}{l}\text { u·bri·à·co } \\
\text { agg., s.m. AU } \\
\text { 1. agg., s.m., che, chi si trova in stato di alterazione delle proprie } \\
\text { facoltà mentali dovuto ad abuso di alcolici: alla festa eravamo tutti } \\
\text { ubriachi, ubriaco fradicio, completamente ubriaco } \\
\text { 2. agg., intontito, frastornato: essere ubriaco di sonno, di stanchezza | } \\
\text { esaltato da un sentimento così intenso da offuscare la capacità di } \\
\text { giudizio: essere ubriaco di amore, di felicità }\end{array}$ \\
\hline Definição Dire & $\begin{array}{l}\text { agg. 1- Che è in uno stato di ubriachezza: Era ubriaco, per questo } \\
\text { camminando ondeggiava. 2- Stordito, che è in uno stato di } \\
\text { esaltazione: Per la vittoria della loro squadra i tifosi erano ubriachi di } \\
\text { gioia. / n.m. Persona sotto l'effetto dell'alcol: Per la strada un ubriaco } \\
\text { pronunciava ad alta voce frasi sconnesse. } \\
\text { [lat. ebrius = ubriaco], m.pl. ubriachi, f.pl. ubriache, agg.: contr. } 1 \\
\text { sobrio }\end{array}$ \\
\hline Definição II Sabatini-Coletti & $\begin{array}{l}\text { ubriaco [u-bri-à-co] agg., s. (pl.m. -chi, f. -che) } \\
\text { • agg. } \\
\text { 1 Che è in stato di ubriachezza SIN fam. sbronzo; region. } \\
\text { ciucco: } u \text {. fradicio } \\
2 \text { fig. Esaltato SIN ebbro: u. di gioia; anche, privo della } \\
\text { capacità di reagire SIN stordito: } u \text {. di sole } \\
\text { • s.m. (f. -ca) Persona u. } \\
\text { • sec. XIV }\end{array}$ \\
\hline Definição II Devoto-Oli 2008 & $\begin{array}{l}\text { ubriaco } \\
\text { <u-bri-à-co> (meno com. ubbriaco; arc. ebriaco; region. imbriaco) } \\
\text { agg. (pl.m. - chi) } \\
\text { Sopraffatto o intossicato dall'abuso di bevande alcoliche: } \\
\text { tutte le sere è u. (anche s.m., f. -a); iperb.: u. fradicio;: sei } \\
\text { u.?, rivolgendosi a persona che si comporta come se non } \\
\text { fosse ben consapevole dei propri atti e delle proprie parole• } \\
\text { In medicina: andatura da u., tipica delle persone affette da } \\
\text { atassie locomotorie. } \\
\text { 2. fig. Esaltato, sconvolto per effetto di un sentimento } \\
\text { violento e travolgente; con valore attenuato, euforico, } \\
\text { frastornato, stordito: u. di gioia; ero u. per tutte quelle luci e } \\
\text { quelle grida.accr. ubriacóne (v.). } \\
\text { Dal lat. tardo ebriacus, der. di ebrius 'ebbro' | sec. XIV }\end{array}$ \\
\hline Definição Lo Zingarelli 2004 & $\begin{array}{l}\text { FLESSIONE } \\
\text { aubriaco o (pop., tosc.) briaco, †ebbriaco, †ebriaco, (raro) ubbriaco } \\
\text { [lat. tardo ebriacu(m), per ebriu(m) 'ebbro'; av. 1292] } \\
\text { A agg. (pl. m. -chi) (assol.; + di) } \\
1 \text { Detto di chi si trova in condizioni di intossicazione alcolica acuta, } \\
\text { con accessi di ebbrezza a insorgenza improvvisa cui consegue sonno }\end{array}$ \\
\hline
\end{tabular}




\begin{tabular}{|c|c|}
\hline & $\begin{array}{l}\text { profondo, come conseguenza diretta e immediata dell'ingestione in } \\
\text { un'unica volta di una forte quantità di alcol: essere ubriaco; un vecchio } \\
\text { ubriaco | Essere ubriaco duro, marcio e sim., essere completamente } \\
\text { ubriaco | Sei ubriaco?, si dice a chi si comporta, parla o agisce in } \\
\text { modo assolutamente anormale. SIN. Ebbro. } \\
2 \text { (fig.) Detto di chi si trova in uno stato di esaltazione, eccitazione, } \\
\text { euforia e sim., per lo più tanto intensa da offuscare la sua capacità di } \\
\text { giudizio: essere ubriaco d'amore, di passione, d'odio, di gioia; è ormai } \\
\text { ubriaco di tutte queste lodi. } \\
3 \text { (est., fig.) Stordito, frastornato, rintronato: essere ubriaco di rumore, } \\
\text { di luci; sono ubriaco per la troppa confusione | Essere ubriaco di } \\
\text { sonno, di stanchezza, non tenersi in piedi per il sonno, per la } \\
\text { stanchezza. } \\
4 \text { Maiale ubriaco, braciola di maiale preparata con aglio, prezzemolo } \\
\text { e vino rosso, piatto tipico della cucina toscana. } \\
\text { B s. m. (f. -a) } \\
\text { * Chi è ubriaco. } \\
\text { || ubriachello, dim. | ubriacone, accr. (V.). }\end{array}$ \\
\hline Definição Parola Chiave & agg. [PL. m. -chi] 1 Che è in stato di ubbriachezza $\mathbf{S}$ sbronzo \\
\hline Definição Proposta & Persona sotto l'effetto dell'alcol. \\
\hline
\end{tabular}


Ficha lexicográfica para as novas palavras que constarão nas notas de rodapé 51

\begin{tabular}{|c|c|}
\hline Unidade lexical & Urlare (urla) \\
\hline Contexto & $\begin{array}{l}\text { "Mi portano in prigione perché chiedevo pane e giustizia!" urla, } \\
\text { mentre la folla, che è a suo favore, si avvicina minacciosa. (68) }\end{array}$ \\
\hline Definiçao De Mauro Paravia & $\begin{array}{l}\text { ur.là-re } \\
\text { v.intr. e tr. Fo } \\
\text { 1a. v.intr. (avere) emettere urla, grida acute e prolungate: urlare di } \\
\text { dolore, urlare per la paura, per lo spavento, urlare come un ossesso, } \\
\text { come un'aquila } \\
\text { 1b. v.intr. (avere) estens., parlare concitatamente e con tono di voce } \\
\text { eccessivamente alto: non urlare, ho capito!, non c'è bisogno di urlare } \\
\text { 2. v.intr. (avere) spec. di lupi, cani e sim., ululare } \\
\text { 3. v.intr. (avere) fig., produrre un suono acuto e prolungato, simile a } \\
\text { un urlo: si sentiva urlare la sirena dell'ambulanza } \\
\text { 4a. v.tr., dire, proferire a voce molto alta: urlare minacce, ingiurie, } \\
\text { urlare il nome del vincitore } \\
\text { 4b. v.tr., cantare a voce spiegata: urlare una canzone }\end{array}$ \\
\hline Definição Dire & $\begin{array}{l}\text { v.intr. Gridare: Quando giochi non urlare a squarciagola! / v.tr. Dire a } \\
\text { voce molto alta: Quando il festeggiato spense le candeline sulla torta, } \\
\text { tutti urlarono "Auguri!" } \\
\text { [lat. ululare = ululare], v.intr.: sin. Strillare }\end{array}$ \\
\hline Definição II Sabatini-Coletti & $\begin{array}{l}\text { urlare [ur-là-re] v. } \\
\text { • v.intr. (aus. avere) [sogg-v] Detto di animali, emettere } \\
\text { strida partic. lunghe e forti; detto di persone, emettere grida; } \\
\text { estens. parlare a voce molto alta SIN gridare, strillare: u. a } \\
\text { squarciagola; u. di dolore } \\
\text { • v.tr. [sogg-v-arg] Dire qlco. a voce altissima: u. bestemmie } \\
\text { • sec. XIV }\end{array}$ \\
\hline Definição II Devoto-Oli 2008 & $\begin{array}{l}\text { Urlare } \\
\text { <ur-là-re> v.intr. e tr. (come intr., aus. avere) } \\
\text { 1. intr. Emettere grida forti e prolungate, per sofferenza, spavento o } \\
\text { eccitazione; gridare (anche con le prep. di, da, per): saltava qua e là, } \\
\text { urlando come un ossesso; la folla urlava in preda all'entusiasmo; } \\
\text { urlava di dolore; si misero a u. dallo (o per lo) spavento; Urlar li fa la } \\
\text { pioggia come cani (Dante).2. intr. Di lupi, cani, ecc., emettere ululati, } \\
\text { ululare: i lupi urlavano nella notte.3. intr. (estens.). Parlare con voce } \\
\text { eccessivamente alta, strillare: per farsi ascoltare dagli alunni era } \\
\text { costretta a u.; non u., ti sento benissimo; siccome non hai più } \\
\text { argomenti ti sei messo a u.4. intr. (estens.). Emettere, produrre un } \\
\text { suono prolungato e acuto simile a un urlo: l'allarme ha continuato a u. } \\
\text { per quasi un'ora.5. tr. Pronunciare, dire qualcosa a voce altissima } \\
\text { (anche con la prep. a): continuava a u. parole incomprensibili; mi urlò } \\
\text { da lontano il suo nome; a chiunque si avvicinasse urlava insulti e } \\
\text { parolacce; con che e il cong., o con la prep. di e l'inf.: perse la calma } \\
\text { e gli urlò che se ne doveva andare; le urlarono di spostarsi dal ciglio } \\
\text { della strada• Esprimere, esternare un proprio sentimento o stato } \\
\text { d'animo con delle urla: urlò a tutti la sua rabbia; gli ho urlato tutto il } \\
\text { mio disprezzo nei suoi confronti Cantare a voce spiegata e su toni } \\
\text { alti: u. una canzone; si mise a u. un motivetto. }\end{array}$ \\
\hline Definição Lo Zingarelli 2004 & $\begin{array}{l}\text { FLESSIONE } \\
\text { qurlare }\end{array}$ \\
\hline
\end{tabular}




\begin{tabular}{|c|c|}
\hline & $\begin{array}{l}\text { [lat. parl. *urulare, forma dissimilata di ululare; sec. XIII] } \\
\text { A v. intr. (aus. avere) } \\
1 \text { Emettere urli, ululati e sim., detto dei lupi, dei cani e di altri animali. } \\
\text { SIN. Ululare. } \\
2 \text { (est.) Emettere urla, grida, detto dell'uomo: urlare di dolore, } \\
\text { spavento, terrore, raccapriccio; urlare come un dannato, un disperato, } \\
\text { un ossesso; urlare a squarciagola, a perdifiato. } \\
3 \text { (est.) Alzare la voce spec. accalorandosi in rimproveri, discussioni, } \\
\text { polemiche e sim.: non c'è bisogno di urlare così; se urlate in questo } \\
\text { modo io me ne vado; "basta, basta," urlò "via quel bicchiere" (SVEVO) } \\
\text { I (est.) Parlare a voce troppo alta: le persone educate non urlano; } \\
\text { smetti di urlare, che non sono sordo! SIN. Sbraitare. } \\
\text { B v. tr. } \\
1 \text { Dire a voce molto alta: urlare insulti, parolacce; non capisco cosa } \\
\text { stiano urlando. } \\
2 \text { Cantare a piena voce: urlare un motivo, una canzone. }\end{array}$ \\
\hline Definição Parola Chiave & $\begin{array}{l}\text { v.intr. [aus. avere] Emmettere grida acute e prolungate (detto di } \\
\text { animali): Le scimmie urlano quando avvertono il pericolo *gridar }<> \\
\text { Parlare a voce molto alta(detto di persona) } \mathbf{S} \text { gridare, strillare: urlava } \\
\text { a squarciagola; smettila di urlare! *berrar }\end{array}$ \\
\hline Definição Proposta & Gridare, parlare con voce molto alta. \\
\hline
\end{tabular}


Ficha lexicográfica para as novas palavras que constarão nas notas de rodapé 52

\begin{tabular}{|c|c|}
\hline Unidade lexical & Vendetta \\
\hline Contexto & $\begin{array}{l}\text { Intanto Renzo va a piedi da Monza a Milano in uno stato d'animo } \\
\text { combattuto tra la rabbia e il desiderio di vendetta. (47) }\end{array}$ \\
\hline Definiçao De Mauro Paravia & $\begin{array}{l}\text { ven·dét·ta } \\
\text { s.f. FO } \\
\text { 1. offesa morale o danno materiale arrecato ad altri per ottenere } \\
\text { soddisfazione di un'offesa o di un danno subito: una vendetta crudele, } \\
\text { tremenda; compiere una vendetta, giurare vendetta, covare la } \\
\text { vendetta; ottenere, ricevere vendetta, essere vendicato, ritenersi } \\
\text { vendicato; far vendetta di un torto subito, vendicarlo | esporre qcn. } \\
\text { alla vendetta, metterlo nelle mani di chi vuole vendicarsi } \\
\text { 2. punizione inflitta dalla giustizia divina: non temere la vendetta di } \\
\text { Dio } \\
\text { 3. LE persecuzione: ove una volta la fortuna cessi | dalle vendette } \\
\text { (Foscolo) }\end{array}$ \\
\hline Definição Dire & $\begin{array}{l}\text { n.f. Danno che si arreca a qualcuno per ricambiare un'offesa subita: } \\
\text { Non nutrire propositi di vendetta verso quel tuo compagno. } \\
\text { [lat. vindicta = vendetta, punizione], Contr. perdono }\end{array}$ \\
\hline Definição II Sabatini-Coletti & $\begin{array}{l}\text { vendetta [ven-dét-ta] s.f. } \\
1 \text { Danno morale o materiale inferto ad altri quale ritorsione } \\
\text { per offese o danni precedentemente subiti: giurare, meditare } \\
\text { una v.; uccidere per v.; v. trasversale \|l nel detto la miglior } \\
\text { vendetta è il perdono, che esalta il principio cristiano del } \\
\text { perdono, dell'indulgenza verso i colpevoli } \\
2 \text { Punizione, intesa perlopiù come giusto castigo divino: } \\
\text { peccatore che va incontro alla v. di Dio \|l fig. gridare v., di } \\
\text { colpe e misfatti che meritano una punizione; scherz., di } \\
\text { mancanze imperdonabili: nel compito hai fatto degli errori } \\
\text { che gridano v.! } \\
\text { • sec. XIV }\end{array}$ \\
\hline Definição II Devoto-Oli 2008 & $\begin{array}{l}\text { Vendetta } \\
\text { <ven-dét-ta> s.f. } \\
\text { Danno materiale o morale inflitto privatamente ad altri per } \\
\text { pareggiare un danno o un oltraggio subito: giurare v.; } \\
\text { premeditare, macchinare la v.; fu ucciso per v.; si suppone } \\
\text { che il movente del delitto sia la v.; v. trasversale, tipica della } \\
\text { mafia, che colpisce non la persona direttamente, bensì i suoi } \\
\text { parenti• Far v. di..., vendicare; seguito da un nome di } \\
\text { persona o da un aggettivo possessivo, vendicare la morte } \\
\text { della persona stessa: E giurò far del suo fratel vendetta } \\
\text { (Pulci); talvolta, con sign. attenuato, rivalersi, } \\
\text { contraccambiare: Far potess'io vendetta di colei Che } \\
\text { guardando e parlando mi distrugge (Petrarca); quando mi } \\
\text { capiti a tiro saprò ben prendermi la mia v.!2. Giusta } \\
\text { punizione; nel linguaggio devoto, il castigo divino; il giorno } \\
\text { della v., il giorno del Giudizio Universale; part.: gridar v., a } \\
\text { proposito di gravi colpe assolutamente non perdonabili e per } \\
\text { le quali la stessa umanità esige una punizione esemplare } \\
\text { (delitto, tradimento, perfidia che grida v.) e, scherz., di cose } \\
\text { malfatte (questi compiti gridano v.) o di quanto reclama } \\
\text { castigo o risarcimento per il danno subito (hai ridotto le } \\
\text { scarpe in uno stato che grida v.)• V. di Montezuma, altro } \\
\text { nome della diarrea del viaggiatore• poet. Persecuzione: a } \\
\text { noi Morte apparecchi riposato albergo, Ove una volta la }\end{array}$ \\
\hline
\end{tabular}




\begin{tabular}{|c|c|}
\hline & $\begin{array}{l}\text { fortuna cessi Dalle vendette (Foscolo). } \\
\text { Lat. vindicta 'la verga con cui si toccava lo schiavo che } \\
\text { doveva essere posto in libertà', poi 'rivendicazione; } \\
\text { liberazione; vendetta; castigo', der. di vindicare 'pretendere, } \\
\text { rivendicare', poi 'vendicare'| sec. XIV }\end{array}$ \\
\hline Definição Lo Zingarelli 2004 & $\begin{array}{l}\text { FLESSIONE } \\
\text { avendetta } \\
\text { [lat. vindicta(m) 'verga con cui si toccava lo schiavo che doveva } \\
\text { essere posto in libertà', poi 'rivendicazione, liberazione', quindi } \\
\text { 'vendetta, punizione', da vindicare 'pretendere, rivendicare', poi } \\
\text { 'vendicare'; 1266] } \\
\text { s. f. } \\
1 \text { Offesa, danno più o meno grave inflitto a qlcu. per fargli scontare un } \\
\text { torto o un'ingiustizia da lui provocati: vendetta privata; giurare } \\
\text { vendetta; una catena di vendette; vendetta, vendetta, tremenda } \\
\text { vendetta; vuole che la vendetta sia grande (COMPAGNI) | Vendetta } \\
\text { trasversale, che non colpisce direttamente chi ha arrecato un danno } \\
\text { ma un suo congiunto o suoi interessi | Far vendetta di, vendicare | } \\
\text { Prendere vendetta, vendicarsi | Ricevere vendetta, ottenere, essere } \\
\text { vendicato | Far la vendetta di un altro, vendicare un oltraggio in vece } \\
\text { sua | Consegnare, esporre e sim. alla vendetta di qlcu., mettere qlcu. } \\
\text { nelle mani o alla mercé di chi vuole vendicarsi. SIN. Rivalsa. } \\
2 \text { Castigo: la giusta vendetta del cielo; la vendetta degli dei | || giorno } \\
\text { della vendetta, del giudizio universale | Gridare vendetta, invocare a } \\
\text { gran voce la giusta punizione; (est.) si dice di colpe totalmente } \\
\text { imperdonabili (anche scherz.): un misfatto che grida vendetta; infamie } \\
\text { che gridano vendetta al cospetto di Dio; ha cantato con una voce che } \\
\text { gridava vendetta. } \\
\text { || vendettaccia, pegg. | vendettuccia, dim. }\end{array}$ \\
\hline Definição Parola Chiave & $\begin{array}{l}\text { s.f. } 1 \text { Danno o offesa che si arreca volontariamente a qualcuno per } \\
\text { punirlo di danni o offese precedentemente subiti: in prigione meditava } \\
\text { la vendetta contro chi l'aveva tradito; è stato ucciso per vendetta } \\
\text { "vingança } 2 \text { Un delitto, un'ingiustizia che grida vendetta = che merita } \\
\text { una giusta punizione *um crime, uma injustiça que clama vingança }\end{array}$ \\
\hline Definição Proposta & $\begin{array}{l}\text { Danno causato a qualcuno per ricambiare una offessa ricevuta. } \\
\text { Pagare con la stessa monetta. }\end{array}$ \\
\hline
\end{tabular}


Ficha lexicográfica para as novas palavras que constarão nas notas de rodapé 53

\begin{tabular}{|c|c|}
\hline Unidade lexical & Vicenda (vicende) \\
\hline Contexto & $\begin{array}{l}\text { Le vicende storiche che si svolsero tra ‘500 e '600, soprattutto le } \\
\text { guerre tra Francia e Spagna, ebbero riflessi negativi sull'Italia, che } \\
\text { passò rapidamente dall'indipendenza al dominio straniero. (24) }\end{array}$ \\
\hline Definiçao De Mauro Paravia & $\begin{array}{l}\text { vi·cèn·da } \\
\text { s.f. } \\
\text { 1. FO storia costituita da una serie di fatti e situazioni che si } \\
\text { susseguono: la vicenda del film è molto avvincente, è una vicenda } \\
\text { piena di passione, mi ha raccontato una triste vicenda | BU l'alternarsi } \\
\text { delle stagioni, dei giorni, e sim. } \\
\text { 2. TS agr. non com. } \square \text { rotazione agraria } \\
\text { 3. FO evento, caso: le vicende della vita, le alterne vicende della } \\
\text { guerra | OB LE faccenda, affare: io vo infino a città per alcuna mia } \\
\text { vicenda (Boccaccio) } \\
\text { 4. OB LE ciò che tocca fare, o che tocca fare a propria volta: si } \\
\text { spesso vien chi vicenda consegue (Dante) } \\
\text { 5. OB pariglia: rendere la vicenda }\end{array}$ \\
\hline Definição Dire & $\begin{array}{l}\text { n.f. 1- Fatto, evento: Questa sera ti racconteremo tutta la vicenda. 2- } \\
\text { Successione di fatti o cose che si alternano tra loro: la vita è una } \\
\text { vicenda di speranze e delusioni. / loc.avv. (a vicenda) } \\
\text { Reciprocamente: Si sono sempre aiutati a vicenda. } \\
\text { [lat. vicis = vicenda], n.f.: sin. } 1 \text { avvenimento }\end{array}$ \\
\hline Definição II Sabatini-Coletti & $\begin{array}{l}\text { vicenda [vi-cèn-da] s.f. } \\
\begin{array}{l}1 \text { Avvenimento o serie di avvenimenti che riguardano la vita } \\
\text { e la storia di una o più persone: v. liete, tristi; è una penosa } \\
\text { v.; le ultime v. politiche hanno sorpreso tutti } \\
2 \text { non com. Avvicendamento, alternanza: la v. delle stagioni } \\
\text { II a v., l'un l'altro: aiutarsi a v.; a turno } \\
\mathbf{3} \text { agr. Rotazione delle colture } \\
\text { • sec. XIV }\end{array}\end{array}$ \\
\hline Definição II Devoto-Oli 2008 & $\begin{array}{l}\text { vicende >> } \\
\text { vicenda } \\
\text { <vi-cèn-da> s.f. } \\
\text { 1. Successione che implica un'idea di alternanza: la v. delle stagioni; } \\
\text { la vita è una v. di gioie e dolori, di speranze e delusioni; talvolta, sin. } \\
\text { di avvicendamento (per es. delle coltivazioni: risaia in v.)• lett. } \\
\text { Movimento alternato.2. Evento, sia con riferimento alla vita quotidiana } \\
\text { che alla vita sociale e politica dei popoli: narrare le proprie v.; liete, } \\
\text { tristi v.; v. storiche. } \\
\text { 3. arc. Quanto di volta in volta spetta a ciascuno: Si spesso vien chi } \\
\text { vicenda consegue (Dante)• Contraccambio: rendere la v.• Affare, } \\
\text { faccenda: io vo infino a città per alcuna mia vicenda (Boccaccio).4. } \\
\text { loc. avv. A vicenda, scambievolmente, l'un l'altro: aiutarsi, insultarsi a } \\
\text { v.; sono cose che si elidono a v.; Vanno a vicenda ciascuna al } \\
\text { giudizio (Dante) } \\
\text { Lat. volg. *vicenda, gerundivo di un verbo connesso con *vix vicis } \\
\text { 'vece' I prima metà sec. XIV }\end{array}$ \\
\hline
\end{tabular}




\begin{tabular}{|c|c|}
\hline Definição Lo Zingarelli 2004 & $\begin{array}{l}\text { FLESSIONE } \\
\text { avicenda } \\
\text { [lat. parl. *vicenda, nt. pl., da vicis 'vece'; av. 1243] } \\
\text { s. f. } \\
1 \text { (lett. o disus.) Serie di cose, fatti, avvenimenti, situazioni e sim. che } \\
\text { si succedono alternandosi: la vicenda degli anni, delle stagioni; una } \\
\text { continua vicenda di delusioni e speranze | L'umana vicenda, la vita, } \\
\text { l'esistenza. } \\
2 \text { (agr.) Avvicendamento delle colture, rotazione | Prato da vicenda, } \\
\text { artificiale, rinnovato periodicamente. } \\
3 \text { Caso, fatto, evento: una triste vicenda; le vicende della vita; } \\
\text { conoscere le vicende personali di qlcu.; narrare le proprie vicende | } \\
\text { Con alterne vicende, con un alternarsi di eventi favorevoli e } \\
\text { sfavorevoli. } \\
4 \text { (raro, lett.) Turno, volta, giro | A vicenda, a turno, l'un l'altro: vegliare } \\
\text { a vicenda; amarsi, complimentarsi a vicenda. } \\
5 \text { †Contraccambio, ricompensa | †ln vicenda, invece. } \\
6 \text { †Faccenda, bisogna: io vo infino a città per alcuna mia vicenda } \\
\text { (BOCCACCIO). }\end{array}$ \\
\hline Definição Parola Chiave & $\begin{array}{l}\text { s.f. } 1 \text { Avvenimento, caso o serie di avvenimenti e casi che riguardano } \\
\text { la vita e la storia di una o più persone: la sua è una pietosa vicenda; } \\
\text { un film che narra una vicenda sentimentale; le dolorose vicende di un } \\
\text { popolo; le alterne vicende della vita *história; caso; altos e baixos } 2 \\
\text { A vicenda = reciprocamente, l'un l'altro: aiutarsi a vicenda; si sono } \\
\text { ingannati a vicenda *reciprocamente }\end{array}$ \\
\hline Definição Proposta & Evento(i), fatto(i). \\
\hline
\end{tabular}


Ficha lexicográfica para as novas palavras que constarão nas notas de rodapé 54

\begin{tabular}{|c|c|}
\hline Unidade lexical & Nobiluomo \\
\hline Contexto & $\begin{array}{l}\text { Alessandro Manzoni nasce a Milano nel } 1785 \text { da una famiglia ricca e } \\
\text { famosa:sua madre, Giulia Beccaria, era figlia dello scrittore Cesare } \\
\text { Beccaria e suo padre, Pietro, era un nobiluomo. (4) }\end{array}$ \\
\hline Definiçao De Mauro Paravia & $\begin{array}{l}\text { no·bi·luò·mo } \\
\text { s.m. TS arald. } \\
\text { discendente maschio di una famiglia aristocratica, privo di titoli } \\
\text { nobiliari particolari (abbr. N.H., N.U.) | CO estens., uomo che } \\
\text { appartiene all'aristocrazia }\end{array}$ \\
\hline Definição Dire & $\begin{array}{l}\text { n.m. Uomo che appartiene ad una famiglia aristocratica, gentiluomo: } \\
\text { Nel castello abita un nobiluomo. } \\
\text { composto da nobil(e) + uomo, pl. Nobiluomini }\end{array}$ \\
\hline Definição II Sabatini-Coletti & $\begin{array}{l}\text { nobiluomo [no-bi-luò-mo] s.m. (pl. nobiluomini) } \\
\text { - Uomo privo di un particolare titolo nobiliare ma appartenente per } \\
\text { nascita a famiglia aristocratica SIN gentiluomo, signore } \\
\text { - sec. XVI }\end{array}$ \\
\hline Definição II Devoto-Oli 2008 & $\begin{array}{l}\text { nobiluomo } \\
\text { <no-bi-luò-mo> (o nobilomo) s.m. (pl. nobiluòmini) } \\
\text { Uomo appartenente a famiglia di nobile discendenza, ma senza alcun } \\
\text { titolo nobiliare specifico. }\end{array}$ \\
\hline Definição Lo Zingarelli 2004 & $\begin{array}{l}\text { FLESSIONE } \\
\text { nobiluomo o nobil uomo } \\
\text { [da nobil(e) uomo; av. 1597] } \\
\text { s. m. (pl. nobiluòmini) } \\
\text { * Uomo discendente da famiglia nobile, ma privo di titoli nobiliari } \\
\text { specifici }\end{array}$ \\
\hline Definição Parola Chiave & s.m. Uomo di famiglia nobile *fidalgo \\
\hline Definição Proposta & Uomo di famiglia aristocratica. \\
\hline
\end{tabular}


Ficha lexicográfica para as novas palavras que constarão nas notas de rodapé 55

\begin{tabular}{|c|c|}
\hline Unidade lexical & Soprannome \\
\hline Contexto & $\begin{array}{l}\text { "Sentite, non bisogna spaventarsi. So io cosa bisogna fare. Renzo, } \\
\text { vai a Lecco dal dottor Azzeccagarbugli, quell'avvocato alto, magro e } \\
\text { con gli occhiali. Attento, però, a non chiamarlo così, perché è un } \\
\text { soprannome!..."(4) }\end{array}$ \\
\hline Definiçao De Mauro Paravia & $\begin{array}{l}\text { so·pran·nó·me } \\
\text { s.m. } \\
\text { 1. AD appellativo scherzoso o ingiurioso di una persona, che prende } \\
\text { generalmente spunto da particolari caratteristiche personali: affibbiare } \\
\text { un soprannome a qcn. } \\
\text { 2. OB cognome }\end{array}$ \\
\hline Definição Dire & $\begin{array}{l}\text { n.m. Nome che si dà a qualcuno al posto di quello vero, nomignolo: Il } \\
\text { soprannome del mio compagno di banco è "Stecchino". } \\
\text { Derivato da nome, pl. soprannomi }\end{array}$ \\
\hline Definição II Sabatini-Coletti & $\begin{array}{l}\text { soprannome [so-pran-nó-me] s.m. } \\
\text { • Appellativo scherzoso o ingiurioso attribuito a una persona, } \\
\text { con riferimento a caratteristiche fisiche o morali, qualità, } \\
\text { provenienza ecc. SIN nomignolo } \\
\text { • sec. XIV }\end{array}$ \\
\hline Definição II Devoto-Oli 2008 & $\begin{array}{l}\text { Soprannome } \\
\text { <so-pran-nó-me> (arc. sopranome) s.m. } \\
\text { 1. Appellativo scherzoso, ironico o anche malevolo imposto a una } \\
\text { persona in conseguenza di certe caratteristiche fisiche o qualità o } \\
\text { attitudini, o in base al luogo di nascita o di provenienza: Pel di carota, } \\
\text { lo smilzo, lo scoiattolo, il levantino.2. arc. Cognome. }\end{array}$ \\
\hline Definição Lo Zingarelli 2004 & $\begin{array}{l}\text { FLESSIONE } \\
\text { asoprannome (o -o-) o †sopranome (o -o-) } \\
\text { [dal lat. mediev. supernome(n), comp. di super 'sopra' e nomen, genit. } \\
\text { nominis 'nome', con sovrapposizione di sopra-; av. 1292] } \\
\text { s. m. } \\
1 \text { †Casato, cognome: gli era de' Grimaldi caduto il soprannome } \\
\text { (BOCCACCIO). } \\
2 \text { Appellativo, spesso legato a particolari caratteristiche individuali o } \\
\text { ambientali, che si sostituisce al vero nome e cognome di una } \\
\text { persona: Giovan Francesco Barbieri è noto con il soprannome di 'il } \\
\text { Guercino'; nel quartiere è conosciuto col soprannome di Gambacorta; } \\
\text { è così furbo che per soprannome lo chiamano la volpe. }\end{array}$ \\
\hline Definição Parola Chiave & $\begin{array}{l}\text { s.m. Nome, diverso dal cognome e dal nome proprio, con cui viene } \\
\text { chiamata una persona in un dato ambiente *apelido }\end{array}$ \\
\hline Definição Proposta & $\begin{array}{l}\text { Nome ironico o malevolo che si dà ad una personaa partire da } \\
\text { una caratteristica física o morale, luogo di provenienza, qualità, } \\
\text { ecc. }\end{array}$ \\
\hline
\end{tabular}




\section{3 - Fichas}

lexicográficas das notas

reformuladas a constar

$$
\text { no rodapé }
$$


Ficha lexicográfica para definição reformulada 1

\begin{tabular}{|c|c|}
\hline Unidade lexical & Signorotto \\
\hline Contexto & $\begin{array}{l}\text { Don Abbondio sa che quei due sono dei "bravi", cioè dei giovani al } \\
\text { servizio di Don Rodrigo, un prepotente signorotto del luogo. (8) }\end{array}$ \\
\hline Definição existente & $\begin{array}{l}\text { - signorotto: uomo ricco e violento, proprietario di un castello e al } \\
\text { comando di un gruppo di giovani pronti a tutto per lui (i bravi). (8) }\end{array}$ \\
\hline Definiçao De Mauro Paravia & $\begin{array}{l}\text { si·gno· ròt·to } \\
\text { s.m. Co } \\
\text { 1. signore che è titolare di un piccolo feudo o che detiene sotto il suo } \\
\text { dominio un territorio di piccole dimensioni } \\
\text { 2. estens., nobile, possidente di campagna; chi appartiene alla piccola } \\
\text { nobiltà o a una classe agiata, spec. avendo piccole proprietà terriere }\end{array}$ \\
\hline Definição Dire & Não consta. \\
\hline Definição II Sabatini-Coletti & $\begin{array}{l}\text { signorotto [si-gno-ròt-to] s.m. } \\
\text { 1 Signore che esercita autorità su un territorio limitato: un s. } \\
\text { di campagna } \\
2 \text { spreg. Signore prepotente } \| \text { fare il s., in senso iron., } \\
\text { spadroneggiare } \\
\text { - sec. XVI }\end{array}$ \\
\hline Definição II Devoto-Oli 2008 & $\begin{array}{l}\text { Signorotto } \\
\text { <si-gno-ròt-to> s.m. } \\
\text { Signore che risiede nella sua proprietà rustica; di solito alludendo a } \\
\text { una posizione di prestigio nei confronti degli abitanti del luogo e a una } \\
\text { certa tendenza all'arbitrio e al sopruso: un s. di campagna. } \\
\text { Der. accr. e pegg. di signore | sec. XV }\end{array}$ \\
\hline Definição Lo Zingarelli 2004 & $\begin{array}{l}\text { Signorotto } \\
\text { [1502] } \\
\text { s. m. } \\
1 \text { Alter. di signore. } \\
2 \text { Signore di un piccolo dominio o di una modesta proprietà: un } \\
\text { signorotto di campagna. }\end{array}$ \\
\hline Definição Parola Chiave & Não consta. \\
\hline Definição Proposta & $\begin{array}{l}\text { Signore ricco, nobile, proprietario di terre e che comanda un } \\
\text { territorio di dimensioni limatate. }\end{array}$ \\
\hline
\end{tabular}


Ficha lexicográfica para definição reformulada 2

\begin{tabular}{|c|c|}
\hline Unidade lexical & Azzeccagarbugli \\
\hline Contexto & $\begin{array}{l}\text { Renzo, vai a Lecco dal dottor Azzeccagarbugli, quell'avvocato alto, } \\
\text { magro e con gli occhiali. (11) }\end{array}$ \\
\hline Definição existente & $\begin{array}{l}\text { - Azzeccagarbugli: soprannome inventato dal Manzoni per indicare } \\
\text { un avvocato capace di tirare fuori dai guai ogni persona (azzeccare: } \\
\text { riuscire; ingarbugliato: confuso, pieno di nodi da sciogliere). (11) }\end{array}$ \\
\hline Definiçao De Mauro Paravia & $\begin{array}{l}\text { az'zec } \cdot \mathbf{c a} \cdot \mathbf{g a r} \cdot \mathbf{b u ̀} \cdot \mathbf{g l i} \\
\text { s.m.inv. CO } \\
\text { avvocato cavilloso e intrigante ma di scarsa dottrina }\end{array}$ \\
\hline Definição Dire & $\begin{array}{l}\text { n.m.inv. Avvocato da strapazzo, persona intrigante: Quel tipo è } \\
\text { soltanto un azzeccagarbugli. }\end{array}$ \\
\hline Definição II Sabatini-Coletti & $\begin{array}{l}\text { azzeccagarbugli [az-zec-ca-gar-bù-gli] s.m. inv. } \\
\text { - Avvocato di scarso prestigio professionale, che si presta a } \\
\text { manovre scorrette } \\
\text { • a. } 1840\end{array}$ \\
\hline Definição II Devoto-Oli 2008 & $\begin{array}{l}\text { Azzeccagarbugli } \\
\text { <az-zec-ca-gar-bù-gli> s.m. e f. (invar.) } \\
\text { Avvocato da strapazzo, vile e intrigante; per antonomasia, dal nome } \\
\text { del celebre 'dottore' di manzoniana memoria. } \\
1849\end{array}$ \\
\hline Definição Lo Zingarelli 2004 & $\begin{array}{l}\text { [dal nome di un celebre personaggio manzoniano; 1849] } \\
\text { s. m. inv. } \\
\text { * Leguleio da strapazzo | Intrigante (V. nota d'uso STEREOTIPO). }\end{array}$ \\
\hline Definição Parola Chiave & Não consta. \\
\hline Definição Proposta & $\begin{array}{l}\text { Denominazione creata dall'autore per designare una persona che } \\
\text { si crede capace, o vuol fare credere di essere capace, di } \\
\text { risolvere tutti i problemi. Dal verbo azzeccare (colpire la cosa } \\
\text { giusta) e dal sostantivo garbuglio (confuso, con problemi). }\end{array}$ \\
\hline
\end{tabular}


Ficha lexicográfica para definição reformulada 3

\begin{tabular}{|c|c|}
\hline Unidade lexical & Trina \\
\hline Contexto & $\begin{array}{l}\text { Le donne portavano abiti interi e rigidi, con il collo chiuso dalla } \\
\text { caratteristica 'gorgiera' di lino o incorniciato da alti colletti di trina; (25) }\end{array}$ \\
\hline Definição existente & - trina: merletto o pizzo. (25) \\
\hline Definiçao De Mauro Paravia & $\begin{array}{l}\text { trì·na } \\
\text { s.f. } \\
\text { 1. Co merletto, pizzo } \\
\text { 2. TS orefic. nelle pietre preziose tagliate a rosetta, l'insieme delle } \\
\text { facce triangolari comprese tra la corona e la cintura della piramide }\end{array}$ \\
\hline efinição Dire & n.f. Merletto, pizzo. \\
\hline Definição II Sabatini-Coletti & $\begin{array}{l}\text { trina [trì-na] s.f. } \\
\qquad \begin{array}{l}\text { Merletto, pizzo } \\
\cdot \text { sec. XVI }\end{array}\end{array}$ \\
\hline Definição II Devoto-Oli 2008 & $\begin{array}{l}\text { <trì-na> s.f. } \\
\text { 1. Lo stesso che merletto; fig.: pare una t., a proposito della } \\
\text { straordinaria finezza di esecuzione d'un intaglio o d'un lavoro in } \\
\text { marmo.2. Nel taglio a rosetta delle pietre preziose, l'insieme delle } \\
\text { facce triangolari comprese tra la stella e la cintura della piramide.dim. } \\
\text { trinétta } \\
\text { Lat. trina, femm. sing. sost. di trini, distributivo di tres 'tre' | sec. XV }\end{array}$ \\
\hline Definição Lo Zingarelli 2004 & $\begin{array}{l}\text { [lat. trina(m), da trinus 'di tre', sottinteso 'fili'; 1482] } \\
\text { s. f. } \\
\text { * Pizzo, merletto: l'aria è crivellata / come una trina / dalle } \\
\text { schioppettate (UNGARETTI) | Trina di punto, eseguita con l'ago e un } \\
\text { solo filo su un fondo di pergamena o carta che fa da modello | Trina } \\
\text { ricamata, ricamo traforato eseguito su fondo di tessuto che, } \\
\text { nell'aspetto, ricorda la trina di punto | Parere, sembrare una trina, si } \\
\text { dice di lavoro eseguito traforando con estrema precisione e minuzia } \\
\text { un materiale solido e pesante ottenendo effetti di estrema lievità; } \\
\text { (est.) di concrezione, cristallizzazione e sim. che per la forma è simile } \\
\text { a un pizzo. } \\
\text { || trinetta, dim. | trinettina, dim. }\end{array}$ \\
\hline Definição Parola Chiave & Não consta. \\
\hline Definição Proposta & $\begin{array}{l}\text { Dettaglio delicato fatto a macchina o a mano per abbellire abiti e } \\
\text { biancheria femminile. }\end{array}$ \\
\hline
\end{tabular}


Ficha lexicográfica para definição reformulada 4

\begin{tabular}{|c|c|}
\hline Unidade lexical & Volto \\
\hline Contexto & Gli occhi vivaci e profondi risaltano in quel volto magro e volitivo. (26) \\
\hline Definição existente & - volto: viso. (26) \\
\hline Definiçao De Mauro Paravia & $\begin{array}{l}\text { 1'vól-to } \\
\text { s.m. } \\
\text { 1. Fo faccia, viso: un volto regolare, scavato; essere, farsi scuro in } \\
\text { volto, essere o diventare corrucciato, incupito, rabbuiato; cambiare in } \\
\text { volto, mutare l'espressione, spec. impallidendo o arrossendo | LE } \\
\text { sguardo: tacito coram me ciascun s'affisse, | ignito si che vincea 'I mio } \\
\text { volto (Dante) } \\
\text { 2. FO fig., carattere, natura di una persona: scoprire il vero volto di } \\
\text { qcn. } \\
\text { 3. Fo fig., aspetto esteriore, modo di apparire di qcs.: il duro volto } \\
\text { della realtà }\end{array}$ \\
\hline Definição Dire & $\begin{array}{l}\text { n.m 1- Viso: Quella ragazza ha un volto davvero simpatico. 2- Aspetto } \\
\text { esteriore: La realtà ha mille volti. 3- Indole, modo di essere: Non è } \\
\text { facile scoprire il vero volto di una persona. }\end{array}$ \\
\hline Definição II Sabatini-Coletti & $\begin{array}{l}\text { volto [vól-to] s.m. } \\
\qquad \begin{array}{l}1 \text { Viso, faccia: farsi rosso in v. } \\
2 \text { fig. Aspetto, sembianza: i mille v. della realtà storica; } \\
\text { anche, intima essenza, natura: conoscere il vero v. di qlcu. } \\
\text { • sec. XIV }\end{array}\end{array}$ \\
\hline Definição II Devoto-Oli 2008 & $\begin{array}{l}\text { volto } \\
\text { < vól-to> s.m. } \\
\text { Sin., di tono più elevato, di viso o faccia: avere un bel v.; esser triste, } \\
\text { acceso in v.; fig., solo in espressioni in cui si accosti a 'maschera': ha } \\
\text { la maschera al v., è un ipocrita Un v. nuovo, v. nuovi, nell'ambito del } \\
\text { cinema, della televisione e del teatro, a proposito di attori esordienti• } \\
\text { lett. Per sineddoche, gli occhi, la vista; metaforicamente, la superficie } \\
\text { terrestre: Dal duro volto de la terra il sole Non tollea ancora il velo } \\
\text { oscuro et atro (Ariosto)• più com. Equivalente di 'aspetto': il v. } \\
\text { crudele della natura; sotto quale v. ti nascondi?; volto mutevole d'aria } \\
\text { e di colli (Quasimodo) Carattere, essenza, natura: finalmente ha } \\
\text { mostrato il suo vero v.; non è ancora preparato ad affrontare il duro v. } \\
\text { della competizione. } \\
\text { Lat. vultum 'viso' }\end{array}$ \\
\hline Definição Lo Zingarelli 2004 & $\begin{array}{l}\text { viso (2) } \\
\text { [lat. visu(m) 'vista, sguardo', poi 'aspetto', da videre 'vedere'; } 1225 \\
\text { ca.] } \\
\text { s. m. } \\
1 \text { Parte anteriore della testa dell'uomo, in cui hanno sede gli organi } \\
\text { della vista, dell'olfatto e della parola: viso bello, delicato, magro, } \\
\text { ossuto, paffuto; viso sporco, tinto, dipinto, imbellettato, roseo, pallido, }\end{array}$ \\
\hline
\end{tabular}




\begin{tabular}{|c|c|}
\hline & $\begin{array}{l}\text { cereo; pulirsi, lavarsi, asciugarsi il viso; coprirsi il viso con le mani; } \\
\text { essere, diventare rosso in viso per la vergogna; avere il viso bagnato } \\
\text { di lacrime. SIN. Faccia, volto | Viso pallido, ogni uomo di pelle bianca, } \\
\text { secondo una espressione usata dagli indiani d'America; (fig., scherz.) } \\
\text { chi, per scarsa esposizione al sole, è privo di abbronzatura | II viso gli } \\
\text { si è allungato, di persona che è dimagrita parecchio in breve tempo | } \\
\text { Guardarsi in viso, fissarsi l'un l'altro | Viso a viso, a viso a viso, a } \\
\text { faccia a faccia | Poter mostrare il viso, (fig.) non aver motivo per } \\
\text { vergognarsi | Non aver mai visto qlcu. in viso, non conoscerlo | (fig.) } \\
\text { Dire, spiattellare qlco. sul viso a qlcu., dirgliela senza alcun riguardo, } \\
\text { delicatezza e sim. | A viso coperto, con il volto coperto, mascherato | } \\
\text { A viso aperto, con franchezza e coraggio | Gettare qlco. sul viso a } \\
\text { qlcu., (fig.) rinfacciargli qlco. | tMutar viso, cambiare di umore, } \\
\text { turbarsi. } \\
2 \text { (est.) Espressione del volto: viso allegro, sorridente, serio, } \\
\text { corrucciato, imbronciato; gli si legge in viso la gioia, il dolore, la } \\
\text { commozione, la disperazione | tCon viso fermo, senza mutar viso, } \\
\text { con espressione impassibile, senza scomporsi e sim. | Viso dell'armi, } \\
\text { (lett.) dell'arme, espressione minacciosa, feroce e sim., come quella } \\
\text { di chi si lancia contro l'avversario con le armi in pugno | (fig.) Fare il } \\
\text { viso duro, mostrare la massima severità, intransigenza e sim. | Fare, } \\
\text { mostrare buon viso a qlcu., accoglierlo con manifestazioni di } \\
\text { contentezza, dimostrare di gradirne l'arrivo, la presenza e sim. | (fig.) } \\
\text { Fare buon viso a cattivo gioco, adattarsi con serenità a situazioni, } \\
\text { condizioni o realtà sgradite, spiacevoli | tMal viso, che esprime } \\
\text { scontento, fastidio e sim. | (fig., raro) Aver viso di, aver il coraggio, } \\
\text { l'ardire di. } \\
3 \text { (est.) Fisionomia particolare, aspetto inconfondibile di una persona: } \\
\text { quel viso non mi è nuovo; è un viso noto a tutte le polizie d'Europa. } \\
4 \text { fOcchio, sguardo, vista: Tu hai l'udir mortal si come il viso (DANTE } \\
\text { Par. XXI, 61). } \\
5 \text { (fig.) tIntelletto. } \\
\text { II visaccio, pegg. (V.) | visetto, dim. (V.) | visino, dim. | visoccio, accr. | } \\
\text { visone, accr. | visuccio, visuzzo, vezz. o pegg. }\end{array}$ \\
\hline Definição Parola Chiave & $\begin{array}{l}\text { s.m. } 1 \text { Viso, faccia: Il suo volto era triste; un volto delicato } 2 \text { Carratere, } \\
\text { natura: ti eri fidato di lui, ma ti ha tradito mostrando il suo vero volto } \\
\text { *rosto }\end{array}$ \\
\hline Definição Proposta & Faccia, viso \\
\hline
\end{tabular}


Ficha lexicográfica para definição reformulada 5

\begin{tabular}{|c|c|}
\hline Unidade lexical & Alito \\
\hline Contexto & $\begin{array}{l}\text { Sulla riva, una barca aspetta Renzo, Lucia e Agnese: non tira un alito } \\
\text { di vento,... (34) }\end{array}$ \\
\hline Definição existente & - alito: (qui) soffio. (34) \\
\hline Definiçao De Mauro Paravia & $\begin{array}{l}\text { à·li·to } \\
\text { s.m. AD } \\
\text { 1. aria espirata, respiro: appannare un vetro con l'alito, resistere fino } \\
\text { all'ultimo alito di vita; avere l'alito pesante, cattivo } \\
\text { 2. estens., leggero soffio di vento }\end{array}$ \\
\hline Definição Dire & $\begin{array}{l}\text { n.m. 1- Fiato, respiro. 2-Soffio leggero: Oggi non soffia neppure un } \\
\text { alito di vento. }\end{array}$ \\
\hline Definição II Sabatini-Coletti & $\begin{array}{l}\text { alito [à-li-to] s.m. } \\
\qquad \begin{array}{l}1 \text { Respiro, fiato: a. pesante } \\
2 \text { estens. Soffio leggero SIN refolo: a. di vento } \\
\text { - sec. XIII }\end{array}\end{array}$ \\
\hline Definição II Devoto-Oli 2008 & $\begin{array}{l}\text { Alito } \\
\text { <à-li-to> s.m. } \\
\text { 1. Fiato, respiro: aver l'a. cattivo. } \\
\text { 2. estens. Lieve soffiar di vento. } \\
\text { Dal lat. halitus 'alito' e questo da halare 'esalare, emettere un soffio' I } \\
\text { prima del } 1292\end{array}$ \\
\hline Definição Lo Zingarelli 2004 & $\begin{array}{l}\text { Alito } \\
\text { [vc. dotta, lat. halitu(m), da halitare 'alitare'; sec. XIII] } \\
\text { s. m. } \\
1 \text { Fiato emesso dalla bocca respirando: avere l'alito cattivo, pesante. } \\
2 \text { (fig.) Leggero soffio: non spira un alito di vento. }\end{array}$ \\
\hline Definição Parola Chiave & $\begin{array}{l}\text { s.m. } 1 \text { Fiato: alito cattivo; appannò il vetro con l'alito *hálito; bafo } 2 \\
\text { Leggero soffio (di vento) *aragem }\end{array}$ \\
\hline Definição Proposta & un po' d'aria, un po' di vento. \\
\hline
\end{tabular}


Ficha lexicográfica para definição reformulada 6

\begin{tabular}{|c|c|}
\hline Unidade lexical & Rabbrividire \\
\hline Contexto & $\begin{array}{l}\text { A poco a poco il loro paese si allontana: si vedono le case, il } \\
\text { palazzotto di Don Rodrigo, e Lucia rabbrividisce.(34) }\end{array}$ \\
\hline Definição existente & - rabbrividire: sentire brividi (di freddo, paura, orrore). (34) \\
\hline Definiçao De Mauro Paravia & $\begin{array}{l}\text { rab·bri·vi·dìre } \\
\text { v.intr. e tr. Co } \\
\text { 1. v.intr. (essere, rar. avere) sentire brividi di freddo o di paura: } \\
\text { rabbrividi e si chiuse il cappotto } \\
\text { 2. v.intr. (essere, rar. avere) fig., provare sgomento, paura o } \\
\text { raccapriccio: rabbrividi al pensiero di quello che sarebbe potuto } \\
\text { succedere } \\
\text { 3. v.intr. (essere, rar. avere) BU avere un brivido di piacere, provare } \\
\text { una sensazione di gradevole sorpresa } \\
\text { 4. v.intr. (essere, rar. avere) LE oscillare sotto le intemperie: } \\
\text { rabbrividian le rose | sotto la pioggia (Carducci) } \\
\text { 5. v.tr. BU provocare una sensazione di sgomento, di paura: il } \\
\text { pensiero della morte la rabbrividiva }\end{array}$ \\
\hline Definição Dire & $\begin{array}{l}\text { v.intr. Tremare per il freddo o per la paura: Ho dimenticato la giacca } \\
\text { ed ora rabbrividisco dal freddo. }\end{array}$ \\
\hline Definição II Sabatini-Coletti & $\begin{array}{l}\text { rabbrividire [rab-bri-vi-di-re] v.intr. (aus. essere, non com. avere; } \\
\text { rabbrividisco, rabbrividisci ecc.) [sogg-v] } \\
1 \text { Avere i brividi per il freddo } \\
2 \text { fig. Provare un senso di paura, di ribrezzo o di orrore; } \\
\text { anche in costr. causativa: un racconto da far } r \text {. } \\
\text { • sec. XVIII }\end{array}$ \\
\hline Definição II Devoto-Oli 2008 & $\begin{array}{l}\text { Rabbrividire } \\
\text { <rab-bri-vi-dì-re> v.intr. (rabbrividisco, rabbrividisci, ecc.; aus. essere, } \\
\text { meno com. avere) } \\
\text { 1. Avere, sentire i brividi: questo gelo mi fa r.; r. per il freddo, per la } \\
\text { febbre. } \\
\text { 2. fig. Provare una sensazione di spavento, orrore o raccapriccio; } \\
\text { inorridire, raccapricciare (anche con la prep. di): al solo ripensarci } \\
\text { rabbrividisco; quella vista mi fece } r \text {.; } r \text {. di paura, di terrore. } \\
\text { Der. di brivido, col pref. } r a(d)-\mid \text { sec. XVIII. }\end{array}$ \\
\hline Definição Lo Zingarelli 2004 & $\begin{array}{l}\text { Rabbrividire } \\
\text { [comp. di r(i)- e abbrividire; av. 1742] } \\
\text { v. intr. (io rabbrividisco, tu rabbrividisci; aus. essere, raro avere) } \\
1 \text { Avere, sentire i brividi: rabbrividire al gelo invernale. } \\
2 \text { (fig.) Provare paura, orrore e sim.: rabbrividire allo spettacolo } \\
\text { doloroso. SIN. Inorridire, fremere. }\end{array}$ \\
\hline Definição Parola Chiave & $\begin{array}{l}\text { v.intr.[ rabbrividisco, rabbrividisci; aus. essere] Avere um brivido, } \\
\text { sentire i brividi: a quella vista rabbrividi; rabbrividire di freddo, di paura } \\
\text { *arrepiar-se }\end{array}$ \\
\hline Definição Proposta & Sentire freddo per la paura. \\
\hline
\end{tabular}


Ficha lexicográfica reformulada 7

\begin{tabular}{|c|c|}
\hline Unidade lexical & Inchino \\
\hline Contexto & $\begin{array}{l}\text { Lucia, che non ha mai visto un monastero, rimane incantata ad } \\
\text { osservare, in attesa di fare il suo inchino alla signora. (45) }\end{array}$ \\
\hline Definição existente & $\begin{array}{l}\text { - inchino: antico cenno di rispetto o di saluto, fatto chinando la testa e } \\
\text { piegando il busto. (45) }\end{array}$ \\
\hline Definiçao De Mauro Paravia & $\begin{array}{l}\text { 'in-chìnno } \\
\text { s.m. CO } \\
\text { 1. l'inchinarsi, come atto di omaggio, di saluto o di venerazione: fare } \\
\text { un inchino, allontanarsi con un inchino } \\
\text { 2. fig., atto di ossequio, comportamento interessato e servile }\end{array}$ \\
\hline Definição Dire & $\begin{array}{l}\text { n.m. Atto di riverenza che si compie piegandocisi verso il basso o } \\
\text { abbassando il capo: Quell'uomo salutò la signora con un inchino. }\end{array}$ \\
\hline Definição II Sabatini-Coletti & $\begin{array}{l}\text { inchino [in-chì-no] s.m. } \\
\text { • Atto di riverenza, consistente nel piegare il busto } \\
\text { abbassando il capo e, talvolta, accennando a una } \\
\text { genuflessione: fare un } i \text {. } \\
\text { • sec. XIV }\end{array}$ \\
\hline Definição II Devoto-Oli 2008 & $\begin{array}{l}\text { inchino } \\
\text { <in-chì-no> agg., lett. } \\
\text { Piegato in atto umile di sottomissione. } \\
\text { Der. di inchinato, p. pass. breve di inchinare | } 1548\end{array}$ \\
\hline Definição Lo Zingarelli 2004 & $\begin{array}{l}\text { inchino (1) } \\
\text { [da inchinare; av. 1328] } \\
\text { s. m. } \\
\text { * Segno di riverenza che si compie piegando la persona o solo il capo } \\
\text { (in alcuni casi, spec. un tempo, anche spostando leggermente } \\
\text { all'indietro la gamba sinistra): un piccolo, grande inchino; fare un } \\
\text { inchino; salutare con un inchino. SIN. Riverenza. }\end{array}$ \\
\hline Definição Parola Chiave & $\begin{array}{l}\text { s.m. Gesto di riverenza, di rispettoso saluto Che si fa piegando II capo } \\
\text { o II busto verso II basso S riverenza: salutò la signora facendo un } \\
\text { inchino *reverência }\end{array}$ \\
\hline Definição Proposta & $\begin{array}{l}\text { Forma rispetosa di salutare qualcuno piegando la testa e il busto } \\
\text { verso il basso. }\end{array}$ \\
\hline
\end{tabular}


Ficha lexicográfica reformulada 8

\begin{tabular}{|c|c|}
\hline Unidade lexical & Scenata \\
\hline Contexto & $\begin{array}{l}\text { II padre scoprì un suo bigletto d'amore e le fece una scenata } \\
\text { terribile.(54) }\end{array}$ \\
\hline Definição existente & - scenata: lite, accesa discussione. (54) \\
\hline Definiçao De Mauro Paravia & $\begin{array}{l}\text { Sce } \text { nà·ta } \\
\text { s.f. CO } \\
\text { manifestazione eccessiva, incontrollata: scenata di gelosia | violento e } \\
\text { plateale rimprovero }\end{array}$ \\
\hline Definição Dire & $\begin{array}{l}\text { n.f. Manifestazione di uno stato d'animo molto violenta e rumorosa, } \\
\text { chiassata: Per quel brutto voto la mamma mi ha fatto una scenata. }\end{array}$ \\
\hline Definição II Sabatini-Coletti & $\begin{array}{l}\text { scenata [sce-nà-ta] s.f. } \\
\text { • Manifestazione vistosa e accesa di rabbia, di risentimento, } \\
\text { di rancore: s. di gelosia; chiassoso diverbio in luogo } \\
\text { pubblico: c'è stata una terribile s. tra i due } \\
\text { •a. } 1842\end{array}$ \\
\hline Definição II Devoto-Oli 2008 & $\begin{array}{l}\text { Scenata } \\
\text { <sce-nà-ta> s.f. } \\
\text { Sfogo incontrollato di collera e di risentimento contro qualcuno: gli ha } \\
\text { fatto una sc. terribile; anche, litigio o diverbio rumoroso e } \\
\text { sconveniente: non voglio scenate qua dentro! } \\
\text { dim. scenatina. pegg. scenatàccia. } \\
\text { Der. di scena | prima metà sec. XIX }\end{array}$ \\
\hline Definição Lo Zingarelli 2004 & $\begin{array}{l}\text { Scenata } \\
\text { [da scena; 1803] } \\
\text { s. f. } \\
\text { * Violenta manifestazione di sdegno, ira e gelosia, accompagnata da } \\
\text { urla, minacce e sim., fatta anche in presenza di terzi: fare una scenata } \\
\text { a qlcu.; assistere a una scenata. SIN. Chiassata, piazzata. }\end{array}$ \\
\hline Definição Parola Chiave & $\begin{array}{l}\text { s.f. Violenta manifestazione di risentimento, d'ira, di rimprovero: fare } \\
\text { una scenata a qualcuno *descompostura Litigio violento, con urla, } \\
\text { accuse, insulti, minacce: in quella casa ci sono continue scenate } \\
\text { *cena; escândalo }\end{array}$ \\
\hline Definição Proposta & Reazione verbale violenta. \\
\hline
\end{tabular}


Ficha lexicográfica reformulada 9

\begin{tabular}{|c|c|}
\hline Unidade lexical & Raccolto \\
\hline Contexto & E il secondo raccolto scarso.(62) \\
\hline Definição existente & $\begin{array}{l}\text { - raccolto: insieme dei frutti della terra raccolti nell'anno (es. grano). } \\
\text { (62) }\end{array}$ \\
\hline Definiçao De Mauro Paravia & $\begin{array}{l}\text { rac.còl-to } \\
\text { p.pass., agg., s.m. } \\
\text { 1. p.pass. } \square \text { raccogliere, raccogliersi } \\
\text { 2a. agg. CO stretto insieme: fiori raccolti in un mazzo } \\
\text { 2b. agg. CO raggomitolato su se stesso: il mendicante stava raccolto } \\
\text { in un angolo } \\
\text { 3. agg. CO concentrato, assorto: espressione raccolta, stava raccolto } \\
\text { in preghiera } \\
\text { 4. agg. CO di ambiente, che aiuta il raccoglimento: una stanza } \\
\text { raccolta } \\
\text { 5a. s.m. AU il raccogliere i frutti della terra quando sono giunti a } \\
\text { maturazione: era tempo di raccolto | estens., il periodo dell'anno in cui } \\
\text { si raccoglie } \\
\text { 5b. s.m. AU l'insieme dei prodotti raccolti, spec. cereali } \\
\text { 5c. s.m. AU la produzione di un campo nel corso di un anno } \\
\text { 6. s.m. CO il risultato di un'iniziativa, spec. benefica, volta a } \\
\text { raccogliere denaro: il raccolto del ballo di beneficenza, il raccolto della } \\
\text { sottoscrizione a favore degli orfani }\end{array}$ \\
\hline Definição Dire & $\begin{array}{l}\text { agg. 1- Piegato su se stesso, raggomitolato: Il gatto se ne stava } \\
\text { raccolto sul divano. 2- Che infonde tranquillità, appartato, detto di } \\
\text { luogo: Sto bene in salotto, perché è un ambiente raccolto. 3- Intento, } \\
\text { concentrato, detto di persona: La donna era raccolta in preghiera. 4- } \\
\text { Radunato insieme: Le notizie raccolte non sono sufficienti per la } \\
\text { nostra ricerca. 5- Staccato dalla pianta o dal terreno: II contadino ci ha } \\
\text { regalato una cesta di pesche appena raccolte. / n.m. Insieme dei frutti } \\
\text { di una o più colture: La grandine ha distrutto il raccolto di olive. }\end{array}$ \\
\hline Definição II Sabatini-Coletti & $\begin{array}{l}\text { raccolto }^{2} \text { [rac-còl-to] s.m. } \\
\text { • L'insieme dei frutti di una singola coltivazione: il } r \text {. dell'uva, } \\
\text { del grano; con uso assol., l'insieme dei prodotti delle colture } \\
\text { nel corso dell'annata SIN raccolta: } r \text {. scarso; l'epoca in cui si } \\
\text { raccoglie un determinato prodotto: partirò dopo il } r \text {. } \\
\text { • sec. XV }\end{array}$ \\
\hline Definição II Devoto-Oli 2008 & $\begin{array}{l}\text { raccolto }^{1} \\
<\text { rac-còl-to> agg. } \\
\text { Ripiegato su sé stesso, raggomitolato, rannicchiato: il gatto } \\
\text { stava tutto r.; Supin giacea in terra alcuna gente, Alcuna si } \\
\text { sedea tutta raccolta (Dante). } 2 \text {. Profondamente concentrato } \\
\text { in un pensiero, assorto: restò a lungo } r \text {. davanti alla bara del } \\
\text { padre; stare r. in preghiera.3. Improntato a una dignitosa } \\
\text { compostezza: un atteggiamento r.; un'espressione } r \text {. Di } \\
\text { sentimenti, contenuto: una gioia r.4. Di cosa, ravviato e } \\
\text { stretto insieme: capelli r. sulla nuca.5. Di luogo, appartato, } \\
\text { che ispira un senso di pace e tranquillità: un cortile silenzioso } \\
\text { e r. come un chiostro. } \\
\text { P. pass. di raccogliere }\end{array}$ \\
\hline
\end{tabular}




\begin{tabular}{|l|l|}
\hline & \\
\hline Definição Lo Zingarelli 2004 & $\begin{array}{l}\text { Raccolto } \\
\text { A part. pass. di raccogliere; anche agg. } \\
1 \text { Nei sign. del v. | Stretto insieme: capelli raccolti sulla nuca. } \\
2 \text { (fig.) Dignitoso, composto: atteggiamento raccolto | Di dimensioni } \\
\text { ridotte ma ben disposto, detto di luoghi: casa raccolta | Tranquillo, } \\
\text { ordinato: quartiere raccolto | Contenuto, detto di sentimenti: una gioia } \\
\text { raccolta. } \\
\text { || raccoltamente, avv. Con raccoglimento. } \\
\text { B s. m. } \\
1 \text { Insieme dei frutti raccolti o da raccogliersi nell'annata: si spera in un } \\
\text { buon raccolto. } \\
2 \text { †Riepilogo | Somma. } \\
\text { || raccoltetto, dim. | raccoltino, dim. | raccoltone, accr. }\end{array}$ \\
\hline Definição Parola Chiave & $\begin{array}{l}\text { s.m. II complesso dei prodotti della terra raccolti durante l'annata: } \\
\text { quest'anno il raccolto è scarso, abbondante *colheita }\end{array}$ \\
\hline Definição Proposta & \begin{tabular}{l} 
Prodotto di una coltura agricola, coglitura. \\
\hline
\end{tabular} \\
\hline
\end{tabular}


Ficha lexicográfica reformulada 10

\begin{tabular}{|c|c|}
\hline Unidade lexical & Stufato \\
\hline Contexto & L'oste gli porta anche dello stufato.(66) \\
\hline Definição existente & - stufato: carne a pezzi cotta a fuoco lento in un tegame. (66) \\
\hline Definiçao De Mauro Paravia & $\begin{array}{l}\text { stu·fà·to } \\
\text { p.pass., agg., s.m. } \\
\text { 1. p.pass., agg. } \square \text { stufare, stufarsi } \\
\text { 2. s.m. CO pietanza di carne in umido cotta a lungo con fuoco molto } \\
\text { basso in un tegame ben chiuso: stufato di manzo, d'asino | modo di } \\
\text { tale cottura: carne cotta, fatta in stufato }\end{array}$ \\
\hline Definição Dire & $\begin{array}{l}\text { n.m. Carne cotta a lungo e a fuoco basso: /l cameriere mi ha servito } \\
\text { lo stufato con le patate. }\end{array}$ \\
\hline Definição II Sabatini-Coletti & $\begin{array}{l}\text { stufato [stu-fà-to] s.m. } \\
\text { • Pietanza di carne cotta a fuoco lento in tegame chiuso: s. di } \\
\text { maiale, di manzo } \\
\text { • sec. XVIII }\end{array}$ \\
\hline Definição II Devoto-Oli 2008 & $\begin{array}{l}\text { Stufato } \\
\text { <stu-fà-to> s.m. } \\
\text { Vivanda di carne tagliata a pezzetti, variamente condita, fatta un po' } \\
\text { rosolare e quindi, ricoperta d'acqua o di brodo, cotta in un tegame } \\
\text { fondo e ben chiuso, a fuoco lento. } \\
\text { dim. stufatìno }\end{array}$ \\
\hline Definição Lo Zingarelli 2004 & $\begin{array}{l}\text { Stufato } \\
\text { A part. pass. di stufare; anche agg. } \\
{ }^{*} \text { Nei sign. del v. } \\
\text { B s. m. } \\
\text { * Carne a pezzetti cotta a fuoco lento in un tegame fondo ben chiuso, } \\
\text { condita con sale, pepe, aglio, pomodoro, olio o burro: uno stufato di } \\
\text { lepre. } \\
\text { \|l stufatino, dim. }\end{array}$ \\
\hline Definição Parola Chiave & $\begin{array}{l}\text { s.m. Carne cotta a lungo, in una pentola ben chiusa, con vari } \\
\text { condimenti: stufato di manzo *refogado }\end{array}$ \\
\hline Definição Proposta & Carne cotta a lungo. \\
\hline
\end{tabular}




\begin{tabular}{|c|c|}
\hline Unidade lexical & Zimbello \\
\hline Contexto & $\begin{array}{l}\text { I clienti si divertono ad ascoltare e Renzo, ormai ubriaco, è diventato } \\
\text { lo zimbello del gruppo.(67) }\end{array}$ \\
\hline Definição existente & - zimbello: persona oggetto di scherzi da parte di altri. (67) \\
\hline Definiçao De Mauro Paravia & $\begin{array}{l}\text { zim·bèl·lo, zim·bèl·lo } \\
\text { s.m. } \\
\text { 1. TS venat. uccello vivo legato con una fune e manovrato in modo } \\
\text { tale da richiamare altri uccelli verso la trappola tesa dal cacciatore | } \\
\text { estens., uccello da richiamo } \\
\text { 2a. CO fig., mezzo od oggetto usato come lusinga } \\
\text { 2b. CO persona che costituisce oggetto di scherno: essere lo zimbello } \\
\text { della compagnia }\end{array}$ \\
\hline Definição Dire & $\begin{array}{l}\text { n.m. 1- Uccello vivo legato ad un bastoncino o ad una cordicella, } \\
\text { usato come richiamo per altri uccelli durante la caccia. 2- Persona } \\
\text { oggetto di risa e canzonature: Sei diventato lo zimbello della } \\
\text { compagnia. }\end{array}$ \\
\hline Definição II Sabatini-Coletti & $\begin{array}{l}\text { zimbello [zim-bèl-lo] s.m. } \\
1 \text { Uccello vivo che viene legato a un bastoncino o a una cordicella, } \\
\text { per adescare altri uccelli } 2 \text { fig. Espediente per richiamare l'attenzione } \\
\text { o l'interesse di qlcu.: gli sconti su alcuni prodotti sono solo lo z. per } \\
\text { attirare clienti; anche, persona che, all'interno di un gruppo, diventa } \\
\text { bersaglio di scherno: per la sua ingenuità è lo z. di tutta la classe. sec. } \\
\text { XIV }\end{array}$ \\
\hline Definição II Devoto-Oli 2008 & $\begin{array}{l}\text { Zimbello } \\
<\text { Tim-bèl-lo> (arc. cimbello) s.m. } \\
\text { 1. Uccello vivo da richiamo usato nell'uccellagione con le tese per } \\
\text { attirare gli uccelli liberi di passo negli appostamenti• anal. Tonno } \\
\text { lasciato per richiamo nelle camere dell'isola della tonnara.2. fig. Ogni } \\
\text { accorgimento impiegato per attirare altri nella sfera dei propri } \\
\text { interessi• più com. Persona che è fatta oggetto di scarsa } \\
\text { considerazione e che è spesso bersaglio di scherzi più o meno } \\
\text { crudeli: non ho nessuna intenzione di diventare il vostro z. }\end{array}$ \\
\hline Definição Lo Zingarelli 2004 & $\begin{array}{l}\text { zimbello (o z-) } \\
\text { [ant. provz. cembel, propr. 'piffero, fischio' e quindi 'richiamo (per } \\
\text { adescamento di uccelli)' e poi lo stesso 'uccello catturato', dal lat. parl. } \\
\text { *cymbellum, dim. di cymbalum 'cembalo'; 1340] } \\
\text { s. m. } \\
1 \text { Uccello vivo, legato a un palo con un lungo filo perché, } \\
\text { svolazzando, funga da richiamo ad altri uccelli, nell'uccellagione | } \\
\text { (est.) Ogni uccello da richiamo, a caccia | (est.) Tonno lasciato nella } \\
\text { tonnara per attirare altri tonni.2 (fig., raro) Richiamo, lusinga, } \\
\text { allettamento | Per zimbello, allo scopo di invogliare, allettare.3 (fig.) } \\
\text { Oggetto di burle, spasso e risa: per la sua goffaggine è lo zimbello di } \\
\text { tutti. }\end{array}$ \\
\hline Definição Parola Chiave & $\begin{array}{l}\text { s.m. } 1 \text { Uccello vivo che viene legato a una cordicella in modo che } \\
\text { svolazzando attiri altri uccelli: caccia con lo zimbello chamariz } \\
2 \text { Chi diventa bersaglio di scherzi o dello scherzo altrui: è diventato lo } \\
\text { zimbello del paese *objeto de escárnio }\end{array}$ \\
\hline Definição Proposta & $\begin{array}{l}\text { Persona ridicola a causa del suo comportamento, chi provoca } \\
\text { risate. }\end{array}$ \\
\hline
\end{tabular}




\begin{tabular}{|c|c|}
\hline Unidade lexical & Treccia \\
\hline Contexto & $\begin{array}{l}\text { Ma appena chiude gli occhi, quante immagini affiorano nella sua } \\
\text { mente. Due sole non sono accompagnate dall'amarezza e dalla } \\
\text { paura: quelle di una treccia nera (Lucia) e di una barba bianca (Fra' } \\
\text { Cristoforo). (69) }\end{array}$ \\
\hline Definição existente & $\begin{array}{l}\text { - treccia: pettinatura femminile in cui si intrecciano alternativamente i } \\
\text { capelli divisi in tre ciocche. (69) }\end{array}$ \\
\hline Definiçao De Mauro Paravia & $\begin{array}{l}\text { tréc. cia } \\
\text { s.f. AU } \\
\text { 1. gruppo di tre ciocche di capelli lunghi, intrecciate in modo alternato, } \\
\text { che costituiscono un'acconciatura tipicamente femminile: farsi la } \\
\text { treccia, le trecce, portare le trecce } \\
\text { 2a. estens., intreccio di fili, nastri o strisce di pelle, cuoio e sim. } \\
\text { 2b. TS tess. passamano ottenuto intrecciando più fili | gruppo di fili da } \\
\text { cucito multicolori, intrecciati, che vengono sfilati all'occorrenza } \\
\text { 2c. TS artig. nella fabbricazione dei cappelli di paglia, insieme di fili } \\
\text { intrecciati pronti per la confezione del cappello } \\
\text { 2d. TS elettr. cordone formato da due o tre fili elettrici avvolti l'uno } \\
\text { intorno all'altro } \\
\text { 3. TS arch. motivo decorativo, dipinto o scolpito, che ricorda la forma } \\
\text { di una treccia } \\
\text { 4. CO pane lavorato in forma di treccia | tipo di mozzarella che ha tale } \\
\text { forma } \\
\text { 5. CO filza di frutti secchi; resta: una treccia di fichi, di aglio } \\
\text { 6. TS mat. figura avente determinate proprietà topologiche } \\
\text { 7. TS sport nella pallacanestro, esercizio preparatorio per migliorare } \\
\text { la tecnica del passaggio in corsa, effettuato da tre o più giocatori che } \\
\text { eseguono spostamenti incrociati } \\
\text { 8. OB muta di cavalli o di altri animali che si facevano correre in circoli } \\
\text { intrecciati sull'aia, per trebbiare i cereali }\end{array}$ \\
\hline Definição Dire & $\begin{array}{l}\text { n.f. 1- Pettinatura costituita dall'intreccio di ter lunghe ciocche di } \\
\text { capelli: Quando ero piccola la nonna mi faceva sempre le trecce. 2- } \\
\text { Qualsiasi oggetto costituito da elementi incrociati: /l bambino ha } \\
\text { comprato una treccia di pane per la mamma. } \\
\text { PI. trecce }\end{array}$ \\
\hline Definição II Sabatini-Coletti & 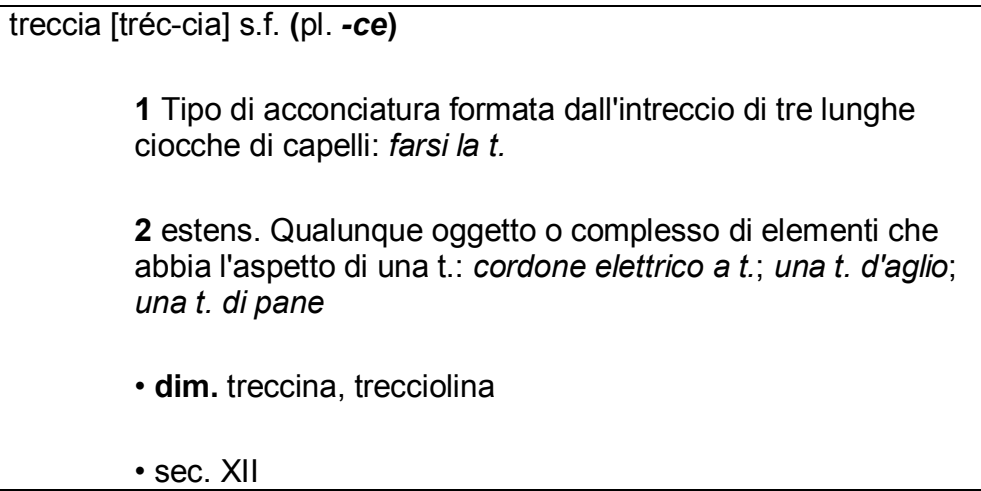 \\
\hline Definição II Devoto-Oli 2008 & $\begin{array}{l}\text { Treccia } \\
\text { <tréc-cia> (arc. trezza) s.f. ( } p l .-c e) \\
\text { 1. Tipica acconciatura femminile che consiste nel dividere la } \\
\text { capigliatura (o ciascuna delle due metà in cui è stata } \\
\text { precedentemente divisa da una scriminatura) in tre ciocche, che } \\
\text { vengono passate alternativamente le une sulle altre, in modo da } \\
\text { formare il tessuto di un unico elemento morbidamente ondulato: farsi } \\
\text { le t.; sciogliere le t.; quando ero piccola portavo le t. }\end{array}$ \\
\hline
\end{tabular}




\begin{tabular}{|c|c|}
\hline & $\begin{array}{l}\text { 2. generic. Ogni elemento costituito da un gruppo di fili, nastri o } \\
\text { strisce, intrecciati• estens. Ogni forma che richiami l'idea di un simile } \\
\text { avvolgimento, come certe decorazioni architettoniche, certe forme di } \\
\text { pane, di mozzarella, ecc. Resta: una t. d'agli. } \\
\text { 3. Nella pallacanestro, azione congegnata di attacco, con palleggi e } \\
\text { passaggi brevi.dim. treccétta, treccìna, treccìno m., trecciòla, } \\
\text { trecciolìna, lett. trecci(u)òlo m. accr. treccióna, treccióne m } \\
\text { Lat. volg. *trichia, dal gr. trikhía 'corda, fune', der. di thríks trikhós } \\
\text { 'capello'| sec. XII }\end{array}$ \\
\hline Definição Lo Zingarelli 2004 & $\begin{array}{l}\text { treccia o ttrezza } \\
\text { [etim. incerta; av. 1250] } \\
\text { s. f. (pl. -ce) } \\
1 \text { Acconciatura spec. femminile costituita da lunghe ciocche di capelli } \\
\text { accavallate in modo alternato: portare le trecce; farsi la treccia; } \\
\text { sciogliere le trecce; si ch'io credea che 'l crino / fosse d'un oro fino / } \\
\text { partito sanza trezze (LATINI). } \\
2 \text { (est.) Intreccio di fili, corde, cavi, nastri e sim., ottenuto accavallando } \\
\text { i vari elementi a foggia di treccia: treccia di paglia; una treccia di fili } \\
\text { metallici| Tipo di passamano ottenuto intrecciando tre o più fili | Nella } \\
\text { fabbricazione dei cappelli di paglia, insieme di fili intrecciati, pronti per } \\
\text { la confezione del cappello | Cordone elettrico, costituito da due o tre } \\
\text { fili avvolti uno sull'altro. } \\
3 \text { In architettura, motivo ornamentale scolpito o dipinto che simula una } \\
\text { treccia di nastri e sim. } \\
4 \text { Nella pallacanestro, esercizio preparatorio per la tecnica del } \\
\text { passaggio eseguita da tre o più giocatori con spostamenti incrociati. } \\
5 \text { (est.) Pezzo di pane in forma di treccia | Pasta di mozzarella, } \\
\text { composta a treccia. } \\
6 \text { (est.) Filza, resta di frutti secchi: una treccia di fichi. } \\
7 \text { (tosc.) Gruppo di cavalli o altri animali che un tempo si facevano } \\
\text { camminare sull'aia formando ripetuti cerchi per trebbiare i cereali. } \\
\text { || treccetta, dim. | treccina, dim. | treccino, dim. m. | trecciolina, dim. | } \\
\text { trecciona, accr. | treccione, accr. m. | trecciuola, dim. | trecciuolo, dim. } \\
\text { m. }\end{array}$ \\
\hline Definição Parola Chiave & $\begin{array}{l}\text { s.f. [pl. -ce] } 1 \text { Tipo di acconciatura, spec. Femminile, formata da tre } \\
\text { ciocche di capelli intrecciate tra loro: farsi la treccia; portare le trecce } \\
2 \text { Qualunque oggetto formato da fili, nastri e simili intrecciati tra loro: } \\
\text { una treccia di filo, di cordoncino, di paglia *trança }\end{array}$ \\
\hline Definição Proposta & $\begin{array}{l}\text { Modo di pettinare i capelli di una donna dividendoli in tre parti e } \\
\text { intrecciandole. }\end{array}$ \\
\hline
\end{tabular}


Ficha lexicográfica para definição reformulada 13

\begin{tabular}{|c|c|}
\hline Unidade lexical & Rannicchiata \\
\hline Contexto & $\begin{array}{l}\text { La trova rannicchiata in terra in una stanza del castello, chiusa a } \\
\text { chiave.(84) }\end{array}$ \\
\hline Definição existente & - rannicchiata: ripiegata su se stessa. (84) \\
\hline Definiçao De Mauro Paravia & $\begin{array}{l}\text { 1'ran·nic·chià·re } \\
\text { v.tr. } \\
\text { 1. Co raccogliere, ripiegare in un piccolo spazio: rannicchiare le } \\
\text { gambe } \\
\text { 2. LE indurre, costringere una persona ad assumere una posizione } \\
\text { raccolta, contratta: la grave condizione | di lor tormento a terra li } \\
\text { rannicchia (Dante) }\end{array}$ \\
\hline Definição Dire & $\begin{array}{l}\text { Rannicchiarsi v.rifl. Piegarsi su se stesso, raggomitolarsi: Il bimbo si } \\
\text { rannicchiò fra le braccia della mamma. } \\
\text { Derivato da nicchia }\end{array}$ \\
\hline Definição II Sabatini-Coletti & $\begin{array}{l}\text { rannicchiare [ran-nic-chià-re] v. (rannicchio ecc.) } \\
\text { • v.tr. [sogg-v-arg] Ripiegare una parte del corpo come se si } \\
\text { trovasse in una nicchia: } r \text {. le gambe } \\
\text { • rannicchiarsi } \\
\text { • v.rifl. [sogg-v] Ripiegarsi in un piccolo spazio, spesso con } \\
\text { specificazione della causa o del modo o del luogo: } r \text {. in un } \\
\text { cantuccio } \\
\text { • sec. XIV }\end{array}$ \\
\hline Definição II Devoto-Oli 2008 & $\begin{array}{l}\text { Rannicchiato } \\
\text { <ran-nic-chià-to> agg. } \\
\text { 1. Ripiegato su sé stesso, contratto o raccolto in un piccolo spazio: se } \\
\text { ne stava r. nella poltrona; aveva la testa r. fra le spalle. } \\
\text { 2. fig. Chiuso in un atteggiamento schivo o scontroso: vive tutto r. in } \\
\text { sé stesso. } \\
\text { 3. fig. Di propositi non ancora ben distinti e maturati: idea che, fino a } \\
\text { quel tempo, era stata come inosservata e rannicchiata in un angolo } \\
\text { della sua mente (Manzoni). } \\
\text { P. pass. di rannicchiare | sec. XIV }\end{array}$ \\
\hline Definição Lo Zingarelli 2004 & $\begin{array}{l}\text { rannicchiato } \\
\text { part. pass. di rannicchiare; anche agg. } \\
{ }^{*} \text { Nei sign. del v. I (fig.) Che sorge isolato e raccolto: un paesino } \\
\text { rannicchiato ai piedi del Monte Bianco. }\end{array}$ \\
\hline Definição Parola Chiave & $\begin{array}{l}\text { Rannicchiarsi v.pr. Piegare le membra, raccogliersi su se stessi in } \\
\text { modo da occupare il minor spazio possibile: si era rannicchiato dietro } \\
\text { un cespuglio per non farsi vedere *acocorar-se }\end{array}$ \\
\hline Definição Proposta & Piegata, in posizione fetale. \\
\hline
\end{tabular}




\begin{tabular}{|c|c|}
\hline Unidade lexical & Erede \\
\hline Contexto & $\begin{array}{l}\text { Intanto molte cose importanti sono accadute a livello politico: la } \\
\text { Francia ha deciso di aiutare il duca di Nevers nella lotta di } \\
\text { successione per Mantova, visto che Ferdinando Gonzaga è senza } \\
\text { eredi.(98) }\end{array}$ \\
\hline Definição existente & $\begin{array}{l}\text { - erede: chi dovrebbe ricevere dei beni o una carica come successore } \\
\text { legittimo (es. il figlio di un re o di un duca). (98) }\end{array}$ \\
\hline Definiçao De Mauro Paravia & $\begin{array}{l}\text { e·rè-de } \\
\text { s.m. e f. AD } \\
\text { 1. chi dopo la morte di una persona ne acquista in tutto o in parte } \\
\text { beni, diritti e obblighi: nominare un erede } \\
\text { 2. scherz., fam., il primo figlio: aspettare un erede, è arrivato l'erede } \\
\text { 3. fig., continuatore di attività, tradizioni e sim. }\end{array}$ \\
\hline Definição Dire & $\begin{array}{l}\text { n.m. e f. 1- Persona alla quale spettano i beni o le cariche di un } \\
\text { defundo: Il regno è passato all'erede al trono. 2- Figlio: Ti presento il } \\
\text { mio erede. 3- Persona che prosegue l'attività di un altro: Questo } \\
\text { pittore è l'erede del defunro Picasso. }\end{array}$ \\
\hline Definição II Sabatini-Coletti & 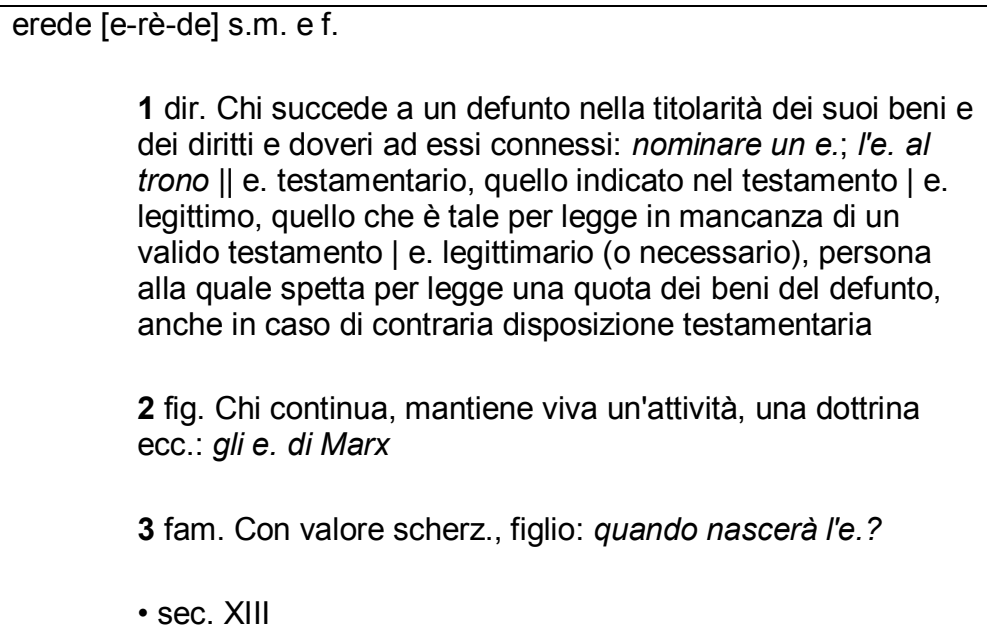 \\
\hline Definição II Devoto-Oli 2008 & $\begin{array}{l}\text { Erede } \\
\text { <e-rè-de> s.m. e f. } \\
\text { La persona che succede nella titolarità totale o parziale del patrimonio } \\
\text { di un defunto, automaticamente o per volontà di questi: istituire, } \\
\text { nominare, dichiarare qualcuno e. proprio e delle proprie sostanze; e. } \\
\text { universale, chi succede nella titolarità dell'intero patrimonio; e. } \\
\text { beneficiario, vedi BENEFICIARIO• fig. Successore e custode di una } \\
\text { tradizione: e. spirituale; è lui l'e. della gloria paterna scherz. Figlio: } \\
\text { come sta l'e.? } \\
\text { Dal lat. heres -edis, di etimo incerto | seconda metà sec. XIII }\end{array}$ \\
\hline Definição Lo Zingarelli 2004 & $\begin{array}{l}\text { erede o tereda, treda, trede } \\
\text { [vc. dotta, lat. herede }(m) \text {, di etim. incerta; } 1262 \text { ca.] } \\
\text { s. m. ef. } \\
1 \text { (dir.) Chi, alla morte di una persona, subentra in tutti i suoi rapporti } \\
\text { patrimoniali attivi o passivi o in una quota di essi: lasciare, nominare }\end{array}$ \\
\hline
\end{tabular}




\begin{tabular}{|l|l|}
\hline \multirow{5}{|l}{} & $\begin{array}{l}\text { qlcu. erede; istituzione di erede | Erede legittimo, chi succede per } \\
\text { legge, in mancanza di testamento | Erede necessario, chi per legge, } \\
\text { in caso di successione testamentaria, ha diritto a una quota del } \\
\text { patrimonio del defunto | Erede universale, chi succede nell'intero } \\
\text { patrimonio | Erede testamentario, chi è stato chiamato alla } \\
\text { successione per testamento | Erede beneficiario, erede che ha } \\
\text { accettato l'eredità con beneficio d'inventario | Erede apparente, chi } \\
\text { possiede i beni di un'eredità e si comporta come erede, senza esserlo } \\
\text { | Erede al trono, in una dinastia, chi è destinato a succedere al } \\
\text { sovrano regnante | (scherz., fam.) Figlio primogenito, spec. maschio: } \\
\text { finalmente ha avuto il tanto sospirato erede. }\end{array}$ \\
& $\begin{array}{l}2 \text { (fig.) Chi conserva e prosegue attività, tradizioni e sim.: erede della } \\
\text { famiglia; l'erede delle virtù familiari | Erede spirituale, o (ellitt.) erede, } \\
\text { chi continua ed estende o elabora ulteriormente idee e attività di una } \\
\text { grande personalità in ogni settore dell'umanità: gli eredi di Freud, di } \\
\text { Marx, di Mazzini. }\end{array}$ \\
\hline Definição Parola Chiave & $\begin{array}{l}\text { s.m.f. 1 Chi eredita, del tutto o in parte, i beni di una persona defunta } \\
\text { herdeiro } 2 \text { Erede al trono = chi è destinato a succedere a un sovrano } \\
\text { regnante *herdeiro ao trono }\end{array}$ \\
\hline Definição Proposta & La persona che riceve i beni di un'altra dopo la sua morte. \\
\hline
\end{tabular}


Ficha lexicográfica para definição reformulada 15

\begin{tabular}{|c|c|}
\hline Unidade lexical & Posate \\
\hline Contexto & $\begin{array}{l}\text { "Dateli a me, che andrò a sotterrarli qui nell'orto di casa con le } \\
\text { posate!" (99) }\end{array}$ \\
\hline Definição existente & - posate: insieme di forchette, coltelli, cucchiai. (99) \\
\hline Definiçao De Mauro Paravia & $\begin{array}{l}\text { 1po-sà-ta } \\
\text { s.f. } \\
\text { 1. AD spec. al pl., ciascuno degli utensili (come ad es. il coltello, il } \\
\text { cucchiaio, la forchetta, ecc.) usati a tavola per portare il cibo alla } \\
\text { bocca o per servire le vivande dal piatto di portata: un servizio di } \\
\text { posate d'argento, posate da pesce, da frutta, da dolce, mettere le } \\
\text { posate in tavola, cambiare le posate } \\
\text { 2. BU estens., coperto, posto a tavola }\end{array}$ \\
\hline Definição Dire & $\begin{array}{l}\text { n.f. Utensile usato a tavola per mangiare: Quando si apparecchia, } \\
\text { accanto ad ogni piatto si mettono le posate. } \\
\text { Derivato da posare }\end{array}$ \\
\hline Definição II Sabatini-Coletti & $\begin{array}{l}\text { posata [po-sà-ta] s.f. } \\
\text { • Ciascuno degli utensili (cucchiaio, coltello e forchetta) che } \\
\text { si usano a tavola per mangiare } \\
\text { • sec. XVII }\end{array}$ \\
\hline Definição II Devoto-Oli 2008 & $\begin{array}{l}\text { posata }{ }^{2} \\
<\text { po-sà-ta> s.f. } \\
\text { Utensile da tavola; al pl., cucchiaio, forchetta e coltello: p. d'argento, } \\
\text { di alpacca; mettere le p. in tavola; con valore collettivo, il completo di } \\
\text { posate per ciascuno dei commensali (sin. di coperto): una p. per } \\
\text { l'ospite!dim. posatìna } \\
\text { Der. di posare }{ }^{1} \text { | prima metà sec. XVII }\end{array}$ \\
\hline Definição Lo Zingarelli 2004 & $\begin{array}{l}\text { posata (2) } \\
\text { [da posato; av. 1704] } \\
\text { s. } f . \\
1 \text { Denominazione generica di ciascuno degli utensili (cucchiaio, } \\
\text { coltello, forchetta) che si usano a tavola per prendere, dividere, } \\
\text { portare alla bocca le vivande: ho perso una posata d'argento; un } \\
\text { servizio di posate; lavare, asciugare le posate; mettere le posate in } \\
\text { tavola. } \\
2 \text { (raro) Posto apparecchiato a tavola: aggiungere una posata. SIN. } \\
\text { Coperto. } \\
\text { II posataccia, pegg. I posatina, dim. I posatona, accr. I posatuccia, } \\
\text { dim. }\end{array}$ \\
\hline Definição Parola Chiave & $\begin{array}{l}\text { s.f. Ciascuno degli utensili (coltelli, forchette, cucchiai, ecc.) che si } \\
\text { usano per mangiare: mettere le posate in tavola *talher }\end{array}$ \\
\hline Definição Proposta & Gli oggetti usate per mangiare: forchetta, coltello e cucchiaio. \\
\hline
\end{tabular}




\begin{tabular}{|c|c|}
\hline Unidade lexical & Palo strappato \\
\hline Contexto & $\begin{array}{l}\text { Ecco cosa vedono durante il viaggio di ritorno: vigne spoglie, rami a } \\
\text { terra, pali strappati, cancelli portati via, per non parlare del desordine } \\
\text { e della sporcizia che trovano nelle loro case.(100) }\end{array}$ \\
\hline Definição existente & - palo: legno lungo e dritto. (100) \\
\hline Definição De Mauro Paravia & 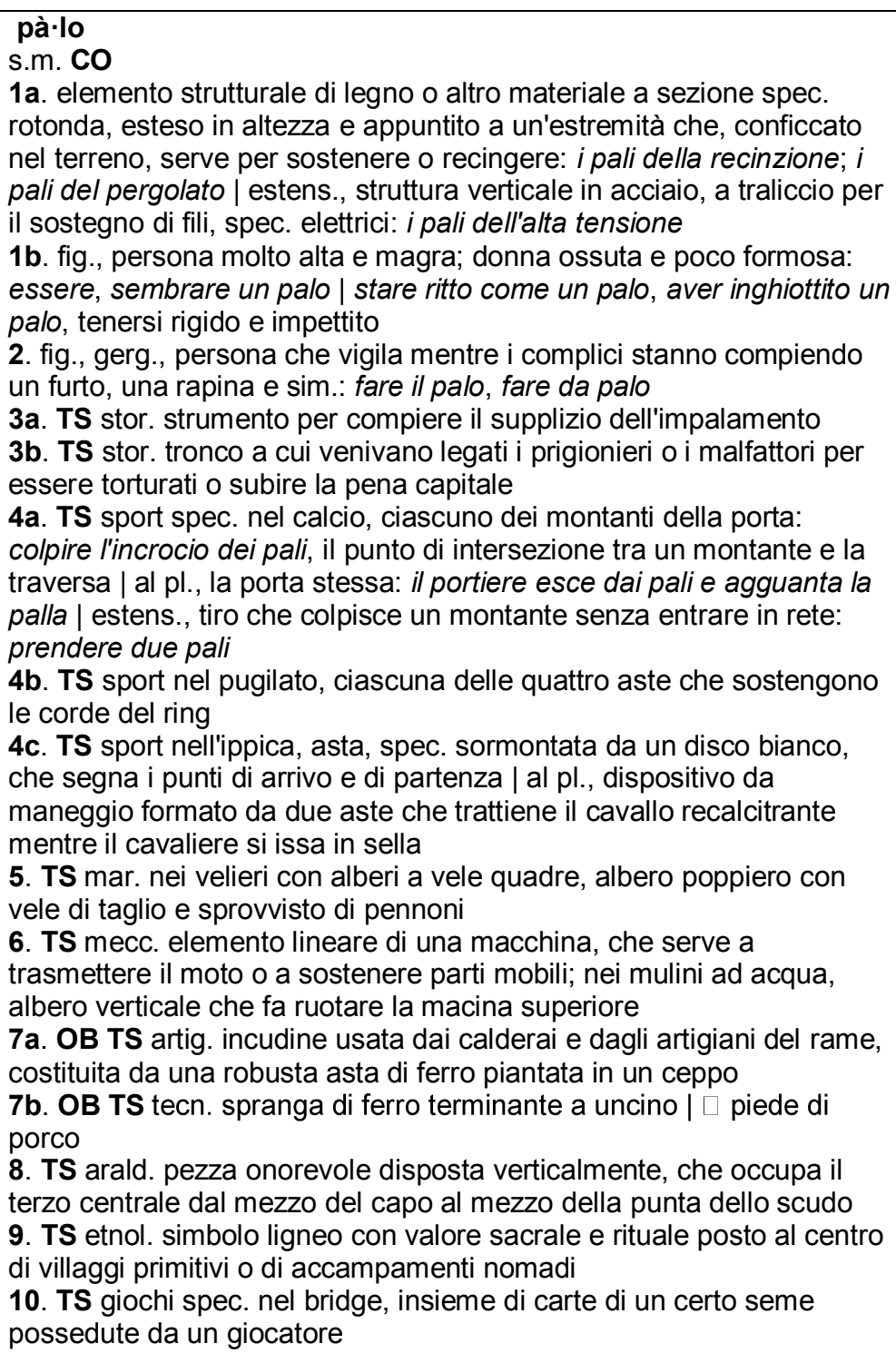 \\
\hline Definição Dire & $\begin{array}{l}\text { n.m. 1- Asta verticale di materiale vario, conficcata a terra e utilizzata } \\
\text { per sostenere o recintare: Ho legato la catena del cane ad un palo. 2- } \\
\text { Chi sta di guardia mentre i complici compiono una rapina: All'arivo } \\
\text { della polizia il palo ha avvertito i complici ed è fuggito. 3- Nel calcio, } \\
\text { ciascuna delle due aste verticali che delimitano la porta: /l pallone ha } \\
\text { colpito il palo senza entrare in rete. } \\
\text { [lat. Palus = palo], sin. } 3 \text { montante }\end{array}$ \\
\hline Definição II Sabatini-Coletti & $\begin{array}{l}\text { [pà-lo] s.m. } \\
\qquad 1 \text { Asta di legno o altro materiale, piantata nel terreno a scopo }\end{array}$ \\
\hline
\end{tabular}




\begin{tabular}{|c|c|}
\hline & $\begin{array}{l}\text { di recinzione o di fondamento o sostegno per strutture } \\
\text { superiori o cavi sospesi: } p \text {. di fondazione; } p \text {. del telegrafo || } \\
\text { dritto, piantato come un p., di persona rigidamente eretta, } \\
\text { impettita || figg. saltare di p. in frasca, passare da un } \\
\text { argomento all'altro senza logica | fare il p. o da p., vigilare } \\
\text { che non arrivi qlcu., mentre i complici rubano } \\
2 \text { sport. Ognuno dei due elementi verticali che reggono la } \\
\text { traversa di una porta di calcio, di hockey, di rugby o di altri } \\
\text { sport; estens. tiro che colpisce un palo || p. di partenza, } \\
\text { d'arrivo, nell'ippica, quelli che indicano la partenza e l'arrivo | } \\
\text { restare al p., non partire fig. perdere una buona occasione } \\
3 \text { mar. In un'imbarcazione a vele quadre, albero di poppa } \\
\text { con vele di taglio } \\
4 \text { Nel bridge e in altri giochi di carte, numero di carte di un } \\
\text { seme possedute da un giocatore; estens. il seme stesso } \\
\text { - dim. paletto, palettino | accr. palone } \\
\text { - sec. XI }\end{array}$ \\
\hline Definição II Devoto-Oli 2008 & 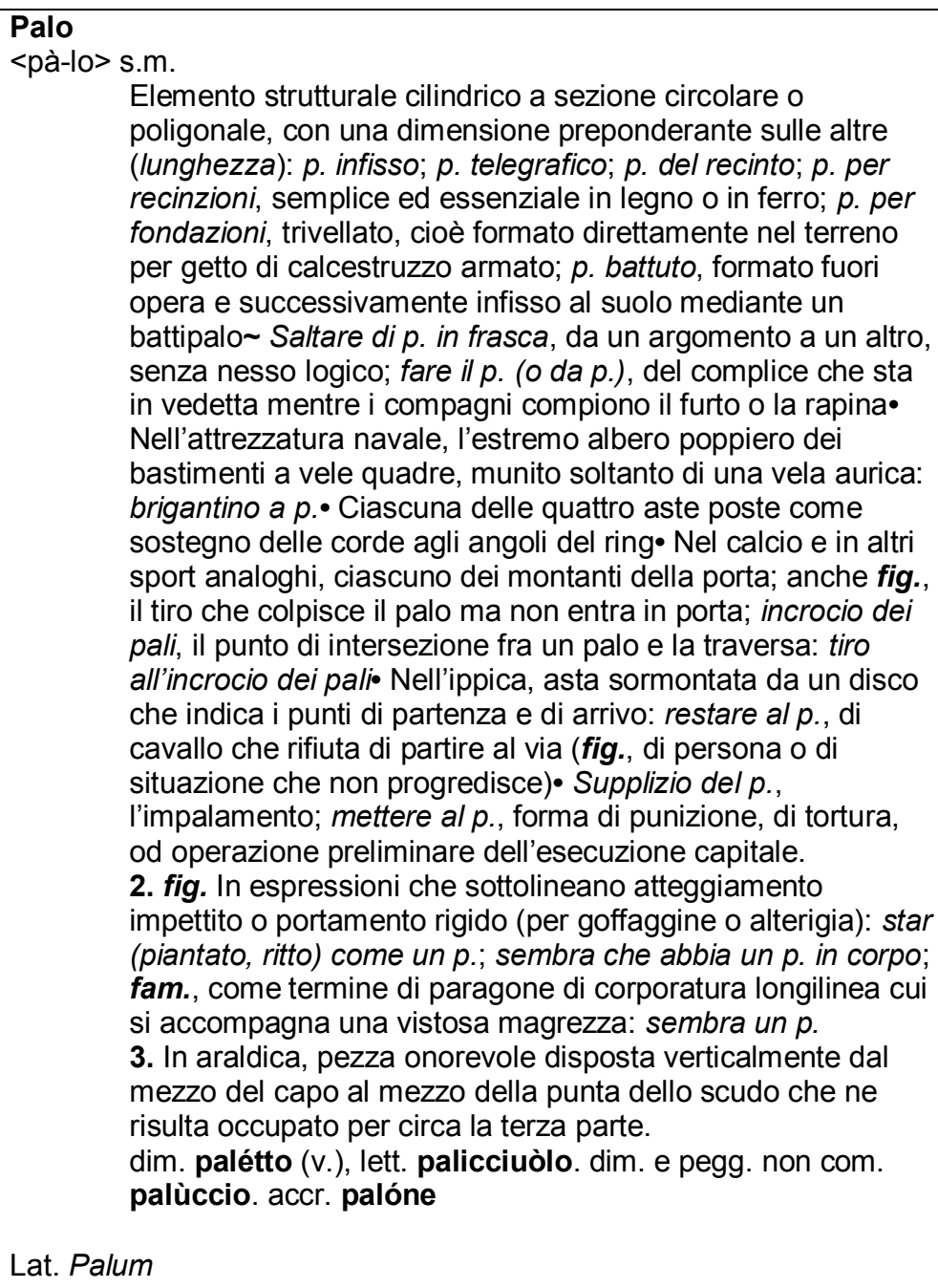 \\
\hline Definição Lo Zingarelli 2004 & [lat. palu(m); stessa etim. di pala (1); 1130] \\
\hline
\end{tabular}




\begin{tabular}{|c|c|}
\hline & $\begin{array}{l}\text { S. m. } \\
1 \text { Lungo legno a sezione tondeggiante, appuntito a un'estremità, che } \\
\text { si conficca nel suolo per recingere, sostenere e sim.: le piante giovani } \\
\text { sono sostenute da pali | Dritto come un palo, di persona che sta rigida } \\
\text { e impettita | (fig.) Ha ingoiato un palo, di chi cammina o sta in } \\
\text { posizione rigida | Saltare di palo in frasca, (fig.) cambiare argomento } \\
\text { in modo del tutto illogico e imprevedibile | Rimanere fermo al palo di } \\
\text { partenza, nell'ippica, detto di cavallo che, al momento del via, si rifiuta } \\
\text { di partire; (fig.) restare fermo allo stadio iniziale. } \\
2 \text { Sostegno verticale o inclinato, in metallo, cemento armato e sim., di } \\
\text { lunghezza grande rispetto alle dimensioni trasversali, usato in } \\
\text { fondazioni o come struttura di linee elettriche | Palo trivellato, } \\
\text { elemento di una fondazione ottenuto eseguendo un getto di } \\
\text { calcestruzzo in una profonda cavità praticata nel terreno. } \\
3 \text { (fig., gerg.) Chi sta di guardia mentre i compagni compiono un furto, } \\
\text { una rapina e sim.: fare il palo, da palo. } \\
4 \text { Nel gioco del calcio, ciascuno dei due montanti che, con la traversa, } \\
\text { costituiscono la porta: colpire un palo | Incrocio dei pali, punto di } \\
\text { intersezione fra un palo e la traversa. } \\
5 \text { (mar.) Albero a vele auriche, addizionale a quelli tradizionali di un } \\
\text { determinato tipo di veliero: nave a palo. } \\
6 \text { (arald.) Pezza che occupa verticalmente la terza parte dello scudo. } \\
7 \text { Nel bridge, l'insieme delle carte dello stesso seme possedute da un } \\
\text { giocatore. } \\
\text { || paletto, dim. (V.) | palettino, dim. | palettone, accr. | palettuccio, dim. } \\
\text { | palicciuolo, dim. | paluccio, paluzzo, dim. }\end{array}$ \\
\hline Definição Parola Chiave & $\begin{array}{l}\text { s.m. } 1 \text { Legno lungo, dirrito e tondeggiante che viene infisso nel } \\
\text { terreno a sostegno o recinzione di qualcosa; asta di metallo o } \\
\text { cemento com analoghe funzioni: sorreggere le viti con dei pali; i pali } \\
\text { di una palizzata; i pali della luce, del telefono *estaca; poste } 2 \\
\text { Ciascuno dei legni, e in pratic. Quelli verticali, che delimitano la porta } \\
\text { in un campo di calcio: colpire il palo con un tiro *trave }\end{array}$ \\
\hline Definição Proposta & Pezzo di legno alto e lungo preso con forza dalla terra. \\
\hline
\end{tabular}




\begin{tabular}{|c|c|}
\hline Unidade lexical & Svanire (svanisce) \\
\hline Contexto & $\begin{array}{l}\text { Grande è la consolazione di Renzo nel ritrovare il suo buon frate, ma } \\
\text { svanisce presto, quando si accorge che il male non lo ha risparmiato. } \\
\text { (108) }\end{array}$ \\
\hline Definição existente & - svanire: scomparire. (108) \\
\hline Definição De Mauro Paravia & $\begin{array}{l}\text { sva·nì-re } \\
\text { v.intr. (essere) AU } \\
\text { 1. dileguarsi a poco a poco, scomparire, sparire: l'auto svanì nella } \\
\text { nebbia } \\
\text { 2. estens., di odore, perdere gradualmente forza, intensità, ecc.; di } \\
\text { vino, perdere il sapore caratteristico } \\
\text { 3. di sostanza, spec. alcolica, svaporare: la boccetta era chiusa male } \\
\text { e il profumo è svanito } \\
\text { 4. fig., di sentimento, stato d'animo, ecc., venir meno, cessare di } \\
\text { esistere, estinguersi: all'arrivo del telegramma l'allegria svanì, a poco } \\
\text { a poco l'ira svani e lasciò il posto all'amarezza | non esser più vivo } \\
\text { nella memoria: col tempo i ricordi svaniscono } \\
\text { 5. BU lett., fig., morire }\end{array}$ \\
\hline Definição Dire & $\begin{array}{l}\text { v.intr. 1- Scomparire a poco a poco, dileguarsi: II palloncino sali in } \\
\text { cielo e svani. 2- Detto di emozioni, perdere intensità, attenuarsi: // suo } \\
\text { entusiasmo per il nuovo giocattolo sta svanendo. }\end{array}$ \\
\hline Definição II Sabatini-Coletti & $\begin{array}{l}\text { svanire [sva-nì-re] v.intr. (aus. essere; svanisco, svanisci ecc.) } \\
\text { [sogg-v] } \\
1 \text { Disperdersi, dissolversi poco alla volta; dileguarsi, } \\
\text { scomparire, anche in senso fig.: ogni speranza è svanita } \\
2 \text { Perdere gradatamente forza o intensità, anche in senso } \\
\text { fig. SIN svaporare, indebolirsi: la memoria svanisce } \\
\text { • sec. XIV }\end{array}$ \\
\hline Definição II Devoto-Oli 2008 & $\begin{array}{l}\text { Svanire } \\
\text { <sva-nì-re> v.intr. (svanisco, svanisci, ecc.; aus. essere) } \\
\text { 1. Diminuire o perdere gradualmente di intensità, disperdersi a poco a } \\
\text { poco: con la finestra aperta la puzza di bruciato è svanita; il rumore } \\
\text { dei passi svani lentamente• Allontanarsi a poco a poco fino a non } \\
\text { essere più visibile, scomparire, sparire: il treno svanì nella nebbia; } \\
\text { l'aereo è svanito all'orizzonte S. nel nulla, scomparire senza lasciare } \\
\text { traccia: l'assassino è svanito nel nulla. } \\
\text { 2. estens. Non farsi più vedere in giro, sparire dalla circolazione: la } \\
\text { tua amica non l'ho più incontrata: è svanita. } \\
\text { 3. Perdere l'odore, il sapore o la gradazione alcolica caratteristica; } \\
\text { svaporare: se non chiudi la bottiglia, la grappa svanisce. } \\
\text { 4. fig. Venire meno, perdere forza o vigore, dileguarsi, estinguersi: le } \\
\text { mie speranze sono ormai svanite; le illusioni a poco a poco } \\
\text { svaniscono; la sua rabbia svani dopo pochi istanti; col tempo i ricordi } \\
\text { svaniscono; la memoria a una certa età comincia a s. } \\
\text { 5. poet. Morire, perire. } \\
\text { Der. di vanire, con s- intensivo | sec. XIV }\end{array}$ \\
\hline Definição Lo Zingarelli 2004 & $\begin{array}{l}\text { Svanire } \\
\text { [da vanire, da vano, con s-; sec. XIII] }\end{array}$ \\
\hline
\end{tabular}




\begin{tabular}{|c|c|}
\hline & $\begin{array}{l}\text { v. intr. (io svanisco, tu svanisci; aus. essere) } \\
1 \text { Disperdersi, finire in nulla: tenendo la finestra aperta il calore } \\
\text { svanisce. } \\
2 \text { Dileguarsi, scomparire: l'apparizione svani; il treno svanì in } \\
\text { lontananza | (fig.) Cessare di essere, sfumare: svanirono le illusioni; } \\
\text { ogni speranza è svanita; molte volte... occasioni sufficienti per } \\
\text { produrre notabili effetti, ... svaniscono per mancamento d'uomini che } \\
\text { se ne sappiano valere (SARPI). } \\
3 \text { (raro) Perdere odore, sapore, aroma: all'aria le essenze svaniscono. } \\
4 \text { (fig.) Esaurirsi, indebolirsi: con gli anni la memoria svanisce | } \\
\text { Placarsi: gli è svanita l'ira. }\end{array}$ \\
\hline Definição Parola Chiave & $\begin{array}{l}\text { v.intr. [svanisco, svanisci; aus. essere] Dissolversi, dileguarsi, } \\
\text { scomparire (anche): la nebbia stava svanendo; l'auto svani nel buio } \\
\text { della notte; ormai 'svanita ogni speranza *desaparecer }\end{array}$ \\
\hline Definição Proposta & Passa. \\
\hline
\end{tabular}


Ficha lexicográfica para definição reformulada 18

\begin{tabular}{|c|c|}
\hline Unidade lexical & Grandinare com gocce grosse \\
\hline Contexto & $\begin{array}{l}\text { Appena Renzo esce dal lazzaretto comincia a grandinare con gocce } \\
\text { grosse e impetuose.(117) }\end{array}$ \\
\hline Definição existente & $\begin{array}{l}\text { - grandinare: il cadere della grandine (acqua congelata a forma di } \\
\text { piccole palle di ghiaccio). (117) }\end{array}$ \\
\hline Definição De Mauro Paravia & $\begin{array}{l}\text { gran·di·nà·re } \\
\text { v.intr., v.tr. (io gràndino) Co } \\
\text { 1. v.intr. (essere o avere) impers., cadere della grandine dal cielo: è, } \\
\text { ha grandinato per tutta la notte } \\
\text { 2. v.intr. (essere) estens., abbattersi con violenza: le pallottole } \\
\text { grandinano sul nemico | anche fig.: dure critiche grandinarono sullo } \\
\text { spettacolo } \\
\text { 3. v.tr. OB colpire con la grandine | fig., scagliare con forza e in } \\
\text { abbondanza }\end{array}$ \\
\hline Definição Dire & $\begin{array}{l}\text { v.intr.impers. Cadere giù dal cielo, detto della grandine: leri } \\
\text { grandinava. /v.intr. Venir giù con forza e in grande quantità: Dalle } \\
\text { feritoie grandinavano frecce sugli assalitori. } \\
\text { [lat. grando = grandine] }\end{array}$ \\
\hline Definição II Sabatini-Coletti & $\begin{array}{l}\text { grandinare [gran-di-nà-re] v. (gràndino ecc.) } \\
\text { • v.impers. (aus. essere o avere) [non.sogg-v] Cadere, } \\
\text { detto della grandine } \\
\text { • v.intr. (aus. avere) [sogg-v] fig. Riferito a oggetti, cadere } \\
\text { copiosamente e pesantemente come la grandine: } \\
\text { grandinavano proiettili } \\
\text { • sec. XIV }\end{array}$ \\
\hline Definição II Devoto-Oli 2008 & $\begin{array}{l}\text { Grandinare } \\
\text { <gran-di-nà-re> v.intr. (pres. gràndina; aus. essere e avere) } \\
\text { 1. impers. Cadere la grandine: ha (o è) grandinato per mezz'ora.2. } \\
\text { fig. Venire giù abbondantemente e con violenza (anche con le prep. } \\
\text { su, da): le frecce grandinavano sugli assalitori; da ogni parte } \\
\text { grandinavano pallottole• Susseguirsi in gran numero, con ritmo } \\
\text { incalzante: le punizioni grandinarono.3. arc. Come tr., colpire, } \\
\text { devastare con la grandine• fig. Scagliare fittamente e con forza: I } \\
\text { difensori a grandinar le pietre Da l'alte mura... incominciaro (Tasso). } \\
\text { Lat. grandinare, der. di grando I' }\end{array}$ \\
\hline Definição Lo Zingarelli 2004 & $\begin{array}{l}\text { Grandinare } \\
\text { [lat. grandinare, da grando, genit. grandinis 'grandine'; 1353] } \\
\text { A v. intr. impers. (gràndina; aus. essere o avere) } \\
\text { * Cadere, venire giù, detto della grandine: ha grandinato tutto il } \\
\text { giorno; era grandinato su tutta la regione. } \\
\text { B v. intr. (aus. essere) } \\
\text { * (fig.) Cadere violentemente e in abbondanza come la grandine: } \\
\text { bombe e proiettili grandinavano tutt'intorno; dopo tanti incidenti le } \\
\text { multe grandineranno. }\end{array}$ \\
\hline
\end{tabular}




\begin{tabular}{|l|l|}
\hline & $\begin{array}{l}\text { C v. tr. } \\
* \text { tScagliare con forza e in abbondanza come la grandine: } i \text { difensori } \\
\text { a grandinar le pietre / da l'alte mura... incominciaro (TASSO). }\end{array}$ \\
\hline Definição Parola Chiave & $\begin{array}{l}\text { v.intr.impers. [aus. essere o avere] Cadere la gradine: è (o ha) } \\
\text { grandinato per uin quarto d'ora *cair granizo / v.intr. [aus. essere] } \\
\text { Arrivare addosso con violenzae in grand quantità, come la grandine: } \\
\text { da ogni parte grandinavano le pallottole *cover }\end{array}$ \\
\hline Definição Proposta & Pioggia forte de acqua e ghiaccio. \\
\hline
\end{tabular}


Ficha lexicográfica para definição reformulada 19

\begin{tabular}{|c|c|}
\hline Unidade lexical & Affaccendata \\
\hline Contexto & $\begin{array}{l}\text { Ne vengono poi con il tempo non so quanti altri dell'uomo e dell'altro } \\
\text { sesso, com Agnese sempre affaccendata a portarli qua e lá, dando } \\
\text { loro dei bei bacioni in viso.(122) }\end{array}$ \\
\hline Definição existente & - affaccendata: impegnata. (122) \\
\hline Definição De Mauro Paravia & $\begin{array}{l}\text { af·fac·cen·dà·to } \\
\text { p.pass., agg. } \\
\text { 1. p.pass. } \square \text { affaccendare, affaccendarsi } \\
\text { 2. agg. Co indaffarato: adesso sono troppo affaccendato per } \\
\text { ascoltarti } \\
\text { 3. agg. LE premuroso, sollecito: fu ricevuto con quella cordialità } \\
\text { affaccendata e rispettosa (Manzoni) }\end{array}$ \\
\hline Definição Dire & $\begin{array}{l}\text { agg. Molto occupato in un'attività: Il mio amico, affaccendato a } \\
\text { preparare lo zaino per la gita di domani, non è uscito. } \\
\text { part.pass. di affaccendarsi }\end{array}$ \\
\hline Definição II Sabatini-Coletti & $\begin{array}{l}\text { affaccendato [af-fac-cen-dà-to] agg. } \\
\qquad \begin{array}{l}\text { - Indaffarato, impegnato: è troppo a. per starti a sentire } \\
\text { • sec. XIV }\end{array}\end{array}$ \\
\hline Definição II Devoto-Oli 2008 & $\begin{array}{l}\text { Affaccendato } \\
\text { <af-fac-cen-dà-to> agg. } \\
\text { 1. Che è veramente (o si finge) molto occupato; indaffarato (anche } \\
\text { con la prep. in): adesso è troppo a. per poterti ricevere; essere in } \\
\text { tutt'altre faccende a., aver ben altro da fare.2. lett. Premuroso, } \\
\text { sollecito: fu ricevuto con quella cordialità affaccendata e rispettosa } \\
\text { (Manzoni)• poet. Movimentato: Vedea nel pian discorrere La caccia } \\
\text { affaccendata (Manzoni). }\end{array}$ \\
\hline Definição Lo Zingarelli 2004 & $\begin{array}{l}\text { affaccendato } \\
\text { part. pass. di affaccendare; anche agg. } \\
\text { * Che è molto occupato, che ha molto da fare. SIN. Indaffarato, } \\
\text { intento. CONTR. Sfaccendato. }\end{array}$ \\
\hline Definição Parola Chiave & $\begin{array}{l}\text { agg. Molto occupato in qualcosa S indaffarato: in casa è sempre } \\
\text { affaccendato *atarefado }\end{array}$ \\
\hline Definição Proposta & Occupata, con molte cose da fare. \\
\hline
\end{tabular}




\section{4 - Análise das novas notas propostas e das reformuladas}

Como já abordamos no item 3.4 (Estrutura das notas de rodapé dos livros de literatura adaptada para estrangeiros em língua italiana), a estrutura das notas de rodapé tende a ser bem simples e direta. Na maioria das vezes, são organizadas com equivalências por sinonímia. No caso da obra por nós trabalhada, não existe nenhum desenho nas notas de rodapé, porém a obra é acompanhada das ilustrações de Francesco Gonin, presentes também na obra original e que retrata muito dos costumes da época em que se passa o romance.

Como o nosso público leitor é o brasileiro, procuramos elaborar as notas utilizando palavras que fossem bem próximas ao português, de forma a facilitar o máximo possível a compreensão das mesmas. Um exemplo é a definição de cascina, que propomos como conteúdo denominador casa di agricoltore e não casa de contadino.

Todas as palavras e expressões indicadas no rodapé apresentam um único significado, mesmo sendo polissêmicas. A finalidade das notas nas obras de leitura graduada é elucidar o significado da expressão ou unidade lexical desconhecida e não aprofundar os diversos significados da palavra ou expressão em questão.

Geralmente, as palavras que constam no rodapé são definidas por sinonímia, porém com a unidade lexical soffice encontramos muita dificuldade em empregar sinônimos, já que os sinônimos existentes para tal unidade é um falso cognato na língua portuguesa: mórbido, em português, não significa macio como em italiano. A solução encontrada foi usar o antônimo para compor a definição:

soffice: II contrario di duro. (47)

As explicações (definições) das notas são breves e precisas, pois o autor deve olhar e conseguir identificar o significado da palavra que consta na nota. Quando se trata de verbos, esses aparecem no infinitivo, independentemente da forma flexionada presente no texto. Os substantivos e adjetivos não aparecem flexionados. 
Para definir a expressão in attesa, tínhamos usado inicialmente sperando por ser muito parecida com o português. Depois da discussão com a nossa consultora lingüística, substituímos sperando por aspettando. Ambas possuem o mesmo núcleo semântico, porém sperare é mais no sentido psicológico e aspettare no sentido temporal. Aspettare poderia se encaixar no mesmo significado de sperare se fosse reflexivo, ou seja, aspettarsi.

A unidade lexical grandinare foi eleita pelos alunos como sendo uma a ser reexplicada. Fato interessante é que a palavra gocce, que vem logo depois de grandinare, foi requisitada para constar nas notas de rodapé. Analisando o contexto Appena Renzo esce dal Lazzaretto comincia a grandinare con gocce grosse e impetuose, decidimos repropor a explicação de grandinare, mas utilizando a expressão grandinare con goce grosse. Propomos então a seguinte nota:

grandinare con gocce grosse: pioggia forte de acqua e ghiaccio. (117)

A mesma coisa pode ser notada para explicação de palli strappati, em que foi pedido para pali ser redefinido e strappatti para conter uma explicação. O contexto é "Ecco cosa vedono durante il viaggio di ritorno: vigne spoglie, rami a terra, pali strappati, cancelli portati via, per non parlare Del disordine e della sporcizia che trovano nelle loro casa (100)". Propomos então a seguinte nota:

pali strappati: pezzo di legno lungo e dritto estratto da terra con forza (100)

A unidade lexical soprannome não foi apontada pelos alunos como sendo de difícil compreensão, pois acreditamos que os mesmos acharam que compreenderam tal unidade, mas essa é um falso cognato. Soprannome, em italiano, não possui os mesmo traços semânticos que sobrenome possui em português. Dessa forma, decidimos inserir soprannome nas notas:

soprannome: nome ironico o malevolo che si dà ad una persona a partire da una caratteristica física o morale, luogo di provenienza, qualità, ecc. (4)

No que se refere às reformulações das unidades já existentes, temos que ressaltar que na definição de azzeccagarbugli a autora foi muito concisa, o que tirou 
das palavras semas importantes. Abaixo confrontamos a definição da autora que adaptou a obra e a nossa:

Contexto: Renzo, vai a Lecco dal dottor Azzeccagarbugli, quell'avvocato alto, magro e con gli occhiali. (11)

Definição do livro: Azzeccagarbugli: soprannome inventato dal Manzoni per indicare un avvocato capace di tirare fuori dai guai ogni persona (azzeccare: riuscire; ingarbugliato: confuso, pieno di nodi da sciogliere). (11)

Nossa proposta: Denominazione creata dall'autore per designare una persona che si crede capace, o vuol fare credere di essere capace, di risolvere tutti i problemi. Dal verbo azzeccare (colpire la cosa giusta) e dal sostantivo garbuglio (confuso, con problemi).

Para a unidade lexical scenata, que apresenta como definição lite, "accesa discussione", propomos inicialmente uma única palavra como equivalente, influenciada pela definição do dicionário Parola Chiave (s.f. Violenta manifestazione di risentimento, d'ira, di rimprovero: fare una scenata a qualcuno *descompostura Litigio violento, con urla, accuse, insulti, minacce: in quella casa ci sono continue scenate *cena; escândalo), que seria scandalo. A nossa consultora lingüística, todavia, corrigiu-nos e propôs a seguinte definição: "reazione verbale violenta", já que scandalo é uma reação que envolve o público e, no contexto do livro, o público não estava envolvido, somente o pai e a filha.

A seguir apresentamos as definições das 191 palavras e/ou expressões indicadas para conter as notas de rodapé do romance adaptado I Promessi Sposi de Marisa Pasqualetti. 
5.5 - Elenco de todas as notas a constar na obra adaptada

I Promessi Sposi, Editora Cideb, 2007 
accadere: succedere. (4)

nobiluomo: uomo di famiglia aristocratica.(4)

soprannome: nome ironico o malevolo che si dà ad una personaa partire da una caratteristica física o morale, luogo di provenienza, qualità, ecc. (4)

colpito: toccato. (5)

minaccia: promessa di future offese. (8)

signorotto: signore ricco, nobile, proprietario di terre e che comanda un territorio di dimensioni limitate. (8)

bussare: battere alla porta per farsi aprire. (9)

curato: parroco. (9)

impaurito: con molta paura. (9)

balbettare: parlare con molte esitazioni, ripetendo più volte la stessa sillaba. (10)

aria: clima, atmosfera. (11)

azzeccagarbugli: denominazione creata dall'autore per designare una persona che si crede capace, o vuol fare credere di essere capace, di risolvere tutti i problemi. Dal verbo azzeccare (colpire la cosa giusta) e dal sostantivo garbuglio (confuso, con problemi). (11)

di corsa: correndo (11)

filanda: luogo dove si trasforma il cotone, la lana o la seta in filo. (11)

ammazzare: far morire, uccidere. (12)

cappone: gallo castrato, dalla carne particolarmente tenera e saporita. (12)

nozze: matrimonio. (12)

minacciare: fare paura a qualcuno promettendo di fargli del male. (12)

spingere: fare pressione su una cosa o persona per spostarla. (12)

ammazzare: far morire, uccidere. (12)

Risorgimento: periodo storico compreso fra il 1847 e il 1870, caratterizzato, tra gli altri eventi, dalle lotte per ottenere l'indipendenza dall'Austria, che portarono all'unificazione dello Stato italiano. (22)

brache: pantaloni larghi che arrivano alle ginocchia. (24)

sfarzoso: ricco, lussuoso. (24)

vicenda: evento, fatto. (24)

biacca: sostanza colorante bianca, pastosa, usata per preparare i cosmetici. (25)

feltro: cappello. (25) 
trina: dettaglio delicato fatto a macchina o a mano per abbellire abiti e biancheria femminile.(25)

raggiungere: arrivare ad un luogo. (26)

volitivo: energico, che esprime un carattere forte. (26)

volto: faccia, viso. (26)

cugino: parente, figlio di una zia. (27)

sorgere: innalzarsi. (27)

imbroglio: inganno, azione poco onesta. (29)

scoppiare: esplodere (28)

acconsentire: dare la propria approvazione. (30)

di nascosto: senza farsi vedere. (30)

scommettere: fare un patto promettendo di pagare in caso di vittoria dell'altro. (30)

turbato: preocupato, agitato, inquieto. (30)

osteria: ristorante semplice. (31)

riscuotere dei soldi: ricevere, incassare del denaro. (31)

scopo: obiettivo. (32)

Deo gratias: antica forma di saluto in latino ("sia ringraziato Dio"). (32)

addosso: Sopra una persona o cosa. (33)

forca: bastone con due punte di metallo usato in campagna. (33)

rintocco: suono delle campane. (33)

scostarsi: separarsi, allontanarsi l'uno dall'altro. (33)

sipario: la tenda che in teatro si alza sul palcoscenico per mostrare al pubblico lo spettacolo. (33)

stupito: sorpreso, meravigliato. (33)

alito: (qui) soffio. (34)

fare la spia: riferire un segreto in cambio di denaro o per provocare danno ad altri.

giace: Si presenta. (34)

pascolo: Terreno con erba destinata al pasto degli erbivori. (34)

pendio: discesa delle colline o dei monti. (34)

rabbrividire: sentire brividi (di freddo, paura, orrore). (34)

sorgenti: che sorgono, che si alzano. (34)

sopruso: ingiustizia, prepotenza, offesa. (38)

accogliere: ricevere. (39) 
impari: non equilibrata, non ad armi pari. (39)

avere: bene, ricchezza, possedimento. (40)

indicibile: che non si può descrivere. (40)

saio: abito da frate. (40)

testa rasata: con i capelli tagliati cortissimi. (40)

cortile: area interna e scoperta di un edifício destinata a dare luce e ventilazione. (44)

cupo: senza gioia, triste. (45)

in attesa: aspettando. (45)

inchino: forma rispettosa di salutare qualcuno piegando la testa e il busto verso il basso.(45)

parlatorio: sala di un monastero o di un carcere, destinata ai colloqui con i visitatori esterni. (45)

branco: gruppo. (46)

piuttosto che: Invece di. (46)

sottrarsi: scappare, fuggire. (46)

carestia: mancanza di cibo che colpisce tutta la popolazione. (47)

il Paese della Cuccagna: luogo immaginario pieno di delizie di ogni genere. (47)

soffice: il contrario di duro. (47)

striccia: residuo lungo e stretto lasciato da una sostanza. (47)

tabernacolo: piccola cappella aperta, posta lungo la strada e contenente immagini di santi. (47)

vendetta: danno causato a qualcuno per ricambiare una offessa ricevuta. Pagare con la stessa moneta. (47)

lineamento: tratto del viso, fisionomia. (53)

raggrinzarsi: fare dei movimenti che formano delle grinze, delle rughe. (53)

cadetto: figlio non primogenito. (54)

paggio: giovane servitore dell'epoca. (54)

scenata: reazione verbale violenta. (54)

indispettita: irritata. (55)

educanda: (qui) ragazza che studia dalle suore. (56)

Madre Badessa: suora a capo di un convento. (56)

fare finta: fingere, simulare. (57)

insolito: strano, non comune. (57) 
sventurata: sfortunata, infelice. (57)

forno: bottega che vende il pane o altri prodotti fatti con la farina (a Milano, nel Seicento, forno si diceva 'prestino' e ancora oggi i milanesi chiamano il panettiere 'prestinaio'). (62)

guadagnare: ricevere il salario. (62)

raccolto: prodotto di una coltura agricola, coglitura. (62)

questa è bella!: questo fatto è proprio strano! (63)

radunarsi: riunirsi, raggrupparsi. (63)

rincarare: alzare il prezzo, vendere più caro. (63)

riversarsi: entrare in massa. (63)

sfondare: rompere, aprire rompendo. (63)

spargersi: diffondersi. (63)

a buon mercato: a prezzo basso, economico. (64)

boccone: piccola quantità di cibo. (65)

disperdersi: andare uno di qua e uno di là. (65)

folla: molte persone insieme. (65)

sedare il popolo: calmare, accontentare, soddisfare le richieste dei rivoltosi. (65)

tramontare: si dice di quando il sole va via, al termine della giornata. (65)

calamaio: piccolo contenitore con l'inchiostro per scrivere. (66)

fiasco: grossa bottiglia rivestita di paglia, usata per il vino. (66)

stufato: carne cotta a lungo. (66)

spuntare del giorno: mattina. (67)

trascinare: tirare con forza. (67)

ubriaco: persona sotto l'effetto dell'alcol. (67)

zimbello: Persona ridicola a causa del suo comportamento, chi provoca risate. (67)

urlare: gridare, parlare con voce molto alta.(68)

affiorare: emergere, venire fuori. (69)

incolto: non coltivato. (69)

miglio: unità di misura riferita alle distanze, con valori diversi secondo i luoghi e i tempi (oggi in Italia si usa il chilometro). (69)

sdraiarsi: Stendersi su una superficie per riposare. (69)

treccia: modo di pettinare i capelli di una donna dividendoli in tre parti e intrecciandole. (69)

infiammare: accendere. (70) 
podestà: persona che anticamente amministrava la città, come oggi il sindaco. (70) spostiarsi: cambiare luogo. (70)

scorta: gruppo di guardie al seguito di un personaggio potente, con il compito di proteggerlo. (71)

contendersi: lottare, litigare per avere. (74)

elemosina: carità, soccorso dato ad un povero che tende la mano per strada. (75)

sopruso: atto di prepotenza, maltrattamento, impiego arbitrario dell'autorità. (75)

sportello: porta di un veicolo. (83)

vita: parte del corpo sopra i fianchi, dove si mette la cintura. (83)

fazzoletto: pezzo di tessuto, generalmente di cotone, usato per pulire il naso o da mettere al collo o sul capo. (84)

soffocare il grido in gola: impedire di gridare. (84)

sfogarsi: raccontare i propri problemi. (84)

svenire: perdere coscienza, perdere i sensi. (84)

riparare un torto: rimediare a un danno, a un male. (86)

radunato: riunito. (87)

rovinare: distruggere, danneggiare. (87)

chiasso: forte rumore prodotto da persone. (88)

distrarre: divertire, fare pensare ad altro. (88)

sarto: artigiano che cuce e confeziona vestiti. (88)

benestante: ricco. (89)

rannicchiata: piegata, in posizione fetale. (89)

sbalordita: meravigliata, stupita, sorpresa. (90)

scudo: moneta dell'epoca. (90)

addirittura: anche. (98)

erede: la persona che riceve i beni di un'altra dopo la sua morte.(98)

lotta di successione: lotta per ottenere il trono o un altro potere, fino a quel momento in mano ad altri. (98)

morire come mosche: morire in molti. (98)

ospizio: edificio per ospitare persone in difficoltà (poveri, anziani, malati...). (98)

siccità: tempo secco, mancanza di pioggia. (98)

posate: gli oggetti usate per mangiare: forchetta, coltello e cucchiaio. (99)

palo strappato: pezzo di legno alto e lungo preso con forza dalla terra. (100)

vigna spoglia: campo di viti, senza uva. (100) 
bubbone: grosso gonfione sotto la pelle che può aprirsi e diventare infetto. (101)

livido: macchia scura sulla pelle, che di solito si forma dove si è avuto un colpo. (101)

panca: (qui) sedile di una chiesa. (101)

spregiudicato: persona che non ha timore di rischiare. (101)

ungere: coprire con olio (es. si ungono i mobili prima di lucidarli). (101)

vernaccia: tipo di vino bianco. (101)

chirurgo: medico che sa fare anche operazioni. (102)

monatto: chi nell'epoca della peste trasportava i malati e i morti. (102)

stropiccio: rumore di qualcosa che si muove strusciando contro un'altra. (102)

barella: letto usato per trasportare malati o feriti. (103)

bergamasco: zona intorno alla108) città di Bergamo. (103)

filatoio: dove si lavorano i filati (cotone o seta) per fare dei tessuti. (103)

gaio: problemi, situazioni difficili. (104)

Lanzichenecchi: nei secoli XV-XVII erano chiamati così i soldati mercenari tedeschi. $(104)$

mettere giudizio: imparare a comportarsi con saggezza. (104)

ridurre: degradarsi (104)

scampare: salvarsi da qualcosa. (104)

sporcizia: accumulo di polvere e altre sostanze sgradevoli. (104)

cascina: casa di agricoltori. (105)

tintinnio: suono di oggetti di vetro o metallo (es. bicchieri o piccole campane d'argento). (105)

lazzaretto: luogo dove andavano le persone con malattie incurabili e contagiose. (107)

nei pressi: vicino a, nelle vicinanze di. (107)

in lungo e in largo: in ogni posto. (108)

svanire: passare. (108)

di quando in quando: ogni tanto. (109)

spalancato: aperto. (109)

fiato: respiro. (110)

levarselo dalla testa: scordarselo, dimenticarselo. (110)

mettersi il cuore in pace: rassegnarsi, accettare i fatti dolorosi della vita. (110)

quaggiù: sulla terra. (110) 
grandinare con gocce grosse: pioggia forte de acqua e ghiaccio. (117)

guarire: di nuovo sano dopo una malattia. (117)

mettere su casa: preparare la cena per la nuova famiglia. (118)

scuotere: muovere da una parte all'altra. (119)

stare alla larga: stare lontano. (119)

afferra: prendere con forza. (120)

altrove: da un'altra parte, in un altro luogo. (120)

casuccia: casa piccola e povera. (120)

revocare: annullare, cancellare. (120)

risoluto: deciso. (120)

a patto di: a condizione di. (121)

affaccendata: occupata, con molte cose da fare (122)

a mezzo: a metà, in società. (122)

entrambi: tutti e due. (122) 


\section{CONSIDERAÇÕES FINAIS}

Depois da nossa análise chegamos à conclusão de que, diferentemente da competência gramatical de um aluno de língua estrangeira, é muito difícil conseguir medir com exatidão a competência lexical. A gramática é um conjunto mais fechado de possibilidades, enquanto o léxico apresenta um universo muito amplo e os alunos estão expostos a diferentes inputs ao estudar uma língua estrangeira.

Na sala de aula podemos dar o mesmo input de forma a querer uniformizar a quantidade de informação transmitida. Porém, se um aluno interessa-se mais do que o outro e vai buscar textos na internet ou em outros lugares sobre o que lhe agrada, é evidente que esse discente terá uma competência lexical mais desenvolvida em relação a um que ficaria somente com os textos trabalhados em sala de aula. Esta constatação é importante para justificar a diminuição do nosso corpus de informantes de 11 para sete grupos.

Outro ponto verificado na pesquisa é a importância de nós, professores brasileiros, elaborarmos material para os nossos alunos, sobretudo no que se refere ao conhecimento lexical. É muito mais simples para nós sabermos quais palavras usar para explicar uma expressão não compreendida do que um nativo italiano. Às vezes, o que parece muito simples para os professores nativos italianos é difícil para os docentes brasileiros. A recíproca também é verdadeira.

Analisando e propondo novas notas para o livro adaptado I Promessi Sposi de Marisa Pasqualetti, percebemos que as notas podem conseguir remeter o leitor ao significado perfeito da palavra. Muitas vezes, no entanto, se conseguirem elucidar o contexto, essas já servem como boas notas, pois o objetivo é a leitura e compreensão global do texto e não a tradução, em que o significado perfeito de todas as palavras é importante.

Quanto ao trabalho das obras adaptadas em relação àquelas originais, deixamos já claro desde o início que esse não era o mérito da nossa pesquisa. Contudo, vale muito mais um leitor não especialista na língua lida ler um clássico, mesmo que seja adaptado, do que nunca o ler. Ou então ler a tradução, que se encaixa também, a nosso ver, como uma modalidade de adaptação.

Se o leitor deixa de conhecer características próprias da estética de uma obra considerada clássica até então por ter sido adaptada, tem a chance, por outro lado, 
de conhecer uma narrativa que atravessou séculos e chega aos nossos dias com a linguagem de hoje, mas o conteúdo de outrora.

Devemos admitir que em uma adaptação perde-se possibilidades sonoras e efeitos lingüísticos do texto original. Todavia, ainda assim, evoca sensações, formas e atributos que são universais. A adaptação que usamos, traz, em alguns trechos, a narrativa original, o que faz com que o leitor tenha uma idéia do estilo do autor que está lendo, mesmo que adaptado.

No começo da pesquisa, fizemos algumas perguntas que agora retomamos. A quem é destinado o vocabulário de pé de página das obras adaptadas? Verificamos que a compilação dessas notas não é direcionada a um determinado grupo, mesmo em se tratando de leitura graduada para estrangeiros. Não se leva em consideração nenhuma nacionalidade específica. Ocorre a criação e inserção dessas notas de acordo com o léxico de freqüência da língua italiana. Assim, uma palavra muito simples e conhecida por todos, como é o caso de barba, passa a fazer parte da notas de pé de página pelo simples motivo de ser um termo pouco usado, de baixa ocorrência na fala cotidiana, embora seja um vocábulo conhecido pela grande parte da população italiana. Dessa forma as notas são destinadas a todos e ao mesmo tempo a ninguém, pois não trabalham especificidades da língua italiana em relação a nenhuma outra língua. Tudo fica no plano geral. Justamente por tudo ficar no plano geral, verificamos que a grande parte das notas presentes nos livros de leitura graduada é desnecessária para o público brasileiro, enquanto aprendiz e leitor da língua italiana.

Outra pergunta que propomos a responder com base nas nossas reflexões é: "A simplificação lexical é suficiente para tornar uma obra de fácil leitura?" A compreensão da leitura envolve muito mais fatores que só aquele do conhecimento lexical. É importante conhecer as palavras e os seus vários valores dentro de um texto. Quando o léxico é simplificado, não significa que a leitura será de fácil compreensão, sobretudo porque essa simplificação lexical é muito vaga, não é específica para um grupo, por exemplo, de leitores japoneses ou brasileiros. 0 mesmo livro de leitura facilitada que foi produzido para um leitor B2 do quadro Comum Europeu de Referência das línguas apresentará dificuldades e facilidades diferentes se compararmos leitores que tenham uma língua neolatina como língua materna. Todas essas adaptações de obras clássicas ou escritas mais modernas são uma espécie de metaliteratura, onde a quantidade de input de vocabulário novo 
teoricamente é controlada. Dessa forma, nem sempre o adaptado é visto como um instrumento facilitador, já que defendemos que adaptação não pode ser única para todas as línguas. Se vários gramáticos já entenderem que para anglofanos é difícil entender a diferença de uso do passato prossimo e o imperfetto, enquanto que para estudantes brasileiros isso não é problema, talvez esteja na hora de olhar para o léxico e entender que também aqui existe uma linha nítida de dificuldade e facilidade, dependendo de qual língua materna é o aprendiz?

Dessa forma, esperamos ter deixado a nossa contribuição a um tema que ainda não tinha sido tratado e que pode ser explorado de muitas maneiras. Esperamos ter iniciado uma reflexão de muitas ações no âmbito do ensino e aprendizagem do léxico em língua estrangeira e contribuído lexicograficamente para a melhoria de pelo menos um título, que consideramos muito relevante, entre a as obras de leitura controlada. 


\section{REFERÊNCIAS BIBLIOGRÁFICAS E SITOGRAFIA}

ALMEIDA FILHO, J. C. P. Dimensões comunicativas no ensino de línguas.

Campinas, SP: Pontes, 1998.

APRILE, M. Dalle Parole ai Dizionari. Bologna: II Mulino, 2005.

BALBONI, P. E. Didattica dell'Italiano a stranieri. Firenze:Bonacci Editore, 1994.

2006.

Insegnare la letteratura italiana a stranieri. Perugia: Edizioni Guerra,

. Tecniche Didattiche per l'educazione linguistica, Torino: UTET, 2007.

BARBOSA, M. A. Da constituição e transmissão do saber lexical: um modelo linguístico-pedagógico. In: Revista Brasileira de Linguística, v.. 7, n. 1. São Paulo: Global/SBPL, 1984.

. O percurso gerativo da enunciação, a relação de equivalência lexical e o ensino do léxico. In: XXI Estudos Linguísticos. Anais de Seminários do Gel, Jaú, Gel 1992.

BERNINI, G.; SPREAFICO, L.; VALENTINI, A. Competenze lessicali e discorsive nell'acquisizione di lingue seconde. Perugia: Guerra Edizioni, 2008.

BENUCCI, A. Le lingue Romanze: una guida per l'intercompreensione.Torino: UTET, 2005.

BETTONI, C. Imparare un'altra lingua. Bari: Laterza, 2001.

BIANCHINI, E. Italiano Straniero: piccolo repertorio storico dei barbarismi e dei significati che mutano nella lingua italiana. Perugia: Edizioni Guerra, 1998.

BIDERMAN, M. T. Léxico e vocabulário fundamental. Revista Alfa. N. 40 São Paulo: Editora da Unesp, 1996. p. 27-46. 
BIGNAMI, A. M. I Promessi Sposi: riassunto, personaggi, date, luoghi del romanzo di Alessandro Manzoni. Milano: Edizioni Esagono, 2000.

BUSSOLARO, D. Riassunto de I Promessi Sposi: riassunti, commenti, personaggi temi Svolti. Marano: Editrice II Girasole, 2007.

CHIARA, P.. I Promessi Sposi. Milano: Arnaldo Mondadori, 1996.

CHINI, M. Che cos'è la linguistica acquisizionale. Roma: Carocci, 2007.

COVINO BISACCIA, M. A.; FRANCOMACARO, M. R. La Regola Francescana, Perugia: Edizioni Guerra: 1997.

COTTIGNOLI, A. Manzoni: guida ai Promessi Sposi. Roma: Carocci, 2002.

DARDANO, M. La formazione delle parole nell'italiano di oggi. Roma: Bulzoni, 1978.

. Lessico e semantica: la formazione delle parole. In: SOBRERO, A. (a cura di). Introduzione all'italiano contemporaneo: le strutture. v. 1. Roma; Bari: Laterza: 1993. p. 340-349.

DE GIULI, A.; NADDEO, C. M. Fantasmi. Firenze, Alma Edizioni, 2002.

DELLA VALLE, V. Dizionari italiani: storia, tipi, struttura. Roma: Carocci, 2005. Editori, 2006.

; PATOTA, G. L'Italiano: biografia di una lingua. Milano: Sperling e Kupfer

DE MAURO, T. II dizionario della lingua Italiana. Torino: Paravia, 2006. CD-ROM. 2005.

. La fabbrica delle parole: il lessico e problemi di lessicologia. Torino: UTET, et al. Lessico di frequenza dell'italiano parlato. Milano: Etaslibri, 1993. 
DEVOTO-OLI Vocabolario della lingua Italiana 2008. Firenze: Le Monnier, 2007. CD-ROM.

DIRE Dizionario della Lingua Italiana. Monte San Vito: Raffaello Edizioni, 2001.

DUBOIS, J. et C. Introduction à la lexicographie: le dictionnaire. Paris: Larousse, 1971.

FERRARI, M.; PALLADINO, P. L'apprendimento della lingua straniera. Roma: Carocci, 2007.

FOLCO, D. II Segreto del Vecchio Olmo. Genova: Cideb, 2007.

FREDDI, G. Glottodidattica: fondamenti, metodi e tecniche. Torino: UTET, 2002.

ISQUIERDO, A. N.; KRIEGER, M.G. (Orgs.) As ciências do léxico: lexicologia, lexicografia e terminologia. v. 2. Campo Grande, MS: Editora da UFMS, 2004.

JEZEK, E. Lessico, classi di parole, strutture, combinazioni. Bologna: II Mulino, 2005.

LAFACE, A. Léxico e produção de sentido: contribuição para o desenvolvimento da leitura e reformulação do conhecimento. 1992. 2 v. Tese (Doutorado em Lingüística). Faculdade de Filosofia, Letras e Ciências Humanas, Universidade de São Paulo, São Paulo.

LEFFA, V. J. Aspectos externos e internos da aquisição lexical. In: (org.). As palavras e sua companhia: o léxico na aprendizagem. Pelotas, RS: 2000, v. 1, p. 15-44.

LEPSCHY, G. LEPSCHY, L. La lingua italiana: Storia, varietà dell'uso, grammatica. Milani: Bompiani, 2002.

LO ZINGARELLI 2004. Vocabolario della Lingua Italiana. Bologna: Zanichelli, 2003. CD-ROM

MARAZZINI, C. Breve storia della lingua italiana. Bologna: II Mulino, 2004. 
MARAZZINI, C. La lingua come strumento sociale: il dibattito linguistico in italia dal Manzoni al neocapitalismo. Padova: Manetti Editori, 1977.

MARELLO, C. CORDA, A. Lessico: insegnarlo e impararlo. Perugia: Guerra Edizione, 2004.

MEDAGLIA, C. Amore e Cinema. Genova: Cideb, 2008.

MEZZADRI, M. Insegnare il lessico. In: BALBONI, P. E. I ferri del mestiere. Perugia: Edizione Guerra, 2005. p. 205-219.

MIGLIORINI, B. Storia della lingua italiana. Milani: Bompiani, 2002.

NIZZI, C. I Promessi Sposi a Fumetti.Roma: San Paolo, 2001.

PANICO, V. II Romanzo di Renzo e Lucia: adattamento per la scuola de I Promessi Sposi di Alessandro Manzoni. Ortona: Vestigium Scuola, 1999.

PAROLA CHIAVE Dizionario di Italiano per Brasiliani. São Paulo: Martins Fontes, 2007.

PASQUALETTI, M.; DIADORI, P. I Promessi Sposi. Genova: Cideb, 2007.

PICHIASSI, M. Fondamenti di Glottodidattica. Perugia: Edizioni Guerra, 1999.

PIETRARÓIA, C. M. C. Percursos de leitura: léxico e construção do sentido na leitura em língua estrangeira. São Paulo: Annablume, 1997

Questões de leitura: asspectos práticos e teóricos da leitura em francês língua estrangeira. São Paulo: Annablume, 2001

PORCELLI, G. Comunicare in Lingua Straniera: il Lessico. Torino: UTET, 2004.

POTTIER, B. Sémantique générale. Paris: PUF, 1992. 
REY-DEBOVE, J. La définition lexicographique: recherches sur l'équation sémique. In: Cahiers de Lexicologie. Paris: Didier-Larousse, v. 1, n. 8, 1966, p.71-94.

ROLLA, L. I promessi sposi: edizione ridotta. Novara: Casa Editrice Edisco, 2007.

SANDMANN, A. J. Formação de palavras no português brasileiro contemporâneo. Curitiba: Scientia et Labor/Ícone, 1988.

SCARAMUCCI, M. V. R.; GATTOLIN, S. R. B. (orgs.). Pesquisas sobre vocabulário em língua estrangeira. Campinas, SP: Mercado de Letras, 2007.

TURAZZA. J. S. Estratégias para o ensino do léxico. In: Anais do VII Encontro da Anpoll. Goiânia: Anpoll, p. 660-663.

VEDOVELLI, M. Confronti fra il LIP e le altre liste di frequenza dell'italiano. In: DE MAURO, T. et al. Lessico di frequenza dell'italiano parlato. Milano: Etaslibri, 1993. p. 119-147.

VENTURI, M. A. Aquisição de Italiano L2: interferências relativas à similaridade lexical. 210 f. 2004. Tese (Doutorado em Lingüística). Faculdade de Filosofia, Letras e Ciências Humanas, Universidade de São Paulo, São Paulo.

VITALE, M. La lingua di Alessandro Manzoni. Padova: Cisalpino, 2000.

XATARA, C. O ensino do léxico: expressões idiomáticas. In: Trabalhos em Linguística Aplicada. v. 37, Campinas: Instituto de Estudos da linguagem, 2001. P. 49-59.

YULE, G. Introduzione alla linguistica. Bologna: II Mulino, 1996. 
SITOGRAFIA

www.almaedizini.it

http://www.guerra-edizioni.com/

http://www.bonacci.it/

http://www.blackcat-cideb.com/

http://www.edilingua.it/

www.eulogos.it

www.dueparole.it

http://www.accademiadellacrusca.it/

http://dizionari.corriere.it/ 